Western\&Graduate\&PostdoctoralStudies

Western University

Scholarship@Western

Electronic Thesis and Dissertation Repository

9-8-2017 1:30 PM

\title{
Virtual Archaeology, Virtual Longhouses and "Envisioning the Unseen" Within the Archaeological Record
}

William M. Carter, The University of Western Ontario

Supervisor: Dr. Neal Ferris, The University of Western Ontario

A thesis submitted in partial fulfillment of the requirements for the Doctor of Philosophy degree in Anthropology

(C) William M. Carter 2017

Follow this and additional works at: https://ir.lib.uwo.ca/etd

Part of the Archaeological Anthropology Commons, Digital Humanities Commons, Game Design Commons, Interactive Arts Commons, Interdisciplinary Arts and Media Commons, Museum Studies Commons, Other Anthropology Commons, Other Film and Media Studies Commons, and the Other History of Art, Architecture, and Archaeology Commons

\section{Recommended Citation}

Carter, William M., "Virtual Archaeology, Virtual Longhouses and "Envisioning the Unseen" Within the Archaeological Record" (2017). Electronic Thesis and Dissertation Repository. 4902.

https://ir.lib.uwo.ca/etd/4902

This Dissertation/Thesis is brought to you for free and open access by Scholarship@Western. It has been accepted for inclusion in Electronic Thesis and Dissertation Repository by an authorized administrator of Scholarship@Western. For more information, please contact wlswadmin@uwo.ca. 


\section{Abstract}

We are of an era in which digital technology now enhances the method and practice of archaeology. In our rush to embrace these technological advances however, Virtual Archaeology has become a practice to visualize the archaeological record, yet it is still searching for its methodological and theoretical base. I submit that Virtual Archaeology is the digital making and interrogating of the archaeological unknown. By wayfaring means, through the synergy of the maker, digital tools and material, archaeologists make meaning of the archaeological record by engaging the known archaeological data with the crafting of new knowledge by multimodal reflection and the tacking and cabling of archaeological knowledge within the virtual space. This paper addresses through the 3D (re)imagination of a $16^{\text {th }}$ century pre-contact Iroquoian longhouse, by community paradata blogging and participatory research, how archaeologists negotiate meaningmaking through the use of presence and phenomenology while also addressing the foundations of the London Charter: namely agency, authority, authenticity and transparency when virtually representing constructed archaeological knowledge. Through the use of Ontario Late Woodland longhouse excavation archaeological data, archaeological literature, historical accounts and linguistic research in combination with $3 \mathrm{D}$ animation and visual effects production methodologies, and engaging this mental construction made real in virtual reality by deploying these assets in a real-time gaming and head mounted immersive digital platform, archaeologists can interact, visualize and interrogate archaeological norms, constructs and notions. I advocate that by using Virtual Archaeology, archaeologists build meaning by making within 3D space, and by deploying these 3D assets within a real-time, immersive platform they are able to readily negotiate the past in the present.

\section{Keywords}

Virtual Archaeology, Virtual Reality, Iroquoian Archaeology, Longhouses, 3D, Lawson Site, The London Charter, Tim Ingold, Paul Reilly, Alison Wylie, Paradata, Making, Wayfaring, Archaeological Cables, Tacking, Agency, Authority, Authenticity, Transparency, Presence, Phenomenology 


\section{Acknowledgments}

Life is what lies between the narratives. I count myself extremely lucky to have been able to attend the University of Western Ontario in the Anthropology Department both as an undergraduate and then twenty years later as a $\mathrm{PhD}$ graduate student. They have been formative not only in understanding my place within the grand study of archaeology but in the formation of mutual respect and friendships that develop when people are brought together to discuss, debate and envision the future. My narrative in Virtual Archaeology started in the late 1980's as a fresh-faced idealistic undergrad and in the years of coursecorrections, failures and successes in which that narrative continues to drive my desire to go beyond the doing into a transformative vision of the future.

I have been blessed with an astute Supervisor, mentor and friend who took an immense chance in bringing me into the archaeological fold so late in my academic and professional career. Dr. Neal Ferris provided a path, assembled like-minded people to collaborate with and envisioned how I could personally make a difference in the application and theory of archaeology, virtually. He believed in my ability to go beyond just interpreting to actually contributing to the archaeological practice and record through constant support and guidance.

My research could not have been possible without the technical and creative skill of my two 3D animation collaborators; Andrew Alzner and Craig Barr, both of whom worked diligently to facilitate working prototypes and final virtual archaeological representations. Theoretical and methodological discussions about archaeology (among other topics) were facilitated by long drives between Toronto and London to attend classes with my fellow 
digital archaeology classmate, collaborator and friend, Namir Ahmed. Special mention to Colin Creamer, who came to Sustainable Archaeology as an animation intern during the early stages of the research and stayed at Sustainable Archaeology after graduating to support this project and other research technically.

Dr. Ron Williamson and ASI graciously provided intellectual, professional, financial and personal support for this research. Ron worked hard to ensure I had the material I needed to thoroughly investigate late Iroquoian longhouse construction and use while providing the financial support, in conjunction with Sustainable Archaeology and the Museum of Ontario Archaeology to enable the design, development and implementation of a virtual longhouse environment. While in production, Claire van Nierop plied her social media skills at ASI to ensure the project had a broad exposure to archaeologists and nonarchaeologists alike, which in turn informed and enriched my research through community participation in this project. Caitlin Coleman provided much needed assistance in organizing the internal ASI participation of the interviews and was invaluable with the support of the interview process.

I am humbled by the tremendous support shown to me during my research and writing stage. Dr. Paul Reilly and Dr. Ron Williamson provided unconditional guidance and editorial support as I worked through the theoretical implications of Virtual Archaeology, Iroquoian longhouse morphology and archaeological knowledge construction. Thanks to doctors Andrew Nelson, Dan Jorgensen, Mathew Betts, Anna Bentkowska-Kafel, Jeremy Huggett, Mark Gillings, Colleen Morgan, Shawn Grapham, Mark Gillings, John Creese, Alyson Wylie, Rhonda Bathhurst as well as fellow graduate students John Dunlop and Renee Willmon for providing much needed literature leads, papers and suggestions as 
well as my Ryerson MDM3.0 graduate student Ellen Hayes for jumping in with transcription help when needed. A heartfelt thanks to Dr. Michael Spence for not only mentoring and inspiring me in my undergraduate studies many years ago, but for being a virtual library of knowledge who could recall much needed and obscure papers or references when I was unable to zero in on research to further my studies. Many thanks to Anthony Allen from the C.W. Jefferys Online Catalogue, Dr. Dean Snow, the Museum of Ontario Archaeology, ASI \& Dr. Ron Williamson, Dr. John Creese and Dr. Neal Ferris for graciously providing images reproduced within this dissertation. A special thanks to Dean Snow, Mima Kapches and J. M. Wright, for their support both during and after my longhouse research as well as doctors Chris Watts, Bill Englebrecht, and Robert Macdonald for their insightful observations into longhouse construction and use. To my committee members Dr. Juan Luis Suárez, Dr. Jean-Francois Millaire, Dr. William Turkel, Dr. Peter Timmins and Dr. Costis Dallas for their comments, suggestions and support. Many thanks to Barbara Snelgrove, for her third pair of eyes during the final editorial stages of this dissertation.

A very special thanks to Dean Jennifer Mactavish and Vice Provost Christopher Evans, Ryerson University, for providing the flexibility and support to pursue my studies while still working full-time, helping to develop Zone Learning and launching the Master's in Digital Media Program (MDM). To my colleagues in the MDM, Dr. Matthew Kyan and Dr. Alex Ferworn for their technical and professional support as I balanced work with education and to my now 5 cohorts of MDM graduate students who laboured over the years as I regaled on the importance of Tim Ingold, Virtual Reality and dissertation writing. 
Most importantly, to my loving wife Ivy and our sons Ciaran and Rohan for putting up with my years of studying, writing and long absences while I worked my way through $\mathrm{PhD}$ life. 


\section{Table of Contents}

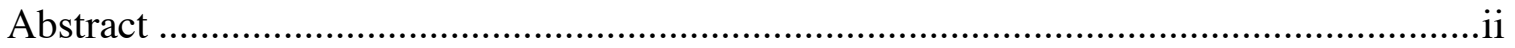

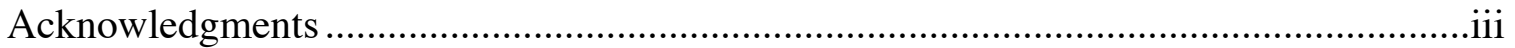

Table of Contents ......................................................................................................

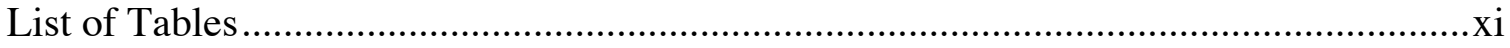

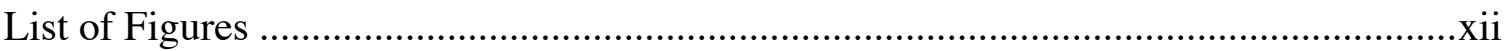

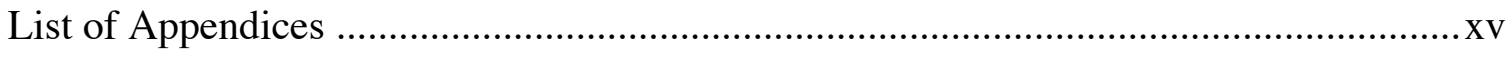

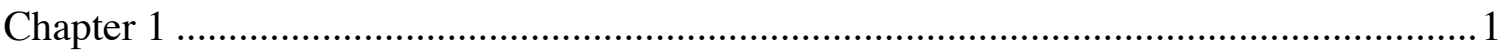

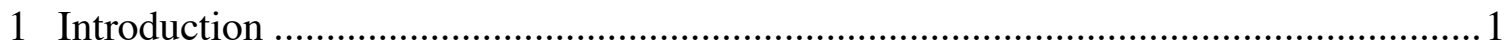

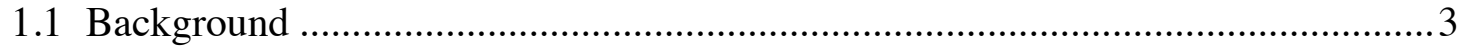

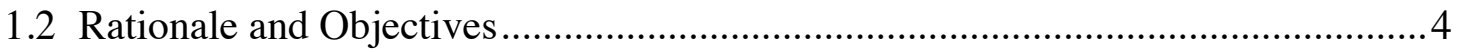

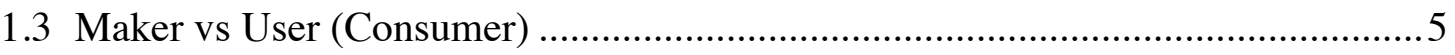

1.4 Pragmatic Eclecticism - Trigger 2.0? ....................................................... 7

1.5 Sustainable Archaeology as Virtual Archaeology .............................................. 9

1.6 The Virtual (re)Imagination and Meaning-Making of an Iroquoian Longhouse .. 10

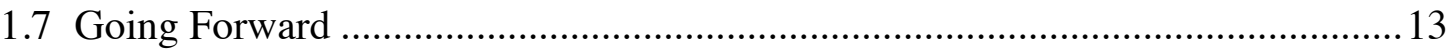

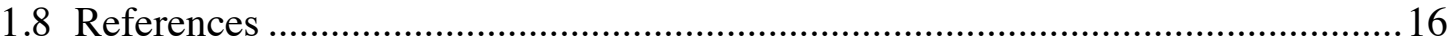

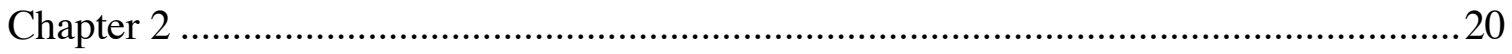

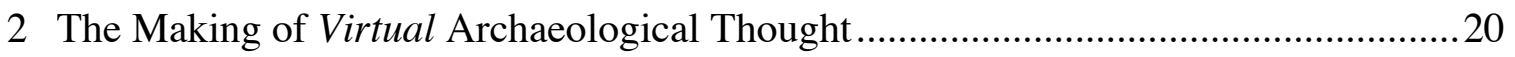

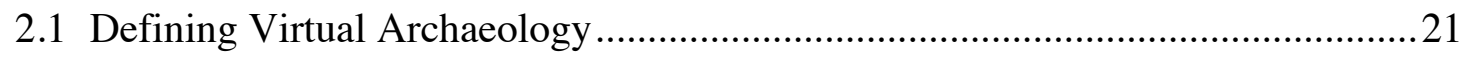

2.1.1 Defining the User ....................................................................... 22

2.1.2 Defining Presence within Virtual Reality ..........................................23

2.2 Setting the Stage for Theorizing Virtual Archaeology ......................................2 24

2.3 Conceiving of a Virtual Archaeology as Interpretive Archaeology: Actors and

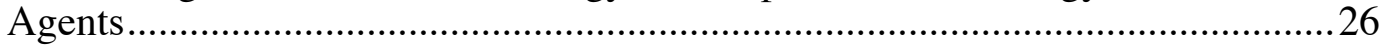

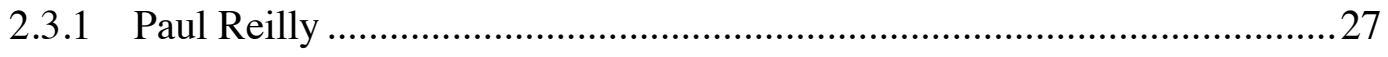

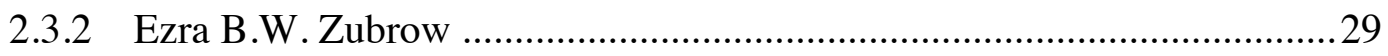


2.3.3 Authority, Artistry and Audience .............................................................. 30

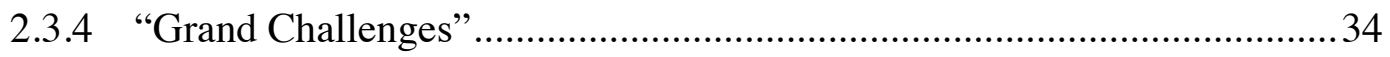

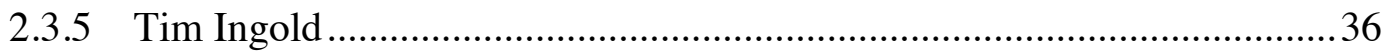

2.4 Making Virtual Archaeology Interpretive: Paradata and The London Charter ....39

2.4.1 The London Charter ...............................................................................

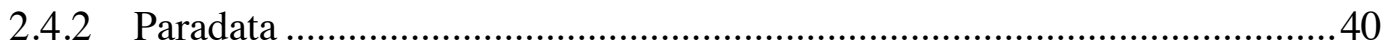

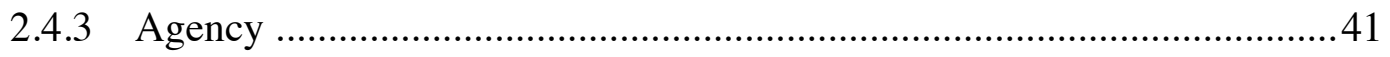

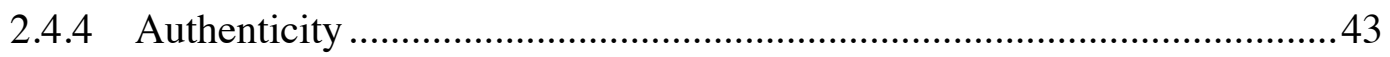

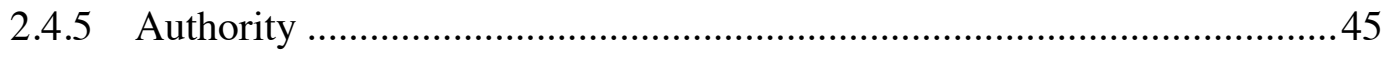

2.5 Implications for Future Research in Virtual Archaeology ....................................46

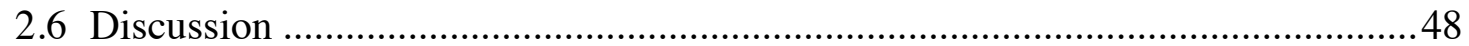

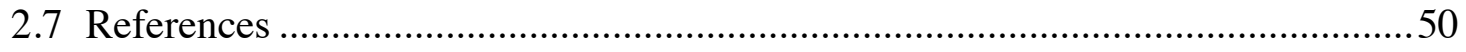

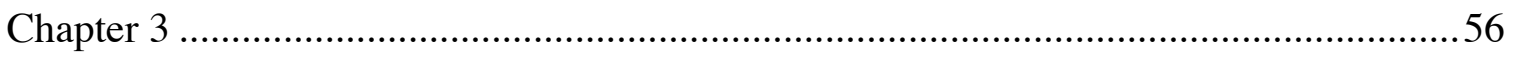

3 The construction of Longhouse knowledge in Virtual Archaeology ..........................56

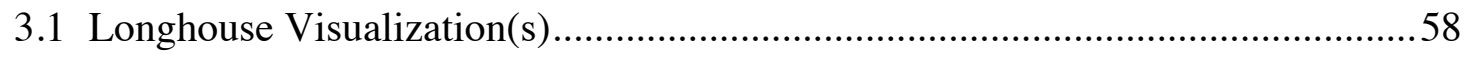

3.2 Creating a Mental Image of a Longhouse …………….........................................61

3.3 (Re)Imagined Physical Heritage ……………….................................................65

3.4 Known and Interpreted Archaeological Knowledge for Virtual Longhouse

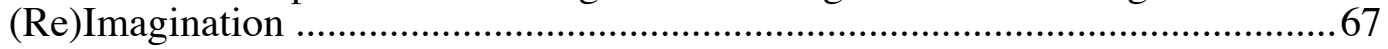

3.4.1 Surveying the archaeological literature - Painting a picture of a Longhouse

3.4.2 Archaeologist perceptions - Meaning-making through Longhouse

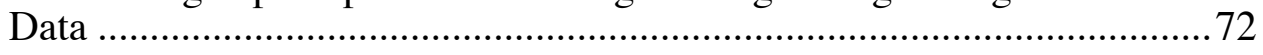

3.4.3 Longhouse Wall Interpretations ...............................................................75

3.4.4 Longhouse Roof Interpretations ................................................................

3.4.5 Longhouse Height and Width Interpretations .........................................78

3.4.6 Longhouse Length \& Hearth Interpretations ............................................79

3.4.7 Longhouse Bunk-line \& Sleeping-berth Interpretations ............................. 80

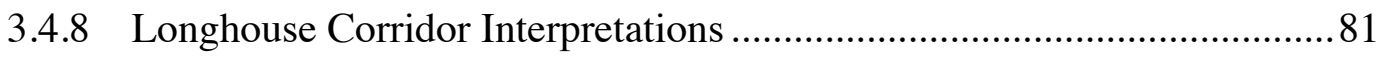


3.4.9 Longhouse Vestibule Interpretations .................................................... 82

3.4.10 Longhouse Construction Material Interpretations.....................................83

3.4.11 Longhouse Phenomenological Interpretations ……………………….....83

3.4.12 Template parameters for the construction of a Late Woodland 3D

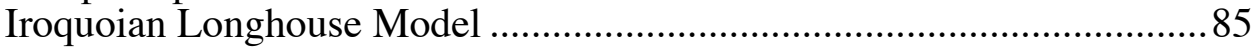

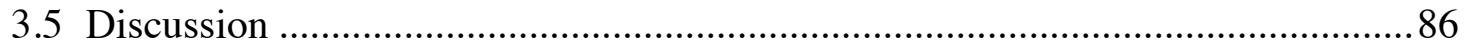

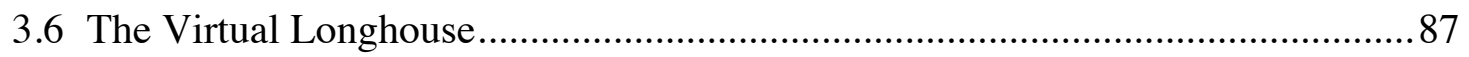

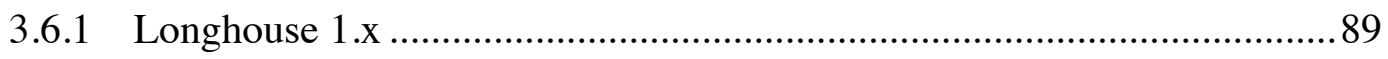

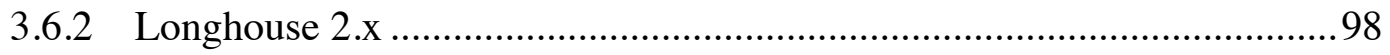

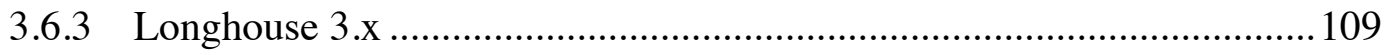

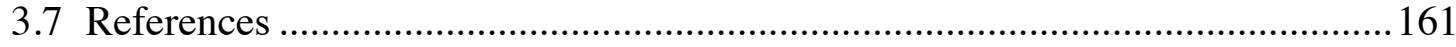

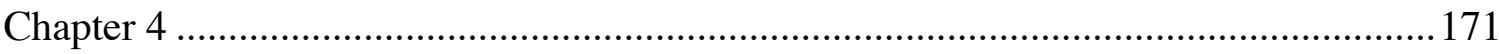

4 The Making of Virtual Meaning in Archaeology ……….............................................171

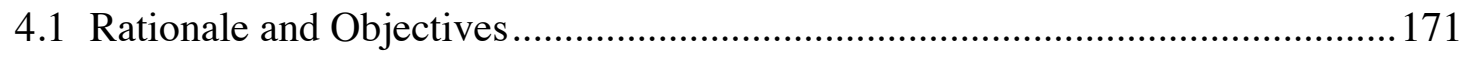

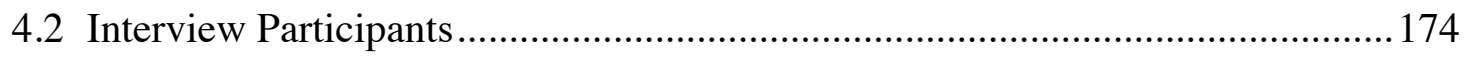

4.3 Interview Locations ......................................................................................... 176

4.4 Virtual Reality Hardware \& Software ............................................................... 181

4.4.1 Immersive vs Non-Immersive Assets ..................................................185

4.4.2 Interview Process ............................................................................... 187

4.4.3 The Virtual Longhouse Experience .........................................................190

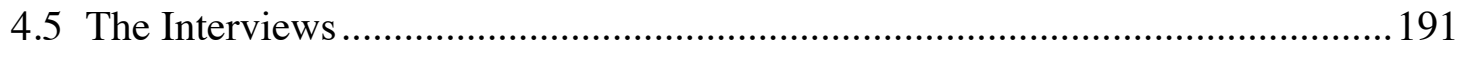

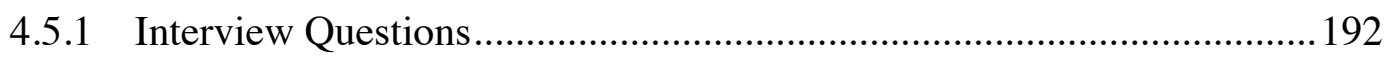

4.5.2 The Interviews Themselves and the Original Research Questions ..........194

4.5.3 “Oh, I Wasn't There" ..........................................................................222

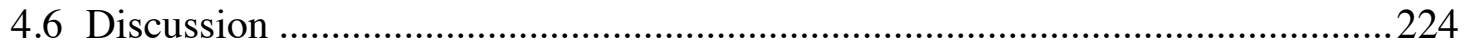

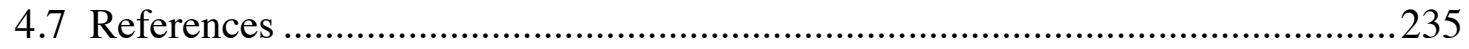

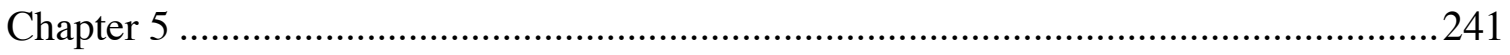


5 Conclusions: Virtual Making and Meaning-Making ............................................24

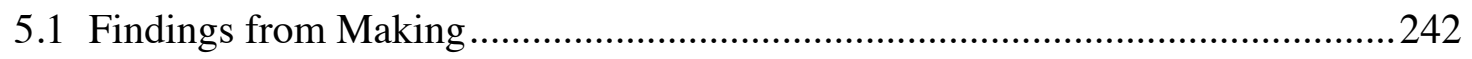

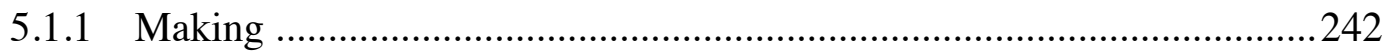

5.1.2 Paradata and the London Charter ...................................................251

5.1.3 Cabling \& Tacking in Virtual Archaeology .........................................256

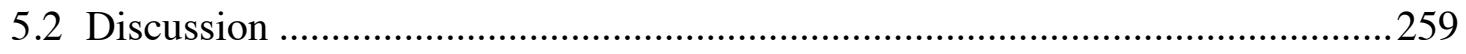

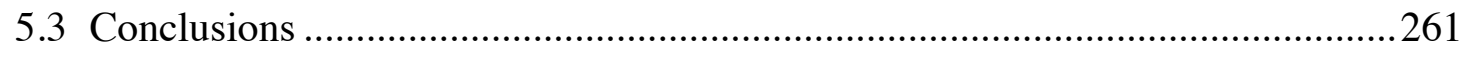

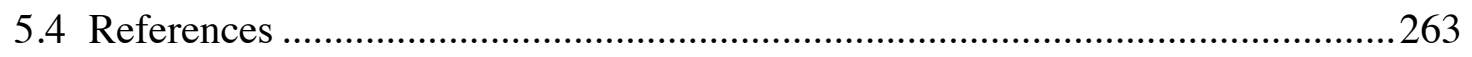

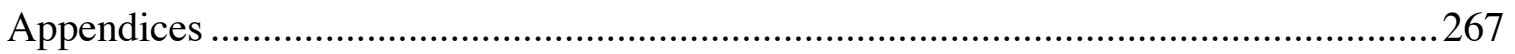

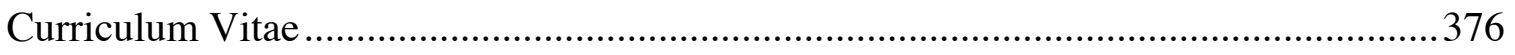




\section{List of Tables}

Table 1 Virtual Longhouse Interviewees ............................................................. 175 


\section{List of Figures}

Figure 1 - Postmolds \& Straws, Dougherty-Sluis site, Neal Ferris (2012)

Figure 2 - Part of a Palisaded Huron-Iroquois Village. C.W. Jefferys and McLean (1942:16). Image Reprinted with permission from C.W. Jefferys Online Catalogue.

Figure 3 - Longhouse Framing Examples from Snow (1997:77). Reprinted with permission from Dean Snow.

Figure 4 - From Anderson (2009:70). Reprinted with permission, Museum of Ontario Archaeology, London, Ontario .76

Figure 5 - Screen capture of "Post Clustering" taken from Burkholder II House 1 site map, Creese (2012a:63). Reproduced with permission from John Creese.

Figure 6 - Example of a Procedural Modeling Network, A. Alzner (2016)

Figure 7 - Theoretical procedural pipeline for the automatic creation of 3D modeled longhouses, Carter (2011)

Figure 8 - Houdini Procedural Longhouse Modeling Network, A. Alzner (2013)

Figure 9 - Procedural Longhouse Modeling Network based on Dodd (1984), A. Alzner (2013)

Figure 10 - Examples of pre-production visualization sketches A. Bartholomew (2012)

Figure 11 - Lawson Site Recreation Animated Fly-through, Sustainable Archaeology (2012)

Figure 12 - Lawson Site Game Engine Test, Sustainable Archaeology (2012).....

Figure 13 - Longhouse 3.x base modeling template, Carter and Barr (2016) ...... 114 
Figure 14 - Longhouse 3.x "h" frame bunk supports with $10 \mathrm{~cm}$ pole and post diameters, (Carter and Barr 2016)

Figure 15 - Example of cordage, bunk slat direction, bedding and cedar back dividers, (Carter and Barr 2016) 126

Figure 16 - Initial framing configuration with production notes, Carter and Barr (2016)

Figure 17 - Iroquois Longhouse Fort Erie Project 1982. Blueprint provided courtesy of ASI and reproduced with permission.

Figure 18 - Second framing revision, Carter and Barr (2016)

Figure 19 - Revision based on paradata blog feedback, Carter and Barr (2016) .......

Figure 20 - Third Framing Revisions, Carter and Barr (2016) .....

Figure 21 - Fourth Framing Revisions, Carter and Barr (2016)

Figure 22 - Cedar inner wall and doorway, Carter and Barr (2016).....

Figure 23 - Alexandra Site, ASI (2008). Reproduced with permission from ASI. 140

Figure 24 - Full exterior framing, Carter and Barr (2016)

Figure 25 - Full exterior framing, Carter and Barr (2016)

Figure 26 - Photo-realistic rendering of the Longhouse, Carter and Barr (2016) ...... 146

Figure 27 - Stylized game rendering of the Longhouse, Carter and Barr (2016) ........... 146

Figure 28 - (Re)Imagined exterior of Longhouse 3.x, Carter and Barr (2016)

Figure 29 - (Re)Imagined interior of Longhouse 3.x, Carter and Barr (2016)

Figure 30 - Interview venue and Interviewee (ASI). Reproduced with consent. 177

Figure 31 - Interview venue and Interviewee (Ryerson). Reproduced with consent......178 
Figure 32 - Interview venue with Interviewee \& Author (SA). Reproduced with consent.

Figure 33 - Off-site Interviewee in personal home (Paul Walker 2016). Reproduced with consent.

Figure 34 - Initial Oculus Rift testing (Toronto Heritage Event 2015). Reproduced with consent 182

Figure 35 - Interview venue and Interviewee (SA/MOA). Reproduced with permission.

Figure 36 - Longhouse 3.x Maya rendered test (Carter 2016). 185

Figure 37 - HTC Vive Immersive rendered image (Carter 2016).

Figure 38 - HTCVive immersive setup at Sustainable Archaeology. Reproduced with permission.

Figure 39 - Desktop non-immersive setup at the DMZ. Reproduced with permission. .189

Figure 40 - Gartner Hype Cycle (Gartner Inc. 2016 -

http://www.gartner.com/newsroom/id/3412017).

Figure 41 - Examples of physical tools to enable virtual engagement. Reproduced with permission. 


\section{List of Appendices}

Appendix A 1: Paradata Blog Site contact sheet .268

Appendix A 2: Index page - http://theskonkworks.com/ .269

Appendix A 3: About page - http://theskonkworks.com/animation-production/. .270

Appendix A 4: What page - http://theskonkworks.com/animation-production/what-i-do/

Appendix A 5: Who page - http://theskonkworks.com/animation-production/who-i-am/

Appendix A 6: Filmography page - http://theskonkworks.com/animationproduction/filmography/.

Appendix A 7: Virtual Archaeology Index 1 page - http://theskonkworks.com/virtualarchaeology/

Appendix A 8: Virtual Archaeology Index 2 page

Appendix A 9: Virtual Archaeology Index 3 page 276

Appendix A 10: Virtual Archaeology Index 4 page

Appendix A 11: Longhouse 1.0 Index page -

http://theskonkworks.com/category/featured/longhouse-1/ .278

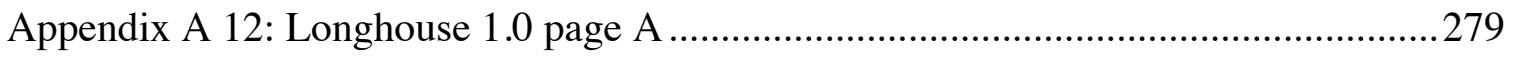

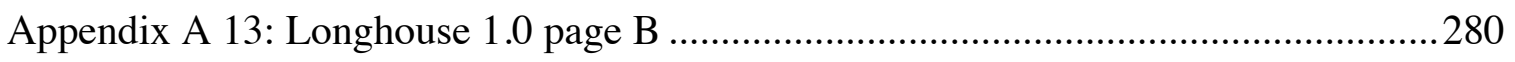

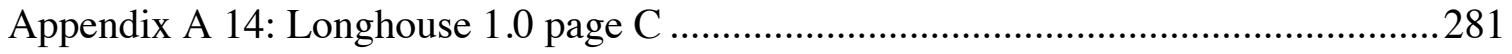

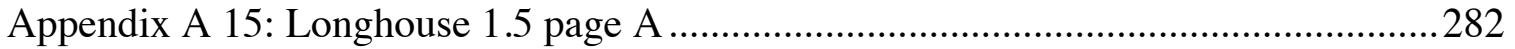

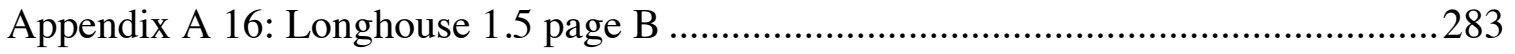

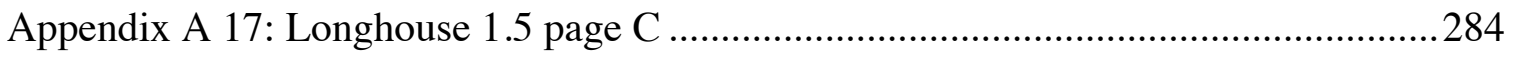

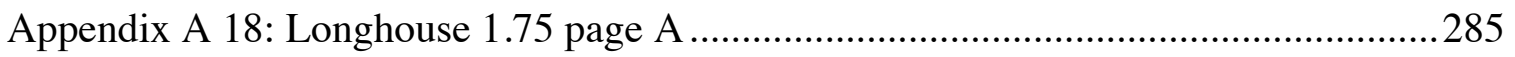


Appendix A 19: Longhouse 1.75 page B

Appendix A 20: Longhouse 2.0 Index page -

http://theskonkworks.com/category/featured/longhouse-2/

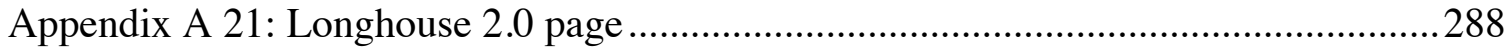

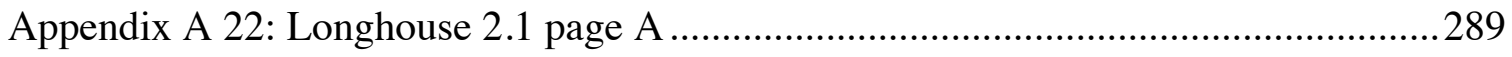

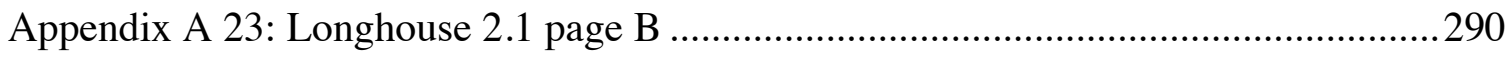

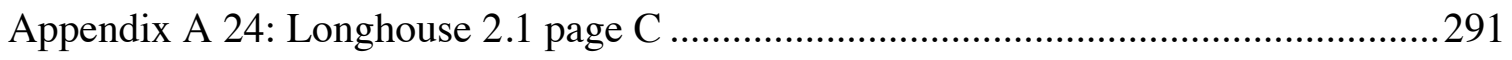

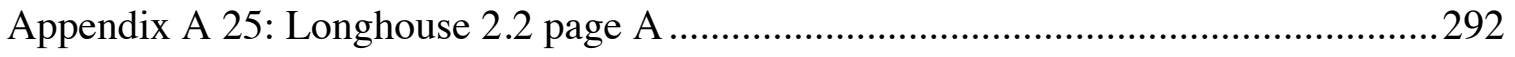

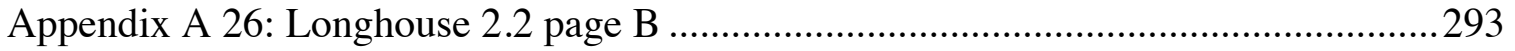

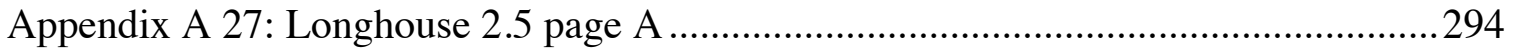

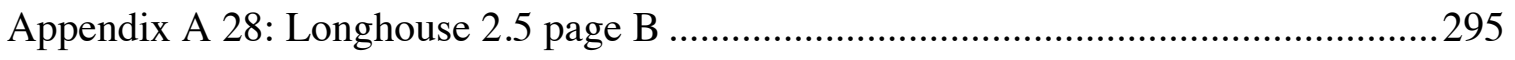

Appendix A 29: Longhouse 3.x Index page A -

http://theskonkworks.com/category/featured/longhouse-3/ .....................................296

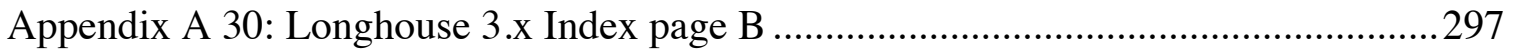

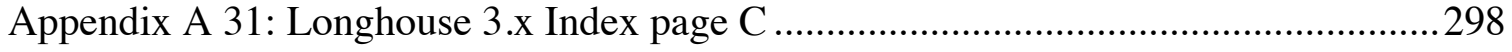

Appendix A 32: Longhouse 3.x Index page D .......................................................299

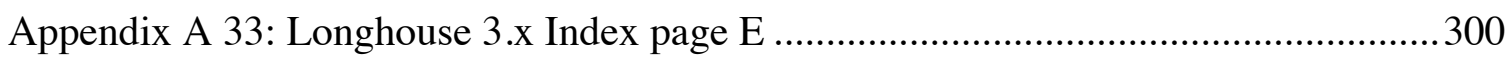

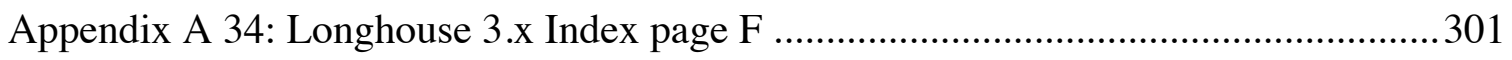

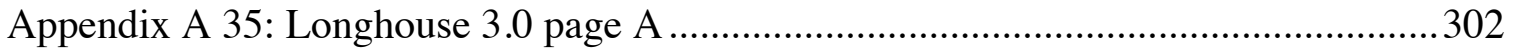

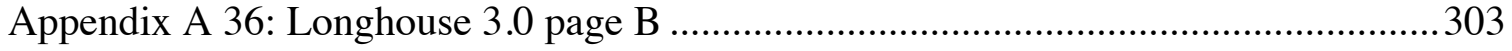

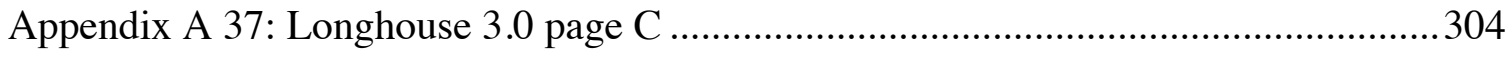

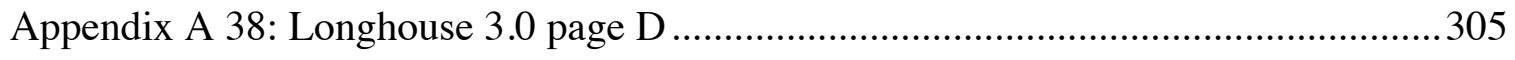

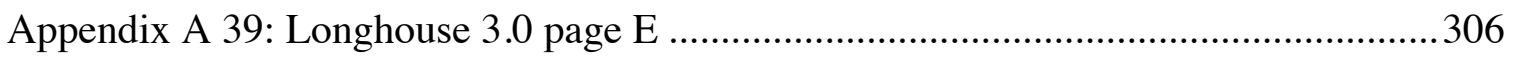


Appendix A 40: Longhouse 3.0 page F.

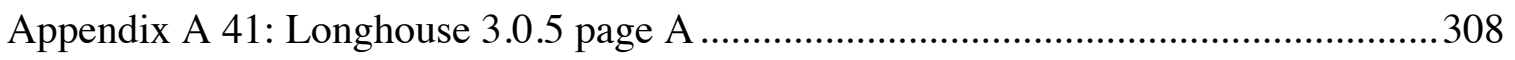

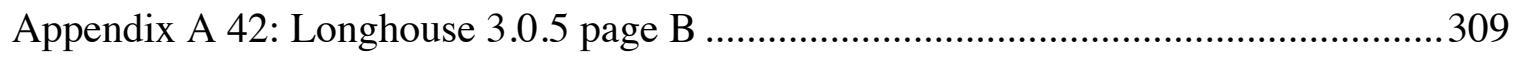

Appendix A 43: Longhouse 3.0.5 page C ................................................................310

Appendix A 44: Longhouse 3.0.5 page D ....................................................................311

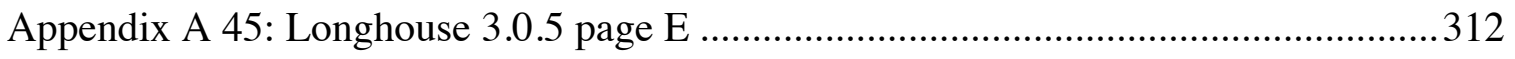

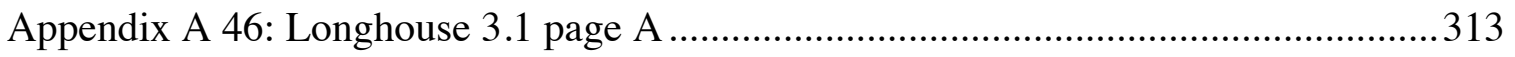

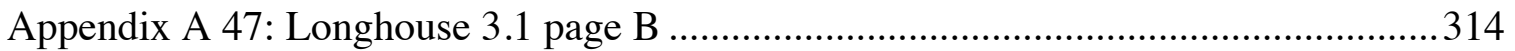

Appendix A 48: Longhouse 3.1 page C ........................................................................ 315

Appendix A 49: Longhouse 3.1 page D ......................................................................316

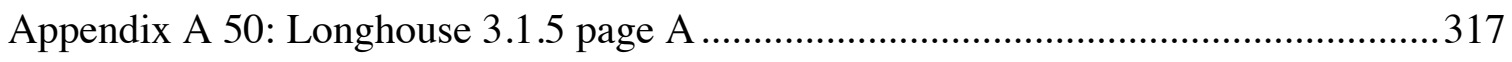

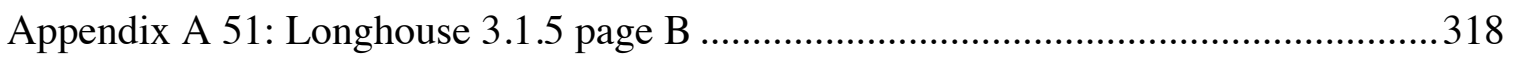

Appendix A 52: Longhouse 3.1.5 page C ..................................................................

Appendix A 53: Longhouse 3.2 page A ..........................................................................320

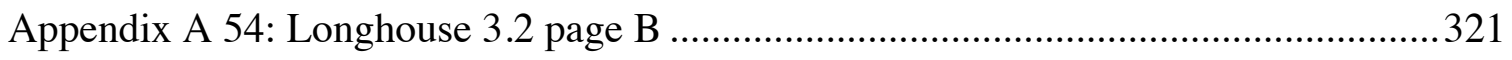

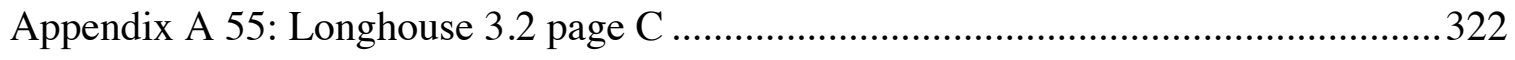

Appendix A 56: Longhouse 3.2 page D .......................................................................323

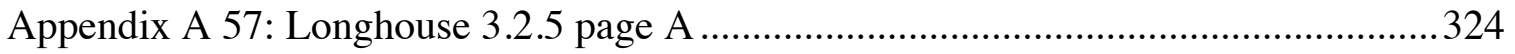

Appendix A 58: Longhouse 3.2.5 page B ……………............................................... 325

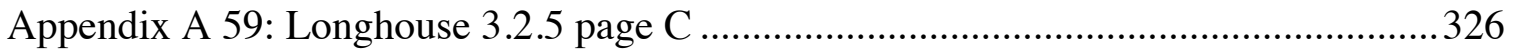

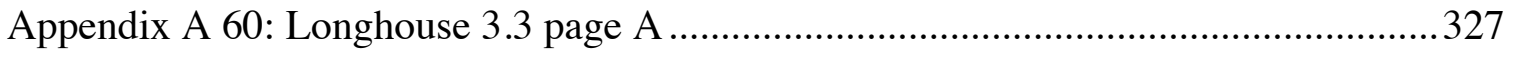

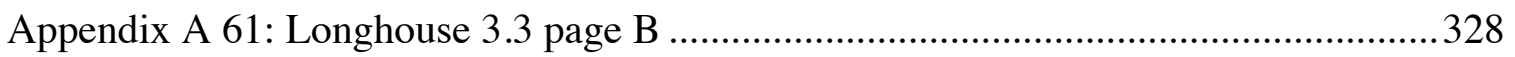


Appendix A 62: Longhouse 3.3 page C

Appendix A 63: Longhouse 3.3 page D

Appendix A 64: Longhouse 3.3 page E .331

Appendix A 65: Longhouse 3.3.5 page A.

Appendix A 66: Longhouse 3.3.5 page B

Appendix A 67: Longhouse 3.3.5 page C

Appendix A 68: Longhouse 3.4 page A

Appendix A 69: Longhouse 3.4 page B .336

Appendix A 70: Longhouse 3.4 page C 337

Appendix A 71: Longhouse 3.4 page D .338

Appendix A 72: Longhouse 3.4.5 page A .339

Appendix A 73: Longhouse 3.4.5 page B .340

Appendix A 74: Longhouse 3.4.5 page C 341

Appendix A 75: Longhouse 3.5 page A .342

Appendix A 76: Longhouse 3.5 page B 343

Appendix A 77: Longhouse 3.5 page $C$ .344

Appendix A 78: Longhouse 3.5 page D .345

Appendix A 79: Longhouse 3.5 page $\mathrm{E}$ .346

Appendix A 80: Longhouse 3.5.5 page A .347

Appendix A 81: Longhouse 3.5.5 page B 348

Appendix A 82: Longhouse 3.5.5 page C .349

Appendix A 83: Longhouse 3.5.5 page D .350 
Appendix A 84: Longhouse 3.5.6 page A

Appendix A 85: Longhouse 3.5.6 page B

Appendix A 86: Longhouse 3.5.6 page C

Appendix A 87: Longhouse 3.5.6 page D .354

Appendix A 88: Longhouse 3.5.6 page E .355

Appendix A 89: Longhouse 3.5.6 page F .356

Appendix A 90: Longhouse 3.5.7 page A .357

Appendix A 91: Longhouse 3.5.7 page B 358

Appendix A 92: Longhouse 3.5.7 page $C$ .359

Appendix A 93: Longhouse 3.5.8 page A 360

Appendix A 94: Longhouse 3.5.8 page B .361

Appendix A 95: Longhouse 3.5.8 page $C$ .362

Appendix A 96: Longhouse 3.5.8 page D .363

Appendix A 97: Longhouse 3.5.8 page $\mathrm{E}$ .364

Appendix A 98: Longhouse 3.5.8 page $\mathrm{F}$ .365

Appendix A 99: Longhouse 3.5.9 page A .366

Appendix A 100: Longhouse 3.5.9 page B .367

Appendix A 101: Longhouse 3.5.9 page C 368

Appendix B 1: YouTube Longhouse Special Projects Index page https://www.youtube.com/user/theskonkworks .369

Appendix B 2: Procedural Animation Example - https://youtu.be/C-uZsG-NH4U .......369 
Appendix B 3: Procedural Pole Birthing Test - https://youtu.be/VfBRBLb15wM ........370

Appendix B 4: Post Clustering Test - https://youtu.be/uRJdWoXVKMY ....................370

Appendix B 5: Procedural Longhouse Framing Test (Houdini) -

https://youtu.be/LBCa4xELkuE

Appendix B 6: Procedural Longhouse Framing Test2 (Houdini) -

https://youtu.be/5KdJF6boYYo

Appendix B 7: Procedural Longhouse, Interior Support and Exterior Walls from Dodd (1984) - https://youtu.be/eX7Upvoloak

Appendix B 8: Procedural Longhouse Test (Maya) - https://youtu.be/29KJZo7NKrk ..372

Appendix B 9: Lawson Site Rendered Sequence - https://youtu.be/qg7u5iL4pRg .373

Appendix B 10: Lawson Site Unreal Game Sequence - https://youtu.be/0O8sMVRJD3Q

Appendix B 11: Longhouse Example at Siggraph 2016 - https://youtu.be/ULIMey10HkY

Appendix B 12: Longhouse Unity Walkthrough Test - https://youtu.be/eTMxKZSifi4 374

Appendix B 13: Full Longhouse Unity Test - https:/youtu.be/1IKYFuAuOKo

Appendix B 14: Final Unity Longhouse Walkthrough - https://youtu.be/9YUrFOWvN_s 


\section{Chapter 1}

\section{Introduction}

This chapter will introduce and frame the concept of Virtual Archaeology as a making and meaning-making methodology and theoretical approach to archaeological knowledge construction. The research for this dissertation focuses on the $3 \mathrm{D}$ construction of a virtual, archaeologically-based, prototypical $16^{\text {th }}$ century Late Woodland ancestral northern Iroquoian longhouse. It allowed me to test cultural historical assumptions established in archaeological literature about the architecture and internal layout of these residential structures, and to experiment with the physics and logic of these assumptions, all manifested virtually. Once constructed, I used the virtual space of this longhouse to conduct semi-structured interviews and participant observations to explore whether Virtual Archaeology (VA) is an effective means to enhance and expose the conceptual frameworks and mental templates archaeologists operationalize to help bridge the gaps between physical, contextual data and archaeological meaning making. In this way, the build and subsequent participant interaction with that space facilitated an interrogation of archaeological meaning-making informed by material and historical data as made "real" in a virtual archaeological space.

By focusing on the virtual space of a typical northern Iroquoian longhouse, I have chosen to visualize a unique cultural manifestation that apart from the remnants of post-hole stains, below ground cultural features and hearths, is an archaeological enigma lacking above ground visual representation archaeologically or historically. Nonetheless, there exists a more generally understood "pre-existing mental image" (see Ingold 2011:22) of these structures derived from limited historical descriptions, albeit generalized from a narrow period of time and from a range of regional and cultural variations in material expression, and from contemporary attempts to reconstruct these structures. As such, through the excavation process, archaeological crews "make real" mental reconstructions that loosely adhere to the archaeological data they discover (see Watts 2009). In exploring how archaeologists internalize archaeological data, spaces and landscapes, material artefacts and oral and written histories through the use of virtual 3D model 
creation, this research has provided an opportunity to "envision the unseen" within virtual reality.

Through the process of making and manipulating the material, and the material in turn manipulating the maker, we expose a series of "wayfaring points". Wayfaring is a process for taking stock of a moment of time in which the act of making and the materiality of the raw material requires the artisan or maker to stop, evaluate and make course corrections in order to achieve a representative version of their vision or template of the material (Ingold 2011, 2013; see also Crawford 2015). Ingold uses the metaphor of wayfaring to describe this process of assessment and correction. Here artisans, or craft persons, are defined as makers who deploy their accumulated knowledge through reflexive application to the physical, material and materiality of the making process. I would argue that past and present longhouse builders' work adopt such a wayfaring approach during their construction of these buildings and spaces. Likewise, in the act of making a $3 \mathrm{D}$ virtual space, there is a similar wayfaring experiential process, one that both mirrors the physical experiential process of longhouse construction through the virtual materiality of that digital counterpart, while also confronting and negotiating archaeological knowledge and assumptions embedded in that research on ancient longhouse architecture and living.

In this process of making, and as makers who make course corrections at wayfaring points, the decisions made embody elements of power, agency and authority (Crawford 2015; Ingold 2011, 2013), which draw into question the authenticity of the representative virtual form created. As such, as a virtual artisan wayfarer, I embody and assert a technical, creative and archaeological "expertise." This creates a unique perspective to archaeological meaning-making that required me to be reflexive of the power, agency and implicit authority I embed in the process of making within virtual space. Thus as a wayfaring artist, I will need to transparently negotiate the process between virtual builder, viewer and archaeologist, in order to reveal the "continuous correcting" that occurs as decisions are made virtually through the build and through the (re)imagining of a longhouse within the 3D environment (Ingold 2011, 2013). 
While it has been a dimension of archaeological practice for over 25 years now, VA has on the whole failed to build a solid foundation upon which to build robust archaeological inquiry (Reilly 2015). Rather, practice has been distracted by the application of the tool as novelty for public entertainment/education and, more constructively, as a visual aid within archaeology, with little consideration on how these tools can expose and even shape our understandings of the archaeological record (Dallas 2007; Gillings 2005; Huggett 2012). I assert that VA has the potential to provide transformative ways of thinking not only about the practical construction and material realities of longhouse building and dwelling, but also about the mental embodiment of longhouse culture and use that archaeologists have employed in their constructions of ancestral northern Iroquoian lifeways. Thus, the proximate aim of this research is to examine archaeological understandings of agency, authority, authenticity and transparency manifest within a virtual archaeological environment through archaeological thought production. Ultimately, I will seek to enhance understandings of archaeological meaning-making as applied to and revealed by virtual visualization and interaction in archaeology.

\subsection{Background}

The transforming organic nature of ancestral northern Iroquoian longhouses I am exploring in this research is that they are ideal examples of Ingold's (2011:19-32) notion of "materials versus materiality." The organic materials used in the construction of these structures and dwelling spaces dictates the style, use and longevity of the physical materiality of the longhouse itself, which eventually melds back into the environment from which it came, with no above ground traces of those materials or that living materiality left behind (Ingold 2011:26). For archaeologists, this material absence serves as the foundation for imposing archaeological understandings of the ancient materiality of longhouse embodiment. Thus to visualize and describe the material, mental and social properties of longhouses over their life history as ancient-built conceptions of structures, residences and living spaces is to "tell the stories of what happens to them as they flow, mix and mutate" (Ingold 2011:30). The virtual construction of a longhouse represents the physical and mental interpretation of what that longhouse was, and this is much more 
than visualizing data. It is also a contemporary narrative in which multiple voices, conceptions and opinions are expressed along the pathway of knowledge creation.

Compounding the challenges of archaeologists to synthesize what is in effect two dimensional representations of archaeological data in the forms of site plan maps, excavation illustrations, photography and final written reports in order to then visualize the remaining buried vestiges of a three dimensional material space conceptualized virtually is that, in popular forms of virtual reality, the pervasive use of photo-realism in the entertainment industry has created an expectation -and fallacy - that if it "looks" real, it must be authentic (Denard 2012). This is a theme that plays out time and again in the use of archaeological visualization, whether it is for knowledge makers or for the general public (Colley 2015; Earl 2005; Frankland and Earl 2011). Although the tradition of archaeological illustration has altered little since antiquity scholars began their renaissance studies (e.g. Moser 2012), virtual reality puts a unique spin on this tradition of presenting archaeological visual data in an authoritative and authentic manner (Perry 2015). In doing so, by taking a creative approach to the interpretation of archaeological data within virtual representations, the agency of that data becomes layered on and seen through the creator's lens: what that "artist's impression" intends the virtual space to convey (see Earl 2013; Frankland and Earl 2011; Frischer et al. 2000; Perry 2015; Moser and Smiles 2008; Watterson 2014; 2015). The digital production of objects, landscapes and narratives, and the exclusion of other viable alternatives, makes overt issues of authenticity and authority in archaeological meaning-making, creating an interpretive agency in both real and virtual worlds, and as such need to be acknowledged overtly and transparently (Bentkowska-Kafel et al. 2012; Cochrane and Russell 2007; Colley 2015; Earl 2013; Forte 2014a; Huggett 2012, 2015; Pauketat and Alt 2005; Perry 2009; Richardson 2013; Robb 2010).

\subsection{Rationale and Objectives}

VA has become a powerful means of presentation and interpretation of archaeological landscapes and artefacts - a unique tool for knowledge building, meaning making and 
heritage accessibility (e.g., Dallas 2009; Earl 2013; Forte 2014a, 2014b; Huggett 2013; Perry 2015). It has become a "mediating tool" allowing researchers to experiment with the data and to tease out the tensions that arise from limited and multiple conceptions of the past - a multi-sourced and even multi-vocal environment created to "stimulate interpretation," explore alternative tellings of the past, and advance new research directions in archaeology (Dallas 2009; Earl 2013; Huggett 2013). Nonetheless, while the practice/study/craft of archaeological visualization has managed to present itself and its output as representative of archaeological meaning-making and authoritative presentations of the past, this has occurred without the practice really establishing the basis for that authority (see Earl 2013; Perry 2015). Thus the challenges VA represents within the broader field of archaeological knowledge creation is going beyond the perceived notion of the technology being a novel means to illustrate archaeological data, and to demonstrate that VA can be a transformative vehicle to engage with material pasts in a way that allows for multiple visions of that heritage to be represented, tested and valued.

\subsection{Maker vs User (Consumer)}

This research will be a messy exploration (see Law 2004). This is an exploration of theory and practice fraught with angst as I wrestle with the issues of virtual reality and archaeological meaning beyond just tools for public engagement. How do we as archaeologists make meaning, and how do we do it (differently) within virtual reality? We are creators of meaning, makers of whole systems of thought, theory and facts, yet is it our training, our innate ability to conceptualize the proverbial tea leaves of ancient human existence, or is it an element of intellectual creativity envisioned from the smallest remnants of a (material) culture's past, that is the essential element in an archaeologist's mental toolkit? When or how perpetual is the moment of creative thought for an archaeologist? And more importantly, how do we visualize archaeological data into meaningful explanation? By understanding how archaeologists perceive knowledge construction within the virtual environment there is a better opportunity to maximize a 
virtual reality - or Virtual Archaeology - in the pursuit of archaeological meaning making.

As a trained archaeologist, computer animator and visual effects artist, I am a visual maker; one who creates whole new systems of visual fictions, meanings or facts. Tim Ingold speaks of wayfaring points; course corrections along lines of life that make meaning of our personal journeys (2011). He positions these moments not necessarily as life changing, but as life enhancing. For myself, my wayfaring points position my understanding of archaeology today. In the accumulation of my wayfaring points over the years, the thread has always been visual, yet I have never questioned my art, motivation or the reasoning behind it. I have created for financial gain and in doing so for personal joy, but always in the interpretation of the vision of others. I make meaning of the material provided; interpret, develop and execute a visual representation of the accumulated creative assets and information available, discovered or provided to me. Similar in many respects to the archaeologist attempting to connect the cultural material he/she must interpret.

As a maker and one whose wayfaring points have been the pursuit of knowledge within anthropology and archaeology, I often wonder about the moment of time when an object, landscape or even abstract thought is given agency. What were factors that brought that object to life and why (see Spector 1993)? What were the motivations, inspirations or causations of the ancient maker(s) as they unpack their own personal baggage and the environmental and social pressures of their time while constructing objects of utility, worship or built landscape, which we as archaeologists also attempt to unpack along with our own baggage when visually creating a mental image of the cultural material we interpret (see Spector 1993)? Collectively in the past and present, we all source years of knowledge while creatively interpreting the temporal and physical placement of objects to construct a narrative, by means of a personal lens, which is representational of material before us. It is this "artist's eye," the moment when meaning is visually brought together from often-disparate sources, that is at the center of my research (see Watterson 2014; 2015). It is much a journey of my own interpretation of the visual material as it is of the 
archaeologists and non-archaeologists who will experience, question and make their own meaning of it.

My journey will be the interpretation of the archaeologists' virtual mental image into a representation of visual reality. I will examine the process in which archaeological data, cultural historical sensibilities and artistic creation is interpreted, repositioned and presented. How the tools both enable and constrain our meaning-making and how those negotiations affect the visual outcomes. How the material and the materiality are active participants in the process of creating meaning and subsequently how we interpret and construct knowledge. Lastly how other archaeologists interpret meaning from my own visual mental constructions and whether the tools, methods and theories are relevant and valid in their own interpretation of the archaeological landscape. It is an "inflicted perspective" (see Shanks 2012:38) of archeological discourse in the pursuit of new theoretical frameworks.

This isn't a discussion on the value or place of VA in public archaeology, digital heritage or even a broader consumer consumption of archaeological material and information. It certainly isn't about the "way-cool" fetishization of digital technology for the unbridled sake of using digital technologies to make new things or experiences. This research is about spanning the gap between archaeological data and the making of meaning from that data through virtual reality. It is about the application of VA in the process of making new archaeological meaning by archaeologists for archaeologists and stakeholders alike. VA is a starting point for a new form of archaeological discussion and debate, a conversation starter in the pursuit of new archaeological thought.

\subsection{Pragmatic Eclecticism - Trigger2.0?}

Pragmatic Eclecticism has no formal definition, yet like Trigger, I have reveled in its "problems of competing approaches and theoretical convergences" (Klejn 2006:141). It's perhaps a form of pragmatism struggling to express itself through the multivocal theoretical archaeological environment (Trigger 1991). It borrows from both "Pragmatic 
Synthesis" and "New Pragmatism" the notions of alternative views and lenses that "seeks to learn from the past to inform the future and to play an active role in the variety of current discourses" ( Preucel and Mrozowski 2010:35; see also Trigger 2006). It arises from years of post-conference discussions about the actual practice and application of archaeological thought today. It's neither anti nor pro archaeological theoretical establishment, but an acceptance of the daily practical necessity needed when applying various theories to the archaeological material and data we struggle to make into meaning about the past.

It is about a procedural and experiential change in thought, theory and process. Call it the "Canadian" approach, a Trigger2.0, a "Pragmatic Eclecticism" (Neal Ferris personal communication, March 2016), in which constructed archaeological meaning is neither Processual, Post-Processual, Marxist, Feminist, New, or Interpretive, but a combination of some or all of these theoretical approaches (see Trigger 2006). It is an acceptance that we as archaeologists actively borrow, build, blend and constitute as needed an eclectic mix of theoretical thought in our efforts to make sense of the material before us (see Pearce et al. 2006:118). It is a pragmatic sensibility in the interpretation of the material record and the application of those sensibilities within the virtual environment. Unconsciously I personally practice it daily, but struggle constantly with the tensions of trying to make my practice fit into more traditional theoretical approaches. Its relevance to VA is significant in the fact that there isn't one single approach that can properly encapsulate the role VA can play in archaeological thought creation.

Alison Wylie predates this notion and describes this as "Archaeological Cables and Tacking" (1989, 1993, 2002). In it, knowledge construction is multi-dimensional and within those dimensional threads, cables of thought, knowledge and skill are interwoven to create both analogous and competing viewpoints (Wylie 2002a). As will be discussed, the theoretical and methodological application of VA is in itself an excellent example of how archaeological knowledge construction and meaning-making is multi-faceted and multi-directional. Material culture initiates the vertical tracks of knowledge construction, based on a known and quantifiable archaeological record, while diagonal tracks carry the interpretive interpretations that enable meaning-making (see Dallas 2015; Wylie 2002). 
As with the notion of pragmatic eclecticism, archeological knowledge construction is tightly wound or "cabled" between the constraints of known knowledge. It is however between the borders if you will of the virtual and the physical, of the known and the unknown, that new knowledge is created.

I will explore the theoretical underpinnings of a VA, the methodological frameworks that continue to evolve, and finally the interaction of archaeologists within virtual reality and its effect on their ability to make meaning of the archaeological record virtually.

\subsection{Sustainable Archaeology as Virtual Archaeology}

... a sustainable archaeology requires [the] acknowledgement and balancing of the spectra of values embedded in archaeological sites and objects, which really only are converted into cultural heritage when those diverse perspectives access and engage with the accessible record beyond archaeology. Indeed, when we step beyond our own particular interests as archaeologists, it should be readily evident that it is the people and communities we interact with and who draw meaning, identity, vitality, and even sustenance from heritage places and the material past that are THE cultural resources of greatest importance in cultural heritage management. As such a sustainable archaeology cannot just be about minimizing harvest and maximizing use of the recovered record by archaeologists. It is, at its core, about conceptually shifting applied and other forms of practice from pursuing archaeological agendas to being in the service of this spectrum of contested values that converge where heritage is made and carried forward."

Ferris et al. 2013:400

Virtual Archaeology satisfies the pursuit of a sustainable archaeology by looking at archaeology through multi-vocality and interactivity; through the accessibility of this digitized material past - an accessibility and virtual engagement not limited to 
archaeologists. It offers a broader vision of a sustainable archaeology as it supports the central sustainable principle of supporting alternative, creative viewpoints. In short it allows people to "think differently".

This research is informed by the practice of a sustainable archaeology. It is the practical application of "Pragmatic Eclecticism", which draws from the multivocal and interactive lens in which we make meaning. My motivations for archaeological meaning making are directly a result of a sense of risk and loss of cultural material that I perceive is apparent in the broader field of cultural studies (see Shanks 2012). This sense of loss forces us as archaeologists to make sense of the past for the present (see Shanks and Hodder 1995) without considering the future. Hence in this context, a sustainable "virtual" archaeology allows for the reuse and reinterpretation of the archaeological context for archaeologists and stakeholders alike for the present and the future while respecting the unseen archaeological record, and how we come to variously "see" it.

\subsection{The Virtual (re)Imagination and Meaning-Making of an Iroquoian Longhouse}

To test these notions of making, wayfaring, tacking and meaning-making within VA, I needed first to digitally (re)imagine an archaeologically informed interactive virtual environment. The process of designing, developing and implementing virtual archaeological data is a relatively new approach to Iroquoian archaeological research and broader knowledge dissemination within Ontario, although physical world public interpretive reconstructions and case studies of experimental archaeology have been undertaken over the last several decades (as examples see Fecteau 1979; Williamson 2004; Wright 1974, 1995). As such, my VA research reflects on my own and participants' experiences of interpreting the data from a visual knowledge building perspective, while addressing and developing protocols to address agency, authority, authenticity, transparency and traditional Iroquoian archaeological research within virtual reality. 
By virtualizing an Iroquoian longhouse and by disseminating this project by means of social media and direct participant engagement to the archaeological community, I gained additional insight into how archaeologists conceptualize and "understand" these unique residential structures through the archaeological data they uniquely recover, interpret, and "translate" into description and narrative. What I was most interested in exploring is how these archaeological understandings, as built environments and material spaces foreign to archaeologists' own lived experiences but culturally and materially understood within the daily lives of ancient peoples (see Ferris 2013), arise in interpretive models of this record.

The first stage of my research consisted of reviewing the available scholarly literature and then building a virtual ancestral northern Iroquoian longhouse that generally conforms to $16^{\text {th }}$ century archaeological longhouse data, while interrogating the multitude of detailed physical characteristics of the above ground materiality and space created around and within those longhouses, which can only be assumed archaeologically (Carter and Barr 2016). This also included reviewing relevant material culture literature, experimental archaeology observations and experiences, along with archaeological community participation, in order to help inform the creation of representative 3D assets (digital artistic components used in the longhouse build). These assets then served as templates and as a technical framework for the development of the virtual Longhouse environment (Carter and Barr 2016).

Using traditional 3D animation and visual effects, as well as film, television and gaming production techniques derived from twenty years of personal production experience, and following previous test projects conducted at Sustainable Archaeology, I engaged a professional technical artist to complement the creation, production and deployment of the virtual Longhouse environment. Using a conventional film and television clientservice provider production model, I worked with the 3D computer artist through my direction and informed by written, visual and verbal archaeological research and opinion, which served as the basis for my "artist's impression" of the assets to be built within the 3D environment (see Frankland 2010). As this archaeological data became a 3D visual reality, I reflexively made course corrections based on; i) new research I became aware of; ii) comments from the archaeological community; or iii) limitations in the artist's 
rendering , technical abilities and software capabilities. Likewise, inherent hardware and software limitations to achieve the representation desired at a resolution preferred also became points of decision-making. At all stages, as the virtual environment was being researched and built, these decisions, observations and experiential workarounds were documented by a "paradata" process (Bentkowska-Kafel et al. 2012; Denard 2012), allowing me to reflexively consider the nature of the archaeological, historical, oral and experimental information I was utilizing, as well as my own direction, interpretation and expectations of the content being developed (see Carter and Barr 2016).

Paradata is essentially a diary or blog of the thoughts, methods and techniques (see Appendix A) used to negotiate the cultural historical, archaeological and technical challenges I made through a conscious effort to communicate the decisions, anxieties and reflections by making meaning of the archaeological record in an open, community based environment (see Beacham 2006; Bentkowska-Kafel et al. 2012; Denard 2012; Huvila 2013). This proved immensely valuable as it situated my research and allowed community participation, which in turn further informed my knowledge making. Participants from many backgrounds; Indigenous, professional, academic and the public itself were able to follow the trials and tribulations of the project, and organically participate through the raising of additional questions, providing valuable feedback and directing me to new knowledge. As such, this became the archive of the projects' decisions and meaning-making as well as a valuable crowdsourcing of multivocal knowledge. More importantly it is the physical manifestation of Alison Wylie's (1989, 1993, 2002) notions of making overt what she argues is covert in conventional archaeology - the "tacking" or wayfaring points that are usually hidden in archaeological meaning-making. This was an experiential process and as such, when new theoretical, methodological, technical, artistic or archaeological data was discovered, suggested, contested or created, it was measured for fit within the project and incorporated accordingly (see Appendix A for a full example of the paradata process).

The second stage of my research involved the interaction of individuals within the virtual longhouse environment to test the utility of the model presented, the potential of VA to engage with and advance archaeological cultural historical studies, all in order to reveal 
the operational logics archaeologists use to inform their interpretive understandings of ancient material spaces. This stage consisted of pre-participation questionnaires, semistructured interviews during and after engagement, and observing participant behaviour within the longhouse virtual environment. Working with heritage stakeholders, I sought participants representing specific knowledge of the archaeological record of ancestral northern Iroquoians. These participants encompassed: i) academic and professional archaeologists who have had limited exposure to VA, but moderate to substantial experience working with ancestral northern Iroquoian archaeology; ii) academic and professional archaeologists who have moderate to substantial exposure to VA, but more limited experience working with northern Iroquoian archaeology; and iii) heritage professionals from descendent populations, who have or have not had experiences with VA, but do have experience in knowledge of Iroquoian archaeology/history/material culture. To develop a representative base, I sought a broad set of adult individuals in age, gender, professional experience and backgrounds. My goals were to: i) document overt participant preconceptions for both their anticipated VA experience and longhouse environments; ii) observe how participants engage with and choose to interact with the virtual longhouse; iii) observe and discuss how participants perceive the virtual environment in terms of authenticity, authority and agency; iv) document their interpretation of the representation and placement of digital assets, landscapes and built structures; as well as v) record any alternate meaning-making they themselves expressed or advanced after interacting with this virtual environment.

\subsection{Going Forward}

This dissertation is constructed in two parts. The first is a fully realized archaeologically informed, 3D interactive and immersive virtual (re)imagination of a Late Woodland, $16^{\text {th }}$ century Iroquoian longhouse built on a Unity game engine platform, along with an accompanying paradata blog website (see Appendix A). The second part of this dissertation is in the format of a three-paper dissertation, with an introduction and concluding chapter. It is intended that the virtual (digital) and written material inform this dissertation equally. 
I am exploring the potential of VA to engage with and make meaning differently from the archaeological record, and as such, this dissertation is interrogating archaeological knowledge and meaning-making. The vehicle for doing this is the archaeology of the Late Woodland, and specifically the predominant form of residential structure documented archaeologically - the longhouse - and especially the form of the longhouse found during the latter part of Late Woodland in the northeast (post ca. AD 1400). While I will also be exploring ethnohistorical data and oral histories about the longhouse, I will be doing so strictly from within the ways archaeologists engage with these datasets, to inform their understandings of the longhouse. Likewise, while I acknowledge Indigenous ways of knowing these structures and spaces in the past and present differently and as contemporary experts of longhouse construction and living, and sought feedback from Indigenous users of the virtual longhouse created, for this dissertation I wanted to focus solely on archaeological ways of making meaning of the Indigenous ancient past. However, I believe based on the research presented that VA affords the opportunity to build a common space where archaeological and Indigenous ways of knowing can be engaged with equally and separately, but that is a subsequent stage of this research program, apart from what the dissertation specifically embarked on, and one that obviously will need to be a collaborative negotiation of wayfaring points and paradata along the way to such an Indigenous VA.

In Chapter 2 I will discuss the foundations of VA, comparing Paul Reilly's initial vision of the future of VA in 1985 and 1991 with its application and use today. We will explore the theoretical underpinnings, or lack thereof, of VA to understand how we as makers of meaning fit within the VA knowledge creation process. How Gillings (2005) created a call-to-arms building upon Reilly $(1985,1989,1991)$ to enable a theoretical approach to VA, and how, since then, those aims have still not been met (see Beale and Reilly 2014; Reilly 2015a, Reilly 2015b; Reilly, Todd, and Walter 2016). I will look at the recent shift to approaching VA frameworks embodied in the London Charter and how those frameworks may or may not support an engaged and transparent knowledge translation and mobilization process. Lastly this chapter will discuss the archaeologist as maker of meaning within virtual space as a new form of VA epistemology.

Chapter 3 will put theory into practice as I explore the use of VA through the development of three VA projects over the course of 5 years. The notion of procedural 
knowledge creation: ${ }^{1}$ the ability to freely change knowledge construction in real-time, is discussed in Longhouse 1.x. In Longhouse 2.x I shifted from the actual application of archaeological and cultural historical data as being the base for archaeological visualization to the use of non-archaeological, animation \& gaming industry-centric methodologies in the service of real-time visualization of a cultural historical site. Lastly in Longhouse 3.x, I combine the process of making and the technical, theoretical, cultural historical and archaeological sensibilities in the construction, translation and mobilization of archaeological meaning-making.

Chapter 4 focuses on the deployment of Longhouse 3.x within an archaeological stakeholder community, comparing and contrasting the realities of personal knowledge interpretation and visualization with their consumption and own personal meaningmaking within VA. I will compare and contrast the process of knowledge construction through the virtual creation process in Chapter 3 and the passive knowledge creation of non-maker participants within already constructed virtual archaeological spaces. I will consider if, through meaningful engagement, sustained analysis, and critical reflection with the archaeological material within VA it brings us to what Earl and Wheatley (2002) and Gillings (2005) consider to be the third stage of theoretical assimilation into the overall archaeological discipline.

Chapter 5 concludes with a reflection on the stated aims from this chapter and the assertion that VA has reached the critical third stage of assimilation within archaeology after almost 25 years of contestation, technological advances and theoretical maneuvering. It will outline next steps, new knowledge created and discuss the implications of solidifying or not, new ways of knowing not as VA but as a broader meaning-making in archaeology.

\footnotetext{
${ }^{1}$ See Gillings 2005 for the conceptual theoretical notion of procedural modeling in virtual archaeology.
} 


\subsection{References}

Beacham, Richard

2006 Oh, to Make Boards to Speak! There is a Task! Towards a Poetics of Paradata. In The Virtual Representation of the Past, edited by M. Greengrass and L. Hughes, pp. 171-178. Farnham, Ashgate.

Beale, G, and P Reilly

2014 Additive Archaeology: The Spirit of Virtual Archaeology Reprinted. In Archaeological Research in the Digital Age: Proceedings of the 1st Conference on Computer Applications and Quantitative Methods in Archaeology Greek Chapter (CAA-GR), Institute for Mediterranean Studies - Foundation of Research and Technology (IMS-FORTH), edited by C. Papadopoulos, E. Paliou, A.

Chrysanthi, E. Kotoula, and A. Sarris, pp. 122-130. Rethymno.

Bentkowska-Kafel, Anna, Hugh Denard, and Drew Baker (editors)

2012 Paradata and Transparency in Virtual Heritage. Farnham, Ashgate.

Carter, Michael, and Craig Barr

2016 Lh3 .x: A Virtual Late Iroquoian Longhouse (Re)Imagination. Electronic Document. Sustainable Archaeology and the Museum of Ontario Archaeology, London, Canada.

Dallas, Costis

2007 Archaeological knowledge, virtual exhibitions and the social construction of meaning. Archeologia e Calcolatori(1): 31-63.

2009 From artefact typologies to cultural heritage ontologies: or, an account of the lasting impact of archaeological computing. Archeologia e Calcolatori 20: 205221.

2015 Curating Archaeological Knowledge in the Digital Continuum: from Practice to Infrastructure. Open Archaeology 1(1): 176-207.

Denard, Hugh

2012 A New Introduction to the London Charter. In Paradata and Transparency In Virtual Heritage, edited by A. Bentkowska-Kafel, D. Baker \& H. Denard, pp. 57-71. Farnham, Ashgate.

Earl, Graeme

2013 Modeling in Archaeology: Computer Graphic and Other Digital Pasts. Perspectives on Science 21(2): 226-244.

Earl, Graeme P., and David Wheatley

2002 Virtual Reconstruction and the Interpretative Process: A Case Study from Avebury. In Contemporary Themes in Archaeological Computing, edited by David Wheatley, Graeme P. Earl, and S. Poppy, pp. 5-15. Oxbow Books, Oxford. Fecteau, R D

1979 The Longhouse Experiment. KEWA: Newsletter London Chapter, Ontario Archaeological Society 79(2): 1-3.

Ferris, Neal

2013 Place, Space, and Dwelling in the Late Woodland. In Before Ontario: The Archaeology of a Province, edited by Marit K Munson and Susan M Jamieson, pp. 99-111. McGill-Queen's Press, Montreal and Kingston.

Ferris, Neal, John R Welch, and Aubrey Cannon 
2013 Towards a Sustainable Archaeology. In Archaeology and Sustainability, edited by Scarlett Chiu and C. Tsang, pp. 387-410. Center for Archaeological Studies, Research Center of Humanities and Social Sciences, Academia Sinica, Taipei, Taiwan.

Frankland, T.J.

2010 A CG Artist's Impression: Depicting Virtual Reconstructions Using NonPhotorealistic Rendering Techniques. In Thinking Beyond the Tool: Archaeological Computing and the Interpretative Process, edited by Angeliki Chrysanthi, Patricia Murrieta-Flores, and Constantinos Papadopoulos. Archaeopress, Oxford.

Frankland, Tom, and Graeme Earl

2011 Authority And Authenticity in Future Archaeological Visualisation. In Proceedings of Ads-Vis2011: Making Visible the Invisible: Art, Design and Science in Data Visualisation: 62-68.

Frischer, Bernard, Franco Niccolucci, Nick Ryan, and Juan Barceló

2000 From CVR to CVRO: The Past, Present, and Future Of Cultural Virtual Reality. In Proceedings of the International Symposium on Virtual Reality Archeology and Cultural Heritage (VAST'00), edited by F. Niccolucci British. Archaeological Reports, Vol. 834: 7-18.

Gillings, Mark

2005 The Real, the Virtually Real, and the Hyperreal: The Role of VR in Archaeology. In Envisioning the Past: Archaeology and the Image, edited by S., Smiles and S. Moser, pp. 223-239. Blackwell, Oxford.

Huvila, Isto

2013 The Unbearable Complexity of Documenting Intellectual Processes: Paradata and Virtual Cultural Heritage Visualisation. Human IT: Journal for Information Technology Studies as a Human Science, 12(1): 97-110.

Ingold, Tim

2011 Being Alive: Essays on Movement, Knowledge and Description. Routledge, New York.

Klejn, Leo S

2006 A History of Archaeological Thought. European Journal of Archaeology 9(1): $141-143$.

Law, John

2004 After Method: Mess in Social Science Research. Routledge, New York. Moser, Stephanie, and Sam Smiles

2008 The Image in Question. In Envisioning the Past: Archaeology and the Image, edited by S. Moser and S. Smiles, pp. 1-12. Blackwell Publishing Ltd, Oxford.

Pearce, R., MacDonald, R., Smith, D., Timmins, P., and Warrick, G.

2006 Bruce Trigger's Impact on Ontario Iroquoian studies. In The Archaeology of Bruce Trigger: Theoretical Empiricism, edited by R. F., Williamson, and M. S. Bisson, pp. 114-134. McGill-Queen's University Press, Montreal.

Perry, Sara

2015 Crafting Knowledge with (Digital) Visual Media in Archaeology. In Material Evidence. Learning From Archaeological Practice, edited by R. Chapman and A. Wylie, pp. 189-210. Routledge, New York and London. 
Preucel, Robert W, and Stephen A Mrozowski

2010 The New Pragmatism. In Contemporary Archaeology in Theory: The New Pragmatism, edited by R.W. Preucel and S.A. Mrozowski, pp. 1-50. Wiley, New York.

Reilly, P.

1989 Data Visualization in Archaeology. IBM Systems Journal 28(4): 569-579.

1991 Towards a Virtual Archaeology. In Computer Applications in Archaeology, edited by K. Lockyear and S. Rahtz, pp. 132-139. British Archaeological Reports, Oxford.

2015a Putting the Materials Back into Virtual Archaeology. In Virtual Archaeology (Methods and Benefits), edited by D. Hookk, pp. 12-21. The State Hermitage Publishers, St. Petersburg.

2015b Additive Archaeology: An Alternative Framework for Recontextualising Archaeological Entities. Open Archaeology 1(1): 225-235.

Reilly, Paul, Stephen Todd, and Andy Walter

2016 Rediscovering and Modernising the Digital Old Minster of Winchester. Digital Applications in Archaeology and Cultural Heritage 3(2): 33-41.

Shanks, Michael

2012 The Archaeological Imagination. Left Coast Press, Walnut Creek, CA.

Shanks, Michael and Ian Hodder

1995 Processual, Postprocessual and Interpretive Archaeologies. In Interpreting Archaeology: Finding Meaning in the Past, edited by A. Alexandri, V. Buchli, J. Carman, I. Hodder, J. Last, G. Lucas and M. Shanks, pp.145-165. Routledge, New York.

Spector, Janet

1993 What this awl means: Feminist archaeology at a Wahpeton Dakota village. St. Paul, Minnesota Historical Society Press.

Trigger, Bruce $\mathrm{G}$

1991 Distinguished Lecture in Archeology: Constraint and Freedom - A New Synthesis for Archaeological Explanation. American Anthropologist 93(3): 551-569.

2006 A History of Archaeological Thought. Second edition. Cambridge University Press, New York, NY.

Watterson, Alice

2014 Engaging with the Visual: Re-Thinking Interpretive Archaeological Visualisation. Ph.D. dissertation, Digital Design Studio, The Glasgow School of Art, Glasgow, UK.

2015 Beyond Digital Dwelling: Re-thinking Interpretive Visualisation in Archaeology. Open Archaeology 1(1): 119-130.

Watts, Christopher M.

2009 Coming to our Senses: Toward a Unified Perception of the Iroquoian Longhouse. In Archaeology and the Politics of Vision in a Post-Modern Context, edited by J. Thomas and V. Jorge, pp. 209-224. Cambridge Scholars Publishing, Newcastle. Williamson, Ronald F

2004 Replication or Interpretation of the Iroquoian Longhouse. In The Reconstructed Past: Reconstructions in the Public Interpretation of Archaeology and History, edited by John H. Jameson, Jr., pp. 147-166. Altamira Press, New York. 
Wright, J.V.

1974 The Nodwell Site. Archaeological Survey of Canada Paper 22. National Museum of Canada, Ottawa.

1995 Three dimensional reconstructions of Iroquoian longhouses: A comment. Archaeology of Eastern North America 23: 9-21.

Wylie, Alison

1989 Archaeological Cables And Tacking: The Implications of Practice for Bernsteins' 'Options Beyond Objectivism and Relativism'. Philosophy of the Social Sciences 19(1): 1-18.

1993 A Proliferation of New Archeaologies: "Beyond Objectivism and Relativism." In Archaeological Theory: Who Sets the Agenda?, edited by N. Yoffee and A. Sherratt, pp. 20-26. Cambridge University Press, Cambridge.

2002 Archaeological Cables and Tacking: Beyond Objectivism and Relativism. In Thinking from Things: Essays in the Philosophy of Archaeology, University of California Press, Berkeley, pp. 161-167. University of California Press., Berkeley and Los Angeles. 


\section{Chapter 2}

\section{The Making of Virtual Archaeological Thought}

Emboldened by the power and authority of 20 years of professional computer animation skill and practice, I initially succumbed to the fetishization of technology (see Huggett 2004), claiming providence and mastery of 3D animation and Virtual Reality (VR) within archaeology. Like many who have come before me, I originally saw Virtual Archaeology (VA) method and practice as a means in which to visualize the archaeological record with little regard to the theory, reflexivity or meaning-making implicit in the act. Indeed, the outcome of many early visualizations was the zombification of content in which the participant, as a virtual visitor, wandered aimlessly through quasi-representational reconstructions of archaeological landscapes, passively looking - but without seeing - meaning, interaction or even justification.

Notwithstanding this predominant impression of what it has meant to do VA over the last couple of decades, it is also fair to say that VA has benefitted from the interwoven cabling (see Wylie 2002) of a relatively small cadre of scholars who have been more reflexive, and able to advance a notion of a more theorized VA. People such as Reilly, Zubrow, Gillings, Earl \& Wheatley, Huggett and Dawson, Levy \& Lyons, all of whom grounded archaeological notions within a desire to negotiate the tensions of what it means to make meaning within the VA archaeological environment. For me, these scholars have imprinted on me what I believe is a novel approach towards a VA theoretical foundation. Reilly (e.g., 1991) provides a framework for VA by the convergence of archaeological practice within technology. Zubrow (2006) questions the dualities of archaeological method and theory within Virtual Archaeology for which VA actors and agents scaffold into a broad theoretical VA base. Gillings (2005) initiates a methodology in which Earl and Wheatley (2002), Frankland (2010), Frankland and Earl (2011), Bentkowska-Kafel et al. (2012), Denard (2012), Perry (2015) and Watterston (2015) have all exemplified as a means of a balanced process between the tools, skills and theoretical construction of knowledge. Dawson, Levy and Lyons (2011) demonstrate that public and more importantly, indigenous stakeholder engagement within VA is a 
shift beyond basic consumption to one that enables a deep connection to the material past and differing ways to make meaning of that past. Huggett (2015) and his "Grand Challenges" of VA move us beyond just technological tool use into a final stage of archaeological epistemology. Finally, to these VA researchers, I would also add Ingold $(2007,2010,2011,2013)$, who provides an unlikely theoretical structure, not necessarily virtual archaeologically focused, but nonetheless epistemologically relevant to the creation of virtual archaeological thought. Below I will attempt to unpack the ideas these authors, beginning with Paul Reilly, the archaeologist-cum-archeotechnovisionary, threading my way through some of VA's supporting actors and harnessing Tim Ingold's notions of making and meaning-making as a novel and empowered means of conceptualizing a virtual archaeological knowledge construction.

\subsection{Defining Virtual Archaeology}

Virtual archaeology has been variably understood as a definitional concept, and as a set of practices, methods and theoretical implications within the broader discipline of archaeology (see as an example Barceló et al. 2000; Barceló 2000; Frischer et al. 2000; Frischer 2008; Miller and Richards 1995; Zubrow 2006). Paul Reilly coined the term "Virtual Archaeology" in 1991 as a means to establish a dialogue in which new ways of negotiating the archaeological record through the digital intersection of archaeological practice and theory could be engaged (Beale and Reilly 2014; Reilly 1985, 1991). Since then and as Reilly freely admits, the use of "virtual" to describe the construction of archaeological knowledge through technology has been conflated with the public's perception of "virtual reality" and thus has entirely become ocular centric, ignoring the founding tenants of Reilly's intentional use. The term now popularized by digital and public archaeologists has seeped into the consciousness of archaeologists and public alike, making VA a victim of its own pop-cultural reference. But for Reilly, VA was to be a "sandpit", a digital play-space, in which to tease out new archaeological knowledge by engaging in the duality of archaeological data and visual representation and interpretation of that data (Paul Reilly, personal communications, May 2016). So the emphasis was not necessarily a novel way of visualizing the archaeological record per se, 
but a way in which new archaeological knowledge could be made. Those who are passionate about VA as well as those who casually use VA as a convenient "catch-all" phrase, need to move past just paraphrasing Reilly and dig deep into what VA really meant when he coined the term (see Reilly 1985 as well as Beale \& Reilly 2014).

Using Reilly's notions, and following Eiteljorg (2000), my definition of VA would be that it is the intersection of archaeological practice and digital visual technologies through the construction of knowledge. Critically, it encompasses the process of meaningmaking; that the being in the moment encompassing all the decisions, course corrections, networked lines of knowing that entails (as well as the skill, artistic impressions and theoretical grounding) that constitutes "making." It is through this process of VA making that brings new knowledge and differing ways of knowing the past to the archaeological record. To me, this is the aim, and strength, of a Virtual Archaeology. I am unconcerned with the platform or delivery, only with the notion that the knowledge creation and dissemination we create is virtually produced.

\subsubsection{Defining the User}

Throughout this paper my emphasis will be on the archaeologists who are "producers" of VA. They are the individuals who have harnessed the academic and technical skills to produce archaeological knowledge by means of VA. They have taken time to interrogate what it means to produce virtual archaeological knowledge and question the means and methods in which to convey that knowledge. The intent is not to elevate their position as gatekeepers of archaeological meaning-making, but to reflexively acknowledge the role of the virtual archaeologist as narrators of archaeological material culture within the virtual environments. I also speak of the "public," who, because of technological advances in image capture, data analysis and even 3D visualization, can now be both “consumers" and "producers" of archaeological knowledge (see Richardson 2013). For my purposes, the "public" per se is any user of virtual archaeological content who is not a virtual archaeologist. This includes a wide range of stakeholders such as archaeologists with no ability to create a VA, heritage professionals and other researchers, descendent 
groups and those who variously connect directly with the heritage of that content, and the general public at large. They may lack the grounded notions of what it means to make archaeological meaning virtually, but they are no passive participant simply content to be fed curated information, either. Now they are reflexively engaging with and contributing to the creation of new knowledge and meaning of the past (see Dawson et al. 2011; González-Tennant 2010, 2012, 2013). They are active users in the consumption of VA and have the potential to outstrip archaeologists in the production of digital material that is archaeologically informed (see Richardson 2013).

\subsubsection{Defining Presence within Virtual Reality}

Presence within VR is the sense of being fully immersed within the time, context, or space virtually represented within a 3D environment (see Dawson et al 2011). Presence relies on stimulating stored memory perceptions triggered phenomenologically through elements such as sight, smell, touch and sound which enables the participant to draw parallels between those previous lived experiences and the imagined virtual environment in which they are immersed (see Gibson 1986; Merleau-Ponty 1964). As presence is an illusionary subjective experience that draws from personal memory, each participant will make individual meaning of the virtual objects and environments presented (see Slater and Wilbur 1997). Thus presence enables meaning-making through the "correspondence" of the user and the virtual material in which they engage (see Ingold 2013). Therefore, VA within the context of immersing the user within (re)imagined virtual archaeological space, is the construction of new knowledge through the sense of presence.

Ivan Sutherland's work on human interaction within virtual environments in the 1960's cemented the notion of a human being able to physically interact within a virtual "digital" environment (Sutherland 1965; see also Frischer et al. 2000; Klein 2007). Sutherland created physical user-engaged devices that allowed humans to engage with virtual worlds in combination with ocular and sensory environmental tools. Sutherland called these engagements visual realism, virtual worlds and augmented mixed reality (Frischer et al. 2000). For Sutherland:

The ultimate display would, of course, be a room within which the computer can control the existence of matter. A chair displayed in such a room would be good 
enough to sit in. Handcuffs displayed in such a room would be confining, and a bullet displayed in such a room would be fatal. With appropriate programming such a display could literally be the Wonderland into which Alice walked

Sutherland 1965:508.

He clearly envisioned the notion of presence in a dualistic manner, in which the digital world would enable a physical life-like experience. Like Sutherland, Dawson, Levy and Lyons (2011:389) suggest that the notion of presence within virtual reality is two-fold, in which presence "...involves feelings of being transported to another place or time ("you are there') or of objects being transported from the virtual world into the user's physical environment ('it is here')." Both simulate through the application of combined digital and physical senses; sound, smell, touch, sight and even taste to envelope the user temporally and contextually as well as digitally and physically. Stuart Jeffery suggests that VA is more than just data-driven representations; we experience the world in creative intangibles, the ability to interact with the past physically and intellectually (2015). That sense of presence or the willing "suspension of belief" is strongly driven by narrative (Jeffrey 2015:150). Erik Champion (2015) builds upon the concept of a narrative driven experience and describes the notion of "presence" within virtual heritage as being culturally situated. He states that culture presence is "...the feeling of being in the presence of a similar or distinctly different cultural belief system..." (Champion 2011:179), and as such, cultural agents may be overtly projected such as simulated avatars, or as innocuous as 3D representations of cultural objects and landscapes within a virtual space, and all contributing towards cultural narrative (Champion 2015; see also González-Tennant 2013). For my purpose, the notion of "presence" is a state of reflexivity within a virtual space in which the user may experience narrative driven cues that elicit cultural, temporal or contextual emotions and knowledge building both physically and digitally within a heritage environment.

\subsection{Setting the Stage for Theorizing Virtual Archaeology}

Virtual Archaeology has on the whole failed to construct a solid foundation upon which to build robust archaeological inquiry (Reilly 2015). Rather, practice has been distracted 
by the application of the tool as a novelty, as a visual aid within archaeology, with little consideration of how these tools can expose and even shape our understandings of the archaeological record (Dallas 2007; Gillings 2005; Huggett 2012). Despite these failings, VA has become a powerful means of presentation and interpretation of archaeological landscapes and artefacts - a unique tool for knowledge building, meaning-making and heritage accessibility (e.g., Dallas 2009; Earl 2013; Forte 2014a, 2014b; Huggett 2013; Perry 2015). It has become a "mediating tool" between the knowable and unknowable dimensions of the archaeological record, allowing researchers to experiment with their data and to tease out the tensions that arise from limited and multiple conceptions of the past - a multi-sourced and even multi-vocal environment created to "stimulate interpretation," explore alternative tellings of the past, and advance new research directions in archaeology (Dallas 2009; Earl 2013; Huggett 2013). Nonetheless, while the practice/study/craft of archaeological visualization has managed to present itself and its output as representative of archaeological meaning-making and authoritative presentations of the past, this has occurred without the practice really establishing the basis for that authority (see Earl 2013; Perry 2015). Thus the "Grand Challenges" VA represents within the broader field of archaeological theory and method is going beyond the perceived notion of the technology being a novel means to illustrate archaeological data, and to demonstrate that VA can be a transformative vehicle to engage with material pasts in a way that allows for multiple visions of that heritage to be represented, tested and valued (see Huggett 2015).

Jeremy Huggett (2013) separates three distinct phases of computer-engaged archaeology consisting of: computer archaeology, which drew from a purely scientific pursuit of analyzing quantitative data from the 1950's to the 1980's; archaeological computing from the 1970's to the 1990's, which began to see archaeological data as dynamic yet still scientifically driven; and finally digital archaeology, which has shifted the focus away from data per se to more user directed and created interpretations of data. Each phase has been punctuated by a sharp increase in the use of technology to support archaeological practice, primarily as a tool set to analyze and visualize archaeological data. However, with the inclusion of VA in the late 1980's, there has been a convergence from technology and data driving user engagement to today's modern digital archaeology in which technology and data is driven by user engagement, controlling the 
narrative and thus deeper reflections of archaeological meaning-making. As such, as archaeologists, we are now generating narrative content that allows non-archaeologists to differently engage and make meaning from that data.

We are now at a stage within the digital archaeology phase where a new breed of "trained digital" archaeologists such as Allen (2016), Cox (2012, 2015, 2016) and Masinton (2016) are emerging digital archaeological practitioners who were born in an era in which digital technologies is ubiquitous to the daily routine of life and work in society generally, and in archaeology in particular. For these scholars, a digital framing of archaeological theory and method is intuitive to how they negotiate their practice, and posess what is called in the study of entrepreneurship the "talent triangle" (Wise 2006): i.e., technical, creative and domain knowledge all equally supporting each other. As such, the shift in VA is moving away from what Huggett had called the "fetishization of technology" (2004), or to paraphrase, what I would call the "fetishization of the image," and have moved towards the actual "making of things" (Beale and Reilly 2014; Reilly and Beale 2015; Reilly 2015; see also Ingold 2007, 2011, 2013).

Huggett's (2013) third stage of a digital archaeology aligns with earlier predictions of an eventual maturing of a VA (Reilly 1996; see also Earl and Wheatley 2002; Gillings 2005), in which VA is no longer about the technology but about a unique means of knowledge creation, dissemination and meaning-making in archaeology. It informs producers and consumers of archaeological knowledge alike, informs and is informed by the methods of creating meaning, and shifts from end product production to the journey of making as informed by the knowable and unknowable dimensions of the archaeological record (see also Eiteljorg 2000).

\subsection{Conceiving of a Virtual Archaeology as Interpretive Archaeology: Actors and Agents}




\subsubsection{Paul Reilly}

Paul Reilly’s (1991) term "Virtual Archaeology" was meant to encompass new ways of negotiating and digitally representing archaeology through novel visualization and data analysis, which would enable a critical reflexivity on archaeology through technological innovation. Lead by archaeologist Birthe Kolijbye-Biddle, IBM researchers Andy Walter and Stephen Todd, Reilly and this unique team, sought to innovate the investigation in the 1980's of the Old Minster of Winchester by developing a virtual reconstruction, using 3D computer graphics to construct and animate this place within a 3D space (Reilly 1991; Reilly et al. 2016). The intention was to research and develop computational processes to capture traditional archaeological data within computational data modeling that could be stored, referenced, made interdependent and retrievable not only within the field but during the post excavation analysis (see Boismier and Reilly 1988; Reilly and Richards 1987; Reilly 1989). There was a duality to the application of the term virtual in which the data sets informed the simulated graphical archaeological formation of knowledge but were always bound by a digitally reflexive interpretation of that data.

In Reilly's eyes, VA was to be a means in which to tease out new archaeological knowledge by engaging in this duality (Paul Reilly, personal communications, May 2016). So the emphasis was not necessarily a novel way of visualizing the archaeological record per se, but a way in which new archaeological knowledge could be made. The spirit of VA as Reilly coyly remarked more than 25 years after, is "not about what was and what is," but about "what might come to be" (Beale and Reilly 2014:124). For Reilly, archaeological data provide the foundation for knowledge construction and has for the most part driven archaeologist-based VA.

Other early VA enthusiasts such as Barceló (2000, 2001; Barceló et al. 2000; Frischer et al. 2000) and Forte (2011; Forte and Siliotti 1997) saw value in the early digital processing of data in which computerized scientific modelling was the driving force for archaeological visualization. For Barceló (2000), computer modelling was about computing variables through algorithms to reveal patterns that explained archaeological site locations across landscapes and across time without visualizing those landscapes, 
without knowing space between these dots. In many ways, this was an antithesis of a VA and more a static calculus for a geography through time (see also Daly \& Evans 2006).

However, technology also democratizes data, allowing consumer and producer to intermingle (Paul Reilly, personal communication, May 2016; see also Zubrow 2006). Specifically, Reilly saw the process of accepting VA as a viable presentation of archaeological data as two-fold: the public first, followed by an acceptance in the archaeological community as a tool to provide meaningful insight into the material past. A "catalyst for visualization," then, was not in the construction of new archaeological knowledge, but through a repurposing of archaeology beyond archaeology for public consumption (see Reilly 1996:43). Certainly the majority of virtual archaeological projects over the last 20 years has been primarily public facing and universally attempts to visualize existing knowledge (see Barceló 2000; Daly and Evans 2006; Forte and Siliotti 1997; Frischer et al. 2000). For Reilly, then, this was a critical first stage that needed to happen in the development of a VA as a conceptual way of making meaning in archaeology. For Reilly (e.g., 1996:42) a shift is now occurring in VA practice in which archeologist centric "exemplary projects" - those transformative, high impact, best practice examples that inform knowledge construction through the visualization of data and the convergence of archaeological practice - increasingly advance VA as a reflexive interrogation of archaeological interpretation and knowledge about the past (see Allen 2016; Cox 2012, 2015, 2016; Masinton 2016; Morgan 2009; Watterson 2014 as examples).

For exemplary projects to cross the boundaries from public consumption of archaeology to internal archaeological knowledge creation, a "culture of visualization" - an acceptance of a VA as a conceptual approach to interpreting the material record (see Reilly 1996:39) - needed to take root in archaeological practice. This began in the early 1990's as "invisible schools of archaeological data visualization" slowly came together (Reilly 1996:46). These schools did not consist of graphically-trained archaeologists, but rather of unskilled archaeologists who worked with experts from outside of archaeology. As a result, an uneven balance lingered in the marriage of archaeological data and the visualization of archaeological interpretation of that data. For Reilly (personal 
communication, May 2016), this uneven balance and lack of internalized expertise in the process and technologies of visualization has meant that it has taken much longer to reach a democratization of visualization technology - i.e., a broad expertise internal within archaeological practice as a result of practitioners' having broad access to relatively inexpensive and intuitive to operate technologies - giving rise to a new generation of "born digital" archaeologists. Attaining this digital democratization was necessary in order to achieve a new stage in practice where "archaeologist", "technologist" and "artist" can now all be embodied within the same practitioner (see Allen 2016; Cox 2012, 2015, 2016; Masinton 2016 as examples), rather than untrained archaeologists having to negotiate digital technicians and artists to generate visualizations that are compromises rather than transformative acts of archaeological meaning-making. With born digital archaeologists applying their expertise to create visualizations, a new era of virtual archaeological epistemology can begin, where archaeologists create and are fully aware of the constraints of technology and archaeological interpretation in their attempts to transform archaeological meaning-making through the visualizations they create. This transformation in the ability and conceptual frame of practitioners enables a born digital lens applied to archaeological practice that holistically encompasses the material record and process of meaning-making within a virtual environment.

\subsubsection{Ezra B.W. Zubrow}

Ezra Zubrow's (2006) work provides one of the first attempts to theoretically position VA as more than just a methodology or practice. By postulating that VA can be seen in two very distinct lights: i) a non-theoretical, methodological tool, and ii) that the process of visualization is a "re-emphasis on the individual as the primary actor" through the use of technology and thus potential creator of new archaeological theory (Zubrow 2006:9), he demonstrates the tensions in which VA lies within the broader context of archaeology proper (Daly and Evans 2006; Forte 2014b; Watterson 2015).

The use of technology within archaeology has traditionally been characterized as being "scientific", firmly grounded by facts and figures and thus objective by nature (see 
Zubrow 2006). As such, the application of a VA should be methodological by nature, repeatable and uninfluenced by personal interpretation. Conversely, archaeological data is interpretive both in the field as well as in the way it is selected for and re-purposed for technological transformation. Thus technology is not immune to the subjective interpretations of its user, enabling archaeologists to play out multiple scenarios and interpretations, mixing, mashing and reinterpreting archaeological data through the fluidity of technological scaffolding. As such, the archaeologist and not the technology is the primary actor in the determinacy of archaeological meaning-making.

Zubrow struggles with the duality or "perceived incompatibility" (Watterson 2014:53) of a VA as methodologically scientific, rigorous and founded on archaeological data, and yet made relative through the process and act of re-purposing that data into virtual contexts (see Dallas 2009; Forte 2014b; Watterson 2014). Our take-away from Zubrow is his genuine attempt to move VA from a technological fetishization (see Huggett 2004) and into the realm of established theory (see Daly and Evans 2006; Zubrow 2006). In recognizing that theory and theory making is inherently foundational within virtual archaeological knowledge creation, he builds upon Reilly's initial notion and purpose of VA (1985) and our goal of understanding the "why".

\subsubsection{Authority, Artistry and Audience}

Since the time that Zubrow engaged with the notion of VA as being theoretically based, a number of scholars have been grappling with some of the conceptual issues and challenges of what virtual archaeological means, and means to archaeological practice more generally. Notably, Gillings (2005) advanced a kind of call-to-arms for any archaeologist constructing knowledge within VA, critically observing that the methodology of visualization within VA has been the "tail wagging the dog" (Gillings 2005: 2). For Gillings the question to counter that rampant enthusiasm for VA is why? Without a reason to seek new knowledge and ways of knowing, VA is constantly stuck in an endless circle of methodological debate (Gillings 2005; 2006). Nonetheless, Gillings saw the potential of virtual reality as transformative in how archaeologists would 
envision the past, that it had "...potential to alter and give rise to new ways of thinking about and interpreting that past" (Gillings 2005:3).

The fetishization that has dominated VA includes both technology and its output (see Huggett 2004). With the use of sophisticated visual effects (VFX) and other visualization techniques within media for everyday public consumption there is an unbalanced expectation that what we as archaeologists produce virtually should be no less than what the public consumes daily. This notion forces archaeology to view visualization as an end product rather than as the journey of knowledge construction. The tendency has been to "apply VR techniques first and then think about them later" (Gillings 2005:1), leaving VA in a "continual state of becoming" (Gillings 2005:5). This notion has consequences in terms of archaeological expectations. Yes, technology has provided a means of rapid prototyping and generating endless iterations of the material past, but this continual generation of product sidelines reflection and meaning-making in favour of bigger and better visual representations without meaning or purpose. Fundamentally, the norm seems to be that technology will solve all problems (e.g., visualizing the knowable and unknowable dimensions of the material past), and in doing so, represent the solution in perfect form. This fallacy leads virtual archaeologists to strive for richer and more embellished visualizations of the past, as opposed to allowing the visualizations to speak for themselves - limitations of data and interpretation included. As much as the technology is fetishized, so is the final product.

Like others discussed here (e.g., Earl and Wheatley's 2002; Huggett 2013; Reilly 1996) Gillings (2005) believed that the utilization of virtual reality in archaeology sat in the middle of three developmental stages, which could be reduced to the notions of novel use, critical self-reflection, and full integration within the discipline. Shifting to critical self-reflection requires moving to a point in which our virtual archaeological pursuits are more than just the final images, interactions or visualizations we produce. "Realism" is a term used extensively within virtual discussions, however we fail to inform those consuming our virtual archaeological visualizations that the level of realism generated does not necessarily correspond with accuracy or authenticity (see Gillings 2005), or, for that matter, authority. Yet if I look at Pixar's recent film The Good Dinosaur (2015), the 
technical wizardry that Pixar deployed to create a hyper photorealistic environment with stylized characters did not detract from the impression it created of a highly authentic, ancient environment in which these characters lived. There is a level in technological production beyond which an audience will have an unquestionable acceptance of what they experience and as such the process of creation masks the "conceptual baggage" (Gillings 2005:5) inherent in the production of those visualizations. Instead Gillings (2005:9) sees virtual models as being "constructs which can never be wholly authentic." Taking that notion further, our "duty-of-care" if you like, is not in generating an accurate final visualization of the archaeological landscape or object but in the acknowledgement that what we visualize is a representation, loaded with baggage, that should be tested, debated and questioned (see also Frankland and Earl 2011).

Earl \& Wheatley (2002) suggest that the anxiety archaeologists feel about the VA process of knowledge construction is primarily due to the dichotomy of the very subjective nature of creative meaning-making, along with what some would say is the perceived objectiveness of technology (see also Eiteljorg 2000). This "spurious authority" (Earl and Wheatley 2002:6) is derived from the notions that computers are intelligent, emotionless tools that generate facts and thus anything produced by them are sacrosanct truths. By extension, computer-aided visualizations produced by archaeologists or nonarchaeologists alike are accurate representations of that data (see Eiteljorg 2000) purely because of the implied technological authority arising from that creative meaningmaking. From a critical perspective, then, what we visualize has a direct correlation to the “artist's impression" during the making stage (Earl and Wheatley 2002:6), a recognition that an artistic eye also informs archaeological knowledge construction. ${ }^{2}$ As Frankland \& Earl (2011:62) posit, "archaeologists are constantly striving to "make visible the invisible.",

\footnotetext{
2 The archaeologist as artist has a long history in archaeology, with illustration playing an important role in knowledge construction, albeit poorly recognized as such (Perry 2015; see also Morgan 2012, 2016; Watterson 2014, 2015).
} 
Understanding the process of the archaeologist as artist as one that creatively builds from the knowable archaeological record to visualize meaning-making from that record facilitates a new way to communicate and interact with the audiences of these visualizations. Notably, Dawson, Levy and Lyons' (2011) work in archaeological visualization created a reflexive interaction of archaeology and audiences, through the virtual representation of archaeological interpretation. By taking the approach that the viewer (either scholar, member of a descendant community, or the general public) is an active participant in the discovery and experience of a VA environment, their work has highlighted the importance of being able to experiment with that interaction and visualization process.

Dawson, Levy and Lyons used a semi-enclosed 3D theatre called a CAVE (Cave Automated Virtual Environment) to project their visualization of a virtual Thule whalebone dwelling. Combined with audio and sound effects, the 3D virtual space and the physicality of the space gave participants a sense of "presence," which in turn elicited an emotional attachment to the environment they were experiencing (Dawson et al. 2011). They were able to use advanced technologies and software to paint a vibrant picture of light, atmospherics and textures that previously in archaeological visualizations had been presented more as lifeless sterile environments. Combined with sound, physicality and 3D environment, the visualization managed to make the experience "emotive" and "effectual" for participants. Within the CAVE environment, Indigenous participants began to recount past memories of oral histories taught to them about life within such structures, mostly now lost visually and experientially (Dawson et al. 2011). Dawson, Levy and Lyons utilized evidence-based data in the creation of their 3D assets and in doing so were able to demonstrate that VA can be both grounded in traditional archaeological methodology while being able to emotionally connect the participant with the material and environment. 


\subsection{4 "Grand Challenges"}

Jeremy Huggett has long offered a reflexive gaze on computer and digital forms of archaeology (e.g., Huggett 1995, 2015), and one of the core themes to his reflexivity focusses on how virtual (digital) archaeology has struggled with the immensity of its ability to fundamentally change how the archaeological record can be interpreted. That we are now fully engaged within a "post-textual archaeological" age (Huggett 1995; see also Sherratt 1993) where archeological data can now not only be consumed but also produced by archaeologist and non-archaeologist alike (Paul Reilly, personal communication, May 2016). There has been an explosion of hardware and software tools available at the consumer level for the production of new content, but also for the dissemination of authentic and non-authentic archaeologically related data, opinions, visualizations and a plethora of other related assets throughout the Internet (Bond 2016). This material can be shared, repurposed, repositioned, politicized, and remixed with authorship solidly in question. Thus for Huggett (2015:81) archaeology's "grand challenges" are to recognize and reflect critically on the application, use and implications of technology within archaeology. By doing so we begin to theoretically position VA and move past it's perceived methodological roots towards paradigm shift in which VA informs and creates new knowledge while acknowledging the challenges in the dissemination of that knowledge.

Examples of the challenges to using digital technologies within archaeology are plentiful. In 1995 as part of a major project led by Carnegie Mellon University, artist Lowry Burgess and computer scientist Carl Loeffler were engaged to develop a new VR project entitled "Virtual Pompeii" (Frischer et al. 2000; Morgan 2009). Heavily supported by what was then the largest computer graphics company in the world - Silicon Graphics Inc. (SGI) - Virtual Pompeii was an ambitious attempt to give the viewing public a firsthand experience through the use of one of the earliest public versions of a VR head mounted display and real-time graphics of life in ancient Pompeii during the Roman era (Frischer et al. 2000; Morgan 2009). However, the project was plagued with the problems right from the start as the developers, neither archaeologists or cultural historians of that era, liberally interpreted the archaeological data, regularly borrowing 
reference material that was completely unrepresentative of the environment they were attempting to reimagine virtually (Frischer et al. 2000). Further, substantial corporate sponsorship from SGI would have added additional pressure to deliver a spectacular test of its technology, forcing the production team to compromise accuracy for visual and real-time interactive effectiveness.

As with "Virtual Pompeii," the visualization attempts of the "Palmyra Arch" is rife with issues surrounding authenticity, authority and transparency. The "Palmyra Arch" project (2015-2016) was conceived by The Institute for Digital Archaeology (IDA) to reconstruct the recently destroyed Palmyra's monumental Roman arch (193-211 CE) in Syria by the hands of ISIS (Islamic State in Iraq and Syria; see Bond 2016). Although it is unclear if the IDA is working on behalf of the Syrian people, their financial backers or the technology they are brokering, the project itself is innovative in terms of the use of technology. Through crowdsourcing images of the arch before its destruction, IDA "stitched" together a facsimile of the exterior visual representation of the $\operatorname{arch},{ }^{3}$ which was then made into a 3D texture map. These series of images were then used to make a 3D envelope model of the object in virtual space, which in turn was fed into a computerized marble cutter, which in essence 3D prints at scale the virtually stitched texture map and model. The technique itself was not the issue. The "need" for virtually recreating the Palmyra Arch and printing copies that appeared in London and New York arose from the urgency the individuals involved in the project felt for saving this heritage. But like "Virtual Pompeii," the project has been unable to answer basic questions of "why" and for "whom" this is needed, and by gesture converts complex, problematic Syrian heritage into a Western appropriation and consumption of replicated conflict archaeology. Technological fetishism has clouded the actual production process, which in turn has not addressed the theory or method of this reconstruction archaeologically, academically or publicly. Like "Virtual Pompeii" it fails to address the basic challenges of VA.

\footnotetext{
${ }^{3}$ As described on the IDA's website: http://digitalarchaeology.org.uk/
} 
Archaeological knowledge has increasingly become democratized by technology, both in terms of the accessibility of ease of use of technology to generate content, and the accessibility to this content by more and more diverse audiences. With this change comes grand challenges to the discipline itself (Huggett 1995), underscoring the point that, just as archaeology more generally has come to realize, all data, whether visualized or not, is “theory-laden" (see also Reilly 1985). Conversely, in this consumer-cum-producer world, archaeological knowledge and in particular the visualization of that knowledge is at risk of production without any theoretical considerations whatsoever (Paul Reilly, personal communication, May 2016). Ultimately the data can and will be used in ways archaeologists never intended. However, archaeology is about the creation of knowledge, the representation in the moment, the questioning and reflection, and not the digital or physical manifestations of material culture (see Huggett and Ross 2004). Huggett (2015) believes that the core of our archaeological exploration is to ask "why." The inadequacies of many VA examples to date to ask that question mean that we haven't taken the time to understand the purpose of virtualizing; that we create imagery and multitudes of raw data without really focusing on the questions we hope to ask and explore within this technique. Data is more than just raw information; it has a purpose and a need in the construction of archaeological knowledge. Thus should the process of making new data, whether virtual or not, constitute a transition from objects to theories (Jeremy Huggett, personal communications, June 2016)?

\subsubsection{Tim Ingold}

If scholars like Reilly are VA visionaries, Tim Ingold is the unintended theoretical foundation to a VA, by offering a range of conceptual framing of the archaeological interpretive process that closely align with the process and implications of a VA. These concepts include “making” (see Ingold 2011, 2013), “wayfaring” (see Ingold 2010b, 2011), "materials and materiality" (see Ingold 2007, 2011) and the act of "being in the moment", of making itself (see Ingold 2011; Perry 2015). Although I would hazard that Ingold may never contemplated transference of this theories to the virtual archaeological world, they nonetheless have resonance in the act of knowledge creation digitally that for 
me provide that theoretical framing of the VA knowledge-making process that builds on the vision for VA set out by Reilly and others.

For example, through the process of making and manipulating the material, and the material - in turn - manipulating the maker, there occurs a series of decision or wayfaring points. Wayfaring is a process for taking stock of the moment in time in which the act of making and the materiality of the raw material requires the artisan wayfarer ${ }^{4}$ to stop, evaluate and make course corrections in order to achieve a representative version of their vision (Ingold 2011, 2013; see also Crawford 2015). In this process encompassing the maker's many wayfaring points of decision-making along the way towards creation, these decisions embody elements of power, agency and authority (Crawford 2015; Ingold $2011,2013)$ that constrain and define the authenticity of the representative virtual form created. As such, virtual artisan wayfarers embody and assert varying technical, creative and archaeological "expertise." This creates a unique perspective to archaeological meaning-making that requires the artist to be more or less reflexive of the power, agency and implicit authority they embed in the process of making within virtual space. Thus wayfaring virtual artists need to transparently negotiate the process between virtual builder, viewer and archaeologist, in order to reveal the "continuous correcting" that occurs as decisions are made virtually through the (re)imagining of 3D archaeological objects or environments (Ingold 2011,2013).

For Ingold, "making is a correspondence between maker and material" (Ingold 2013:xi). As archaeologists, our palette is the excavation itself (see Ingold 2013). It is a negotiation between the physicality of the material and landscape with the construction of interpretation and meaning-making through the act of revealing the past (see Ingold 2013; see also Wylie 2002). However if we take a phenomenological approach, in which all of our senses are engaged through the landscape, materials and the imagined wayfaring points of the maker, we can envision the mindset of the maker of the archaeological material, but also that of the archaeologists who might have interpreted the material

\footnotetext{
${ }^{4}$ Defined as a craftsperson that uses their accumulated knowledge through the reflexive application of the physical, material and materiality of the making process.
} 
previously. Thus, the correspondence is not only contextual but temporal as well (see Spector 1993; Watts 2009). In effect, the virtual construction of archaeological landscapes is multiscaler, in which the maker in the virtual space is variously empathetic to and aware of all temporal agents making in the past; materially and archaeologically.

Ingold points to an exercise called "walking the plank" in which he invites readers to engage in the simple act of sawing a piece of wood (Ingold 2011:51-62). As simple as it might sound, there are a series of interconnected processes both physical and mental that enable the ability for the maker to not only make but also "be" within the synergies of the user, the tool and the material (see Ingold 2011, 2013). In the first stage the user formulates a mental image of what he/she would like to create in the act of making. This mental construction is based on the cumulative organization of knowledge already formed and the influences, agency and authority the user imbues within. Next, tools are chosen and there is a "coupling of action" in which the user and the tool become one, but influencing the other (Ingold 2011). Lastly the material to be worked is added to the symbiotic chain of interdependent elements. The materiality of the material worked upon plays an enormous role in not only how the tools are used but in influencing changes or course corrections of the mental image as represented by the final product (Ingold 2007, 2013). As such the user, the tools and the material all contribute to the construction of a new end product but also in the formation of new knowledge. Making is not about the act itself, but the interplay between the knowledge creator, the tools and the materiality of the construction material on hand. Ingold is clear that the making process is informed by the world in which the maker lives. That all materials and tools (my emphasis) have their own life and contrary to the notion that we as makers impose our reality on the world itself, it is opposite. The conditions of the material, the tool, the environment, aptly dictate the outcomes of the maker's mental map.

Turning our attention to VA then, making within 3D space is informed by the tools, the dexterity and knowledge of the tools by the user, and the medium or materiality of the objects or environments coming into existence. This is an important interplay because as an individual maker, being informed through the process of creating and informing the construction of knowledge, no two virtual representations will ever be the same (see 
Ingold 2013). One can imagine the same processes coming into play for the ancient makers as well. Differences in landscapes, the availability of building materials and each of the construction elements all foster unique instances of composition, as did the talent of the builder's colleagues to work the material and even the weather at the time. Moreover, these only constitute a fraction of the variables to contemplate in the act of making physical a mental concept, whether in virtual or physical space. Thus Ingold brings the realization that the act of making, and of being in the moment, is the means of knowledge creation. Although this research is twofold: the act of making and the interplay of a non-maker experience within a constructed virtual archaeological landscape, both experiences lend themselves to Ingold's notions of being within the moment and allowing the experience to inform archaeological meaning-making.

\subsection{Making Virtual Archaeology Interpretive: Paradata and The London Charter}

Since Reilly's introduction of VA as a call to debate and define the intersection of technology and archaeology, theorists and practitioners have actively engaged in determining a framework in which this new process would or would not fit within the universality of archaeological study and dissemination (Barceló 2000; Beale and Reilly 2014; Dallas 2009; Forte 2014a; Frischer 2008; Frischer et al. 2000; Huggett 2012a, 2012b, 2013, 2015; Miller and Richards 1995; Morgan 2009; Reilly 1989, 1991; Ryan 2001). In an effort to reflect on the tensions of agency, authenticity and authority, stakeholders of all sorts have built various framework iterations in an attempt to ensure transparency in the process of VA meaning-making (Denard 2012; Frankland and Earl 2011; Huggett 2015; Miller and Richards 1995; Moser and Smiles 2008).

\subsubsection{The London Charter}

In 2006 the London Charter was established to help build a framework around archaeological research within a digital era and more specifically on the visualization of archaeological data (Denard 2012). Developed as a roadmap for "best practices," it has 
attempted to address issues of agency, authenticity and authority within archaeological digital media practices by those who are actively engaged in the visual reproduction of archaeological or archaeological-like data and landscapes through a "transparent," holistic framework (Denard 2012). At the heart of the London Charter is a desire for a reflexive transparency with respect to the process by which computer visualizations of heritage material are accomplished (Denard 2012) by making explicit the answers to the question: what steps did the creator take to address the cultural, historical, theoretical and political contexts, among others, that ultimately build on the agency of a particular digital heritage object or environment (Beacham 2006; Denard 2012; Forte 2014b; Frankland and Earl 2011; Gabellone et al. 2013; Huggett 2015; Huvila 2013; Perry 2015)? The byproduct of this transparent process is called "paradata," the ancillary referencing, process and discovery material that is used during the visualization process; essentially "tracking the interpretive trail" that archaeologists, artists, technologists and heritage interpreters make when referencing the available data to envision a viable visualization (Beacham 2006; Denard 2012; Huggett 2015; Huvila 2013; Perry 2015).

\subsubsection{Paradata}

The concept of paradata within archaeology dates back to the early 1990's as a reaction to the notion of traditional archaeological illustration being less than scientific and more about artistic license (see Adkins and Adkins 1989; Huvila 2013). Multiple attempts have been made to both deploy the methodology of paradata as well as frame it within new theoretical interpretations, however its application, as simple as you might think it to be, has been convoluted (Huvila 2013, 2014). The very real and current anxiety over recent technological democratization of software and hardware that allow for easy creation and hyper-real visualizations at the consumer level raises concerns that the production of heritage visualizations, whether grounded in actual data, theory and methodology or not, will influence both researchers and the public adversely into thinking they are seeing and experiencing de facto visual truth (Bentkowska-Kafel et al. 2012; Denard 2012; Frankland and Earl 2011; Perry 2015). 
The framers of the London Charter hoped that if transparency through paradata was at the heart of any heritage-centric, reflexive visualization process, consumers and researchers alike would better understand the elements that influenced the creation of the visualization (Denard 2012; Bentkowska-Kafel et al. 2012; Huvila 2013). By doing so a better grounding of the decision making and where authenticity, authority and ultimately agency of the virtual image produced arose from would help to dispel the notion of the image being "fact" as opposed to being an "interpretation" of the archaeological, heritage or cultural data.

\subsubsection{Agency}

The practice, methods and conceptual interpretation of archaeology are grounded in the basic human need to tell a story (see Zubrow 2006). Even the scientific and minute recording of every detail of an archaeological landscape, an excavation site or the artefacts that reveal themselves in the process, follow a narrative story arc which is crafted by the various players that are brought together in the endeavour (see Ferris 1999). These players include: the people who originally lived lives within the material and landscapes being studied; the archaeologists and all of the associated specialists that assist in the archaeological process; the stewards of the material after the excavation; the public and the descendent stakeholders; and those future researchers, interpreters and consumers of the material. All of these groups carry with them their own perceptions, conventions and canons that contribute to a rich plethora of interpretation and meanings, and even misunderstandings, of the past. Thus authenticity can be as elusive as the narrative that unfolded when the landscape, built environment or even the artefact was crafted by its original creators (Ferris 1999).

In interpreting the archaeological record, we are intentionally making meaning (Ferris 1999; Gosden 2005; Robb 2010; Salmond 2012). Our narratives arise from a specific time and space and in the process of doing so; those meanings are products of the limitations of data and conceptual framings that exist in that moment and in that individual's interpretation of the past (Ferris 1999; Gosden 2005; Robb 2010; Salmond 
2012). We assemble objects and landscapes into a canon of meaning in an attempt to interpret what the archeological record is saying to us (see Gosden 2005). However the process of creating a narrative that makes sense is always only an approximation; in reality we are determining what we think we want the objects to say (see Moser and Smiles 2008).

The same can be said for the virtual environment. Technologists, artisans, and knowledge experts (archaeologists, museologists, historians, Descendants, etc.) variably contribute to the creation of virtual worlds. Each brings with them their own set of meaning-making and in doing so, we need to acknowledge the complexity of virtual heritage meaning-making involved in the process (Frankland and Earl 2011; Perry 2015). We have to move away from the notion that VR is "theoretically neutral" (Gillings 2005) and as such, must recognize the contributions, positive or negative, that have helped to build upon the virtual experience as well as the underlying conceptions of the archaeological data that the virtual world attempts to illuminate. The tension(s) that arise specifically within VA is the need to be "true" to the archaeological data, while reimagining it through the visual narrative process (Moser and Smiles 2008). Virtual reality is an interpretation of self within a different space, time or plane (see Sutherland 1965). It is narrative generating and thus both the technology and the process of creating VR have borrowed heavily from the entertainment industry (Frankland and Earl 2011; see also Denard 2012). In doing so, by taking a creative approach to the interpretation of the archaeological data, the agency of that data is now added to by the logics of that industry, as understood by and seen through the creators' lens; what "artist's impression" intend the virtual space to convey (see Earl 2013; Frankland and Earl 2011; Frischer et al. 2000; Moser and Smiles 2008; Perry 2015).

However, subjective layering is nothing new to the archaeological process. Archaeologists must unpack and make meaning of the material culture left behind in order to provide interpretive insight. That interpretive insight, by default, is archaeologist-centric and reflects the values and logics of that "industry" and "artist." But with the democratization of the visual medium and its production process, a tension has developed between the archaeological researchers' need to continue to engage in 
traditional scientific interpretation, and the seemingly endless ability for nonarchaeological stakeholders to remix, reinterpret and essentially reimagine archaeological material by digital means. That tension does not necessarily need to be negative. The commodification of VA is allowing for new interpretive venues to be explored. As technology and VA now allow for multiple iterations, these additional re-imaginings of the past adds layers of interpretive agency to the understanding of heritage academically, professionally and publicly. Those layers are helping to test the fit and limitations of archaeologists' interpretation within a broader societal interpretation and engagement of the heritage material and landscape.

\subsubsection{Authenticity}

As discussed, VR as applied to VA has its own theoretical and methodological baggage (Barceló 2000; Dallas 2009; Forte 2011, 2014; Frischer et al. 2000; Frischer 2008; Huggett 2012a, 2012b, 2013, 2015; Reilly 1991, 2015; Ryan 2001). Reilly laid out the conditions of computer-aided archaeology in VR; in which the supremacy of the archaeological data is paramount to its visualization (Beale and Reilly 2014; Gillings 2005; Reilly 1989, 1991, 2015). In practice however, interpretative license is necessary to bridge the gaps between the known and unknown: what is seen and what is assumed within the archaeological record (see Shanks 2012).

Archaeologists are acutely preoccupied with the accuracy and authenticity of the archaeological data in general and the means in which this data is later interpreted (Frankland and Earl 2011; Frischer et al. 2000; Moser and Smiles 2008). Authenticity within archaeological research and visualization is a little like "chasing the dragon's tail," elusive and all consuming (see Gillings 2005). Unless archaeologists could transport themselves back to the exact time and space when the "cultural material event" occurred, they will never know the precise meaning and context of the archaeological landscape, material or objects. In effect, we're making it up as we go, based on previous research, various material datasets and contexts, training, logics of extracting meaning from material, speculation and a little creative ingenuity (see Shanks 2012). This isn't to say 
that thoughtful people haven't ruminated, reflected and anguished on the subject, only that in the end, we see - or should see - archaeological data as a base upon which to build our narrative, not as the final arbiter of fact.

Being reflexive in both acquisition and interpretation of data has enabled archaeological research the ability to present a more holistic narrative of the past. In this practice, it has helped to give the impression of authenticity, which, scaffolded by ever increasing capabilities of visualizing technology, provides a compelling narrative platform in VA. The risk, however, is the general public's acceptance of examples of this virtual narrative platform as the hyper-real; where the real and the virtual or fictional are indistinguishable (Gillings 2005). Their increased exposure to more sophisticated VFX and virtual realities within the entertainment industries, has in a way, morphed their understanding of what is and is not "real" (Denard 2012; Gillings 2005). The clean and sterile but "accurate" representations of linked and real-time archaeological data that Reilly and others have envisioned, while closer to reflecting accepted academic rigor, are challenged for their authenticity when juxtaposed to hyper-real, artistically impressioned representations within entertaining visualizations (see Gillings 2005). In a sense, those who consume and engage with archaeological visualizations are pre-conditioned today to acquaint the "hyper-real" with being actually "real" (Gillings 2005), so that "viewers might interpret the visual realism as a definitive statement or the "historical truth"' (Frankland and Earl 2011:63).

The blurring of the lines between "real" and "hyper-real" has increased to meet the growing demand of the public for more narratives with an archaeological/heritage storyline. As such, archaeologists are no longer the keepers or creators of digital archaeological narratives (see Huvila 2014). Within this consumer-based digital world, archaeology has become a pop-science; where an increasing demand for sexy, quasiacademic and increasingly user-driven narratives are being serviced by television, film, game, interactive and educational producers eager to satisfy the viewing public's needs and desires. These are the new masters of spinning popular narratives and as such, as VA emerges as a legitimate academic and research medium for accessing the archaeological past, archaeologists and archaeology are looking towards VA as a legitimate platform to 
advance academic knowledge, at the same time this virtual platform risks generating more and more content that can fuel public misconceptions and narratives of what archaeology and the past "is," through a digital or in our case, virtual lens.

\subsubsection{Authority}

To date, part of the problem in the acceptance of VA as a legitimate research tool in archaeology has been the historical use of VR in the archaeological process. As with archaeological illustration, VR and other forms of 3D modelling have been seen as augmentations to an overall archaeological methodology; a way to display archaeological material without really using the tools to investigate, probe, reflect or challenge multivocal findings and assumptions (Frankland and Earl 2011; Gillings 2005; Huggett 2012a, 2015). Archaeologists have subscribed to the fallacy that this "new" (now over 50 years old) technology will enliven, engage and enhance archaeological investigation and in doing so, convert the viewing audience - narrowly defined within archaeological practice as other archaeologists - to this form of sophisticated $21^{\text {st }}$ century story telling. But what if VR is really meant to disrupt our notion of what it means to convey an archaeological narrative? We need to shift our attention from a static "getting it right" to a more fluid consideration of what can be accomplished and how that interrogates meaning-making in archaeology (see Gillings 2005).

To paraphrase Gosden (2005), what do we want VR to say? The tensions that lie throughout virtual archaeological theory force practitioners to maintain a fine balance between the rigidity of traditional method and theory - and past conventional notions of

what archaeological data are and how they are to be presented and analyzed - and the flexibility to essentially present any desired visual interpretation that advances knowing. VA isn't "wholly authentic", as VR environments are constructs which embody the constraints and compromises of the visualization process (see Gillings 2005).

Worth noting is that the "mashable" nature of the digital, while enabling archaeologists to more freely experiment with the unknowable dimensions of the archaeological past, also 
empowers non-archaeologists to form their own narratives and interpretations, which can be both a negative and positive addition to the overall interpretive heritage knowledge building process. This new public archaeological narrative process has surfaced over the last few years primarily due to the quantum leap in consumer related technology, that now allows anyone in the world with WiFi access and a smartphone, tablet or computer to Tweet, Instagram, Facebook, YouTube or utilize a plethora of other digital tools to create and share content, anytime and anywhere they want. If the framers of The London Charter found the task of trying to bring the archaeology community in-line with the manufacturing and dissemination of digital archaeological or heritage data, images and narratives, the effort required to propel the estimated 2 billion social media users in the world (Kemp 2015) toward adhering to a framework of any sort when communicating about heritage material is completely impossible, and, more to the point, irrelevant except to archaeologists.

\subsection{Implications for Future Research in Virtual Archaeology}

It has been a short 25 years since Reilly introduced the notion of VA as a method to accurately visualize and build upon archaeological data in a meaningful and systematic way (Barceló 2000, 2001; Beale and Reilly 2014; Dallas 2009; Frischer et al. 2000; Huggett 2012b; Reilly 1991). At that time, the technology that Reilly used was extremely costly and required years of programming and hardware expertise to operate effectively, to produce a visualization that does not come close to the quality that can be achieved today. The real-time computing processing power, digital storage within memory and the physical input devices that were once limited to researchers like Reilly are so ubiquitous that they are now integrated into objects such as children's toys, handheld devices, watches and even glasses, converging the digital with the real world. Faster graphics cards and processing power have enabled users to experience virtual environments in real-time or near to real-time experiential realities. The ocular, sensory and haptic controls that Ivan Sutherland envisioned in the 1960's have become a common consumer reality that now allow the public to have "presence" within virtual environments (Frischer et al. 2000; González-Tennant 2010; Morgan 2009; Sutherland 
1965). Devices such as the Ocular Rift and HTCVive goggles, when worn, mimic human head movements and visually display the VR environment to allow the participant to see in 360 degrees. Other devices such as a Myo armband allow users to control and pickup items within virtual environments, essentially giving them 3D hands and arms. Gaming console hand controllers allow users to walk, jump and even fly thereby providing a physical feedback that alerts the user of the physicality of the movement within the digital environment, though these are rapidly being replaced with motion controllers, interactive limb and hand controllers, and even haptic feedback gloves. Additionally, sound has been recognized as an important element to immersively experiencing virtual environments, providing audio clues as to place, time and space (Chalmers and Zányi 2010). Lastly, digital smell, although not yet fully developed at the consumer level, can also enhance a user's virtual experience (Chalmers and Zányi 2010). These digital applications all contribute to an embodied phenomenological experience in virtual space.

As discussed with the CAVE environment used by Dawson, Levy and Lyons (2011), an embodied experience for descendent stakeholders is not only empowering to the participant but beneficial to the archaeologist in unlocking unintended knowledge that further enriches the archaeological record. Digital reproduction of objects, landscapes and narratives do have agency and a materiality both in the real and virtual worlds and as such must be treated with equal consideration and respect (Brown and Nicholas 2012; Earl 2013; Forte 2014b; Huggett 2012a, 2015; Pauketat and Alt 2005; Richardson 2013; Robb 2010; Salmond 2012). The Māori of New Zealand believe that the essence of their sacred cultural objects, whether digitized or traditionally photographed, is transferred when the digital reproduction is made (see Salmond 2012). This transference does not diminish the agency of the original cultural artefact, but extends it to the digital representation, requiring the digital receive the same considerations and respect as the physical (Salmond 2012). For the Māori, then, digital reproductions are not a copy, but an extension of the "crafted objects and landscapes of memory" which implicitly embodies agency (Brown and Nicholas 2012:310). Appropriation and misuse of sacred digital objects and landscapes in this democratized digital world we now live in, is but one 
example of how virtual environments and objects can be misused and lie in conflict with Descendent cultural norms (Brown and Nicholas 2012).

\subsection{Discussion}

Archaeology is about the creation of knowledge about the past through the documentation and analysis of the material past. Creating that knowledge begins at trowel's edge, continues on through the lab or archives, and in the formation of explanatory narratives of the past drawn from the patterns observed in archaeological data, through archaeologists' conceptual framing of that materiality as human history. VA inserts into that process a robust layer of meaning-making, one that allows for the visualization of that data and those narratives, and in so doing, interrogates data, conceptions of materiality and the past, and the knowledge processes archaeologists engage with is making meaning. In short, archaeological data is found, virtual data is manufactured and the nature of new knowledge is determined by the methods used in the creation and interweaving of the physical with that (visualized) knowledge (see Reilly 1985:64). This creating the unknown from the known is the interplay of VA.

Graphical VA is more than just metadata from the raw excavation process, but rather is a visceral, agency laden manifestation of the construction of an archaeological narrative to get at new meaning. For me, it is critical to move beyond graphical VA as a "nifty" visualization process for public consumption and bring it into the real light of archaeological theory and meaning-making. When one removes the idea that visual (re)imagination of archaeological knowledge is solely for static illustration of archaeological data and objects, or for public edutainment and consumption, the archaeologist is free to mix, mingle and reinterpret freely. This liberating approach allows for making and meaning-making to become reflexive and experiential. Coupled with the practice of paradata production, the authenticity emerges from the making process of the virtual environment and not necessarily in the material culture being represented. As Ingold (2013) and Wylie (2002) point out, archaeological knowledge construction is a process of archaeological cabling and tacking in the act of making; the synergies between user knowledge, tool and the materiality of the object worked and the construction of new 
knowledge in the process of making. Authority and authenticity is not only transferred to object through the user, but is reinforced by the paradata associated with the process itself.

As such my provocation, to borrow from Reilly (personal communication, May 2016), is that the end product of visualizing data, be it 3D printed, graphically represented, or VR enhanced, is not the goal of the virtual archaeologist. It is the intersection of archaeological practice and technology through the construction of knowledge, the being in the moment, the wayfaring decisions, course corrections, networked lines of knowing along with the skill, artistic impressions and theoretical grounding that encompasses "making;" and through this process brings new knowledge. To me, this is the ultimate aim, and strength, to a Virtual Archaeology. 


\subsection{References}

Allen, Richard

2016 @PalaeoPi. Twitter. Electronic document, https://twitter.com/PalaeoPi, accessed June 1, 2016.

Barceló, Juan

2000 Visualizing What Might Be: An Introduction to Virtual Reality Techniques in Archaeology. In Virtual Reality in Archaeology: Computer Applications and Quantitative Methods in Archaeology 1998. BAR International Series 843, edited by Juan Barceló, Maurizio Forte, and D. Sanders, pp. 9-36. Archeopress. British Archaeological Reports (S843), Oxford.

Barceló, Juan A, Maurizio Forte, and Donald H Sanders (editors)

2000 Virtual Reality in Archaeology. Archaeopress, Oxford.

Barceló, Juan Antonio

2001 Virtual Reality for Archaelogical Explanation. Beyond «Picturesque»

Reconstruction. Archeologia e Calcolatori(12): 221-244.

Beale, G, and P Reilly

2014 Additive Archaeology: The Spirit of Virtual Archaeology Reprinted. In Archaeological Research in the Digital Age: Proceedings of the 1st Conference on Computer Applications and Quantitative Methods in Archaeology Greek Chapter (CAA-GR) Rethymno, Crete, 6-8 March 2014. Institute for Mediterranean Studies - Foundation of Research and Technology (IMS-FORTH), edited by, Papadopoulos, C., E. Paliou, A. Chrysanthi, E. Kotoula, and A. Sarris, pp. 120 128.

Bentkowska-Kafel, Anna, Hugh Denard, and Drew Baker (editors)

2012 Paradata and Transparency in Virtual Heritage. Farnham, Ashgate.

Boismier, W A, and Paul Reilly

1988 Expanding the Role of Computer Graphics in the Analysis of Survey Data. Computer and Quantitative Methods in Archaeology. British Archaeological Reports, International Series 393, Oxford, UK.

Bond, Sarah

2016 The Ethics of 3D-Printing Syria's Cultural Heritage. Electronic document, http://www.forbes.com/sites/drsarahbond/2016/09/22/does-nycs-new-3d-printedpalmyra-arch-celebrate-syria-or-just-engage-in-digitalcolonialism/\#3eb894e277db, accessed Sept. 22, 2016.

Carter, Michael

2015 Special Projects - Virtual Archaeology. Electronic document, http://theskonkworks.com/, accessed July 4, 2015.

Champion, Erik

2011 Playing with the Past. Human-Computer Interaction Series. Human-Computer Interaction Series. Springer, London.

2015 Defining Cultural Agents for Virtual Heritage Environments. Presence:

Teleoperators and Virtual Environments 24(3): 179-186.

Cowgill, George L. 
1967 Computer Applications in Archaeology. Computers and the Humanities 2(1): 1723.

Cox, Grant

2012 Archaeology and CGI: The Shrine of the Hunters at Çatalhöyük. ArtasMedia. Electronic document, https://www.youtube.com/watch?v=pAV8z6NesOA, accessed May 5, 2016.

2015 Catalhöyük-The Shrine of the Hunters (FVI). ArtasMedia. Electronic document, https://artasmedia.com/2015/03/10/catalhoyuk-the-shrine-of-the-hunters-f-v-i/, accessed May 5, 2016.

2016 The Witham Bowl Re-Model. ArtasMedia, Electronic document, https://artasmedia.com/2016/05/05/withambowlremodel/, accessed May 5, 2016.

Crawford, $\mathrm{M}$

2015 The World Beyond Your Head: On Becoming an Individual in an Age of Distraction. Penguin Canada, Toronto.

Dallas, Costis

2009 From Artefact Typologies to Cultural Heritage Ontologies: Or, an Account of The Lasting Impact of Archaeological Computing. Archeologia e Calcolatori 20: 205221.

Daly, Patrick, and Thomas L Evans

2006 Archaeological Theory and Digital Pasts. In Digital Archaeology. Bridging Method and Theory, edited by Thomas L Evans and Patrick Daly, pp. 2-7. Routledge, London.

Dawson, P., R. Levy, and N. Lyons

2011 'Breaking the fourth wall': 3D Virtual Worlds as tools for Knowledge Repatriation in Archaeology. Journal of Social Archaeology 11(3): 387-402.

Denard, Hugh

2012 A New Introduction to the London Charter. In Paradata and transparency in virtual heritage, edited by A. Bentkowska-Kafel, D. Baker \& H. Denard, pp. 57-71. Ashgate, Farnham.

Earl, Graeme P., and David Wheatley

2002 Virtual Reconstruction and the Interpretative Process: A Casestudy from Avebury. In Contemporary Themes in Archaeological Computing, edited by David Wheatley, Graeme P. Earl, and S. Poppy, pp. 5-15. Oxbow Books, Oxford, UK.

Eiteljorg, $\mathrm{H}$

2000 The Compelling Computer Image-A Double-Edged Sword. Internet Archaeology (8). Electronic document, http://intarch.ac.uk/journal/issue8/eiteljorg/index.html, accessed June 12, 2016.

Forte, Maurizio

2011 Cyber-Archaeology: Notes on the Simulation of the Past. Virtual Archaeology Review 2(4): 7-18.

2014a Virtual Reality and Cyberarchaeology. In 3D Recording and Modelling in Archaeology and Cultural Heritage Theory and Best Practices, edited by Fabio Remondino and Stefano Campana, pp. 3-6. ArcheoPress. British Archaeological Reports (S2598), Oxford. 
2014b 3D Archaeology: New Perspectives and Challenges - The Example of Çatalhöyük. Journal of Eastern Mediterranean Archaeology and Heritage Studies 2(1): 1-29.

Forte, M., S. Alberto, and C. Renfrew (editors)

1997 Virtual archaeology: Re-creating Ancient Worlds. Henry N Abrams.

Frankland, T.J.

2010 A CG Artist's Impression: Depicting Virtual Reconstructions Using NonPhotorealistic Rendering Techniques. In Thinking Beyond the Tool:

Archaeological Computing and the Interpretative Process, edited by, Angeliki

Chrysanthi, Patricia Murrieta-Flores, and Constantinos Papadopoulos.

Archaeopress, Oxford.

Frankland, Tom, and Graeme Earl

2011 Authority and Authenticity in Future Archaeological Visualisation. In

Proceedings of Ads-Vis2011: Making Visible the Invisible: Art, Design and

Science in Data Visualisation: 62-68.

Frischer, Bernard

2008 From Digital Illustration to Digital Heuristics. Beyond Illustration: $2 D$ and $3 D$

Digital Technologies as Tools for Discovery in Archaeology 1805.

Frischer, Bernard, Franco Niccolucci, Nick Ryan, and Juan Barceló

2000 From CVR to CVRO: The Past, Present, and Future of Cultural Virtual Reality. In Proceedings of the International Symposium on Virtual Reality Archeology and Cultural Heritage (VAST'O0), edited by F. Niccolucci British. Archaeological Reports, Vol. 834: 7-18.

Gillings, Mark

2005 The Real, The Virtually Real, and the Hyperreal: The Role of VR in Archaeology. In Envisioning the Past: Archaeology and the Image, edited by S., Smiles and S. Moser, pp. 223-239. Blackwell, Oxford.

Gibson, James Jerome

1986 The Ecological Approach to Visual Perception. Psychology Press, New York. González-Tennant, Edward

2010 "Virtual Archaeology and Digital Storytelling: A Report from Rosewood, Florida," African Diaspora Archaeology Newsletter: Vol. 13 : Iss. 3 , Article 1. Available at: http://scholarworks.umass.edu/adan/vol13/iss3/1

2012 Intersectional Violence, New Media, and the 1923 Rosewood Pogrom. Fire!!! The Multimedia Journal of Black Studies 1(2): 64-110.

2013 New Heritage and Dark Tourism: A Mixed Methods Approach to Social Justice in Rosewood, Florida. Heritage \& Society 6(1): 62-88.

Huggett, Jeremy.

1995 Democracy, Data and Archaeological Knowledge. BAR International Series 600: 23-26.

2004 Archaeology and the New Technological Fetishism. Archeologia e Calcolatori 15: 81-92.

2013 Disciplinary Issues: Challenging the Research and Practice of Computer Applications in Archaeology, In Archaeology in the Digital Era, edited by, Earl, G., T. Sly, A. Chrysanthi, P. Murrieta-Flores, C. Papadopoulos, I. Romanowska, D. Wheatley, pp. 13-24. Amsterdam University Press, Amsterdam.

2015 Challenging Digital Archaeology. Open Archaeology 1(1): 79-85. 
Huggett, J., and S. Ross

2004 Themed issue edited by Jeremy Huggett and Seamus Ross. Internet Archaeology(15). Electronic document, http://intarch.ac.uk/journal/issue15/inf_index.html, accessed May 25, 2016.

Ingold, Tim

2007 Materials Against Materiality. Archeological Dialogues 14(1): 1-16.

2010a Ways of Mind-Walking: Reading, Writing, Painting. Visual Studies 25(1): 15-23.

2010b Transformations of the Line: Traces, Threads and Surfaces. Textile: The Journal of Cloth and Culture 8(1): 10-35.

2011 Being Alive: Essays on Movement, Knowledge and Description. Routledge, New York.

2013 Making: Anthropology, Archaeology, Art and Architecture. Routledge, New York. Jeffrey, Stuart

2015 Challenging Heritage Visualisation: Beauty, Aura and Democratisation. Open Archaeology 1: 144-152.

Jones, Andrew M

2003 From the Perception of Archaeology to the Anthropology of Perception: An Interview with Tim Ingold. Journal of Social Archaeology 3(1): 5-22.

Klein, Herbert

2007 From Romanticism to Virtual Reality: Charles Babbage, William Gibson and the Construction of Cyberspace. Interdisciplinary Humanities 24(1): 36-51.

Masinton, Anthony

2016 @amasinton. Twitter. Electronic document, https://twitter.com/amasinton, accessed June 1, 2016.

Merleau-Ponty, Maurice

1964 Eye and Mind. In The Primacy Of Perception: And Other Essays on Phenomenological Psychology, the Philosophy of Art, History, And Politics, edited by J.M. Edie, pp. 159-190. Northwestern University Press, Evanston, IL. Miller, Paul, and Julian Richards

1995 The Good, the Bad, and the Downright Misleading: Archaeological Adoption of Computer Visualisation. BAR International Series 600: 19-22.

Morgan, Colleen L.

2009 (Re)Building Çatalhöyük: Changing Virtual Reality in Archaeology. Archaeologies 5(3): 468-487.

2012 Emancipatory Digital Archaeology. Ph.D. dissertation, University of California, Berkeley.

2016 Analog to Digital: Transitions in Theory and Practice in Archaeological Photography at Çatalhöyük. Internet Archaeology 42: 1-24.

Moser, Stephanie

2012 Early Artifact Illustration and the Birth of the Archaeological Image. In Archaeological Theory Today, edited by Ian Hodder, pp. 292-322. Cambridge University Press, Cambridge.

Moser, Stephanie, and Sam Smiles

2008 The Image in Question. In Envisioning the Past: Archaeology and the Image, edited by S. Moser and S. Smiles, pp. 1-12. Blackwell Publishing Ltd, Oxford. Perry, Sara 
2015 Crafting Knowledge with (Digital) Visual Media in Archaeology. In Material Evidence. Learning from Archaeological Practice, edited by R. Chapman and A. Wylie, pp. 189-210. Routledge, New York and London.

Reilly, Paul

1985 Computers in Field Archaeology: Agents of Change? Current Issues in Archaeological Computing 271, pp. 63-78.

1989 Data Visualization in Archaeology. IBM Systems Journal 28(4): 569-579.

1991 Towards a Virtual Archaeology. In Computer Applications in Archaeology, edited by K. Lockyear and S. Rahtz, pp. 132-139. British Archaeological Reports, Oxford.

1996 Access to Insights: Stimulating Archaeological Visualisation in the 1990s. In: Gedai, I. (Ed.), The Future of Our Past '93-'95. Hungarian National Museum, Budapest.

2015 Putting the Materials Back into Virtual Archaeology. In Virtual Archaeology (Methods and Benefits), edited by D. Hookk, pp. 12-21. The State Hermitage Publishers, St. Petersburg.

Reilly, P., and G. Beale

2014 Virtual Archaeology in a Material World: New Technologies Enabling Novel Perspectives. CAA 2014 Paris: 21 st Century Archaeology, France. 22 pp.

2015 Additive Archaeology: the Spirit of Virtual Archaeology Reprinted, In:

Papadopoulos, C., Paliou, E., Chrysanthi, A., Kotoula, E., Sarris, A. (Eds.) Archaeological Research in the Digital Age: Proceedings of the 1st Conference on Computer Applications and Quantitative Methods in Archaeology Greek Chapter (CAA-GR), Institute for Mediterranean Studies - Foundation of Research and Technology (IMS-FORTH), Rethymno, 2015, pp. 120-128.

Reilly, Paul, and Julian Richards

1987 New perspectives on Sutton Hoo: The Potential of 3-D Graphics. In Computer and Quantitative Methods in Archaeology, edited by C.L.N. Ruggles and S.P.Q. Rahtz, 393, pp.173-185. BAR International Series, Oxford, UK.

Reilly, Paul, Stephen Todd, and Andy Walter

2016 Rediscovering and modernising the digital Old Minster of Winchester. Digital Applications in Archaeology and Cultural Heritage 3(2): 33-41.

Richardson, Lorna

2013 A Digital Public Archaeology? Papers from the Institute of Archaeology 23(1): 112.

Ryan, Nick

2001 Documenting and Validating Virtual Archaeology. Archeologia e Calcolatori 12: 245-273.

Schnapp, Alain

1997 The Discovery of the Past. Harry N. Abrams, New York.

Shanks, Michael

2012 The Archaeological Imagination. Left Coast Press, Walnut Creek, CA.

Shanks, Michael, and Ian Hodder

1995 Processual, Postprocessual and Interpretive Archaeologies. In Interpreting Archaeology: Finding Meaning in the Past, edited by Hodder, I., M. Shanks, A. Alexandri, V. Buchli, J. Carman, J. Last, and G. Lucas, pp. 144-165. Routledge. 
Slater, Mel, and S Wilbur

1997 A Framework for Immersive Virtual Environments (FIVE): Speculations on the Role of Presence in Virtual Environments. Presence: Teleoperators and Virtual Environments 6(6): 603-616.

Spector, Janet

1993 What this Awl Means: Feminist Archaeology at a Wahpeton Dakota village. Minnesota Historical Society Press, St. Paul.

Sutherland, I. E.

1965 The Ultimate Display. Proceedings of the International Federation of Information Processing Congress, 2, pp. 506-508.

Watterson, Alice

2014 Engaging with the Visual: Re-Thinking Interpretive Archaeological Visualisation. Ph.D. dissertation, Digital Design Studio, The Glasgow School of Art, Glasgow, UK.

2015 Beyond Digital Dwelling: Re-thinking Interpretive Visualisation in Archaeology. Open Archaeology 1(1): 119-130.

Watts, Christopher M.

2009 Coming to our Senses: Toward a Unified Perception of the Iroquoian Longhouse. In Archaeology and the Politics of Vision in a Post-Modern Context, edited by J. Thomas and V. Jorge, pp. 209-224. Cambridge Scholars Publishing, Newcastle upon Tyne, UK.

Wise, Sean

2006 May 17. The Talent Triangle. The Globe and Mail, On-Line edition, Report on Business. Retrieved from http://www.theglobeandmail.com/report-onbusiness/the-talent-triangle/article1099632/?page=all, accessed May 1, 2016.

Wylie, Alison

2002a Archaeological Cables and Tacking: Beyond Objectivism and Relativism. In Thinking from Things: Essays in the Philosophy of Archaeology, University of California Press, Berkeley, pp. 161-167. University of California Press, Berkeley and Los Angeles.

2002b Thinking from Things: Essays in the Philosophy of Archaeology. University of California Press, Berkeley.

Zubrow, Ezra B W

2006 Digital Archaeology. In Digital Archaeology. Bridging Method and Theory, edited by Thomas L. Evans and Patrick Daly, pp. 10-31. Routledge, London. 


\section{Chapter 3}

\section{The construction of Longhouse knowledge in Virtual Archaeology}

Their cabins are in the shape of tunnels or arbors, and are covered with the bark of trees. They are from twenty-five to thirty fathoms long, more or less, and six wide, having a passage-way through the middle from ten to twelve feet wide, which extends from one end to the other. On the two sides there is a kind of bench, four feet high, where they sleep in summer, in order to avoid the annoyance of the fleas, of which there are great numbers. In winter they sleep on the ground on mats near the fire, so as to be warmer than they would be on the platform. They lay up a stock of dry wood, with which they fill their cabins, to burn in winter. At the extremity of the cabins there is a space, where they preserve their Indian corn, which they put into great casks made of the bark of trees and placed in the middle of their encampment. They have pieces of wood suspended, on which they put their clothes, provisions, and other things, for fear of the mice, of which there are great numbers. In one of these cabins there may be twelve fires, and twenty-four families. It smokes excessively, from which it follows that many receive serious injury to the eyes, so that they lose their sight towards the close of life. There is no window or any opening, except that in the upper part of their cabins for the smoke to escape. This is all that I have been able to learn about their mode of life; and I have described to you fully the kind of dwelling of these people, as far as I have been able to learn it, which is the same as that of all the tribes living in these regions. They sometimes change their villages at intervals of ten, twenty, or thirty years, and transfer them to a distance of one, two, or three leagues from the preceding situation.... This is the form of their dwellings, which are separated from each other some three or four paces, for fear of fire, of which they are in great dread.

Champlain (1616)1907:61-62 
In more or less detail, Ontario, post-contact Late Woodland Iroquoian longhouses have been described historically, anthropologically and archaeologically in the same manner for over 400 years (see Bartram 1751; Chadwick 1897; Dodd 1984; Dodd et al. 1990; Engelbrecht 2003; Heidenreich 1972; Lafitau 2013; Snow 1997; Trigger 1987; Warrick 1988, 1996, 2000; Wright 1974, 1995; Sagard 1939). A brief survey of the archaeological data from various excavated sites, early to Late Woodland, throughout Ontario (e.g., Anderson 2009; Bekerman and Warrick 1995; Birch 2012, 2015; Birch and Williamson 2012; Cooper and Robertson 1993; Creese 2012a; Dodd 1984; Dodd et al. 1990; Finlayson 1985; Fox 1990; Noble 1975; Timmins 1997; Williams-Shuker and Allen 1998; Williamson 1998), suggests that this data is interpreted and consistently visualized by written description, 2D representation or 3D physical reconstruction among professional, academic, heritage and stakeholder communities almost universally as the quote described above. With the exception of sweat lodge discoveries within or attached to longhouses (Bursey 2001; MacDonald 1988; MacDonald and Williamson 2001; Robertson 2004), which I will not be discussing in this dissertation, the only contested cultural historical discussions arising from this extensive literature on the archaeological vestiges of longhouses have been on framing style and thus exterior look and interior functionality (Kapches 1990, 1993, 2007; Snow 1997; Wright 1974, 1995, Warrick 1988, 1996).

Yet, I am intrigued by the lack of visual referencing, whether it is written, oral, visual or archaeologically based. Visual representations of longhouses tend to be restricted to images of village layouts, appearing as museum dioramas or illustrated on the cover of publications (e.g., Finlayson 1985; Lennox 1984), or, in another example, as a longhouse cross section of a "spatially dynamic" living space based on archaeological excavation data (Kapches 1990:50). Interestingly, both the Finlayson and Kapches depictions were imagined by the same artist (Ivan Kocsis), and represent the most prominent visualizer of Ontario Late Woodland archaeology, due to his participation in Ontario archaeology, and the use of his work by all Ontario museums with archaeological emphases, as well as by the Ontario Archaeological Society (see Kapches et al. 2008). Perhaps aided by the work of artists such as Kocsis, there seems to be a kind of universal mental image among 
Ontario archaeologists and the public alike of what village and longhouse living looked like. Despite or because of this, Late Woodland period longhouses are the perfect context to explore meaning-making in VA, if only for the fact that so little is known about them physically above the soil line.

This paper will review the available archaeological literature to determine the best model to template the $3 \mathrm{D}$ design and construction of an Ontario based, late pre-contact Late Woodland (1500-1650 A.D.), ancestral Iroquoian longhouse within a virtual environment. The purpose is to accumulate a broad sense of what is known about this architectural structure to best determine the parameters needed to establish a functional 3D building template of a longhouse, modeled with the widest set of permeations, to allow for a robust, archaeologically informed, maker (user) centric knowledge building experience. In many ways, this will run contrary to traditional modes of knowledge construction within archaeology as the goal is not to develop definitive notions of longhouse construction and use, but to provide the greatest range of possibilities within the 3D environment to allow for archaeologists and others to mix and remix the archaeological data to satisfy their individual mental image of longhouse construction and use. The archaeological data informing the 3D modeling process is, in essence, dynamic, living and constantly (re)interpretive, essentially having no minimum or maximum parameters, just the ability for infinite interpretive possibilities. Thus, this $3 \mathrm{D}$ model creation process acknowledges and is purposely designed to capture the immense breadth and depth of longhouse variability: contextually, culturally, temporally, socially, environmentally and materially within the archaeological record. However, to do this, I need to develop a base understanding of longhouse construction to create a prototypical mental image of what a longhouse is in order to negotiate the variability represented within the archaeological record.

\subsection{Longhouse Visualization(s)}

The most abundant and significant structure found within Iroquoian settlements is the longhouse. While most Iroquoian longhouses follow a similar template of 
construction, form and internal arrangement, their variation through time, across cultural boundaries and even between adjacent structures make them one of the most interesting settlement features to study.

Lennox and Fitzgerald 1990:441

Longhouses occupy a special narrative among descendent Iroquoian societies and modern archeologists. The North American longhouse continues to be a powerful symbol of community for descendent populations, representing an architectural lineage that exemplifies agency and a unique way of life (see Heidenreich 1972; Kapches 1993; Mohawk 1978; O'Gorman 2010; Watts 2009; Woodworth 1998). At the base level, the longhouse represents community in both physical and social traditions, embodying the physical to convey community worldviews (Hayden 1968; Heidenreich 1972; Mohawk 1978; O’Gorman 2010; Ramsden 2009; Varley \& Cannon 1994).

It is generally accepted within Ontario Iroquoian archaeological interpretations that a longhouse is a communal multigenerational or intersociety dwelling that represents a social, cultural, spiritual, economic or familiar "community" (see Creese 2012a; Hayden 1968; Heidenreich 1972; Kapches 1993, 1990, 1987; O'Gorman 2010; Snow 1997; Steckley 1987; Trigger 1976; Warrick 1984, 1996; Watts 2009; Williamson \& MacDonald 2015; Williamson 2004; Wright 1995). Physically, they provided a place of residence and daily living, shelter, storage and the interior, experiential landscape of community and family living among village-based communities (e.g., Ferris 2013; Heidenreich 1972). At a more conceptual level, longhouses conveyed community engagement, societal norms and ordering, and to an outsider, a strong, interdependent and substantial community (see Kapches 1993; Heidenreich 1972; O'Gorman 2010; Varley \& Cannon 1994; Watts 2009). Iroquoian oral tradition and language underscore this conceptual societal importance. For example, John Steckley (1987:21) notes that, to have an "empty" longhouse and/or to be excluded from a longhouse because it was ",annonchi” or full, was an insult beyond repair. Longhouse structures were not just buildings, but rather, living, breathing entities that would react to the environment and 
ecosystem that both contained and constrained them (see Fogt \& Ramsden 1996; Williamson 2004; Woodsworth 1978).

The traditional means of recognizing a longhouse, palisade or other pole-based structure during site excavations is through the identification of circular posthole stains revealed on the surface of the occupation layer, or through the cross sectioning of a potential posthole stain during excavation. This is especially the case in Ontario, where large-scale excavations aided by mechanical stripping of topsoil exposes entire archaeological locations of ancient villages and all related pole structures (as first advanced at the Draper site excavations in the 1970s; Finlayson 1985). If identified as a potential posthole across the expanse of these large surface excavations, generally a simple plastic straw or more rarely now wooden dowel is used to visually demarcate the structural pole positions, and over a larger space demark the outline of the longhouse, structure or palisade in the field (see Figure 1; Ferris and Horne 1988). Once posthole positions are mapped in 2D, archaeologists generate a surficial plan of architectural settlement patterns, and generally connect-the-dots and suggest longhouse outlines and thus occupation within an archaeological landscape (see Figure 4 as an example).

What I have just described is the extent to which most Ontario archaeologists come to "know" where longhouses are during their excavations, and represent and visualize longhouses within their post-excavation report/research writing stage. It also represents the greatest technological achievement, or at least disciplinary convention, in longhouse visualization to date. 


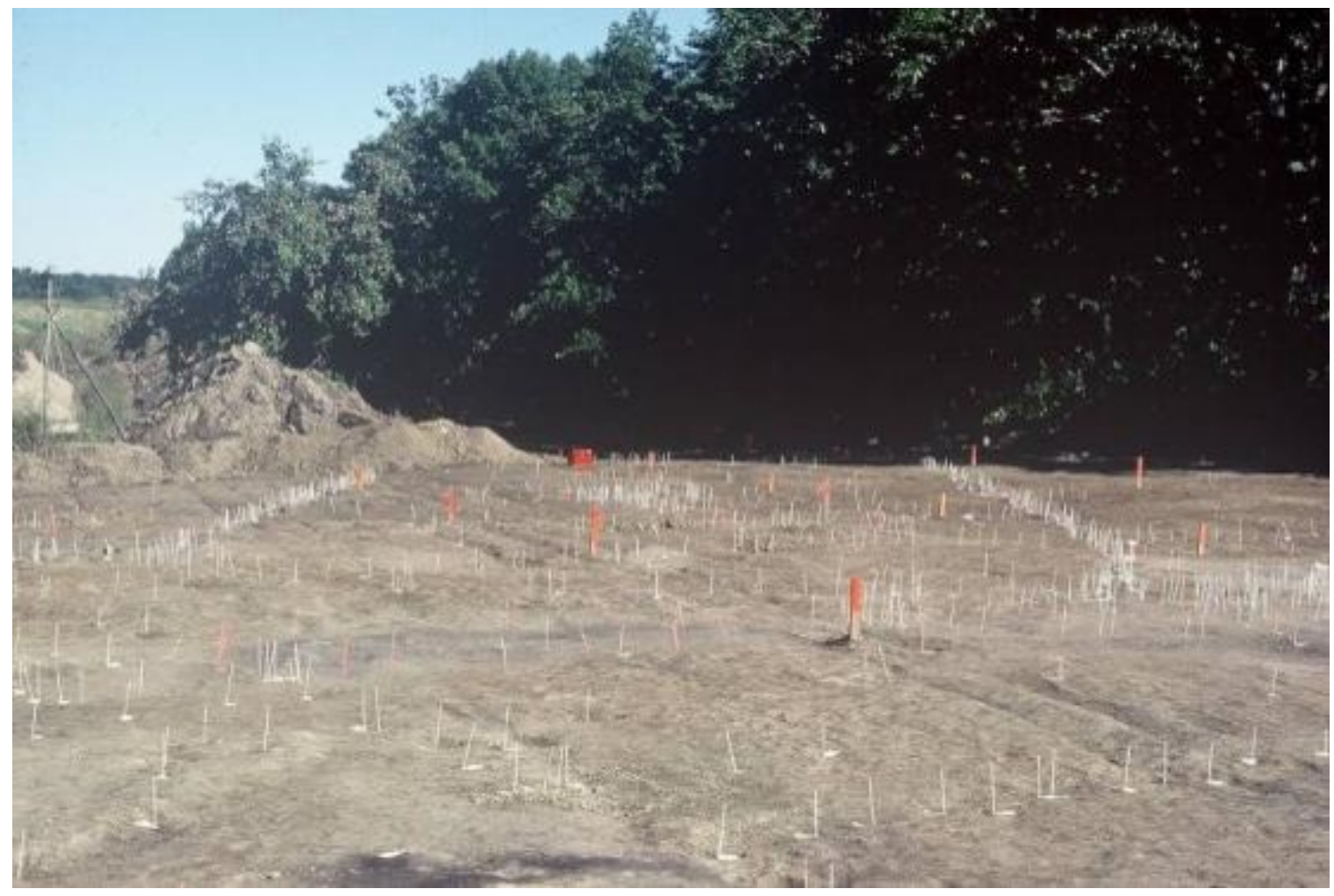

Figure 1 - Postmolds \& Straws, Dougherty-Sluis site, Neal Ferris (2012)

\subsection{Creating a Mental Image of a Longhouse}

Moving from straws in the ground to a fully realized vision of a longhouse, and critically of the internal and external space created by that architecture, whether in the field or writing a report in an archaeologist's office, is a huge stretch. Cognitive philosopher Daniel Dennett (1993) has suggested that our brains are wired to hold only a certain level of detail and thus our mental images are stored in long-term memory and are static until new detail can replace old. Thus our mental image of a particular object, landscape or situation sometimes remains the same or is accepted as being de facto (Dennett 1993), as mental images are static and can be resistant to new input.

Snow (1997) has demonstrated that Champlain's original narrative description of longhouse life has been liberally repurposed by Sagard-Théodat (1632), Brebeuf (1634- 
1635) and Lafitau (1724), all building only slightly in detail or scope on the original Champlain variant. Archaeologists, in turn, continually repurpose this core observation, fixed both in time and space, to serve as something more universal in application in its utility to visualize longhouses. Historical images of longhouses, primarily visualized as map details and almost uniformly similar in representation - i.e., flat front, 60/40 wall/roof configuration (Snow 1997) also reinforce this universal visualization. For example, Canadian Historical Illustrator C.W. Jefferys notes that his illustration, Part of a Palisaded Huron-Iroquois Village (see Figure 2; Jefferys and McLean 1942:16), is based on Sagard-Théodat's (1632) and Jacques Cartier's narrative descriptions of palisade and longhouse construction. Archaeologically, excavations do reflect core elements of longhouse design through observable settlement patterns: elliptical outline, rounded to squared ends, central corridor, bunk lines, and open interior ends as construction traits seen archaeologically. But these elements only further reify in archaeological interpretations a single, historically fixed notion of the longhouse, shaping archaeological understandings of 3D longhouse space and architecture. 


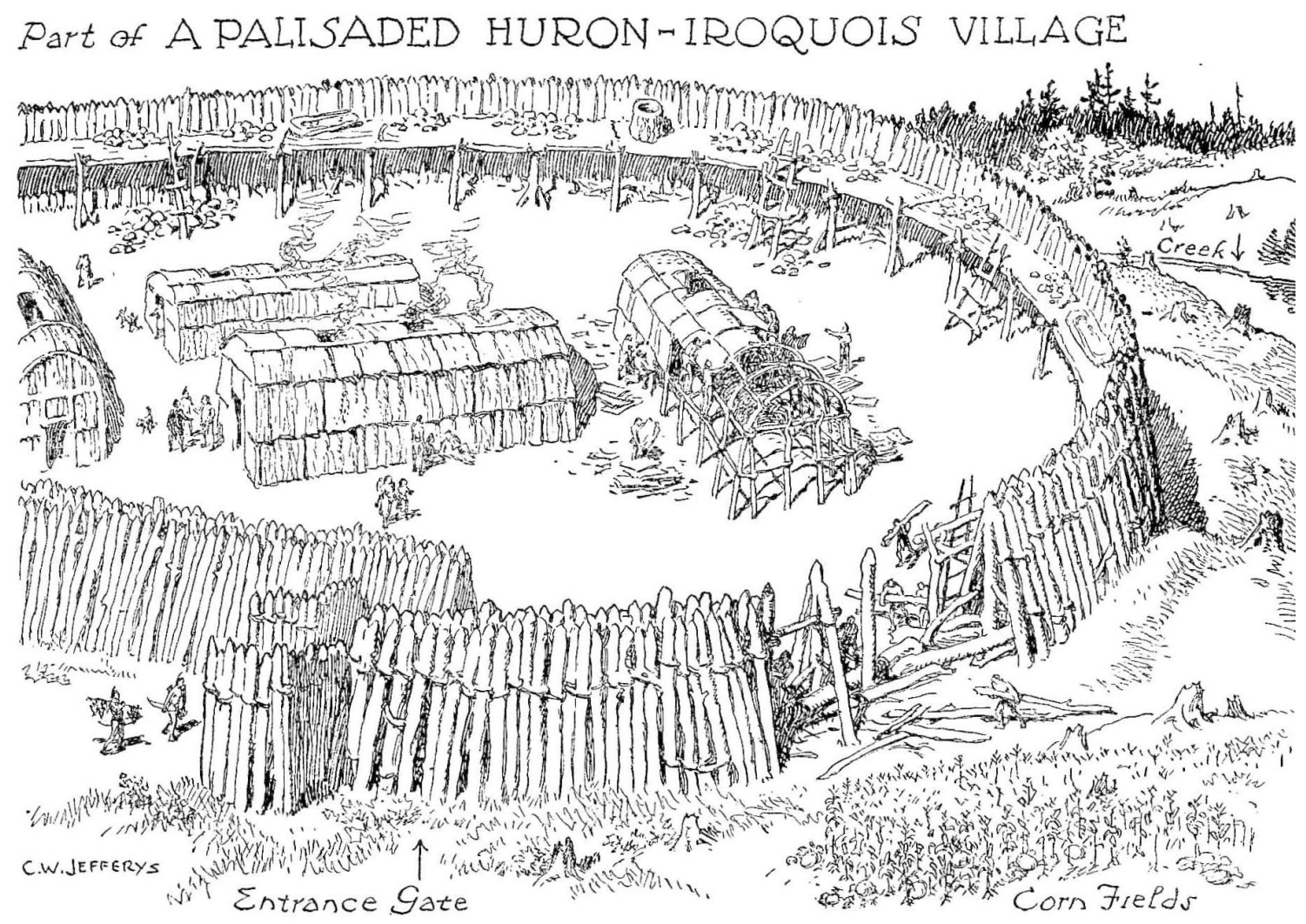

Figure 2 - Part of a Palisaded Huron-Iroquois Village. C.W. Jefferys and McLean (1942:16). Image Reprinted with permission from C.W. Jefferys Online Catalogue.

That fossilized visualization of a longhouse as "the longhouse" from all archaeological excavations belies the variable nature and agency of the process Iroquoian longhouse builders negotiated across time and space. This process embodies Ingold's (2011:10) notion of a "dwelling perspective" - the creation of form from thought based on the surrounding landscape (cultural, environmental, political, material) and worked from materials at hand). Longhouse builders didn't just simply build but were bound by their past lived experiences manifested as mental interpretation of dwelling as well as the raw available materials to form habitat representations of their current worldview. These dwellings can be viewed as a non-verbal form of communication that encapsulated the temporal pressures of the longhouse makers and their community (Engelbrecht 2003; Mohawk 1978; O'Gorman 2010; Watts 2009; Woodworth 1998). This is a material tradition that developed through the Late Woodland, across close to a 1000 years, over a 
wide geography of differing raw materials and accessibility to those, and through significant social change and community organization, both inside the longhouse, inside the village, and across villages. Thus, the material build of a longhouse at any given moment was a mediation of a visualized mental idealized template with the constraints of the immediate needs of the builders, the site of the build and the materials used in the build. These mental, physical and cultural dimensions speak to a robust making tradition more diverse than implied by the historically derived mental templates archaeologists tend to envision.

Watts (2009) makes the point that if we only look at longhouses by maps (post stains and feature plans) we fail to embody the essence of what a longhouse might have been, the many ways it was known to builders, or how its agency as a material space shaped the human physical experience - of knowing a longhouse beyond the architecture through the dwelling in and among them (see also Ferris 2013). Longhouses as dwelling spaces are foreign to the conventions and understanding of dwellings held by archaeologists in their own worlds, and our own norms thus have limited capacity to visualize variability and difference, constraining not just visualizing but also making meaning from this unique archaeological material manifestation.

Whether archaeological assumptions of how a longhouse looks and feels, inside and outside the structure, has become a derivative of historical derivatives, the current mental image of a longhouse that dominates archaeological visualizations of this materiality of residence tends to be universally accepted as authentic. Those archaeologically visible settlement patterns do speak to a robust mental template of a longhouse, one that stayed relatively true through time, as builders incorporated extended walls and ceiling to house more than a single family unit, one that managed to negotiate central and side spaces of the longhouse, benches, entranceways, etc., and those broadly common elements sustained over those centuries of time and geographic space. So at that elemental level, derivative archaeological visualizations have power of authenticity because these basic, 2D elements we can see archaeologically are constants, and thus reify or keep static our conceptions of a visualized 3D longhouse. But the conceptual dichotomy in archaeological visualizations is that $3 \mathrm{D}$ space is marginalized to quibbles or trifles over 
architectural characteristics that explain below ground settlement patterns. These practical elements to living in that space may have played a much more secondary role in defining core understandings of what living in and being of a longhouse was to ancient dwellers than these elements take on for archaeologists. Thus this is where archaeological authenticity becomes circular, since it only ever validates the archaeological data as correct, without ever really getting at that knowing of people who lived in longhouses.

This then is the challenge of the virtual archaeologist, to recognize that what archaeologists don't really pay attention to, the unknowable dimensions of above ground space, which may be more meaningful to knowing longhouses as materially lived spaces beyond archaeological settlement patterns (e.g., considering light, sound, and texture across those core spaces we only know below ground; the implications of hand prints on support posts, or for that matter if those posts were carved, while seeing those carvings through the dimness of smoke and bad light). The virtual longhouse ultimately must negotiate, and add, a phenomenological materiality not accessible or visual solely through archaeological data.

\section{3 (Re) Imagined Physical Heritage}

Archaeologists around the world have sought to reconstruct archaeological sites to create greater understanding, and greater appreciation, of ancient spaces (e.g., Jameson Jr 2004). In the northeast, archaeologists have thought to engage with their interpretations of longhouse form and space through physical reconstructions of longhouses and villages, and have used these constructed spaces either as experimental archaeology or as contributions to interpretive reconstructions (see Williamson 2004). In a first such example, J.V. Wright (re)imagined a longhouse as a physical construction based directly from site data, at the location of the Nodwell site in Bruce County, Ontario (Wright 1974, 1995). Wright and his team used the exact location of post mold stains as a template map to attempt to reconstruct a longhouse (Wright 1974, 1995). Not only did Wright provide a visual and physical representation of archaeological data, he provided a phenomenological experience for the builders and visitors following its completion. The 
building team had to make decisions on longhouse construction purely based on assumptions from the archaeological record, Wright's interpretation of that data, and practical in-time experiential learning (Wright 1995).

These kinds of experimental attempts to physically reconstruct ancient longhouse structures in turn provides a phenomenological environment to test assumptions based on the historical and archaeological record, that has provided a starting point for the (re)imagination and experimental archaeology of these structures (Fecteau 1979; Williamson 2004; Wright 1995). Beyond Wright's archaeological experiment, modern longhouse construction has primarily been in the service of heritage/museum attractions (see as examples Ska-Nah-Doht Conservation Area, Sainte-Marie among the Hurons, Lawson site at the Museum of Ontario Archaeology, Pinetree in Brantford, Tawiscaron in Fort Erie, Crawford Lake Conservation Area near Milton, or the Tsiionhiakwatha/ Droulers archaeological sites in Quebec), or in the symbolic representation of modern Indigenous cultural, political and societal sustainability (see DeRuiter and Wu 2016).

These physical reconstructions of longhouses are archaeological representations of meaning-making that provide not only visual but also a physical and subsequently phenomenological interpretation of the archaeological record, for example Fecteau (1979) and others attempting to spend a winter's night in one of the Ska-Nah-Doht reconstructions. The case study by Williamson (2004) also takes into account contemporary motivations of these reconstructions: connecting the public and descendent groups directly to ancient physical spaces as representative of the Crawford Lake or Droulers archaeological sites, or new locales such as Tawiscaron in Fort Erie or Pine Tree in Brantford. These reconstructions may borrow from archaeological data, but also negotiate modern building codes and health and safety requirements to provide the public with access, and as such are also a mediation between an ideal notion of the past and the constraints of the present. And while these reconstructions allow for a knowing of the archaeologically unknowable, i.e., 3D space in and around longhouses, these physical reconstructions, once manifest, become "an example," with advantages and limitations. Ideally, the potential value of VA is that, as it lacks the construction, health and safety constraints, financial costs, and natural deterioration over time of a physical building, it 
can be highly revisable, financially efficient and longer lasting as a digital build. I should note, however, that I am not advocating for the abandonment of physical (re)constructions, only that there is the potentiality to harness new technology alongside physical representations in the application of new modes of coming to know longhouses as lived spaces.

\subsection{Known and Interpreted Archaeological Knowledge for Virtual Longhouse $(\mathrm{Re})$ Imagination}

\subsubsection{Surveying the archaeological literature - Painting a picture of a Longhouse}

Research on Iroquoian longhouses has been represented by substantially different modes of representation throughout the history and practice of longhouse archaeology in Ontario, Quebec and the Northeast United States. Early writers such as Bartram (1751), Morgan (1881), Thwaites (1896), Chadwick (1897), Beauchamp (1905), Waugh (1916) and Sagard (1939) either romanticized accounts of early commercial or religious explorers or offered early parochial cultural historical descriptions of "Native Life." By the end of the nineteenth century, people such as David Boyle and his successor Roland B. Orr of the Royal Ontario Museum were conducting some of the first Ontario archaeological research (see Anderson 2009). At that point, with excavations typically focussed on the recovery of objects and remains and of limited spatial extent, ancient architecture and longhouses were only a minor focus of research. By the twentieth century, archaeologists such as William J. Wintemberg were undertaking larger scale excavations, and documenting settlement patterns on Ontario Late Woodland sites (Wintemberg 1900, 1939; see also Jury 1946; Jury and Jury 1954).

Increasingly during the second half of the twentieth century, village and by extension longhouse excavations played an increasingly important role in demonstrating agricultural, social, material and cultural dynamics of the pre and post contact Iroquoian 
groups of Ontario (see as an example Kenyon 1968; Noble 1968; Wagner et al. 1973; see also Heidenreich 1972; MacNeish 1952; Ritchie 1956; Trigger 1963). By 1966 J.V. Wright's materials-based classification of Late Woodland developments in Ontario included identifying longhouses as a distinct and continuous cultural trait of "Iroquoian development" within the archaeological context (see Ferris 1999; Wright 1966).

With the emergence of large scale research excavations and professional cultural resource management as a means for site mitigation in the face of land development, including large scale or complete village excavations undertaken by mechanical stripping of topsoil, these factors facilitated an explosion of longhouse excavation data not merely as an addendum to the cultural material context, but as a means in which to understand the Iroquoian archaeological record, theoretically, experientially and experimentally (see as examples Fitzgerald 1979, 1982, 1984; Fox 1982; Hayden 1977; Lennox 1981; Noble 1975; Trigger 1978b, 1987; Wright 1974).

Through the experience of large scale recovery of settlement patterns at Draper in 1975 and 1978, by the 1980's longhouse excavation had matured into a robust field of data acquisition and quantitative interpretation (see as examples Dodd 1984; Finlayson 1985; Knight 1987; Ramsden 1988; Warrick 1988). With substantial data recovered from well over 400 longhouse excavations throughout Ontario, longhouse research shifted towards an effort to better interrogate that archaeological data by ethnohistorical means (see Chapdelaine 1993; Dodd et al. 1990; Engelbrecht 2003; Kapches 1990, 1993; Lennox and Fitzgerald 1990; Lennox et al. 1995; Snow 1997; Warrick 1996; 2000; Wright 1995). And in the last few decades, longhouse archaeology has shifted towards understanding its influence within the network of agents that comprise Iroquoian lifeways (Creese 2012a; Kapches 2007; O'Gorman 2010; Williamson 2004).

Although archaeological data, ethnohistorical material and cultural historical perspectives continue to inform the ways we create meaning, the more recent phenomenological turn that aims to envision all elements of longhouse life (e.g., narrative, light, sound, texture, smell, taste, environment, peoples), has in many ways enriched the subject matter beyond the traditional modes of archaeological knowledge building (see as examples Birch and 
Williamson 2012, 2013, 2015; Creese 2012a, 2012b, 2013; Ferris 1999, 2014; Watts 2009).

It is from this abbreviated history but rich archaeological dataset on the history of longhouse archaeology in Ontario that I am able to explore how to envision these pathways within virtual space. In starting my VA research to visually reproduce a 3D virtual Iroquoian longhouse, a core assumption right from the beginning was that I would follow the process that J.V. Wright had initiated so many years ago when reconstructing a longhouse at the Nodwell site from the physical archaeological record. In doing so the referencing of data was separated into quantitative archaeological site settlement data, and the constructed qualitative interpretations of longhouse style, space, form and use not directly represented within the archaeological record itself.

As implied above and reflected in any of the summaries that exist of the Late Woodland period (e.g., Ellis and Ferris 1990; Ferris and Spence 1995; Williamson 2015; Wright 2004), at this point there is a wealth of information on the archaeology and archaeological imagining of longhouses and longhouse living in the archaeological past of Ontario. Nonetheless it would be wrong to suggest my conceptualization of longhouses, and the data I relied on for the virtual build of a longhouse from later in the Late Woodland period was an exhaustive review of every available map of a longhouse or historical description of a longhouse from this region and time. Rather, I relied on a core of research and historical descriptions that helped frame my initial approach to the longhouse build, and certainly contributed to many of the wayfaring points that arose in mediating through that data during the build.

For the purposes of this project, quantitative archaeological site data that became the developmental base for the digital 3D asset creation part of this build was gleaned specifically from Anderson (2009), Birch \& Williamson (2013) and Dodd (1984, 1990), with Creese (2012a, 2012b, 2013), Cooper and Robertson (1993), Kapches (1990, 1993), Heidenreich (1972), Williams-Shuker and Allen (1998) providing supporting data. While Dodd's work, in particular, spans the entirety of the Late Woodland period, most of the longhouse information used to inform my virtual build of a longhouse related to the later 
Late Woodland and Terminal Woodland periods, encompassing both archaeological data and historical observations. As such, the general "template" of this longhouse would be informed by data reflective of a later stage of longhouse development in Ontario.

Qualitative interpretations in archaeological discussions of longhouses tend to rely heavily on historical descriptions of longhouses, particularly of the spaces created within these structures, and the framing construction methodologies described across all of Iroquoia from present day Ontario and New York State. The data referred to for this study were specifically drawn from Bartram (1751) Kapches (1990, 1993, 2007), Sagard (1632), Snow (1997), Thwaites (1896), Wright (1974, 1995) and Williamson (2004). Further quantitative and qualitative data on longhouse construction, form, orientation, space, village functionality and use came from Norcliffe and Heidenreich (1974), Woodworth (2001), Birch and Williamson (2013), Hatch and Bondar (2001), Jones (2010, 2014), Jones and Wood (2012), Jordan (2013), Keener (1999) Noble (1975) and (Finlayson 1985). Fecteau (1979) and Varley and Cannon (1994) provided useful data with regards to smoke and fire generation as well as hearth placement, while Steckley (1987) was relied on for linguistic interpretations of oral traditions of longhouse elements. Beauchamp (1905), Bursey (2001), Creese (2012a, 2013) MacDonald (1987) and Watts (2009) all offered insights on the use of storage and storage vestibules. Beauchamp (1905), Engelbrecht (2003), Campbell and Campbell (1994), Chadwick (1897) Morgan (1881) and Wright (1995) provided working knowledge on longhouse construction materials. Cultural historical perspectives on Iroquoian social, economic and cultural dynamics that might encompass longhouse living were derived from Birch and Williamson (2015), Chapdelaine (1993), Dodd et al (1990), Jamieson (1990) Lennox and Fitzgerald (1990), Ramsden (1990) Trigger (1963, 1976, 1978a, 1978b, 1987), Warrick $(1984,1988,1996,2000)$.

Archaeological research and European historical accounts suggest that the residents of a longhouse were made up of multiple extended families, variably interconnected socially and familiarly across longhouses in a village, and across villages (Heidenreich 1972; O’Gorman 2010; Trigger 1976; Warrick 1984, 1996; Williamson \& MacDonald 2015). Thus, these local networks of longhouse memberships helped to create political, 
economic and cultural interdependencies and alliances between extended longhouse families in other villages (Birch \& Williamson 2013; Heidenreich 1972; Williamson \& MacDonald 2015).

These residential structures were integral parts of the community in which construction techniques were fine tuned to utilize available resources and sturdy enough to sustain several decades or more of living within the same structure (Williams-Shuker and Allen 1998; Creese 2012a). Theoretically, longhouse builders and residents operated within social networks that extended beyond individual longhouses or villages that would have allowed a flow of information in longhouse building techniques, styles and methods, providing a variance in construction methodologies (see Birch and Williamson 2012; Snow 1997), and also variance in longhouse layout within villages. At a general level, longhouse and village locations, especially by ca. $1500 \mathrm{AD}$, generally reflect a common set of criteria: i) viewsheds, which often included a defensive position usually occupying higher ground, ii) proximity to a reliable water source, and iii) proximity to arable land in which to grow crops (see Birch \& Williamson 2013; Chapdelaine 1993; Heidenreich 1972; Jones 2006, 2012; Latta 1980; Warrick 1984). Regional disparities across southern Ontario in building materials, the influx of new building techniques, micro-environments and community partialities to specific materials all would have provided a rich and variable building environment (Williams-Shuker and Allen 1998; Watts 2009; Williamson 2004).

Due to increased social pressures emerging through centuries of societal coalescence, Ontario Iroquoian villages of the sixteenth and seventeenth centuries were generally palisaded and would potentially have existed for anywhere from five to thirty years' duration (see Hatch 2001; Heidenreich 1972; Trigger 1976; Warrick 1984). Archaeological evidence suggests that longhouses in villages from this period tended to be grouped parallel to each other or in clusters, which may have reflected distinct social segmenting of distinct clans or lineages, or of previously distinct community members in subsequent, coalescent villages (see Birch 2012; Fogt and Ramsden 1996; Hatch and Bondar 2001; Heidenreich 1972; Warrick 1984). Typically, there was a range in longhouse lengths within a village, including smaller, single hearth examples often 
interpreted as occupied by only one or two families (e.g., Anderson 2009; Finlayson 1985), and even an informal review of village settlement patterns suggest house ends and internal features could vary across the village. Likewise, episodes of rebuilding, repair or extension/contraction would change the shape and internal layout of an individual longhouse over the course of its use life (e.g., Birch and Williamson 2013).

\subsubsection{Archaeologist perceptions - Meaning-making through Longhouse Data}

In the following sections, I will be reviewing the archaeologically unknowable above ground structural elements in a longhouse, and the variable assumptions archaeologists have made to try and understand these above ground elements of longhouses from below ground archaeological data and historical data. The interpretation of archaeological data combined with archaeologists' personal mental maps, both $2 \mathrm{D}$ and 3D, provides the core set of variables for my initial visualization of a longhouse in virtual reality. It also becomes a template in which to interrogate interactively, temporally and contextually these variables after an initial virtual 3D object was constructed. The purpose here is not to provide absolutes or otherwise imply authority and authenticity to the archaeological and historical data reviewed below. Rather, this review helps acknowledge and enable variation within the interpretation of the archaeological record as a broader functionality of virtual longhouse construction.

\subsubsection{Longhouse Framing Interpretations}

The integral structural element in longhouses tended to be its major support posts (see Wright 1971, 1995; Kapches 1990, 1993; Snow 1997). These elements framed the various interior living spaces, provided guidance for the construction of the living areas, and supported the external shell of the longhouse. There is enough ambiguity in historical accounts and archaeological data that, at least from my review of the archaeological literature, there tends to be three distinct archaeological interpretations of how internal 
structural supports were laid out and designed to hold the roof of the longhouse; all three of which implying distinct external visual differences in longhouse form (see Figure 3; see also Williamson 2004):

1) Wright's $(1971,1995)$ reconstruction of a longhouse at Nodwell suggests a $\pi$ shaped internal support infrastructure, designed to support a ratio of 4:1 in height between the main building and a separate arbor roof (Cross-section $\mathrm{C}$ in Figure $3)$;

2) Based on extensive historical European oral accounts and two specific visual representations of Seneca longhouse floor plans from the 1700s, notably Bartram's (1751), Snow (1997) suggests that longhouses might have had a 60/40 split between longhouse body and a separate upper roof (Cross-section A in Figure 3);

3) Kapches (1993), using Iroquoian oral history and archaeological data, suggested that the longhouse walls and roof might have been entirely integrated by long exterior posts lashed at the center roofline forming a continuous arbor effect (Cross-section B in Figure 3). 


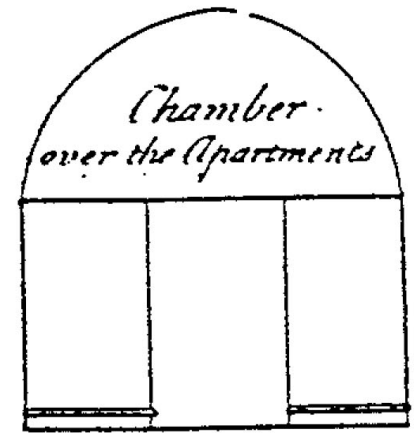

A

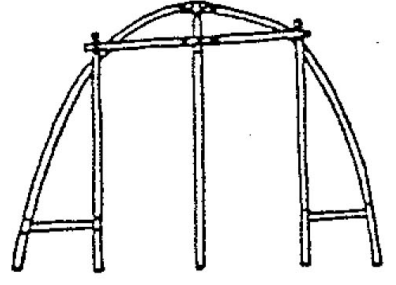

B

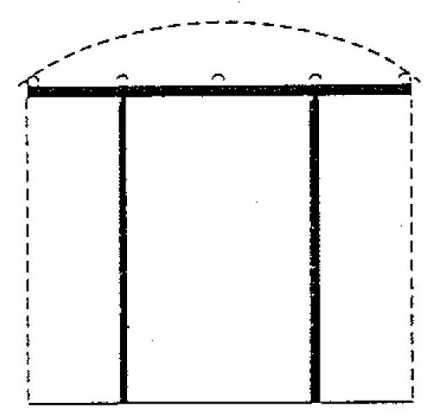

C

Figure 7. Three alternative longhouse cross sections: A from Bartram (1751), B from Kapches (1993:148), C from Wright (1995:13).

Figure 3 - Longhouse Framing Examples from Snow (1997:77). Reprinted with permission from Dean Snow.

While I am prepared to assume that there could have been regional or temporal variation at play making more than one of these cross-sectional interpretations of longhouse structure valid, and likewise it is probably better to think of these three architectural support styles as more of points along a continuum than either-or options, it is important to underscore that the material archaeological record is entirely void of any tangible evidence that could support or refute any of these framing theories (see Kapches 1993; Snow 1997; Wright 1995). However, the supporting structural frame was the backbone of the longhouse and as such, the wall and roofing systems would be highly dependent on the frames to ensure structural integrity (see also Latta 1985:48), and in turn would have influenced the exterior look and the interior functionality of a longhouse.

Support frame posts are assumed to have been paired or clustered along the center axis of the longhouse and large in diameter, reflecting their role in supporting the roofing systems (see Figure 3: A \& C), but also the bunking systems along the sides of the corridor which presumably would have needed to support the weight of numerous 
families and their goods on a daily basis (see Kapches 1993). A broad review of the literature suggests that interior support posts had a wide range of diameters, from $6-25 \mathrm{~cm}$ with an average of 6-12.8cm (see as examples Dodd 1984:275; Kapches 1993:142; Heidenreich 1972:45; Snow 1997:76).

\subsubsection{Longhouse Wall Interpretations}

My review of the archaeological literature and a sampling of 2D excavation maps involving the excavation of longhouses in Ontario underscores that two main archaeological elements tend to be represented in the archaeological excavation record: cultural features (including fire hearths), and post molds, including support post hole stains and wall post hole stains (see Figure 4). Post molds represent the bottom end of wall and support posts put into the ground, and the stain recorded by archaeologists is the organic soil occupying the hole created by that post. Methods of placing posts in the ground were likely variable by soils and post size. Longhouse wall posts can be quite variable in diameter, for example ranging from $4-18 \mathrm{~cm}$ in diameter at the Parsons site, a fifteenth century Iroquoian village in north Toronto (Williamson 2004:161), with an overall average from the 10 longhouses excavated of $6.4 \mathrm{~cm}$ (Williamson 2004:161). Lennox (1981:19) suggests that the Hamilton site's sidewall posts were constructed with 5-10cm diameter posts. Heidenreich (1972:45) mentions 7.62-12.7cm (3-5 inch) diameters as typical for longhouse wall posts. Dodd's (1984:233) analysis of 314 Mid to Late Woodland Iroquoian longhouses yielded an average of $8.85 \mathrm{~cm}$ for wall posts (Dodd 1984:272). Even in these brief examples, it should be noted that there is a wide variation of wall post diameters from across Ontario excavated sites, indicating a variability possibly dictated by available material resources, individual building preferences, rebuilding/remodeling or localized/regionalized construction techniques, and certainly affected by soil alterations and excavation strategies that remove the upper (presumably wider diameter) portions of these post hole stains from archaeological documentation. 


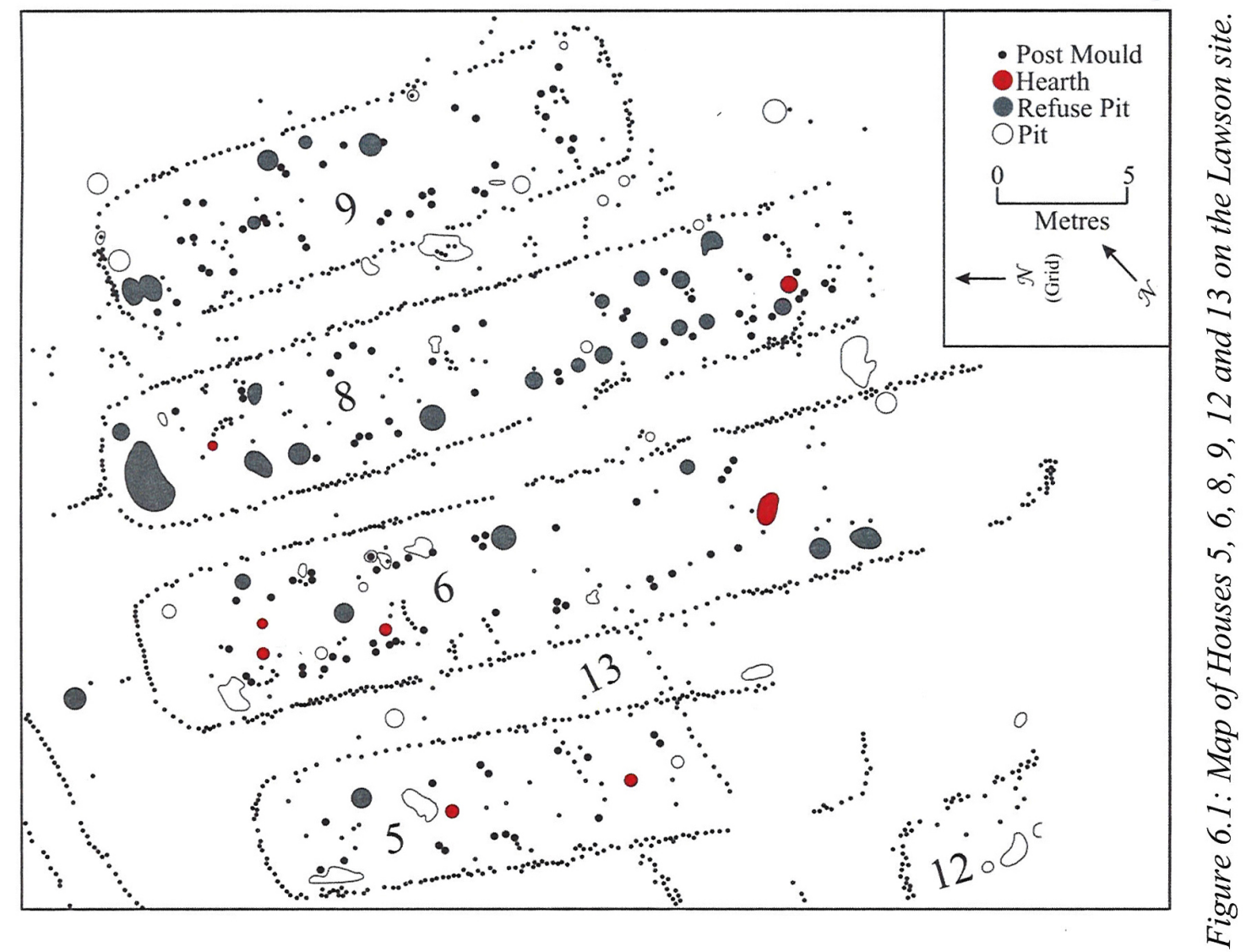

Figure 4 - From Anderson (2009:70). Reprinted with permission, Museum of Ontario Archaeology, London, Ontario.

Wall post density is a standard measurement used in longhouse archaeology to describe the number of exterior wall posts used per meter on an excavated longhouse. Generally, the calculation is an average of posts along a post-line and offers insight into house wall construction, renovation and repair. Martha Latta (1985:47) in her evaluation of the Auger Site, an early $17^{\text {th }}$ century Huron phase village, indicated a relatively standardized range of $2.7 / \mathrm{m}$ to $3.6 / \mathrm{m}$ post densities of the four houses excavated at the site. The house lengths ranged from $25-12 \mathrm{~m}$ yet the wall post densities remained relatively the same indicating a standardization or preference in wall construction within this community (Latta 1985:47). Dodd (1984:271) reports an average wall post density of $3.5 / \mathrm{m}$ in her analysis of Late Woodland longhouses, while Birch and Williamson (2012:69) report ranges of $3.2 / \mathrm{m}$ to $4.4 / \mathrm{m}$ for the 98 longhouses excavated at the Mantle site. In all of 
these examples post density increased only marginally with house lengths longer than $40 \mathrm{~m}$ demonstrating a uniformity of building techniques and/or continual maintenance methods.

Heidenreich (1972:48-49), relying on seventeenth century European accounts of Huron life, mentions that the outer walls of longhouses had double rows of staggered posts, and further suggests that this construction method was used to help "weave" sheets of bark between the poles. Fitzgerald (1984:8) indicated that House 1 of the Raymond Reid site is archaeologically consistent with a double offset pole spacing, possibly pointing to an intentional weaving system for the bark shingles. Snow (1997:82) suggests that Mohawk longhouses had a lighter "second house frame," made from smaller diameter posts, which was placed over top of the bark sheets as a method to securely keep shingles in place.

\subsubsection{Longhouse Roof Interpretations}

Kapches (1993), Snow (1997), Williamson (2004) and Wright (1974, 1995) have considered how longhouse roofs were constructed and what they looked like. As seen in Figure 3 and discussed in detail by these archaeologists notions of roof framing are pieced together primarily from Eurocentric historical accounts by Sagard-Théodat (1632), Brebeuf (1634-1635) and Lafitau (1724), modern linguistic analysis of Iroquoian and European oral and written examples of longhouse structural elements (see Steckley 1987), extremely limited visual historical examples (see Snow 1997; Wright 1995) and from the archaeological record (e.g., considering angle and orientation of post mold profiles as reflective of construction design).

Kapches (1993), Snow (1997), Williamson (2004) and Wright $(1974,1995)$ contend that the interior framing structure of the longhouse would have dictated how the roofing system is then implemented. Kapches (1993) and Williamson (2004) both favour a method of continuous long poles forming the side walls of the longhouse that are terminated by being strapped down at the top to form the middle apex of the center line of the longhouse roof. In other words, there was a continuous wall into roof. Snow (1997) 
and Wright (1995) favour about a 60/40 and 80/20, respectively, of percent wall and percent roof contributing to overall longhouse height. Implicit in these interpretations is that the roofing structure is a separate element to the longhouse-rafters constructed above their preferred internal framing superstructures. These interpretations offer a sense of variable roofing design, but generally major horizontal elements that would be likely required not only to support and reinforce vertical poles, connect vertical to arched roofing poles, and also to act as latching points for bark shingles, are entirely absent from consideration. More generally, archaeologists tend to avoid talking about any longhouse feature that cannot be deduced by the physical longhouse features they unearth, underscoring how their visual template of a longhouse is "built" from 2D below ground elements. So for such a contested and critical element to understanding longhouse form, very little is actually said of longhouse roofing systems beyond the historically influenced visual look of the external shell itself.

Roofing interpretations by Kapches (1993), Snow (1997), Williamson (2004) and Wright (1974, 1995) all favour some sort of moderate incline or pitch within the roof shape, though we can't rule out the possibility of flat or even completely unknown forms. The roof itself would have contained a very important feature: its smoke holes which would allow escape of interior smoke from the heating and cooking fire hearths below, and also allow in light and possibly a secondary source of air flow. Historical accounts (see Champlain 1907:124; Sagard 1939:95; Steckley 1987:30) indicate only that there were holes in the roof to allow for the escape of smoke, but they do not go into detail on the number, shape, size or even strategic location. Steckley (1987:30-31; see also Wright 1995:16) indicates that there were linguistic examples within the Huron language to convey the notion of smoke holes and their ability to be opened or closed within longhouses.

\subsubsection{Longhouse Height and Width Interpretations}

One of the main questions of architectural design that remains enigmatic, and variable depending on assumptions of roof construction and its internal support, is actual 
longhouse height, and beyond archaeological data to reliably confirm. This can only be qualitatively gleaned from European accounts, which state that height tended to be equal to longhouse width (e.g., Bartram 1751; Kapches 1993; Heidenreich 1972; Snow 1997; Thwaites 1896; Wright 1995). Based on Dodd's (1984; see also Knight 1987) extensive analysis of Ontario Late Woodland longhouses, that the average mean widths of longhouses from the 1500-1650 A.D. timeframe were between 6.5-7.2m, with Wright (1971), Snow (1997) and others indicating ranges of 6-7.5m as minimum and maximum width/height variables. I would speculate that interior house height was also important to help raise the substantial layer of smoke that would have filled the interior of the longhouse from the numerous active fire hearths along the corridor (see also Fecteau 1979). It is worth noting that historical records are completely silent on whether longhouse height increased or decreased independent of width, leaving archaeologists to struggle with visualizing potential variances in longhouse heights across the Late Woodland, but at least providing my research with a relatively useful correlate between width and height.

\subsubsection{Longhouse Length \& Hearth Interpretations}

Dodd's (1984) research on longhouses documented from the sixteenth century suggests that there is a substantial historical and archaeological range in length between 5 to $72 \mathrm{~m}$, with unique examples both above and below that range (see also Cooper and Robertson 1993; Creese 2013; Fitzgerald 1984; Knight 1987; MacDonald 1987; Noble 1975). Overall Dodd (1984) suggests a mean length of about $19.8 \mathrm{~m}$ for later Late Woodland longhouse lengths.

Lengths are also supposed to correlate with the number of hearths in a structure (Dodd 1984). Champlain and Sagard reported seeing longhouses with 8 to 12 hearths and the archaeological record documents longhouses with that many hearths (see Heidenreich 1972; Snow 1997); however, as Bartram noted, exceptionally long longhouses can have a single hearth (see Bartram 1751, Snow 1997), also noted archaeologically (MacDonald 1986; Ron Williamson personal communication, 2016). In Varley and Cannon's (1994) 
work on hearth spacing, house length and use, hearth position and frequency is not always consistent within the archaeological record and hearth position could and likely did move throughout the interior of common longhouse structures over the use life of the structure. Generally, archaeologists tend to assume that most residential longhouses had 3-5 hearths, with two families sharing each hearth, and each family maintaining a distinct, bark-enclosed raised compartment on either side of the hearth (see as examples Chapdelaine 1993; Kapches 1993; Heidenreich 1972; Williamson 2004; Wright 1974).

\subsubsection{Longhouse Bunk-line \& Sleeping-berth Interpretations}

Based on limited European accounts, the first or sleeping platform of these raised compartments were about 1.2-1.5 m (4-5 feet) off of the ground (Champlain 1907:313314; Lafitau 1977:19-22; Sagard 1939:91-95; Snow 1997:65). And space below this platform would have been for storing additional firewood and possessions (Heidenreich 1972). Snow (1997:83) notes, however, that later seventeenth century European accounts suggest that these platforms were only $30 \mathrm{~cm}$ off the ground, while the second platform, the canopy or storage shelf, was just 1.5-1.8m off the ground (see Snow 1997:70). These variable ethnohistorical observations may well reflect differing estimations of size, or observer ability to estimate accurately, or they may capture accurately patterns observed in single longhouses, or trends in longhouses that differed across space or time. This variability will need to be negotiated in the particularity of my virtual longhouse build, but should not be considered either-or choices in the accuracy of seventeenth century historical accounts.

When some researchers have referred to oral history they note that a prevalent Iroquoian building measurement was "ten" (see Kapches 1993:141; Williams-Shuker and Allen 1998:6), and that ten was equivalent to $1.5 \mathrm{~m}$ and based on the length of an adults body sleeping position (see also Snow 1997:70). It is worth noting that this estimation, echoed in European accounts, is also consistent with European stature for the time at about $1.6 \mathrm{~m}$ in size, or roughly the same as their Iroquoian hosts (Komlos 2003). Dodd (1984) discovered based on the archaeological record that the standard range of the sleeping 
compartments would have been $1.5-2 \mathrm{~m}$ in depth from exterior wall to the start of the communal central corridor, based on the position of support posts documented in archaeological excavations (see also Williams-Shuker and Allen 1998). Interestingly Snow (1997:83) uses an interpretation of Lafitau (1977:19-22), which states, “These platforms, shut in on all sides, except that of the fire, serve them as beds and benches to sit on", suggesting that the family space was enclosed. The notion that the sleeping compartments could have been enclosed, individualized "apartments" was previously suggested by Kapches (1993:150) who indicated that the Ball site, a proto-Historic Huron village, displayed rows of perpendicular smaller diameter post holes that demarcated potential apartments along the bunk-line of the longhouses. Partitioned bunks are archaeologically rarer in Ontario than in New York State (see Kapches 1993; Snow 1997), it nonetheless is an intriguing dimension to visualize individualized, or at minimal, specific immediate-family environments within longhouse space.

\subsubsection{Longhouse Corridor Interpretations}

In the middle of the longhouse running along the long axis of the structure was the central corridor, historically and archaeologically the location of hearths and various activity areas that presumably included food preparation and cooking (see Kapches 1993). The central corridor would have been a constant and sometimes congested ebb and flow of activity from children playing, to dogs running in and out, to the chatter and discussions of men and women going about their daily routines or discussing important business (see Watts 2009). This communal zone, or "hearth area" (Kapches 1990:52) generally appears to have been 2-3m wide, from bunk line to opposite bunk line (Dodd 1984; Kapches 1993; Snow 1997; Wright 1997). It is worth noting that, depending on specific time period (e.g., Dodd 1984; Kapches 1990; see also Birch and Williamson 2012; Finlayson 1985; Lennox 1984; Timmins 1997; Williamson 1998), spaces between hearths could be sizeable or not, which could have been a factor of resident population size, whether the house was primarily occupied in colder weather, if non-food preparation activities were also taking place in these spaces, or other social or material realities. But certainly by the later part of the Late Woodland, it is reasonable to assume that these hearth areas were 
really extensions of adjoining family spaces that likely had to be negotiated through various social conventions between members of families, and with other longhouse residents (Ferris 1999; Kapches 1990; Ramsden 1990b). It is also worth noting that, over the life of a longhouse, the focus and use of these hearth areas may have drifted, as reflected by overlapping features, shifting hearth locations, and overlapping and intersecting tertiary pole placements (see Dodd 1984; Kapches 1990). Such changes to the use life of longhouse spaces, and even of longhouses themselves, underscores the difficulty of directly translating the accumulated settlement patterns represented in the archaeological record into a moment in time reconstruction of the structure represented by that archaeological pattern (e.g., Williamson 2004; Wright 1995).

\subsubsection{Longhouse Vestibule Interpretations}

The end porches or vestibules of longhouses provided the defining stylistic differences between structures. Many exhibited rounded compartments as the long side walls of the longhouse curved into rounded ends, while other longhouse ends were less round and almost flat, though that was a less common pattern among Ontario archaeological examples, and it has been suggested that flat ends were actually temporary walls so that longhouse expansion could take place later on (Chadwick 1897; Snow 1997). Entrances were generally evident for either end of the longhouse, and tended to be present archaeologically as a gap in the line of posts making up the longhouse wall, ranging in width from less than a meter to a meter and a half (Dodd 1984). The interior vestibules made up at either end of the longhouse potentially contained the bulk of the larger communal storage of firewood or containers of corn and other goods (e.g., Kapches 1993; Heidenreich 1972; Watts 2009). Where there are visibly distinct spaces past hearth areas (not always the case for earlier Late Woodland structures or smaller longhouses documented in the later period), their length tended to average around 4m (e.g., Dodd 1984; Kapches 1993; but note Kapches 1990 and Timmins 1997). Lafitau (1977:22) suggests that end spaces could be closed off from bunks and hearth areas by an interior wall inserted at the point the longhouse end began to curve, connecting the exterior wall to the interior internal support posts in that location (see also Snow 1997:82). 


\subsubsection{Longhouse Construction Material Interpretations}

Archaeologists tend to assume that, across the Northeast, Iroquoian builders of longhouses favoured a mixed use of cedar, birch, elm or pine for longhouse building elements (see Campbell \& Campbell 1994; Heidenreich 1972; Kapches 1993; Wright 1995). Relying on stone axes, heavy timbers beyond about $25-30 \mathrm{~cm}$ in diameter would have been difficult to harvest in quantity (see Heidenreich 1972:45). As discussed, the average pole size used for walls and interior posts tended to be around $10 \mathrm{~cm}$ in diameter, which would indicate a heavy reliance on young growth timber.

Researchers using historical accounts and linguistic research (e.g., Engelbrecht 2003; Heidenreich 1972; Steckley 1987; Williamson 2004) suggest that the longhouse tended to be sheathed in bark shingles, preferably cedar or elm, and may have averaged $1 \times 2 \mathrm{~m}$ in size. Linguistic research and historical accounts suggest that these shingles were generally harvested in the spring when the running sap made bark removal easier, and that they were kept in water to preserve them from warping and cracking before use (see Beauchamp 1905). How shingles were attached to the supporting structure is unknown other than a brief description in Lafitau (1977:19-22) that suggests bark cordage at the ends of the shingles allowed them to be strapped to the supporting structure.

Heidenreich (1972:45) estimates that for a large hypothetical village of 1000 people and 36 longhouses, 16,000 exterior wall posts with a diameter of 7.62-12.7cm (3-5 inches), 250 interior support posts with a diameter of $25.4 \mathrm{~cm}$ (10 inches) and 15,050 square meters $(162,000$ sqft $)$ per house of bark covering would be required to support construction of the longhouses only.

\subsubsection{Longhouse Phenomenological Interpretations}

There has been little exploration as to the phenomenological experiences of Late Woodland Iroquoian longhouse from the archaeological record. Visualization of this phenomenological being in the longhouse, contextualizing the haptic, olfactory and 
auditory senses virtually, may provide a unique opportunity to engage all stakeholders (public, private, academic and descendant) in redefining what longhouse living meant as a physical/material and cultural/social experience (Watts 2009). The ability to experience the application of sight, sound, smell, and touch in context helps to embody the overall phenomenological archaeological experience (Dawson et al 2011) and in turn may provide further understanding to the archaeological record. Dawson et al (2011) described this as the concept of "presence" in which the viewer or participant is transported to another place, world or dimension, immersed in all senses, allowing for an emotional connectedness absent during an excavation, the sterile artifact repository, or museum display.

In visualizing a longhouse environment, we also need to consider seasonality, as the lifeway of a longhouse had its ebb, flow and congestion through the year as well. During the summer the longhouse space may have been virtually deserted as people went to work the fields as well as activities such as hunting, fishing and trading (see Kapches 1993; O'Gorman 2010). In the fall people would increasingly congregate back home, reside more and more inside, and engage in the social life of a populated village and longhouse (Heidenreich 1972). In the winter and early spring, the longhouse was constantly occupied as a hub of activity, communal warmth and social engagements playing out through the thick haze of smoke from the constantly burning cooking and heating hearths (Heidenreich 1972). Speculative as this might be, we might represent the activity within the longhouse as it would be understood by the seasons. For instance, would women engage in mat and fishing net weaving during the winter months inside the longhouse? If so, how would finished and unfinished products be stored within the longhouse? Would they be hung from the rafters with the drying food stores or stored under the bunks? Does our ability to move $3 \mathrm{D}$ versions of these objects within a reimagined longhouse space shed light on routine daily life?

Another dimension to phenomenologically representing lived space is to consider whether or how this space captured intangible values and how can this be represented virtually? William Woodworth (1998), an Iroquois descendant, architect and anthropologist commented while visiting the Holly Site that the central longhouse there appeared to be oriented to take advantage of the full sun of the Winter Solstice. Taking full advantage of that orientation during the solstice an explosion of light would dramatically penetrate the darkness of the longhouse extending from the eastern door and reaching the western door (Woodworth 1998). This dramatic light would illuminate the 
longhouse in a manner that would underscore any spiritualistic nature of the event, and of the interior longhouse space itself. Thus, light and longhouse orientation can combine to play an important role in our attempt to phenomenologically experience a longhouse within virtual space beyond the tangible materiality of that space (Dawson et al. 2011; Woodworth 1998).

Virtualizing longhouse construction, occupation and use within a 3D environment potentially offers a new and relatively untested methodology for a community that has a substantive collective wisdom to make sense of the archaeological material in a more personal, meaningful way (see Watts 2009). It also affords the ability to enhance sensory elements that do not last in-situ within the archaeological record: light, sound, smell and touch (Watts 2009). By digitally reproducing these and other variables, 3D visualization is a unique means to test existing ways of thinking about dwelling and residential spaces beyond the archaeology of them (Dawson et al. 2011).

\subsubsection{Template parameters for the construction of a Late Woodland 3D Iroquoian Longhouse Model}

Following a sampling of archaeological site data from Anderson (2009), Birch \& Williamson (2013), Creese (2012a, 2012b, 2013), Cooper and Robertson (1993), Kapches (1990, 1993), Heidenreich (1972), Lennox (1981), Snow (1997), Varley and Cannon (1994), Williams-Shuker and Allen (1998), Williamson (2004), Wright (1974, 1995), among others, and specifically from Dodd's (1984) evaluation of over 417 Iroquoian longhouse excavations, I was able to define a series of, in effect, basic building blocks or personally relatable building parameters, to help inform core physical attributes to a Late Woodland, ca. 16th century Northern Iroquoian longhouse, which include:

- An average length of $18 \mathrm{~m}$;

- An average width of $7.6 \mathrm{~m}$;

- A centre corridor width of $4.0 \mathrm{~m}$;

- Sleeping platforms/family cubicles ranging from $1.1-1.8 \mathrm{~m}$ in width, 3.7-4m in length, and 1.8-2m in height; 
- The sleeping platform itself was noted as being anywhere from $0.30-1.5 \mathrm{~m}$ off the ground, with the roof of the demarking a second bunk, above which personal storage was commonly thought to be kept, being roughly $1.8-3 \mathrm{~m}$ from ground level (i.e., creating around $1.5 \mathrm{~m}$ of space between the first and second bunk platforms);

- Average interior support posts were between $8.6-12 \mathrm{~cm}$ in diameter, but could be significantly larger in diameter;

- Exterior wall post diameter ranged as well, and mostly below $10 \mathrm{~cm}$ in diameter. On average there was 3.5 poles per meter along the length of the longhouse;

- Typical fire hearth spacing was 2.9-3.6m between hearths. A common historical assumption for this time period was that each hearth supported two families, one on either side of the longhouse.

- There were 4 support posts that defined the space encompassed by each fire i.e., four per living section within the longhouse.

\subsection{Discussion}

Almost universally the narrative description of a typical Iroquoian longhouse conveyed by archaeologists, no matter its temporal placement over the Ontario Late Woodland, is the same; a long cigar shaped, wooden framed multifamily dwelling, clad with bark (Dodd et al. 1990; Latta 1985; Lennox and Fitzgerald 1990; Jamieson 1990; Ramsden 1990a; Snow 1997; Williamson 2004; Wright 1995). While a closer look per site or even per excavated longhouse underscores a great deal of longhouse to longhouse variability in structural layout, use patterns and even material construction, that idealized or mental template archaeologists hold, continues to be reinforced by the limited visual imaging historians, archaeologists and others imagine for the diversity and antiquity of this iconic residential and social structure of the southern Ontario Late Woodland.

This section is less a definite statement on the archaeology or ethnohistory of longhouses, and is more precisely a survey and assessment of the nature and variability of the longhouse elements commonly documented by archaeologists, or variably imagine from 
that record. Understanding how archaeologists make meaning from the archaeological cacophony of below ground information they extract will be a critical dimension of my own making process in the next stages of my virtual archaeological exploration into longhouse construction and use.

\subsection{The Virtual Longhouse}

However contested archaeological assumptions of longhouse construction, material, space and use are, they do represent a starting point for interrogating the physicality of a "typical" Iroquoian longhouse. They are the assumptions of archaeological interpretation that I ultimately could test, compare, contrast and reflect upon through the virtual construction of such a structure guided by this archaeological knowledge.

In undertaking this VA research, I took a three-phased approach to the investigation, characterized by "wayfaring" moments of discovery (see Ingold 2011 and Carter 2017). Longhouse 1.x, was an initial, entirely archaeological data driven study to determine the viability of developing toolsets to automatically generate 3D visualizations from existing archaeological site map data. This investigation led to the implementation of a procedural animation-modeling framework that would allow for different longhouse construction parameters to be user controlled and altered based on the users' understanding and mental image of what a longhouse "should" look like to them.

In Longhouse 2.x, a trained animation team took an entirely artistic driven approach and was tasked with recreating the Lawson Site (a $16^{\text {th }}$ century village site that has been subjected to over 100 years of archaeological investigation; Anderson 2009), using traditional film \& television visual research methods (see Catmull and Wallace 2014; Prince 2011). Once these models and environments were created, they were ported into a real-time video game engine in order to determine how the technology and pipeline could enable real-time user integration within a virtual archaeological environment from both an Oculus Rift and traditional game monitor perspective. 
Lastly, in Longhouse 3.x, I combined the knowledge generated through the previous two longhouse experiment iterations with the inclusion of an "Archaeologist's Lens," which will be explained further below, to virtually imagine what a longhouse might look and feel like from an archaeologist's perspective.

These three stages to my VA research helped to frame my digital creation of archaeological knowledge, but also represented a concerted effort to provide a representative framework for future construction of knowledge within virtual archaeology using 3D and 2D modeling techniques, gaming platforms for interactivity as well as head mounted and traditional screen based visualization toolsets. These three computer-aided methodologies for achieving VA illustrate one of many possible narratives in which past material culture can be represented in the present for the future.

As discussed in Chapter 2, a critical method I adopted through the development of these longhouse iterations was the intentional reveal of the research's "paradata", the ancillary process of reflexively referencing through the visualization process (see BentkowskaKafel et al. 2012; Denard 2012). Essentially this process allows for "tracking the interpretive trail" that archaeologists, artists, technologists and heritage interpreters make when referencing the available data to envision a plausible visualization (Beacham 2006; Denard 2012; Huggett 2015; Huvila 2013; Perry 2015). Explicitly revealing my own paradata then was at the core of my implementation of both the London \& Seville Charters $^{5}$ in my research (see as examples Denard 2012; Gea et al. 2013; Pletinckx and Tartessos 2011). Thus, weekly production and critical reflection of knowledge in the form of a publicly open Internet blog website (www.theskonkworks.com; see Appendix A \& B) was my test to determine the feasibility of transparently discussing the negotiations, quandaries, frustrations and eureka moments of my virtual archaeological production. These blogs document in plain language the influences and choices of knowledge construction that helped shape the direction my research took. The public forum of the website in turn invited a wide range of others to engage with those paradata

\footnotetext{
5 The London \& Seville Charters are a framework methodology for the application of Virtual Archaeology within Heritage visualizations.
} 
reveals, furthering those reflexive moments. Throughout this chapter I will be referring to some of the responses to the material posted which in turn influenced and produced new knowledge in a participatory research methodology.

\subsubsection{Longhouse 1.x}

Influenced by Reilly, Kolijbye-Biddle, Walter and Todd's attempt to virtually reconstruct the Old Minster of Winchester in the 1980s informed only by the archaeological record (see Reilly and Richards 1987; Reilly 1989; Reilly et al. 2016), I started this research with the notion that the in situ archaeological data had to inform the visualization process (see Reilly 1985). Thus, to begin building a 3D longhouse within virtual space, the task was simple; could I birth virtual 3D poles from archaeological straws directly from an archaeological site map? Not a placement of 3D objects onto the map, but a birthing of the pole using actual archaeological field data (the circumference of the archaeological post molds and their relative position as recorded).

The base infrastructure of any Iroquoian longhouse construction is its interior frame as Dodd (1984) as well as Birch and Williamson (2013) indicated in their field research of excavated longhouses; the posts of which serving as robust wooden supports that became the framing for the entire structure. As such, I wanted to focus initially on building that interior frame from archaeological data. Using a computer animation technique from the VFX industry called "procedural animation," we attempted to use the data from Creese (2012:63) to birth all the support posts from the Burkholder II House 1 site he illustrated. By adopting this technique, we were able to control specifically which poles to birth, their circumference and assumed height (Figure 5). 


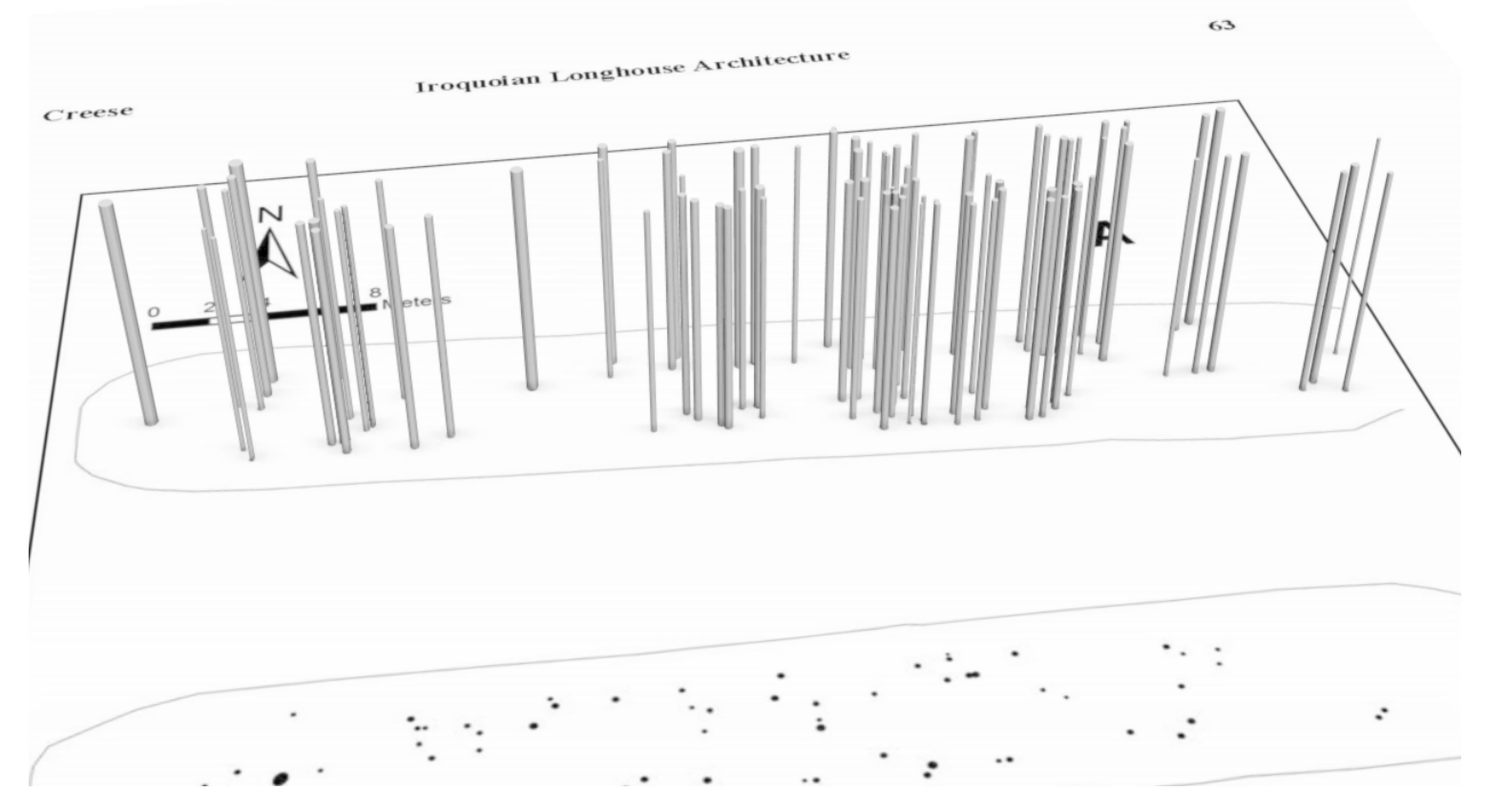

Figure 5 - Screen capture of "Post Clustering" taken from Burkholder II House 1 site map, Creese (2012a:63). Reproduced with permission from John Creese.

This simple technique is a powerful means of rapidly visualizing all of the pole positioning and circumferences from the archaeological site data at once. Although not attempted in this test, this method provides a potentially new interpretive approach to understanding the possible temporal sequencing of the poles themselves, as each pole has the ability through the procedural modeling methodology to be individually animated, or birthed, based on interpretations of that archaeological data (e.g., which of several overlapping rows of posts came first; whether a house contracted or was expanded, etc.). Separate research would be needed to fully develop this methodology, but for our purposes I wanted to confirm the possibility of auto-generating 3D assets directly from the 2D archaeological site data. In doing so, like the Old Minster visualization, the raw archaeological data becomes the base template for any further virtual archaeological interpretations. 


\subsubsection{Procedural Modeling}

Procedural modeling for 3D animation is a technique that was developed by Kim Davidson and Greg Hermanovic in 1985 (K. Davidson, personal communication, March 1996), both members of the group of artists and programmers who founded the computer animation industry. It was my extensive exposure to this technique through my use of the Houdini animation software system that ultimately would lead to my foundational approach to the use of procedural modeling in archaeology.

A procedural modeling method is quite simple. Instead of building static 3D models, the entire building process is retained within a dynamic set of user controlled operators or nodes that each controls a specific stage of the building process. So, for example in the case of Longhouse 1.x, at the top of the modeling network would be an "input" operator that could read in any 2D image of an archaeological settlement site map in jpeg, tiff or png format. The next operator would isolate the key features of that image as determined by the user; in our case the post mold positions and diameters as represented on the site excavation map. The last operator would "birth" poles from their 2D post representations on the site excavation map to a height in 3D space equal to the width of the longhouse as represented on the initial map input.

Beyond that simple 2D to $3 \mathrm{D}$ procedural process, assumed variations on pole taper, texture, straightness and other attributes all can be added to an additional note or operator in the process, in order to provide additional visual effects. Additional parameters can then be added to visualize pole sequencing based on temporal determinacies or even the actual material used. Thus, depending on the original site settlement map originally inputted at the beginning of the procedural model operators, all modeling nodes or operators already in place would visually and structurally change automatically, representing the changes in data provided and user input. 


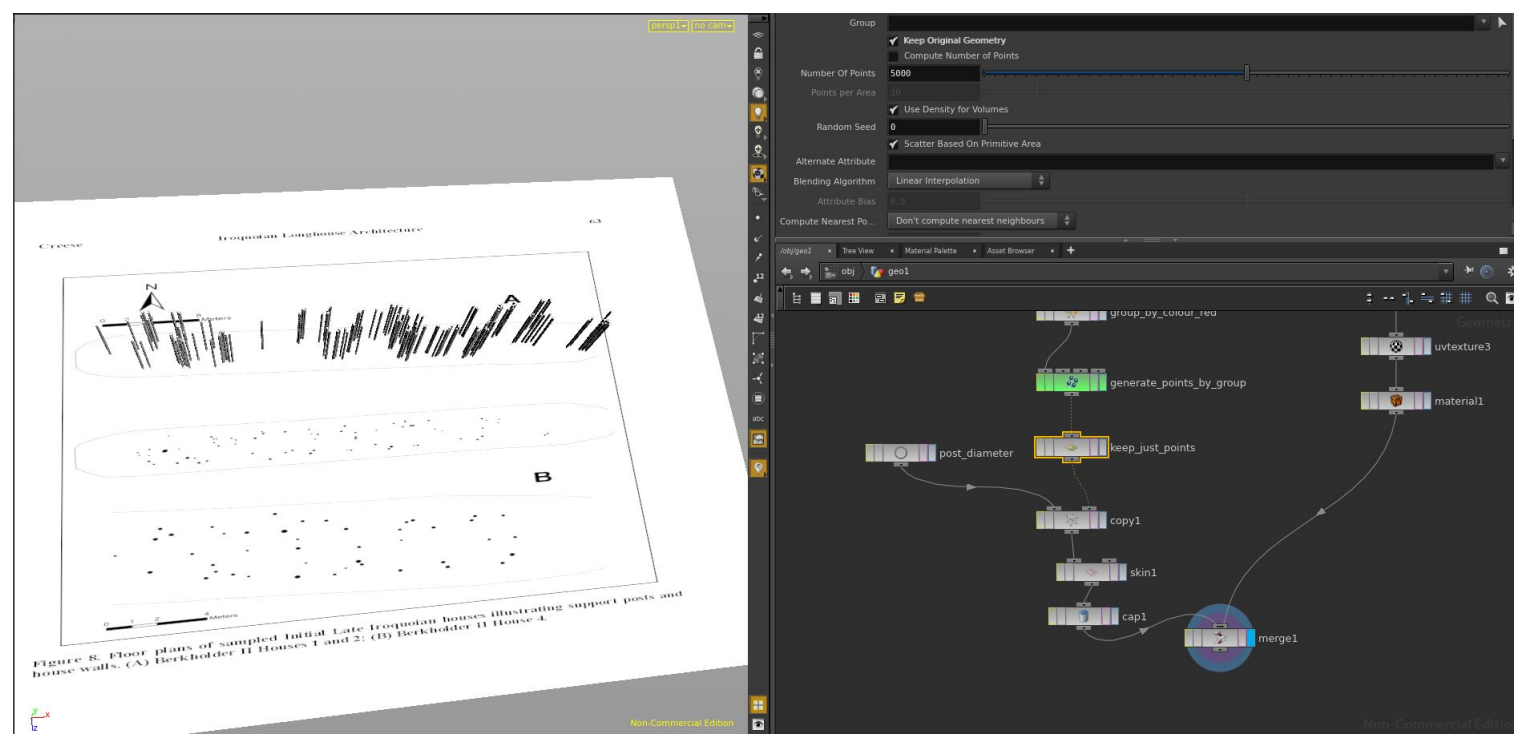

Figure 6 - Example of a Procedural Modeling Network, A. Alzner (2016)

So, for example, in the case of our Longhouse 1.x, the building process begins as seen in Figure 6, within the Houdini modeling environment. On the right side is the procedural modeling network chain and on the left is the final animated sequence. As each node or operator has a specific function in the modeling process, the user can be given specific minimum and maximum values or be allowed to adjust each of the nodes/parameters freely. The data is passed from the top input down to the final output; in this case the animation represented on the left side of Figure 6. If the top input changes (e.g., a new site or house map), all of the parameters that are below also change to reflect the new data input, again within prescribed ranges. Thus a basic pipeline can be derived to allow for automatic pole creation of most archaeological site excavation settlement maps.

\subsubsection{Theoretical Procedural Pipeline for Automatic 3D Longhouse Creation}

With the ability to automatically build 3D poles from any site map, the next challenge was to be able to fully visualize a longhouse. In keeping with the spirit of Reilly (1991, 2014, 2015), Forte $(2010,2014)$ and Barceló (2000) to have data be at the center of archaeological visualization, I wanted to see if we could design a procedural pipeline 
based on a range of known longhouse archaeological data or even dynamic real-time data gained from reconstructions. The notion of accuracy in the representation of an actual Iroquoian longhouse is relative, given the variability seen archaeologically and historically, and given the 1000 year tradition this cultural and physical construct encompasses. Given this, the pipeline itself can be highly flexible and less restrictive due to the variability of the archaeological record as it pertains to longhouse construction and use, and to the more speculative nature of archaeology to interpret above ground elements of the longhouse. In many ways where archaeological data ends, creative meaningmaking begins.

In the technical pipeline detailed in Figure 7, I used the same methodology as the procedural pole birthing technique in Figure 6. The additional representational parameters in Figure 7 integrate archaeological data with archaeological speculative interpretation of above ground architectural elements. It essentially provides a visualization tool in which to mix and match cultural historical perspectives and assumptions through automatic generation of visualization. As the model moves through the procedural pipeline, alternative options are dynamically provided for, albeit within a set of known values. For instance, Wright (1995) discusses the prevalence of below ground tapering of post ends evident archaeologically as indicative of a factor Iroquoian longhouse makers would have considered when choosing materials for construction (i.e., selecting species and types of trees that could easily be tapered as poles). In essence, each type of wood has a specific materiality; such as ease of tapering, and thus everything from rigidity to structural use would be parameters to be considered in material selection before incorporating poles into the construction of the dwelling. A parametric node thus would represent these choices. Within a procedural modeling network such attributes and choices can be accounted for, added or removed/disabled to test the variability and interpretive viability of archaeologists' interpretations of a longhouse construction. 


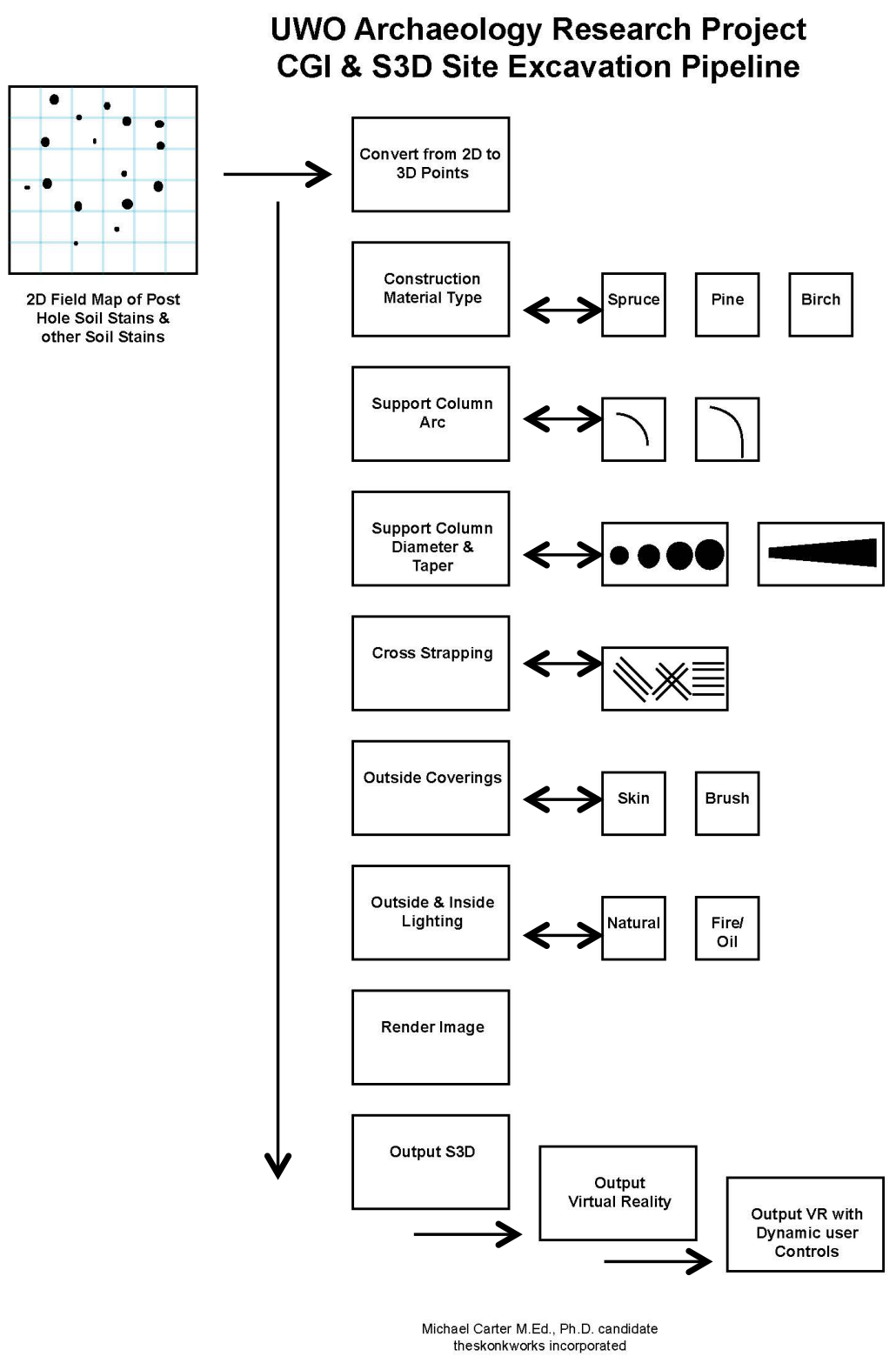

Figure 7 - Theoretical procedural pipeline for the automatic creation of 3D modeled longhouses, Carter (2011)

\subsubsection{Procedural Longhouse Test}

In Longhouse 1.x I aimed to build a low-resolution test to determine if a workable pipeline could be deployed. To increase real-time rendering speed, I chose to separate the 
pole birthing process from the second half of the parametric longhouse creation. By doing so these two processes would have to be combined later on when available desktop computing and rendering power was available for real-time interaction.

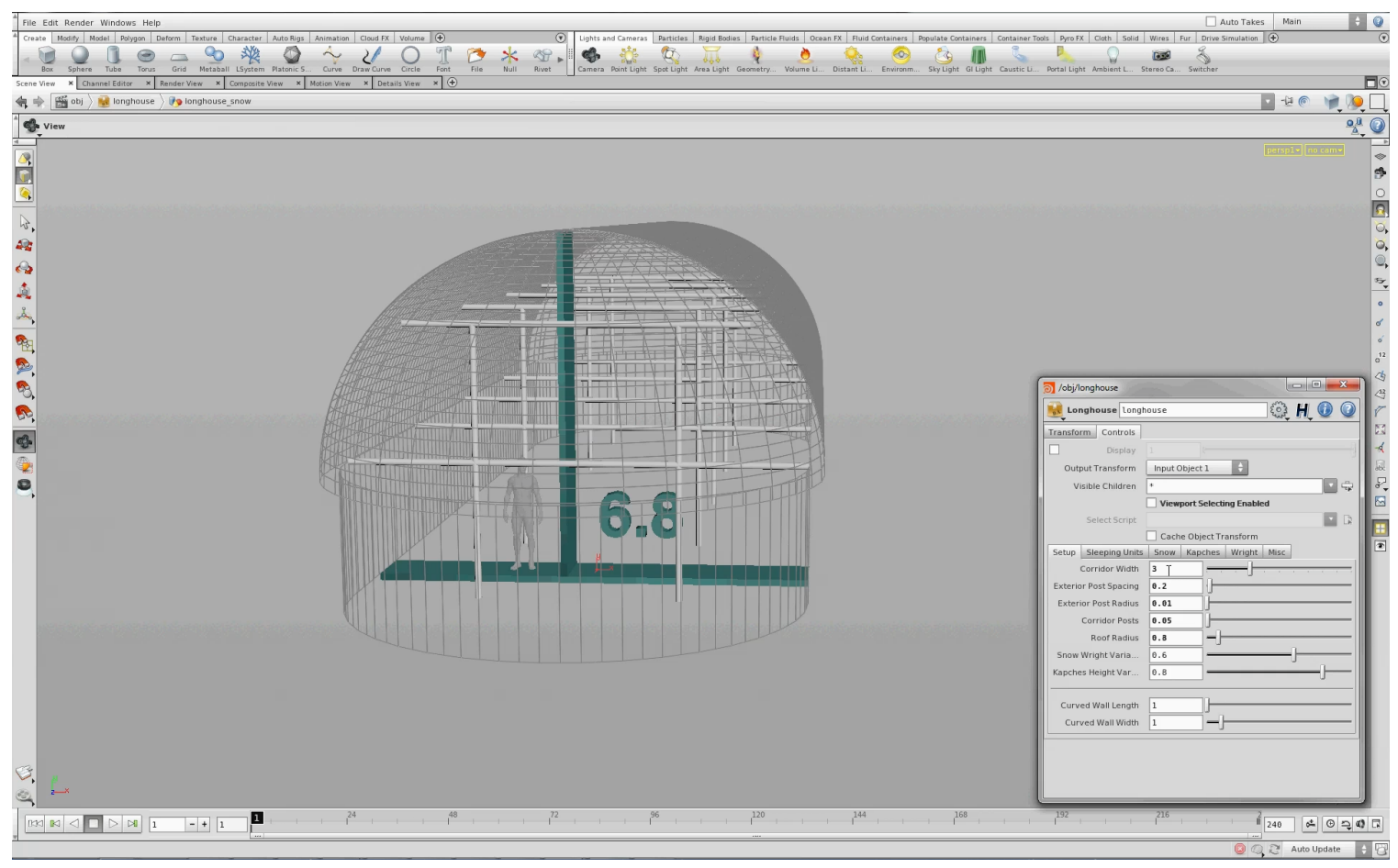

Figure 8 - Houdini Procedural Longhouse Modeling Network, A. Alzner (2013)

The two main parameters that had a consistent minimum and maximum value were longhouse width. Dodd (1984:270), Snow (1997:66) and Heidenreich (1972:47) seemed to agree with an average $6 \mathrm{~m}-7.5 \mathrm{~m}$ width for the archaeological data, consistent among both Ontario Iroquoian and New York Iroquois longhouse datasets. Longhouse length generally ranged from $5 \mathrm{~m}-72 \mathrm{~m}$, with an average medium length of $19.8 \mathrm{~m}$ noted for the archaeology of ancestral Huron-Wendat peoples (Heidenreich 1972), though it needs to be stressed that longhouse length was highly variable across sites and through time, so was a less rigid constraint than width. Height, although not archaeologically known, was considered to be equal to the width, based solely on the descriptions by Brebeuf within the accounts of Le Jeune's 1634-1635 letters within the Jesuit Relations (Snow 1997:66, 
citing JR8:107). Hence our initial base parameters we used were width=height and length with respective $\min / \max$ variances drawn out from the archaeological literature (see Figure 8).

The parameter sliders on the right of Figure 8 thus show user controllable variables. Move the sliders between the minimum and maximum values as represented within the archaeological record, and the longhouse build automatically and procedurally changes. As height, width and length changes, so too do the procedural elements represented within the model. Everything from bunk and main corridor width to number of potential cooking and heating hearths are dependent on these three main parameters. For example, if the length changes, there is concomitant increase in the number of wall poles, bunking, hearth placements, smoke holes and the end of the longhouse itself (as partially represented in Figure 8). If width changes the corridor widens but the bunking does not, however the diameter of the structural or support poles might increase to support the additional load.

Framing assumptions I had previously identified in Kapches, Snow and Wright's interpretations of longhouse construction were also added as parametric options. In Figure 8 Snow's 60/40 wall/roofing system is visible and in Figure 9 his support frame system is being used. However, the control panel on the right of both images also provides options to adopt a Kapches or Wright longhouse framing methodology as an alternative. 


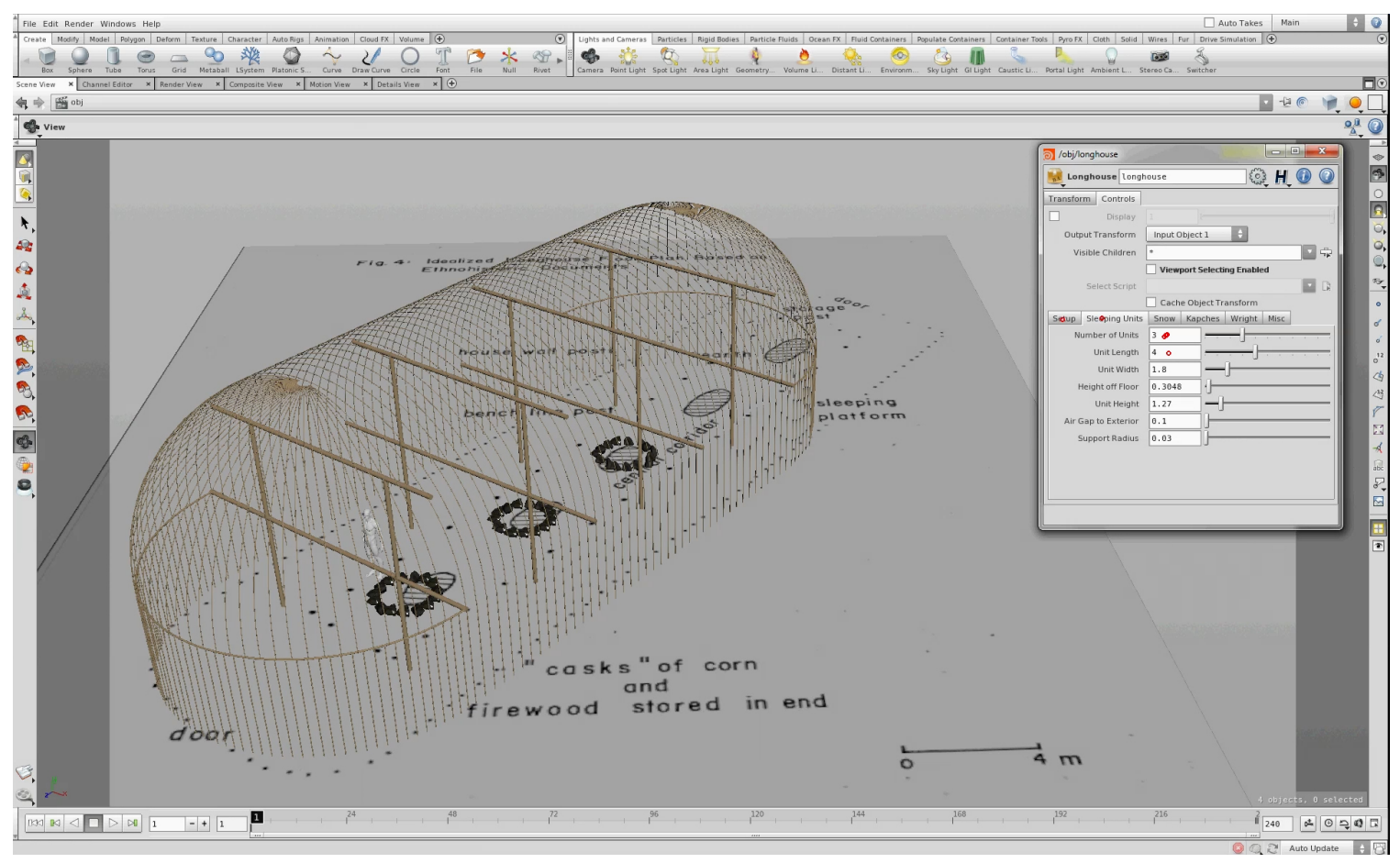

Figure 9 - Procedural Longhouse Modeling Network based on Dodd (1984), A. Alzner (2013)

\subsubsection{Longhouse 1.x Discussion}

Longhouse 1.0 was a proof of concept that a procedural pipeline could be built and along the way it did pose some challenges. It was very quickly evident that interaction was wholly dependent on the base software's ability to process in real-time. This forced us to section off computationally heavy processes such as pole birthing with interactive longhouse framing or full interactive texture mapping as separate production modules. Thus pole positioning in this testing was static insomuch as we were not able to change excavation maps dynamically in real-time and have the completed longhouse change to suit. However, the notion of the procedural methodology being able to represent interactive longhouse construction in 3D and in real-time was apparent and deployable. Based on our initial testing, the use of procedural modeling and animation from a commercially available software application clearly indicated that archaeological data could be incorporated within a 3D procedural network to visualize excavated longhouse settlement patterns. Kapches, Snow and Wright variations in suggested longhouse styles 
could be directly incorporated into this procedural modeling.

Alison Wylie (1993, 2002) suggests that "tacking", as a means of constructing the unknown in the archaeological record, is through mixing and actively interrogating archaeological thought. Pauketat and Alt (2005:213) believe there is a tacking between "lines of evidence and multiple scales of analysis". Thus, this modeling process becomes a basis for interrogating all data variables and testing them against each other, and alongside more creative, artistic driven interpretations of the archaeological record, providing a transformative ability to engage all data and representative knowledge equally. This construct allows anyone the opportunity to either engage with data beyond the constraints of established interpretive or disciplinary regimes, or, within defined constraints, refute individual interpretive models. It is a technological means of tacking, to interrogate the authorized knowing of archaeology and longhouse interpretation.

From a VA perspective, Longhouse 1.x was a means to apply a practical, technical solution to visualize the variance in longhouse framing notions while at the same time merging those notions with the representative known 2D archaeological data on which those notions are built. What it lacked was the ability to demonstrate the correlation between the known archaeological record and the tacking required to interrogate some of the notions represented by Kapches (1993), Snow (1997) and Wright (1995). Beyond the actual pole positioning and their relative circumference, all other above ground longhouse elements could be constructed, adhering to either of the three structural models advanced by Kapches, Snow and Wright. It demonstrated that all these models could be viable interpretations, and probably were, variably across time and space, from the simple perspective of visualizing longhouse form from birthed poles of archaeological features.

\subsubsection{Longhouse 2.x}

Longhouse 2.x originally emerged as an opportunity to explore the process of creating digital longhouse assets based on archaeological and historical data, undertaken by computer graphic artists. This opportunity came about as a result of my serving as project lead with the Museum of Ontario Archaeology and Sustainable Archaeology, directing 
the training of 10 Loyalist College Animation interns working on a Museum and Sustainable Archaeology project in the summer of 2012. This project was funded through a Museum Technology Grant from the Ontario Ministry of Tourism, Culture and Sport, and supported by a MITACS/theskonkworks sponsored internship. This project combined basic archaeological research with the 3D visualization of archaeological material in order to develop a mass visualization pipeline that Sustainable Archaeology would adopt for diagnostic classes of artifacts in their repository (see Ahmed, Carter, and Ferris 2014). More germane to this discussion, the project also included a component allowing the students to generate a digital representation of the sixteenth century Lawson site.

At the Museum of Ontario Archaeology the students had direct access to the partially reconstructed Lawson Iroquoian village site, located on the Museum's grounds, and first excavated by David Boyle in the 1890s, and later on by William J. Wintemberg in the early 1920s (Anderson 2009). During their training students were introduced to traditional film, television and gaming production pipelines for use in the visualization of archaeological data, and specifically to visualize the Lawson site village. This project effectively encompasses the Longhouse 2.x phase of my efforts to visualize Iroquoian longhouses in virtual reality.

In addition to the archaeological data and partial reconstructions of longhouses the Museum provided the students access to, the students also visited the Ska-Nah-Doht Village \& Museum, which is a reconstructed Early Iroquoian Longhouse Village site that provided an excellent example of differing architectural styles as well as interpretive differences in reconstructed 3D spaces. The students had the opportunity to physically experience the reconstructed spaces, understand the materials used in the reconstructions and get a sense of the sound, light and atmospherics produced in such dwellings.

\subsubsection{Animation \& Visual Effects Approach to Longhouse Visualization}

The original goal for the students was to produce an animated sequence that would visually describe what the Lawson site might have looked like during the height of its 
inhabitation. The final output was to be in keeping with the traditional approaches a typical student of animation would have produced for a final thesis and as a result suited our needs to examine the variance in visual representation of archaeological materials between archaeologists and non-archaeologists.

Following traditional film, television or gaming methodology, where characters, props and landscapes are influenced by other modes of artistic expression and real-life examples (see Prince 2011), the students used the physical materials of the village and longhouse reconstructions at the Lawson site and Ska-Nah-Doht Village, and the archaeological data from Lawson (specifically the fully excavated portion of the site), to start envisioning what a 3D representation of a longhouse, palisade and interior village space would look like. I asked the students to approach the task as they would normally do so when scouting locations for background or set development for animation or VFX production.

Referencing artistic works, including Indigenous heritage depictions, in this case from artists such as Ivan Kocsis or C.J. Jeffery; physical objects, in this case artifacts from the Museum's archaeological collections (including from the Lawson site); locations and settings, in this case the surrounding natural landscapes of the two reconstructions the students visited; and seeking out relevant online and text reference material, ${ }^{6}$ in this case on the archaeology and history of Ontario Indigenous peoples, is a standard technique followed when planning and doing any form of film, television or gaming pre-production visualization (see Prince 2011). This also included, during visits to the reconstructions, taking pictures, listening to interpreters provide background information, and doing location sketches for future reference.

Despite access to this extensive suite of information about the material and place of longhouses, the students were also given free technical and artistic rein over what to envision in 3D when production started. In representing what essentially was a recasting

\footnotetext{
${ }^{6}$ This latter task intending to visually "appropriate" suitable objects or symbols that could be populated within the animated Lawson site, to convey a sense of realism, mood, setting, and place in the students' animation.
} 
and reinterpretation of archaeological and historical interpretation into modern reconstructions, the risk of this process was that there were multiple voices and competing visions shaping the end product, arising from the students, the archaeology graduate student team lead, SA and Museum personnel, and myself. Layered upon this, of course, were all the previous museum specialists, artists, technologists, archaeologists and Indigenous participants that had physically constructed the Lawson and Ska-NahDoht longhouses in their current form, and the ancestors that had formed the archaeological record at Lawson to begin with. Thus, the clarity of agency and authenticity became blurred, as the students were essentially visualizing within 3D a host of other voices, intents and perspectives.

As noted in Chapter 2, this overlapping of intent is the negotiation of differing understandings that VA requires, especially when the non-archaeologist artist maker is tasked with visualizing archaeological interpretation. The experience of Longhouse 2.x was intentionally designed to recreate that common developmental experience noted for past examples of VA, allowing me to "see" divergences of intents. What clearly emerged through the Longhouse 2.x experience was a drift in artistic intent over the life of the project. This drift included artists becoming more familiar with the subject content allowing for a reflexivity back on their own creative development. For example, in Figure 10 , the longhouse interior depicted on the right includes a bunk platform made of posts all evenly and neatly cut, and aligned perpendicular to the central corridor. However, during the students' trip to Sha-Nah-Doht, their tour guide pointed out that the absence of a saw may have meant that longhouse builders in the sixteenth century would have thought about bunk construction and neat alignment of poles differently, perhaps with the bunk platform including posts aligned parallel to the central corridor, as subsequently depicted in the later image on the left. Indeed, as an example, the two different artistic renderings over time represent the same artist's different takes of the physical reconstruction of the longhouses visited and the mental map constructed virtually in the artist's mind, drawn from their experiences and from the information they were processing about the subject matter. 

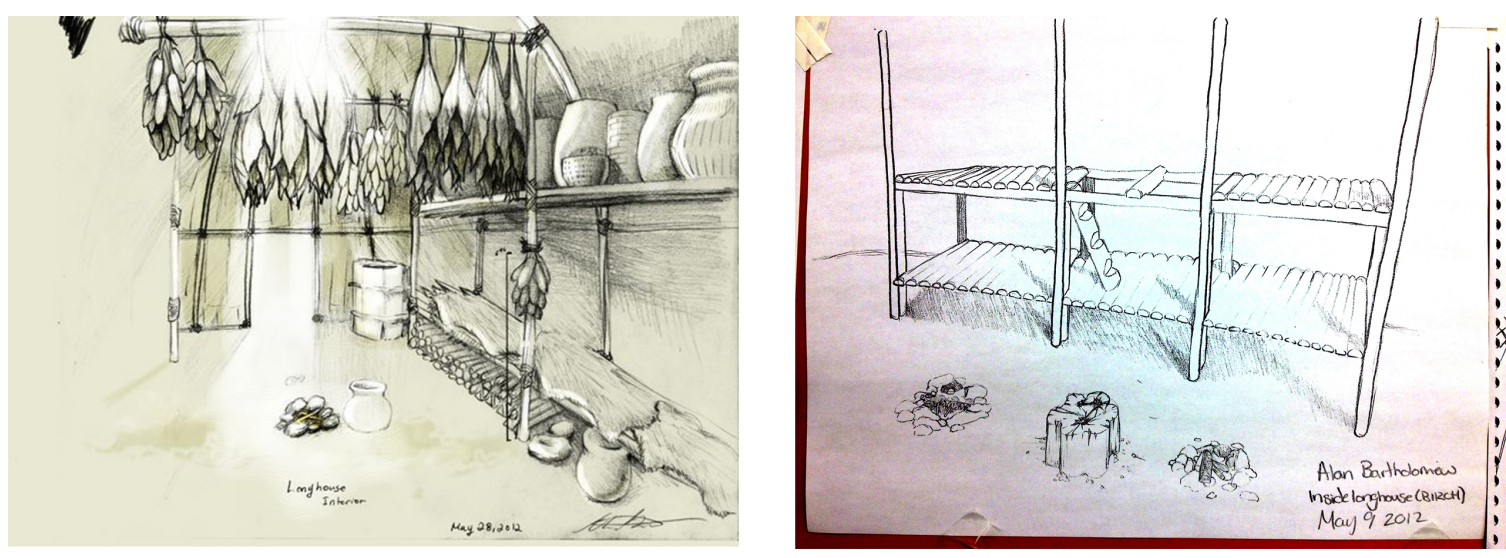

Figure 10 - Examples of pre-production visualization sketches A. Bartholomew (2012)

In Film and Television production, variance in interpretation is a continuously negotiated process (see Catmull and Wallace 2014; Prince 2011). Although the Director or Art Director is the conveyor of artistic direction, they too are negotiating with competing visions from their producers, historical consultants, set designers, prop makers, camera and lighting crews, clients, studio executives and ultimately the consumers of their end product (see Catmull and Wallace 2014). Loss of individual artistic voice is common in a collaborative production environment (Anthony Masinton, personal communication, March 2016). Likewise, in archaeological interpretation and subsequent museum reinterpretations of that meaning-making for public consumption, the archaeological voice, the qualitative and quantitative data of archaeology, and interpretative intents all compete with and are negotiated by other creators and users of this knowledge, to the point that we can always question the authenticity of the visual representation itself (Frankland and Earl 2011; Gillings 2005; Perry 2015).

The luxury afforded our project was the ability to incorporate 3D scanned Lawson Site artifacts, as well as the artistic renditions of objects, and place them together within the reimagined 3D archaeological landscape. In a traditional Film \& Television process, these objects would be considered "props" to help enhance the phenomenological feel of the background, landscape or subject matter. So the integration of 3D models of Lawson site artifacts alongside more generically created props of archaeologically unknowable 
materiality such as blankets, skins, foodstuffs and baskets, gave the depicted longhouse space a seemingly higher level of authenticity, despite many of the objects in this above ground space not being archaeologically verifiable.

As seen in Figure 11, filling in the space above 2D archaeological settlement patterns with an enclosed, shadowed and cluttered arrangement of 3D things and textures creates a visualization far removed from archaeologically knowing that longhouse space. This simple act of filling longhouse space with the materials we archaeologically and historically "know" would have been present (pots, baskets, foodstuffs, etc.) provides a presence and authenticity to the animation. The act of additionally placing 3D scans of artifacts from the Lawson site provided the students with a sense of grounding their animated sequence with some degree of authority, of truthing the animation with those digital representations of archaeological "facts" from the site.

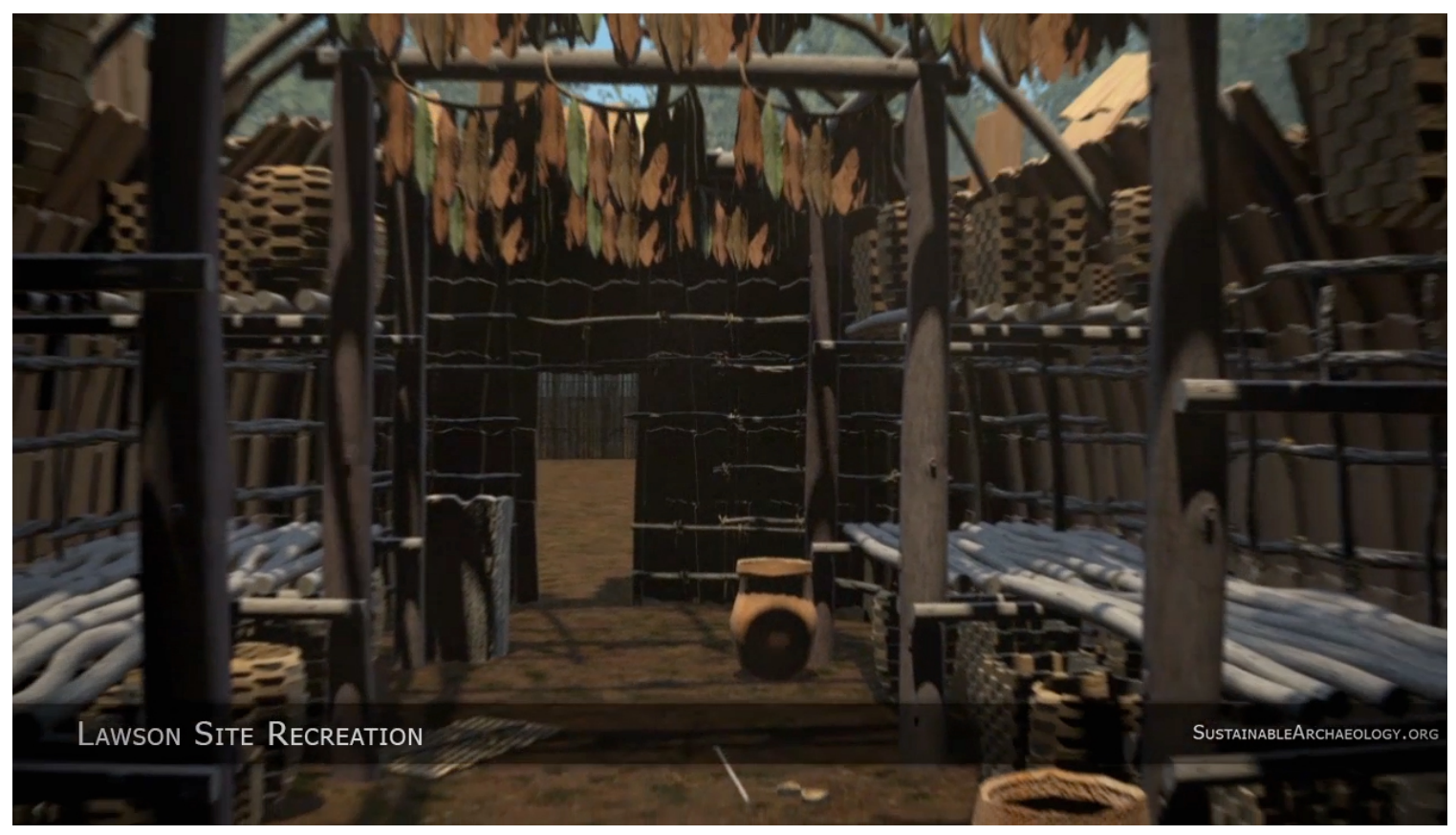

Figure 11 - Lawson Site Recreation Animated Fly-through, Sustainable Archaeology (2012)

Using Autodesk Maya, the students began to build models based on the information collected through their site visits and basic research. Unlike in Longhouse 1.x, only basic 
information on longhouse dimensions and construction methodologies were provided. This lack of adherence to archaeologically verifiable constraints enabled the students to think about all of the factors potentially involved in the construction of a longhouse from their perspective as makers, and thus I only provided architectural information when/if needed. Construction on the animated longhouse village became an interpretation of the existing physical reconstructed houses they had visited, and the visualisation of the historical material and archaeological data they had been exposed to. As the models began to materialize, the students started asking the same questions posed by Kapches (1993), Snow (1997) and Wright (1974, 1995). They questioned the construction methodologies, reflected on their own interpretations, and struggled at times with the technology to produce what they felt should be an accurate representation of a longhouse and village. For example, the students created about 3 or 4 individual bark tiles for the longhouse coverings, and about a half dozen individual poles, and then continuously recreated them in random groupings to generate all the wall coverings and palisades. This is a fairly common animation practice for saving development time, and was a choice made by the students, one that sacrificed true authenticity of detail in favour of a more generalized authenticity of space.

Whereas Longhouse 1.x was about being able to interactively visualize the archaeological record through known data, Longhouse 2.x, in its non-interactive format, was about the process of artistic re-interpretation of previous attempts to visualize the unknown in the archaeological record by archaeologists and museum professionals digitally. It allowed the physicality of the built reconstructions and a non-specialist understanding of the materiality of longhouse living to influence the artists' notions of representation within a 3D environment. This process was unconstrained by the limits of archaeological data, providing a flexibility in the artistic interpretation of these archaeological representations, and an accommodation of archaeological data to "fit" within an artistic making process. Nonetheless, there emerged a sensitivity and practicality to how longhouses would have been possibly built by Iroquoian peoples among the students, which began to inform and constrain the choices they made and how their representations would materialize within 3D space. 


\subsubsection{Interactive Gaming approach to Longhouse Visualization}

In 2011, when I started my research for this dissertation, VR was still grounded in the notion that large, physical, very expensive, immersive domes or CAVE's (physical spaces the user stood within and around which an immersive environment was projected), was the only viable option for an authentic experiential virtual experience. I had been influenced by Dawson et al (2011), and their use of CAVE technology to provide an immersive experience of a recreated Thule Whale dwelling. However, my own predilection, based on years of being in the animation business, was to develop a more cinematographic, film-like approach presented on-screen. Using an opportunity to test our already 3D modeled assets within a newly released PC based Unreal game engine, coupled with a chance interaction of high school students, completely changed my understanding of how users could/would interact within a virtual environment.

The animation project had never intended to use any form of gaming engine for real-time interactivity - the intent was simply to create an animated representation of the Lawson site at a single point in time. However, a delay in the acquisition and delivery of the 3D scanners for making artifact models at SA meant the students in the project had time to experiment with their animation. This included trying to port those 3D modeled assets they had created for the animation sequence of the Lawson site in various other software platforms. This included a version ported into Minecraft, but more germane here, the assets were also ported in the Unreal 2.0 gaming engine. This platform allows for a 360 degree interaction and movement through the space objects created through that animation, as is typically the way gamers interact with computer game environments.

In order to create this space, the students took the original Lawson site excavation map and started positioning their virtual 3D longhouses within a palisaded space aligned with those archaeological settlement patterns. The Unreal gaming environment was then populated with 3D longhouses and accessory assets, by this I mean objects, cooking hearths, etc. (see Figure 12). Atmospherics such as smoke, additional assets such as exterior activity areas, foodstuffs, land and sky proxies, were all added to generate a full 
and all-encompassing village environment inside a palisade. ${ }^{7}$ The game engine itself allows for a first-person shooter (FPS) perspective or point of view (POV) for the gamer to move through, look around and interact with the virtual environment, and the basic controls the user is provided with are movement (walk/run), jump and interaction through mouse click. The engine also provided the classic "footstep" sound that most FPS games ubiquitously have.

To also combine the students' 3D artifact scans, virtual activity stations were built within the game and when activated (by clicking on a green leaf activation button floating in air), these stations would inform the player of the material or social importance of the feature or artifact. Lastly the students on their own initiative rebuilt the actual exterior of the contemporary Museum of Ontario Archaeology and Sustainable Archaeology facilities within the 3D game, and positioned them as they were in relation to the virtual/real Lawson site. The outside of the front entrance to Sustainable Archaeology thus became the starting point for the virtual experience, allowing the user to walk from Sustainable Archaeology and the Museum (in the present), and through the palisade in into the living space of the Lawson site (the past). ${ }^{8}$

\footnotetext{
7 Due to time and computing constraints, only a representation of that portion of the Lawson site that had been fully excavated, i.e., the north third of the site and multi-rowed palisade, was completed, while the rest of the village was wallpapered in and could not be accessed by the user.

8 An animation sequence of a user walk through of the Unreal port is accessible at: https://www.youtube.com/watch?v=nMgc12SnzU4
} 


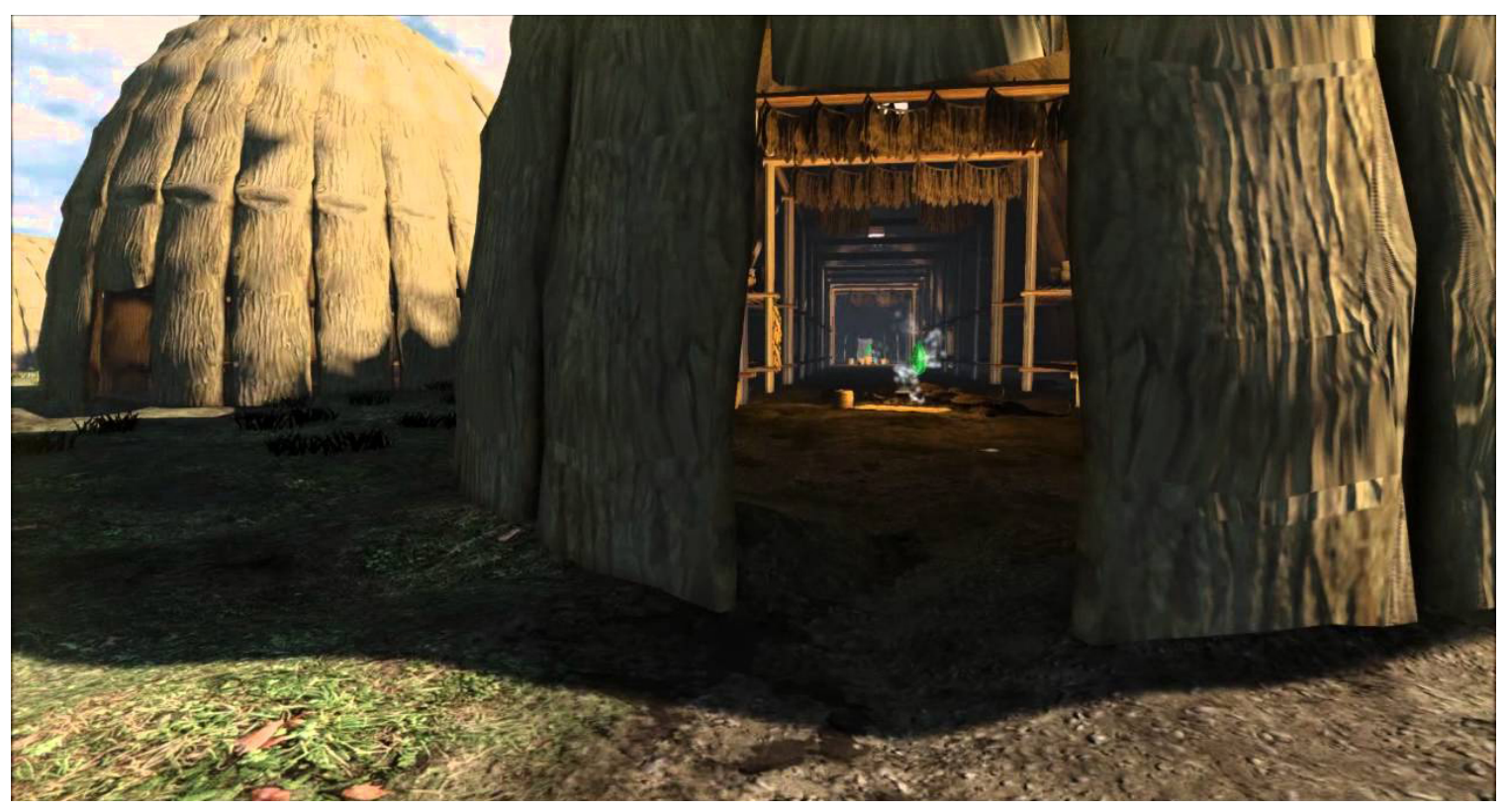

Figure 12 - Lawson Site Game Engine Test, Sustainable Archaeology (2012)

The real "magic" happened after the game was completed. During a random local high school class visit to the Museum of Ontario Archaeology and Sustainable Archaeology, Namir Ahmed, the UWO Archaeology graduate student project lead, was explaining to the class the work the student animation unit was doing. Of course, the high school students wanted to test out the game and so most of the excitement grew around the interactivity within an environment and technology in which all the high school students were not only accustomed to, but were also the first generation to have been born completely acculturated into the conventions of this kind of digital technological interface. The "ah-ha" moment came when the students, after playing the video game, attempted to relive the same virtual experience outside in the partially reconstructed palisade and single longhouse of the Lawson Site. At that moment we realized that the research going forward was not about accurately reconstructing longhouses, but about connecting stakeholders to the archaeological landscape through a real-time, virtual and phenomenological experience. 


\subsubsection{Longhouse 2.x Discussion}

Longhouse 2.x provided an opportunity to experiment not only with the process of making in virtual space, but also the application of multiple forms of technology towards the pursuit of a VA. Along the way, themes of interactivity, authenticity, authority and a cacophony of artistic, archaeological, museum and public voices shaping the visualizations emerged. The whole point was to try and engage with the archaeology in ways that could be visualized beyond archaeological research to not only interpret but also visualize the archaeological unknown. The negotiation between archaeological and historical "facts," creativity and technology played out in the process of individual artistic meaning-making. Longhouse 1.x and 2.x were experiments in utero where I could negotiate a balance between de facto archaeological data and the creativity required to move beyond what is known of the archaeological data towards the construction of new knowledge.

Although the impetus along the path towards a fully engaged, archaeologically informed $3 \mathrm{D}$ environment started with the use of the decidedly $2 \mathrm{D}$ excavation site map in Longhouse 1.x, and the desire to allow for real-time user defined engagement, current technical limitations stymied our ability to fully realize the potential of a procedural animation process in archaeological visualization. As such this research was a proof of concept and opportunity to consider how to leverage the technology and creative potential of a VA to explore longhouse space and materiality. In many ways Longhouse 1.x was the development of a separate tool set, allowing for an automatic "pole birthing" of site excavation maps or in the future, as an augmented reality overlay within the field itself. Allowing archaeologists the opportunity to visually predict or interrogate in situ posthole archaeological data above the soil line, almost immediately upon discovery.

Longhouse 2.x, on the other hand, tested the implications of non-archaeologists' interpreting and visualizing the archaeological environment within 3D. For the student artists engaged in Longhouse 2.x negotiating archaeological and reconstructed templates of what a longhouse "was;" they came to know longhouses visually as they have been authoritatively represented in archaeology and in museums. However, in their grappling with the details - the unknown or unrepresented - the students began to more deeply 
question and experiment within the $3 \mathrm{D}$ environment. They were making new meaning from the - resources available to them and as such the 3D process enabled them to think beyond the $2 \mathrm{D}$ and physical representations of longhouses to perhaps engage in "making" (Ingold 2011, 2013), empowering their reflexivity.

Lastly, although the thread throughout this paper has been on the artistic and archaeological exploration and creation of new meaning within the $3 \mathrm{D}$ environment, the happy circumstance that brought the students' 3D efforts into a real-time gaming engine also proved to be a focus for the direction my research needed to follow, through the use of both a highly interactive AND immersive platform to allow potential users to engage with these longhouse visualizations. This became the vehicle I would use to explore the making process itself as the means of meaning-making in VA and the dissemination of archaeological knowledge beyond 2D representations of archaeological data.

\subsubsection{Longhouse 3.x}

"Now that it's winter, each family sleeps up off the ground on raised platforms, mother on one end, father on the other, children squeezed in between. They are smart enough to peel the bark from the wood they burn but it's still sometimes so smoky that my eyes are often irritated. These longhouses are truly a wonder, like giant beehives woven together with saplings and covered in sheets of bark. Up in the rafters hang corn and beans and squash and tobacco and dried fish and all manner of food that I've never seen before."

Boyden 2013:29

As problematized as Joseph Boyden's fictionalized account of longhouse life in his book The Orenda might be in terms of authority and appropriation, the image he conveys of interior longhouse space is representative of the mental constructs that most archaeologists surveyed for this research identified with when asked about their personal 
mental image of Iroquoian longhouse life. Thus, the final task - Longhouse 3.x - was to (re)imagine the essence of those mental constructs into a form of reality (virtual).

Our initial port of 3D longhouse assets into an Unreal game engine as part of the Longhouse 2.x undertaking convinced me that building and deploying the longhouse within a gaming environment was an ideal interactive, experiential, knowledge mobilization deployment strategy. It would not only enhance the phenomenological virtual experience, but would be on a platform technology that most archaeologists and non-archaeologists would be comfortable in using with little or no training. Longhouse 3.x would be the culmination and application of cultural historical and archaeological data assumptions I had compiled, the technical toolsets deemed appropriate for production of the assets and virtual environment, and my own artistic interpretations of the culminating research. Longhouse 3.x also represented a departure from the anxiety of about how the technology could be harnessed. I was confident that the existing production and deployment tools, the hardware as well as the animation, visual effects and gaming techniques could be deployed effectively in the pursuit of archaeological knowledge, and to how archaeologists make meaning in VA.

\subsubsection{Production Process/Pipeline}

It should be noted right from the start that this was a creative process, informed by the archaeological record, linguistic and historical information as well as participatory opinions from archaeologists and interested stakeholders and public alike. Throughout the (re)imagination of the known and unknown archaeological knowledge, I was negotiating the archaeological and academic literature, with the current hardware and software technological limitations, along with the reflexive comments from external participants, the skill, expertise and sensibilities of my 3D artistic partner and lastly my own shifting sensibilities as I grappled with what it meant to construct archaeological knowledge within a virtual environment. I was applying animation, visual effects and gaming production techniques in the service of visualizing archaeological data when available, then creatively visualizing constructed knowledge when raw data was 
impossible to discern. The specific tools used and the techniques employed did not allow for physics-based calculations and should not be considered structurally accurate. The tools and techniques are artistically based and thus any build I made could ignore natural physics with the objects represented, modelled and put together. For example, poles could have been any length, shape or floating in air; longhouse bench rows could have risen many stories in height, longhouse roofs could have held massive piles of snow or boulders, even if I depicted them as made from paper towels, and so on. The "physics" of the build was going to be my own negotiation of what could and could not occur in the "real world," with what appeared "right" in the visualization. In essence, I was creating a $3 \mathrm{D}$ version of a $2 \mathrm{D}$ image and in doing so, I hoped that by adding depth we were able to phenomenologically experience a virtual representation of the archaeological literature and notions of constructed knowledge of longhouse space as I understood and re-made them to better understand and interrogate longhouse materiality from a VA perspective.

Production of three-dimensional animation assets and environments is an iterative process. It's a push and pull between the artistic skill of the user, the tools being deployed, the subject matter and of course the chorus of opinions, notions and viewpoints of participants and observers alike. Ingold $(2011,2013)$ and Crawford (2015) consider this to be the core of "making." It is a synergy of the practitioner, tool and material, which all separately have their own narratives and when combined, create new narratives or in our case, knowledge. Ingold also speaks of "wayfaring points" (2011:12, 143, see also Carter in press) as the course corrections, decisions and shifts in direction over the life of the making process. These two notions, making and wayfaring, are at the very center of Longhouse 3.x and the production process described is a manifestation of this approach.

My extensive experience in the animation and visual effects industry taught me that I needed the artistic and technical talent of others, making up a larger team, for this project to succeed. I also knew that I didn't want to struggle with both the technology and the research at the same time, so I recruited computer animation specialist Craig Barr to assist with the digital production of the assets and the programming of those assets into a Unity game engine. Craig and I worked remotely; all of our communication was through 
email, SKYPE or when necessary, telephone. Production was dictated by Craig's availability to work on the project, which in hindsight proved to be beneficial in allowing longer reflective time spans between revisions. Craig also played an important role throughout the project in raising concerns, observations and making alternative suggestions to the data and the direction we were taking, which is typical of a normal digital media production process.

To provide some context to the actual production, I reviewed with Craig the research of Dodd (1984), Kapches (1993), Snow (1997), and Wright (1995) to acquaint him with the basics of the type of archaeological data being used and some of the cultural historical perspectives we were going to source. He was also given the background on the Longhouse 1.x and Longhouse 2.x projects so he could understand some of the technical, artistic and academic sensibilities that played out during those projects. Craig would create modeled assets based on my interpretation of the archaeological data and the cultural historical perspectives researched. When the model making process itself had to inform or otherwise fill in knowledge gaps, I would make a decision on the direction to take, thus creating new meaning along the way. As much as possible, revisions were kept at a minimum so as to meet Craig's production schedule and budget.

We decided that for Longhouse 3.x, we would model within the software application Autodesk Maya, and create texture maps with the software application Autodesk Mudbox, and then port those model and texture assets into the Unity game engine for the creation of the virtual environment. In the 3D modeling process the artist is typically supplied with inspirational images or written descriptions that are used as a template in which to build the model. The model is built digitally using 3D geometric shapes, lines and objects, which are merged together to create a visually solid form such as a character or a building. Texture maps are actually $2 \mathrm{D}$ images that are placed or painted onto the $3 \mathrm{D}$ model like stickers on a toy plane, which then provide the surface of the model with colour and texture. All data produced was stored on a cloud based storage service (Dropbox) within clearly defined file naming conventions and production directories. Separate backup systems for asset recovery in case of storage failures or loss were deployed on standard large volume storage devices. 
In addition to Craig's participation, I used a participatory research methodology through weekly blogging of the production process within a public forum in order to provide an active, engaged and reflective process that allowed the knowledgeable public and archaeological community to add their voice in the (re)imagination of the longhouse. Participant viewers were given the chance to reflect and respond to the direction and decisions I was making through the blog or by personal communication, which then gave me the opportunity to better inform and revise the process with Craig. Overall, I implemented what proved to be a deeply iterative and consultative process that enriched and supported our knowledge and understanding of this longhouse build to the extent that new forms of meaning-making emerged, challenged our assumptions, and eventually were evaluated and incorporated into our build.

\subsubsection{Creation of the base 3D Longhouse Assets}

This next section will examine the step-by-step creation of the $3 \mathrm{D}$ elements that in unison, helped to represent the archaeological material I have (re)imagined within virtual space. I have chosen to present the production process in a linear fashion as it was originally engaged in, which at times might not seem logical, but in practicality, represents the wayfaring points I made in the making and knowledge construction process. The intention is to demonstrate that the construction of a longhouse digitally is a symphony of related and divergent elements, which are intertwined in the creation of model features and asset elements, thus at certain stages specific elements have to be addressed before others and then looped back around for additional enhancements.

To develop a base template in which to build the entire 3D model, we began by modeling the initial framing design of a longhouse based on the average building parameters discussed earlier: $7.6 \mathrm{~m}$ wide, including $4 \mathrm{~m}$ of centre corridor space between support posts and $1.8 \mathrm{~m}$ of bunking space to either side of that central corridor; $7.6 \mathrm{~m}$ tall; and 18 exterior wall poles per $4 \mathrm{~m}$ with each framing section $4 \mathrm{~m}$ apart going lengthwise (see Figure 13). Following Engelbrecht (2003:92), our assumption was that the main support poles used would likely have been hardwood species due to its resistance to rotting once 
placed in the ground. At first, only basic geometry was used to represent the interior and exterior framing elements, with a metric measurement standard used within the 3D modelling environment to mimic size and object relationship to real-world data. Following examples from Dodd (1984:275), Kapches (1993:142), Heidenreich (1972:45) and Snow (1997:76), which have all suggested ranges of 6-12.8cm diameter support posts within the archaeological record, I chose to use $10 \mathrm{~cm}$ diameter interior support posts to initialize the interior frame. The notion was to settle on a standard pole measurement that we could later randomize in terms of diameter sizes to simulate digitally the wide variance of pole diameters represented by the archaeological data. Similarly, following Snow (1997:76) and Dodd (1984:256), 10cm diameter exterior for wall posts diameters was relied on initially, tapering to a variable $1-2 \mathrm{~cm}$ 's at the end to represent natural growth patterns (see Wright 1995:15).

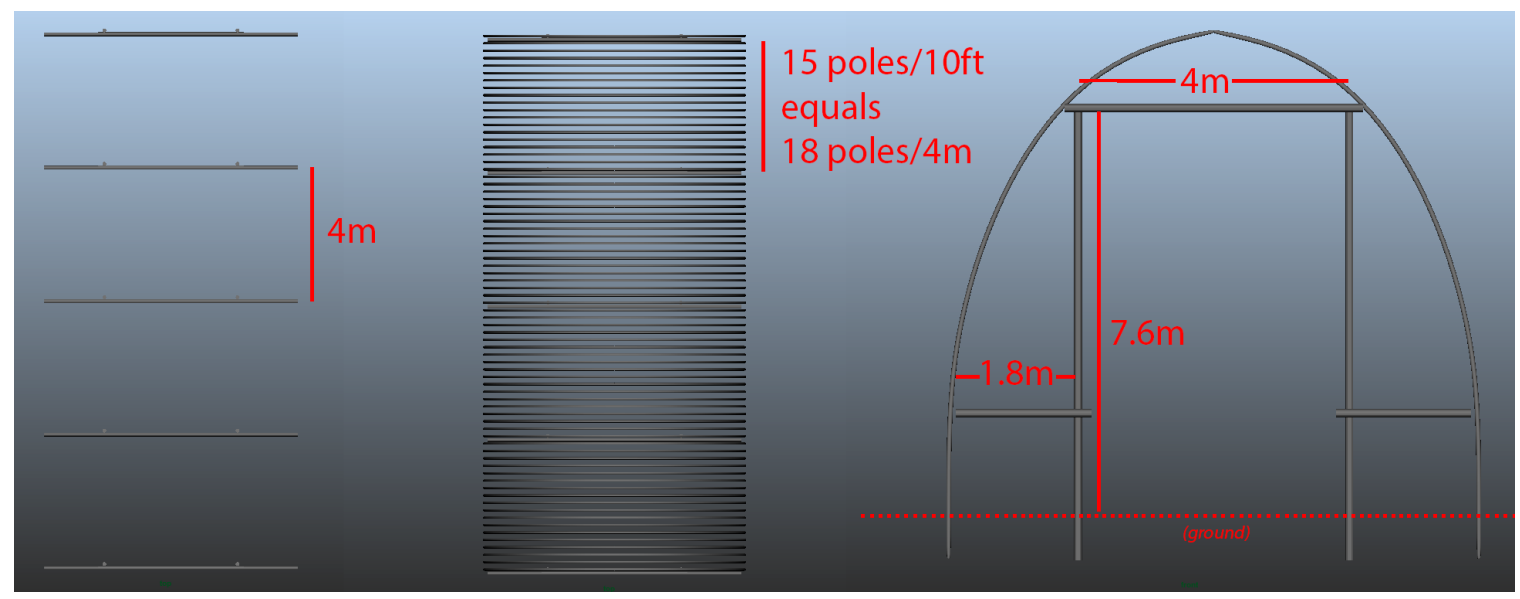

Figure 13 - Longhouse 3.x base modeling template, Carter and Barr (2016)

I was greatly influenced by the experimental archaeology conducted by Smith, Williamson, Fecteau and Pearce in the winter of 1979 (Fecteau 1979). These archaeologists spent $30 \mathrm{hrs}$ in a reconstructed longhouse at Ska-Nah-Doht that January, in $-15 \mathrm{c}$ temperatures, to test the heat and smoke factors of longhouse living. The longhouse itself was $21.3 \mathrm{~m}$ long by $6 \mathrm{~m}$ wide and $4.5 \mathrm{~m}$ high, which would have had a short and squat profile created by the tying off of posts in an arbour effect (Fecteau 1979), but not an ideal dimension based on historical references of houses being as tall as they are wide. 
For the experiment there were four rooftop vents and four fires with smoke layering at the 0.9 to $1.5 \mathrm{~m}$ height (Fecteau 1979). It is worth noting that Stock and Willmore (2003), in their analysis of Iroquoian ossuaries, have indicated that the mean height of an Iroquoian male was $1.68 \mathrm{~m}$ with a range between $1.64 \mathrm{~m}-1.71 \mathrm{~m}$, thus according to the experiment, and assuming the height of the reconstructed longhouse was accurate, the smoke layer would have started just below the average height of most longhouse occupants, making the living conditions while standing quite difficult (Sagard 1939:95).

This research became a key deciding factor for the framing methodology I was going to use for our virtual longhouse, because of how I envisioned that smoke layer within the longhouse. One could argue, for example, that both the Wright and Snow models of framing methodology (see Figure 3), would produce the same depth of smoke layering, but I felt that the Kapches model provided a more natural funnelling of the smoke upwards and out of the smoke holes primarily because of the arbour effect of the rafters. Wright's framing model proposed a more abrupt, flatter roof, and although Snow's model, based on Bartram's observations, was more barrel vaulted, in my mind the Kapches model would naturally create more of a point in the roof forcing the smoke to continually move upward. It also seemed reasonable to me that if the roofline at SkaNah-Doht had been another $1.5 \mathrm{~m}$ taller to more closely match historical notions of longhouse width=height ratios, then the smoke layer could have been above the average height of the longhouse occupants. This isn't to say that smoke wasn't a problem, as the physical anthropological record reveals substantial skeletal nasal degradation (see Merrett 2003), as well as vision issues (Sagard 1939:95), but only that the framing style of the house might have made daily use more bearable. Further, as we experimented with our procedural longhouses in Longhouse 1.x, I was never satisfied with the look of Wright's model, although the Crawford Lake Conservation Area reconstruction successfully built at least exterior representations based on that model. It was almost as if I was subconsciously drawn to the Kapches framing methodology solely due to the mental images based on years of my exposure to the Ska-Nah-Doht and Sainte-Marie-amongthe-Hurons reconstructions that used a similar roofing approach. Whether it was my justification for the smoke layer, or a subconscious image implanted by years of exposure 
to a particular norm, we decided that we would use the Kapches bent arbour method for framing within VR. However, to start the actual build, we would have to determine a key template element for the interior support structure, namely how the sleeping platforms would be integrated into the actual superstructure of the longhouse.

\subsubsection{Construction of Sleeping Platforms}

With regards to the sleeping platforms, written accounts from the Jesuit Relations indicated that longhouse residents would sleep head outwards toward the main corridor (and the heating source) and their feet towards the exterior walls during the fall/spring seasons, and huddled on the ground close to the fire during the winter. Following Stock and Willmore's (2003) average male Iroquoian height at $1.69 \mathrm{~m}$, it is worth noting that the common Iroquoian building measurement was "ten" (see Allen \& Williams-Shuker 1998; Kapches 1993), which is believed to be 1.5 meters in length or equal to the normal size of a body in the sleeping position. From archaeological data Dodd (1984) discovered that the range of the sleeping compartments depths was $1.5-2 \mathrm{~m}$, based on bunk line pole positions. Given this archaeological, bio-archaeological and historical information, we concluded that working with a bunk depth of $1.8 \mathrm{~m}-2 \mathrm{~m}$ would amply support average Iroquoian height.

Our next iteration of the model, utilizing the data compiled for sleeping platforms, was to add placeholder horizontal and vertical bunk post and pole supports. To establish a template pattern, a standard diameter of $10 \mathrm{~cm}$ was used for support posts, however there is no mention whatsoever in the historical, linguistic or archaeological record on the diameter, direction or length of the horizontal poles used to create the base sleeping platform, or what was used to create the compartment's roof (i.e., the second bunk) above the family cubicles. We had to rely on our sensibilities to determine how the bunk itself was constructed. In an attempt to better understand how the bunks might have been constructed, we borrowed the same technique of making an " $h$ " support system on either side of the main corridor from the test version in Longhouse 2.x (see Figure 14). This made complete sense as several attempts to digitally attach the horizontal support poles 
of the bunks to exterior wall posts looked haphazard and I surmised would have not likely supported the total weight load of the bunk frame as well as the numerous people and goods they would hold.

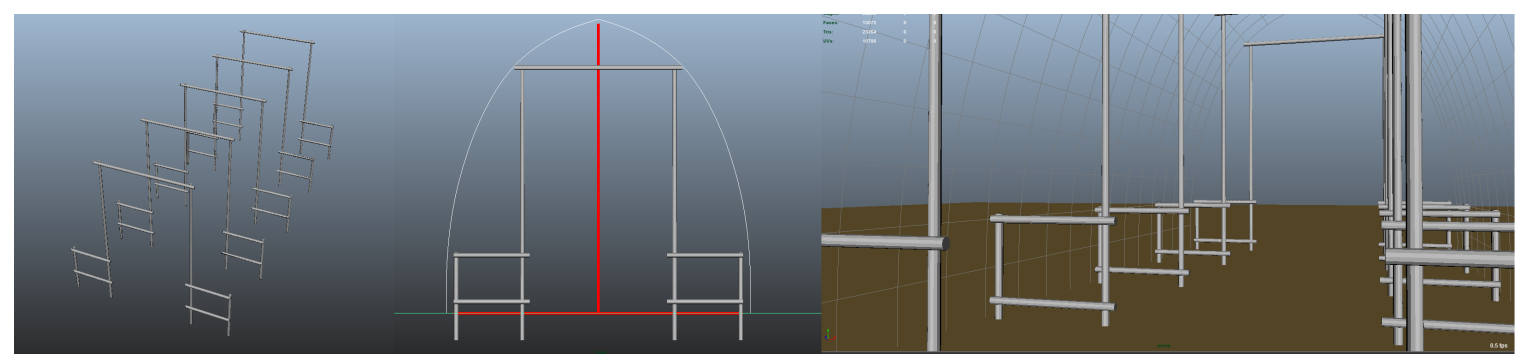

Figure 14 - Longhouse 3.x "h" frame bunk supports with $10 \mathrm{~cm}$ pole and post diameters, (Carter and Barr 2016)

As the skeleton of our internal frame began to take form, the base diameters of the posts didn't have the visual appearance of strength and robustness that I was expecting. After talking with Ron Williamson (personal communication, July, 2015), he pointed out that the data gleaned recently from the 95 longhouses at the massive Mantle Site (Birch and Williamson 2012) averaged $15 \mathrm{~cm}$ in diameter, in line with the notion in the research I reviewed (see Section 3.4) that support posts had a wider and higher range of diameters than wall posts. So we applied this diameter along with an adjusted taper in length to mimic natural tree growth (see Wright 1995:15), which produced a more visually satisfying result, suggestive of the critical support these posts needed to provide both bunks and superstructure.

The next step in a typical 3D modeling build is to assign the textures to the model assets. As we started applying textures to the interior wooden superstructure support posts and bunk poles, an immediate question arose: did Iroquoian builders strip bark from posts used in construction, perhaps to serve as a fire safety measure for those construction elements in close proximity to hearths? Modern reconstructed longhouses at Crawford Lake, Ska Nah Doht and the Lawson site all retained bark for posts, poles and wooden construction elements in the interior of longhouses. After discussions with archaeologists, and returning to available historical writings (Bartram 1751; Beauchamp 1905; 
Champlain 1907; Lafitau 1977; Sagard 1632; Thwaites 1896), we still couldn't satisfactorily answer the question. A chance discussion with a fellow virtual archaeologist about the problem led to the suggestion that bark might have stayed on the support post as it was erected in place, but over time, out of boredom or necessity due to insect activity, the bark would have been stripped or fallen away. So we visually tested the notion of bark removal in areas directly adjacent to the sitting or laying parts of sleeping bunks where it would be easily removed. The resulting visual created a smooth yet worked-in look of the high-touch areas of the posts and poles giving the visual representation the sense of a live-in feel.

As part of my intentional participatory approach to this research project, participants following along with the paradata I was posting through my research blog made suggestions when I raised the question we were pondering of bark removal at the construction stage. Two comments stand out. One post stated:

Re: stripping bark from posts.... In PNG [Papua New Guinea] where I work, people use a kind of antarctic beech (Nothofagus) that is very rot-resistant especially the heartwood. What they do is to fell the posts and then plant them vertically in the ground and exposed to the elements for several months (or even longer). Sometimes the bark is stripped off mechanically, but in any case - by the end of their period in the ground the softer outer wood has rotted away, leaving the durable heartwood. When they get to that point, they then take them out of wherever they were standing (often on a track near where they were originally felled), and carry them to the village where they are then planted into the (wet) clayey soil. They last for years - often longer than the men who cut them. House thatch is renewed every few years or so, and some of the wood and bark lining for the walls and floors rots away - but at the end of the lifespan of a house, the main beech posts (am kun = 'house bone') remain and are re-used. In fact, they are just about the only material objects (apart from stone, bone and shell) that endure and are inherited. (June 26, 2015).

Additional comments were provided in another comment: 
For instance, I think the general idea behind stripping bark from a log is for longevity - bark would retain both insects and moisture, both of which would act to decompose the wood more quickly and shorten its use life/strength quality. I also know from unfortunate, personal experience that you don't want to put a post straight into the ground - ground moisture and insects will rot it pretty quickly. Today we can use cement and/or pressure/insecticide treated wood to avoid such issues - but we know from longhouse post molds that there does not appear to be any additional support for posts sunk into the ground. So - perhaps logs were treated in some way? Which in turn may have an impact on how they appear in reconstructions. (June 26, 2015).

This discourse brought together a wide range of perspectives, sensibilities and experiences (personal and research) on a relatively minor dimension raised initially in our visualization, one that needed answering for the immediate aim of figuring out how to depict texture on sleeping platform posts. In other words, in negotiating a relatively minor pragmatic matter in our visualization, we triggered extensive discussion around the possible authenticity choice a, b or c might or might not convey in the visualization. These kinds of discussions around relatively minor dimensions of virtually building a longhouse I raised in the paradata of the build would repeatedly serve to allow us to negotiate material dimensions of unknowable longhouse space and material when historical and archaeological data was silent or contradictory. And these discussions then often triggered wayfaring moments and a new way for us to think about longhouse materiality.

For example, the comments posted to the blog about bark were simply offering opinions and personal logics about whether bark would or wouldn't have been removed. But it in turn helped shift our thinking about why bark removal might have been preferred. This shifting sensibility itself in turn led me to additional research, not of whether or not bark was removed from posts, but about bark itself as a material value. That led me to consider Waugh's (1916) work, specifically his referencing the use of bark for a multitude of 
household and work related tools. This led me to conclude that it would be feasible to assume that either longhouse builders or residents (i.e., during construction or afterwards) would have harvested the majority of bark from post and poles to meet these other uses bark served in their day to day life, either intentionally during construction or over time as people took bark from dried-out posts in the longhouse for other needs. Thus, circling back to the pragmatic question of whether we should depict interior support posts as bark covered or not, my re-thinking led me to conclude that, visually, posts in the interior living space, minimally at eye level and in reach of residents' grasp, would have been bare of bark at some point in the life of the longhouse. To get to that conclusion was a meandering path of exploration and a typical wayfaring moment triggered by paradata musings as we progressed through our virtual build.

Visually, if post bark would have been removed it meant that our 3D model of interior posts should have an almost pristine and smooth new lumber look. As well, an additional layer of texture mapping was applied later to visually suggest a well occupied build-up of creosote on these smooth post surfaces, a texture that definitely would have been present, given the numerous hearth fires contributing to the smoke layer within the structure. As well, as no tree grows perfectly straight, we gave the 3D posts a slight randomness and curvature to represent what would likely have been more typical tree growth patterns. Tree knots and protrusions on the support posts were also added to better visualize the natural materiality and variation of the posts being used.

Another mediation we had to negotiate was the height to set sleeping platforms. Seventeenth and eighteenth century accounts (e.g., Champlain 1907; Lafitau 1977; Sagard 1632) suggest sleeping platforms were raised 1.22-1.52m (4-5ft) from ground level (Snow 1997). But Snow (1997:83) has challenged these historical observations by citing later eighteenth century accounts that suggest the height of the sleeping level or bottom platform was only $30 \mathrm{~cm}(1 \mathrm{ft})$ off the ground, and that the canopy or storage shelf on top was 1.5-1.8m (5-6ft) off the ground, with storage for additional firewood and possessions below the sleeping level (Heidenreich 1972). Clearly for Snow, while there are minimal archaeological means of knowing this element of longhouse interiors, the lower height made more sense to him than the higher levels. 
It is not difficult to see practical limitations for either option, at least from a twenty-first century sensibility. If over a metre high, sleeping platforms would have been difficult to climb up into, and would have required some kind of step or stair device. Likewise, it would have brought people closer to the smoke layer hovering below the ceiling. That height would have also made it awkward to use the edge of the platform to sit. On the other hand, a platform at only $30 \mathrm{~cm}$ off the ground would be so low that it also would have been awkward to sit on. As well, there is far less under-platform storage available at that height, and indeed it would have been difficult for adults to even access that space, which could seem a practical waste of space in the design of bunks at that height. Given that cultural features, including storage pits, can be found in the ground under platform areas of excavated longhouses, there had to be some access to this below-platform space on a continuing basis in at least those examples. More directly relevant to this research, the notion of having to choose one option over another, or that any historical account is itself "more accurate" for all time and across the geography of all longhouse-residing peoples, is anathema to being open to the diversity and range of variations that likely encompassed this one element over the long-lived history of the longhouse. Neither option is "better". None of the historical accounts is a more "accurate" portrayal of platform height, and moreover, none of these choices encompass the full range of variation that almost certainly did exist through time and region.

But what height should our visualization adopt? Both platform positions made sense to us, though it struck me that a platform height of $1.2 \mathrm{~m}$ seemed too impractical for especially the old and young in a longhouse to negotiate on a daily basis. But I did not want to choose an arbitrary, alternative height other than those ranges historical research pointed to, since choosing a third height that only made better sense to me felt like abandoning a commitment to work within the archaeological data. And since I understood that all 3D longhouse elements are changeable, I chose to succumb to my own sensibilities between the two documented height ranges, knowing I would be visualizing an element that might elicit disagreement from users. So we ended up using Snow's preference of a $30 \mathrm{~cm}$ height from ground. 
Selecting a height allowed us to turn our attention to how to visualize the platforms themselves. As with the students' initial assumptions during the Longhouse 2.x experience, our first attempt in Longhouse 3.x was to form the platform as short poles running the depth of the platform as short $1.8-2.0 \mathrm{~m}$ poles (i.e., from outer wall to central corridor). But this made us realize that, given pre-contact Iroquoian longhouse builders only had the use of stone axes and fire for harvesting of the trees and forming of lumber, the notion they would be chopping all platform poles into even length slats would have been a considerable amount of work for relatively no benefit. As Waugh (1916:8) states:

A method described by David Jack was to tie some saplings around the tree, forming a small, scaffold-like structure. Sods were placed on this, water was poured over them and a fire built up below. By alternatively hacking with stone axes and burning, the tree was finally cut through. If it was desired to cut it into lengths, a double pile of sods was made around the trunk where it was to be divided, and fired applied to the space between. Chief Gibson's description of tree-felling was essentially the same, except that, according to him, a quantity of rags was tied to the end of a pole and used for wetting the trunk and localizing the action of the fire. Both Lafitau and Kalm give similar descriptions, indicating the method to have been one in common use.

Lafitau, Moeurs des Sauvages Ameriquain, pt. 2, p.110 \& *Kalm, Travels, vol. II, p.38.

So we assumed that it would have been more efficient to harvest fewer but longer poles, which would serve as platform poles for the bunk, laid along the compartment spaces on either side of the length of the longhouse, and parallel to the central corridor (see Figure 15). In keeping with Wright (1995:18-19), we decided that white ash would have been the preferred wood for sleeping benches, since white ash tends to grow straight with very little branches. Poles from white ash also have relatively consistent diameters along their length and as a hardwood that would be a sturdier long-term construction choice. 
According to the USDA Forest Service9 , a 20-year-old White Ash will generally be $10 \mathrm{~cm}$ in diameter and $20 \mathrm{~m}-30 \mathrm{~m}$ in length, making it suitable for longer bunk pole supports.

Following this notion of using white ash poles further, in a hypothetical 24 meter longhouse we could assume that: a) there would be two bunk lines on either side running 16 meters (i.e., ending before the curve of the longhouse storage vestibule ends); b) at 4 meters in length per sleeping compartment, there would have been a total of 4 compartments on each side of the central corridor, or a total of 8 compartments in the longhouse, demarked by vertical support posts at their corners; c) given white ash pole diameter of around $10 \mathrm{~cm}$, we would assume that a maximum of 18-20 white ash poles would be needed to fill the depth of sleeping platforms from exterior wall to support posts; d) given average white ash pole lengths of $12 \mathrm{~m}$, these would have extended across all sleeping platforms on a side of the longhouse, and likely reinforced at support posts, in order to ensure an assumed 180-220 kg (400-500 lb) weight of people could reasonably be supported at each compartment along the length of these platform posts.

When we posted this section of our completed 3D build of sleeping platforms on the production blog, an experimental archaeologist in Quebec reached out to indicate that his preferred method for longhouse benching was short poles:

"In a 3D model I made the choice to position the bottom bench poles in perpendicular fashion as opposed to parallel with the length of the bench. My idea was that shorter poles can support an equal amount of weight while being thinner which would allow to make use of the straightest limbs trimmed off the trees. Imagine the amount of branches piling up when building a longhouse that would be a readily available material for that purpose. I also thought that thinner poles might be more comfortable than logs... I tested a polished stone axe that I made for a primitive shelter course with a survivalist group and it works very well on both green and dry wood. I was able to cut an alder sapling about 2 inches in diameter in under 10 minutes and as a group we cut a dozen in about 1 hour. We also used hand held chert bifaces and they work well too but take twice the time

\footnotetext{
${ }^{9}$ USDA Forest Service Plant Guide https://plants.usda.gov/plantguide/pdf/cs_fram2.pdf, accessed July 12, 2014.
} 
and energy. A stone axe made with adequate materials and techniques is quite efficient and very durable." (November 6, 2015).

This commentator reflected back at us some of the logics that had originally informed our own initial assumptions, as well as those of the students' working on Longhouse 2.x, i.e., that platform poles laid perpendicular rather than horizontal to the central corridor of a longhouse made better "sense." This individual was even able to invoke experimental archaeology to substantiate their perspective, and in turn invited us to think of how pole alignment may have contributed to physical "comfort" or "discomfort," and how universal or culturally and temporally relative that concept is. We did find the logics of the comment compelling, which underscores the susceptibility that decisions - wayfaring points along the making process - are to fresh insight and alternative choices, especially when these insights better align with the maker's own sensibilities. The implications of intensive 3D construction and the reveal of paradata for feedback is the negotiated opining on the various choices to be made on a single part of the model. In this instance, after several back and forth remodelling attempts, it was decided to keep our lengthwise pole benching approach. We also took into account the commentary and historical research to assume the ends of poles wouldn't have been uniformly rounded or even of uniform lengths, so we attempted to burnish pole ends, recognizing that over time and use, the ends themselves would become rounded and dull (see Figure 15).

Also lacking any historical data to offer insight is how poles were bound together and with other structural elements of the longhouse. Were poles hitched or knotted together, assuming pole construction was not reinforced solely through means like dovetailing or notching. The only visual reference I could locate was of a cross hitch represented as a detail on a Powhatan longhouse in an engraving by Theodor De Bry entitled The Tovvne of Pomeiooc, dated to 1590 (Hulton et al. 1964:415). Wright (1995:10) following Sagard (1939:240), mentions strips of basswood cordage used for binding in longhouse construction, which would correspond with Beauchamp (1905:147) indicating that inner bark was used for rope, among other uses (see also Snow 1997). Given these limited 
hints to guide us, our 3D detail used a threaded looping knot along with a cross hitch knot for pole lashing (see Figure 15).

Any kind of data or representation of bedding materials used on the sleeping benches was again non-existent. I originally had the mental image of deer, bear and wolf skins as the appropriate bedding, but in discussions with Ferris he suggested that smaller fur bearing animals could also be used to fashion a cloak or blanket laid on top of cedar boughs (see Figure 15) as the underlying bedding layer. We know deer was a key resource for clothing (see Birch and Williamson 2013), and thus in later iterations of our 3D bunking system deerskins were abundantly represented. An Ontario Archaeologist commenting on the production blog site stated:

"This is excellent, especially the explanation of the thought process into the design. I am really looking forward to following this through to its conclusion. The entire notion of sleeping on the bunks is an interesting one; most people were in the lodges during cold months and no doubt sleeping close to the hearths. As for the summer, I could imagine most sleeping in exterior contexts and Sagard and others describing bench use to escape fleas on days of inclement weather etc. The comments about logs and boughs are interesting as are the original ones about "sleeping mats," whatever they were. Boughs etc. were no doubt placed on the logs.” (June 6, 2015).

In this instance, the commentator's positive and authoritative concurrence with the paradata logics detailed for our choice, in effect, reinforced our integration of skins, furs and boughs on the sleeping platforms, even though any number of alternatives also would have been viable. For example, Bartram (1751), Champlain (1907), Lafitau (1977) and Thwaites (1896) all mention the use of bark or reed mats for sleeping on the ground, generally in the winter, and generally surrounding hearths (see also Snow 1997), so it is entirely plausible that these mats may have also been alternatives to cedar boughs for bottom layer bedding as well. 


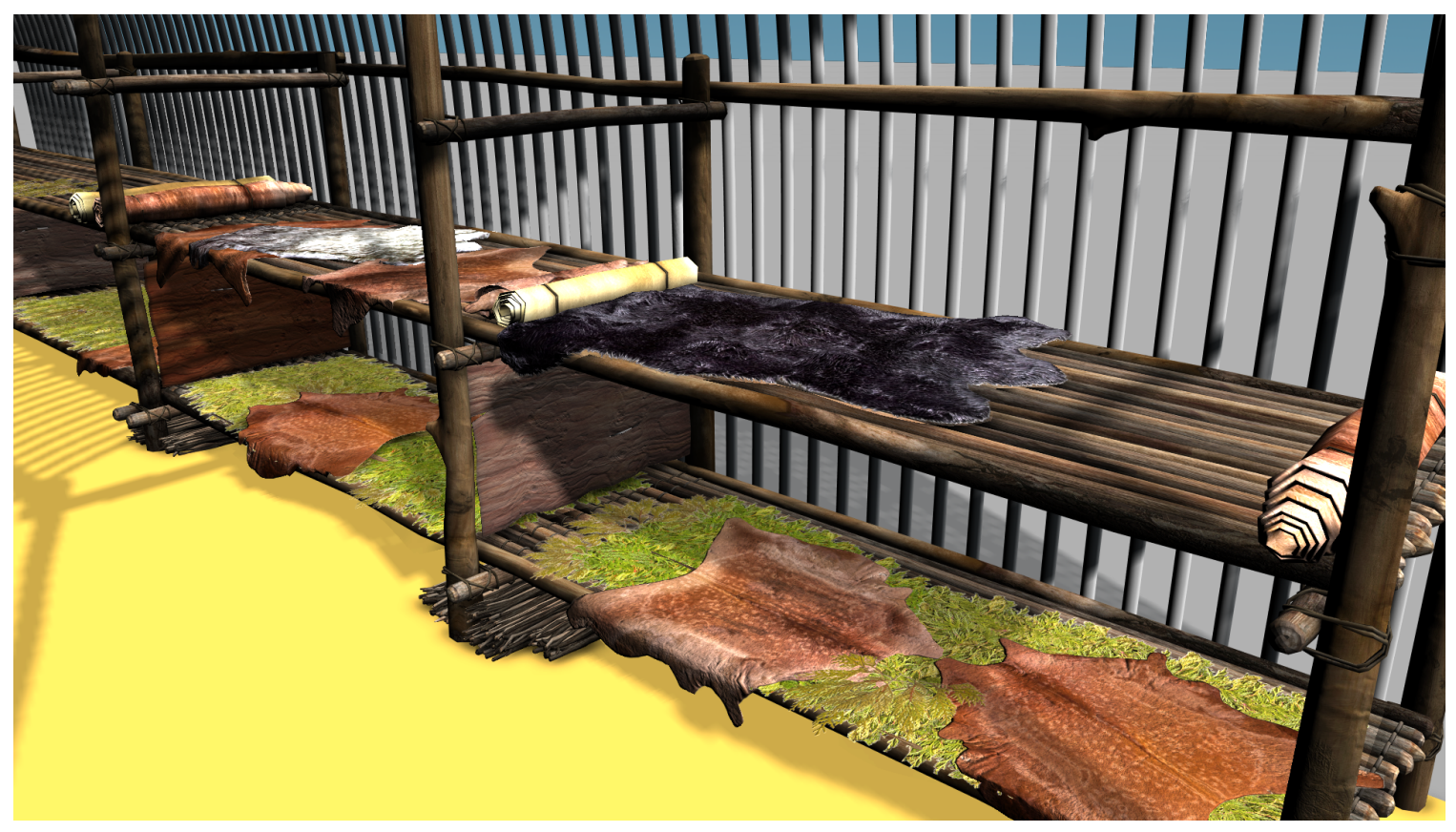

Figure 15 - Example of cordage, bunk slat direction, bedding and cedar back dividers, (Carter and Barr 2016)

The process of visualizing sleeping compartments proved complex, in order to address all the large and small elements that would have gone into their construction, and all elements largely beyond access through archaeological data. The process also proved to be iterative and representative of my interpretation of the archaeological data and the cultural historical material available, as well as my negotiation of the many opinions expressed through paradata feedback directed at me by archaeologists and others regarding these elements. A good example of this is seen in Figure 15, where I included a construction element whereby sheets of cedar were used to delineate each family's sleeping apartment/berth, as suggested by Snow (1997:83) and Kapches (1993:150). This building technique isn't mentioned in any Ontario Iroquoian historical data, but the privacy implicit in putting up dividers between family compartments seemed to me "better" than the mental image of one long set of bunks, undesignated and totally open to other longhouse members. I recognized that my Western sensibilities were particularly influenced by the notion that longhouses might have had visually delineated family units 
as part of the bunking system. I also felt that using cedar dividers would be an interesting sleeping compartment element to test visually.

Using these cedar bark sheets as dividers also led to a discussion between myself, Craig, and several commentators about whether similar bark sheets (cedar, birch, etc.) were also useful as interior roof and wall coverings. However, that notion was quickly discarded since we thought that as people sleeping on the platform would be pressing against the sheets on the exterior wall with their feet (assuming that everyone slept with their heads towards the fire), and cedar bark when dry would be more brittle and less forgiving to wear and tear, and thus would deteriorate rapidly. We have no record whatsoever of this practice or even an extended use of cedar sheets for wall covering on longhouses, but the creative process, and the paradata exercise, nonetheless invited us to imagine longhouse wallpaper applications, less because of archaeological or historical insight, and more because the process invites a reflexive consideration of the past through the material understandings of the maker in the present.

\subsubsection{Support Framing adjustments, Wall and Roofing systems}

With an interior template superstructure frame and bunking system in place, the next phase of our build was to start adding the exterior wall and roofing. Mindful of Williamson's (2004) observation that any discussion on the representation of longhouses above the soil line is moot, we realized any decision made for this component of the build was going to be speculative. I was reluctant to impose an entirely fanciful design on this critical component of the build, especially because this is such a defining element for how the longhouse would look inside and outside, so it meant we had to rely on the historically-informed conjecture (see Figure 3) already in the literature between Kapches (1993), Snow (1997) and Wright (1995). In truth, all three of these options may have existed at any given point and at any given time in the past, likely as no more than three variants along a longer spectrum of exterior wall and roofing design choices; all contributing to that iconic curved upper wall and roof appearance. 
In the end I chose to explore the visual design of the Kapches (1993) integrated wall and roofing notion, primarily because it felt more in tune with my personal understanding of how one would construct a longhouse quickly and efficiently, without the extensive time of cutting wall poles off to a standard length in order to accommodate a separate roofing structure. It also helped that the Kapches (1993) model was consistent with the longhouse roofing designs we had experienced in the Ska-Nah-Doht and Lawson site reconstructions.

Our first attempt at understanding how the support structure would work with arching wall posts is reflected in Figure 16. Referencing Dodd (1984:233), we assumed that exterior wall posts were $6-10 \mathrm{~cm}$ in diameter, and on average there would be 3.5 poles per meter along the length of the longhouse. We also assumed a pole would have to be longer than $7.5 \mathrm{~m}$ (the width and thus height of our test longhouse) in order to have enough length to be embedded in the ground and be bent and then be secured down at the top to some sort of roofing system. We also introduced a slight taper from the base of the post to the tip of the roof end.

The initial build made it immediately clear to us that wall posts would somehow need to be "moulded" around additional support structure poles to allow for the wall posts to be bent, but also tied down to create the tension and hold the form of the distinctive arbour roof. The assumption we worked with was that the exterior posts would be placed into the ground and then bent over the support infrastructure at the roof. We assumed the support post infrastructure would be tied off and connect the tops of the sleeping platform support posts along either side of the interior corridor of the longhouse, and that bunk platform cross poles, or rafters, would assist in keeping the side walls relatively straight until above the height of the second bunk platform (see Figure 16). How, though, would the act of bending posts over these supports and tying them off have been accomplished?

There are several videos posted to YouTube of people attempting to build longhouses in the recent past, including examples (e.g., Motoprof1441 2012) of a two or more-person task pulling down the ends of wall posts planted in the ground, in order to bend them into shape. The result is the creation of that arbour-style roof as described by Champlain (1907:61-62) and others. It is easy to imagine that two or three people would be able to 
undertake this type of construction methodology readily enough. I should caution, however, that all this reasoning and the resulting visualization is not architecturally or physical world based. I acknowledge that we were making broad assumptions at every level in thinking through the logics of wall and roofing systems, and, thus in the process either creating incorrect assumptions about ancient methods of construction and labour, or potentially filling the gaps in knowledge through new virtual meaning-making.

To create a continuous arbour roof and wall system, Iroquoian builders would have needed to force the wall posts to bend at certain points, and thus it seems plausible to assume that interior poles that ran lengthwise and supported by the main bunking infrastructure would have been a critical attachment spot for exterior wall posts. We decided that our assumed posts serving as rafters would be another 1.22-1.52 meters higher, supported by the main interior posts, creating a higher attachment spot for bending wall posts into the core portion of the roof (see Figure 16).

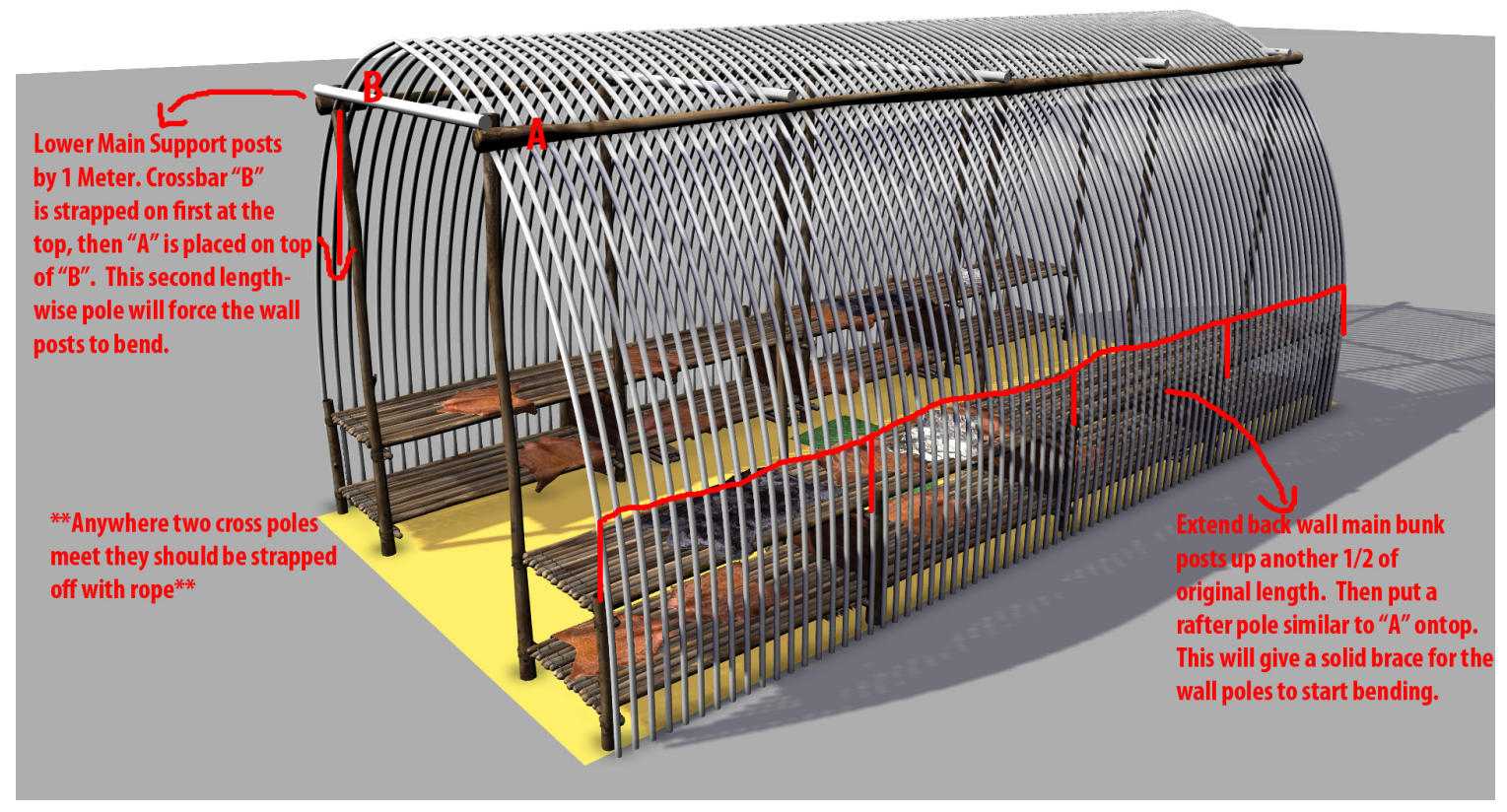

Figure 16 - Initial framing configuration with production notes, Carter and Barr (2016) 
There is no clear data to support the existence of additional support poles that might have attached to the framing superstructure. But when the initial test image was rendered with our inclusion of such supports (Figure 16), the result looked, or rather "felt" to us as though more cross supports were needed above the higher bunk platform. Apart from an illustration by Kapches (1993:146) on the use of longitudinal poles for rafter supports or cross beams, though, what was missing from the literature was any mention or speculation of a framing system for the rafters or any visual guide (see Figure 3 ) to really discern what such an upper support system would look like. To better visualize past this sense that we had a "design flaw" in our first iteration, we were able to consult architectural blueprints that had been developed for the 1982 modern interpretation of a longhouse reconstruction in Fort Erie, Ontario, undertaken by Archaeological Services Inc. (see Williamson 2004; see Figure 17). That blueprint, as well as the notions Kapches' model invoked for the kind of roofing system needed for this bent pole design, led us revise our model. 


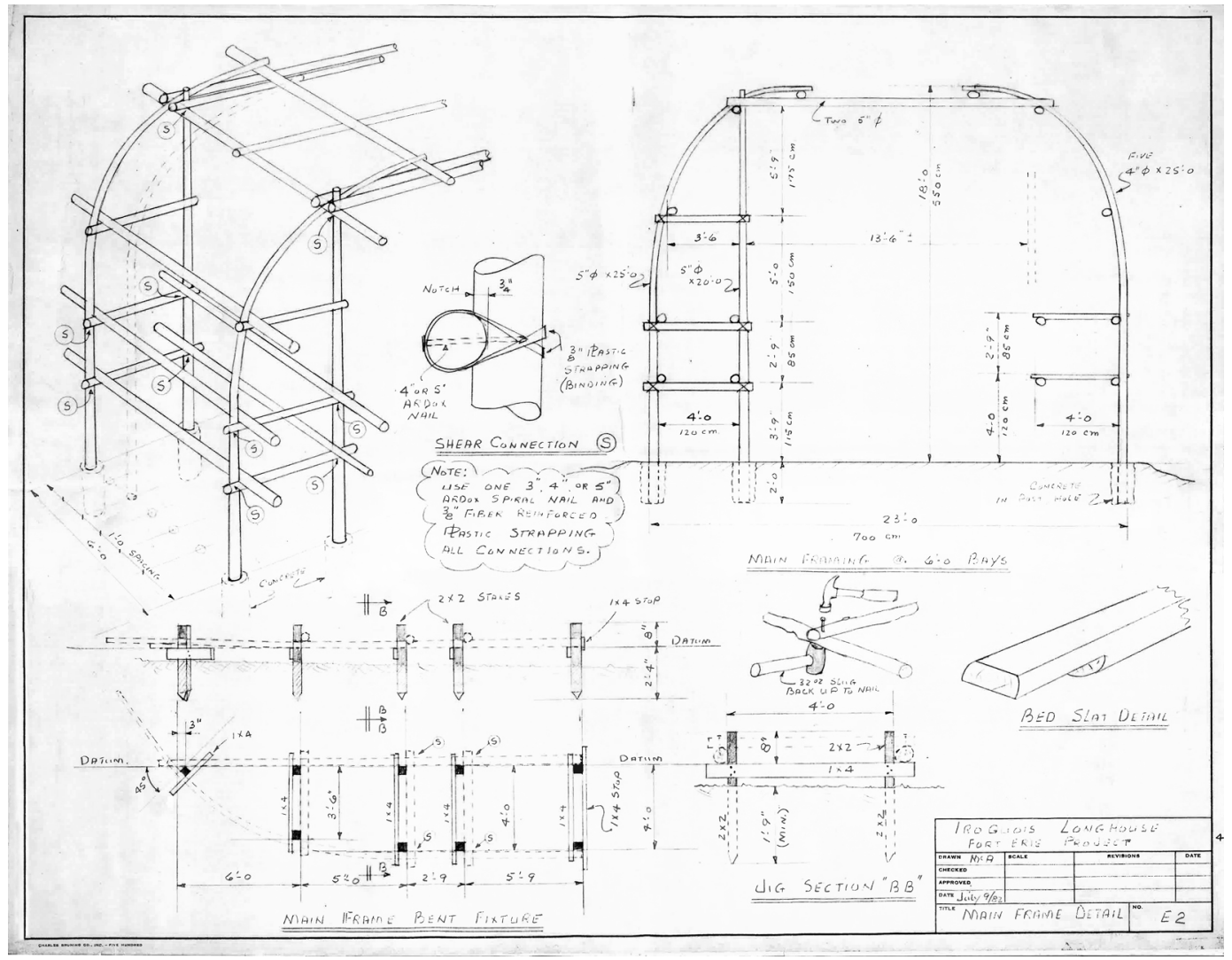

Figure 17 - Iroquois Longhouse Fort Erie Project 1982. Blueprint provided courtesy of ASI and reproduced with permission.

Figure 18 illustrates how we started to play with the idea of additional horizontal structural poles for lashing points drawn from our examination of the Fort Erie reconstruction. To ensure that the new supports used for the mid-section lashing of the wall posts were stable we added additional cross beam supports to the bunking system to reinforce the new structural elements. 


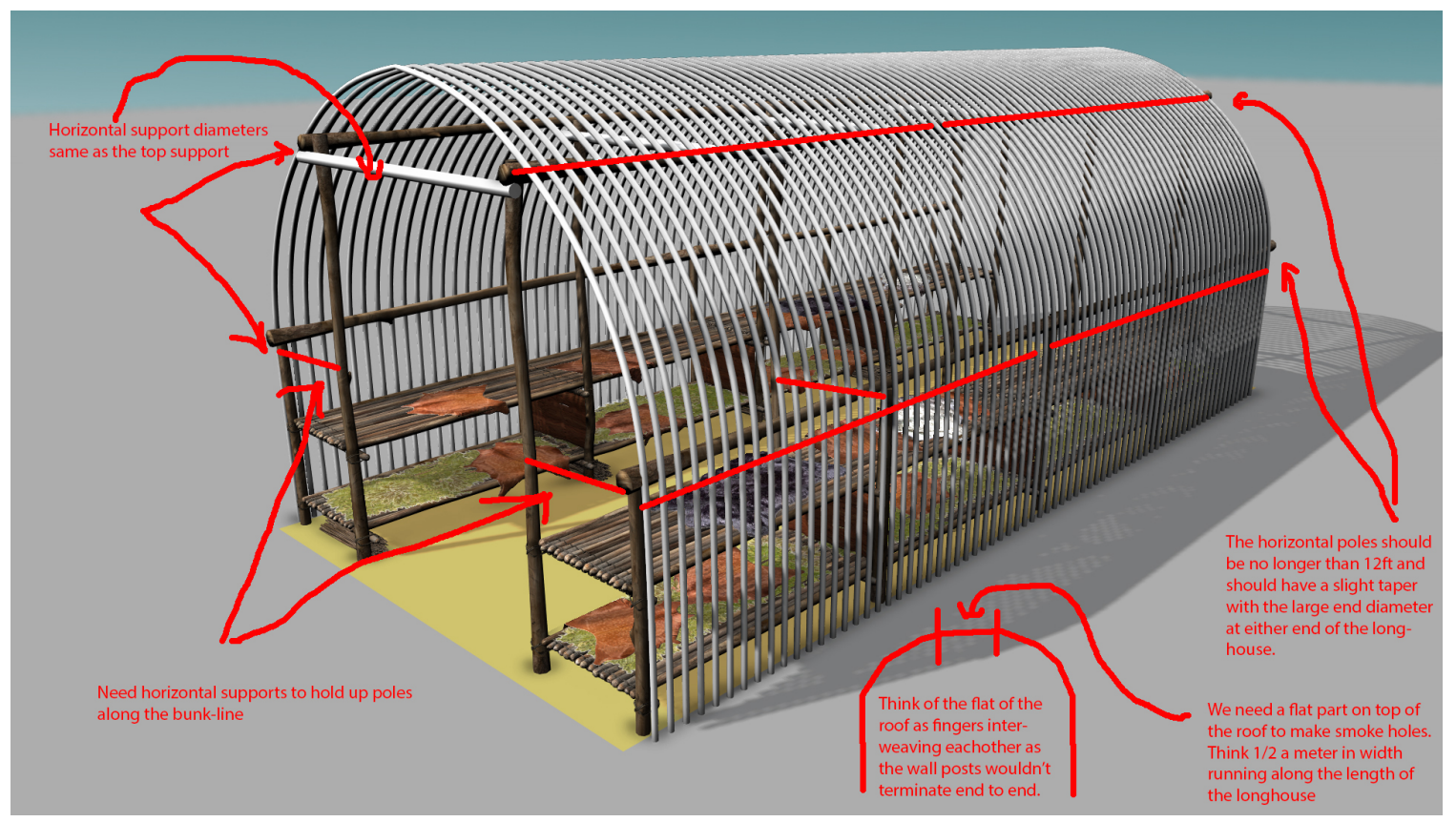

Figure 18 - Second framing revision, Carter and Barr (2016)

Another experimental archaeologist specializing in physical longhouse reconstruction in the United States commented on the production blog site just after Figure 18 was posted:

"This looks good; clearly thought out with close attention to detail. I would make one suggestion. Add ties across the short axis to connect the opposing sides to each other. You have some ties shown (colored white) to connect your arcade purlins together. You have them shown on every arcade post, which is good. I would add the same thing at the lower level to connect the opposing walls to keep the posts stable and plumb. This is an easy change. Look where you have the red lines drawn and labeled "Need horizontal supports to hold up poles along the bunk line": instead of making these separate, just make them be one continuous tie all the wall across the short axis. In a rigid framed structure, this would be absolutely mandatory or the outward thrust of the roof would push the walls out and collapse the structure (Trust me from having seen it happen multiple times in replica structures). In a flexed structure, these ties are arguably less critical but still necessary. If I were building this structure in the real world (I currently only 
build rigid frames, not flexed), I would put those ties in every spot where you've got a post connecting to your wall plate. It makes sense because not only does it stabilize your wall plates, it would be easier for prehistoric people to execute. (August 17, 2015).

Once again, the authority conveyed through the feedback received on what is, essentially, a consideration of how to architecturally improve a roofing and wall system that may or may not correlate to the range of approaches used in the past, was both interesting and influential to my own decision-making. The insight offered was thoughtful and "made sense," further addressing the design flaw concerns we had been grappling with. As such, I quickly drew up a third revision of the wall and roofing design to be implemented.

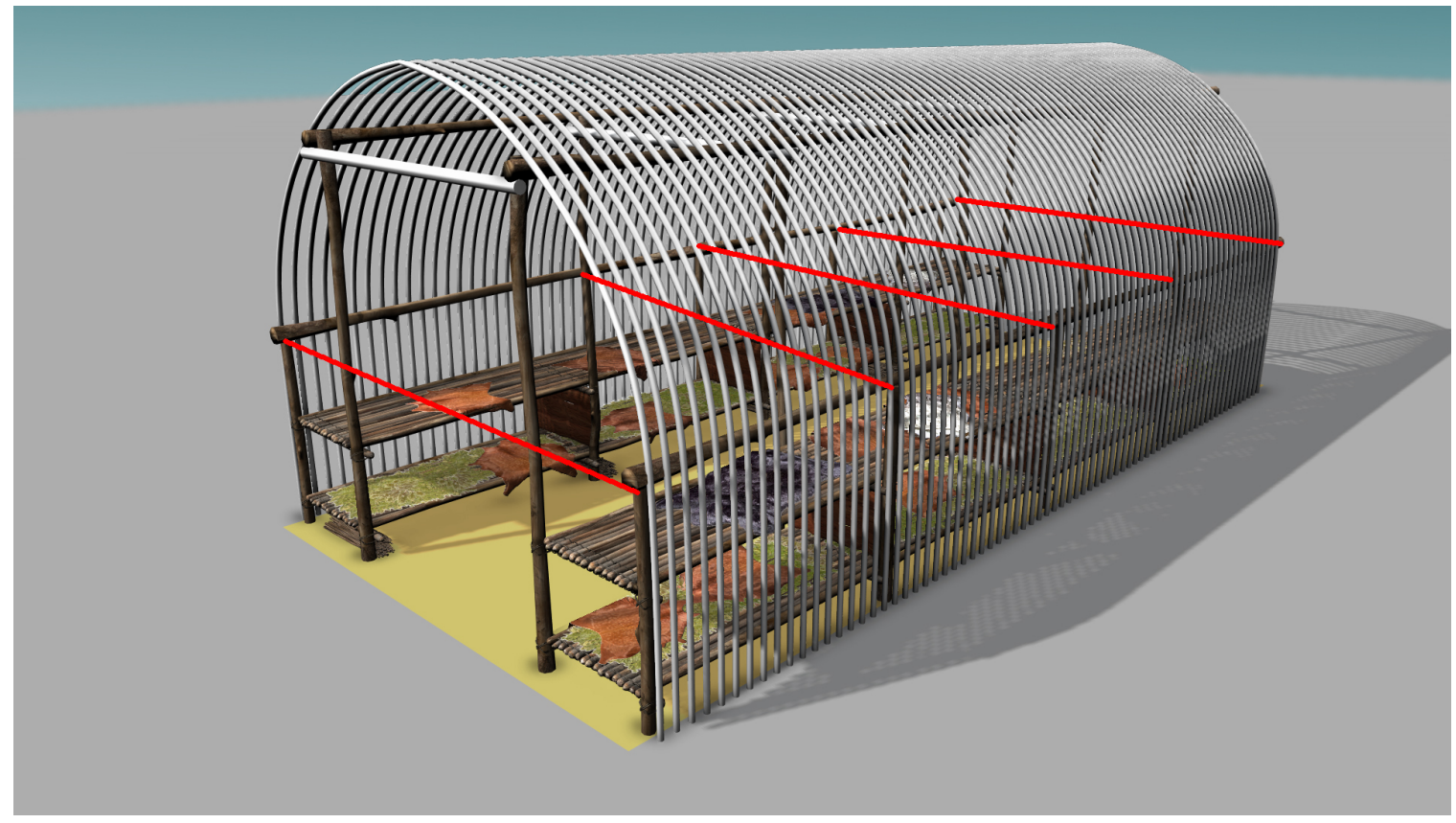

Figure 19 - Revision based on paradata blog feedback, Carter and Barr (2016)

At this point in the process it was increasingly becoming the case that additional crosspoles and rafters began to visually merge the appearance of the roofing design and shape of the Kapches, Snow and Wright models. Based on the feedback we were receiving and 
an increasing confidence in the knowledge construction I was gaining through my own artistic impression, I was able to recognize less either-or in the models we had been considering, and more of an overlapping of design elements. As such, I decided in the next iteration of the build to use the 60\% wall height as suggested by Snow (1997), creating more of a hybrid model between Snow's wall height, and the continuous wall post to roofing methodology taken from Kapches (1993). My assumption was that builders would have continuously tied down the exterior wall post framing to the interior support poles. Having the mid-section interior cross-beams and supports at about $60 \%$ of longhouse height would also allow the exterior wall poles to be bent "more naturally," and, I assumed, would provide a more stable and secure structure. Figure 19 illustrates an increase in the height of the crossbeams and changes in the resulting exterior curve of the wall posts. I envisioned two major tie-down points for the exterior wall at the mid-section and top of the rafters. With all of the potential tension on the mid and top sections of the wall posts, it also made sense to tie wall posts to the interior bunking system at the horizontal poles supporting the lower bunk. Additionally, we randomized the placement of posts along wall lines, similar to how they are recorded in the archaeological record, suggestive of a roughly straight line, but not precisely straight. Lastly, following Wright's (1995) observations on pole height vs. taper, we applied a greater taper and random length to the poles. All these adjustments to the design are illustrated in Figure 20. 


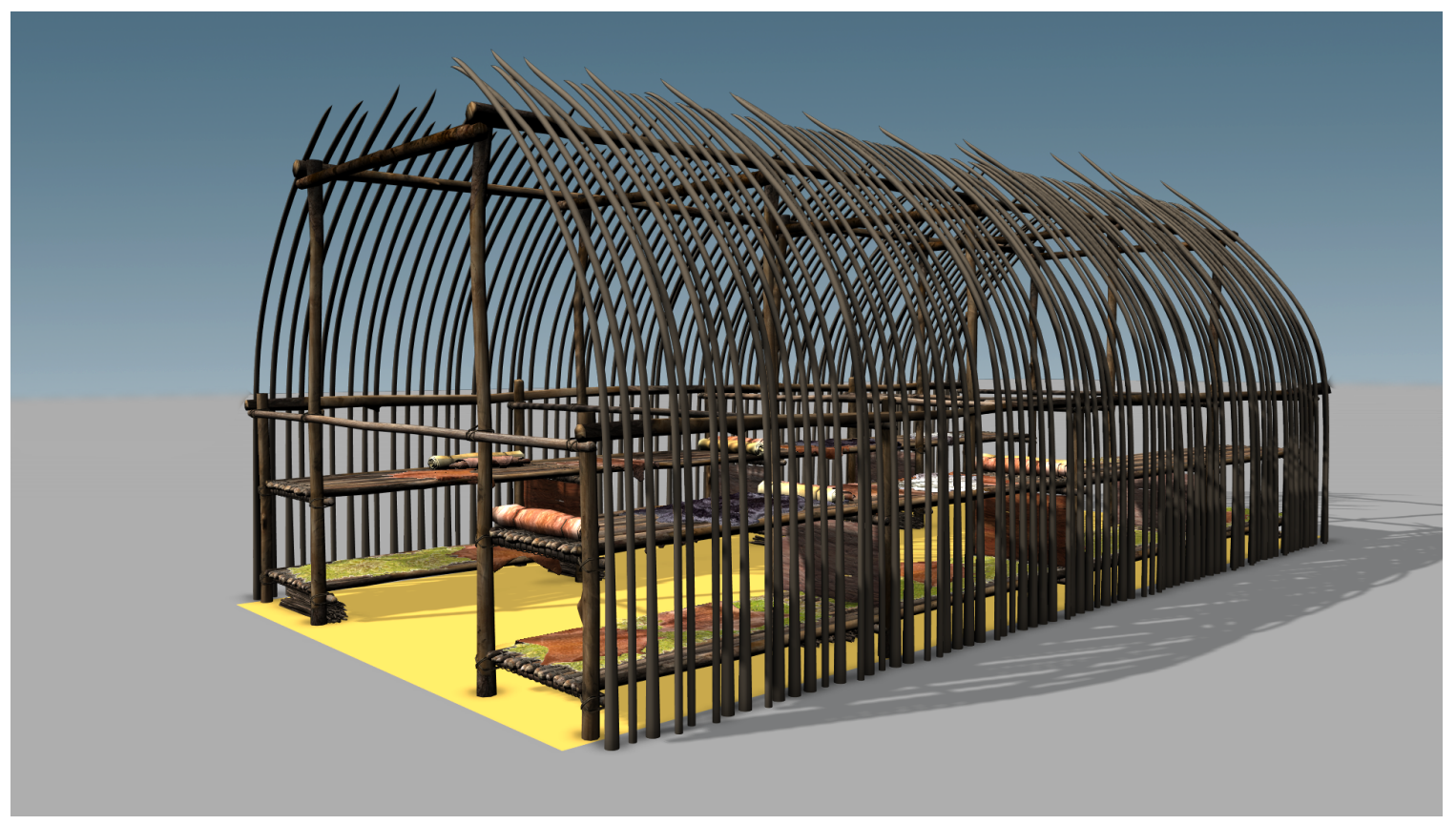

Figure 20 - Third Framing Revisions, Carter and Barr (2016)

\subsubsection{Roofing, Fire Hearths and Smoke Holes}

An interesting question we had to resolve was how to form the roof at the point bent wall posts met and reached their termination? Were these posts tied off to each other, or would there have been additional horizontal supports for the tops of wall posts to be tied to? There are no visual or written historical material to cite in determining how the very top of the roof was constructed, though there are numerous references to longhouses having formal smoke holes at the very top of the roof to allow for smoke to dissipate. And presumably the roof structure needed to support a covering to seal the interior of the longhouse from the elements. Originally I considered the concept of fingers from two hands inter-joining, but that design raised questions about how smoke holes could then be inserted: would the ends of the poles be cut off while on top of the longhouse, or were these poles pre-cut before they were installed? Was the roof domed to the center point, or was there a more flat, central corridor-aligned component to the roof to allow for the construction of formed smoke holes? 
The ASI blueprint (see Figure 17) also influenced our thinking and in the end we adopted a similar design, with an additional horizontal set of tie-off posts running parallel to the length of the longhouse, and half way between the supports posts of the sleeping platforms and the true centerline of the longhouse. This created a rectangular and flatter central roofline, from which square-ish smoke holes could be formed while covering the rest of the roof. Figure 21 illustrates how we started to play with the idea of a flattish roof and how the opposite wall poles might have terminated.

In terms of placing smoke holes for hearth fires, the archaeological record clearly indicates that hearths can be found throughout the inside floor plan of a longhouse. Generally, as Dodd (1984) indicated, they tend to be grouped along the centre/middle of the longhouse. However, Varley and Cannon's (1994) discussion on hearth spacing also indicates that hearths did move over the life of a longhouse, and there could have been both a cooking hearth and a heating hearth near each other. Further, there is no indication that the number of hearths actually represented the number of family units within the longhouse, despite historical accounts that may suggest that was the case in some instances. For example, the excavation map of the Lawson Site (see Figure 4), which was informing our research, shows two fire hearths in House \#5 somewhat in line along the centre of the house. However, House \#6 has one larger hearth at one end of the house and three smaller hearths grouped at the other end. Of course, archaeological excavation methodology may affect these patterns, since hearths generally are relatively shallow features, and thus some hearths could have been scraped away during excavations before being documented. It does help to visualize the problem of where to put the smoke holes if we were to reconstruct directly from the archaeological data, but the variability of archaeological data, longhouse to longhouse, suggests that, at the very least, ceiling smoke vents may not have necessarily needed to be aligned with hearth locations.

In terms of considering the number and placement of smoke vents, Fecteau (1979) noted that the reconstructed house used for their winter experiment had four smoke vents along the centre of the roofline that were $40 \mathrm{~cm}$ in diameter and had hinged covers that could be opened with a pole from inside. There were five larger hearths on the ground, measuring about $60 \mathrm{~cm}$ in diameter, running down the middle of the longhouse. Further, in my 
discussions with Neal Ferris, he questioned whether vents would be directly aligned with hearth placements, since rain or melting snow would have provided a constant dripping on the hearth below, adding to interior smoke accumulation. A movable bark vent cover (Fecteau 1979; see also, Bartram 1751; Lafitau 1977:19-22; Wright 1995:16) would not be totally effective in keeping dripping water out. And given that archaeological data suggests hearth placement likely shifted over the life of a longhouse, I made the assumption that the smoke vents in the ceiling may well have been offset from the hearths below. Lastly, Fecteau's (1979) description indicates a "diameter" of $40 \mathrm{~cm}$. But longhouse construction is clearly linear and with limited fine cutting tools I could not see Iroquoian builders up on the top of a $7 \mathrm{~m}$ high structure trying to cut a circular hole in the roof. And the rectangular and flat roofline we developed would remedy the need for that. As a result, we assumed the shape of smoke vents was rectangular or squarish and that the builders would use a similar shaped piece of bark shingling to act as a cover. The spacing for the smoke holes was left large enough to allow for possible movement or repositioning of wooden shingles along the axis of the corridor below.

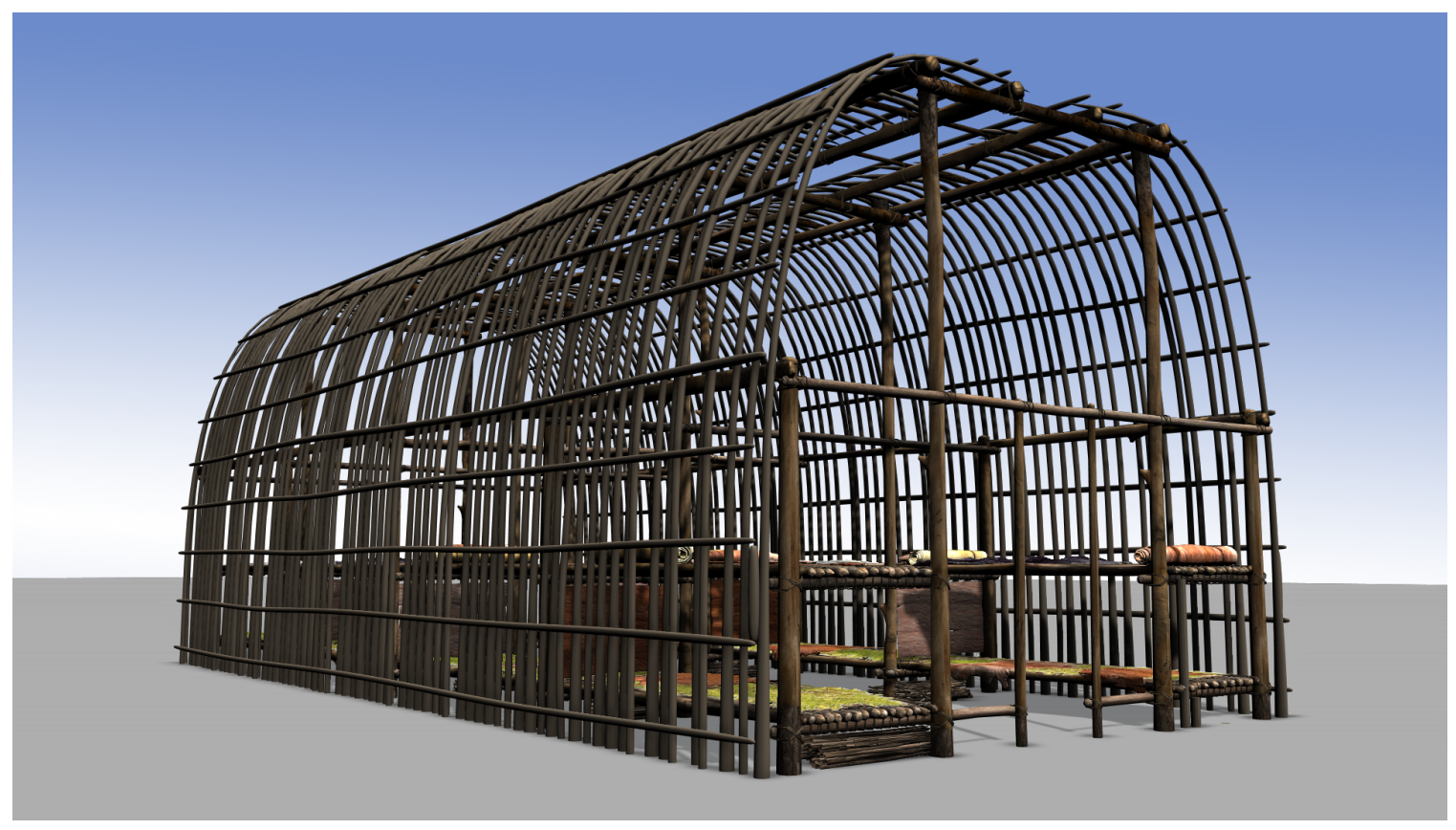

Figure 21 - Fourth Framing Revisions, Carter and Barr (2016) 


\subsubsection{Inner Walls}

Simultaneously as the framing of the entire longhouse was being finalized, internal doorframes were added on both ends of interior living space of the longhouse. From historical accounts (Lafitau 1977:22) there are indications that an inner wall with doorway stood between the end vestibule area and main living are, constructed with the same lightweight cedar shingling/walls that was mentioned in Snow's (1997) account of bunk compartment walls (see also Kapches 1993:150). This made a lot of sense to us as we thought that it would have kept the heat within the main section of the longhouse and would allow for a double door during the winter. We didn't know how the sheets were attached to the interior framing structure, but it had been suggested by Lafitau (1977:1922) that bark cordage was used to tie off the sheets to each other and to the superstructure (see also Snow 1995:69). As cedar bark was used, which is considerably more pliable and lightweight, smaller gauge rope cordage could have been implemented. After some discussion on how the cedar sheets would hang it was concluded that a doorframe had to be constructed in the design of the inner wall to act as a brace and attachment points for the sheets, as well as playing an important role in providing overall structural stability to the main portion of the longhouse. The framing of the door was about 1 metre wide by 2 metres in length, however, William Engelbrecht (personal communication, October 2015) suggested that a lower doorway would have provided a measure of defensive capabilities as guests would have had to duck down in order to navigate a low passageway. In our case and strictly for game engine purposes, we chose to leave the doorway and the exterior vestibule entrance at a $2 \mathrm{~m}$ height (see Figure 22). 


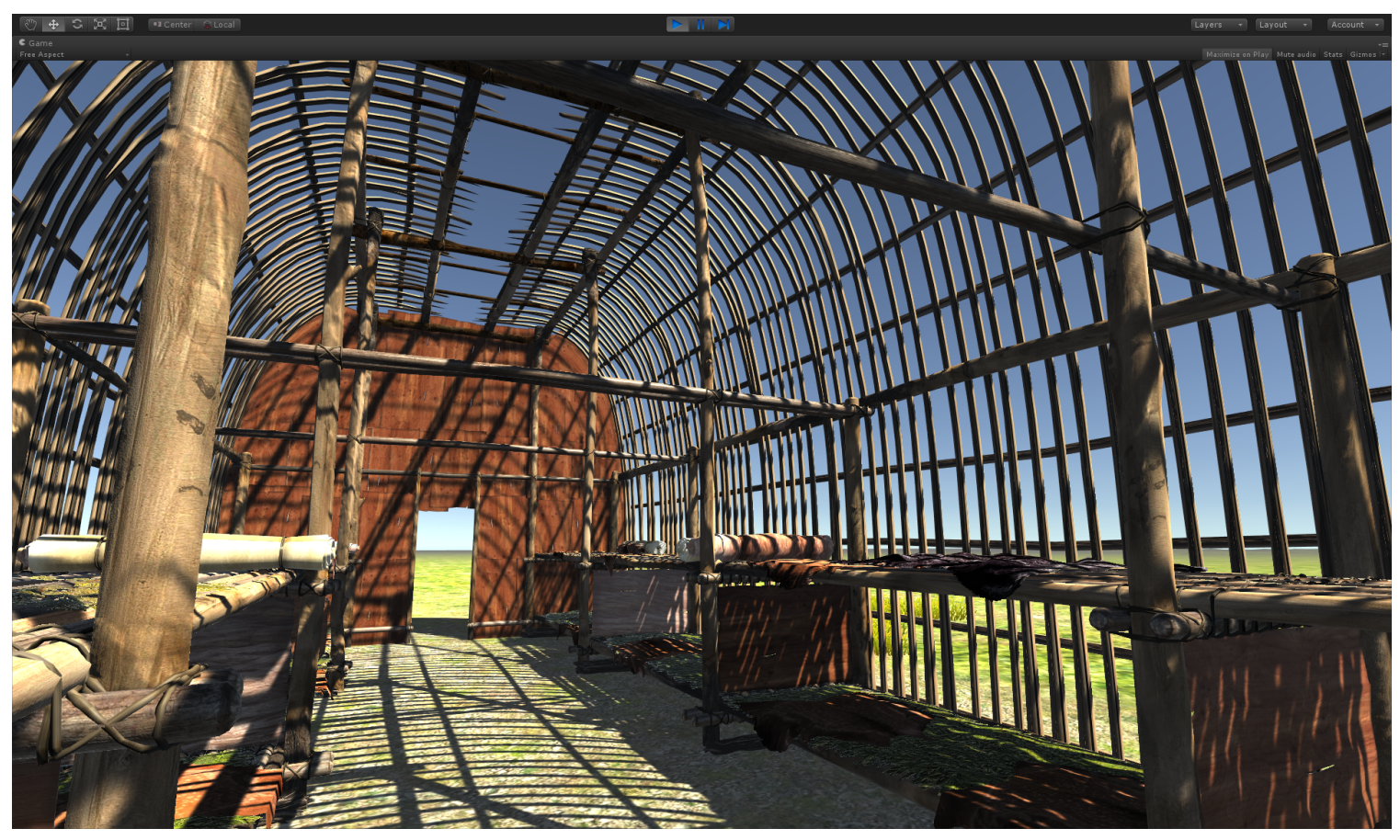

Figure 22 - Cedar inner wall and doorway, Carter and Barr (2016)

\subsubsection{Vestibules and Longhouse Ends}

Although Snow (1997) and Wright (1995) both tended to support a flat faced longhouse end, I was inclined to rely more on the shape of the many longhouses documented archaeologically for the sixteenth century that exhibit more rounded ends, similar to the Kapches (1993) model. The resulting vestibules created between the exterior ends of the longhouse and the interior end walls to the living space are generally assumed to have been used for storage of bulk food supplies and firewood, as well as possible sleeping areas during the warmer seasons (Bursey 2001; Creese 2012a, 2012b, 2013; Kapches 1990, 1993; MacDonald 1987; Watts 2009). According to Dodd's (1984) research, the vestibules on either end of the longhouse had the same width and height dimensions of the main longhouse, and were generally $4.2-4.7 \mathrm{~m}$ deep, from interior living space wall to longhouse entrance. There was also an indication that the front of the vestibule would taper from main longhouse width, reducing from $7 \mathrm{~m}$ to about $5.3-5.8 \mathrm{~m}$ wide by the entrance. 
The settlement patterns revealed during the 2008 Alexandra site excavation by ASI (see Figure 23) clearly shows building expansions of the end of a longhouse that occurred over three different occasions, all of which demonstrates the vestibule taper mentioned by Dodd (1984). It is also a nice visual to demonstrate the reconstruction process that occurred when a longhouse needed to expand. Evident in the post mould patterns for this house at Alexandra is that the end of the vestibule continues to be rounded, and there seems to be clear space in the post line for a doorway. Most significant is the slight veering to the right of the actual walls as the extension is grafted onto the original existing longhouse. Lastly, the final expansion has a relatively clear vestibule. This is significant as it demonstrates that the vestibule was designed to be removed and rebuilt quickly during expansions, but that there was a continued need for the vestibule space after expansion, underscoring its importance to the daily life of longhouse residence.

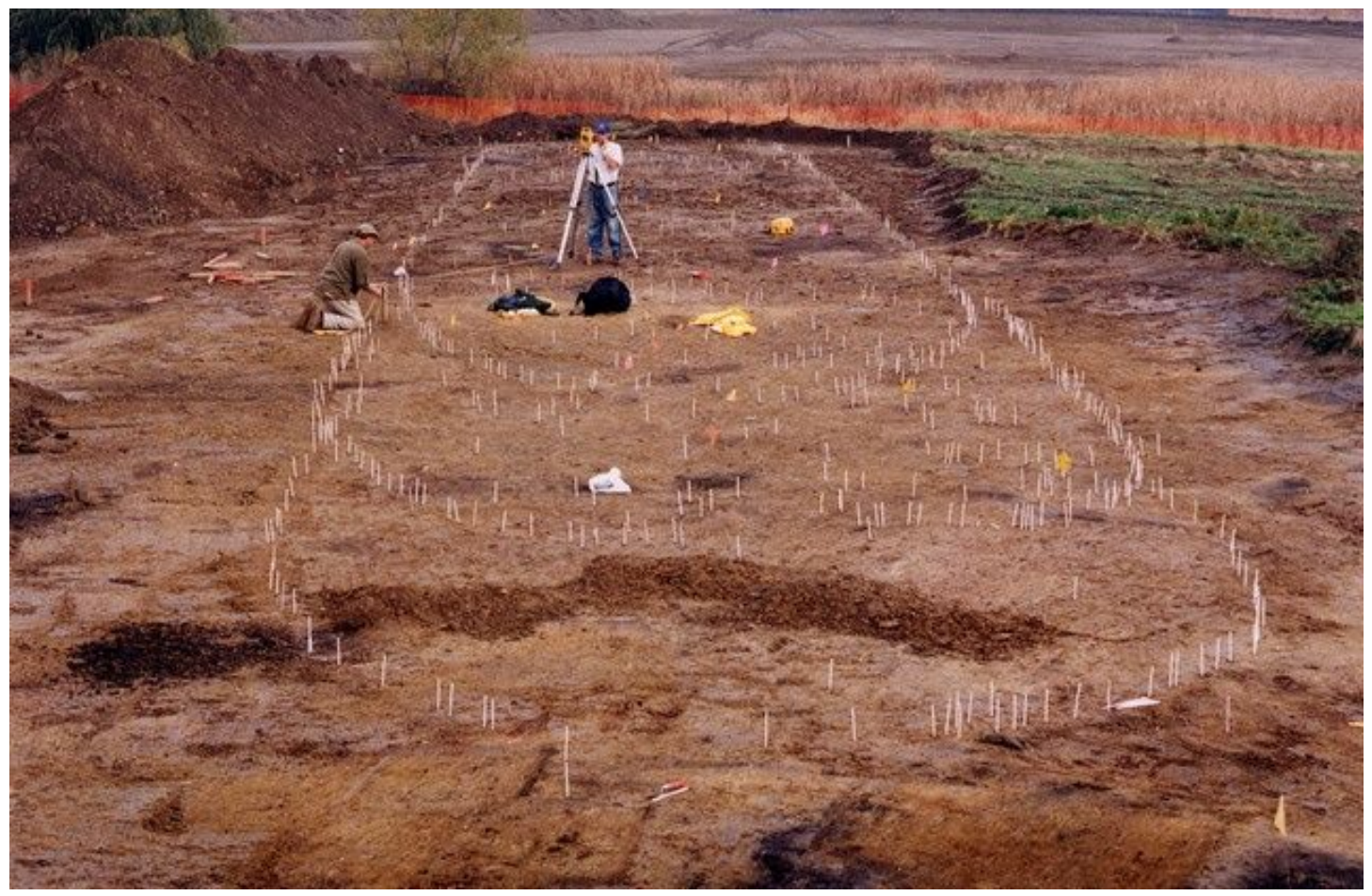

Figure 23 - Alexandra Site, ASI (2008). Reproduced with permission from ASI. 
In Figure 24, which depicts our construction complete with end vestibules, it is clear that the number of poles used in order to replicate the archaeological record had to be increased, since the archaeological record does not show a decrease in the number of posts used to form the walls of the vestibule/door area. Also, using a flat roof causes slight issues with having the bent vestibule posts terminate properly at the roofline, and would have to be extremely long to be tied off properly with the main part of the longhouse. Generally, I acknowledge that we need to revisit the roof and connection of the vestibule superstructure with the main part of the longhouse, since we ended up still not fully convinced of the current termination points on the roof from the vestibule, and so it remains an estimated guess and something for future research.

That we failed to accurately represent the post spacing clearly evident in Figure 23 of the Alexandra site settlement pattern is an example of Ingold's $(2011,2013)$ notion of how the tools and the materiality of the material dictates how the maker negotiates their mental image and the realities of the making process. We knew we had to terminate the upper ends of the wall posts, but by adding additional posts to the model the termination at the top end of the roof became a visual, jumbled mess. Further, as revealed in the archaeological record, there were clearly doors within the vestibule walls. The question for us, then, was how did Iroquoian builders connect the two halves of the vestibule together above the top of the doorframe? Ultimately these were questions we just couldn't answer satisfactorily so I made the decision to find a simple visualization solution through a series of short, interconnecting horizontal poles that could act as a frame for when we finally place the bark shingles onto the longhouse/vestibule. While this element does not look quite right, we were anxious to move on to exterior wall coverings so in this instance we "made do" with what we had come up with - another dimension of the making process and compromise between mental ideal and physical (or our case digital) real. 


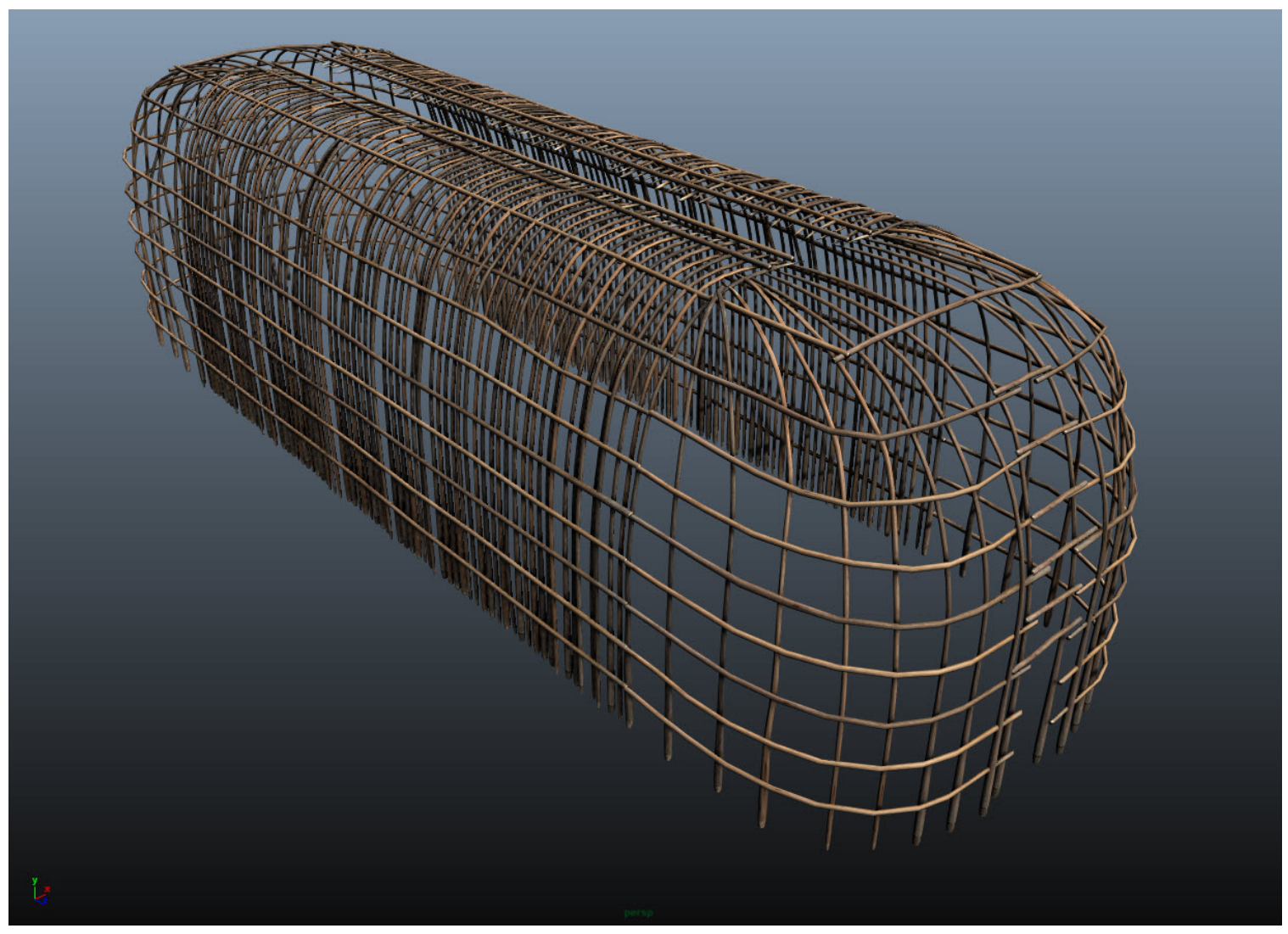

Figure 24 - Full exterior framing, Carter and Barr (2016)

\subsubsection{Exterior Shingling and Framing}

The exterior wall and roofing systems of a longhouse create frames for attaching wall and roof coverings, made typically of bark shingles. Although historical commentators such as (Champlain 1907:313-314) speak in generalizations about longhouses being covered in bark shingles, Lafitau (1977:19-22) goes into detail regarding the use of shingles and how they are secured onto the frame:

The square frame being raised, the Iroquois make the roof framing with long poles bent in an arc which they cover also with bark sheets a fathom long and from one foot to fifteen inches wide. These bark sheets overlap like slates. They are secured outside with new poles like those which form the arch inside and strengthened again by long pieces of split saplings which run the entire length of 
the lodge from end to end and are fastened at the ends of the roof on the sides, or on the wings, by pieces of wood cut with crooked ends which are spaced at regular intervals for this purpose.

White elm has been suggested as the most suitable bark shingling specifically for the southcentral Ontario region, with the shingle placed horizontally for easy discharge of any water following the natural growth pattern of the bark (Birch and Williamson 2013; Champlain 1907; Norcliffe and Heidenreich 1974). Shingles have been commonly referred to as being 1x2m rectangles, placed in overlapping layers (Snow 1997:82). Using a photographic image of white elm bark as a texture map, we recreated $1 \times 2 \mathrm{~m} 3 \mathrm{D}$ modeled bark shingles, positioning them as described historically in an overlapping manner (see Figure 25). This example then allowed us to test lighting, shading and texture repetition patterns to determine the best rendering attributes of the $3 \mathrm{D}$ object when it was finally applied to the longhouse in the virtual environment.

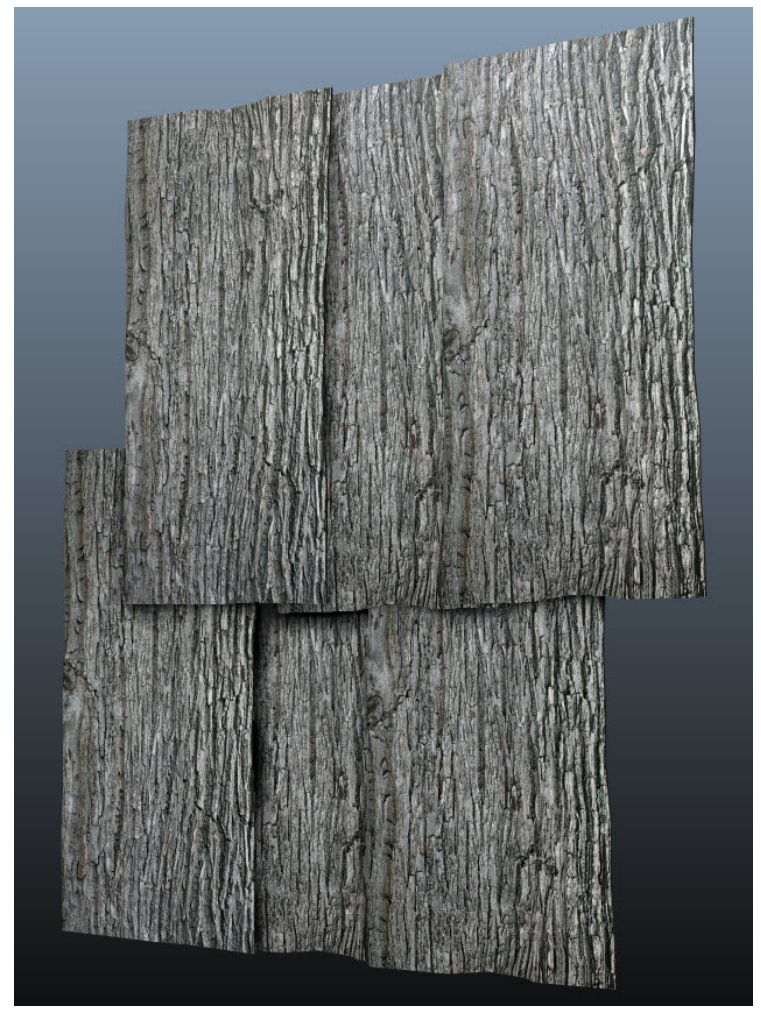

Figure 25 - Full exterior framing, Carter and Barr (2016) 
Once fully shingled, Snow (1997:82), following localized eighteenth century examples including Lafitau (1977:19-22), suggested the addition of a bracing exo-skeleton that was used to keep the shingles in place and to act as a support system to increase the rigidity of the entire structure. However, Heidenreich (1972:48-49) suggests that the outer wall was designed as a staggered single row of posts that allowed for a weaving of bark shingles between posts. The archaeological record and interpretation within Ontario supports Heidenreich's notions. Nonetheless, from the actual visualization of bark adhering to longhouse walls, either method (i.e., second exterior wall of posts; staggered interwoven row of posts) may well have looked, during construction and after finishing, much the same. As problematic as it might be, in this instance, influenced by Lafitau's description and Snow's notion of the effectiveness of external framing structures in securing bark shingles in place, I felt it was a unique interpretation that needed to be further examined visually. In visualizing in 3D this method of holding bark shingles in place through a second row of posts, the external framing became almost like a scaffolding system, which at least in my mind would allow for easy access to the higher portions of the longhouse itself.

Lastly, it should be noted that once shingles were placed on the walls and roof, the only light penetrating the structure emanates from the exterior doorways, the smoke vents, as well as any gaps between the bark shingles, meaning that the light from the heating and cooking hearths in the interior of the longhouse would have been an important lighting effect in that space.

\subsubsection{From Maya to Unity}

Up until this point, the longhouse builds had primarily been made within Autodesk Maya for modelling and lighting tests, and Mudbox for specialized modelling and texture mapping. Working within Maya afforded us the ability to create highly detailed models and if so desired, light to render the scene with photorealistic quality. Autodesk Maya has 
been the main software tool for model, animation and rendering animation for Hollywood feature films for over 30 years. Individual photo-realistic images are rendered statically, and then assembled to produce a sequence or movie. However, one of the issues we increasingly faced as our builds developed more and more detail and texture, was the scale of the of 3D data we were populating within the actual model. The more modeled surfaces, the higher resolution the texture maps and the photo-realistic lighting, the much larger the size of the digital data files.

In a gaming engine like Unity, all 3D assets are rendered interactively, in real-time, which means that everything from lighting, to atmospherics to characters or environments are dynamic calculations and wholly dependent on the computational power of the hardware and software platform running the game. In other words, all those files are continuously re-rendered based on the POV (point of view) of the user in that 3D gaming space. Move from the outside to inside of a building, or from a sunny to overcast day, and light and texture appearances change in real-time. Distance, light sources, angle of perspective and movement all require constant re-rendering of elements, shadows, addition of new elements coming into view, and so on. Not surprisingly, for most gaming environments this means that consumer-based gaming platforms do not have the computing, and critically graphical power, speed and memory to render hyper photorealistic images in real-time, and thus the objects being rendered must be at a lower resolution both in object and texture space. The end result is a stylized quasiphotorealistic image (compare Figures 26 \& 27). 


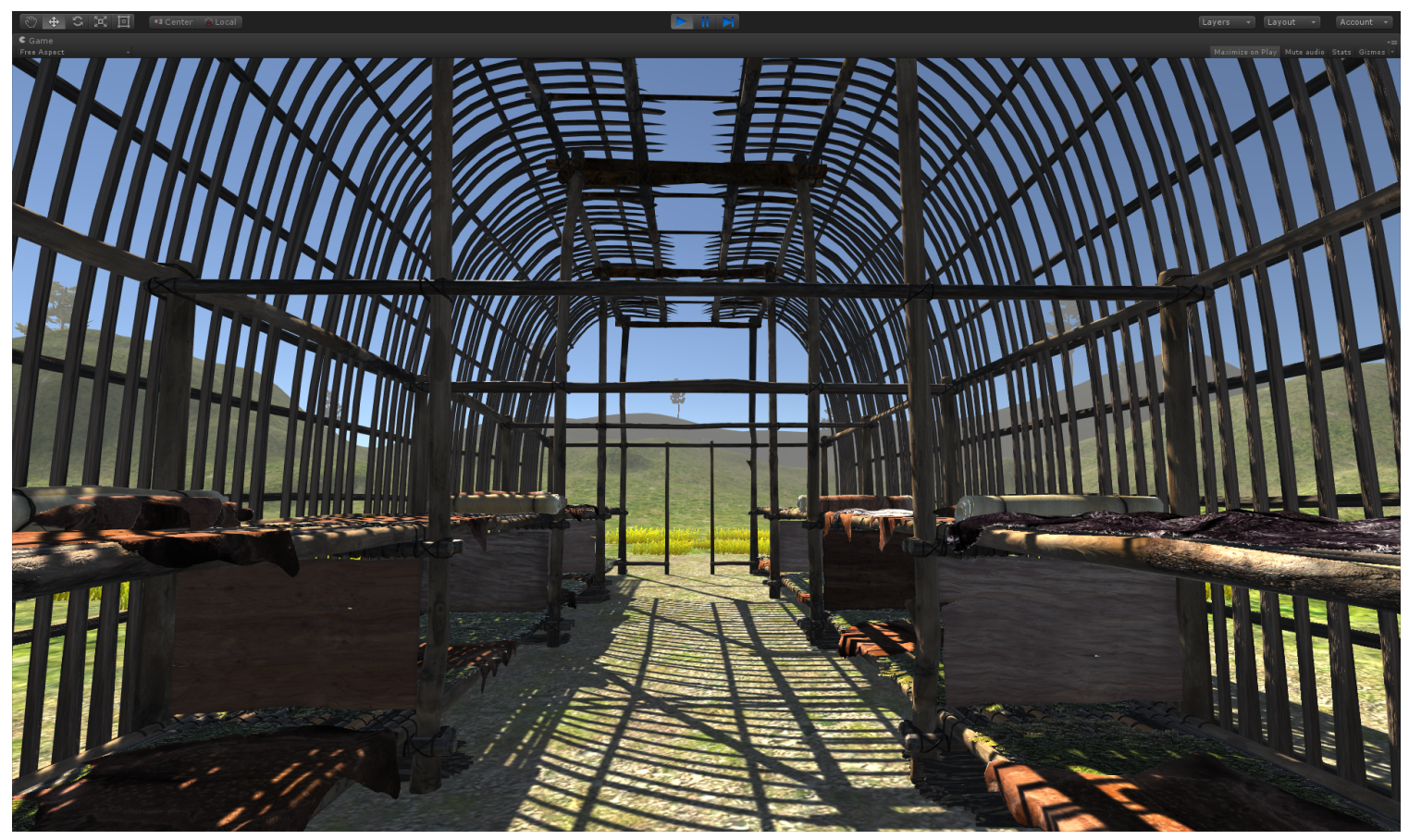

Figure 26 - Photo-realistic rendering of the Longhouse, Carter and Barr (2016)

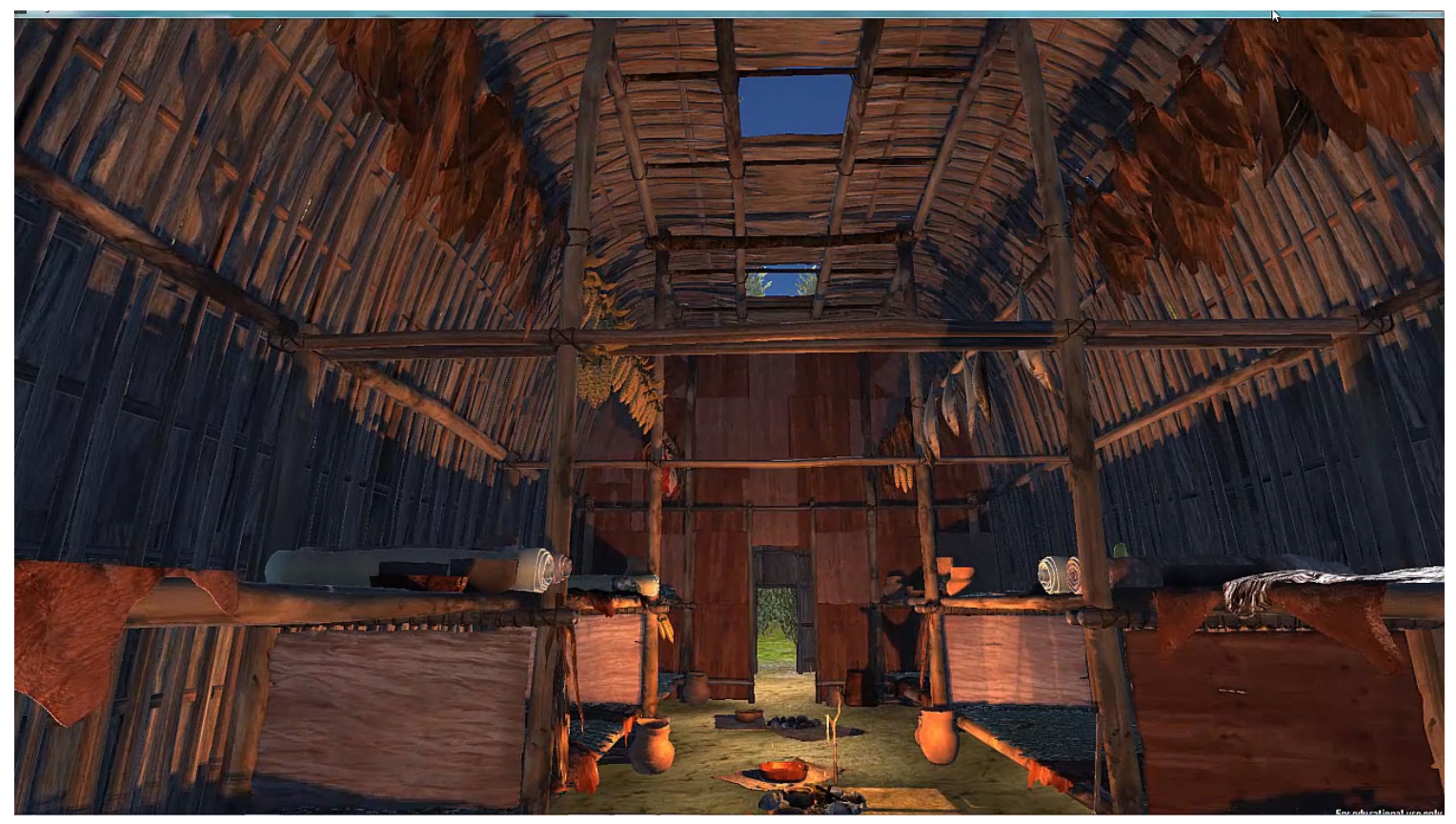

Figure 27 - Stylized game rendering of the Longhouse, Carter and Barr (2016) 
Given my desire to provide an immersive engagement with the longhouse build, a difficult task for the project was to decide what of the 3D assets and textures we had meticulously built in Maya could be sacrificed by lowering their resolution so as to increase the interactivity of the user within a gaming space. Further, those decisions had to be weighed against the additional prop, environmental and atmospheric 3D interactive assets that also needed to be added into the overall longhouse environment to create a phenomenological presence for the users (e.g., objects, smoke, light, etc.). Although only two points are needed to make a line (or what in 3D computer graphics terminology is called a spline), a minimum of three points is required to make a surface, or polygon (see Carter 2017). To make a second surface, only an additional point needs to be added, and so on. These networks of interconnected triangulated surfaces or polygons create the visual shell of the object we have just captured. The more polygons there are, the higher the visual resolution of the 3D model.

As an example of the trade-offs we had to make, cordage-lashing elements we created in the longhouse build that weren't going to be seen in the dim lighting of the interior were either reduced or removed from the version in the gaming engine. We also chose to simplify texture maps. For example, post polygon counts were reduced along with any detail that wouldn't be directly visible. Care however was taken to find the right balance, or "sweet spot," in terms of reducing fidelity of the assets while still ensuring they looked convincing.

\subsubsection{Setting the Scene}

Like Longhouse 2.x, we chose to focus on a single hero ${ }^{10}$ longhouse that users could enter, explore and potentially interact with. All other assets within the 3D landscape would be representational proxies with even lower model resolution and texture maps (e.g., grass, rocks, water, etc.). Initially our hero longhouse was accompanied by other,

\footnotetext{
${ }^{10}$ In gaming terminology, a hero character, object or landscape is the main focal point within the game.
} 
substantially lower resolution longhouses as in Longhouse 2.x, but we found that if we wanted to keep a substantial amount of the material detail of our hero longhouse, we couldn't have more than one structure in the scene (see Figure 28).

From a logical, narrative perspective, we knew we could "explain" the presence of a single longhouse from the archaeological record, in which there are several cases of a single longhouse found external to the main palisaded village (e.g., Finlayson 1985; Pearce 1984). So we decided to provide our detailed hero longhouse with a lower resolution palisade in the far background. To meet the criteria of strategic village placement near a water source, defensive viewsheds and potential arable land, a local environment with a broad shallow river was created and the longhouse placed on a slightly elevated knoll near the river's edge but within visual distance of the suggested village.

The longhouse was positioned in a NW-SE direction to mimic what we understood to be the preferred orientation ${ }^{11}$ of later Iroquoian longhouse placement (Anderson 2009; Birch and Williamson 2012; Cooper and Robertson 1993), though certainly that is not a universal pattern for sixteenth century longhouses, and many context specific considerations likely informed the placement of longhouses, especially those placed outside of a palisaded place (e.g., Anderson 2009; Lennox 1981; Pearce 1984).

A mixed 3D forest of ash, birch, elm and pine along with suggestions of forest and field grasses and brush was added to create a distant end to the vista, and denote potential sources of raw material (Jones and Wood 2012). Textures for the ground were purposely made to look as if there was continuous foot traffic around and to the longhouse by differentiating it with more dirt textures against a green base. Lastly a bright blue late summer daytime sky was added.

\footnotetext{
${ }^{11}$ Norcliffe \& Heidenreich (1974) concluded that NW-SE orientation helped with thermal efficiency against prevailing winds.
} 


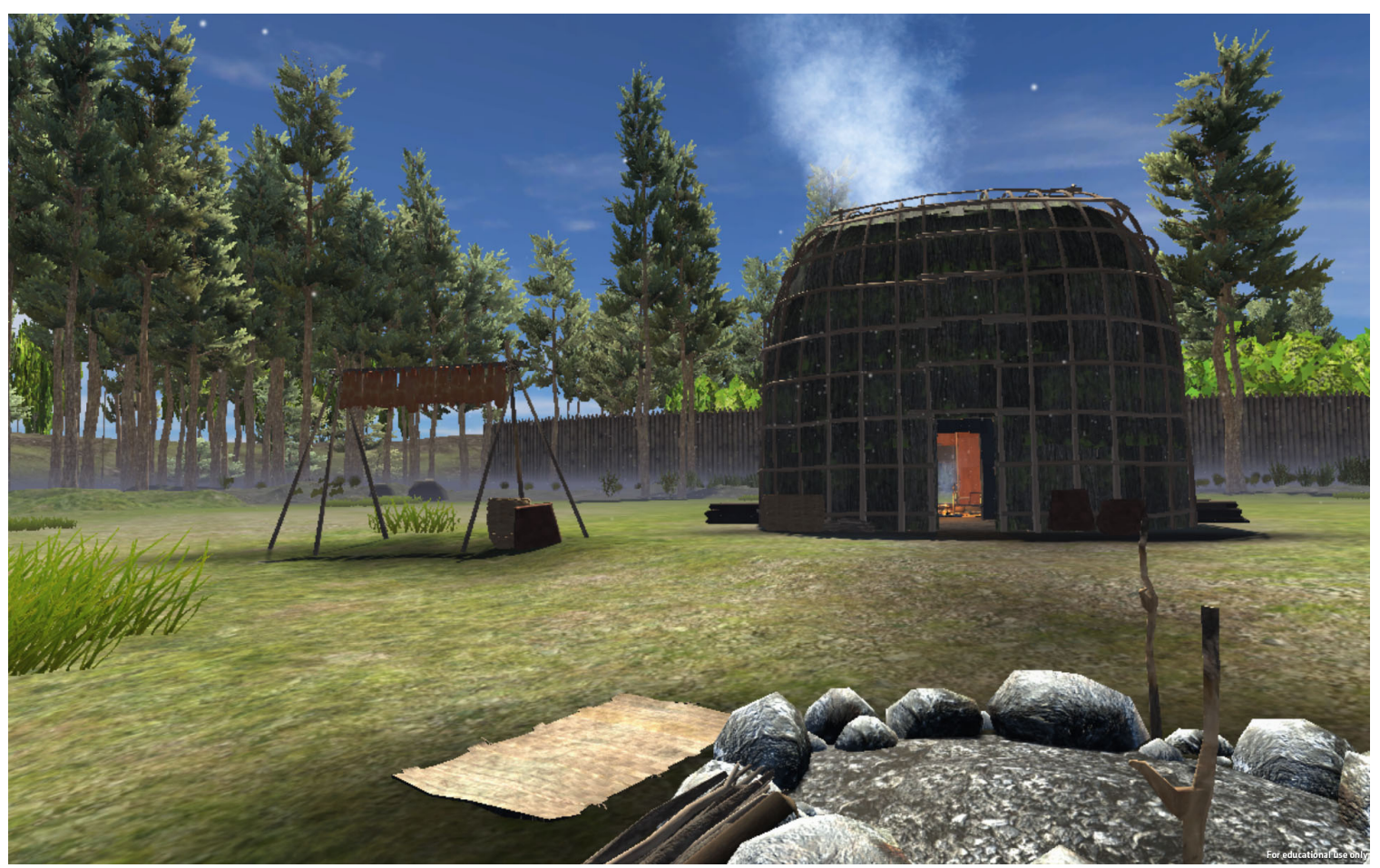

Figure 28 - (Re)Imagined exterior of Longhouse 3.x, Carter and Barr (2016)

\subsubsection{Mood Boards, Props, Atmospherics and the Construction of Presence}

While I will explore in a subsequent chapter whether the notion of presence is required for the creation of meaning for archaeologists within virtual space, the process in film, television and gaming to set-the-mood requires a constructed lens to provide the participant a sense of presence. Prop devices such as sound, light, atmospherics, objects and landscapes are used to enhance the emotional connectiveness of the participant with the landscape or environment with which they will interact.

To develop the sense of presence in film, television and games, mood boards are a production design tool utilized as a culminating visual detail reference for the setting (Hagen 2011). Generally, the art director, someone who is charged with setting the visual tone of the image, sequence or film, will glean references from a vast array of sources. Some researched visual material may be accurate representations of contemporary or historical settings, and some entirely fantastical or fictional representations, all of which 
are appropriated, mixed and mashed to develop a desired, highly interpretive, and entirely subjective creative look and feel to a setting. In our case to develop the sense of presence both inside and out of our 3D longhouse, we needed to negotiate between purely fictional visual representations of longhouse life and the known archaeological and historical record. That same process is used for creation of the lighting and sound mood of a particular scene or set, both of which were also engaged with here (Hagen 2011).

Appropriated images were drawn from personal photographs of modern reconstructed longhouse visits posted on the Internet, and from the websites of Museums including Ska-Nah-Doht, Sainte-Marie among the Hurons, Crawford Lake and the Tsiionhiakwatha/ Droulers archaeological sites, along with Iroquoian archaeological and ethnographic artifacts from permanent on-line Museum collections. Photographs from archaeologically-informed physical reconstructions of longhouses came from J.V. \& Joyce M. Wright's personal collections, as well as VFX longhouse material developed for the 2013 Yap Films documentary, The Curse of the Axe about the excavated Mantle site, courtesy of Ron Williamson and ASI.

Longhouses had an annual cycle and life cycle, depending on season, how long the longhouse was occupied, etc., but in our visualization we could only represent one season at one moment in the longhouse's life, so it was decided that late summer/early fall would be represented, as the community started building its supplies for the long winter ahead. We also decided to represent the longhouse relatively early in its life history, at a point it would have been well lived in, but before major repairs or serious structural rot would have been evident.

Following descriptions of food storage from Champlain, Sagard and Brebeuf as well as examples of container-making from Waugh, wood supplies and bark barrels and baskets were added to the vestibule and within the interior of the house. With suggestions from Lominy (personal communication, November 2015) on fish and meat curing, representational 3D strips of meat and fish, textured to suggest constant smoking from the fires, was added hanging from the rafters of the main section of the house (see Figure 29). Drying rope cordage, tobacco and corn was also hung from the rafters. Supplies of wood 
were added under the bottom of sleeping benches, while the presence of other personal foodstuffs such as gourds, corn and squash were placed on the sleeping compartments' top shelf. Deer hide was readily represented for potential bedding. Following a discussion with Neal Ferris, we even added sections under the lower bunk in which small personal storage pits would have been potentially dug and then covered with smaller twigs and sticks.

Hearths were added, one for every two opposite bunks along the length of the longhouse (see Figure 29). Special attention was made to ensure that the fire logs themselves were represented as ember-like under a slow burn. This was critical as previous versions of the same environment we had reproduced had raging fires and substantial sparking, which in reality would have likely caused the longhouse to go up in flames. Ceramic bowls and pots were added around the hearths, along with animated cooking broths and replicates of wooden utensils, bowls and bark containers, all depicted from images acquired from our mood board research. We placed many of these items on woven mats surrounding the hearths. A long pole for opening and closing the smoke vents in the ceiling was vertically leaned up against a far bunk to denote the ability to do so.

Sixteenth century ceramic vessels that had been illustrated for use in Longhouse 2.x based on Lawson site collections were included (see Figure 29). These pots were then placed to the side of bunk compartments and on the top shelf of family bunks to suggest how they might have been stored when not in use. Although all of the items represented within this highly subjective environment are based on cultural historical assumptions, the ceramics represent an actual visual reality of the archaeological record-in-making within virtual space. The inclusion of all these items helped to ground the virtual with the reality, and create an immersive-ness of the archaeological materiality archaeologists interpret from excavated contexts and artifacts. 


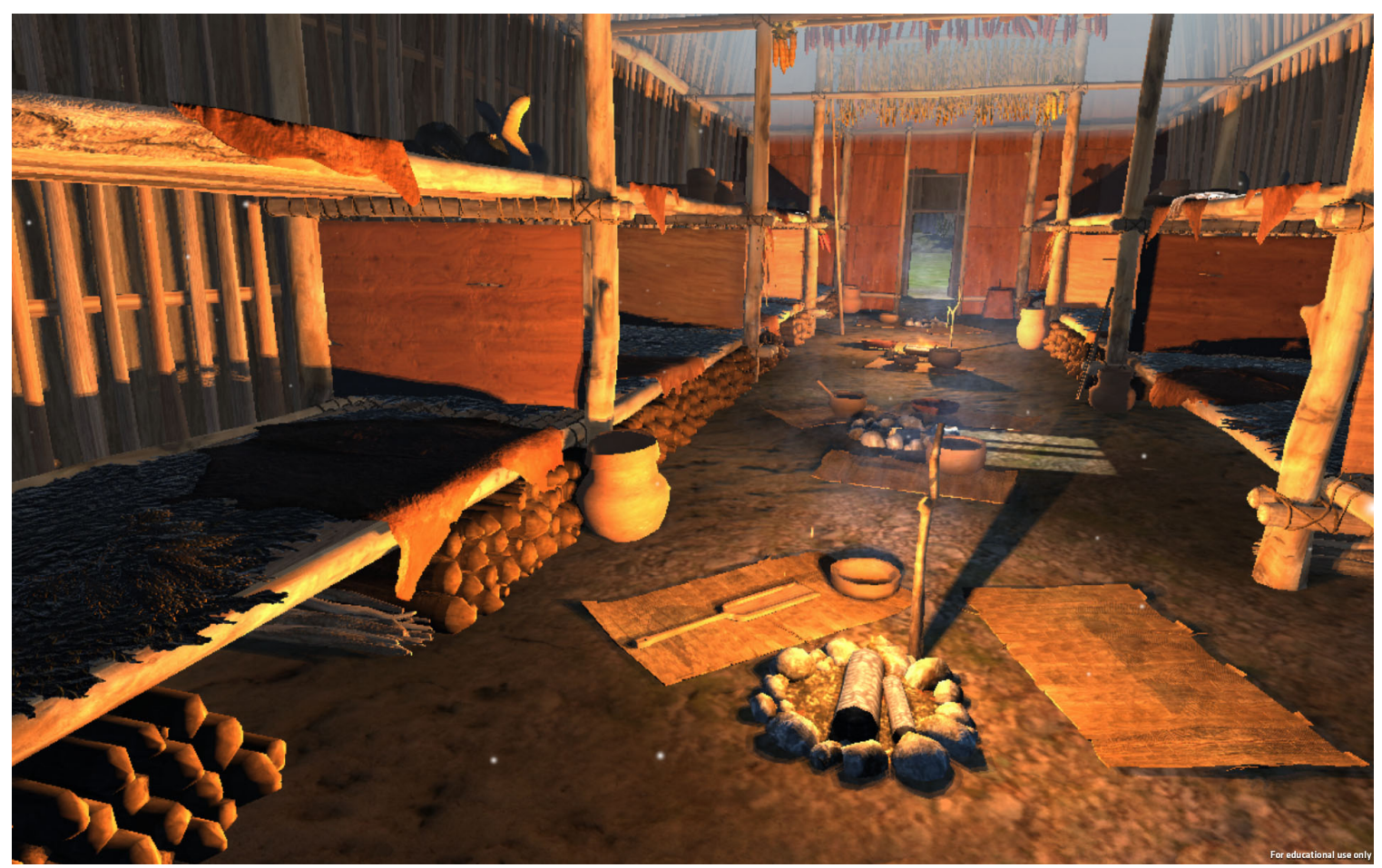

Figure 29 - (Re)Imagined interior of Longhouse 3.x, Carter and Barr (2016)

Dawson et al (2011) and Cox (2015) have each argued that the notion of presence within virtual space is enhanced by visual atmospheric conditions such as lighting, smoke, dust and dirt, and Dawson (personal communication 2016) has reportedly used interior sounds to heighten presence further. This notion of presence was built into Longhouse 3.x using several elements. Atmospheric lighting in particular came from several sources: the smoke hole vents in the ceiling, the doorways on either end of the longhouse, through the gaps in bark shingles, and specifically from the active hearths. Although representationally the glow from our virtual fires are likely a little too illuminating, the contrast between the interior oranges and exterior daylight blues help to cast interesting shadows throughout the space. For instance, if a hypothetical virtual longhouse occupant was to do fine craft work, they couldn't have done it inside the bunks for the lack of light. Smoke emanating from the fire hearths added to the dulling of light within the rafters.

Ron Williamson quickly pointed out that the smoke layer was substantially higher than what he and his colleagues experienced at Ska-Nah-Doht (Fecteau 1979). 
Notwithstanding various architectural, seasonal and fire use differences between that experiment in 1979 and our assumptions informing smoke height based on roof height in this visualization, our depiction of where smoke concentrated was a negotiated interactive element that we chose to represent due to real-time computational limitations. Ideally, I would have preferred to establish the start of the smoke layer around the top of the upper bunk line. We did add particles of floating dust to demonstrate a closed, heavily particleladen environment. Lastly, the dirt on the ground texture, within the bunks, creosote in the rafters and dirty handprints on the poles attempted to give the interior of the space a lived-in presence.

\subsubsection{A Note on the Lack of Representational Avatars within Longhouse $3 . x$}

From the onset, there was a conscious effort not to represent people in any form within the 3D space. Although there have been recent discussions about the lack of "peopling" within virtual heritage which in turn creates a sterile, hollow representation of the virtual reconstruction (see Champion 2015; Earl and Wheatley 2002; Gillings 2005; Watterson $2014,2015)$, representation of the "other" is an area of virtual archaeology generally, and of Canadian Indigenous participatory archaeology specifically, that requires discussion with communities before attempting. From Dawson et al (2011) an embodied experience for descendent stakeholders is not only empowering to the participant but beneficial to the archaeologist in unlocking unintended knowledge that further enriches the archaeological record. But depicting people raises a whole range of problematic considerations, and encompasses an entirely new set of decisions beyond those focused on for this build.

Likewise, digital reproduction of objects, landscapes and narratives do have agency both in the real and virtual worlds, and as such must be treated with equal consideration and respect (Brown and Nicholas 2012; Earl 2013; Forte 2014b; Huggett 2012a, 2015; Pauketat and Alt 2005; Richardson 2013; Robb 2010; Salmond 2012). The Māori of New Zealand believe that the essence of their sacred cultural objects, whether digitized or 
traditionally photographed, is transferred when a digital reproduction is made (see Salmond 2012). This transference does not diminish the agency of the original cultural artifact, but rather conveys that agency equally onto the new digital representation, and so requires the same considerations and respect as the original (Salmond 2012). Like the Māori, some Canadian First Nations people also view digital reproductions not as copies, but as extensions of the "crafted objects and landscapes of memory," which implicitly embodies agency (Brown and Nicholas 2012:310).

Appropriation and misuse of sacred objects and landscapes, and their digital counterparts, is but one example of how virtual environments and objects can be misused and lie in conflict with descendant cultural norms (Brown and Nicholas 2012). The recent example of Indigenous consultation and involvement in the production of the computer game Assassin's Creed III, exemplifies how the video game maker, Ubisoft, recognized not only the value but also the obligation to involve descendants within the virtual interactive process (Newman 2012). This community/descendent approach helped to envision a 3D virtual environment without unduly appropriating or misrepresenting the subject matter. A future framework in which to visually represent longhouse ancestors as avatars within virtual space would be to adopt a potentially similar relationship that Ubisoft has fostered, with descendent communities shaping the creative process alongside technical and subject matter experts.

\subsubsection{Longhouse 3.x Discussion}

Longhouse 3.x was not just an attempt to visualize a longhouse. It was my attempt to consume, digest and reflect on existing archaeological and historical knowledge, and then through virtual reality, discover knowledge gaps and how they are negotiated between what we know from the archaeological and historical records, and what "feels right" about longhouse construction and use. At times, the process of building within a 3D environment informed us how longhouse builders might have addressed some of construction and design problems we encountered. Further, there was a sensibility that we took and acted on to inform decisions in the absence of data to construct new knowledge. 
The creation and continuance of constructed digital meaning within a real-time interactive environment played a significant role in this knowledge construction process. At the initial level, data was interpreted and chosen purely on my sensibilities, and then those of my colleagues, funders, supervisors and artistic partners. As that data grew, new technological constraints overtook my need for detailed visual cultural historical representation, forcing us to pick and choose which data would survive and which would be deleted for the sake of real-time rendering speed and optimum output capabilities, in effect, decision moments as wayfaring points or course corrections along the lines of life (Ingold 2011). However, what effect does our constructed knowledge have with memory and loss when we delete the data to which we have given agency (Carter 2017)? Like the materiality of the longhouse itself, does the data disappear and become forgotten? The final output, in our case Longhouse 3.x, is a composite of all the data we contemplated, decided on, and once intended to visualize, represents a continual reworking of the virtual data until the moment when our mental image, archaeological sensibilities and technological platform can meet, and we can declare the moment of this project completed.

Like Sagard-Théodat (1632), Brebeuf (1634-1635) and Lafitau (1724), I mentally cribbed from Champlain's (1616) original narrative description in an effort to idealize what a longhouse should look like. In doing so, I reinforced Dennett's notion that our mental image remains static (1993), negating archaeological, temporal, regional, cultural or even material based variations in longhouse design and habitation. I attempted to reduce these complex and important symbols of Iroquoian life, by averaging, assuming and weighing practicalities as I understood them, in the unconscious attempt to template over 1000 years of architectural variability and craftsmanship into what has essentially been a universally accepted mode of longhouse visual understanding. However, it was through that making process and empowered by the flexibility of technology that was I able to start questioning the accepted archaeological notions of longhouse environments. 
Longhouse framing and visual style, as we have seen, can be highly contested. Kapches (1993) Wright (1995) and Snow (1997) all provide variant models, which are interpretive of the localized data they have collected but more importantly individualized to their own meaning-making. Yet I chose to mix elements of all three framing styles that suited my own sense of making sense, understanding of the data, my own priorities and consideration of how these elements would or would not visualize differently, and ultimately my own interpretations of the known archaeological notions of what a longhouse is materially. The idea of Snow's $60 \%$ wall height made sense as we tried to conform the Kapches model of exterior framing in 3D, knowing visually that when we built this variant, the exterior walls would immediately require additional support. Snow and Wright's notion of a separate roof didn't fly for us, as this would have required a more complicated and labour intensive design, both digitally and physically, thus the Kapches model of a continuous wall/roofing posts seemed more efficient in terms of material processing as well as construction.

The position of the bunks and whether they were separated cubicles caused no end to debates. Further, the bunk heights I chose to represent were directly influenced by Snow's (1997:83) interpretation of Lafitau's 1724 depiction of bunk height, despite the much earlier accounts from Champlain and others. I chose to represent a second wall of posts on the exterior of the longhouse to support bark coverings, as suggested by Snow, despite suggestions from archaeology and history that a single, staggered wall might be more commonly the design from at least Ontario. These choices reflected for me, visually, elements that appealed to my own assumptions or visually could look the same regardless of specific method used, and might also provoke responses from users working from slightly different mental cannons longhouse design.

I am also cognizant of Williamson's (2004) and Watts' (2009) assertions that ultimately it doesn't really matter what the variance architectural detail is, but how one communes with the space in terms of recognizing that longhouses were more than just poles, posts and bark. They were living, breathing entities that were more than their habitat functionality. 
Ultimately by (re)imagining a stylized, quasi-sixteenth century longhouse, my own notion of what I was doing in virtually constructing a longhouse shifted from accurately interpreting the archaeological record to creatively playing with contested elements and conceptions of what this materiality was in the past and across space. This was primarily made possible by my understanding that no matter what decision I made, with more time and effort, I could change any parameter within this 3D environment, or be persuaded to do so; the VA of this build allowing us the ability to depict a new longhouse variant at will. Archaeological norms and assumptions about this material object, domestic materiality of space, and experiential life beyond archaeological ways of knowing could all be explored, interrogated, and reasoned for or against by adjusting minor design features like bunk height or longhouse privacy.

In our progressive technological investigation of virtual longhouse construction, each stage represented a unique and novel approach to the representation of known and unknown longhouse archaeological knowledge in 3D virtual space. Longhouse 1.x allowed for a thorough understanding of how procedural animation could work in the service of visualizing raw archaeological data. It allowed for a merging and testing of variant archaeological notions, which ultimately informed the hybrid model we attempted to visualize in Longhouse 3.x. It was also a visual representation of Wylie's notion of "tacking" $(1993,2002)$, the ability to mix and intertwine the same archaeological data into newly constructed thought.

Longhouse 2.x demonstrated that non-archaeologists, using 3D technology, could engage with the archaeological record to visualize beyond that archaeological data. Although the mental image and meaning-making the students of this project had was limited to the archaeological information and data they were exposed to and consumed, they still could represent and animate 2D archaeological data in ways not experienced before, influencing how we would construct elements within Longhouse 3.x.

Longhouse 3.x was a culmination of both the archaeological known and unknown dimensions of longhouse construction. But more than that, it demonstrated visually the mental shifts, or wayfaring points, we as makers negotiated in struggling to complete the 
task of creating new meaning from the archaeologically unknown. That personal participatory engagement intertwined with the collaborative participation with the paradata of the process both informed and enhanced the construction of new knowledge. Further, the technology emboldened myself as creator with the authority to create alternative variants and ultimately narratives of the archaeological record. To offer up and challenge established norms, yet provide a visual archaeological language still consistent with idealized notions of ancient Iroquoian longhouses.

Beyond the intentional and unintentional micro and macro variations and shifts of known longhouse archaeological knowledge, something more powerful became revealed through this process of working virtually. Ingold (2011:17) speaks of making as the "the synergy of practitioner, tool and material," in which the skill of the maker, the tools being used and the materiality of the object being formed are all narratives that work with and against each other. As tensions between narratives are negotiated, these moments represent wayfaring points, course corrections and drifts in sensibilities. It is in these moments that new knowledge is created, tested and accepted. I believe that VA allows for "making" to extend the process to the "coupling of perception and action" (Ingold 2011:17); essentially recognizing the differences in repetition and acknowledging those differences as being integral to the overall construction of new knowledge - the drift inherent in tradition that gives rise to innovation. Thus, in those moments of drift (time constraints, divergent opinions, questioning my own sense of "right" through the very visualization I was crafting based on that sense of "right"), I was able to postulate or at least consider some of the same challenges archaeologists negotiated as they attempted to make meaning of the archaeological record, and explore new ways of knowing provided through a VA of making 2D archaeological data into 3D space.

The value of paradata and the participatory research that it enables was critical to ensuring drift was a part of the making process. The community of archaeological, historical and other participants greatly enriched this highly reflective and reiterative process, while at time second-guessed decisions we had already made. It is through transparently accepting the limitations in interpretation, technology and skill that helped me as a maker embrace the wayfaring drifts in my sensibilities. This participatory 
research and process of creation of knowledge clearly showed the value transparent and authentic dialogue has in building a stronger representative knowledge building environment, and the potential it has, down the line, for facilitating potential Indigenous voices in undertaking more robust VA undertakings of their material and physical past, beyond archaeological sensibilities.

Ultimately, as Ferris (2013), Watts (2009) and Williamson (2004) point out, longhouses aren't defined by their structure or visual style but by the pathways and lives that lived in and around them. Now that we've constructed a longhouse in 3D and ported those assets into a real-time gaming engine, how do we capture the essence of those pathways and how do they inform our construction of knowledge? In many ways, the construction of longhouse knowledge within VR was an effort to mimic Watts' (2009) notion of experiential embodiment within the archaeological longhouse environment. It was also a culminating effort in the attempt to virtually represent the archaeological data and the cultural historical perspectives on longhouse construction and use from a personal, VA lens. As a point of departure, Watts (2009:212) talks about his first longhouse excavation at the Grandview Site, just east of Toronto. In it he states:

I do not know anything more about the longhouses by looking at the plan and identifying the posts and features. But there is something to be said about having experienced the relationships between these things, on the ground, at the time of the excavations.

I have yet to fully excavate a single longhouse from the archaeological record, however like Watts and similarly with the labour and commitment that virtual archaeologist Grant Cox engaged in his (re)imagination of Çatalhöyük (Perry 2015), I feel just as emotionally connected reconstructing a longhouse in virtual reality as someone on an excavation site. The sound of the keyboard, the hum of the computer, the discussions with artistic and technical partners; the turning of book, article and reference pages as one builds knowledge "just-in-time" within the moment that thought transcends into visual data on the screen. This was a personal interpretation of the data, which I freely chose to remix to 
my vision and assumptions of what would be "right." Further research will explore if that vision helps to illuminate or confound the archaeological perspectives as envisioned by that community. 


\subsection{References}

Ahmed, Namir, Michael Carter, and Neal Ferris

2014 Sustainable Archaeology Through Progressive Assembly 3D Digitization. World Archaeology 46(1): 1-18.

Anderson, Jacob M

2009 The Lawson Site: An Early 16th Century Neutral Iroquoian Fortress. Museum of Ontario Archaeology Special Publication Number 2, London.

Bartram, John

1751 Observations on the Inhabitants, Climate, Soil, Rivers, Productions, Animals and Other Matters Worthy of Notice, Made by Mr. John Bartram, in His Travels from Pensilvania to Onondago, Oswego and the Lake Ontario, in Canada. J. Whiston and B. White, London. Electronic document, https://archive.org/details/cihm_11915, accessed June 14, 2017.

Beauchamp, William Martin

1905 Aboriginal use of wood in New York. New York State Museum, Bulletin 69, Archaeology 11. New York State Education Department, Albany.

Bekerman, André, and Gary A Warrick

1995 Origins of the People of the Longhouse: proceedings of the 21st Annual Symposium of the Ontario Archaeological Society Inc., held at Toronto, Ontario in October, 1994 (15). The Society.

Bentkowska-Kafel, Anna, Hugh Denard, and Drew Baker (editors)

2012 Paradata and Transparency in Virtual Heritage. Farnham, Ashgate.

Birch, Jennifer

2012 Coalescent Communities: Settlement Aggregation and Social Interaction in Iroquoian Ontario. American Antiquity 77(4): 646-670.

2015 Current Research on the Historical Development of Northern Iroquoian Societies. Journal of Archaeological Research 23(3): 263-323.

Birch, Jennifer, and Ronald F Williamson

2012 The Mantle Site: An Archaeological History of an Ancestral Wendat Community. AltaMira, Lanham.

2013 Organizational Complexity in Ancestral Wendat Communities. In From Prehistoric Villages to Cities: Settlement Aggregation and Community Transformation, edited by Jennifer Birch, pp. 153-178. Routledge, New York.

2015 Navigating Ancestral Landscapes in the Northern Iroquoian World. Journal of Anthropological Archaeology 39: 139-150.

Boyden, Joseph

2013 The Orenda. Hamish Hamilton, Toronto.

Bursey, Jeffrey

2001 Storage Behavior in the Northeast: A Review of the Evidence. North American Archaeologist 22(3): 179-199.

Carter, Michael

2017 Getting to the point: Making, Wayfaring, Loss and Memory as Meaning-Making in Virtual Archaeology. Virtual Archaeology Review, 8(16). Electronic document, http://dx.doi.org/10.4995/var.2017.6056, accessed May 31, 2017.

Carter, Michael, and Craig Barr 
2016 Lh3.x: A Virtual Late Iroquoian Longhouse (Re)Imagination. Electronic

Document. Sustainable Archaeology and the Museum of Ontario Archaeology, London, Canada.

Catmull, Ed, and Amy Wallace

2014 Creativity, Inc: Overcoming the Unseen Forces That Stand in the Way of True Inspiration. Random House.

Chadwick, Edward Marion

1897 The People of the Longhouse. The Church of England Publishing Co. Limited, Toronto.

Champion, Erik

2015 Defining Cultural Agents for Virtual Heritage Environments. Presence:

Teleoperators and Virtual Environments 24(3): 179-186.

Champlain, Samuel

1907 Voyages of Samuel de Champlain 1604-1618. Edited by W. L. Grant. Charles Scribner's Sons, New York.

Chapdelaine, Claude

1993 The Sedentarization of the Prehistoric Iroquoians: A Slow or Rapid

Transformation? Journal of Anthropological Archaeology 12(2): 173-209.

Cooper, Martin S, and David A Robertson

1993 The Norton Site (AfHh-86): The Rediscovery of a Late Iroquoian Village in London, Ontario. Ontario Archaeology 56: 33-62.

Cox, Grant

2015 Çatalhöyük-The Shrine of the Hunters (FVI). ArtasMedia. Electronic document, https://artasmedia.com/2015/03/10/catalhoyuk-the-shrine-of-the-hunters-f-v-i/,

Crawford, $\mathrm{M}$ accessed May 5, 2016.

2015 The World Beyond Your Head: On Becoming an Individual in an Age of Distraction. Penguin Canada Books Inc., Toronto.

Creese, John L.

2012a Post Molds and Preconceptions: New Observations about Iroquoian Longhouse Architecture. Northeast Anthropology(77): 47-69.

2012b The Domestication of Personhood: a View from the Northern Iroquoian Longhouse. Cambridge Archaeological Journal 22(3): 365-386.

2013 Rethinking Early Village Development in Southern Ontario: Toward a History of Place-making. Canadian Journal of Archaeology 37(2): 185-218.

Dawson, P., R. Levy, and N. Lyons

2011 'Breaking the fourth wall': 3D virtual worlds as tools for knowledge repatriation in archaeology. Journal of Social Archaeology 11(3): 387-402.

Denard, Hugh

2012 A New Introduction to the London Charter. In Paradata and Transparency in Virtual Heritage, edited by A. Bentkowska-Kafel, D. Baker \& H. Denard, pp. 57-71. Ashgate, Farnham.

Dennett, Daniel C

1993 Consciousness Explained. Penguin, United Kingdom.

DeRuiter, John, and Zhuyun Wu

2016 Six Points Property Master Plan: A Vision for the Future Home of the Wyandot and Anderdon Nation. Electronic document, https://deepblue.lib.umich.edu/handle/2027.42/117630, accessed April 30, 2016. 
Dodd, Christine F

1984 Ontario Iroquois Tradition Longhouses. Archaeological Survey of Canada Paper, No 124, pp. 181-437. Mercury Series, National Museum of Man, Ottawa.

Dodd, C.F., Poulton, D., Lennox, P. A., Smith, D.G., and Warrick, G.

1990 The Middle Ontario Iroquoian stage. In The Archaeology of Southern Ontario to A.D. 1650, edited by C. J. Ellis, and N. Ferris, pp. 321-359. Occasional Publications of the London Chapter, Ontario Archaeological Society, No. 5, London.

Earl, Graeme P., and David Wheatley

2002 Virtual Reconstruction and the Interpretative Process: A Case study from Avebury. In Contemporary Themes in Archaeological Computing, edited by David Wheatley, Graeme P. Earl, and S. Poppy, pp. 5-15. Oxbow Books, Oxford, UK.

Engelbrecht, William E

2003 Iroquoia: The Development of a Native World. Syracuse University Press, Syracuse.

Fecteau, R D

1979 The Longhouse Experiment. KEWA: Newsletter London Chapter, Ontario Archaeological Society 79(2): 1-3.

Ferris, Neal

1999 Telling Tales: Interpretive Trends in Southern Ontario Late Woodland Archaeology. Ontario Archaeology 68: 1-62.

2013 Place, Space, and Dwelling in the Late Woodland. In Before Ontario: The Archaeology of a Province, edited by Marit K Munson and Susan M Jamieson, pp. 99-111. McGill-Queen's Press, Montreal and Kingston.

2014 Being Iroquoian, Being Iroquois: A Thousand-year Heritage of Becoming. In Rethinking Colonial Pasts Through Archaeology, edited by Neal Ferris, Rodney Harrison, and Michael Wilcox, pp. 371-396. Oxford University Press, Oxford.

Ferris, Neal, and Malcom Horne

1988 The Straw that Broke the Dowel's Back: A recent advance in Archaeological Field Technology. Arch-Notes 2(March/April): 36-42.

Finlayson, William David

1985 The 1975 and 1978 Rescue Excavations at the Draper Site: Introduction and Settlement Patterns. Archaeological Survey of Canada Paper, No 130. Mercury Series, National Museum of Man, Ottawa.

Fitzgerald, William R

1979 The Hood site: Longhouse burials in an Historic Neutral village. Ontario Archaeology 32: 43-60.

1982 Lest the Beaver Run Loose: the Early 17th Century Christianson Site and Trends in Historic Neutral Archaeology. Archaeological Survey of Canada Paper, No 111. Mercury Series, National Museum of Man, Ottawa.

1984 An Introduction to the Raymond Reid (HiHa-4) Hamlet. Arch Notes 84: 3-24. Fogt, Lisa, and Peter G Ramsden

1996 From Timepiece to Time Machine: Scale and Complexity in Iroquoian Archaeology. In Debating Complexity: Proceedings of the 26th Annual Conference of the Archaeological Association of the University of Calgary, Archaeological Association of the University of Calgary, Calgary, pp. 39-45. 
Fox, William A

1982 The Calvert Village: Glen Meyer Community Patterns. KEWA, Newsletter of the Ontario Archaeological Society, London Chapter 82(7): 5-9.

1990 The Middle Woodland to Late Woodland transition. The Middle Ontario Iroquoian stage. In The Archaeology of Southern Ontario to A.D. 1650, edited by C. J. Ellis, and N. Ferris, pp. 171-188. Occasional Publications of the London Chapter, Ontario Archaeological Society, No. 5, London.

Frankland, Tom, and Graeme Earl

2011 Authority and Authenticity in Future Archaeological Visualisation. In Proceedings of Ads-Vis2011: Making Visible the Invisible: Art, Design and Science in Data Visualisation: 62-68.

Gea, Juan M Carrillo, Ambrosio Toval, José L Fernández Alemán, Joaquín Nicolás, and Mariano Flores

2013 The London Charter and The Seville Principles as Sources of Requirements for EArchaeology Systems Development Purposes. Virtual Archaeology Review 4(9): 205-211.

Gerard-Little, Peregrine A., Michael B. Rogers, and Kurt a. Jordan

2012 Understanding the Built Environment at the Seneca Iroquois White Springs Site using Large-Scale, Multi-Instrument Archaeogeophysical Surveys. Journal of Archaeological Science 39(7): 2042-2048.

Gillings, Mark

2005 The Real, the Virtually Real, and the Hyperreal: The Role of VR in Archaeology. In Envisioning the Past: Archaeology and the Image, edited by S., Smiles and S. Moser, pp. 223-239. Blackwell, Oxford.

Hagen, Ulf

2011 Designing for Player Experience: How Professional Game Developers Communicate Design Visions. Journal of Gaming \& Virtual Worlds 3(3): 259275.

Hatch, James W, and Gregory H Bondar

2001 Late Woodland Palisaded Villages from Ontario to the Carolinas. In Archaeology of the Appalachian Highlands, edited by L P Sullivan and S C Prezzano, pp. 149167. University of Tennessee Press, Knoxville.

Hayden, Brian

1977 Corporate Groups and the Late Ontario Longhouse. Ontario Archaeology(28): 316.

Heidenreich, Conrad E

1972 The Huron: A Brief Ethnography. Department of Geography Discussion Paper no. 6. York University, Toronto.

Huggett, J.

2004 Archaeology and the New Technological Fetishism. Archeologia e Calcolatori 15: 81-92.

Hulton, Paul Hope, David Beers Quinn, William Curtis Sturtevant, C E Raven, Raleigh Ashlin Skelton, Louis Booker Wright, and Edward Croft-Murray

1964 The American Drawings of John White, 1577-1590: With Drawings of European and Oriental Subjects. British Museum.

Ingold, Tim 
2011 Being Alive: Essays on Movement, Knowledge and Description. Routledge, New York.

2013 Making: Anthropology, Archaeology, Art and Architecture. Routledge, New York. Jameson Jr, John H

2004 The Reconstructed Past: Reconstructions in the Public Interpretation of Archaeology and History. Altamira, Walnut Creek.

Jamieson, J Bruce

1990 The Archaeology of the St. Lawrence Iroquoians. In The Archaeology of Southern Ontario to A.D. 1650, edited by C. J. Ellis, and N. Ferris, pp. 385-404.

Occasional Publications of the London Chapter, Ontario Archaeological Society, No. 5, London.

Jeffrey, Stuart

2015 Challenging Heritage Visualisation: Beauty, Aura and Democratisation. Open Archaeology 1: 144-152.

Jefferys, Charles W., and T.W. McLean

1942 The Picture Gallery of Canadian History Volume 1. Ryerson Press, Toronto. Jones, Eric E., and James W. Wood

2012 Using Event-History Analysis to examine the causes of Semi-Sedentism among Shifting Cultivators: A Case Study of the Haudenosaunee, AD 1500-1700. Journal of Archaeological Science 39(8): 2593-2603.

Jordan, Kurt

2013 Incorporation and Colonization: Postcolumbian Iroquois Satellite Communities and Processes of Indigenous Autonomy. American Anthropologist 115(1): 29-43.

Jury, Wilfrid

1946 Southwold Prehistoric Earthworks. Canadian Historical Review 27(4): 391-393.

Jury, Wilfrid, and M Elsie

19541954 Sainte Marie Among the Hurons. Oxford University Press, Toronto.

Kapches, Mima

1990 The Spatial Dynamics of Ontario Iroquoian Longhouses. American Antiquity: 4967.

1993 The Identification of an Iroquoian Unit of Measurement: Architectural and Social/Cultural Implications for the Longhouse. Archaeology of Eastern North America: $137-162$.

2007 The Iroquoian longhouse: Architectural and Cultural Identity. In Archaeology of the Iroquois: Selected Reading and Research Sources edited by J.E. Kerber, pp. 174-188. Syracuse University Press, Syracuse.

Kapches, Mima, Dean Axelson, and Charlie Garrad

2008 Reminisces of Ivan Kocsis. Arch Notes 13(5): 16-17.

Keener, Craig S.

1999 An Ethnohistorical Analysis of Iroquois Assault Tactics Used against Fortified Settlements of the Northeast in the Seventeenth Century. Ethnohistory 46(4): 777-807.

Kenyon, Walter

1968 The Miller Site. Art and Archaeology Division, Occasional Paper (14). Royal Ontario Museum, Toronto.

Knight, Dean H 
1987 Settlement Patterns at The Ball Site: A 17th Century Huron Village. Archaeology of Eastern North America 15: 177-188.

Lafitau, Father Joseph Francois

1977 Customs of the American Indians Compared with the Customs of Primitive Times Vol 2. Edited by W. N. Fenton and E. L. Moore. Publications of The Champlain Society 49, Toronto.

Latta, Martha A

1985 A 17th Century Attigneenongnahac Village: Settlement Patterns at the Auger Site (BdGw-3). Ontario Archaeology 44: 41-54.

Lennox, Paul

1981 The Hamilton Site: A Late Historic Neutral Town. Archaeological Survey of Canada Paper, No 103. Mercury Series, National Museum of Man, Ottawa.

1984 The Hood Site: A Historic Neutral Town of 1640 AD; The Bogle I and Bogle II Sites: Historic Neutral Hamlets of the Northern Tier. Archaeological Survey of Canada Paper 121, pp. 1-183. National Museum of Canada, Ottawa.

Lennox, Paul A, and William R Fitzgerald

1990 The culture history and archaeology of the Neutral Iroquoians. In The Archaeology of Southern Ontario to A.D. 1650, edited by C. J. Ellis, and N. Ferris, pp. 405-456. Occasional Publications of the London Chapter, Ontario Archaeological Society, No. 5, London.

Lennox, Paul A, and J E Molto

1995 The Archaeology and Physical Anthropology of the EC Row Site: A Springwells Phase Settlement, Essex County, Ontario. Ontario Archaeology 60: 0-5.

MacDonald, Robert

1987 Notes on Longhouse Storage Cubicles. Arch-Notes 87(3): 5-11.

1986 The Coleman site (AiHd-7): A late prehistoric Iroquoian village in the Waterloo region. Unpublished MA thesis, Department of Anthropology, Trent University, Peterborough.

1988 Ontario Iroquoian sweat lodges. Ontario Archaeology 48: 17-26.

MacDonald, Robert I, and Ronald F Williamson

2001 Sweat Lodges And Solidarity: The Archaeology of the Hubbert Site. Ontario Archaeology 71: 29-78.

MacNeish, Richard S

1952 A Possible Early Site in the Thunder Bay District, Ontario. Bulletin No. 126, pp. 23-47. National Museum of Canada, Ottawa.

Merrett, Deborah C

2003 Maxillary Sinusitis among the Moatfield people. In Bones of the Ancestors: The archaeology and osteobiography of the Moatfield Site, edited by Susan Pfeiffer and R. F Williamson, pp. 242-261. Canadian Museum of Civilization, Gatineau, Quebec.

Motoprof1441

2012 The Building of the Iroquois Long House 2005. YouTube. Electronic publication, https://youtu.be/amvv4P4DzJU, accessed May 25, 2016.

Noble, William C

1968 Iroquois Archaeology and the Development Of Iroquois Social Organization (1000-1650 AD): A Study in Culture Change Based on Archaeology, Ethnohistory 
And Ethnology. Unpublished Ph.D. dissertation, Department of Archaeology, University of Calgary.

1975 Corn and the Development of Village Life in Southern Ontario. Ontario Archaeology 25: 37-46.

Norcliffe, G B, and C E Heidenreich

1974 The Preferred Orientation of Iroquoian Longhouses in Ontario. Ontario Archaeology 23(3): 3-30.

O'Gorman, Jodie A

2010 Exploring the Longhouse and Community in Tribal Society. American Antiquity 75(3): 571-597.

Pauketat, Timothy R., and Susan M. Alt

2005 Agency in a postmold? Physicality and the archaeology of culture-making. Journal of Archaeological Method and Theory 12(3): 213-237.

Pearce, Robert

1984 Mapping Middleport: A Case Study in Societal Archaeology. Unpublished Ph.D. dissertation, Department of Anthropology, McGill University, Montreal.

Perry, Sara

2015 Crafting Knowledge with (Digital) Visual Media in Archaeology. In Material Evidence. Learning From Archaeological Practice. edited by R. Chapman and A. Wylie, pp. 189-210. Routledge, New York and London.

Pletinckx, Daniel, and Premio Tartessos

2011 Virtual Archaeology as an Integrated Preservation Method. Virtual Archaeology Review 2: 33-37.

Prince, Stephen

2011 Digital Visual Effects in Cinema: The Seduction of Reality. Rutgers University Press.

Ramsden, Peter G

1988 Palisade Extension, Village Expansion and Immigration in Trent Valley Huron Villages. Canadian Journal of Archaeology 12: 177-183.

1990a The Hurons: Archaeology and Culture History. In The Archaeology of Southern Ontario to A.D. 1650, edited by C. J. Ellis, and N. Ferris, pp. 361-384.

Occasional Publications of the London Chapter, Ontario Archaeological Society, No. 5, London.

1990b Death in Winter: Changing Symbolic Patterns in Southern Ontario Prehistory. Anthropologica: $167-181$.

Reilly, P.

1985 Computers in Field Archaeology: Agents of Change? Current Issues in Archaeological Computing 271, pp. 63-78.

1989 Data Visualization in Archaeology. IBM Systems Journal 28(4): 569-579.

Reilly, Paul, and Julian Richards

1987 New perspectives on Sutton Hoo: the potential of 3-D graphics. In Computer and Quantitative Methods in Archaeology, edited by C.L.N. Ruggles and S.P.Q.

Rahtz, pp. 173-185. BAR International Series, Oxford, UK.

Reilly, Paul, Stephen Todd, and Andy Walter

2016 Rediscovering and Modernising the Digital Old Minster of Winchester. Digital Applications in Archaeology and Cultural Heritage 3(2): 33-41.

Ritchie, William A 
1956 Prehistoric Settlement Patterns in Northeastern North America. Prehistoric Patterns of the New World: 72-84.

Robertson, David A

2004 The Hutchinson Site: A Place to Prepare for the Final Journey. Ontario Archaeology 77(78): 95-120.

Sagard, G.

1939 The Long Journey to the Country of the Hurons, edited by George M. Wrong and translated by H.H. Langton. Champlain Society, Toronto.

Snow, Dean R

1997 The Architecture of Iroquois Longhouses. Northeast Anthropology 53: 61-84.

Steckley, John

1987 An Ethnolinguistic look at the Huron Longhouse. Ontario Archaeology 47: 1932.

Stock, Jay, and Katherine Willmore

2003 Body Size, Bone Mass and Biomechanical Analyses of the Adult Post-Cranial Remains. In Bones of the Ancestors: The Archaeology and Osteobiography of the Moatfield Ossuary, edited by S. Pfeiffer and R.F. Williamson, pp. 309-332. Canadian Museum of Civilization, Quebec.

Thwaites, Reuben Gold

1896-1901 The Jesuit Relations and Allied Documents: Travels and Explorations of the Jesuit Missionaries in New France, 1610-1791. 73 vols. Burrows Brothers, Cleveland.

Timmins, Peter Andrew

1997 The Calvert Site: An Interpretive Framework for the Early Iroquoian Village. Archaeological Survey of Canada Paper, No 156. Mercury Series, National Museum of Man, Ottawa.

Trigger, B G

1963 Settlement as an Aspect of Iroquoian Adaptation at the Time of Contact. American Anthropologist 65(1): 86-101.

1978a Early Iroquoian Contacts with Europeans. Handbook of North American Indians 15: 344-356.

1978b Iroquoian Matriliny. Pennsylvania Archaeologist 48(1-2): 55-65.

1987 Children Of Aataentsic: A History of the Huron People to 1660 (Vol 195). McGill-Queen's Press, Montreal.

Varley, Colin, and Aubrey Cannon

1994 Historical Inconsistencies: Huron Longhouse Length, Hearth Number and Time. Ontario Archaeology 58: 85-101.

Wagner, Norman Ernest, Lawrence E Toombs, and Eduard R Riegert

1973 The Moyer Site: A Prehistoric Village in Waterloo County. Wilfrid Laurier University, Waterloo.

Warrick, Gary

1984 Reconstructing Ontario Iroquoian Village Organization. Archaeological Survey of Canada Paper, No 124. Mercury Series, National Museum of Man, Ottawa.

1988 Estimating Ontario Iroquoian village duration. Man in the Northeast 36: 21-60.

1996 Evolution of the Iroquoian Longhouse. In People Who Lived in Big Houses: Archaeological Perspectives on Large Domestic Structures, edited by G. Coupland and E.B. Banning, pp. 11-26. Prehistory Press Madison, Wis. 
2000 The Precontact Iroquoian Occupation of Southern Ontario. Journal of World Prehistory 14(4): 415-466.

Watterson, Alice

2014 Engaging with the Visual: Re-Thinking Interpretive Archaeological Visualisation. Ph.D. dissertation, Digital Design Studio, The Glasgow School of Art, Glasgow, UK.

2015 Beyond Digital Dwelling: Re-thinking Interpretive Visualisation in Archaeology. Open Archaeology 1(1): 119-130.

Watts, Christopher M.

2009 Coming to our Senses: Toward a Unified Perception of the Iroquoian Longhouse. In Archaeology and the Politics of Vision in a Post-Modern Context, edited by $\mathrm{J}$. Thomas and V. Jorge, pp. 209-224. Cambridge Scholars Publishing, Newcastle upon Tyne, UK.

Williams-Shuker, Kimberly, and Kathleen M S Allen

1998 Longhouse Remains at the Carman Site: Paper Presented at the Cayuga Museum Northeast Archaeological Symposium, October 23-24, 1998. Electronic document, http://www.pitt.edu/ klwst25/cayuga.html, accessed Nov 10, 2016.

Williamson, Ronald F

1998 The Myers Road Site: Archaeology of the Early to Middle Iroquoian Transition. Occasional Publication of the Ontario Archaeological Society, London Chapter, No 7, London.

2004 Replication or Interpretation of the Iroquoian Longhouse. In The Reconstructed Past: Reconstructions in the Public Interpretation of Archaeology and History, edited by John H. Jameson, Jr., pp. 147-166. Altamira Press, New York.

Wintemberg, William J

1900 Indian Village Sites in the Counties of Oxford and Waterloo. Annual Archaeological Report of the Ontario Provincial Museum appended to the Report of the Minister of Education: 37-40.

Wintemberg, William John

1939 Lawson Prehistoric Village Site, Middlesex County, Ontario. Archaeological Survey of Canada Paper, No 94. National Museum of Man, Ottawa.

Wright, J.V.

1966 The Ontario Iroquois Tradition. Bulletin 210. National Museums of Canada, Ottawa.

1974 The Nodwell Site. Archaeological Survey of Canada Paper, No 22. Mercury Series, National Museum of Man, Ottawa.

1995 Three Dimensional Reconstructions of Iroquoian Longhouses: A Comment. Archaeology of Eastern North America 23(Fall): 9-21.

Wylie, Alison

1989 Archaeological Cables And Tacking: The Implications of Practice for Bernsteins' 'Options Beyond Objectivism and Relativism'. Philosophy of the Social Sciences 19(1): 1-18.

1993 A Proliferation of New Archeaologies: "Beyond Objectivism and Relativism." In Archaeological Theory: Who Sets the Agenda?, edited by N. Yoffee and A. Sherratt, pp. 20-26. Cambridge University Press, Cambridge. 
2002 Archaeological Cables and Tacking: Beyond Objectivism and Relativism. In Thinking from Things: Essays in the Philosophy of Archaeology, University of California Press, Berkeley, pp. 161-167. University of California Press, Berkeley and Los Angeles. 


\section{Chapter 4}

\section{The Making of Virtual Meaning in Archaeology}

Virtual Archaeology (VA) has become a powerful tool in the presentation and interpretation of archaeological landscapes and artifacts as a means of knowledge building, meaning-making and heritage accessibility (e.g., Dallas 2009; Earl 2013; Forte 2014a, 2014b; Huggett 2013; Perry 2015). It has become a "mediating tool" allowing researchers to experiment with data and to tease out the tensions that arise from limited and multiple conceptions of the past - a multi-sourced and even multi-vocal environment created to "stimulate interpretation," explore alternate tellings of the past, and advance new research directions in archaeology (Dallas 2009; Earl 2013; Huggett 2013). Nonetheless, while the practice/study/craft of archaeological visualization has managed to present itself and its output as representative of archaeological meaning-making and authoritative presentations of the past, this has occurred without the practice really establishing the basis for that authority (see Earl 2013; Perry 2015). Thus, the challenges VA represents within the broader field of archaeological theory and method are going beyond the perceived notion of the technology being a novel means to illustrate archaeological data, to demonstrate how it can be a transformative vehicle to engage with material pasts in a way that allows for multiple visions of that heritage to be represented, tested and valued.

\subsection{Rationale and Objectives}

To explore these notions, I created an interactive, phenomenological, virtual 3D representation of a prototypical $16^{\text {th }}$ century Iroquoian longhouse from southern Ontario (see Chapter 3). The developmental base for the 3D longhouse asset creation was gleaned specifically site-based archaeological research from Snow (1997), Wright (1974, 1995), Kapches (1993), Dodd (1984), Dodd et al (1990) and Birch \& Williamson (2013); with Creese (2012a, 2012b, 2013), Cooper and Robertson (1993), Heidenreich (1972), and 
Williams-Shuker (1998) providing supporting data. Historical perspectives on structural construction methodologies were specifically drawn from Bartram (1751) Kapches (1990, 1993), Sagard (1939), Snow (1997), Thwaites (1896), Wright $(1974,1995)$ and Williamson (2004). Further quantitative and qualitative data on longhouse construction, orientation and setting came from Norcliffe and Heidenreich (1974), Woodworth (2001), Birch and Williamson (2013), Hatch and Bondar (2001), Jones (2010, 2014), Jones and Wood (2012), Jordan (2013), Keener (1999) Noble (1975) and (Finlayson 1985). Fecteau (1979) and Varley and Cannon (1994) provided useful data with regards to smoke and fire generation as well as hearth placement, Steckley (1987) on the oral traditions of longhouse elements, and Beauchamp (1905), Bursey (2001), Creese (2012a, 2013) MacDonald (1987) and Watts (2009) on the use of storage and storage vestibules. Beauchamp (1905), Engelbrecht (2003), Chadwick (1897) Morgan (1881) and Wright (1995) provided working knowledge on the material and materiality of longhouse construction materials. Cultural historical perspectives on Iroquoian political, social, economic and cultural structure were derived from Birch and Williamson (2015), Chapdelaine (1993), Dodd, Poulton, Lennox, Smith and Warrick (1990), Jamieson (1990) Lennox and Fitzgerald (1990), Ramsden (1990) Trigger (1963, 1978a, 1978b, 1987), and Warrick $(1984,1988,1996,2000)$.

The process of designing, developing and implementing virtual archaeological data is a relatively new approach to archaeological research and broader knowledge dissemination within Ontario, although physical world public interpretive reconstructions and case studies of experimental archaeology have been undertaken over the last several decades (see Fecteau 1979; Williamson 2004; Wright 1974). As such, my current research reflected on my own and the longhouse VR participants' experiences of interpreting the data from a visual knowledge building perspective, while addressing and developing protocols to address agency, authority, authenticity, transparency and traditional archaeological research of the pre contact Late Woodland within VR. By virtualizing an ancient Iroquoian longhouse and by disseminating this project by means of social media and direct participant engagement to the archaeological community through interactive, immersive and experiential virtual means, I hoped to gain additional insight into how 
archaeologists conceptualize and "understand" their datasets for these unique residential structures, since they are the archaeological experts of these excavated settlement patterns. What I was particularly interested in exploring is how these archaeological understandings, as built environments and material spaces foreign to archaeologists' own lived experiences but culturally and materially understood within the daily lives of ancient peoples (Ferris 2013) arise in interpretive models of this record.

To test these assumptions, 23 participants were engaged to interact within the virtual longhouse environment. These participants were primarily archaeologists working in Ontario or New York familiar with the archaeological record being visualized. In addition, a small number of animation professionals and Indigenous and heritage scholars were also interviewed in this virtual build, though the primary focus of the study remained on the way archaeologists make meaning of their datasets.

In order to test the utility of this model, and the potential of VA to engage with and make meaning from archaeological studies, and reveal the operational logics archaeologists use to inform their interpretive understandings of ancient material spaces, participants were exposed to immersive and non-immersive versions of the virtual archaeological landscape. Longhouse 2.x had suggested these two options as effective means of allowing people to experience immersive environments, first through an interactive computer screen experience with a joystick or keyboard controlling motion, and second through use of immersive goggles. Less than a year after the Longhouse 2.x build was completed, Sustainable Archaeology obtained an Oculus Rift, SDK1. Longhouse 2.x was ported into that platform, allowing people to experience the walk into the Lawson site and longhouse immersively, with the goggles providing a $360^{\circ}$ enclosure within the build. The effectiveness of these goggles at creating a VR version of a sixteenth century longhouse was influential in considering just how VR experiences of Longhouse 3.x would be delivered to participants, especially considering that, by the summer of 2016, commercial versions of these goggles, with much higher resolutions, were available to be used.

My immediate goals in having participants experience the virtual longhouses were to: i) document overt participant preconceptions for both their anticipated VA experience and 
longhouse environments; ii) observe how participants engage with and choose to interact with the virtual longhouse; iii) observe and discuss with participants how they perceived the virtual environment in terms of authenticity, authority and agency; iv) document their reaction to the representation and placement of digital assets, landscapes and built structures, as well as v) record any alternative meaning-making they themselves expressed or advanced after interacting with this virtual environment.

\subsection{Interview Participants}

To test whether or not archaeologists would glean any form of knowledge construction within virtual space I conducted three separate qualitative interview sessions in three different venues over a course of 30 days in the months of July and August of 2016. There were approximately twenty-two in person and one written interview(s) conducted. As seen in Table 1, the interviewees represented a mix of eighteen archaeologists, two animation industry specialists and two heritage/museum specialists. In addition, a twentythird person, a VR specialist who is the spouse of the written interviewee, also participated remotely but did not provide full feedback. 


\section{Table 1 Virtual Longhouse Interviewees}

\begin{tabular}{|c|c|c|c|c|c|c|c|c|}
\hline \multicolumn{9}{|c|}{ Virtual Longhouse Interviewees (July - August 2016) } \\
\hline Interviewee & $\begin{array}{c}\text { Interviewee } \\
\text { Identification } \\
\text { Letter }\end{array}$ & $\begin{array}{c}\text { Self- } \\
\text { Identified as } \\
\text { Female }\end{array}$ & $\begin{array}{c}\text { Self- } \\
\text { Identified as } \\
\text { Male }\end{array}$ & $\begin{array}{c}\text { *Age } \\
\text { (Younger) }\end{array}$ & $\begin{array}{c}\text { *Age } \\
\text { (Older) }\end{array}$ & Archaeologist & \begin{tabular}{|c|} 
Had previous \\
Longhouse \\
Excavation \\
Experience \\
\end{tabular} & $\begin{array}{c}\text { Was } \\
\text { Academically } \\
\text { Referenced }\end{array}$ \\
\hline 1 & $\overline{\mathbf{A}}$ & $\checkmark$ & & $\checkmark$ & & $\checkmark$ & $\checkmark$ & \\
\hline 2 & B & & $\checkmark$ & & $\checkmark$ & $\checkmark$ & $\checkmark$ & $\checkmark$ \\
\hline 3 & $\mathbf{C}$ & & $\checkmark$ & & $\checkmark$ & & & \\
\hline 4 & D & & $\checkmark$ & & $\checkmark$ & & & \\
\hline 5 & $\mathbf{E}$ & $\checkmark$ & & & $\checkmark$ & $\sqrt{ }$ & $\sqrt{ }$ & $\checkmark$ \\
\hline 6 & $\mathbf{F}$ & $\checkmark$ & & $\sqrt{ }$ & & $\sqrt{ }$ & & \\
\hline 7 & $\mathbf{G}$ & $\checkmark$ & & $\checkmark$ & & $\checkmark$ & & \\
\hline 8 & $\mathbf{H}$ & & $\checkmark$ & $\checkmark$ & & $\checkmark$ & & \\
\hline 9 & $\mathbf{I}$ & $\checkmark$ & & & $\checkmark$ & $\checkmark$ & $\checkmark$ & \\
\hline 10 & J1 & & $\checkmark$ & & $\checkmark$ & $\checkmark$ & $\checkmark$ & \\
\hline 11 & J2 & & $\checkmark$ & $\checkmark$ & & & & \\
\hline 12 & J3 & $\checkmark$ & & $\sqrt{ }$ & & & & \\
\hline 13 & $\mathbf{K}$ & $\checkmark$ & & $\checkmark$ & & $\checkmark$ & & \\
\hline 14 & $\mathbf{L}$ & $\checkmark$ & & $\sqrt{ }$ & & $\checkmark$ & & \\
\hline 15 & M & & $\checkmark$ & & $\checkmark$ & $\checkmark$ & $\checkmark$ & $\checkmark$ \\
\hline 16 & $\mathbf{N}$ & $\checkmark$ & & $\checkmark$ & & $\checkmark$ & $\sqrt{ }$ & \\
\hline 17 & $\mathbf{O}$ & & $\checkmark$ & & $\checkmark$ & $\checkmark$ & $\checkmark$ & \\
\hline 18 & $\mathbf{P}$ & & $\checkmark$ & $\checkmark$ & & $\checkmark$ & $\checkmark$ & \\
\hline 19 & $\mathbf{Q}$ & & $\checkmark$ & $\checkmark$ & & $\checkmark$ & $\checkmark$ & \\
\hline 20 & $\mathbf{R}$ & $\checkmark$ & & $\checkmark$ & & $\checkmark$ & & \\
\hline 21 & $\mathbf{S}$ & & $\checkmark$ & $\checkmark$ & & & & \\
\hline 22 & $\mathbf{T}$ & $\checkmark$ & & & $\checkmark$ & $\checkmark$ & $\checkmark$ & $\checkmark$ \\
\hline 23 & $\mathbf{U}$ & & $\checkmark$ & & $\checkmark$ & $\checkmark$ & $\checkmark$ & \\
\hline Total & & 111 & 1212 & 13 & 10 & 18 & 12 & 4 \\
\hline Percentage & & $48 \%$ & $52 \%$ & 57\% & $43 \%$ & $78 \%$ & $52 \%$ & $17 \%$ \\
\hline
\end{tabular}

Of the twenty-three interviewees, $48 \%$ identified as female and $52 \%$ identified as male. Although the age of each individual was not specifically asked, impressionistically by years of experience there was a broad range of people in the mix, extending from young professionals early in their career, to participants who have retired or who are at retirement age.

In the pool of participants, ten people identified as being archaeologists specializing in Iroquoian or Iroquois archaeology. Two participants were Indigenous descendants who were also scholars with knowledge of longhouse traditions and use, and some with extensive familiarity with the archaeological record from Ontario. Four participants had direct experience in the use of computer-based archaeology such as GIS mapping and Lidar. Two participants were 30-year veterans within the animation and visual effects industry and had extensive experience in the design, creation and production of $3 \mathrm{D}$ assets. One participant had both experience excavating southwestern Ontario Iroquoian 
sites and in the production of VR for heritage use. All of the interviewees at ASI Heritage (ASI) were employees of the company.

\subsection{Interview Locations}

Interviews where scheduled based on geographic location, participant, and suitable space availability. Due to the portable nature of the equipment used, there was great flexibility in providing the VR experience in almost any venue. All participants travelled to one of the three locations on their own accord and/or were already available as some of the interviews were conducted at their place of employment.

The computer equipment used facilitated delivering the VR longhouse on a computer screen, or delivered by means of immersive goggles. In the latter case, we used the VR platform of the HTC Vive, rather than a commercial version of the Oculus Rift, in part because the Vive is designed to allow users to walk around rather than stay seated, guided by sensors setup up around an open space that tracked the user's movement and kept them in the equivalent virtual space. This mobility proved critical in allowing users to explore the longhouse space. It also had the effect of minimizing motion sickness, which was more commonly experienced "moving" about virtually from a seated position.

Each venue had to have a substantial amount of available floor space in order for the interviewees to physically engage within the digital world. Below I review the physical and environmental characteristics of each venue as this experience placed the interviewee within a fully immersive digital environment, but they were still subject to the physical conditions of the environment in which they moved. Heat, light, sound, other people and objects within the room all played a part in the subject's interpretation of the digital environment and as such provided some interesting feedback with regards to presence, contextually, temporally and archaeologically. 


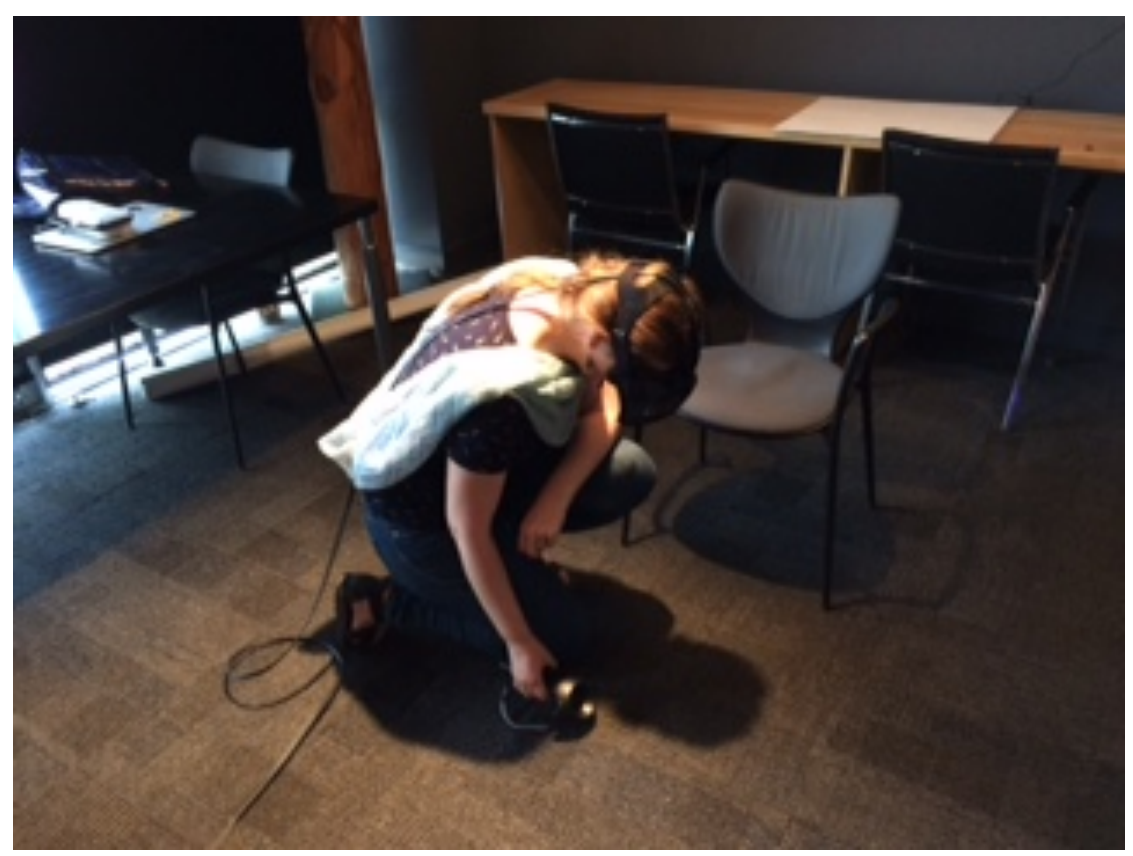

Figure 30 - Interview venue and Interviewee (ASI). Reproduced with consent.

The first venue was conducted at the ASI head office in downtown Toronto (see Figure 30). The room chosen was a small 27.9 square meters (estimated) boardroom on the second floor of the company office with floor to ceiling windows facing east. The ceiling was estimated to be roughly 3.66 meters high. Due to the east facing windows and the late July date, the room was considerably hot which resulted in the air-conditioning turning on and off frequently even with the shades (with a $40 \%$ transparency) pulled down. The lighting was a mixture of diffused light coming from the east facing windows, ceiling lights adjusted to be mid-ranged and stronger pot lighting emanating from the hallway and kitchen area on the opposite side of the remaining diffused glass wall. The room had movable chairs and a boardroom table that was pushed aside to provide the required minimal $1.54 \mathrm{~m} \times 1.22 \mathrm{~m}$ physical activity space to explore virtual space. Along either end of the room were ledges about $1.22 \mathrm{~m}$ off the ground I used to mount one of the Vive's sensor towers and the monitor and computer on the opposite side. 


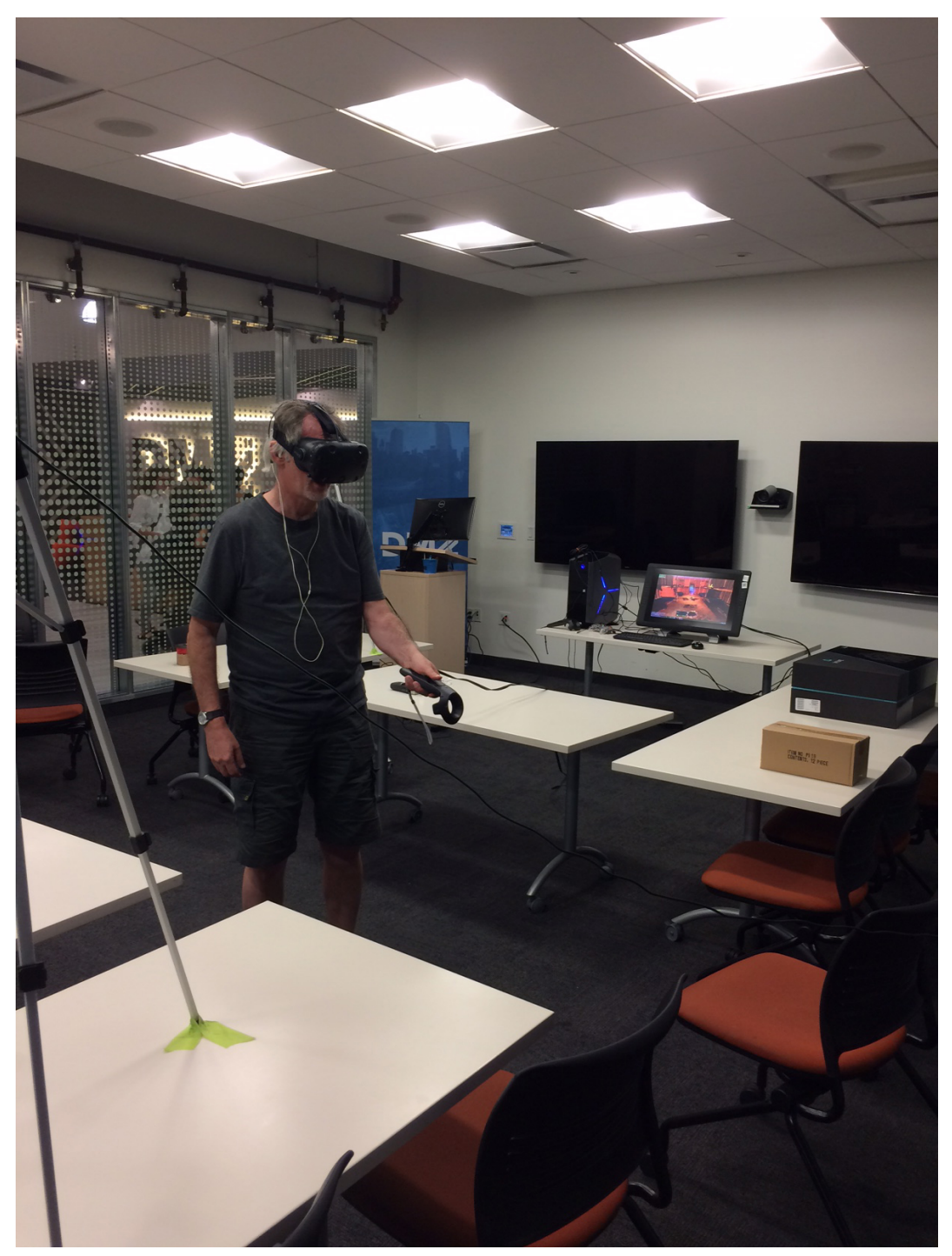

Figure 31 - Interview venue and Interviewee (Ryerson). Reproduced with consent.

The second venue was conducted at the Digital Media Zone (DMZ), an incubator facility at Ryerson University where my offices are located (see Figure 31). The room itself is approximately 55.7 square meters with movable chairs and desks. The ceiling was roughly 4.27 - 4.9 meters high. This venue was used in early August, again during an abnormally long heat wave, which caused the air conditioner to emit a low constant droning sound. The space is an inner room environment located right at the main entrance to the DMZ with floor to ceiling glass windows on two sides. Based on the experience at ASI, I arranged the tables to roughly mimic the physical placement of the longhouse 
bunks within virtual space so that when participants were experiencing the virtual environment physically, they could actually feel a boundary in physical space. Strong florescent lighting lit the entire room. I used the available tables to place both sensor towers at the 3.7 meter level and to hold the monitor and computer. Due to the placement of this particular room, non-participants could view the sessions from outside of the room and there was a constant noise of people going about their business. Included within this experience was a pesky fly that distracted participants during the formal interview but added an unforeseen element of phenomenology when they were experiencing the virtual reality session.

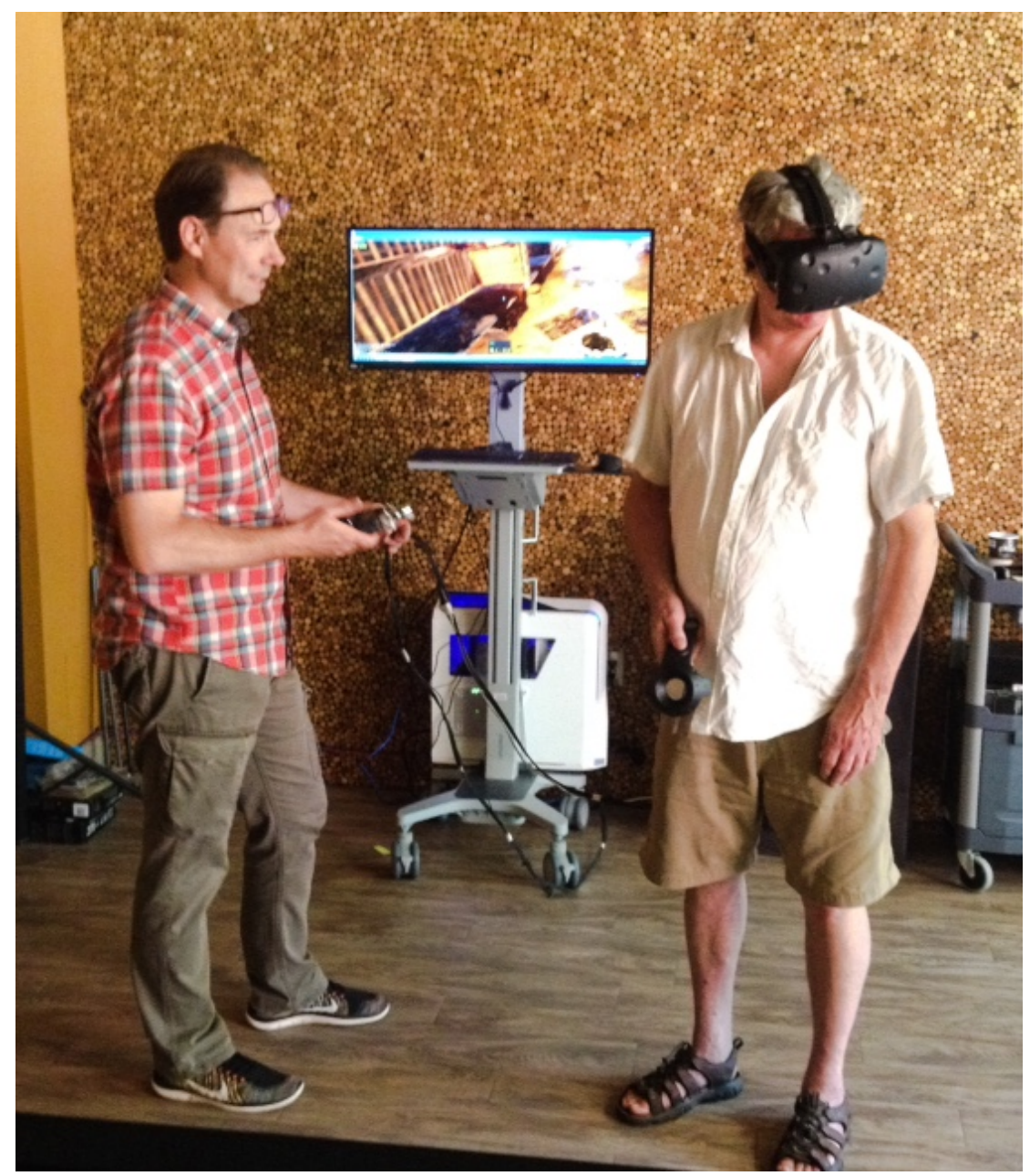

Figure 32 - Interview venue with Interviewee \& Author (SA). Reproduced with consent. 
The last venue was conducted in the Collaborative room at Sustainable Archaeology: Western next to the Museum of Ontario Archaeology (see Figure 32). This room was roughly 74 square meters and acts both as a traditional boardroom and virtual reality experience environment. Of the three venues, this was the only one I did not have to personally setup equipment, with the physical space already calibrated, monitors and computers on purpose built stands in place, and the sensor towers already situated to create an approximate 5 metre $\mathrm{x} 5$ metre space to explore. There is a south facing glass wall that opens up entirely into a wooded vista, however for this session we kept the doors closed. Being mid-August, this interview was also conducted during the heat wave we were experiencing during the time, so the temperature fluctuated between hot due to the sun and then cold when the air-conditioning automatically turned on. The room was only lit with the natural light coming from the floor to ceiling windows however the room was quite dark due to the painted colours and a special wood-like wall feature. Once again a fly seemed to provide amusement and distraction during the interviews.

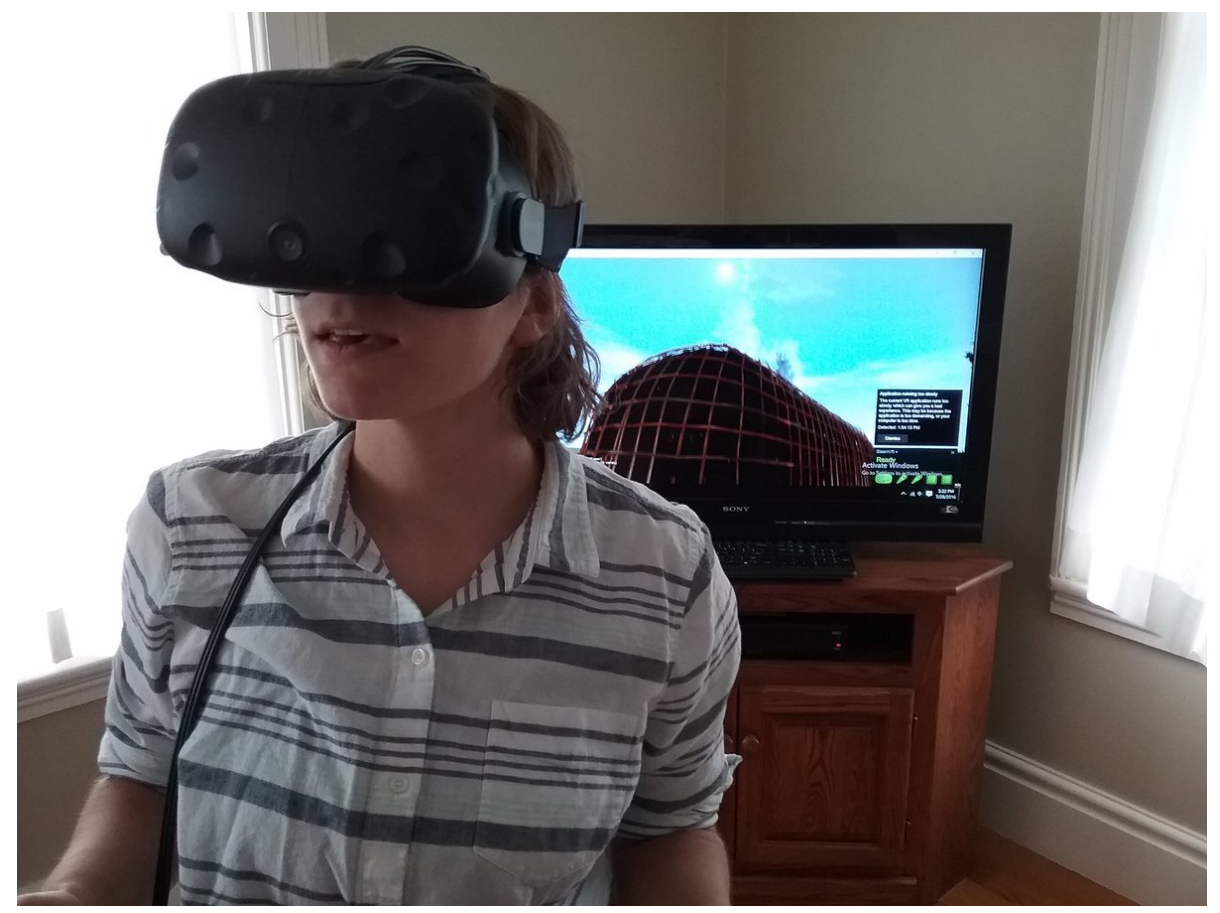

Figure 33 - Off-site Interviewee in personal home (Paul Walker 2016). Reproduced with consent. 
Upon request from one of the ASI employees who was unable to attend the in-person interviews, I provided by Internet a download of the Longhouse 3.x Unity executable game. The employee's spouse had their own HTC Vive and specific hardware to run the virtual experience. The space used was already a pre-configured spot within the living room of their house (see Figure 33). The software was downloaded and successfully installed within minutes.

\subsection{Virtual Reality Hardware \& Software}

Although we had originally built Longhouse 3.x for the Oculus Rift DK2 system using an Alienware 17 Gaming laptop (Intel ${ }^{\circledR}$ Core ${ }^{\mathrm{TM}}$ i7-3630QM processor with an Nvidia Geforce GTX 765M graphics card and 64 DDR4 memory), due to frame rate ${ }^{12}$ issues it was decided that we would conduct all interviews with the new HTC Vive head-mounted system. Frame rate greatly affects the way the eyes view the virtual space being projected into the goggle system. The lower the rate, the higher a strobing effect happens and thus the more people can potentially have physical side effects causing motion sickness. The HTC Vive has a higher frame rate and thus was less likely to cause motion sickness. As a side note, I was greatly affected by motion sickness using the OR-DK2 and had spent less than 5 minutes in pre and postproduction of Longhouse 3.x. However using the new HTC Vive, I was able to spend up to 30 minutes within the environment without experiencing any side effects.

Contrary to popular myth of the ease in which computer animation or assets generated by a computer can be easily changed, they still need to be designed for the eventual delivery platform they were designed for. Thus Longhouse 3.x was designed and built for an Oculus and not an HTC Vive environment therefore a complete conversion of assets and anything built post-Maya within Unity for Oculus had to be stripped out and either rebuilt or converted to work within the HTC Vive. For instance, the interior lighting had

\footnotetext{
${ }^{12}$ Frame rate is the speed in which images are projected in real-time to a screen or viewer.
} 
changed from a photorealistic natural colour, to an almost orange glow, and texture maps to the trained eye began to glitch due to the way mapping was calculated within the HTC Vive environment. As such, the quality of some assets after conversion was less than initially intended. Oculus vs HTC Vive

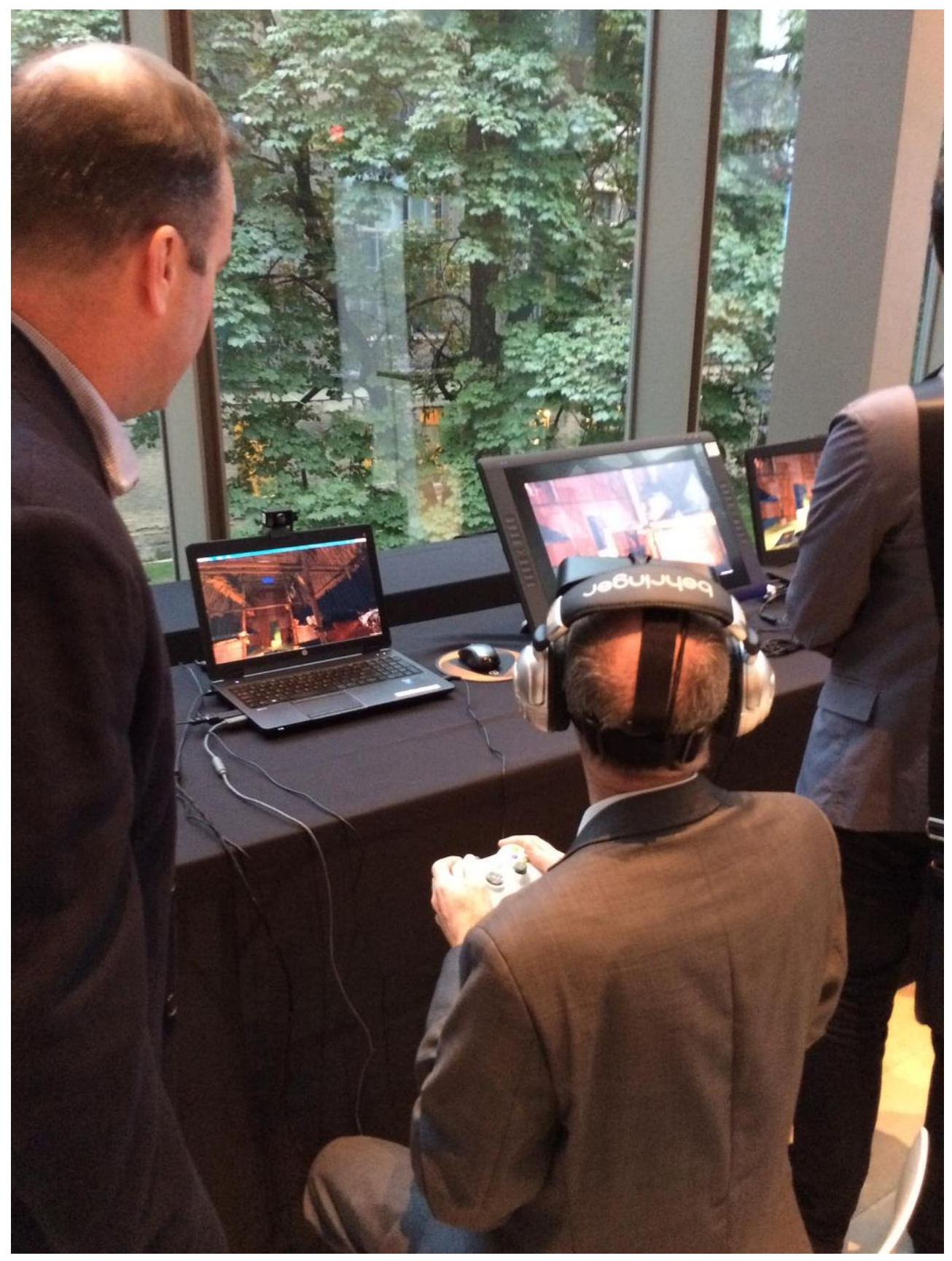

Figure 34 - Initial Oculus Rift testing (Toronto Heritage Event 2015). Reproduced with consent. 
The Oculus system typically requires a high performance gaming graphics card as well as a substantial amount of active ram to deliver a real-time immersive experience. For our test version of the longhouse, the Oculus Rift Development Kit 2 (OR-DK2 or DK2) was used. The Oculus is a headset tethered to a computer that enables the projection of stereoscopic $3 \mathrm{D}$ images directly into a viewing lens close to the retina. A motion sensor in the form of a camera sits on top of the optional computer monitor to track head movements within physical space. With proper calibration and orientation and with the headset on, a participant can look in $360^{\circ}$ in any direction within the virtual space. To move forward, backwards, jump, crouch, kneel or crawl an Xbox 360 hand controller from an Xbox gaming console is used. The participant can stand or sit, move their head to look back, up or down and use the controller for their physical body movements within virtual space (see Figure 34).

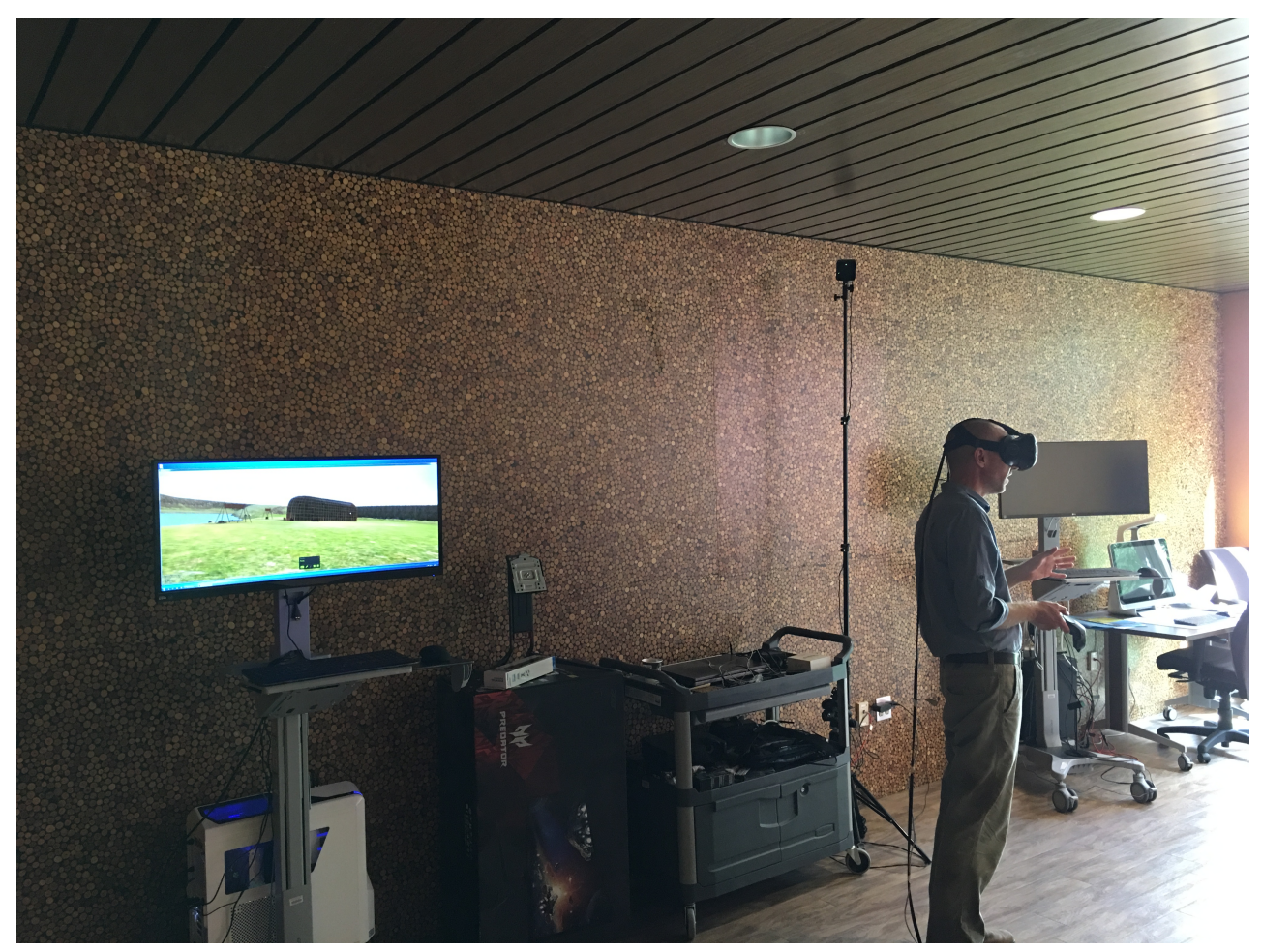

Figure 35 - Interview venue and Interviewee (SA/MOA). Reproduced with permission. 
The HTC Vive operates in a similar fashion as the OR-DK2. It is a head mounted unit, which was also tethered to an extremely powerful processor (Intel ${ }^{\circledR}$ Core ${ }^{\mathrm{TM}} \mathrm{i} 76700 \mathrm{~K}$ CPU), graphics card (NVIDIA GeForce GTX 1080) and ram (64GB DDR4 memory) within a single Alienware Aurora 5 desktop computer. Unlike the OR-DK2, the HTC Vive uses a combination of physical space and digital space to enable virtual presence within a 3D landscape; i.e., the ability to walk around in that space (see Figure 35). The HTC Vive uses two sensor towers that are diagonally positioned no more than 5 meters across from each other. The sensors must be higher than 2.4 meters and be angled at a $120^{\circ}$ downwards towards the center of a diagonal space between them. A virtual bounding box that can vary in size up to about $10 \times 10$ meters is traced out within physical space, which then represents the area a participant may physically move in both virtual and physical space. When a participant comes to the edges of their physical world, a holodeck ${ }^{13}$ like grid warning is displayed in virtual space indicating to the user that they have reached the limits of aligned virtual and physical space. With the combination of the head unit and the sensors, the participants can physically walk, jump, sit, crouch, kneel as well as turn their bodies and heads $360^{\circ}$ in a fully immersive digital space. If a user would like to move beyond the virtual bounding area, they must use a programmed function called a "teleport" which allows users to point to an area beyond their bounding box and click to jump there, thus moving the virtual space in which one can physically walk to another sector within the $3 \mathrm{D}$ environment. This jump function is done through the dual controllers that act as the user's hands within virtual space. The ability to pick up objects or effect change is done through the hand controllers but they must be programmed to do so, and were not programmed to facilitate this function within the longhouse environment for the interviews.

\footnotetext{
${ }^{13}$ Holodeck is a term Gene Roddenbury developed to describe a virtual environment in which one could physically interact for the TV series Star Trek in 1973. It is based on Gene Dolgoff's work on holographic images (see http://www.startrek.com/article/meet-the-man-behind-the-holodeck-part-1).
} 


\subsubsection{Immersive vs Non-Immersive Assets}

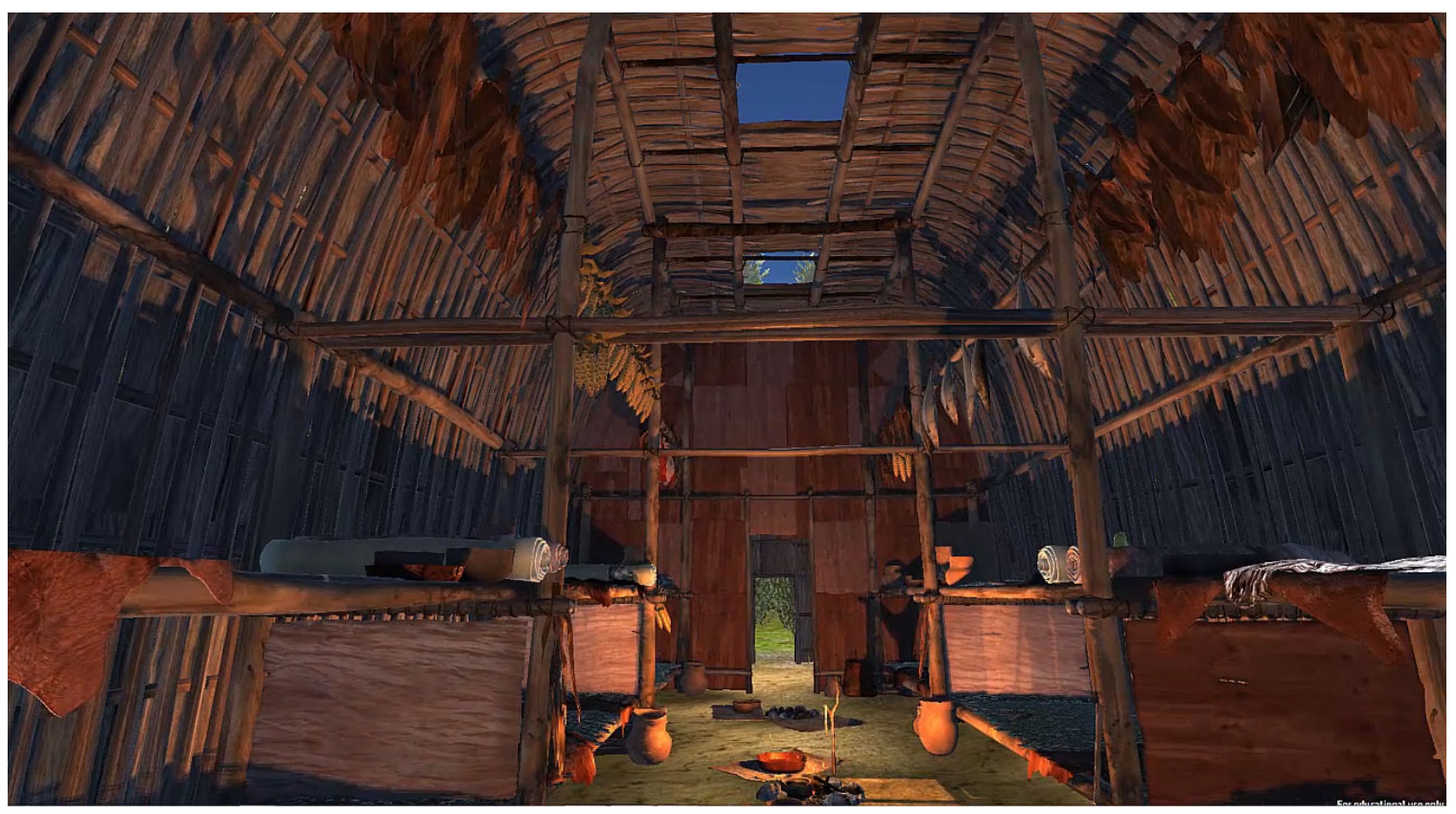

Figure 36 - Longhouse 3.x Maya rendered test (Carter 2016).

The 3D environment is built entirely within a gaming engine. However the game executable $^{14}$ and digital assets within the environment must be prepared according to the intended delivery method. The virtual longhouse was initially built in Autodesk Maya with a photorealistic style. This style is highly data intensive and thus when moving the assets into a gaming engine, certain efficiencies had to be made to ensure the 3D assets could work in real-time. Basically, the visual quality in the modeling, texture maps and lighting were diminished, as the system had to work harder for the user to move at realtime speeds within the 3D environment. In our first executable version of the longhouse we developed a desktop version, which from a visual quality perspective, was a stage below photorealistic (see Figure 36). For the OR-DK2, we were again pushing the boundaries of the amount of data that can be displayed in real-time, thus the quality was

\footnotetext{
${ }^{14}$ A game executable is the compiled and compressed software application of the game itself, allowing it to be played independently from the software that created it.
} 
diminished to accommodate the hardware and software limitations of the platform. Thus two versions of Longhouse 3.x were created; one for the desktop at a higher quality, and one for the OR-DK2 with less quality and detail.

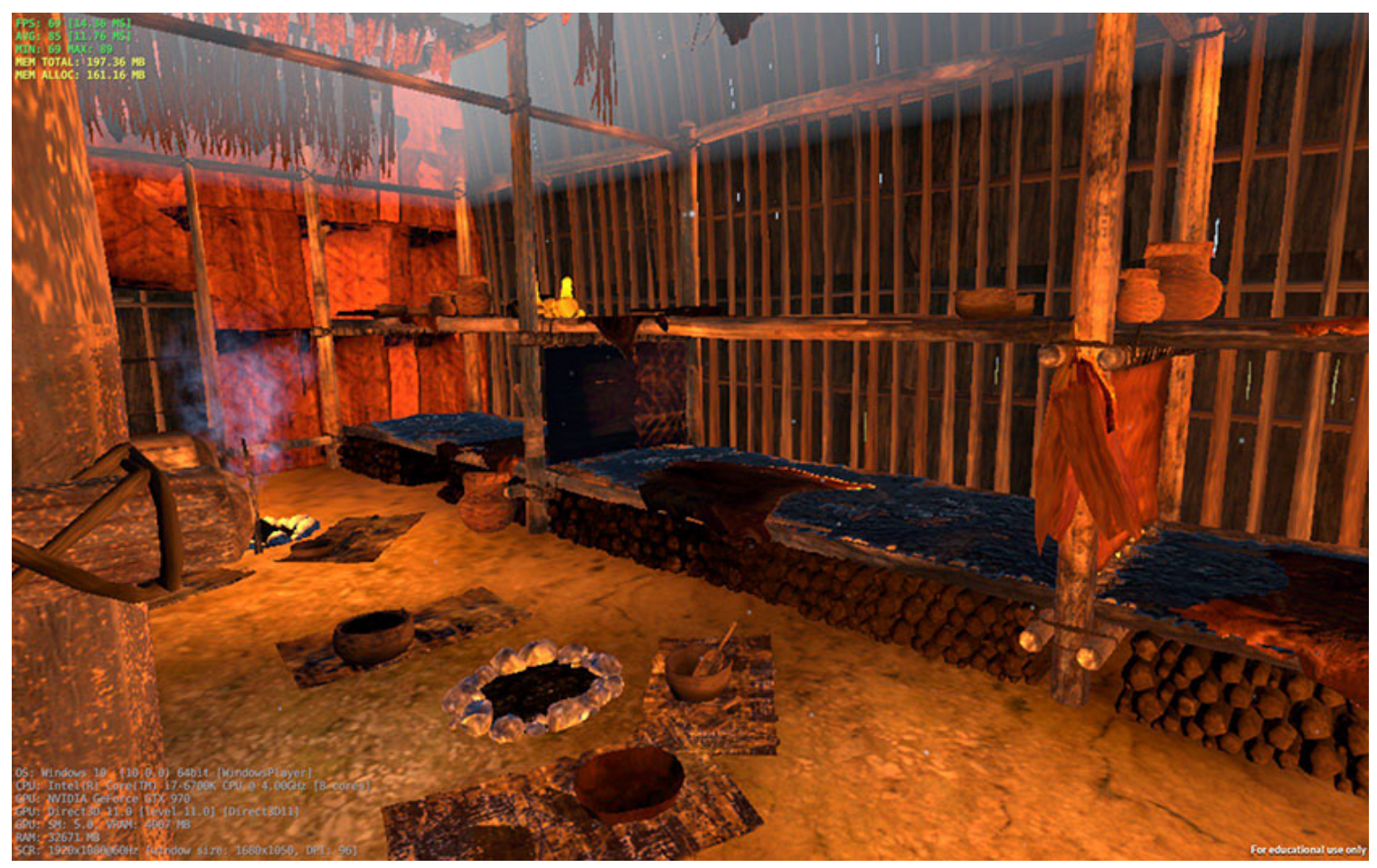

Figure 37 - HTC Vive Immersive rendered image (Carter 2016).

As discussed, a decision was made to convert the OR-DK2 executable into the new HTC Vive delivery format. This created some irregularities with regards to texture maps and polygon densities within the new HTC Vive game environment (see Figure 37). The HTC Vive allowed an immersive real-time interactive user engagement, but would lack some of the highly detailed assets and backgrounds the non-immersive desktop version possessed. I decided that interviewees would be asked to experience both, with the immersive first and the non-immersive right after to gauge their experiences, opinions and potential knowledge construction observations. 


\subsubsection{Interview Process}

I allotted interviewees one to one-and-a-half hour(s) to be interviewed. There was a threestaged process in which the first half consisted of a series of questions in a typical interview like setting prior to users interacting with the immersive environment to frame the participant's knowledge of VA and VR. I also asked at this stage for participants to describe their "mental image/map" of a typical Iroquoian longhouse in as much detail as possible.

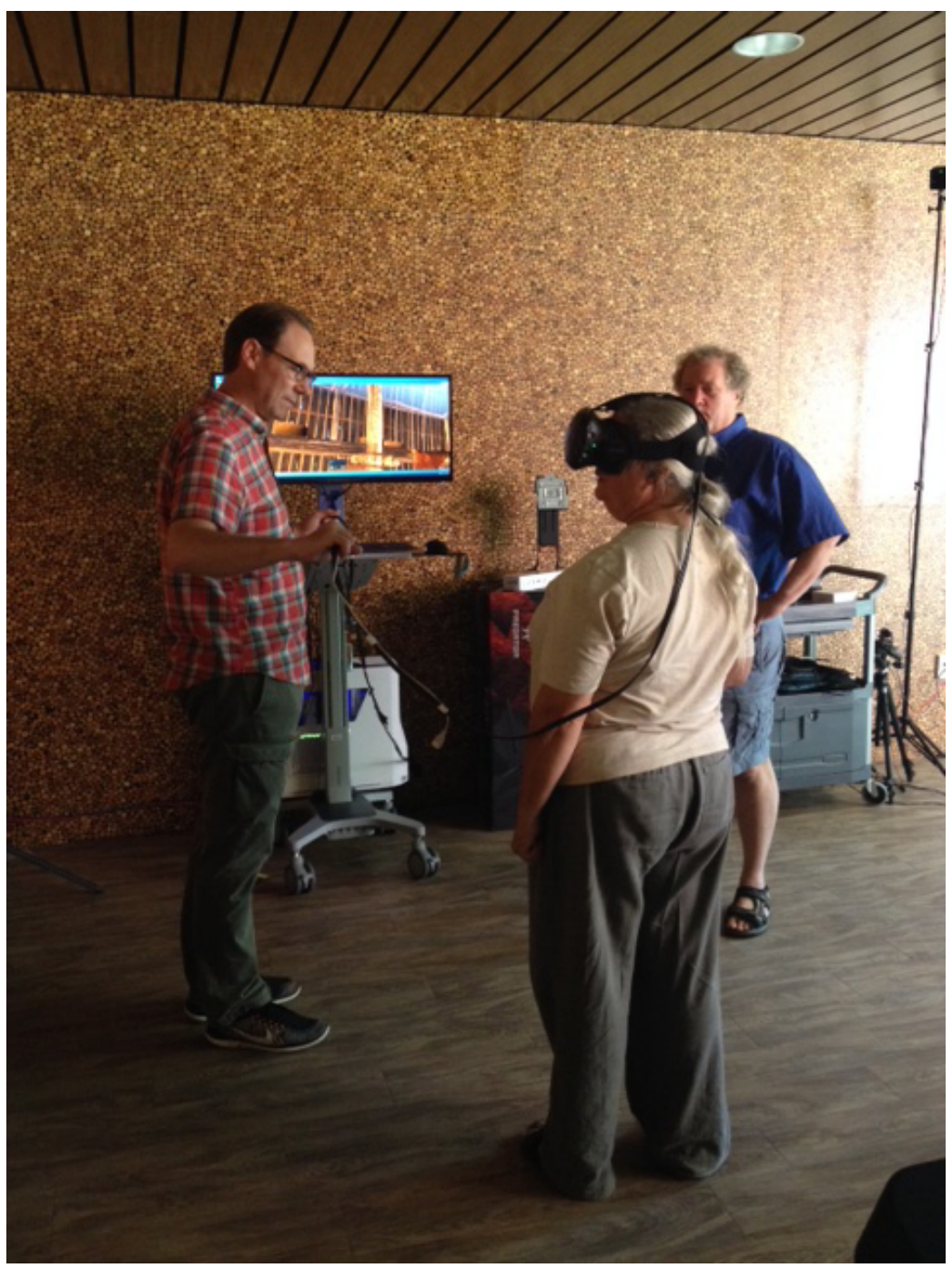

Figure 38 - HTCVive immersive setup at Sustainable Archaeology. Reproduced with permission. 
The second stage consisted of the interviewee donning the HTC Vive gear and then experiencing the prebuilt Longhouse 3.x in an immersive physical/digital environment (see Figure 38). The final stage consisted mostly of questions to determine the extent participants did or did not learn new information with regards to longhouse construction and use. Interviewees were allowed to spend as much or as little time as they felt comfortable at each stage. Most interviews lasted 45 minutes in the immersive HTC Vive session, with the exception of two Iroquoian specialists who spent 90 and 60 minutes respectively interrogating what they were experiencing and asking substantial questions. While participating within the immersive experience, I encouraged participants to freely comment, ask questions or inquire about what they were experiencing. I took notes on their body motion, how they reacted to both physical and virtual space and with permission, took pictures of them wearing the HTC Vive and interacting within the borders between physical and virtual space.

As a large computer monitor was used in conjunction with the head mounted HTC Vive unit, I could see what the participants were doing, where they were looking and if needed, guide them to areas they might want to explore. In one instance, I had a lively discussion with one participant who used their hand held HTC Vive wand, which is also represented as a floating $3 \mathrm{D}$ object in virtual space, to point to key areas of discussion in virtual space and to raise questions on the approaches chosen to visualize the longhouse in $3 \mathrm{D}$. 


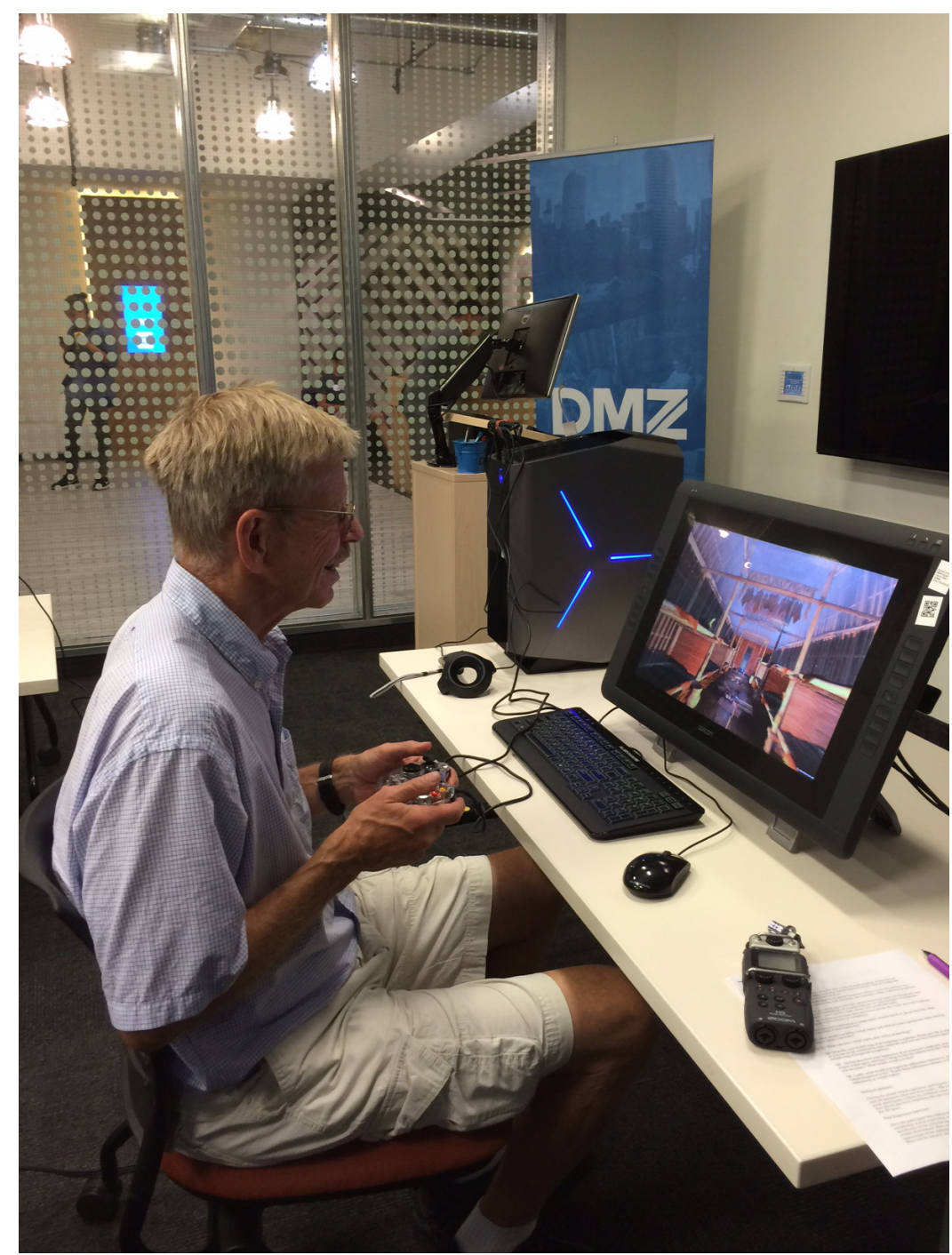

Figure 39 - Desktop non-immersive setup at the DMZ. Reproduced with permission.

Once the immersive HTC Vive experience was concluded, I then asked interviewees to interact with the desktop monitor experience using an Xbox 360 controller to navigate through the much higher resolution and detailed non-immersive version of the longhouse. Participants could stand or sit depending on their preference and used the controller as you would any normal gaming environment (see Figure 39). Most participants spent a shorter amount of time in this mode and the skill of navigation really depended on their previous experience with other traditional console gaming environments like the Xbox, Playstation or Wii. 
Depending on the comfort of the interviewee, and their extended use of either the immersive or non-immersive mode, I chose either to conclude the session by asking my surmising questions while they were still engaged in either mode, or afterwards.

\subsubsection{The Virtual Longhouse Experience}

The 3D longhouse itself was built based on the archaeological literature that took into account longhouse excavation data primarily drawn from $16^{\text {th }}$ century examples of Iroquoian longhouse construction and use, along with data from experiential archaeology, oral and historical accounts. However, as I chose which archaeological data and interpretations of other researchers I would use to construct and visualize the 3D longhouse, the final 3D visualized representation was a hybridization of the key elements from the research I wanted to test visually, along with the construction of my own knowledge while in the "making" mode. Making is a notion brought forth by Ingold $(2011,2013)$ to help establish a theoretical link between the act of physically constructing or "making" as a means of creating new knowledge mentally. As such in the act of creating my digital longhouse, I was both interpreting known archaeological knowledge and constructing new knowledge from the archaeologically unknown.

In the immersive HTC Vive gaming mode, the longhouse consisted of an interior and exterior space. When the headset was donned for the first time by the interviewee, they were immediately placed into the interior of the longhouse. The interior had interactive lighting from two simulated fire hearths running along the axis of the longhouse. Additional interactive lighting came from the exterior doorways, the roof vents in the ceiling and through purpose built gaps in the bark shingles that made up the roof and walls of the structure. Hearths lined the center hall of the longhouse while animated rising smoke, ash and ambers gave the impression of a functioning fire. Non-interactive floating "dust" particles were added to both the interior and exterior of the longhouse. Along the two banks of sleeping and storage apartments either side of the central corridor were static "props" such as food stuffs, pelts, pottery and other household items used to 
convey placement of personal items in the space. In the rafters hung a mixture of drying maize, tobacco, cordage, fish and venison, enveloped in a somewhat static smoke layer.

The exterior of the longhouse was an environment that situated the longhouse outside of a simulated village (visually denoted by a distant palisade), and beside a fast-moving river's edge. Due to the immense amount of detail being served in real-time, the immersive version of the longhouse had sparse vegetation and forest in the surrounding environment. Exterior non-interactive props were used to suggest habitation activities such as an exterior hearth and activity area. In the non-immersive version, the exterior was more fully populated by forest, vegetation and environmental assets (see Figure 29 as an example).

Other than the ability to move one's head in $360^{\circ}$ motion, walk around, kneel or bend over, there were no other interactive elements to this experience. Participants couldn't pick up or bump into objects. They couldn't affect any change whatsoever, other than be able to walk and observe. As well, it should be noted that users were not "visible" in this virtual environment; they could not see their own limbs and bodies, so the sense of being a watcher was heightened by that lack of body reference.

\subsection{The Interviews}

The order in which interviewees participated was entirely based on their availability during the scheduled three interview days. I did not try to order the participants based on age, gender, profession or experience. In one instance two people (the animation industry professionals) were interviewed together. In a second instance due to scheduling issues, Dr. Neal Ferris did an HTC Vive immersive interview of two Indigenous archaeological observers at the same time as I was wrapping up an interview with an archaeologist in the same room at the SA, but luckily the space was large enough and we used separate systems to allow for this to occur. 


\subsubsection{Interview Questions}

\subsubsection{Pre Experience}

Participants were asked to describe their general understanding of what VR is and their assumption regarding what they would be experiencing once they were within the virtual landscape. They were asked to:

- Describe their mental-map of an Iroquoian longhouse. What it looks like and how they would feel when interacting both internally and externally within a physical longhouse environment;

- Consider their perceived impression the nature of a longhouse, and the potential phenomenological elements that may be representative of longhouse living. Namely: smell, texture, light, smoke, fire, sound and touch;

- Identify inconsistencies between their perceived notions of a "real" physical longhouse vs a digital representation of a longhouse.

Q1. Have you ever experienced a virtual reality (archaeology) session and if so, please describe what you remember of that experience?

Q2. How would you define virtual reality (archaeology) and what are your expectations when entering into a virtual experience?

Q3. What role does virtual reality (archaeology) play within archaeology?

Q4. Describe your mental map of an Iroquoian Longhouse. Please provide as much detail as you can on the construction style, materials used and any key elements that define your mental-map of Iroquoian Longhouse.

Q5. Having described your impression of an Iroquoian Longhouse, how would you expect to feel upon entering it? What would the surfaces feel like? What smells might you encounter? What sounds would you hear? 
Q6. Lastly, what would you expect the differences between a "real" longhouse and a virtual longhouse to be? Would those differences enhance or detract from the authenticity in virtual reality (archaeology)?

\subsubsection{During Their Experience}

During the actual virtual experience, participants were given the opportunity to explore and ask questions when and if necessary. My role at this stage was limited to guiding participants if there were technical issues around operating in the environment, or to answer specific questions users raised regarding the representation of the longhouse. In this stage the participants interacted with both the HTC Vive immersive experience and the desktop non-immersive traditional gaming experience.

\subsubsection{Post Experience Interview}

Once participants indicated that their virtual experience was completed to their satisfaction, a post-experience interview was conducted. This interview was focused specifically on the personal meaning-making, or lack thereof, triggered for them when engaged within the virtual environment. They were encouraged to be reflexive in describing their experience and their impressions regarding the authenticity of the representation of the structure, 3D assets and environment. They were asked to determine if visualizing archaeological data and/or the representation of archaeological research in a virtual setting enhanced their ability to better reflect on their notions of longhouse construction and use.

Q7. What were your first impressions when entering into the virtual environment?

Q8. How did the virtual longhouse alter your perceptions of the actual look and feel of a $16^{\text {th }}$ century Iroquoian longhouse? How did the virtual longhouse enhance your original mental map of longhouse construction and use? 
Q9. Was the virtual environment an authentic representation of Iroquoian longhouse construction and use? If not, what would be needed to form an authentic experience within this virtual space?

Q10. Were there any elements of the virtual space that you would have liked to control that would have enhanced your experience?

Q11. After experiencing a virtual reconstructed archaeological environment, how does it inform your perceptions of virtual reality (archaeology)?

Q12. How would you envision using virtual archaeology in your own research? Do you anticipate any barriers?

\subsubsection{The Interviews Themselves and the Original Research Questions}

During the process of transcribing the audio interviews, I chose to selectively highlight responses from the interviews that I felt directly related to my research questions. I was particularly interested in comments pertaining to personal knowledge construction from what the participants were seeing, reinforcement of participants' own archaeological views, indications of any feeling of "presence" within the environment, and comments about the technology as it would be related to archaeology from both a research and public engagement perspective.

\subsubsection{Document Overt Participant Preconceptions For Both Their Anticipated VA Experience And Longhouse Environments}




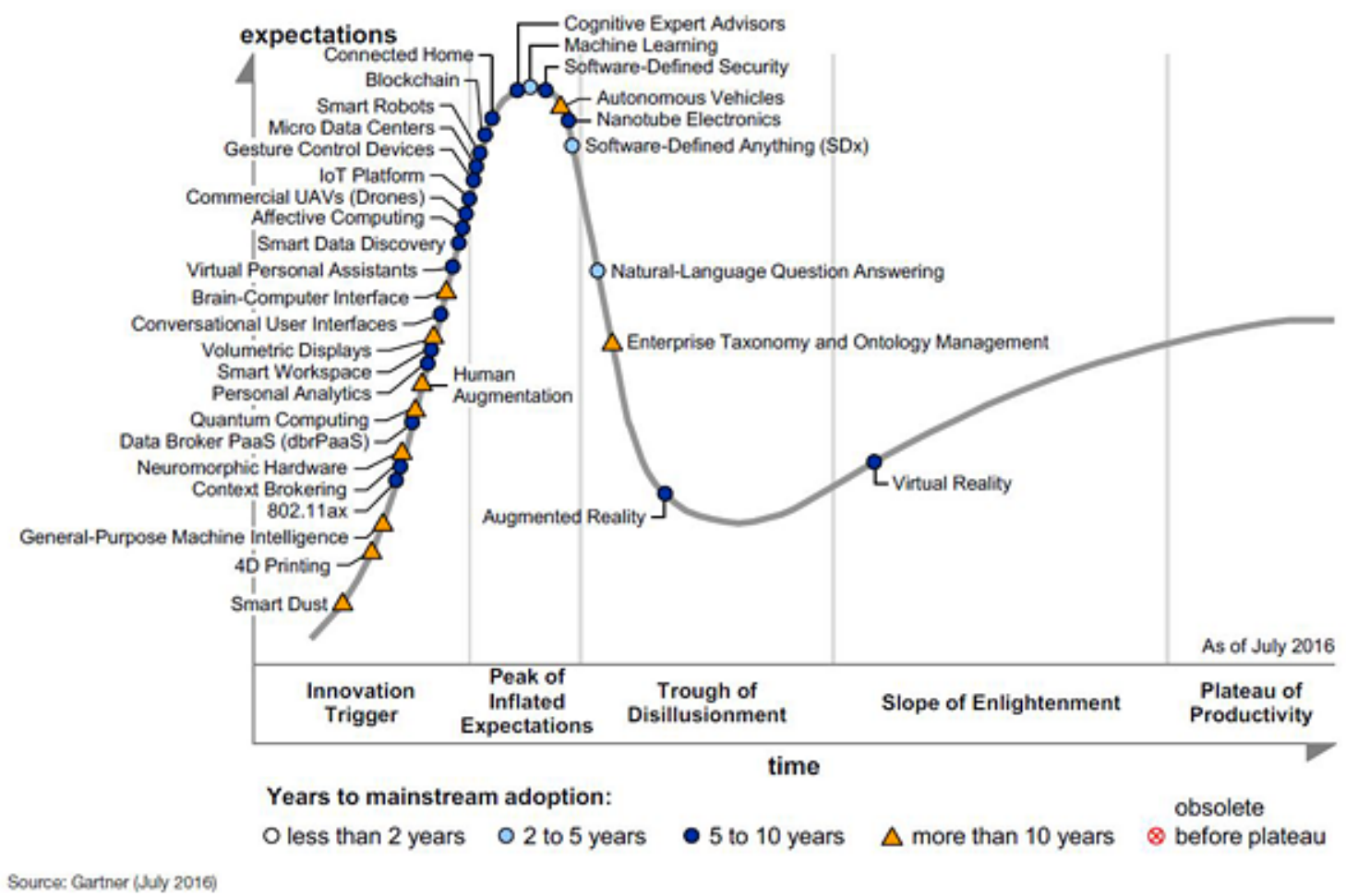

Figure 40 - Gartner Hype Cycle (Gartner Inc. 2016 -

http://www.gartner.com/newsroom/id/3412017).

Notable was the limited exposure all participants, even from the two animation and VFX veterans, to any immersive VR experience at all. Among the archaeologists, they had little or no experience with VR and those that had, had only been exposed to a previous version of the virtual longhouse (Longhouse 2.x), when it was ported into the Oculus Rift SDK 1, and built from the Unreal game engine. Overall there was a genuine enthusiasm mixed with some trepidation on how the interviewees themselves would react within a virtual world. Predictably, a moment of technological fetish (see Huggett 2004) occurred immediately as the participants donned the HTC Vive. This meant it typically took a period of time for the user to cycle through an initial "wow" moment of excitement engaging with the new technology before really taking in the archaeological representation of the virtual space. In many ways this mirrors the "Gartner hype cycle" (Gartner Inc 2016) discussed in Huggett (2013), Beale and Reilly (2014) and Reilly 
(2015a). The Gartner hype cycle consists of five stages: Innovation Trigger, Peak of Inflated Expectations, Trough of Disillusionment, Slope of Enlightenment, and Plateau of Productivity (see Figure 40; Gartner Inc 2016).

Gartner reports that VR in 2016 had reached the fourth stage: the Slope of Enlightenment as the technology and content producers are now at a stage in which public consumers can actually utilize the technology beyond the initial "wow" stage. Similar to what I observed in the interview process, there is a quick rush of excitement as interviewees are experiencing something new for the very first time. Once they become accustomed to the immersive experience and begin to explore the limitations of the platform and the narrative provided, that enthusiasm wanes.. In our interviews, this wanning varied between participants, but it was observed that over half continued to show excitement for more than 10 minutes into the virtual experience, while the other half, mostly younger participants, started to meander beyond the longhouse proper and into the larger virtual environment. However, as the participants became more aware of their surroundings and how they might want to effect change in their own ways or started to see the value of the immersive experience beyond the initial excitement of a new technology, then a Slope of Englightenment occurred. Moreover, two participants who spent the longest time within the virtual space during the study, could be considered as reaching a Plateau of Productivity as they actively interrogated what they were experiencing as compared to their professional or academic understanding of a longhouse environment.

Archaeologists spent the longest time within experience eventually asking probing questions, while the Animation Industry professionals were the first to critique the experience both creatively and technically. Females, which represented $48 \%$ of the participants, were meticulous in their observations and questions, further suggesting additional areas to enhance future experiences. Males talked in more general terms about longhouse features, but senior male archaeologists tended to follow their female counterparts in asking specific quesitons once they were acclimatized to the space. Our two Indigenous professionals commented almost immediately on the lack of people and the sounds of the daily life that would have beem representative of longhouse living. 
About a third of the users commented on the seasonality of the longhouse environment and the desire to see the longhouse represented in all four seasons. Of the archaeologists, about half questioned in detail the placement and representation of food stores hanging from above and within the vestibules of the longhouse. Of that group, a third of those archaeologists specifically inspected the inside of the pots cooking on and beside the fire hearths. Both Indigenous participants discussed the importance of medicines and herbs. They further suggested other household items such as tools, toys and goods that would have hung from posts and/or placed on the sleeping bunks.

During the pre-experience interviews, all but one of the users revealed a consistency in how modern interpretations of the visual, cultural and environmental aspects of longhouse use continue to be consistent with archaeological and historical norms for longhouses. The single person who was unable to provide a mental description of a longhouse was one of the two animation industry interviewees who had been born and raised in New York City and had equated longhouses mentally with the childhood toy "Lincoln Logs" and had envisioned a rural cabin. Whether the mental image is correct or not, the remaining 22 participants indicated that longhouses in their minds can be a long "half cigar shaped" multi-family residential, ceremonial or public administration building made of a wood pole framing structure and shingled with bark. These "textbook" visual notions of longhouse construction is consistent with both the oral and cultural historical representations of longhouse physicality (see Bartram 1751; Chadwick 1897; Dodd 1984; Dodd et al. 1990; Engelbrecht 2003; Heidenreich 1972; Lafitau 2013; Snow 1997; Trigger 1987; Warrick 1988, 1996, 2000; Wright 1974, 1995; Wrong \& Sagard 1939). They are also generally consistent with the contemporary constructions of longhouses found on Museums and cultural center properties across southern Ontario, Quebec and New York State that many of the participants have experienced. What this means is that users' understandings of the above-ground interpretations of longhouses have been formed from their exposure to historical accounts, media representations, and even their recollection of visiting modern physical builds of reconstructed longhouses from the archaeological record. And as noted by Interviewee $M$, the prevailing attitudes in archaeology from the 1980's on was that the proliferation of longhouse sites excavated 
provided more than enough information on use and typology of longhouses. This would indicate that the core attributes of what a longhouse is, were already "known" by users and accepted within archaeological sensibilities as the core authentic elements or tropes that make up a longhouse. Although in reality the opposite is generally true in the archaeological context. As Interviewee M states:

"And of course the reality is that I don't think I've ever seen two longhouses that are the same. They're all different and it's always exciting to see what you're going to find that's different from the ones you've seen before."

A duality in the perception and description of a longhouse surfaced as users articulated their understanding of a kind of universal template to longhouse shape, size and function, then followed by the remembrance of variations to that in their own personal experiences. This duality provided a completely opposite notion of the uniqueness longhouses had beyond the universality expressed. In effect, users' initial longhouse mental map was a waypoint in which participants could comfortably start their journey, yet quickly course correct once their personal narratives began to interrogate.

\subsubsection{Engaging and Interacting With The Virtual Longhouse}

As participants moved from pre-experience interviews to physically interacting within the virtual longhouse environment, perceptions due to individual archaeological interests and interpretations of longhouse use changed. Users uniformly correlated what they were observing with their own personal experiences in other dwellings, like a "cottage" or from their experiences in a physical reconstruction of a longhouse structure. These experiences subsequently informed participants' expectations of the interior of a longhouse. For example, "Earthy," "damp" and "musty" were all terms used regularly in the pre-experience interviews when describing how participants envisioned phenomenologically connecting their mental image with the virtual longhouse interior. Once in the virtual longhouse, three participants each suggested that the physical space 
would have been "better served" if users walked on a dirt floor during the immersive experience to fully simulate being in a longhouse. Interviewee A, in the pre-experience interview stated that the longhouse should be:

"A little bit cold, a little bit wet, or damp I should say, but when you get this fire going it would be smoky and it would warm up...but I would think that it would still not be a dry room. Somehow I don't picture it as a dry space.”

Of course, these kinds of phenomenological elements were beyond the scope of the virtual experience. Nonetheless, participants negotiated the virtual experience based on their past emotional connections to their own physical lived experiences, expectations of longhouse materiality, and the assumptions that formed their mental maps. In particular, the 18 archaeologists were all critical of the virtual longhouse as not being "smoky" or "smelly" enough. They expected an enveloping experience in which the smoke was thick and dense, and permeating all of their senses. Although only $35 \%$ of the interviewees had experienced a physical longhouse with working fires, $100 \%$ of the participants expected this sensation to be an integral part of the virtual experience.

What sounds would have been heard within the longhouse was also actively discussed by senior and junior archaeologists alike and casually referenced by the remaining 5 nonarchaeologist interviewees. As the longhouse was empty of human or avatar interaction, the sounds of children, dogs, the old and the sick were specifically mentioned as layers that would have helped to enhance the notion of "being there" and a proxy for the people missing. Interviewee M saw longhouses as a "living thing" in which both the activity around and within and the structure itself were in a constant state of "dynamic flux." As Interviewee J1 states:

"Of course everybody has their own interpretation of the height, the width, how things are tied, but as I said... none of that stuff really matters to me...it's more of the experiential aspects that are important, and I think that would have resonated with the people that were living in these things." 
This notion was echoed by two-thirds of the archaeologists and specifically by the Indigenous participants throughout the interviews. Users felt that longhouses were organic living entities and although there is a certain academic or cultural-historical curiosity to how these structures were built, it is the interconnected senses of sight, smell and touch - and the range of daily living in and around these structures - that were key to the users' understanding and acceptance of the virtual environment. Whether all of those senses were actively engaged in the session or not, they are important in the foundation of knowledge construction and the assumed pathways of longhouse use.

Once in the immersive virtual space, $100 \%$ of interviewees noted that they felt an immediate sense of "presence," of finding themselves in a space different from the world beyond the goggles. The HTC Vive allows the participant to sit on the border between the virtual and the physical, so there was a sense of being within this sixteenth century longhouse space and the users' awareness that they were in that space. For instance, over half of the participants actively reached out to touch the simulated floating dust and ash particles. Users tended to avoid walking through the virtual fire hearths located down the center of the longhouse even though they couldn't feel the edges of the hearth or even the heat that would have emanated from the fires being represented. This contrasted heavily with the non-immersive game-like experience where younger, experienced gaming interviewees ran freely throughout the digital environment unencumbered by a notion of avoiding fires, and were willing to try and jump to the rafters of the longhouse or dive into the river outside.

While the use of the immersive HTC Vive experience was the most popular means of interacting with the immersive longhouse, with $96 \%$ of interviewees preferring the freedom and flexibility of interacting with the digital space over the traditional desktop gaming experience. With the desktop experience, the gaming controllers were mentioned as an inhibiting factor for $39 \%$ of the participants, which also represented almost all of the older age group of participants, who presumably lacked extensive prior experience 
using these controllers. Additionally, $78 \%$ of the entire group felt constrained by the flat, non-immersive, $2 \mathrm{D}$ experience.

The physical limitations to exploring the virtual space through the HTC Vive also generated some frustrations for users, and generally created a more cautious, methodical approach to engaging the virtual space. Notably, although users were able to physically walk and interact within the digital environment, they were still tethered by a long cable to the computer, which made negotiating the physical space cumbersome. One interviewee indicated that they had to actively negotiate what they were experiencing digitally with the real fear of accidentally running into things within the physical environment, causing their sense of presence to stutter throughout the experience. Another interviewee suggested that the weight of the headset kept them firmly grounded in reality, and after a while became a physical burden to staying in the environment. Also, by limiting sight of the non-digital world, people tended to fumble or require assistance in order to be re-assured that they were not going to run into things, look silly or break something. Although these are more limitations of the platform than the actual longhouse build, it did affect the user's ability to fully engage within the virtual space and thus influenced their critical thinking and meaning-making while experiencing the immersive reality.

In terms of accepting the immersive HTC Vive experience itself, $26 \%$ of participants experienced brief trepidation with the technology during the pre-interview. Interviewee $\mathrm{O}$ stated:

"It's overwhelming. To be drawn into an unfamiliar space. It takes a few moments to adjust to what you're being presented with. Even before you start dealing with the navigations you're just standing still and looking around. And I think that would be very like the experience of being dropped into one of these buildings for the first time." 
I hadn't thought about the unintended sensation of experiencing the longhouse for the first time and how the technology might enable that notion to mimic some of the visual impressions that might have played out for non-community guests. More to the point, the "foreign-ness" of this sixteenth century interior residential space for twenty-first century visitors, even immersively, required some negotiation for users in the process of orienting themselves through the transformation triggered by pulling on the headset.

Of the six interviewees who felt moderate or full trepidation in using the technology, four were older archaeologists and the remaining two were Indigenous participants. Only one participant failed to get past that trepidation due to their uneasiness with the technology, the physicality of the HTC Vive and the ability to navigate physically with their eyes covered, while the other five participants eventually acclimatized to a level of engagement similar to other users. Each participant exhibited varying degrees of acceptance of the immersive experience. It is worth noting, though, that younger participants could immediately engage with and navigate the environment once they understood the basic operational concepts of the technology, and spent the most time outside of the longhouse itself, exploring the forest, river and palisade.

It should be noted that on two occasions individual archaeologists who had both excavated longhouses and had done extensive research on longhouse construction and use, spent the most time overall within the virtual immersive HTC Vive experience itself. They spent 45 and 40 minutes respectively in the virtual build, meticulously inspecting the interior and exterior environments. These archaeologists used the physicality of the HTC Vive system to kneel, bend, stretch and even sit within the digital space, while asking probing questions on decisions I had made in the virtual construction process, and then offering alternative viewpoints from their own experiences. 


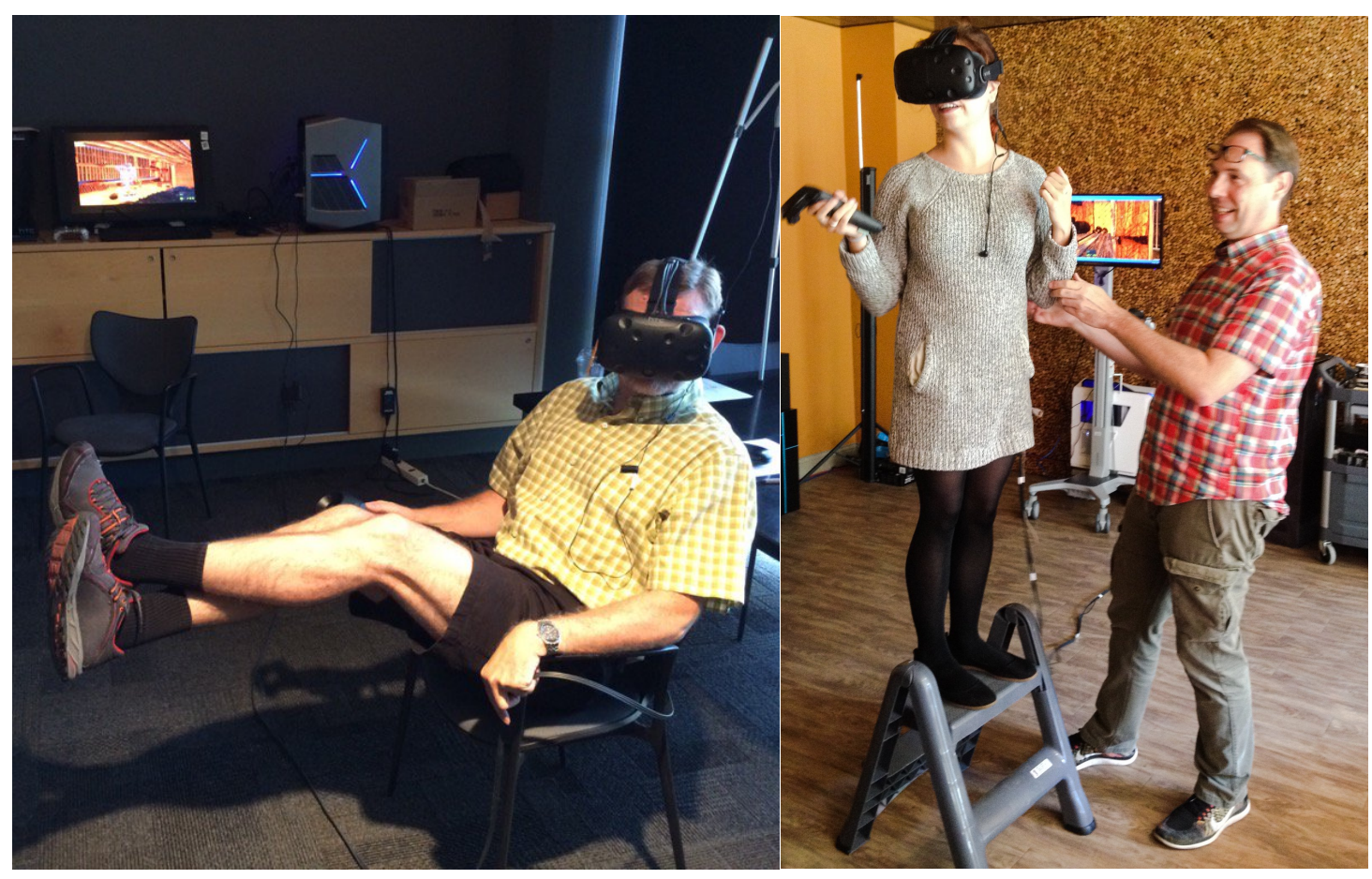

Figure 41 - Examples of physical tools to enable virtual engagement. Reproduced with permission.

While I had not anticipated users wanting the opportunity to enhance the immersive-ness to their experience or otherwise physically enhance their engagement with the longhouse space, in two initial instances, by user requests, I found myself quickly modifying the physical environment to allow the interviewee to either "sit" on the virtual bunk within the longhouse by providing a physical chair, or by providing a stepstool to another participant who could not see storage items on the upper bunks (Figure 41). This provided real interactive moments, which grounded the participant's notion of being physically in the digital environment. As a result, I subsequently altered the interview process to allow for participants to engage the boundaries between the physical and the digital by suggesting they could either sit in the chair or use the stepladder to better experience the virtual environment. By sitting in the digital bunks, a total of eight interviewees took a physical rest and thus some time to inspect some of the less obvious construction methodologies and visual representations around them from the perspective of the longhouse bunk. In doing so, they began to interrogate the choices made more 
thoroughly and to offer alternative options on how they would have addressed the construction of the virtual longhouse.

There were some possible variations in exploring the build that emerged between participants. First, most of the female participants who were archaeologists (10 of 11 women identified themselves as archaeologists), regardless of whether they were "younger" or "older" (see Table 1), took a highly meticulous approach to surveying their surroundings. They stopped regularly to inspect areas of interest inside the main body of the longhouse first, and then purposefully inspected the vestibules. Upon completing their slow and steady review of the interior, they then proceeded to the exterior and performed the same meticulous inspection of the work areas, exterior of the longhouse, palisade, forest and river. Only after they had explored all of these areas did they then return to areas of the build for further inspection. Male participants who identified as archaeologists (8 of 12 overall) tended to be more variable in their approach. While three of the five "older" male archaeologists were also meticulous in their exploration of the build, all three of the younger male archaeologists, and two of the older male archaeologists, initially undertook a rapid "taking it all in" scan of the interior and exterior of the longhouse before returning to specific areas to explore further. Anecdotally, this was similar to the behavior I witnessed at the 2015 Heritage Toronto Gala event ten months prior, when an earlier version of an Oculus Rift Longhouse 3.x experience was deployed. At that event, younger male users sped through the virtual space quickly, while older female and male participants took their time to inspect the numerous details provided. While the study group for this research is too small to attribute any real pattern to this variation, it is worth noting that the variable behavior in the build seen for younger males may simply capture differences in familiarity with gaming environments, in that younger males are more likely to have previously played in 3D gaming environments, and thus deployed orientation skills they developed in gaming to explore this new environment similarly.

Anecdotally it is also worth noting that, when it came up in conversation, archaeologists tended to explore or interrogate the build from their particular areas of professional and personal research interests, actively seeking visual cues as to whether that research topic 
was represented. For instance an archaeologist who indicated they specialized in food preparation went and examined all of the visual representations of food hanging or stored in the virtual containers and even within the cooking pots themselves. A bioarchaeologist sought signs of infant burials within the doorways of the longhouse. Other archaeologists looked for and compared what they saw in the build with their own experiences building physical reconstructions of longhouses. Over $50 \%$ of the participants identified as archaeologists sought known personal archaeological knowledge in which to authenticate what they were experiencing.

Both archaeologists and non-archaeologists also mentioned non-archaeological memories to lend authenticity to the virtual environment, including references to outdoor camping and cottages. As well, both Indigenous participants raised notions of oral traditions and personal cultural experiences during their explorations. For example, the Indigenous archaeologist commented on the lack of representative medicines in the stores of food represented which did not match the early fall season we were attempting to mimic within the virtual environment. The heritage specialist commented on the lack of tool working areas both inside and outside of the longhouse, and lack of totems on the exterior of longhouse around the entrance. Both also commented that they were concerned about the habitants, as it seemed that they just "disappeared" in the middle of their daily activities, an observation echoed by several of the other archaeologist participants.

Overall, almost all of the participants signaled, that, through their comments, questions and actions, they relied on their own personal knowledge to first ground their experience and then once acclimatized the archaeologists in particular began to reflect on the differences and lack of particular areas of interest to interrogate not only in my build, but in the virtuality of the archaeological record itself. Three archaeologists specifically used the experience to reinforce their own norms and understandings by identifying what was and wasn't "correct" in the build, while another eight archaeologists adopted a more reflexive turn to their exploration, generally indicating the value they saw for virtual reality to interrogate, mix and match archaeological perspectives. As Interviewee F noted about 3D visualization: 
"It's a lot easier to reimagine and reinterpret, you can take pieces out, you can put pieces back in, you can have multiple versions that exist at the same time with different theories and different imaginations of what that space would be like."

The greatest level of frustration expressed when in the build by all participants was the lack of interactivity or narrative for the experience provided. Interviewees could "immerse" themselves into my representation of the archaeological record yet they could not affect that environment; they couldn't pick objects up and inspect them or make material changes to the structure itself. Recently, the Oculus Story Studio (OSS) team started conducting experiments on how people would interact in a traditional narrativedriven movie approach but within VR. They discovered that within VR the user has an expectation of interactivity that is not present in traditional 2D platforms such as TV and Film (Burdette 2015). Burdette coined the term "Swayze Effect” after Patrick Swayze's character in the 1990 movie Ghost with Demi Moore. In the movie Swayze could inhabit the physical world, but could not effect changes in that world. Similarly, if creators of VR experiences don't provide participants with the functionality of interacting within virtual environments, participants are limited to being passive observers, losing the sense of presence so critical to sustaining the immersiveness of a virtual reality.

From the perspective of my research aims, Longhouse 3.x's visual representation of archaeological data needed to be interrogated by archaeologists' own notions of longhouse construction and use. Reviewing their interaction within Longhouse 3.x, archaeologists intertwined their own preconceptions of longhouse form and content, newly discovered observations in terms of divergences in the visualization from those preconceptions, and created "queries" of the build derived from their own specialization to experience the longhouse virtually. However there lacked a single unifying and overarching narrative that could engage participants. Jeffery (2015) suggests that archaeology is more than just data-driven representations; we experience the world in creative intangibles in order to have the ability to interact with the past physically and intellectually. That sense of presence or the "suspension of belief" is strongly driven by 
narrative (Jeffrey 2015:150). In our particular case, participants strung together fragmentary data and the ability to only know the past from the present by creating their own narratives, thus facilitating the "suspending of belief" i.e., the willingness to accept the narrative as authentic or somewhat accurate. This tendency in how participants interrogated Longhouse 3.x would suggest that we have to suspend our beliefs in order to advance new narratives.

\subsubsection{Perceiving Authenticity, Authority and Agency}

In 2006 The London Charter was established to help build a framework around archaeological research within a digital era and more specifically on the visualization of archaeological data (Denard 2012). The London Charter, along with specific policies directed for VA known as the Seville Principles (Bendicho 2013; Bendicho et al 2017) developed as a roadmap for best practices in a digital heritage. Among the practices addressed, it has attempted to address the issues of authenticity, authority and agency within archaeological digital media practices by those who are actively engaged in the visual reproduction of archaeological or archaeological-like visualizations through a transparent, holistic framework (Denard 2012). Archaeologists are acutely preoccupied with the accuracy and authenticity of the archaeological data in general and the means in which this data is later interpreted (Frankland and Earl 2011; Frischer et al. 2000; Moser and Smiles 2008). As such, the participants' perceived notions of authenticity, authority and agency within VR were explored in this research.

\subsection{Authenticity}

As a general observation, all interviewees were actively engaged in both interacting with the virtual environment and relaying their comments in real-time as they were experiencing both the immersive and non-immersive environments. In terms of asking about authenticity, there were more highly engaged responses from almost all of the participants: 
"This was just like another new version of a familiar place. As we said before, who knows what "authenticity" really is. It was as authentic as any of the actual reconstructions. If I'm the public, it's probably a totally different experience and what not. They're coming to it with a completely different frame of reference (Interviewee M).

I don't know what an authentic [longhouse] would be. I know that as an archaeologist I'm interpreting what it looked like, what it would have been like, and I don't see this as being any different. So to me it's an interpretation and you can either, yes, you can always disagree with interpretations. That's what we do as scholars. To me, it was in that sense a much more immersive environment of actually seeing it as a place where people would be (Interviewee A).

I can tell you there's no such thing as an authentic experience. I don't think that that's a thing. There's no such thing as authenticity ever. If you abandon that notion, there are things that could probably reflect the archaeological data in a more meaningful light (Interviewee $\mathrm{N}$ ).

I feel like we try our best. I don't think authenticity is really possible, and if we think we've figured out everything, we're probably wrong. But it's a good place to start a discussion... it's a good place to think about how it must have been constructed" (Interviewee K).

Striking was the notion that $96 \%$ of the interviewees preferred the less detailed and lower-quality resolution of the immersive environment as opposed to the highly detailed non-immersive environment. This ran counter to my assumption that archaeologists would prefer a high level of detail and presumed scientific accuracy. Or was it an indicator that what they were observing represented a jumping off point in which to mesh their own interpretations and notions? Borrowing from Benjamin (1968) and Latour \& Lowe (2011), Jeffery (2015:147) describes this perception of the virtual as a "digital aura" where the participant/viewer acknowledges that the digital reproduction contains a 
"sensation of being close to the past." Jeffery (2015:148) goes on to indicate that participants/viewers recognize that the expertise and intentionality that is required to digitally create heritage in $3 \mathrm{D}$ is authentic even if the representation may not be.

I would argue that in many ways the London Charter's concept of "authenticity" is more in line with Jeffery's notion of aura than our traditional archaeological understandings of authenticity (see also Morcillo et al 2017). Further, there has been sustained caution within the archaeological community (see as examples Earl 2013; Frankland 2010; Frankland and Earl 2011; Huggett 2013; Zubrow 2006) that with the advancement of photorealistic capabilities available to both producers and consumers-cum-producers of heritage, there is the potential for a widespread notion by consumers of digital heritage that if it looks real it must be "authentic" (see also Forte 2014b). The London Charter framed authenticity as one of its tenets to ensure that the general viewing public should be informed if the virtual material being engaged with is derived from actual cultural and historical material or if it is a creative amalgamation of archaeological or heritage material and artistic license (see Denard 2012; Gea et al. 2013).

It would seem that when coupled with the concept of "presence" through an immersive experience, the digital aura is heightened and no matter what the level of quality or detail, and potentially within the artistic rendering of the archaeologically unknowable, there is a profound sense of being in a representation of the archaeological record, regardless of whether or not archaeological and heritage professionals "know" there is singular representation of the past.

\subsection{Authority}

As Watterson (2015), Frankland and Earl (2011) and Morgan (2012) have all suggested, the visual representation of the archaeological landscape, environment or artifact is a fleeting construct of the artist and lacks the embeddedness of the archaeological data from which it was based. Frankland and Earl (2011) suggest that the photo-real capabilities now currently available in $3 \mathrm{D}$ rendering poses a particular problem with 
regards to representation as experienced by non-archaeologists. There is a tendency among the viewing public to accept what is presented as visual fact rather than suggested interpretation (see Watterson 2015:123), and as such, what is being seen or experienced is given a heightened level of authority, whether the paradata is readily available or not. ${ }^{15}$ Morgan (2012:86) goes further by suggesting that even the archaeologist is unable to retain all of the information and thus needs to layer achieved interpretation so the audience better understands the visual being presented. These notions fall within the framework of the London Charter, however the mechanism within VA is still yet to be fully realized.

In the case the HTC Vive exercise, I was present throughout the experience and additionally had the ability to see what participants were looking at within the HTC Vive through a separate monitor feed. My direct participation allowed for that "layer" of authority that Morgan (2012) suggests, as the participants could ask questions of a "knowledgeable guide," be given direct answers, and in some instances be directed physically and digitally to areas within the virtual representation that I felt needed further explanation. Within this closed loop, intimate experience between participant and maker, the authority of Longhouse 3.x was clearly identified with me and with my interpretation of the archaeological record.

It could be assumed that without my direct intervention and no pre-warning stating the original intent or direction of the experience, there would be the likelihood that the general viewing public might indeed misinterpret the virtual environment as being a "real" and authorized representation of the past (see Gillings 2005). As discussed previously, participants easily accepted the texture and rendering issues within the immersive environment compared to the almost photo-realistic desktop version when comparing the two experiences, primarily because the HTC Vive experience enabled a sense of presence within the virtual longhouse. As such, participants had already

\footnotetext{
${ }^{15}$ It is worth noting that no participant directly referenced the paradata blogs I used during the Longhouse 3.x build, or otherwise indicated that the wayfaring moments of decision-making I publicly detailed were colouring their sense of the authenticity they took from the build.
} 
negotiated a reduced photo-realistic visualization for the ability to naturally move within the digital space. The notion of presence had far greater authority to the participants than the quality of the visualization.

The opportunity to add an authoritative archaeological lens, or for that matter multi-vocal lenses, is technically doable. The ability to provide user engaged popup indicators within virtual space, in which participants could be provided with the paradata or even the exact referencing used to represent a (re)imagined archaeological detail, would be one means in which to provide a layer of additional knowledge, though it is worth noting that virtual "footnoting" would continually undermine immersive presence, as tended to be noted by Oculus Rift SDK1 users experiencing the Longhouse 2.x build (Neal Ferris, personal communication 2016). Conversely, both of the Indigenous scholars commented on the usefulness of the technology as a platform to facilitate alternative visions and representations of the past, developed for particular participants. One of these participants indicated that there were certain aspects of longhouse culture that were reserved for Indigenous knowing and thus the need to represent and restrict those alternative visualizations for community members only.

For some participants whose direct research on longhouse construction and use was used to visualize the virtual space, there was an immediate acceptance of their authority in the detail represented of what they were seeing virtually. However, there was an opposite, visceral response to alternative representations presented which did not conform to their particular views or asserted interpretations. So authority was negotiated and evaluated based on familiarity but also with the participants' own sense of authority they brought to the experience.

\subsection{Agency}

There are only fragmentary historical representations of longhouses (see Snow 1997; Wright 1995), and any visual constructed knowledge of these residential structures comes from written historical sources such as the Jesuit Relations and other accounts of early 
European explorers (see Bartram 1751; Chadwick 1897; Champlain 1907; Wrong \& Sagard 1939). For archaeologists, our modern vision and physical reconstructions of longhouse use and architecture have relied heavily on those colonizing reports of the early Europeans in the New World to fill in the visually unknowable in archaeology (see Boyden 2013:29 as a literary example). Sioui (1999) suggests that some of what represents current Indigenous history and culture has been informed by non-Indigenous archaeological research and historical accounts that have both positively and negatively impacted on the collective cultural-historical mental maps of Indigenous and nonIndigenous communities alike (see Pannell 1994). These mental conceptions of the past are then further reified in the process of digital visualization drawn from archaeological data and historical moments in time descriptions. So can VA make overt the various agencies of Indigenous ancestors creating the archaeological past, Europeans in history describing and mis-describing Indigenous lifeways, archaeologists and other scholars interpreting that partial archaeological and historical information, and visualization creators negotiating data, interpretation, skill, technical limitation and their own artistic vision?

An embodied experience for descendent stakeholders has the potential to be not only empowering to the participant but beneficial to the archaeologist in collaboratively unlocking unintended knowledge that further enriches archaeological interpretations of that record while also providing meaningful heritage experiences for Indigenous participants. Objects, landscapes and narratives, as well as their digital reproductions, hold, embody and create an agency of heritage in the real and virtual worlds and as such must be treated with equal consideration and respect (Brown and Nicholas 2012; Earl 2013; Forte 2014b; Huggett 2012a, 2015; Pauketat and Alt 2005; Richardson 2013; Robb 2010; Salmond 2012). For example, the Māori of New Zealand believe that the essence of their sacred cultural objects, whether digitized or traditionally photographed, is transferred when the digital reproduction is made (see Salmond 2012). This transference does not diminish the cultural values the original cultural artifact is felt to hold, but rather extends that value as cultural and material agency to the digital representation, which in turn requires the same considerations and respect as the original (Salmond 2012). Like 
the Māori, there is some indication that this view is a dimension of Indigenous digital cultural heritage understanding among at least some First Nations communities, with individuals viewing digital reproductions not as a valueless copy, but as an extension of the "crafted objects and landscapes of memory" which implicitly embody a material agency infused with ancestor and present day Indigenous cultural heritage values (Brown and Nicholas 2012:310; Beth Compton, personal communication 2016).

One of the more unique and recent attempts of 3D virtual reality as a phenomenological experience and means of Indigenous VA is reflected in Dawson et al's (2011) effort to digitally recreate a Thule and Siglit-Inuvialuit whale bone and sod house dwelling within an immersive and emotionally attached virtual space (see also Lee 2017). They attempted to envelope participants through a "CAVE" automatic virtual environment through sight, sound and the natural enclosure of the presentation space itself (Dawson et al 2011). The interactive, phenomenological space created uniquely combined with personal memories and narratives that Indigenous participants held and were rekindled by participating in the virtual space (Dawson et al. 2011). Although Dawson et al did not intentionally set out to create a narrative driven experience, the virtual environment allowed the participants' own narratives to be realized in a setting that reinforced their past experiences.

Given the potential for content and visualization creator agencies to shape user experiences and meaning-making in immersive environments, the implications for an informed and reflexive VA adhering to the intent of the Seville Principles are profound, in that appropriation and misuse of culturally sensitive digital objects and landscapes is but one example of how virtual environments and objects can perpetuate continuing of longstanding cultural appropriations that archaeology generally has needed to redress, and a digital archaeology needs to ensure it does not perpetuate (Brown and Nicholas 2012).

Even the representation of a longhouse and the possible revealing of Indigenous ways of knowing have implications for culturally sensitive information to be accessed by users within the virtual space. For the most part, participants exploring the Longhouse 3.x environment only lightly explored the notion of agency as distinct from authenticity and 
authority in the visualization. As noted, authority fell to me, as maker, for what participants both felt was "right," as well as what was "wrong" about the build. Being open to variable interpretations and alternative visions of longhouse architecture and space did help make overt some of the various agencies shaping the final visualization, but mostly participants focused on the agential implications of the visualization as Indigenous heritage for Indigenous communities in the present.

While the focus of this research and thus emphasis with interviewees was on archaeological meaning-making by archaeologists and heritage professionals, it is worth noting that the insights gained from the participants of the Thule CAVE project were also reflected in the comments from the Indigenous archaeologist and heritage professional who experienced Longhouse 3.x. Both indicated that for them, the visualization was really just the start of a longer conversation and active agency of Indigenous communities re-purposing VA output for community-specific needs. As one of them stated, it is important for Indigenous people to:

"...be able to tell their story in their own way... but it's kind of a hard thing because Western thinking is more about the tangible, more about seeing and doing than it is about sitting and listening... So if something like this can be made, and can be altered for a certain group... then work with them [an Indigenous community] to start telling their story in their way, and then they can just plug people in there, and say, Okay, well, we can't tell you this way because these are our teachings, but we can tell you in a way that's accepted to us. So put this on, walk around this world, interact in this way, and then come back, and talk to us, and see what we're trying to say."

Each of the Indigenous participants felt that alternative representations could be built from the current visualization that would allow Indigenous elders and youth to experience and communicate culturally sensitive ways of knowing, while also providing a secondary experience for non-Indigenous participants to engage with and come to better appreciate and access culturally acceptable modes of understanding. 
It was also clear through comments made by $80 \%$ of the participants generally that they recognized the virtual environment provided an opportunity to extend academic, professional and Indigenous archaeological and heritage narratives and engagement to a broader range of people, and that the build could serve distinct needs and heritage values, for example as a virtual place to teach the past understood through oral histories and traditions. That potential underscores the importance to both make overt the various agencies that shaped any VA iteration that serves as the platform for such communityspecific need, and to provide the user the ability to revise or customize the visualization to "erase" colonial agencies, as well as to insert an Indigenous community agency into repurposing the meaning-making of the visualization to serve their specific, repatriatedknowledge needs and purposes.

\subsubsection{Representation And Placement Of Digital Assets, Landscapes And Built Structures}

The liveliest discussions I experienced with users invariably focused on the placement of objects within the environment, what they were, why they were in a particular spot and whether it was even representational of actual use, location or context. As discussed, over $35 \%$ of the participants specifically noted that they were exploring areas of the build that related to their research and professional interests. As humans, we are drawn to what we know or favour the most, so I saw this initial focus as a means for participants to situate themselves within the virtual space by finding the familiar first. Of course funding, time, software, hardware, talent and applicable and available research negotiate the entire virtual production process. Hence I negated some areas of engagement in favour of others during the development of Longhouse 3.x (see Chapter 3). In doing so however, this exploratory approach by individual participants had the effect of also enriching my own understanding of these choices I had made, and what could be added in future reconfigurations of the virtual longhouse experience to address what participants didn't find. 
There was a substantial discussion regarding the temporal and contextual representation within the virtual space. Object placement and even the types of foodstuffs represented were meant to follow a temporal seasonality. Although every effort was made to simulate a fall-like environment in terms of sun placement, lighting and types of vegetation external to the longhouse, participants noted that some foodstuffs represented within the virtual longhouse would not have been ready yet for harvesting. Most participants tended to query what a lived longhouse would contain and whether the build properly represented that dimension of longhouse living. A few participants noted the lack of personal items, such as cornhusk dolls, lacrosse sticks or medicines drying, one participant notably pointed out that there should be an abundance of stocked medicines in order to supply the longhouse inhabitants over the long winter months. Specialized areas within the longhouse for communal activities were also noted as absent beyond the cooking areas represented.

During the build we purposely added 3D reconstructed items such as bowls and pottery of varying sizes that could have come from the $16^{\text {th }}$ century Lawson Village Site. All participants were observed examining or even wanting to pick up these items and inspect them, but curiously, over $50 \%$ of the interviewees also wanted to know what we had placed, if anything, in them. Some of these vessels contained virtual representations of liquids in an attempt to represent food production as a moment occurring in the virtual experience. Other containers held recognizable food like beans, squash or apples. While very few users spoke about or considered the impact of this material culture in the visualized space, the couple of users who did tended to feel that the placement of actual material culture and food within the virtual space enhanced the believability of the representation presented.

One topic that came up repeatedly in discussions with the archaeologists focused around the placement of wood under the lower sleeping bunks. Our representation of neatly stacked and well-cut wood clearly became fodder for critical discussions raised by some of these archaeologists, who indicated that this element did not align with their sensibilities, and thus had them thinking of what other, "more authentic" representations of kindling and wood storage in a longhouse might be. These discussions tended to 
expand beyond wood storage and helped identify, in the minds of the archaeologists, how to better represent potential goods, tools and supplies virtually, as well as how they would actually be placed within the longhouse. It should be noted that this visual representation only seemed to reinforce the cultural-historical assumptions some archaeologists were working from because the visualizations were not representational of their own mental image of longhouse structure and use. In other words, for some participants, any deviation from their own expectations, even seemingly minor details like bunk height or what should or shouldn't be underneath that bunk, less challenged their pre-conceptions, and more invited an orthodox retrenchment of them. As Interviewee P noted:

"You'll be talking to some big-time experts about Iroquoian archaeology, and they'll all have their own idea of what it should look like. So I have a hard time thinking of, if someone is an expert in this, and already has an idea in their mind of what it looks like, what [this visualization] would give them besides just reinforcing that idea that's already there."

However, I found a willingness by the overwhelming majority of archaeologist participants, even those critical of deviations from their pre-conceptions, to accept the Longhouse 3.x visualization as merely one of many potential interpretations, especially once it was revealed to them in our discussion that the digital representation could be altered or even user-created in the future.

All participants at some point commented that the longhouse appeared empty of life. One interviewee felt like they had stepped into someone's house but had just missed them. A few participants felt the need to frame the emptiness as a negative narrative, in that the longhouse was abandoned in an emergency or because of danger, with the fires still warm and items not taken. Champion (2015) suggests that "Virtual Agents" or avatars help to reduce the sterile nature of most $3 \mathrm{D}$ reconstructed heritage environments. These agents should not be intended to be props, but active conveyers of representative cultural norms (Champion 2015). In our build a decision was made very early on not to digitally represent the inhabitants, given the problematic dynamics of representing individuals "correctly," and not as simple digital avatars as "Other". 
Various suggestions from users on how to better "animate" the representations included that the use of animated dogs or the sounds of people going about their daily lives. These sounds were thought to help enrich the experience and further add to the sense of presence while being culturally sensitive. In an effort to counter the "sterile shells" (Watterson 2015:121) of virtual heritage representations, the addition of non-humanlike agents such as animated dust, smoke and layered texture maps of dirt, handprints and grime became the "passive virtual agents" I deployed in lieu of the physical and aural representations of the human form and presence. Lighting was also manipulated between inside and outside the longhouse. However, these tended to prove too subtle, or fed into the negative narratives of people having just fled the longhouse, and underscore the limitations of relying only on the visual for experiencing the past virtually (see Chalmers 2017).

\subsubsection{Alternative Meaning-Making}

If I was looking for an "ah-ha" moment in meaning-making within virtual reality, it did not readily materialize within the timeframe of the participants' experience within the virtual longhouse. As discussed, each participant experienced various levels of the Gartner Hype Cycle (Gartner Inc 2016) in real-time as they interacted with the build. I had assumed that those participants who had previous experience with VR environments would readily get down to the business of evaluating the virtual longhouse archaeologically. However, the HTC Vive, which truly blurred the line between the borders of physical and digital space, awed participants immediately upon use. Some participants, once that rush of excitement quickly dissipated, moved towards understanding the virtual space from an archaeological experience. But over $50 \%$ of participants took longer to get past that first moment of being in awe of the technology, and only slowly engaged with the build and started "looking" at it through an archaeological lens, usually after some prompting and guidance. 
Two participants, J1 and M, spent 45 and almost 90 minutes, respectively, within the space. Both archaeologists had limited experience previously with VR. The both conveyed an initial euphoric sense of wonderment but quickly began to engage and interrogate the virtual environment. They methodically inspected every aspect of the longhouse interior and exterior, actively questioning and pointing to areas of interest with the HTC Vive controller so I could see on the monitor what they were inquiring about. Rather than leading the discussion, I let the silence between maker and participant guide the rules of engagement, letting their inquiries and focus lead the tour.

The moments these users rested in their explorations were the times they began to really interpret and interrogate both the virtual longhouse as well as their own mental maps of longhouse construction, use and interpretation. Interviewee $\mathbf{M}$ was offered a physical seated position, in-line with the digital benches within the longhouse. Sitting in that position, the participant was closer to the details of the bunk compartment, able to review the details that would have been lost when experiencing the entire longhouse at once. As Interviewee $\mathrm{M}$ had previously reconstructed several physical longhouses, there was an active discussion on building techniques, specifically around the bunk construction comparing the interviewee's experience with what was being seen virtually. Some of that discussion is presented below:

"So it's interesting you've got support posts in against or adjacent to the wall. I've never seen that archaeologically." (Interviewee M)

“The double row of posts?" (M Carter)

"Well I've never seen larger support posts closer to the wall posts. I've only seen larger support posts about two metres or a metre and a half in from the wall." (Interviewee M)

"So that was a good question. If you've got a family of four sleeping on a bunk, how are the crossbeams being attached to the wall posts? Is it a combination of smaller poles that are lashed together, or is it a larger pole?" (M Carter) 
"I think what happened was there was a cross member that was latched onto a wall pole that came out to a support post. So that was the support and then there were longer things [poles] coming off of that to create the bunk." (Interviewee M)

"So did you think that along the bunk pole it was lashed to every one of the wall poles in order to ensure that the pressure or the amount of pounds per square inch were keeping the bunk up?" (M Carter)

"What you could do is put a stringer along, just lash it along the wall, and then run stuff to that. But I'm sure there's different ways you could deal with it." (Interviewee M, emphasis added)

In another instance, Interviewee M was asked if anything struck him as "odd," or if otherwise there was anything that seemed unexpected based on the experience within the virtual space:

"I'm looking at this external grid structure you've got going on here [exterior wall poles] which I've never seen before." (Interviewee M)

"That's actually coming from Dean Snow['s research]. Apparently Iroquoian longhouses in upper New York had this type of external exoskeleton which would match up with the interior actual skeleton." (M Carter)

"This is really interesting because we have long acknowledged that there's probably structural differences between let's say Huron and Neutral longhouses. There's probably differences between New York State houses as well... Basically people coming up with different ways to solve the same kind of problem. Looking at this thinking how interesting the structure is. In some ways it's reminiscent of the pole lattice that you see down at the reconstruction in St. Marie, but it's much more robust and more uniform. I'm just thinking to myself how useful that could be, because you can tie in-between like basically the interior and exterior lashing in-between them." (Interviewee M) 
"It would certainly address one important question [in terms of the exterior bark shingling] which is how do you keep these things on in a storm? Because if asphalt shingles blow off houses today, then how the heck do you keep a bark shingle on something that's just as big, like this big, feathered bird? You just imagine the feathers getting ruffled by a strong wind and blown right off. But this would certainly do that. This whole thing has really got my thinking fired up here and it's really cool. I guess you achieved your objective." (Interviewee M, emphasis added)

Interviewee $\mathrm{J} 1$ was extremely methodical in examining every aspect of the longhouse. Unlike other participants, J1 was quiet and reflective. Using the physicality of the HTC Vive experience, J1 kneeled on the floor, stretched to see in areas beyond the subject's height, and used the HTC Vive controller to probe within representative baskets and pottery as a hand. For J1, the phenomenology of the space played an important role in understanding the lifeways of the longhouse itself. Knowledge construction occurred through what was missing as opposed to what was represented, i.e., by physically entering into the digital space it triggered other sensory notions and expectations around sound, touch and smell. For instance, the floor within the Sustainable Archaeology venue was solidly hard, whereas $\mathrm{J} 1$ felt that the longhouse itself would have had a softer feeling. The digital smoke would have been darker, thicker and dependent on the hourly and seasonal lighting within the longhouse itself. Sounds of domestic activity such as flint knapping and pottery-making would fill the environment. Smells of the fire, drying foodstuffs and the overabundance of people and their daily activities would linger throughout. So unlike Interviewee M's example of knowledge construction and querying the architectural details of the longhouse, for Interviewee $\mathrm{J} 1$ the virtual space brought alive thoughts of other notions of representation through smell, touch and sounds that would have furthered the humanity encompassed within this lived space. 


\subsection{3 "Oh, I Wasn't There"}

Throughout the interview process I was actively seeking variation in the feedback from the interviewees in terms of communicated observations and personal interpretations, more subtle variations in body movements, and overt moments of excitement or displeasure. Patterns began to emerge which suggested that age and experience, previous exposure to other non-immersive technologies and participant expertise played into individual experiences. However, over-arching commonalities demonstrated a kind of universality all participants experienced during their first exposure that played a role in how they interrogated the archaeological record virtually.

All interviewees experienced an initial moment of "awe" as they engaged for the first time within an immersive virtual space. Close to a third of the participants displayed some form of trepidation initially using the technology, which eventually dissipated for most as they eased slowly into navigating the borders between the digital and physical space. Of the entire interview group, only one participant preferred the non-head mounted display desktop environment, primarily due to issues relating to physical discomfort felt while in the immersive experience. But for the rest, Interviewee M sums up the general consensus expressed among the participants:

"It far exceeded my expectations. It didn't take long to feel comfortable navigating it and kind of forgetting about the technology, and really focusing on the house."

Younger participants generally adapted more quickly to the HTC Vive platform and expressed more of a born digital ease in understanding the navigation and limitations of the virtual environment. Older participants as well as most women tended to be more measured and thoughtful in their interactions within the virtual space as well as with their questions and answers. As an example, Interviewee R stated:

"You can really see the layers of construction of the longhouse. I want to be able to look up close and inspect everything. If this were real, I'd touch all the joints, 
and test them. I'd see how much tension is in the building. See how everything is tied together."

Archaeologists with longhouse excavation experience tended to seek out representations of their areas of interest (e.g., pottery, lithics, food use and longhouse construction). As some of these details were not directly related to my research goals or weren't firmly within my knowledge base, these elements were either missing or underrepresented. However, this form of inquiry and critique helped to situate the level in which archaeologists accepted or rejected the interpretations presented, while at the same time also provided me with personal reflection on the limitations of the build and direction for future enhancements. Ultimately engaging from what participants knew of longhouses informed how people negotiated the virtual space archaeologically. This informed their assessment and interrogation of the virtual space they experienced against the knowledge they had of longhouse archaeology. As Interviewee O observed:

"One of the things with this is it gives you a much better feel for actually how much isn't preserved in the archaeological record. All of the superstructure, the beds, the skin, and the sheer amount of firewood that you would need to stay warm. Just things you don't think about when you're writing a report." (emphases added)

Amongst the archaeologists and heritage professionals, there was a sense that VA enabled a unique way to connect to the materiality of the past. Interviewee M suggested that:

"Whatever we do, we don't want to just be making up stories. We need some connection to the data...and this is a tool that can allow us to create full interactions." 
Further, participants tended to acknowledge that interacting with the digital archaeological record enables a potential opportunity for creating new knowledge through the making of alternative notions of longhouse construction and use. Beyond their personal interpretations, there is also the ability for a broader meaning-making engagement, in which all voices and opinions can be visualized, tested and reflected upon. Interviewee $\mathrm{K}$ summed this notion up by saying:

"It's a great way to synthesize...but if you pull together everyone's information and build it into one thing that you walk through, it makes people talk about it. Realize where they disagree."

Lastly, archaeologists displayed a genuine interest in being immersed within the representational past, and acknowledged various expressions of presence conveying a perception of what life might have been like within a longhouse itself. Emphasis was placed by the participants on the value of being able to experience the archaeological record through this still limited phenomenological approach, since it enhanced and offers a conceptually different way of knowing the past in the present than conventional 2D modes of interpreting the archaeological record. Interviewee P stated:

"Using the Vive, the headset, it's really strange because the biggest sensation of being there is when you take it off, and realize, 'Oh, I wasn't there'."

\subsection{Discussion}

The stated aims of examining user experiences in a virtual longhouse was to: i) document participant preconceptions of both their anticipated VA experience and longhouse environments; ii) observe how participants engage with and choose to interact with the virtual longhouse; iii) observe through discussion how participants perceived the virtual environment in terms of authenticity and authority; iv) document their interpretation of the representation and placement of digital assets, landscapes and built structures; and v) 
record any alternative meaning-making they themselves expressed or advanced after interacting with this virtual environment. By engaging with the participants, the environment in which they physically interacted with, the virtual experience and the recording of their oral responses and physical movements, a picture began to emerge of how these participants perceived a virtual heritage and ancient materiality.

However, I began this paper discussing in detail the venue dimensions, environmental conditions and physical surroundings in which each group of participants were interviewed. I did so as the method in which participants were going to interact with the virtual space would be both a physical and digital one in which even the smallest of elements like errant flies buzzing about had the potential to contribute to the overall experience within the virtual space. The heat of the room, the flooring material beneath their feet and even the physical surfaces of the objects in the room contributed or constrained, to a degree, the presence each individual participant experienced during their sessions. I did not pre-emptively anticipate that these conditions would factor into the interviewees' underlying experience and thus had to make course corrections in my own observations as the interviews progressed. Based on those observations, the physicality of the venue, whether rendered in the exact representation of the digital space or not, is a contributing factor in participation interaction and their acceptance of a phenomenological experience within a virtual environment. Future methods of engagement could take these elements into consideration as a strategy for allowing the digital space to have a physical materiality reinforcing the immersive experience (e.g., using earthen ground surfaces, placing wooden poles aligned with support posts, etc.), to further blur the border between virtual and physical space.

The interviewees, to a person, were willing and somewhat knowledgeable participants. They knew what a "longhouse" was, for the most part, and could understand at least the idea of the immersive build. Although the technology and subsequent "wow" factor did hinder the initial critical thinking I had envisioned, once that fetishization had diminished, their feedback and my discussion with them robustly shaped how they interrogated the space they were in as well as their previous conceptions. As such this 
feedback also shaped my own understanding of how VA can better accelerate knowledge dissemination of complex ideas, data and the archaeological unknown.

After spending five years crafting this virtual experience, my assumption going in to the user experience was that most if not all participants would have had some form of experience within VR landscapes. And by having that previous experience, the participants' views would be informed by the archaeological interpretations presented as opposed to the technology. I was shocked however by the anxiousness of some of the users to the technology, and, once in the virtual space, the universal sense of "awe" expressed. That technological fetish (see Huggett 2004) delayed the actual intent of the study until participants could accustom themselves to the mechanics of experiencing the digital world from a physical perspective.

Once immersed however, there was recognition of being in "another new version of a familiar place" (Interviewee M). As was apparent in the majority of participant responses to the questions about pre-conceived notions of longhouse shape, size and use, there was an almost universal conception of the shape and layout of a longhouse, for example: "lozenge shaped" (Interviewee K), "like a mitochondria" (Interviewee N), "long and oval" (Interviewee R) and "pill shaped" (Interviewee I); notably all descriptions that better describes the 2D excavated outline of a longhouse than $3 \mathrm{D}$, above-ground shape. Like the interviewees, I too have been influenced by $2 \mathrm{D}$ excavation maps, as well as interpretive (re)visualizations and physical reconstructions, and found that even after interpreting all the archaeological, historical and modern descriptions of longhouses, I built a 3D representation reflective of that 2D outline and historically-derived mental image my participants also had in their minds. In that familiarity however, participants were able to draw from previous experiences of interpreting and interacting with longhouse archaeological data to inform how they would interpret the virtually unknown dimensions of the archaeological record presented in Longhouse 3.x. So participants' preexisting notions of longhouses helped to ease them into the virtual environment.

There was a general sense of a real acceptance of what participants were seeing when virtually immersed within the environment. Initially two participants had strong reactions to the longhouse I had virtually presented, as the virtual build did not match these 
interviewees' personal expectations of seeing the longhouse represented in a way that conformed to their preferences. In my discussion with each of these participants I pointed out that the longhouse was really only a single representation of one of several possible interpretations. This response was a bit of a passive defense to their objections, but also served to re-direct the discussion towards the notion that the technology to build the virtual space and the platform in which to deliver the experience had the capability to be revised in order to provide multiple experiences and multiple interpretations of a longhouse build, including iterations closer to these individuals' preferences. This discussion allowed these participants to acclimatize to the representation before them as incorrect to their own expectations, while recognizing that VA had the means to interrogate multiple notions of existing archaeological knowledge and provide ways of new knowledge to be built and subsequently challenged virtually.

Participants tended to reveal their own various areas of specialized area of research in archaeology in our discussion and give focus to their examination of what they were seeing virtually. Bioarchaeological, faunal and other specialist archaeologists sought to define the virtual longhouse by what they knew respectively of how their fields intermingled with longhouse archaeology, seeking to discover virtually what they would find archaeologically in the physical world.

All interviewees immediately understood how to translate the physical mechanics of moving in space into a virtual environment. They knelt, sat on the ground, perched on their tiptoes in order to physically and visually interrogate what they were seeing. The technology allowed for this physical translation into the digital, yet some still observed how the weight of the goggles or the cable tether that attached to the computer reminded them that they were still interacting virtually. Unlike the desktop version, which required mastery of game controllers, participants almost unanimously preferred to be able to physically interact directly within the digital environment. This observation was so apparent that there was genuine confusion and dislike interacting with the desktop version. 
Participants wanted to pick objects up, and move them to areas that played better in their notions or mental image of the longhouse environment and use of interior spaces. The ability to effect change, determine the representation or to alter the material layout of the 3D space alludes to what I believe is an innate desire to rapidly test notions for fittedness within participants' knowledge of the building process and lived space. Archaeology is a highly sensory activity, involving hand, body and eye movement, and thus as archaeologists becoming accustomed to their new environment, they wanted to rely on those same senses in order to accept the experience as archaeologically authentic.

Through observation and participant discussion, I felt that the general feeling of a reproducible authenticity within virtual space (or physical space, for that matter) was not an achievable or even desirable construct for this build and research. That tended to be mirrored by the participants as they tended to reflect an acceptance that what they were experiencing was informed by the archaeological record but not necessarily and accurately representative of that record. Even with a lower quality of detail, when coupled with the notion of presence, there was an acknowledgement of being within "an" archaeological past and thus this virtual space was providing the ability to reflect on and potentially construct new knowledge. Participants' observations tended to reflect Jeffery's (2015:147) "digital aura," and the "sensation of being close to the past," as well as the ability to negotiate between the authenticity of the build's intent as distinct from any notion of the build being an authorized representation of the past.

Nonetheless, there was an underlying authority that embodied the experience. Participants knew through our pre-interview discussions and during-interview questions and answers that the virtual environment was a construct of my mental image of longhouse morphology and interpretation of the academic literature. I was their guide throughout the experience, not only physically directing them, but also by physically ensuring they didn't become tangled in cables or walk into a wall, and virtually by pointing out areas that directly spoke to their individual interests. However, once the participant became accustomed to the virtual environment, authority shifted from myself as creator, maker and guide, to the participant as critical evaluator over "my" build and what they felt was "correct" or not. 
Whether archaeologically or culturally representational or not, the virtual environment invited a reflexivity on alternative ways of knowing the archaeological past among the two Indigenous participants. They each drew on their personal knowledge and professional expertise, and offered observations from oral, historical and physical traditions that they felt informed not only the organic nature of longhouse spirituality, but in its daily use as a living, breathing entity and manifestation of community and family. They each noted the potential of this virtual context to serve constructs and dimensions of the longhouse; constructs that could be tailored to specific community membership, and to engage with knowledge and dimensions of life that non-community members could, and notably should not, access. This potential for the immersive environment to service a community-based Indigenous virtual archaeological heritage was also noted by several of the non-Indigenous participants when reflecting on the implications of digitally being able to create alterative iterations of a virtual longhouse.

Object placement proved to be of greatest interest to the few archaeologists who previously participated in physical longhouse excavations. They drew from those experiences to inform them of what was missing within the virtual representation, and question aspects of the physicality of building a longhouse, structural engineering, and also to suggest alternative interpretations for object use and storage within the longhouse. Again they wanted to touch, pick-up, move and effect changes, which spoke to the materiality that archaeologists situate their knowledge construction within.

Seasonality played an important role in participants' observations. Many interviewees commented on their desire to be able to virtually experience the longhouse in all seasons to understand the seasonal cycle of the longhouse. Generally, there was a sense that, in the summer, the longhouse would have been quiet as daily duties and the heat would have driven people outside. The fall would have been a time of intense activity as the longhouse became the center of life as food stores and preparation for the winter would consume the community. Over the winter the longhouse would have taken on a different personality as people spent more time indoors, the cold would have required more heat from hearths, food stores would have dwindled, and the constant exposure to smoke and close quarters of more residents being inside the longhouse for more of the day all would 
have put pressure on the longhouse space. Lastly, during the spring, longhouse-resident activities would have again shifted outside, as exterior repairs, new construction and starting to replenish supplies would again change the dynamic of interior longhouse space. Participants who mentioned seasonality indicated they wanted to better understand the seasonal lifecycles that the longhouse itself represented of community life. And this understanding of the shifting seasonality of the longhouse also underscored for the participants that a singular, authorized representation was possible, since the longhouse, as a material, physical and cultural construct continually changed with the seasons, as well as through space and time.

Generally, researchers are dealing with the archaeological record in the moment, thus the notion of presence, of being within the virtual space temporally and contextually was surprisingly important to the archaeological and heritage professionals interviewed. I would suggest participants demonstrated that archaeologists respond positively to phenomenologically engaging with the archaeological record. They wanted to interact and be connected not only with visualizations of the archaeological data, but with the assumptions and notions that are created when constructing knowledge of the unknowable past through the senses. Combined with the border between the physical and the digital, participants felt they were actively observing the archaeological landscape. However the "Swayze Effect" (Burdette 2015), that inability to effect any change within the virtual space, hindered the degree of immersiveness the participants were able to attain.

Participants variably interrogated the build, and their own assumptions about longhouse construction and use, based on many factors they brought to the experience, and the duration and type of activities they carried out during their time in the build. So the individual, their prior knowledge, and the degree to which they were willing to engage the technology all shaped how participants interrogated archaeological meaning-making of ancient longhouses and longhouse living, which occasionally led to constructions of new knowledge, or at least questioned prior assumptions, within this virtual space. For example, Interviewee $\mathrm{M}$ had a deep and extensive base practical knowledge of longhouses, from the perspective of field experiences, time spent in and building 
longhouses, and their own interpretive framework. Interviewee M spent the longest time within the virtual space, moving past any initial awe of the technology to allow room for a more critical, thorough and methodological interaction with the virtual environment. For this participant their strong base longhouse knowledge, their detailed and prolonged analysis of the virtual space, and their willingness to engage in an interrogation of the meaning-making behind the longhouse visualization led to an open ended and broad discussion that created the most ideal opportunity for querying both the interviewee's own existing knowledge, as well as the virtual representation being experienced.

The ability of the HTC Vive to allow participants to consider alternative notions of longhouse construction and use "inside" the virtual build of Longhouse 3.x helped to initiate healthy discussions on the viability of a multiplicity of possible interpretations about the unknowable dimensions of the archaeological record. Amongst all participants, the slight variations in the Longhouse 3.x visual representation to their personal mental conceptions of what a longhouse would look like inside and outside helped enable interviewees to interrogate archaeological meaning-making beyond those personal conceptions. Although I felt the degree of interrogating existing knowledge was ultimately hard to measure in this interview process, I could see that by challenging the norms of longhouse construction and use, even if by visualizing relatively minor, alternative conceptions of longhouse build and space to those more familiar to individual interviewees, helped to provide participants with the permission to consider the relativity of archaeological interpretations, and play with alternative interpretations from the same archaeological record. As Interviewee M stated:

"We try to reconstruct the past, we think we have ideas about how things work on paper, but then when we actually go to build it, it's different. We discover additional things that we may not have been anticipating. So that's kind of how I see virtual spaces being a tool that could enhance that."

In this sense, the aims of my research, as set out in the start of this chapter, succeeded in presenting VA as a digital means to interrogate knowledge in archaeology. Archaeologist 
participants were willing to allow for "alternative notions" of longhouse construction and use, such as a different height for bunks, different exterior wall construction, different ways for storing wood, etc. Notably however, that discussion operated within the confines of a logical limit to variability: relatively minor technical adjustments that avoided destabilizing core elements of the archaeologist's mental template for a longhouse, i.e., central corridor, aligned bunks on either side, entrances at either end of a lozenge-shaped building plan, etc. In other words, the focus of most discussions was on differences around material details, such as build, space and object content of longhouses, within a more stable template of what a "longhouse is" remaining unquestioned. While not the focus of this research, alternative iterations in the visualization that more directly confronted archaeological sensibilities when it comes to longhouse space and architecture, for example leaving out a portion of the roof, making compartments based on ground surface instead of a bunk line or only existing on one side of the central corridor, making end vestibules living spaces, etc., may well have elicited more critical resistance and reinforcement of pre-existing archaeological sensibilities in our discussions.

Despite not overtly confronting core, archaeologically-based conceptions of above ground longhouse build and space in the visualization, discussions with most participants, and with all the archaeologists with a strong prior sense of what they "should" see, did lead to variable explorations of the conceptual limitations of archaeological interpretations. The digital visualization of my iteration of a sixteenth century longhouse allowed the point to be explored by participants that archaeologically-based knowledge of the material past is a process of archaeologically informed speculation; something participants perhaps intellectually could have acknowledged beforehand, but emotionally in some instances may have been too invested in their own notions of what a longhouse should be. Notably, knowing these limitations to archaeological interpretation did not stop most participants from considering the cultural phenomenon of living in a longhouse, and the presence the digital representation created appears to have allowed for an immersive appreciation of the phenomenological ancient space and daily living suggested by the iteration offered up in Longhouse 3.x 
One value of VA then, is the ability to offer a reflexive consideration of multiple, alternative iterations of the archaeological past, and how those iterations, and the assumptions embedded in them, are negotiated as meaning-making in archaeology. For example, participants overwhelmingly preferred the physical/digital experience of the HTC Vive to the game-like and more passive desktop experience. My assumption as an artist going into the interviews was that interviewees would prefer the almost photorealistic, highly detailed and visually rendered version of the desktop experience over the less detailed, lower quality immersive experience of the HTC Vive. But the overwhelming view expressed was that the immersive environment provided a greater sense of presence, of being contextually within and querying the archaeological record, at a specific time and place. When combined with the ability to walk around, kneel, sit and stretch, this presence helped to situate participants actively within the virtual experience, regardless of the quality of the appearance. Visual resolution and detail proved less of a concern to the participants. It also meant more of a willingness to accept the digital methodology, and the recognition that multiple iterations of the build could be made to address user-identified deficiencies and allow for user preferences to be visualized.

How does this validate VA as meaning-making (and means of interrogating meaning making) in archaeology? That has less to do with being open to alternate archaeological interpretations from the same record, and more with the very essence of meaning-making itself in the archaeological enterprise. These participants provided new insight into the representation of Iroquoian longhouses digitally. They identified areas of concern for future enhancement but also recognized that the virtual experience allows for reflection of alternative means of knowledge construction. Although limited new meaning-making was observed during this iteration, conditions for enhancing revealing the process of knowledge construction through the virtual experience became clearer, as participants negotiated and tested the authenticity, authority, and agency they were also visualizing in the Longhouse 3.x iteration. Ingold's (2011) notions of materiality, making and wayfaring, coupled with Wylie's $(1989,2002)$ notions of cabling and tacking, materialized while I engaged with the research participants as they engaged with the virtual space. If new knowledge construction wasn't overly overt, knowledge 
deconstruction was by compromising the notion of a singular, authorized form of meaning making in archaeology. Further virtual deconstruction of the assumptions in archaeological meaning-making, and how that process facilitates a more pluralist multiplicity of meaning-makings, should be actively set as a future goal of research to advance and demonstrate the strength of a VA as meaning-making of the past within and beyond archaeological data, norms, and sensibilities.

My research and the virtual (re)imagination of the archaeologically known landscape both challenged and reified archaeological ways of knowing to archaeologists. And in the process also made evident to many archaeological participants, as well as nonarchaeologists and the Indigenous archaeologist and heritage professional interviewed, the potential for this platform to serve as a foundational beginning to create alternate spaces and alternate ways of knowing the past in the present that uses this variably "truthed" archaeological iteration to go beyond archaeology. Participant interrogation of the visualization managed to destabilize particulars of archaeological assumptions infusing the unknowable dimensions of the archaeological record for longhouses, while core elements hinted at or directly knowable from archaeological data remained intact. Future research can advance from that destabilization of knowledge making in archaeology to create spaces, visually and conceptually, for other ways of knowing the past. This research would focus on developing visualizations for non-archaeologists that develop user-choices and community-specific knowledge for particular audiences that serve a multitude of uses beyond visual verification or interrogation of archaeological notions of, for example, longhouses. The proximate aim of testing knowledge creation (and, really, challenging it) through a VA inquiry of archaeological ways of knowing, was, if not fully confirmed, certainly demonstrated as having a real role in the future development of VA. 


\subsection{References}

Bartram, John

1751 Observations on the Inhabitants, Climate, Soil, Rivers, Productions, Animals and Other Matters Worthy of Notice, Made by Mr. John Bartram, in His Travels from Pensilvania to Onondago, Oswego and the Lake Ontario, in Canada. J. Whiston and B. White, London. Electronic document, https://archive.org/details/cihm_11915, accessed June 14, 2017.

Beauchamp, William Martin

1905 Aboriginal use of wood in New York. New York State Museum, Bulletin 69, Archaeology 11. New York State Education Department, Albany.

Beale, G, and P Reilly

2014 Additive Archaeology: The Spirit of Virtual Archaeology Reprinted. In Archaeological Research in the Digital Age: Proceedings of the 1st Conference on Computer Applications and Quantitative Methods in Archaeology Greek Chapter (CAA-GR) Rethymno, Crete, 6-8 March 2014. Institute for Mediterranean Studies - Foundation of Research and Technology (IMS-FORTH), edited by, Papadopoulos, C., E. Paliou, A. Chrysanthi, E. Kotoula, and A. Sarris, pp. 120 128.

Benicho, V.M. Lopez-Menchero

2013 International Guidelines for Virtual Archaeology: The Seville Principles, In: Good Practice in Archaeological Diagnostics, edited by C. Corsi, B. Slapsak and F. Vermeulen, pp. 269-284. Springer International Publishing.

Benicho, V.M. Lopez-Menchero, M. Flores Gutierrez, M.L. Vincent and A. Grande Leon 2017 Digital Heritage and Virtual Archaeology: An Approach Through the Framework of International Recommendations. In Mixed Reality and Gamification in Cultural Heritage, edited by M. Ioannides, N. Magnenat-Thalmann, and N. Papagiannakis, pp. 3-26. Springer International Publishing.

Birch, Jennifer, and Ronald F Williamson

2012 The Mantle Site: An Archaeological History of an Ancestral Wendat Community. AltaMira, Lanham.

2013 Organizational complexity in ancestral Wendat communities. In From Prehistoric Villages to Cities: Settlement Aggregation and Community Transformation, edited by Jennifer Birch, pp. 153-178. Routledge, New York.

2015 Navigating ancestral landscapes in the Northern Iroquoian world. Journal of Anthropological Archaeology 39: 139-150.

Boyden, Joseph

2013 The Orenda. Hamish Hamilton, Toronto.

Burdette, Matt

2015 The Swayze Effect. Oculus Story Studio. Electronic document, https://www.oculus.com/story-studio/blog/the-swayze-effect/, accessed May 25, 2016.

Bursey, Jeffrey

2001 Storage Behavior in the Northeast: a Review of the Evidence. North American Archaeologist 22(3): 179-199.

Chadwick, Edward Marion

1897 The People of the Longhouse. The Church of England Publishing Co. Limited, Toronto. 
Champion, Erik

2015 Defining Cultural Agents for Virtual Heritage Environments. Presence:

Teleoperators and Virtual Environments 24(3): 179-186.

Champlain, Samuel

1907 Voyages of Samuel de Champlain 1604-1618. Edited by W. L. Grant. Charles Scribner's Sons, New York.

Chapdelaine, Claude

1993 The Sedentarization of the Prehistoric Iroquoians: A Slow or Rapid

Transformation? Journal of Anthropological Archaeology 12(2): 173-209.

Chalmers, Alan

2017 Experiencing the Multisensory Past. In Mixed Reality and Gamification in Cultural Heritage, edited by M. Ioannides, N. Magnenat-Thalmann, and N. Papagiannakis, pp. 359-370. Springer International Publishing.

Creese, John L.

2012a Post Molds and Preconceptions: New Observations about Iroquoian Longhouse Architecture. Northeast Anthropology (77): 47-69.

2012b The Domestication of Personhood: a View from the Northern Iroquoian Longhouse. Cambridge Archaeological Journal 22(3): 365-386.

2013 Rethinking Early Village Development in Southern Ontario: Toward a History of Place-making. Canadian Journal of Archaeology 37(2): 185-218.

Dallas, Costis

2009 From Artefact Typologies to Cultural Heritage Ontologies: Or, an Account of the Lasting Impact of Archaeological Computing. Archeologia e Calcolatori 20: 205221.

Dawson, P., R. Levy, and N. Lyons

2011 'Breaking the fourth wall': 3D virtual worlds as tools for knowledge repatriation in archaeology. Journal of Social Archaeology 11(3): 387-402.

Denard, Hugh

2012 A New Introduction to the London Charter. In Paradata and Transparency in Virtual Heritage, edited by A. Bentkowska-Kafel, D. Baker \& H. Denard, pp. 57-71. Ashgate, Farnham.

Dodd, Christine F

1984 Ontario Iroquois tradition longhouses. Archaeological Survey of Canada Paper, No 124, pp. 181-437. Mercury Series, National Museum of Man, Ottawa.

Dodd, C.F., Poulton, D., Lennox, P. A., Smith, D.G., and Warrick, G.

1990 The Middle Ontario Iroquoian stage. In The Archaeology of Southern Ontario to A.D. 1650, edited by C. J. Ellis, and N. Ferris, pp. 321-359. Occasional Publications of the London Chapter, Ontario Archaeological Society, No. 5, London.

Earl, Graeme

2013 Modeling in archaeology: computer graphic and other digital pasts. Perspectives on Science 21(2): 226-244.

Engelbrecht, William E

2003 Iroquoia: The Development of a Native World. Syracuse University Press, Syracuse.

Fecteau, R D

1979 The Longhouse Experiment. KEWA: Newsletter London Chapter, Ontario Archaeological Society 79(2): 1-3.

Ferris, Neal 
2013 Place, Space, and Dwelling in the Late Woodland. In Before Ontario: The Archaeology of a Province, edited by, Marit K Munson and Susan M Jamieson, pp. 99-111. McGill-Queen's Press, Montreal and Kingston.

Finlayson, William David

1985 The 1975 and 1978 Rescue Excavations at the Draper Site: Introduction and Settlement Patterns. Archaeological Survey of Canada Paper, No 130. Mercury Series, National Museum of Man, Ottawa.

Forte, Maurizio

2014a 3D Archaeology: New Perspectives and Challenges - The Example of Çatalhöyük. Journal of Eastern Mediterranean Archaeology and Heritage Studies 2(1): 1-29.

2014b Virtual Reality and Cyberarchaeology. In 3D Recording and Modelling in Archaeology and Cultural Heritage Theory and Best Practices, edited by Fabio Remondino and Stefano Campana, pp. 3-6. Archeopress. British Archaeological Reports (S2598), Oxford.

Frankland, T.J.

2010 A CG Artist's Impression: Depicting Virtual Reconstructions Using NonPhotorealistic Rendering Techniques. In Thinking Beyond the Tool:

Archaeological Computing and the Interpretative Process, edited by, Angeliki Chrysanthi, Patricia Murrieta-Flores, and Constantinos Papadopoulos. Archaeopress, Oxford.

Frankland, Tom, and Graeme Earl

2011 Authority and Authenticity in Future Archaeological Visualisation. In Proceedings of Ads-Vis2011: Making Visible the Invisible: Art, Design and Science in Data Visualisation: 62-68.

Gartner Inc.

2016 Gartner's 2016 Hype Cycle for Emerging Technologies Identifies Three Key Trends That Organizations Must Track to Gain Competitive Advantage. Gartner's 2016 Hype Cycles Highlight Digital Business Ecosystems. Electronic document, http://www.gartner.com/newsroom/id/3412017, accessed January 16, 2016.

Gea, Juan M Carrillo, Ambrosio Toval, José L Fernández Alemán, Joaquín Nicolás, and Mariano Flores

2013 The London Charter and the Seville Principles as Sources of Requirements for EArchaeology Systems Development Purposes. Virtual Archaeology Review 4(9): 205-211.

Gerard-Little, Peregrine A., Michael B. Rogers, and Kurt A. Jordan

2012 Understanding the Built Environment at the Seneca Iroquois White Springs Site using Large-Scale, Multi-Instrument Archaeogeophysical Surveys. Journal of Archaeological Science 39(7): 2042-2048.

Gillings, Mark

2005 The real, the virtually real, and the hyperreal: The role of VR in archaeology. In

Envisioning the Past: Archaeology and the Image, edited by, S., Smiles and S.

Moser, pp. 223-239. Blackwell, Oxford.

Hatch, James W, and Gregory H. Bondar

2001 Late Woodland Palisaded Villages from Ontario to the Carolinas. In Archaeology of the Appalachian Highlands, edited by, L. P. Sullivan and S. C. Prezzano, pp. 149-167. University of Tennessee Press, Knoxville.

Heidenreich, Conrad E 
1972 The Huron: A Brief Ethnography. Department of Geography Discussion Paper no. 6. York University, Toronto.

Huggett, J.

2004 Archaeology and the New Technological Fetishism. Archeologia e Calcolatori 15: 81-92.

2013 Disciplinary Issues: Challenging the Research and Practice of Computer Applications in Archaeology, In Archaeology in the Digital Era, edited by, Earl, G., T. Sly, A. Chrysanthi, P. Murrieta-Flores, C. Papadopoulos, I. Romanowska, D. Wheatley, pp. 13-24. Amsterdam University Press, Amsterdam.

Jamieson, J Bruce

1990 The Archaeology of the St. Lawrence Iroquoians. In The Archaeology of Southern Ontario to A.D. 1650, edited by C. J. Ellis, and N. Ferris, pp. 385-404.

Occasional Publications of the London Chapter, Ontario Archaeological Society, No. 5, London.

Jeffrey, Stuart

2015 Challenging Heritage Visualisation: Beauty, Aura and Democratisation. Open Archaeology 1: 144-152.

Jones, Eric E., and James W. Wood

2012 Using Event-History Analysis to Examine the Causes of Semi-Sedentism among Shifting Cultivators: A Case Study Of The Haudenosaunee, AD 1500-1700. Journal of Archaeological Science 39(8): 2593-2603.

Jordan, Kurt A.

2013 Incorporation and Colonization: Postcolumbian Iroquois Satellite Communities and Processes of Indigenous Autonomy. American Anthropologist 115(1): 29-43.

Kapches, Mima

1990 The Spatial Dynamics of Ontario Iroquoian Longhouses. American Antiquity: 4967.

1993 The Identification of an Iroquoian Unit of Measurement: Architectural and Social/Cultural Implications for the Longhouse. Archaeology of Eastern North America: $137-162$.

Keener, Craig S.

1999 An Ethnohistorical Analysis of Iroquois Assault Tactics Used against Fortified Settlements of the Northeast in the Seventeenth Century. Ethnohistory 46(4): 777-807.

Lafitau, Father Joseph Francois

1977 Customs of the American Indians Compared with the Customs of Primitive Times Vol 2. Edited by W. N. Fenton and E. L. Moore. Publications of The Champlain Society 49, Toronto.

Lee, Hyuk-Jin

2017 Phenomenological Classification of Cultural Heritage: Role of Virtual Reality. Virtual Archaeology Review 8 (16): 69-74.

Lennox, Paul A, and William R Fitzgerald

1990 The Culture History and Archaeology of the Neutral Iroquoians. In The Archaeology of Southern Ontario to A.D. 1650, edited by C. J. Ellis, and N. Ferris, pp. 405-456. Occasional Publications of the London Chapter, Ontario Archaeological Society, No. 5, London.

Mohawk, John

1978 A basic call to consciousness: The Hau de no sau nee address to the western world, Geneva, Swittzerland, autumn 1977. Electronic document, https://ratical.org/many_worlds/6Nations/BasicCtC.html, accessed June 11, 2015. 
Morcillo, Jesus Munoz, Franziska Schaaf, Ralf Schneider, and Caroline Robertson-von Trotha

2017 Authenticity Through VR-Based Documentation of Cultural Heritage. A

Theoretical Approach Based on Conservation and Documentation Practices.

Virtual Archaeology Review 8(16):35-43.

Morgan, Colleen L.

2012 Emancipatory digital archaeology. Ph.D. dissertation, University of California, Berkeley.

Morgan, Lewis Henry

1881 Houses and House-life of the American Aborigines. Contributions to North American Ethnology No. 4. US Government Printing Office, Washington.

Noble, William C

1975 Corn and the Development of Village Life in Southern Ontario. Ontario Archaeology 25: 37-46.

Norcliffe, G. B., and C. E. Heidenreich

1974 The Preferred Orientation of Iroquoian Longhouses in Ontario. Ontario Archaeology 23(3): 3-30.

Pannell, Sandra

1994 Mabo and Museums: "The Indigenous (Re) Appropriation of Indigenous Things." Oceania 65(1): 18-39.

Perry, Sara

2015 Crafting Knowledge with (Digital) Visual Media in Archaeology. In Material Evidence. Learning from Archaeological Practice, edited by R. Chapman and A. Wylie, pp. 189-210. Routledge, New York and London.

Ramsden, Peter G

1990 The Hurons: Archaeology and Culture History. In The Archaeology of Southern Ontario to A.D. 1650, edited by, C. J. Ellis, and N. Ferris, pp. 361-384.

Occasional Publications of the London Chapter, Ontario Archaeological Society, No. 5, London.

Reilly, P

2015 Putting the Materials Back into Virtual Archaeology. In Virtual Archaeology (Methods and Benefits), edited by, D. Hookk, pp. 12-21. The State Hermitage Publishers, St. Petersburg.

Sagard, G.

1939 The Long Journey to the Country of the Hurons, edited by, George M. Wrong and translated by H.H. Langton. Champlain Society, Toronto.

Sioui, G.E.

1999 Huron-wendat: The Heritage of the Circle. Edited by J. Brierley. University of

Snow, Dean R.

British Columbia Press, Vancouver.

1997 The Architecture of Iroquois Longhouses. Northeast Anthropology 53: 61-84.

StarTrek.com Staff

2014 Star Trek Meet The Man Behind The Holodeck, Part 1. Startek.com. Electronic document, http://www.startrek.com/article/meet-the-man-behind-the-holodeckpart-1, accessed April 15, 2016.

Steckley, John

1987 An Ethnolinguistic Look at the Huron longhouse. Ontario Archaeology 47: 1932.

Thwaites, Reuben Gold 
1896-1901 The Jesuit Relations and Allied Documents: Travels and Explorations of the Jesuit Missionaries in New France, 1610-1791. 73 vols. Burrows Brothers, Cleveland.

Trevor-Roper, Hugh

1983 The Invention of Tradition: The Highland Tradition of Scotland. In The Invention of Tradition, edited by E Hobsdawm and T Ranger, pp. 15-41. Cambridge University Press, Cambridge.

Trigger, B G

1963 Settlement as an Aspect of Iroquoian Adaptation at the Time of Contact. American Anthropologist 65(1): 86-101.

1978a Early Iroquoian Contacts with Europeans. In Handbook of North American Indians: Northeast, Vol. 15. Edited by, B.G. Trigger, pp. 344-356. Smithsonian Institution, Washington, D.C.

1978b Iroquoian Matriliny. Pennsylvania Archaeologist 48(1-2): 55-65.

1987 Children of aataentsic: A history of the Huron People to 1660, Vol 196. McGillQueen's Press, Montreal.

Varley, Colin, and Aubrey Cannon

1994 Historical Inconsistencies: Huron Longhouse Length, Hearth Number and Time. Ontario Archaeology 58: 85-101.

Warrick, Gary

1988 Estimating Ontario Iroquoian Village Duration. Man in the Northeast 36: 21-60.

1996 Evolution of the Iroquoian Longhouse. In People Who Lived in Big Houses: Archaeological Perspectives on Large Domestic Structures, edited by, G. Coupland and E.B. Banning, pp. 11-26. Prehistory Press Madison, Wisconsin.

2000 The Precontact Iroquoian Occupation of Southern Ontario. Journal of World Prehistory 14(4): 415-466.

Watterson, Alice

2015 Beyond Digital Dwelling: Re-thinking Interpretive Visualisation in Archaeology. Open Archaeology 1(1): 119-130.

Williamson, Ronald F

2004 Replication or Interpretation of the Iroquoian Longhouse. In The Reconstructed Past: Reconstructions in the Public Interpretation of Archaeology and History, edited by, John H. Jameson, Jr., pp. 147-166. Altamira Press, New York.

Wright, James Vallière

1974 The Nodwell Site. Archaeological Survey of Canada Paper 22. National Museum of Canada, Ottawa.

1995 Three Dimensional Reconstructions of Iroquoian Longhouses: A Comment. Archaeology of Eastern North America 23: 9-21.

Wylie, Alison

1989 Archaeological Cables And Tacking: The Implications of Practice for Bernsteins' 'Options Beyond Objectivism and Relativism'. Philosophy of the Social Sciences 19(1): 1-18.

2002 Archaeological Cables and Tacking: Beyond Objectivism and Relativism. In Thinking from Things: Essays in the Philosophy of Archaeology, University of California Press, Berkeley, pp. 161-167. University of California Press, Berkeley and Los Angeles.

Zubrow, Ezra B W

2006 Digital Archaeology. In Digital Archaeology. Bridging Method and Theory, edited by Thomas L. Evans and Patrick Daly, pp. 10-31. Routledge, London. 


\section{Chapter 5}

\section{Conclusions: Virtual Making and Meaning-Making}

Inspiration for this research came about in the most peculiar way. Although over 20 years ago I had theorized the notions of creating 3D representations of longhouses in the field as a means of better visualizing the real-time revealing of the archaeological record, it was in fact the daily exposure to a reproduction of C.W. Jefferys' Part of a Palisaded Huron-Iroquois Village (Jefferys and McLean 1942:16), hanging in the display case of my son's public school that triggered my passion to explore longhouse archaeology virtually. Shortly after Jefferys' death in 1951, his family sold most of his illustrations, which made up the "Picture Gallery of Canadian History" series, to the Imperial Oil Company of Canada. Many of those same illustrations were republished in a series of portfolios that were distributed to schools across Canada. In 1976, Imperial Oil donated the collection to the Library and Archives Canada (Anthony Allen personal communication, 2017). In the case of C.W. Jefferys' longhouse visualization, it sat in a dusty display celebrating the Withrow Site, a continuously used, seasonal Archaic to Woodland encampment in what is today the Riverdale community in Toronto, Ontario (Kapches 1986). Its strategic placement in the school to and from the main office meant I had to pass it regularly, creating an indelible mental image in my head of what I assumed a typical Iroquoian longhouse looked like. I wondered whether new archaeological knowledge could be formed by the transference of longhouse data from the traditional $2 \mathrm{D}$ representations of historic illustrations and excavation maps, to a more interactive and immersive 3D environment. And if by (re)imagining longhouses virtually, could archaeologists, stakeholders, and the public glean new knowledge by experiencing the archaeological record in 3D?

Thus, a primary aim of this research was an attempt to better understand the role of knowledge construction as a means of making new virtual objects and environments embodied by personal wayfaring through personal archaeological meaning-making. My assumption was that VA could interrogate archaeological knowledge construction in a unique, engaging but theoretically situated way. I assumed by experiencing the phenomenological notion of presence virtually archaeologists would embrace not only 
the platform, namely VA, but also my own personal interpretation of the archaeological record and research on material settlement patterns of longhouses through the presentation of a virtual reconstruction of a prototypical $16^{\text {th }}$ century northern Iroquoian longhouse.

This research aim of mine proved to also be an exercise in exploring the fundamental shifts and course corrections (or wayfaring points) representative of the meaning-making process I undertook in both the digital construction of a longhouse, and in the engagement of that build by both myself as maker, and by archaeological and heritage professionals, as consumers. Beyond constructing and interrogating meaning-making, there emerged a unique interpretation of the subject matter that indicated VA, when grounded in theory and practice, becomes a powerful knowledge creation tool, enabling an immersive experiential engagement with the representation of an interpretive construct, one that invited cabling and tacking through this newly constructed knowledge, as well as individuals' previous assumptions, understandings and knowledge of longhouses and longhouse space.

\subsection{Findings from Making}

\subsubsection{Making}

As an animation and visual effects expert, I set off to develop an expertise in visualizing archaeology. I soon realized, however, that it was more the journey and less the end product that was the greatest value for archaeological meaning-making. "Making" as Ingold $(2011,2013)$ has pointed out is knowledge construction in real-time. For the maker, it is both knowledge discovery along a journey and equally the challenging of accepted knowledge, or those mental constructs that we develop subconsciously through exposure to the interpretations or ways of knowing by others.

Although Ingold is widely quoted for his work on sensory experiences as a means to understanding and making meaning of past cultural landscapes (see as examples Birch and Williamson 2015; Brück 2005; Charest 2009; Gillings 1999; Jones 2010; Reilly 2015), it was his specific notions of "ways of thinking through making" (Ingold 2013:xi) 
and "wayfaring" (Ingold 2011:12) where I found my own personal discovery and meaning-making. Perry describes this as "crafting knowledge" (see Perry 2015) and "artisanal epistemology" (Perry 2015:197 via Smith 2004), where knowledge is discovered or made new through the creative process of making. The body of Zilsel's pioneering work (see Zilsel et al. 2003) is also relevant here in that it establishes the notion of the "scholar-craftsman," where meaning-making is intertwined through the creative mental and practical application of crafted knowledge creation in the pursuit of scientific discovery. This was my discovered notion as I endeavored to work through the archaeological record into a virtual environment.

Although Ingold has played with the notions of making as a recurring theme in several volumes of work (see as examples Ingold 2007, 2011, 2013), I am drawn to several distinct notions that Ingold (2011: 49-62), drawing heavily from Keller (2001), advances in order to explain the relationship between maker, tool and material that enable the act of making, and thus meaning-making, to occur. These notions help clarify for me the meaning-making I followed and explored through my research, and serve as a framework here to deconstruct that experience. These notions include: i) working with an umbrella plan, in effect forming that initial, conceptual big picture of artistic intent; ii) the processional quality of tool use, in effect undertaking the journey and implementation of that conceptual artistic intent; iii) the synergy of practitioner, tool and material, in effect the agency arising from that interaction that gives rise to the narrative of making; iv) the coupling of perception \& action, in effect the combination of the two halves of the artist to achieve, and achieve effectively, the intent of making; v) working with the material and not against it, in effect teasing out further the notion of synergy and the material properties of making that both facilitate and constrain the artisan; and lastly vi) accepting course corrections, in effect the improvisational adjustments taken along the process or narrative of making. In combination, these notions of the making process effectively capture my own personal "transformational" (see Ingold 2013:3) making in VA and are discussed in turn below.

\subsubsection{Making Umbrella Plans}

Ingold quotes Charles Keller's notion of an "umbrella plan" (Ingold 2011:54 via Keller 2001:35) as the practical application of organizing thoughts, tools, skills and workspace in order to prepare for the act of making. The umbrella plan is an over-arching, big- 
picture view of what the artisan would like to achieve, but still lacks the minute granularity required for the construction of new knowledge. It is the mental preparation and imaginary practice towards a desired outcome or mental image that positions the practitioner to eventually engage with the task at hand (see Keller 2001:35). In the research for this dissertation, I interrogated both the theoretical and cultural historical literature, creating a conceptual base to undertake VA, while also developing a mental template, based on archaeological, historical, and contemporary reconstructions of longhouses to inform how I might visualize "my" virtual longhouse. I developed a mental inventory of longhouse features, elements and notions that I wanted to make that would engage a virtual space, materiality and past creatively, technically and theoretically.

My conceptual umbrella plan was in turn shaped by the experiences I gained during Longhouse 1.0 and 2.0, where I developed a pipeline to interactively engage with the historical and artistic elements to be developed in VA. By testing the tools and understanding the constraints of the $3 \mathrm{D}$ creation process in Longhouse 1.0, I was mentally negotiating future decisions over what could and could not be represented virtually by the software, and with the skills and knowledge I had available. Likewise, before, during and after Longhouse 2.0, I found myself redefining the initial umbrella plan to accommodate VR technology developments that were leapfrogging our production plans. These were mental and practical rehearsals (Keller 2001:35-36), like all acts of knowledge making that came before, and all in turn then were interrogated by the next act of creation, and as such, facilitated a process of creating meaning unique to this maker.

I would also add that the London Charter and its founding notions of agency, authority, authenticity and transparency (see Denard 2012; Pletinckx and Tartessos 2011) is an additional and necessary part of the umbrella plan of this research, allowing the maker to both understand and recognize the concerns and constraints of attempting to virtualize the past and guide them as the maker engages digitally with unconstructed knowledge. Lastly, the intent of paradata to make overt the process of informing and shaping of decisions as they occur through creation was a conceptual part of the umbrella plan, one that, in the doing of it, also ensured a reflexivity to negotiate the construction of new knowledge and revise my understanding of the umbrella plan I was supposed to be working towards. 


\subsubsection{The Processional Quality of Tool Use}

For Ingold, once an umbrella plan exists, the practitioner/artisan/maker engages with the task itself. It is in many ways the pathway to completion; "getting ready, setting out, carrying on and finishing off" (Ingold 2011:53). There is a narrowing of focus and an acceptance that along the way there will be negotiations between the mental and physical realities which will force the maker to accept course corrections through a series of wayfaring points (Ingold 2011:53). It is in these moments that new knowledge is constructed (and old preconceptions revised), yet still not acknowledged as the central task is still working towards completing the job as conceptualized. Only later in the process of reflection and negotiating those changes made away from that original mental image and umbrella plan do these new notions become concrete.

The completion of Longhouse 1.x and Longhouse 2.x helped shape and revise the umbrella plan to what it encapsulated at the moment of starting Longhouse 3.x. These experiments helped to lay out the tools, working environments, skills and talent needed to execute an archaeologically engaged virtual (re)imagination. They informed as well as kept secret challenges that would need to be negotiated later. As discussed, I had no intention of understanding "making" as a central point of my research when I was "setting out." The end goal initially planned was the visualization of the archaeological record, by any means necessary. However, along the path of discovery, the plan of achieving a virtual representation remained the same task at hand, but my mental course corrections shifted the means of achieving that goal and some of the intents behind the goal based on the new knowledge I was engaging with. Some tools such as the Oculus Rift goggles were chosen and then discarded as new means of delivering a virtual representation became available. As well, I had to negotiate an aim and expectation of achieving a photorealistic but less interactive experience, with the realization that user's preferred a fully immersed but less photorealistic virtual engagement. Throughout these bouts of negotiation and angst, I "carried on" with the task at hand, while acknowledging the shifts in motivation and outcomes that changed along the way. These deviations represent the moments of knowledge construction in which the material, tools, my own expertise and extent of known research proved insufficient to complete the task without creatively engaging with the unknown.

Keller (2001:40) states that, "deciding when a project is finished involves a judgment by the artisan that a part of the physical world sufficiently approximates a mental image of the finished product." This is an important statement as there is an acknowledgement that 
the realized product and the desired final mental image will never be entirely equal. Towards the end of Longhouse 3.x, I moved into a "finishing off" phase, the refinement or more precisely acceptance of what could be achieved with the assembled skills, materials and knowledge at that time, while acknowledging that components of the build (e.g., user-based ability to change elements of the visualization) could not be achieved in this iteration. During the interview process, I was continually reminded that this (re)imagination was far from complete. However, during the "finishing off" phase I wanted to ensure that the final product wasn't "overworked" (see Keller 2001:40) by means of new layers of details that hadn't been fully vetted for fit. Thus the "finishing off" phase is important as a realization by the maker that the initial mental image and the final physical object had reached some kind of alignment the maker can "live" with. Arriving at the realization is a process of negotiation, rationalization, and instance of new knowledge being created.

\subsubsection{The synergy of practitioner, tool and material}

The maker, tool and material all have narratives which when combined make new meaning (Ingold 2011:56-58). Collectively they tell stories, which mingle in the present, dynamically changing, based on the affordances within the taskscape, tool, material and maker (see Gibson 1986). Ingold believes that stories do not come "ready-made" but in fact are drawn out of the engagement with the tools, material and environment in which an artist is engaged (Ingold 2011:56). Thus, in making, new stories or knowledge is made.

I discussed in Chapter 3 and Chapter 4 the contentious and speculative nature of representing something as simple as bunk height within the virtual longhouse. Limited available historic narratives suggest variable bunk heights, which modern archaeological interpretations assumed as either-or choices that are "right" or "wrong." I chose to represent the option of a lower bunk interpretation, which drew a substantial amount of discussion among interviewees and even my supervisor. In following Ingold's notions of the synergy of practitioner, tool and material, I challenged the accepted norms by playing with the elasticity of the tools themselves, my own interpretations of the known research, historical writings and the artistic, practical and archaeological sensibilities I had endeavored to master within myself. Although I chose one bench height interpretation over another, it was in the process of making a lower bunk, in letting the materials speak, 
in creating an alternative story, that old assumptions were confronted and new knowledge was constructed. The outcome was different than the norm, yet still viable if new modes of interpretation are to be engaged.

In effect, this particular visualization made the archaeologist participants "think" about the assumptions inherent in archaeological data. They negotiated in real-time, within a virtual space, a contradiction to those assumptions through the visualization of an alternative interpretation that enabled the users to reflect on the variability, viability and certainty of their meaning-making processes. Even in the seemingly inconsequential detail of bunk height, users were able to "see" contradictions to their own mental constructs that could be allowed in variable representations of the same partial data. The take-away was that my VA "story" allowed for the give and take of assumptions, notions and reflecting on those, i.e., that there is no right or wrong, just an acknowledgement that through the synergy of practitioner and tool, I was able to present one narrative in order to elicit many equally new narratives, and make overt assumptions in older narratives.

\subsubsection{Coupling of Perception \& Action}

Ingold (2011:58-61) views the coupling of perception and action as an indication of mastery within the artistic craft of making. It is the natural completion of one movement that sets up and leads into another; such as walking or sawing a piece of wood (see Ingold 2011:17). The seemingly rhythmic motions of the artist and tool in the creation of an object is in fact a series of dynamic course corrections, all unique in delivery, however producing similar outcomes. Wright (1995) documents the full physical reconstruction of a longhouse, yet provides no paradata for the micro decisions he and those who worked with him adopted along the way. The literature itself fails to detail any coupling of perception and action by the various makers who have endeavored to construct a longhouse. Thus, longhouses continue to be imagined and visualized in the same manner both physically and in 2D by scholar, artist and craftsperson alike, even though longhouses are clearly built through the unique vision, context and time of the maker(s). Is it because the mental images and assumptions we carry with us are static (see Dennett 1993), or is it because we only "see" the cumulative end result of subconscious pivots in the making of the object that inevitably bring us back to that static vision? 
Although the means by which we constructed our virtual longhouse had substantial variation from any previous physical or digital attempts, I was astonished by the similarities of the end result. Longhouse 3.x is an embodiment of the attempt to make digital the mental interpretations of the archaeological record, historical notions of longhouse construction and use, as well as those notions of other longhouse archaeologists. The Longhouse 3.0 virtualization is unique to my understanding of the data, material, technologies and influences of those who interacted with me through the paradata exercise. And yet we still produced an end result of a longhouse shape that was not too far off from what Kapches (1993), Snow (1997) or Wright (1995) would have envisioned. Far from being repetitive, the making process becomes iterative. The core elements of this space: central corridor with hearths; side compartments or bunks; long and oval to elliptical in length; rounded roof; entrances through the long axis of the structure; as well as the texture, building pliability, shape and smell of a common building material; all allow for and yet significantly constrain the core elements "needed" for meeting the artists' vision or mental template of a finished longhouse result. This recognition of what makes a longhouse a longhouse constrains archaeological interpretations, and speaks to a common cultural understanding of a core longhouse-ness among ancient longhouse makers, even as they produced distinctive regional, local and even use-based variants.

\subsubsection{Material constraints}

Ingold (2011:51-62), like Keller (2001:36), goes to great lengths to talk about the materiality of the material being worked; how the material has a narrative and it is through its synergy with the tool and the maker that that narrative materializes. In comparison, the wood used by Iroquoian builders had unique properties of strength, elasticity, and rot-resistance, with each playing a significant and individual role in the decision-making and construction of a longhouse. Although those properties did not constrain our ability to construct digitally, we needed to display those affordances to best represent those unique properties within $3 \mathrm{D}$ space.

For 3D computer graphics, the greatest challenge is understanding the materiality of a digital object within virtual space. 3D objects are made of an interconnected network of polygons, which when joined becomes a surface or face within virtual space (see as example Catmull and Wallace 2014;13-16). That surface joins with other surfaces to 
become the outer shell of the object visualized in 3D space. Surfaces can hold textures, lighting, animation and other model attributes, which in unison helps to convey a visual representation of the physical object being mimicked within virtual space. Like wood, clay or other physical materials, 3D objects have their own unique materiality, constraints and benefits, which dictate- the effectiveness of the 3D model in that virtual space you as craftsperson are attempting to create. The modelling, animation and environmental software, like the tools a carpenter or blacksmith would use, also dictate the way the digital material responds to the maker. Thus, there is an immediate tension between the tools, the material and the maker until the coupling of perception and action is achieved.

Like all scholar-craftsmen, the material we are trying to mold into our vision both binds and blinds us. However, the digital realm does allow us to reach beyond the constraints of the physical world, and as such some elements of the longhouse in our build were fantastical interpretations, such as the supporting posts of the vestibule (see Figure 25) or the flat roof design (see Figure 22) on top of the longhouse. Neither of these elements conform to the physics of the real world or even the probability of ever being a physical design element. However, we are able to "bend" the 3D world in some ways, but not very successfully in others. For instance, the 3D representation of knotted cordage that was used to bind poles and posts of the longhouse benches (see Figure 15) is at best an approximation of the organic nature of the material we were trying to represent. Thus, we were both bound to the rules of 3D modeling and freed from some of the physicality of real-world material constraint. It was a seemingly unnatural contradiction yet one that controlled how the longhouse would eventually be represented within 3D space.

Such micro-negotiations occurred as we attempted to reproduce real-life examples within virtual space. Sometimes it was the organic shape, a substituted texture map or even the inability for the mouse or digital pen to accurately draw a desired shape. All of these compromises played into the creation of the digital longhouse, shifting our mental image from an ideal representation to our actual final outcome.

\subsubsection{Accepting course corrections}

I have spoken at great length on the concept of "wayfaring", a term Ingold (2011:143) uses to describe the points at which we "course correct, or "shift" our expectations in the act of creation through reflexive interrogation of the physical reality of mental intent. It is 
more than a casual acknowledgement that a change has occurred, but rather a conscious recognition that the course correction is changing our direction and mental map.

Based on the skill and synergy of the maker, tools and material, the flow or performance of making is responsive to the course corrections made (Ingold 1999:435-437). The sum of those reflexive interrogations and material, physical course corrections becomes the end product. In our particular case of building the VA of a longhouse, our shifts came in many forms: negotiating contradictions within the historical literature, archaeological data and interpretive culture history, artistic preference, limitations of technical skill, hardware and software limitations, and feedback from the wider community through our paradata website. These interrogations facilitated a continual reflexivity on the decisions we made and new information we discovered, leading to numerous course corrections and the creation of new thought about the archaeologically unknown (i.e., the above ground manifestation of below ground archaeological data). For every wayfaring point, there was angst, doubt and trepidation. However, it becomes a fork in the decisionmaking process that informs whether the decision is a desirable construction of knowledge or an endpoint for one line of reasoning.

Wayfaring points are forks in the decision-making path and as such those discarded paths do represent alternative directions of thought and constructed knowledge within the virtual landscape. With the technical ability of VA and the documentation of paradata in the decision-making of $\mathrm{VA}$, these discarded wayfaring points can be procedurally revisited and retested when/if conditions allow for these alternative notions in the future. Thus the decision to discard or shift direction is like a form of violent memory (see for example Moshenska 2009), one which marks the virtual landscape, not visually but through the acknowledgement that a choice made means the discarding of an alternative path or vision. And so we need to document or remember these wayfaring points in order to re-examine/re-discover possible alternative meaning-making paths not taken but mapped for possible exploration at a later date (see as an example of memory and remembering choices not taken in Tzortzopoulou-Gregory 2010).

Thus wayfaring or course correcting becomes an essential practice because of the procedural nature in which $3 \mathrm{D}$ visualization has been established, combined with the paradata process, which chronicles these wayfaring moments for stakeholders, participants and makers alike. It is both the acknowledgement that wayfaring happens both consciously and unconsciously, and that those decisions need to be recorded or 
mapped, bringing authenticity, authority and to some extent transparency and access to alternative manifestations and meaning-making to the forefront of a VA.

\subsubsection{Paradata and the London Charter}

This project was designed from the beginning umbrella plan to follow the London Charter, and specifically the notions of paradata making the visualization process overt and open to feedback from a wider audience than just the maker. In doing so, I've challenged the concepts outlined in the London Charter on authority, authenticity, agency and transparency to better understand the complexities of deploying the Charter and the reflections needed to maintain at least the spirit and some semblance of what the Charter is trying to achieve in our VA practices. The aims of the London Charter are worth aspiring to, however they are not sacrosanct and must be constantly reflected upon in order to retain clarity of "for what" and "for whom" we have created this new knowledge. I believe that the paradata process is that means which makes real the aims of the London Charter and also allows for those aims to be challenged and reflected upon.

Paradata document the process of interpretation so that the aims, contexts and reliability of visualization methods and their outcomes can be properly understood. Paradata may be seen as a digital equivalent to scholia, as well as an addition to the traditional critical apparatus for describing the process of reasoning in scholarly research. The failure to provide this kind of intellectual transparency in the communication of historical content may result, among others, in visual products that only convey a small percentage of the knowledge that they embody; thus making research findings highly resistant to peer review and further discussion. It is argued therefore that an amount of paradata sufficient to provide genuine intellectual accountability should be published alongside other research outcomes and sustained beyond the lifespan of the technology that underpins visualization.

Bentkowska-Kafel, Denard \& Baker 2012:1-2

Paradata, although discussed theoretically at great lengths in the framing of a VA (see as examples Bentkowska-Kafel et al. 2012; Denard 2012; Frankland and Earl 2011; Huggett 
2014), has not been practically applied within virtual heritage to any great extent (see Huvila 2013:99). Notable exceptions include the King's Visualisation Lab, King's College London, such as Abby Theatre, $1904^{16}$ (Denard 2011) and the Skenographia Project $^{17}$ (Beacham 2003). Both deploy paradata through a traditional first person/maker blog perspective. However, as these were virtual heritage projects specifically designed to follow the London Charter (see Denard 2012), and created by the framers of that Charter, they do not attest to a broader, organic grass-roots acceptance of the paradata process as methodological practice (see Watterson 2014:13).

Recently, Watterson (2014), in an effort to address the issues of virtual archaeological imagery and its effect on the general public's expectations of visualizations within archaeology as being visually authentic, actively engaged in a paradata practice as a foundational aspect to visualizing archeological sites in St Kilda and Skara Brae in Scotland. By recording not only reflections and course corrections, but also the data used to facilitate the construction of knowledge beyond the archaeological findings, Watterson (2014:141) demystified the visualization process for archaeologists and public consumers as well. In essence providing the ingredients used to quantify and explain the archaeological visualization process, demonstrating that the visualization is an interpretation by scientific means, and not a sacrosanct truth.

The underpinnings of my research have been the ability to actively and publicly reflect on Bentkowska-Kafel, Denard and Baker's definition of paradata, as applied to the production of the Longhouse 3.x virtual archaeological project. As such, Appendix A and $B$ represents the entirety of the accumulated paradata for this virtual longhouse project and provides a visual and written diary of my wayfaring points, moments of angst and more importantly, a record of public and stakeholder engagement. It is unclear if Watterson (2014) ever provided transparency through a paradata blog during the St Kilda and Skara Brae research, however Denard (2011) actively encouraged and engaged with the public through blogging comments while working through the visualization of the Abby Theatre project.

For Longhouse 3.x, the greatest example of paradata as a needed methodology within VA has been the ability to exchange and communicate ideas beyond the daily closed loop of

\footnotetext{
16 http://blog.oldabbeytheatre.net/

17 http://www.skenographia.cch.kcl.ac.uk/index.html
} 
the research team. Beyond the ability to link and reference my own observations on the unfolding of the project itself, the paradata process required a personalized leap of faith. Laying bare my opinions, assumptions, and potential successes and failures, in order for these to be consumed, pondered and critiqued, was a daunting decision. As with all forms of social media, one tends to play to the audience assembled, taking cues, seeking reaffirmation and in general, understanding the boundaries in which your audience will allow you to test. However, by endeavoring to present an honest, authentic and as full a picture as possible, the process became an opportunity to experiment unshackled, with the hope that the community was both supportive and constructive with the paradata methodology.

Based on the 60 comments left on the 50 pages of the project paradata blog, private email communications initiated by blog followers, and the 18 registered participants of the blog, the project itself had a modest following of primarily archaeologists, VA enthusiasts, computer animation industry people and finally individuals I was unable to identify and thus categorized as the "general public." There are no means for me to accurately determine who each visitor was, however since the inception of the paradata blog in May of 2015, there have been 3,804 visitors and 8814 unique views, ${ }^{18}$ with an average of 308 views per month. July 16, 2015 generated the highest number of single day views, with 179 views, which corresponded with a Facebook update post by ASI Heritage's ${ }^{19}$ social media manager redirecting their followers to the project site. Oddly enough that particular post was Longhouse 3.0.5 and it dealt directly with envisioning the sleeping platforms, bedding, pole positions and platform height.

Although one of the tenets of paradata and the London Charter is transparency, I was clearly in charge of the narrative and selectively chose what to present within the blog. My initial caution was more about not making the wrong theoretical, methodological or contextual comment when I knew there were diverse sets of people watching the blog. In particular, I knew of at least three archaeologists that I had referenced heavily in my research that kept constant tabs on the project. But by vigilant reflection on what we were doing in the virtual (re)imagination and the decisions I made, and what I was saying in the blogs, this process helped me to be cognizant of the community of active viewing

\footnotetext{
18 As of February 22, 2017

${ }^{19}$ Formally Archaeological Services Inc.
} 
participants. Thus transparency was a negotiated process filtered through the narratives I chose to convey.

Lastly, the comments from the blogging process were critical in my making of the virtual longhouse. The participatory process between myself, and those following the paradata postings helped to support, guide and recommend new shifts in my thinking of the archaeological unknown, creating a more robust virtual building process. I also noticed that these active participants felt engaged with the weekly updates, the trials and tribulations, and in essence became contributing collaborators.

The intention of the paradata process was initially to generate a warts and all diary of the trials and tribulations engaging with the archaeological material - whether literature, raw data, or 2D map representations and those notions - visualized in 3D by my own meaning-making. It was a huge leap of faith to expose my research openly and invite critique willingly and publicly, but one I felt consistent with the vision of the London Charter. However, as I followed this process, I began to realize that the paradata exercise not only made decision-making overt, but proved also to be a useful guide to empower and enable me to reflect and pivot on decisions more rapidly and in some cases more effectively than if I had stumbled around without past posts to refer back to or even the simple act of writing one's thoughts down as an exercise in personal clarity. In effect, the paradata blogs functioned as a kind of digital equivalent to the fieldnotes archaeologists maintain during a site excavation.

Another dimension of the paradata exercise I did not at first anticipate as being influential on the making process itself was the discourse it engendered in real time with an audience responding to my account of the trials and tribulations of the making process. As followers of the paradata blogs increased so did feedback, encouragement and support. This scaffolded my decisions, providing some security that if I were veering too far "away" from their perception of the aim of the project, a public feedback in the form of suggestions and critique would follow, or encouragement, if the choices and decisions I was working through seemed "right" to them. However, this was not a "crowdsourcing" exercise and though I encouraged and supported comments about the recorded paradata, like my effort to distill the academic literature and archaeological record, I chose what I wanted to visualize and purposely chose some areas, such as the internal bunking system, to challenge established norms, while in other instances, such as deciding on the wall and roofing design, some of that feedback helped influence the choices I made. 
There were no public responses that negatively critiqued the work; however I did have one private email sent right at the beginning of my 3D build that expressed initial concern over some of the support framing decisions I had incorporated into my visualization. As discussed in Chapter 3, the Wright (1995), Snow (1997), and Kapches (1993) framing methodologies were distinctive interpretations of the historical, linguistic and archaeological record. I chose to incorporate both the Kapches bent arbour roofing element and Snow's 60\% side-wall height-before-roofing structure notions, creating in essence a hybrid between the two. Wright's $80 \%$ wall and $20 \%$ roof notion was discussed, but was out-right discarded. I now equate that decision with the subconscious mental-image I held, which was reiterated repeatedly through participant interviews, of a longhouse conventionally envisioned as being "half-cigar shaped." The private email I received initially challenged the accuracy of the visualization I created, but in response to the author, I pointed out that the technology allowed the user/maker to choose multiple iterations and as such the current visualization was only intended to be one of many interpretations. The key takeaway was that VA allowed for the blending of interpretations and thus alternative ways in which to engage with the archaeological data. Although my email discussant did not follow up further on the roofing design, they did indicate that this methodology had great potential for future research.

Ultimately, the VA research was not about re-hashing regional archaeological debates about what was and wasn't the right way to assume longhouses from the pre-written past were built, or what was "right" and what was "wrong" in my visualization. In every way, I was virtually demonstrating that these constructs of the archaeologically unknowable part of the record arise from interpretive imagination, grounded from real data, which speaks more to our variable mental templates about what a longhouse "should" be, based on those features we all variably emphasize as being "right." In the end my use of paradata blogging was to specifically articulate that process and that intent. This visualization process and accompanying paradata documentation thus is about representing and revealing the construction of knowledge and archaeological ways of knowing, and exploring the different ways different people, archaeologist and nonarchaeologist, make meaning, underscored by the ability in VR to variably modify that phenomenological space and past as the user sees fit. This is the difference between the kind of archaeology I have attempted to enable, and the cultural historical sensibilities 
embedded in the kind of archaeological research that has not yet been fully exposed to the theory, practice and possibility of VA.

In hindsight, the paradata process I followed proved to be more than just an exercise in transparency. That feedback in real time helped to reinforce the parameters of the build alongside archaeological assumptions about above ground elements of longhouses, with participants often using a degree of certainty in their language and discussion that belied the unknowable reality of these ancient longhouse elements. I should have critically tested the extent in which paradata can influence real change in virtual making, especially when emotional sensibilities are awakened when the interpretations presented don't necessarily meet embedded norms. In retrospect, I could have explored this dynamic further by intentionally throwing notions into the paradata blogs to provoke or "test" archaeological tolerance, and as a check to any willingness I may have had to follow that feedback. The interaction arising from the paradata blog did make the process transparent, but it also had the potential to significantly shape the process and final visualization, an intriguing and unintended consequence of working towards the intent of the London Charter.

The use of the paradata process ultimately enabled a greater reflexive understanding of the task at hand and provided a social media outlet which was not only peer reviewed, but also contributed to the goal of developing an archaeologically informed, virtual (re)imagination of the archaeologically unknown. Paradata made the visualization more "real", more about new or contested insights, and about the subjectivity and selectivity of representation, rather than authenticity or getting it "right".

\subsubsection{Cabling \& Tacking in Virtual Archaeology}

A theoretical grounding of VA continues to be problematic as archaeologists and heritage professionals continue to view VR as more of a novelty, a technologically-heavy method for visualizing archaeological data or whimsical idealizations of ancient pasts (see Dallas 2007; Gillings 2005; Huggett 2012). Although the skilled practice of visualizing the archaeological record has progressed, along with our methodological notions (see as examples Bentkowska-Kafel et al. 2012; Denard 2012; Earl and Wheatley 2002; Frankland 2010; Frankland and Earl 2011; Perry 2009, 2015, Watterson 2014, 2015), there has been little progress on theorizing VA beyond Zubrow (2006), Huggett (2004, 
2012, 2015a, 2015b, 2017) and Reilly (see Beale and Reilly 2017; Reilly 2015a, 2015c; Reilly and Beale 2014, 2015; Reilly et al. 2016). My research has attempted to frame VA, and specifically the making of knowledge and archaeological space digitally, using Ingold's $(1999,2007,2011,2013)$ notions on making and wayfaring, scaffolded by Huggett's $(2004,2012,2015 \mathrm{a}, 2017)$ notions of technological fetishizm and intention, Jeffrey's (2015) notions of aura, Dawson, et al's (2011) concept of engaged presence, and Reilly's (Reilly and Gant 2016) continued challenges to go beyond a catch-phrase and truly engage archaeology virtually through the material record.

Alison Wylie, like Tim Ingold and Paul Reilly, has also shaped my conceptual understanding of a VA. Initially I felt that VA was marginalized, rudderless and relegated to indifference within the greater sphere of archaeological theory. VA, as a theoretical conception of the act of making meaning about the material past, failed to fall neatly amongst the plethora of theoretical notions in which archaeology is theorized. To me it seemed VA would be destined to be a visualization process in the service of wider archaeological conceptual discourses. Wylie's (1989, 1993, 2002) notions of archaeological cabling and tacking not only gave voice to my own philosophy of engaging a multi-vocal approach to making meaning through visualization of the past, but also that these notions could be intertwined, mingled or cabled to form a stronger theoretical grounding. As such, Reilly provided our initial theoretical impetus for VA, while for me, Ingold and Wylie framed a solid foundation for accepting VA as a means of enlightened knowledge construction and meaning-making within archaeology across the cabling and tacking of traditional archaeological theories.

This conception of VA offers a kind of pragmatic eclecticism (Preucel and Mrozowski 2010; Trigger 1991, 2006) at the heart of my theoretical framing of digital making. Virtual Archaeologists are makers of material meaning. We construct networks of knowledge in which power, authority, and authenticity are embedded within and reflexively challenged by digital means through our professional, academic and cultural norms. These challenges represent course corrections and wayfaring points, in which new knowledge paths are taken and others abandoned or shelved. As knowledge is "made" through these moments of reflection, a progressive, non-linear procedural path is created, which is unique to the maker, but through the use of paradata and technology this knowledge can then be known and engaged with by a wider group of archaeological consumers. As such, as decisions are being discarded or promoted, we rationalize these 
decisions by emotional and logical means. We tack between theories, methodologies and practices, searching for, or cording between the archaeological known and unknown to create new knowledge. This is archaeological wayfaring.

However there is another personality trait of the archaeological wayfarer that should be considered, that of the maker. When we make within VA, we are interrogating the archaeological unknown. In a digital analogy to what Iroquoian longhouse builders likely negotiated, as VA makers the material and the materiality dictated the outcomes of our efforts. The tools used and the realities of the digital material and platform chosen, were constraints and facilitators of the creative imagination/interpretation of the maker. Paul Reilly (Beale and Reilly 2014, 2017) suggests that archaeology is a craft-oriented discipline. And as Charles Keller (2001) points out, there is a tacit relationship between the maker, the tools and the material. Subsequently, each has an individual narrative to convey; however in unison, a new narrative of knowledge-making is created.

So for the makers of VA, we are constrained not only by the archaeological record but by the corded knowledge of the maker, the software that enables reimagined virtual landscapes as well as the platforms that deliver these virtual worlds. Each represents in itself previous wayfaring decisions which contribute to the creation of new knowledge. It is through this materiality, digital or physical, which informs the construction of new archaeological knowledge.

VA is archaeological meaning-making. For the virtual archaeologist, or any archaeologist, there is a just-in-time synergy between the materiality of the archaeological object or locale - the "raw data" of archaeology - and the interpretive act and process of meaning-making we embark on as we begin to analyze that data. However, the value of VA is that knowledge construction can be "seen" virtually, allowing the maker to engage with the archaeologically knowable and archaeologically unknowable dimensions of data, independent or interdependent of each other, offering a digitally tangible means of exploring the intersection of those two dimensions of archaeological meaning-making, all plotted through wayfaring moments in real-time. It is a starting point for a reflexive conversation on knowledge in archaeology. It has the 
ability to inform, challenge and inspire new modes of thinking and realities when accompanied by the reflexivity of paradata: the wayfaring points, course corrections, challenges and cultural material that contributed to the virtual making process.

In this process of makers making through course corrections at wayfaring points, the decisions made embody elements of power, agency and authority. As virtual artisan wayfarers, archaeologists embody and assert a technical, creative and archaeological knowledge "expertise." This requires archaeologists to be reflexive of the power, agency and implicit authority they wield and embed in the process of making within virtual space. We need to transparently negotiate the process between virtual builder, viewer and archaeologist, in order to reveal the "continuous correcting" that occurs as decisions are made virtually through making, and the limitations and iterative nature those choices made mean to the particular interpretation visualized and presented within VA. I suggest that the end product, if there truly is an end, is the process - the journey - followed towards new knowledge through the virtual making process. This in my mind is the strength of a pragmatic eclecticism in VA, as it is in the meaning-making of archaeology more broadly.

\subsection{Discussion}

VA is more than just visualizing the past. It is a sensory making experience that draws both theoretically and methodologically from the archaeological record and beyond (see Perry 2015). As such, the act of making meaning is more important than the final outcome; all knowledge is manufactured and thus the journey is the key (see Baker 2012:174 and Watterson 2014:47). As Virtual Archaeologists, we need to first accept that what we do is "archaeology" and second, that in visualizing the archaeologically unknown, we are making new archaeological meaning.

Unlike the insights of Kapches (1993), Snow (1997) Wright (1995) or Watts (2009), the research in this dissertation has been a series of smaller, micro-notions of longhouse construction and use, which continues to build upon the deep archaeological record of 
longhouse research. In our digital build, I was faced with negotiating how the decisions I made in $3 \mathrm{D}$ representation would have been executed in real-life, such as the cordage to bind the posts, poles and shingles, the types of wood used, and for which structural purpose. Along those wayfaring points, I raised observations, puzzled, and constructed my own solutions, deferred to established interpretations, or dismissed resolution for future considerations. Thus, when it comes to knowing the archaeology of longhouses differently, I can't point to a single new advancement of archaeological knowledge through this dissertation. And yet by approaching VA holistically, through the exploration of hundreds of micro-notions, I could appreciate the potential complexities of longhouse construction beyond our traditional mental maps of longhouse shape and size, and perhaps interrogated and destabilized the certainty of normative cultural historical assumptions about above ground, archaeological unknowables of longhouse construction and living.

Beyond the academic discourse, however, I am also left personally in awe of the architectural, engineering, environmental, political, societal and cultural dynamics that worked in unison in the conception and construction of a single longhouse. The engineering, cultural, material, sensory, and environmental materialities that had to be negotiated during construction, and also the substantial maintenance needed over long periods of time. These core dimensions of longhouse and longhouse living all contributed to an internal, conceptual understanding, at any given moment over multiple generations, of what it meant to be "longhouse dwellers." These are the elements we are not able to fully appreciate within a virtual space. They can be alluded to but no matter how immersive we can digitally reconstruct a longhouse environment, it fails to capture the physicality and materiality of conceptually only knowing longhouse living through one's life: something non-digital reconstructions only marginally bring us closer to appreciate.

In terms of VA, however, this research has demonstrated that by making, we construct new knowledge and by doing so, the virtual process lets us test, discard or retest that knowledge within the broader context of the known archaeological record. Further, I was struck by the greater presence archaeologists associated with a fully immersed but less visually detailed environment over a semi-immersed but highly detailed environment. A staggering $96 \%$ of interviewees preferred a fully immersed less detailed experience in which the sense of presence - a "you are there" (Dawson et al. 2011:389) feeling - was of paramount interest to the participants. Nonetheless, the way archaeologists experienced presence was not the same that was experienced by Dawson et al's (2011) Indigenous participants, where the virtual environment unlocked subconscious cultural 
waypoints. For our participants the sense of presence heightened their ability to suspend disbelief, to accept the 3D environment as being within an archaeologically informed virtual construction. By doing so, they were then able to question and reflect on their own notions of longhouse construction and use, from a more holistic perspective of visualizing the above ground unknowable dimensions of the archaeology. Our longhouse was representative of archaeological norms of size and scope, but from a micro-feature perspective, there were details to explore and to challenge. This was the unique role that VA played for our archaeological participants; the ability to ease people into a familiar place, yet provide elements that challenged, or at least raised questions through details of what a longhouse was and is.

\subsection{Conclusions}

The research in this dissertation is far from cumulative. This brief start into the notions of "making" and the dissemination of archaeological "meaning" is just that, a beginning. As Huggett (2015) and Gillings (2005) fundamentally state, we must ask "why" VA is necessary and of value to know the past before we engage with visualizing the present. However, VA is grounded within the archaeological record and in doing so, that practice, method and theoretical orientation that allows us to know the past through the means of archaeology is the foundation from which to shape future archaeological knowing both virtually and materially. In the end we know the past archaeologically. VA gives us new means of reflexively exploring both the strengths and limitations to knowing the past. In addition, while this research has demonstrated that a technological fetish when it comes to virtual applications still dominates archaeologists and public alike, as the ability to experience the virtual archaeological record becomes ubiquitous, the shift from the fetishization of the technology to a more robust, reflexive and critical eye will emerge when experiencing these immersive experiences.

Of course, as this technology becomes ubiquitous, the ability to scan, manipulate and repurpose archaeological assets increasingly extends beyond reflexive archaeological meaning-making, shifting into a consumer-cum-producer stage (Paul Reilly, personal communication May 2016). Archaeologists are not the sole owners of the technological skill and expertise, and the subject matter of archaeology is not the exclusive purview of archaeologists. As such digital heritage assets are continually generated for a diversity of motivations, losing their particular archaeological context and interpretive provenances. 
The research here, and its accompanying digital assets, will be peer reviewed, challenged and subjected to an academic and scientific evaluation. However, without the paradata blog and archaeological data used to inform this build, these virtual visualizations become dis-associated from the very elements that gave them authenticity, agency and transparency. These digital assets, in effect, become consumables, subject to appropriation, repurposing, and narrative assertions not informed by nor constrained by the data, decision-making and expediencies that were critical contexts to integrating the intent and relative aims of the original research.

Writ large there are a diversity of voices exploring and making meaning of the archaeological heritage beyond archaeological norms and sensibilities, as Descendant groups and others assert their own digital authenticity and authority over these digital assets. But this digital capacity also means that archaeological ways of knowing, and the narratives we can offer from the archaeological heritage, have new means of conveying archaeologically-centric understandings of the past as part of that wider consumption of the past. VA also offers the means of making room, digitally, for multiple iterations of the past, ones that explore where archaeological ways of knowing past complement or contradict other ways of knowing, in a process of de-authorizing archaeology as the only way of knowing, but still illustrating why it can be a valuable contribution to knowing.

For me, VA is no longer about the technology, but is more about the unique means afforded the process of knowledge creation, dissemination and meaning-making in archaeology. It informs producer and consumers of archaeological knowledge alike and is informed by the methods, shifting from end-product to the process of actually producing meaning in the archaeological record. VA has the ability to give voice to the archaeological record in a unique way, yet it is still fully grounded in the ways and means of archaeological meaning-making. 


\subsection{References}

Beale, G. and Reilly, P.

2017 After Virtual Archaeology: Rethinking Archaeological Approaches to the Adoption of Digital Technology, Internet Archaeology 44. https://doi.org/10.11141/ia.44.1

Bentkowska-Kafel, Anna, Hugh Denard, and Drew Baker (editors)

2012 Paradata and Transparency in Virtual Heritage. Farnham, Ashgate.

Birch, Jennifer, and Ronald F. Williamson

2015 Navigating Ancestral Landscapes in the Northern Iroquoian World. Journal of Anthropological Archaeology 39: 139-150.

Blazeby, Martin

2003 Skenographia Project. King's Visualisation Lab - King's College London. Electronic document, http://www.skenographia.cch.kcl.ac.uk/introduction.html, accessed January 14, 2017.

Brück, Joanna

2005 Experiencing the Past? The Development of a Phenomenological Archaeology in British Prehistory. Archaeological Dialogues 12(1): 45-72.

Charest, Michelle

2009 Thinking Through Living: Experience and the Production of Archaeological

Dallas, C Knowledge. Archaeologies 5(3): 416-445.

2007 Archaeological Knowledge, Virtual Exhibitions and the Social Construction of Meaning. Archeologia e Calcolatori(1): 31-63.

Dawson, P., R. Levy, and N. Lyons

2011 "Breaking the fourth wall": 3D Virtual Worlds as Tools for Knowledge Repatriation in Archaeology. Journal of Social Archaeology 11(3): 387-402.

Denard, Hugh

2011 Abbey Theatre, 1904. King's Visualisation Lab-King's College London. Electronic document, http://blog.oldabbeytheatre.net/, accessed January 14, 2017.

2012 A new introduction to the London Charter. In Paradata and Transparency in Virtual Heritage, edited by A. Bentkowska-Kafel, D. Baker \& H. Denard, pp. 57-71. Farnham, Ashgate.

Dennett, Daniel C

1993 Consciousness Explained. Penguin UK.

Earl, Graeme P., and David Wheatley

2002 Virtual Reconstruction and the Interpretative Process: A Case Study from Avebury. In Contemporary Themes in Archaeological Computing, edited by David Wheatley, Graeme P. Earl, and S. Poppy, pp. 5-15. Oxbow Books, Oxford, UK.

Frankland, T.J.

2010 A CG Artist's Impression: Depicting Virtual Reconstructions Using NonPhotorealistic Rendering Techniques. In Thinking Beyond the Tool:

Archaeological Computing and the Interpretative Process, edited by Angeliki Chrysanthi, Patricia Murrieta-Flores, and Constantinos Papadopoulos, pp.24-39. Archaeopress, Oxford.

Gibson, James Jerome

1986 The Ecological Approach to Visual Perception. Psychology Press, New York. Gillings, Mark

1999 Engaging Place: a Framework for the Integration and Realisation of VirtualReality Approaches in Archaeology. In Archaeology in the Age of the Internet, 
Proceedings of the CAA97 Conference, edited by Dingwall, L., S. Exon, V. Gaffney, S. Laflin, and M. van Leusen, pp. 187-200. BAR International Series 750. Archaeopress, Oxford.

2005 The Real, The Virtually Real, and the Hyperreal: The Role of VR in Archaeology. In Envisioning the Past: Archaeology and the Image, edited by S., Smiles and S. Moser, pp. 223-239. Blackwell, Oxford.

Huggett, J.

2004 Archaeology and the New Technological Fetishism. Archeologia e Calcolatori 15: 81-92.

2012 What Lies Beneath: Lifting the Lid on Archaeological Computing. In Thinking Beyond the Tool: Archaeological Computing and the Interpretative Process, edited by A. Chrysanthi, P. Murrietta, Flores, and C. Papadopoulos, pp. 204-214. Archaeopress, Oxford.

2014 Promise and Paradox: Accessing Open Data in Archaeology. In Proceedings of the Digital Humanities Congress 2012. Studies in the Digital Humanities, edited by Clare Mills, Michael Pidd, and Esther Ward, pp. 1-14. HRI Online Publications, Sheffield.

2015a Challenging Digital Archaeology. Open Archaeology 1(1): 79-85.

2015b A Manifesto for an Introspective Digital Archaeology. Open Archaeology 1(1): 86-95.

2017 Re-visualising Visualisation. Introspective Digital Archaeology Understanding the Computational Turn in Archaeology. Electronic document, https://introspectivedigitalarchaeology.wordpress.com/2017/01/05/re-visualisingvisualisation/, accessed January 5, 2017.

Huvila, Isto

2013 The Unbearable Complexity of Documenting Intellectual Processes: Paradata and Virtual Cultural Heritage Visualisation. Human IT: Journal for Information Technology Studies as a Human Science, 12(1): 97-110.

Ingold, Tim

1999 Tools for the Hand, Language for the Face: An Appreciation of Leroi- Gourhan's Gesture and Speech. Studies in the History and Philosophy of Biology and Biomedical Science 30(4): 411-453.

2007 Materials Against Materiality. Archeological Dialogues 14(1): 1-16.

2011 Being Alive: Essays on Movement, Knowledge and Description. Routledge, New York.

2013 Making: Anthropology, Archaeology, Art and Architecture. Routledge, New York. Jefferys, Charles W., and T.W. McLean (editors)

1942 The Picture Gallery of Canadian History Volume 1. Ryerson Press, Toronto.

Jeffrey, Stuart

2015 Challenging Heritage Visualisation: Beauty, Aura and Democratisation. Open Archaeology 1: 144-152.

Jones, Eric E.

2010 An Analysis of Factors Influencing Sixteenth and Seventeenth Century Haudenosaunee (Iroquois) Settlement Locations. Journal of Anthropological Archaeology 29(1): 1-14.

Kapches, Mima

1986 1886-1986 The Centennial (?) of the Discovery of the Withrow Site. Arch Notes 86(3): 11-18.

1993 The Identification of an Iroquoian Unit of Measurement: Architectural and Social/Cultural Implications for the Longhouse. Archaeology of Eastern North America: $137-162$.

Keller, Charles M 
2001 Thoughts and Production: insights of a practitioner. In Anthropological Perspectives on Technology, edited by M. Schiffer, pp 33-45. University of New Mexico Press, Albuquerque.

Latour, Bruno

2005 Reassembling the Social-an Introduction to Actor-Network-Theory. Oxford University Press, Oxford.

Moshenska, G

2009 Resonant Materiality and Violent Remembering: Archaeology, Memory and Perry, Sara Bombing. International Journal of Heritage Studies 15(1): 44-56.

2009 Fractured Media: Challenging the Dimensions of Archaeology's Typical Visual Modes of Engagement. Archaeologies 5(3): 389-415.

2015 Crafting Knowledge with (Digital) Visual Media in Archaeology. In Material Evidence. Learning From Archaeological Practice, edited by R. Chapman and A. Wylie, pp. 189-210. Routledge, New York and London.

Pletinckx, Daniel, and Premio Tartessos

2011 Virtual Archaeology as an Integrated Preservation Method. Virtual Archaeology

Reilly, P Review 2: 33-37.

2015a Putting the Materials Back into Virtual Archaeology. In Virtual Archaeology (Methods and Benefits), edited by D. Hookk, pp. 12-21. The State Hermitage Publishers, St. Petersburg.

2015b Palimpsests of Immaterial Assemblages Taken out of Context: Tracing Pompeians from the Void into the Digital. Norwegian Archaeological Review, 48(2): 89-104.

2015c Additive Archaeology: An Alternative Framework for Recontextualising Archaeological Entities. Open Archaeology 1(1): 225-235.

Reilly, P., and Stefan Gant

2016 Different Expressions of the Same Mode: Apprehending the World Through Practice, and Making a Mark. Theoretical Archaeology Group Conference 2016 (TAG 2016), United Kingdom. University of Southampton, Southampton, UK. Electronic document, https://eprints.soton.ac.uk/404236/1/GantReilly\%2520DEOSM\%2520TAGsoton\%2520211216.pdf, accessed on January $14,2017$.

Reilly, P., and G. Beale

2014 Virtual Archaeology In A Material World: New Technologies. CAA 2014 Computer Application in Archaeology Conference, Paris(April). Paris. Electronic document, https://www.researchgate.net/publication/264858984_VIRTUAL_ARCHAEOLO GY_IN_A_MATERIAL_WORLD_NEW_TECHNOLOGIES_ENABLING_NO VEL_PERSPECTIVES, accessed on January 8, 2017.

2015 Additive Archaeology: the Spirit of Virtual Archaeology Reprinted. In Archaeological Research in the Digital Age: Proceedings of the 1st Conference on Computer Applications and Quantitative Methods in Archaeology Greek Chapter (CAA-GR), Institute for Mediterranean Studies - Foundation of Research and Technology (IMS-FORTH), edited by C. Papadopoulos, E. Paliou, A.

Chrysanthi, E. Kotoula, and A. Sarris, pp. 122-130. Rethymno.

Reilly, Paul, Stephen Todd, and Andy Walter

2016 Rediscovering and Modernising the Digital Old Minster of Winchester. Digital Applications in Archaeology and Cultural Heritage, 3(2): 1-9.

Smith, Pamela $\mathrm{H}$ 
2004 The Body of the Artisan: Art and Experience in the Scientific Revolution.

Snow, Dean R

University of Chicago Press, Chicago.

1997 The Architecture of Iroquois Longhouses. Northeast Anthropology 53: 61-84.

Tzortzopoulou-Gregory, Lita

2010 Remembering and Forgetting: The Relationship Between Memory and the Abandonment of Graves in Nineteenth- and Twentieth-Century Greek Cemeteries. International Journal of Historical Archaeology 14(2): 285-301.

Watterson, Alice

2014 Engaging with the Visual: Re-Thinking Interpretive Archaeological Visualisation. Ph.D. dissertation, Digital Design Studio, The Glasgow School of Art, Glasgow, UK.

2015 Beyond Digital Dwelling: Re-thinking Interpretive Visualisation in Archaeology. Open Archaeology 1(1): 119-130.

Watts, Christopher M.

2009 Coming to our Senses: Toward a Unified Perception of the Iroquoian Longhouse. In Archaeology and the Politics of Vision in a Post-Modern Context, edited by J. Thomas and V. Jorge, pp. 209-224. Cambridge Scholars Publishing, Newcastle upon Tyne, UK.

Wright, J V

1995 Three Dimensional Reconstructions of Iroquoian Longhouses: A Comment. Archaeology of Eastern North America 23: 9-21.

Wylie, Alison

1989 Archaeological Cables and Tacking: 'The Implications of Practice for Bernstein's' Options Beyond Objectivism and Relativism'. Philosophy of the Social Sciences 19(1): 1-18.

1993 A Proliferation of New Archeaologies: 'Beyond Objectivism and Relativism'. In Archaeological Theory: Who Sets The Agenda?, edited by N. Yoffee and A. Sherratt, pp. 20-26. Cambridge University Press, Cambridge.

2002 Archaeological Cables and Tacking: Beyond Objectivism and Relativism. In Thinking from Things: Essays in the Philosophy of Archaeology, pp. 161-167. University of California Press., Berkeley and Los Angeles.

Zilsel, P., E. Zilsel, D. Raven, W. Krohn and R., Cohen

2003 Concerning 'Phenomenology and Natural Science'. In The Social Origins of Modern Science, edited by E. Zilsel, pp. 214-215. Springer, Netherlands.

Zubrow, Ezra B W

2006 Digital Archaeology. In Digital Archaeology. Bridging method and theory, edited by Thomas L. Evans and Patrick Daly, pp. 10-31. Routledge, London. 


\section{Appendices}

The following appendices provide a visual example of the supporting raw paradata blog and videos created throughout this research project currently on-line at www theskonkworks.com. In addition to this 2D archived images and Internet links, the HTCVive Longhouse 3.x game executable is now permanently archived at Sustainable Archaeology, Museum of Ontario Archaeology, London, Ontario. 
Appendix A: The collated Paradata blog site (www.theskonkworks.com) of the Virtual Longhouse project starting from first to last entry.

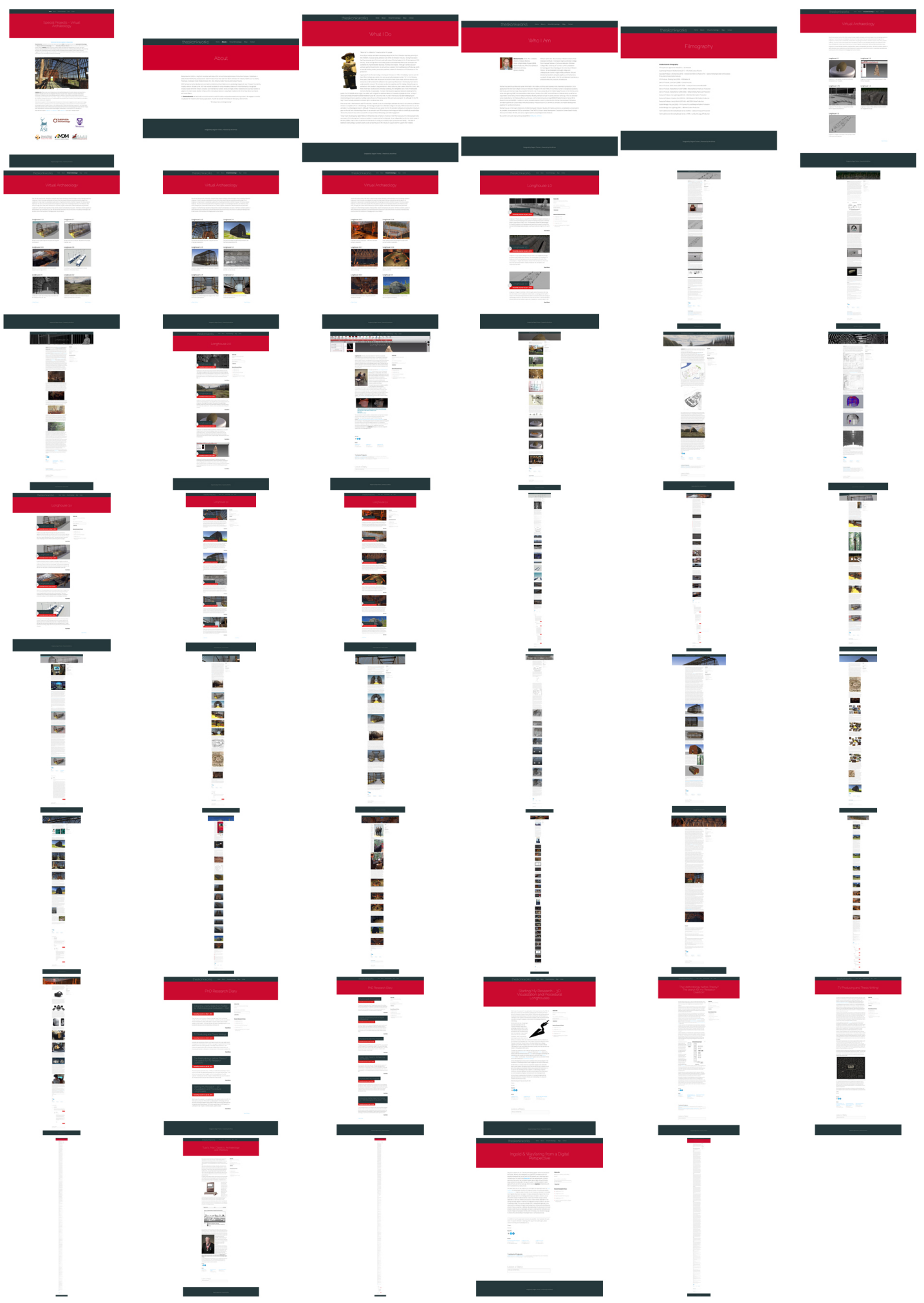

Appendix A 1: Paradata Blog Site contact sheet 
Special Projects - Virtual Archaeology

theskonkworks is pleased to announce the collaboration between ASI (Archaeological Services Inc), Sustainable Archaeology

(SA), Museum of Ontario Archaeology (MOA), the University of Western Ontario (UWO) and assisted by 3D Animation as

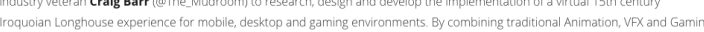

techniques with Arch heeological research, we hope to develo lo a prototyoe production pipeline, content creation and pub ts

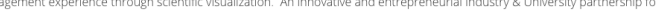

a

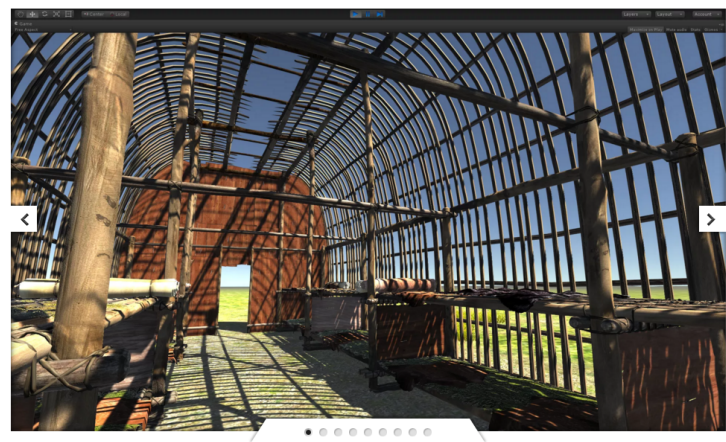
expenence the sights and sounds of a reimagined 15th century Iroquolian house. Designed to incorporate mobile devits

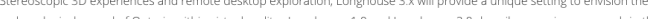
30 isualzar of theory that enables public engagement

hestonm with the study of the archaeological record in a new and groundbreaking way. A personal thanks to Dr. Neal Feris (Sustainable Archaeology/Unversity of Western Untario), Dr. Ron Willalamson (AS), Dr. Dean Snow (Penn State University), Dr. John Creese (North

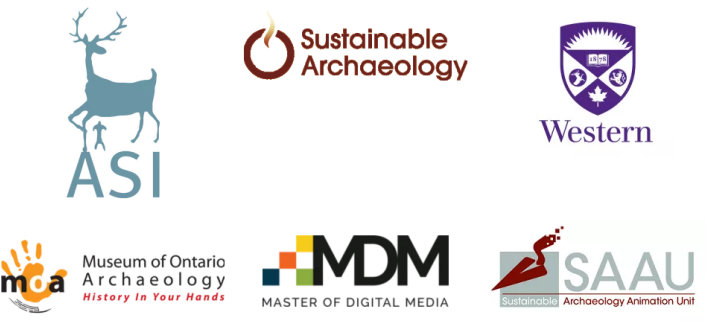




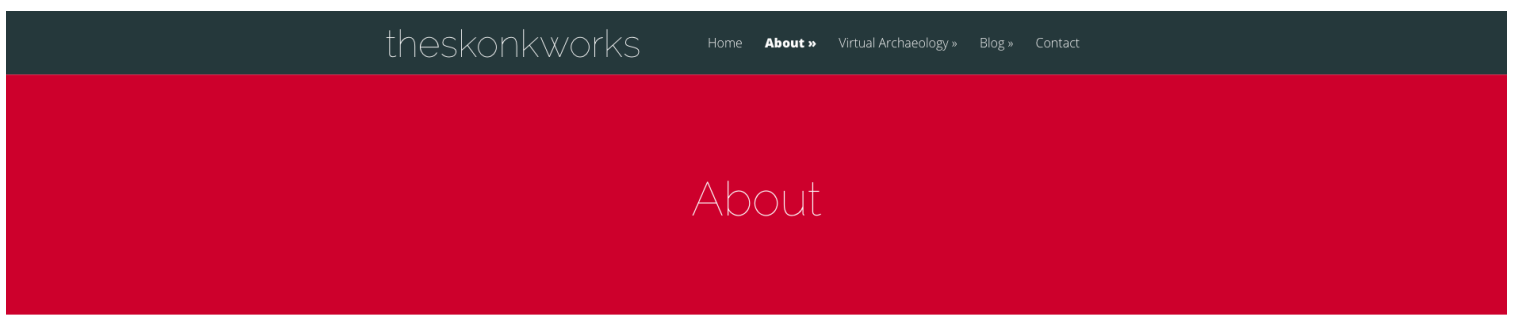

theskonkworks (KKW) is a long form broadcast and feature film Service Producing/Animation Production Company Established in 2005, theskonkworks has produced over 1200 minutes of $\mathrm{CG}$, Flash and Toon Boom animation for industry leaders such as Disney Playhouse, Cookie Jar, Create Media Ventures, NFL, Nick, Nelvana, Codex Pictures and Curious Pictures.

SKW has been an active development, animation production and animation service producing company for over 10 years. Founded by industry veteran, Michael Carter, SKW has received accol ades for being innovatwe, creatve and most Importantly, a recognizzed

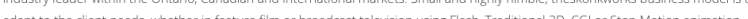
and visual effects

At theskonkworks we help build successful animation and VFX studios and produce award winning content. We engage in scientifif. visualization for research and industry applications. As well we provide mentorship for the Startup environment.

"We olways have something brewing"

Appendix A 3: About page - http://theskonkworks.com/animation-production/ 

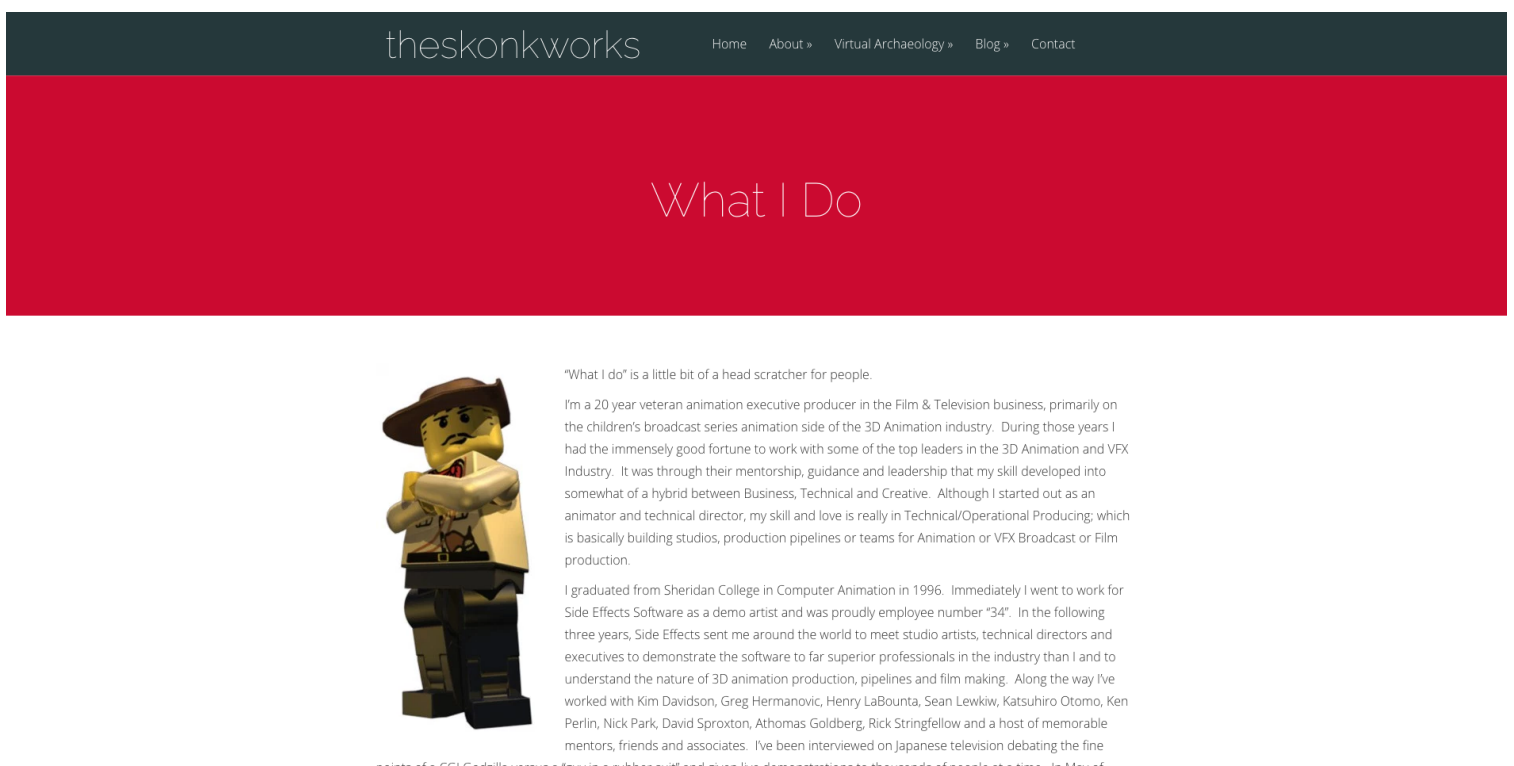

points of a CGI Godzilla v

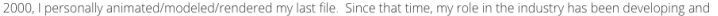

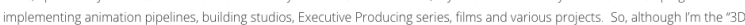
Guy", I havent actually animated, modelled, light or rendered ever since

Prior to my time in the Animation and VFX Industries, I started out as an archaeologist and have returned to the University of Wester Ontario to complete a Ph.D. in Archaeology. Archaeology brought me to Sheridan College in the early 1990's to learn how to use 30

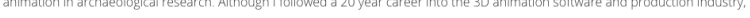
gave me the skin and understanding of how to use animation and vipk tecthiques, technology and skills to scientifically visualize dat Most of my research now centres around the concept of Virtugl Archoeology and Public Engagement.

Today I teach Bootstropping, Digital Medio and Entrepreneurship at Ryerson University in both the Graduate and Undergraduate levels

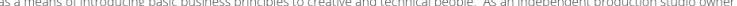
the early 2000's, I had to learn in real-time the intricacies of running a successful project, production and facility. The value of

Appendix A 4: What page - http://theskonkworks.com/animation-production/whati-do/ 

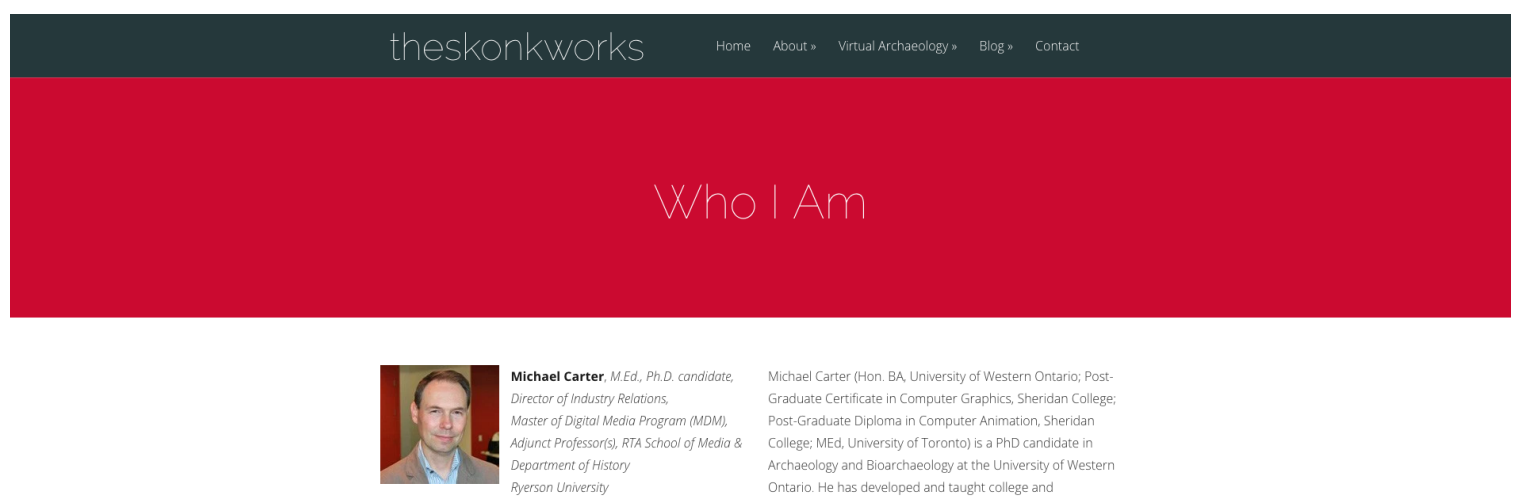

Michael Carter (Hon BA, University of Western Ontario: PostGraduate Certificate in Computer Graphics, Sheridan Colle-ga Post-Graduate Diploma in Computer Animation, Sheridan College; MEd, University of Toronto) is a PhD candidate in Archaeology and Bioarchaeology at the University of Westarion undergraduate cources in digital media animation film and television production computer graphics and mantained successful 20-year career in the film and television business as a producer, executive producer, and executive:

Michael has spent his professional career immersed in the creative, technical and business roles of animation production. Since graduating from Sheridan College's Computer Animation Program in the mid-1990s, he has held a number of progressive positions. both locally and internationally, that propelled him to the role of executive producer for Cal ibre Digital Pictures on the CGllive-action Series Ace Lightning II (BBC Worldwide/Alliance Atlantis) and Shoebox Zoo I (BEC SCotland//lueprint Entertainment), as well as the

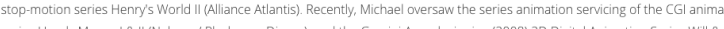
Des

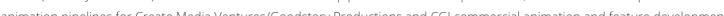
pipelines for Aardman Animations.

Michael has sat on the board of directors of CASO (Computer Animation Studios of Ontario\} as director, vice president, and president As president, he represented CASO as a member of the OMDCS (Ontario Media Development Corporation) Screen-Based Industry Advisory Committee, 3D-Flick, and various regional and municipal digital media initiatives.

My current Curriculum vitae can be accessed here: WM Carter 20150V

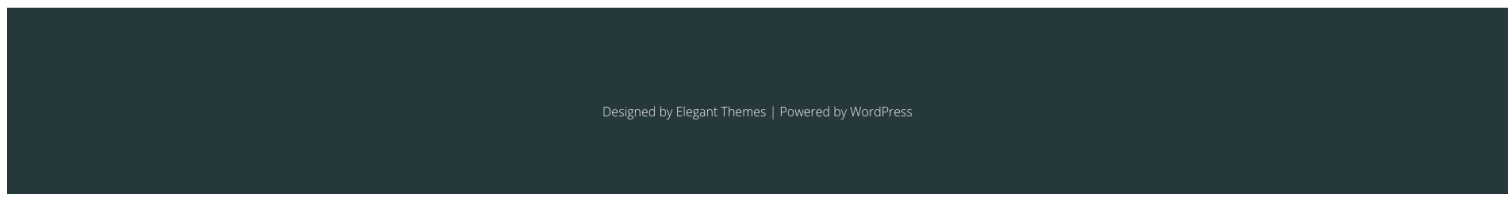

Appendix A 5: Who page - http://theskonkworks.com/animation-production/who-iam/ 


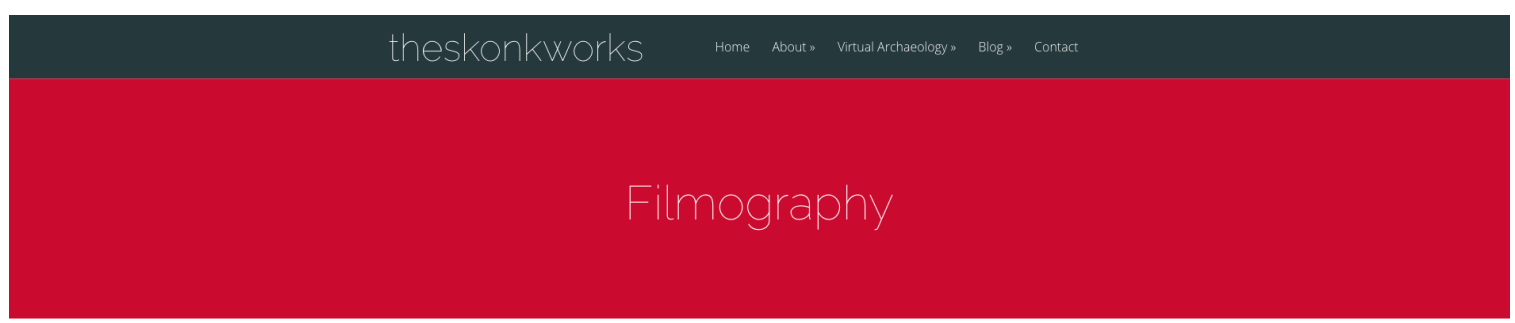

theskonkworks filmography:

VFX Supervisor, Against the Wall (2011) - Life Network

Supenising Producer, NFLRushZone (2011) - NFLUNick'Curious Pictures

Associate Producer, Ultramarines (2010) - Warhammer 4000 CG Feature Film - Games Workshop/Codex UK/Goodstory

Productions/Create Media Ventures

VFX Producer, Thinking Cars (2009) - H3B Media UK

Service Producer, Little Spirit (2008) - Curious Pictures

Service Producer, Will \& Dewitt (2007-2008) - [ookie lar Entertainment/KidswivB

Service Producer, Handy Manny II (2007-2008) - Nelvana/Disney Playhouse Production

Service Producer, Handy Manny 1 (2005-2006) - Nelvana/Disney Playhouse Production

Executive Producer, ACe Lightning (2003-04) - BBC/AACICBC/Calibre Production

Executive Producer, Shoebox Z0o (2003-04) - BBC/Blueprint/CBC/Calibre Production

Executive Producer, Henrys World (2003-04) - AAC/CBCICalibre Production

Studio Manager, Hey Joel (2002) - VH1/Curious Pictures/Blueprint/Calibre Production

Studio Manager, Ace Lightning (2001) - BBC/AAC/Calibre Production

Technical Director, MonsterbyMistake Series II (2000) - Cambium/Catapult Production

Technical Director, MonsterbyMistake Series I (1999) - Cambium/Catapult Production

Appendix A 6: Filmography page - http://theskonkworks.com/animationproduction/filmography/ 


\section{theskonkworks Home About» virtual Archaeology " Biog, contact}

\section{Virtual Archaeology}

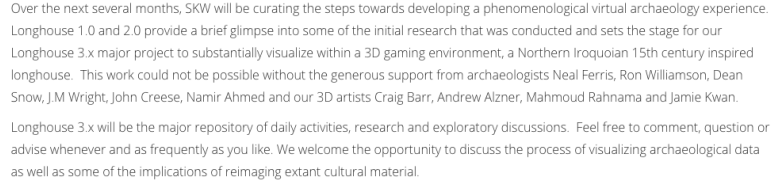

Longhouse 2.1

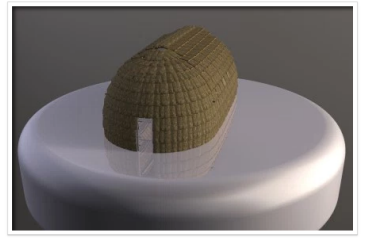

Longhouse 2.1 was originally intended as a preliminary

Longhouse 1.75

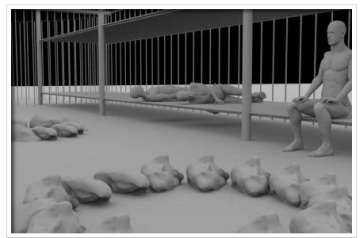

Longhouse 1.75 carne about as a request from Dr. Neal

Ferris to organize and present at a.

Longhouse 1.0

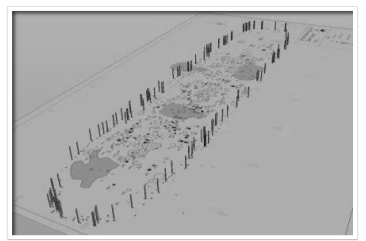

Longhouse 1.0 began in the Winter of 2013 through a series

of discussions with long-time
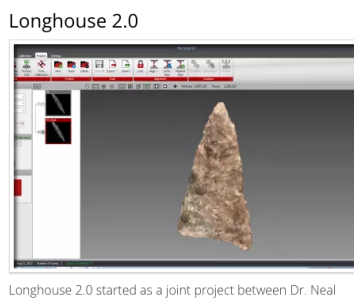

Ferris at Sustainable

Longhouse 1.5

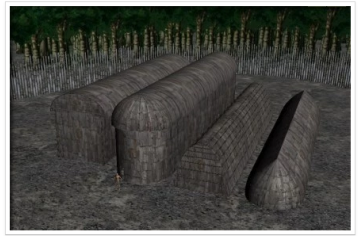

Longhouse 1.5 was a further attempt to test the notion of

user engagement through

\section{Appendix A 7: Virtual Archaeology Index 1 page -} http://theskonkworks.com/virtual-archaeology/ 


\section{Virtual Archaeology}

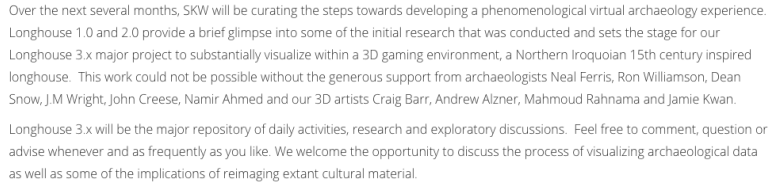

a

Longhouse 3.1.5

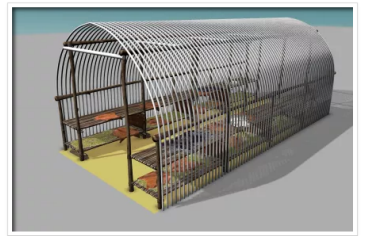

steen a susy couple of days for the project and Craig, who is still down at

Longhouse 3.0 .5

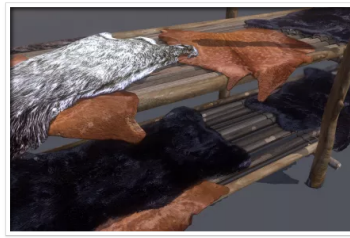

Based on all : f the graat feedback and sone excelest

research leads in 5 tage 305 of

Longhouse 2.5

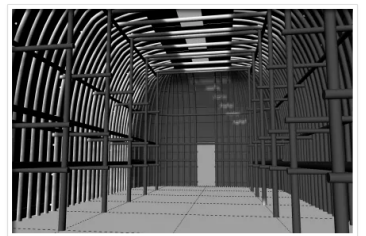
Ron Willamson from ASI. Ron.
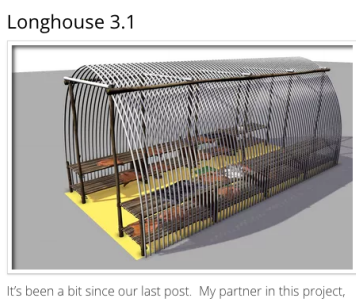

Craig Barr, was

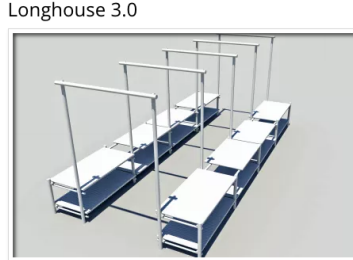

In starting our virtual archaeology project to visually

reproduce a 15 th century Virtual.

Longhouse 2.2

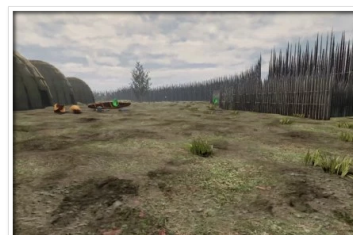

Longhouse 2.2 vecame a watershed moment during ou research primarly due to two seem.

\section{Appendix A 8: Virtual Archaeology Index 2 page}




\section{Virtual Archaeology}

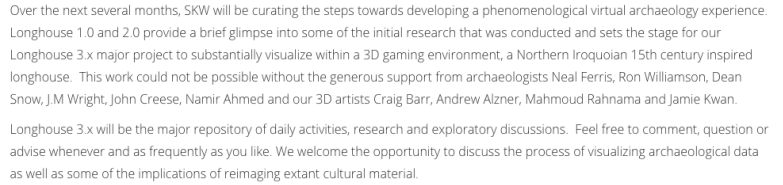

as $a$ a sone of the in

Longhouse 3.4.5

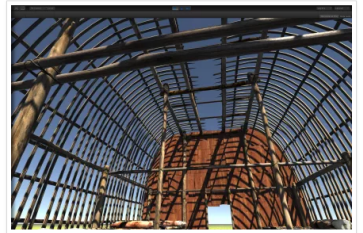
in high gear preparing for

Longhouse 3.3.5

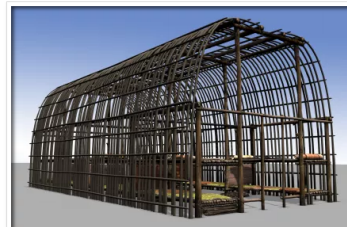

wanted to relay some great news for the project! Craig and! I wanted to relay som

Longhouse 3.2.5

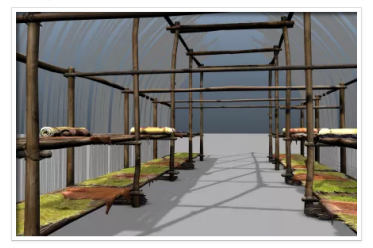

A big shout out to @EAAGlasgow (EAA Glasgow 2015). Wo have loved to participated in.
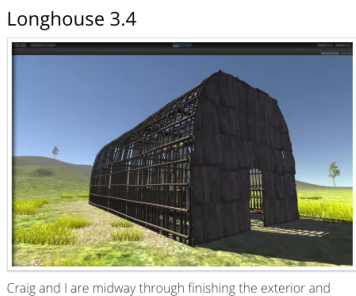
have been preplanning for the

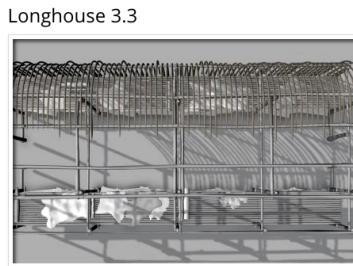

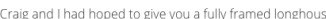
last week, but late into last...

Longhouse 3.2

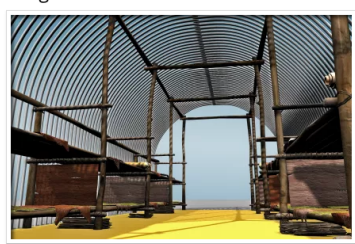

It's been another busy week as we start to refine the longhouse superstructure...

\section{Appendix A 9: Virtual Archaeology Index 3 page}




\section{Virtual Archaeology}

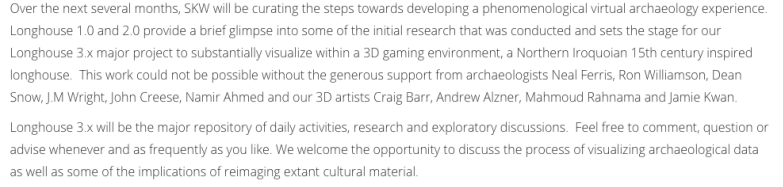

Longhouse 3.5.9

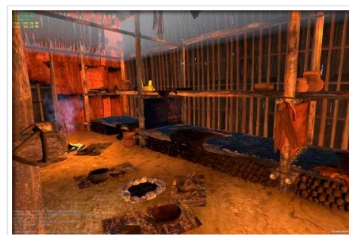

It has been a bit since no

Longhouse 3.5.7

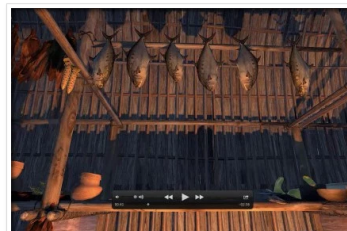

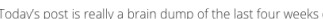

Today's post is really
virtual archaeology.

Longhouse 3.5.5

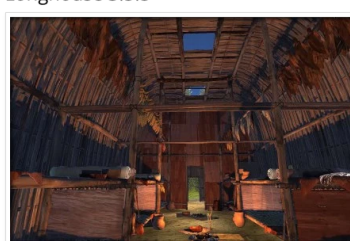

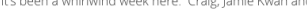
attended the Hertage
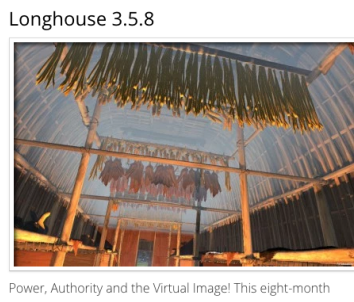

journey has been an exploration

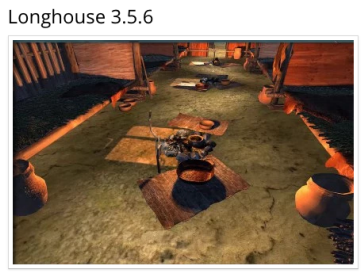

Sorry for the delay over the last couple of weeks. Craig and were busy with the

Longhouse 3.5

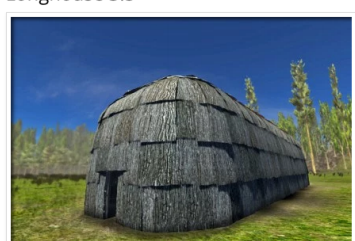

This has been an extremely busy week. Craig and I have been working hard on finalzing.

Appendix A 10: Virtual Archaeology Index 4 page 


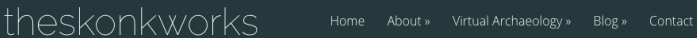

\section{Longhouse 1.0}

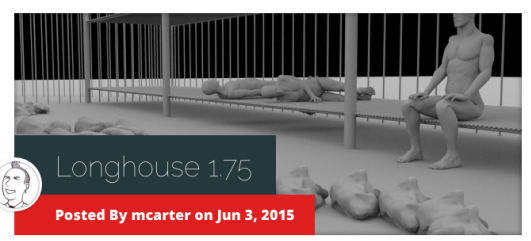

Subscribe

eep up to date by subscribin

Email Add

Subscribe

Recent Research Posts

- Longhouse 3.5

Longhouse 1.75 came about as a request from Dr. Neal Ferris to organize and present al

a session on Virtual Archaeology at the Canadian Archazeological Association Conference

(CAA) in London Ontario of May in 2014. The presentation entitled VFX Methodologies

for Scientific Visual ization in Archaeology was an opportunity to expand on some of the

tools and methodologies being developed, as well as provide some insight into the world

Read More

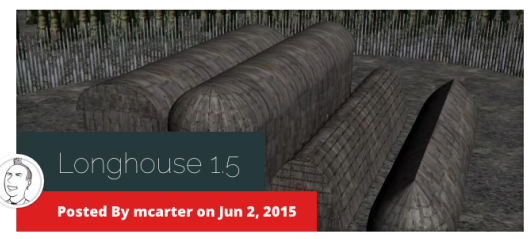

Longhouse 1.5 was a further attempt to test the notion of user engagement through procedurat modet bullang within 3D space. My understanding of the visual zation of longhouses from the arthaeulogital record an ses principally irom the work of four archaeologists,. V. Wright, Milma Kapches, christine Dodd and Dean Snow. Due to the lack of any real physical evidence, models of longhouse use, style, agency, and construction have been

Read More

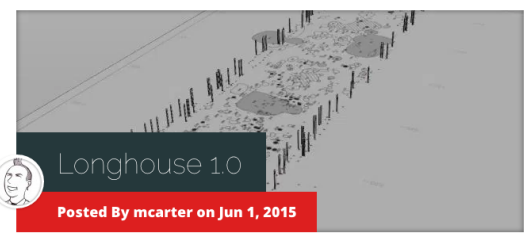

Longhouse 1.0 began in the Winter of 2013 through a series of discussions with Iong. time 3D animation and VFX collaborator Andrew Alzner as a starting point for my Ph. D. research into Phenomenological experiences within virtual environments (see my blog on methodology \& research). Both Andrew and I had met each other in 1996 at Side Effects Soffware (SESI) and had travelled to Japan and LA regularly for customer support. SESS

Read More

Appendix A 11: Longhouse 1.0 Index page http://theskonkworks.com/category/featured/longhouse-1/ 


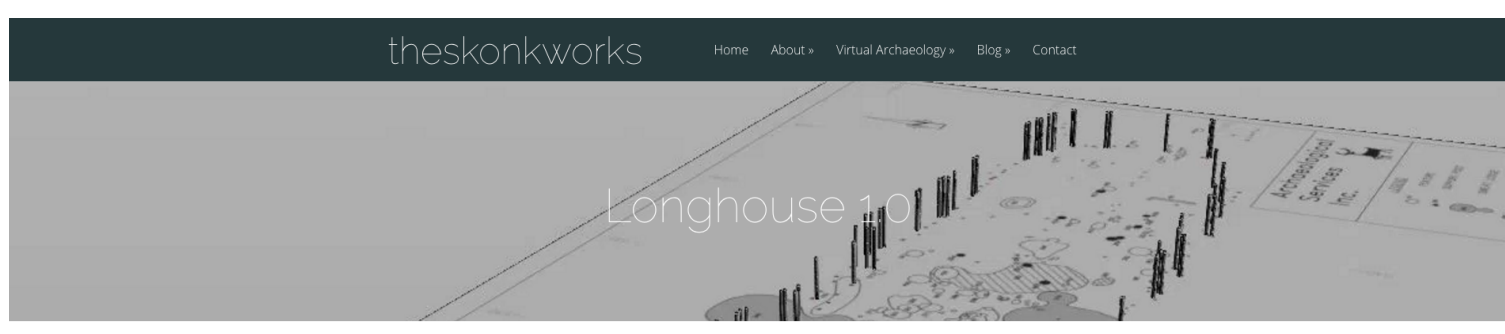

Longhouse 1.0 began in the Winter of 2013 through a series of discussions with longtime $3 \mathrm{D}$ animation and VFX colla borator Andirew Azzer as a starting point for my Ph. D. methodolocy \& recearch) Both Andrew and I had met each other in 1996 at idd Effa Soffware (SESI) and had travelled to Japan and LA regularly for customer support SES was one of the three original Animation and VEX seffware companies founded here in

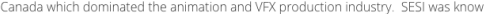

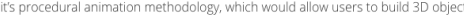
animation or VFX sequences throush a dyramis intererelated and realtime pipeline through a sofware application called Houdin Bascally you bulte 30 object using

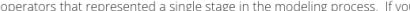
cha living document of the model one was making in 3 D

Procedural 3D Modeling is a cynamic building block technique for organically creating digtal assets. The proposed pipeline has been specifically designed to allow

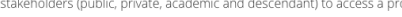

model library in order to buid in reat-time anta within 3 D space, interactive visualizations of extant cultural herrtage strutures. Beyond intrally allowing users to "bulld" their or

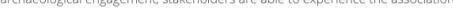
between the physical strutcure, spatial telationships and the phenomenologitalexperiences of these archaeological landscapes. These buit digtal assets can also te reapplied within any numerous engagement tools such as mobile Apps, Internet Websites or even within $3 \mathrm{D}$ gaming engines, turther extending the narrative beyond the individual's brief but personal archaeological experience

In simple terms, procedural modeling is a process in which all of the steens needed to

政

allow the user to alter, change or experiment with the final model at any stage of the

building process. As in this example, a picture of a pot is superimposed in the display

wendow A NURES spline is bull by placing points along the outline of the por and then a

new procedural operator called a "revolye" skins thar single outline soline $360^{\circ}$ creating

the $3 D$ surface. Finally a transform operator is inserted within the middle of the

procedural network and when one parameter changes, that change affects the

relationship of the next modeling operation within the network, causing the model to

alter accordin

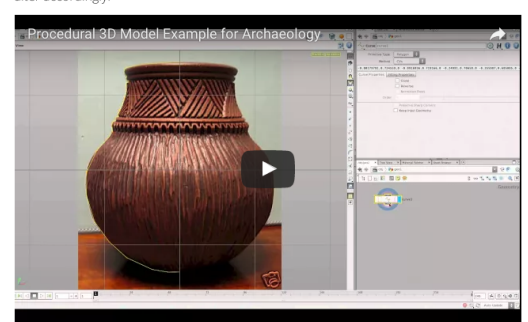

if p possible to use this methodology to develop a process in which the archaeologicd landscape can be methodically reconstructed whille retaring the ability to experiment Whth the assumptions in near real-time visualization Further, once the method is in place the technology can then be packaged in such a way to allow for more pre excavation or auning excavation interpreteations, stakeholder or public engagement and further research.

Using this concept of total user control, we started to develop a dynamic pipeire for the creation 30 longhouses using the SESI Houdini procedural method. We first started with

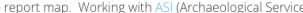
into Houdini:

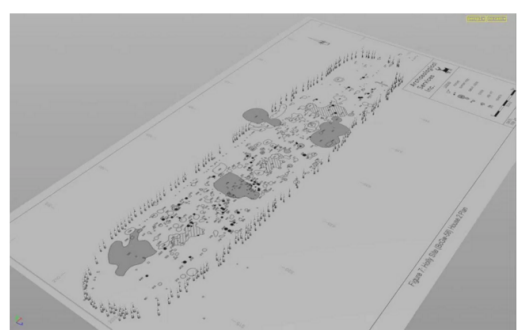
map, we spawned simple 3D models of poles for every post hole. Essentially we "birthed" posts where they were recorded from the archaeological data provided. This all owed us space

Appendix A 12: Longhouse 1.0 page A

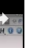

Subscribe

Keep up

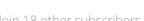

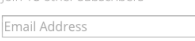

Subscribe

Recent Research Posts

- Longhouse 3.5 .9

- Longhouge 358

- My thira dirat PhD Proposal

- Ingold \& Waylaring from a Digit 
This process was repeated using the same technique, but this time larger pole diameters were selected in order to differentiate the mixed used of pole sizes recorded within the archaeological record. What we were attempting to do was create an automatic pipaline that would size pole ciameters from the field mapping and then sluster and group poles of equal diameter and position

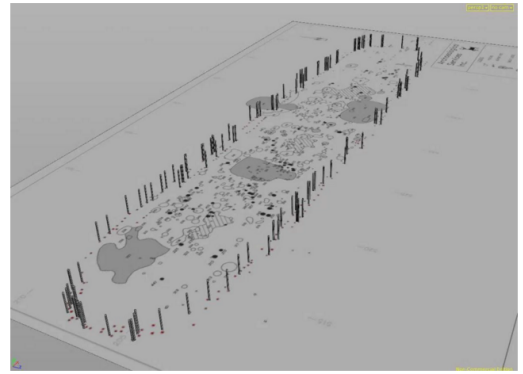

This technique worked well on st was the only dara being detected. However, substantial labour intensive work had to occur with the raw $2 \mathrm{D}$ dara for this technique to work After discussions with Side Effects Software, they prototyped an add titiona procedural modeling network that would allow any site plan to be imputed with post puints being detected, solated and converted into 3D posts. The notion was to allow non-3D users to be able to pick any site plan material and upload it into the pipelne to be able to create their own $3 \mathrm{D}$ mode

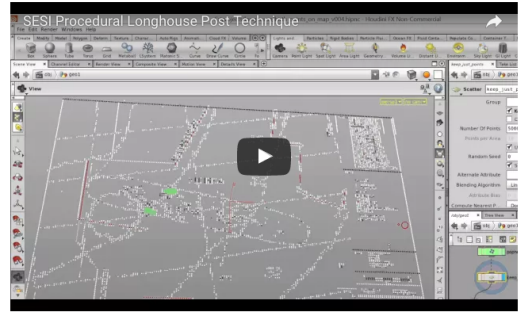

Although much slower in realtime, the process proved successful in pre-post point experience discussions with Dr ush analysis post-clustering theories using this technique but with another popular $3 \mathrm{D}$ animation software application called Autodesk Maya. Working with Toronto based M作 animated the birthing of the posts from the excavation data map.

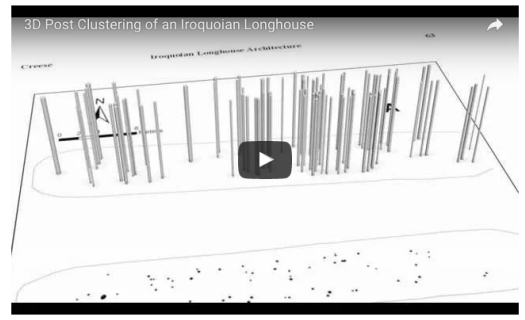

This technique which we coined "3D Post Clustering" allowed us to birth poles from site excavation maps automatically. Additionally the technique would grow the height of the pole in relations to the width of the longhouse as indicated in the literature as being equal in length (Bartram, 1751; Dodd, 1984; Kapches, 1994; Snow, 1997:Tow is Wright, 1995). Visually it allows archaeologists to see within 3D space how the poles might have looked and which poles would be associated with each other based on time and space. We immediately saw a need to determ ine old vs new posts within the archanolngicat record and whother a technique could be developed to detemine which

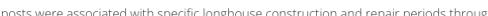
the 3 D visualization of the data

Atthough a simple use of procedural mocelling techniques, this process represented the base of tuture experintmentin ga longhouse construction using archaeological data bringing our research to the next stage, Longhouse 1 t:

Works Cite

Bartram, J (1751) Observations on the inhobitants, Climate, Soil, Rivers, Productions, Animals and Other Matters Worthy of Notice, Made by Mr.John Bartram, in His Travels from

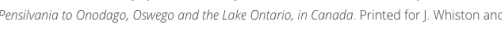
B. White, London

Creese, J. L (2009). Post-moulds and Preconcentions' New Dhservations about Iroquoiar Longhouse Architecture, Northeast Anthropology 77-78, 47-69.

Dodd. C.F. (1984). Ontario Iroquois Tradition Longhouses. Archaeoiogical Survey of Conada, Mercury Series 124. Ottawa: National Museum of Ma

Kapches, M. (1994). The Iroquolan longhouse architectural and cultural identity Meaningtul Archtrecture: Social Interopretations of Buldings, , 25.

\section{Appendix A 13: Longhouse 1.0 page B}




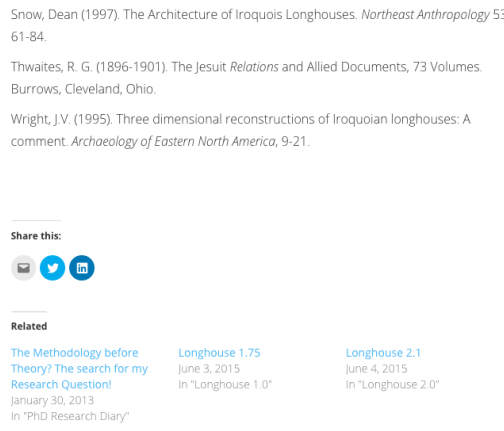

Trackbacks/Pingbacks

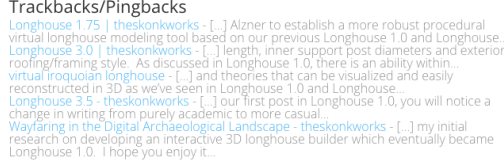

Leave a Reply

Appendix A 14: Longhouse 1.0 page C 

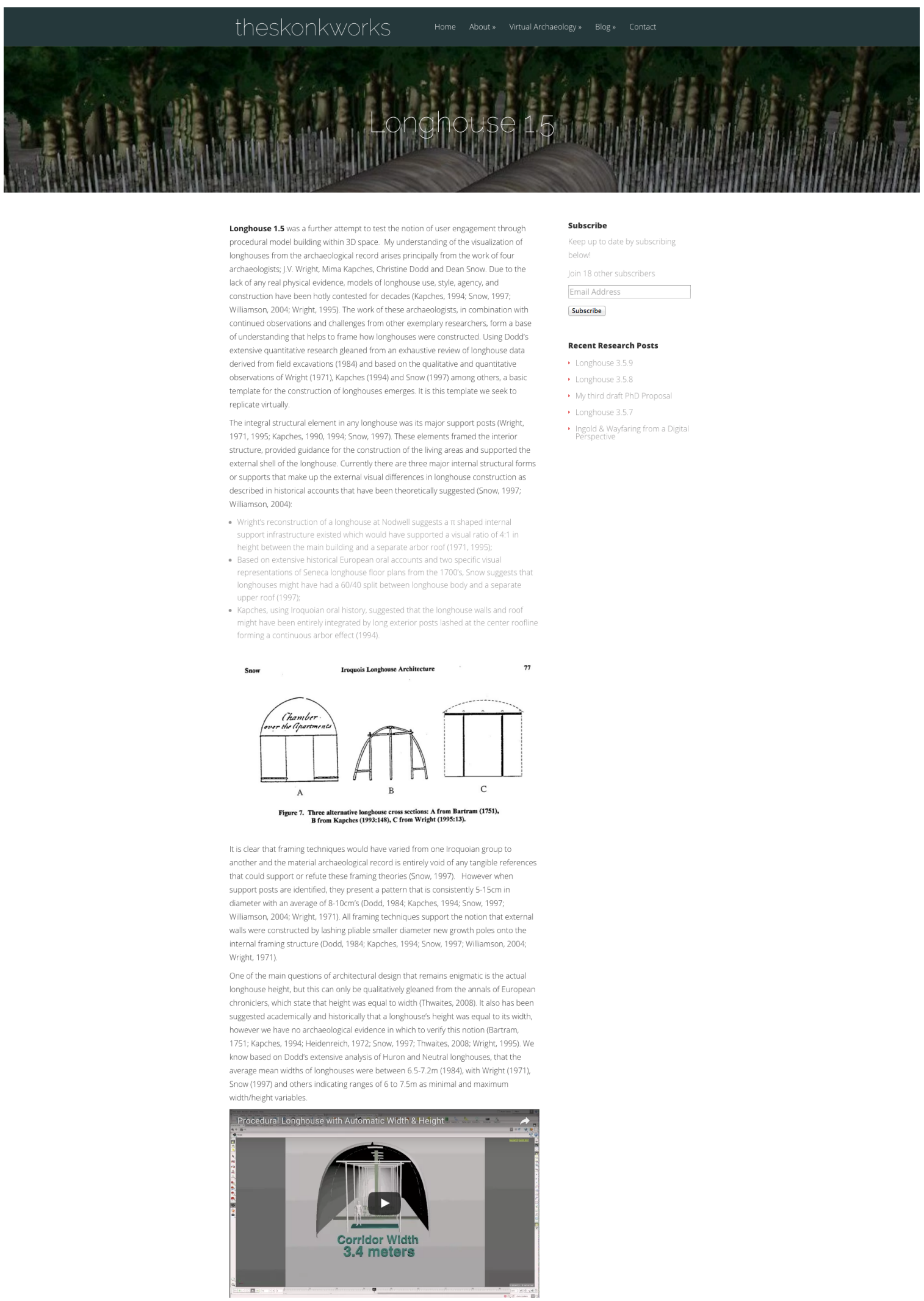

Archaeologically, total longhouse length is easily measured from the physical record

Appendix A 15: Longhouse 1.5 page A 


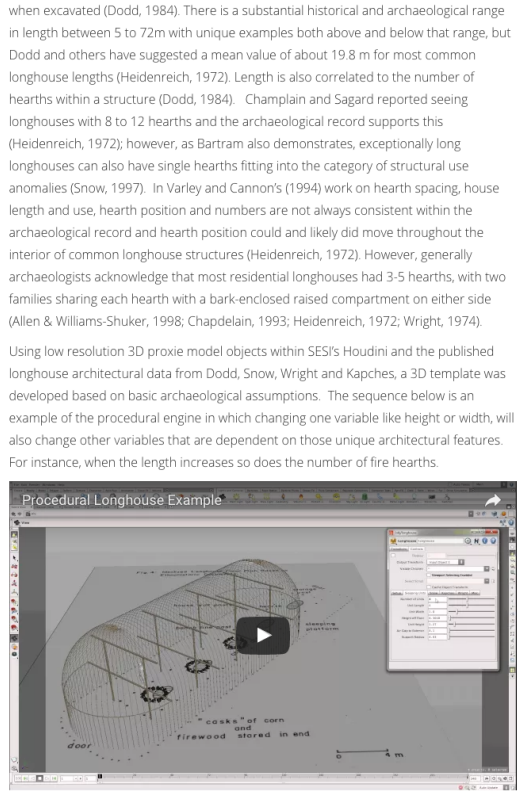

Athough not clear in the vdeo above, we were a so able to change between the Wriis Kapches and Snow interior support framing automatically having all other architectura elements ripple through accordingly. The initial goal of this test was to see if procedural model from the archaeological data could be developed Additionally, user controls were created to al ow other stakehoiders to easily change parameters easily without having to know $3 \mathrm{D}$ animation

A second test was conducted using the same methodology but with further refine controls and additional architectural elements in this attempt the mode elements were greaty simpl fied to allow for faster render and procedural calculations when changes were made in real-time. However, the model huilt was not "birthed" from an actur archaeological site mao, but became a representation of the data presented by Dodd, Wright, Kapches and Snow based on the architectural variables present in the ical recor

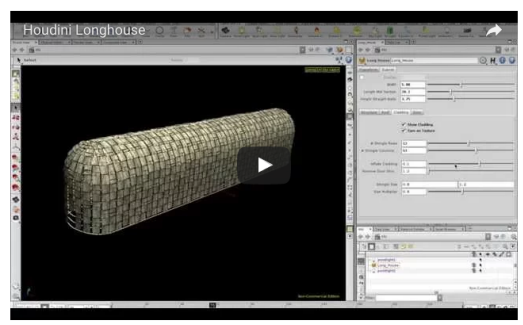

This exercise provide a unique opoortunity to create new tools that could be deployed to interface and the real-time optimization, we can envision a deployable interactive tool set that could be installed in museums or through an App/Neb for school curricul um needs. From a research perspective however, it provides an excellent base to the design. development and implementation of a 3D. vitual phenomenological experience of the archaeological record. Next, we expanded on this procedural methodology to test other Works Cited:

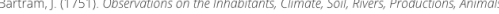
and Other Matters Worthy of Notice, Made by Mr. John Battram, in His Travels from Pensivaniti 10 onodago, Oswego and the Lake Ontanio, in Canada. Printed for J. Whiston and B. White, Londor

Chapdelaine, C (1993) The sedentarization of the prehistoric Irooucians: A slow or rapid transformation? Journol of Ant thropological Archaeology, 12(2), 173-209.

Dodd, C.F. (1984). Ontario Iroquois Tradition Longhouses. Archoeological Survey of Canadd, Mercury Series 124. Ottawa: National Museum of Man

Kapches, M (1994). The Iroquoian longhouse architectural and cultural

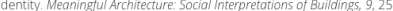

Heidenreich, C. . (1972). The Huror: A BriefE Ethnography. Discussion Paper Series No.6 Toronto: Department of Geography, York University.

Snow, Dean (1997). The Architecture of Iroquois Longhouses. Northeast Anthropology 53:

Thwatites, R G (1896-1901) The lesuit Relations and Allied Documents, 73 Volumes Burrows, Cleveland, Ohio.

Variey, C., \& Cannon, A. (1994). Historital inconistencies. Huron longhouse length hearth number and time. Ontario Archaeology, 58, 85-101.

Appendix A 16: Longhouse 1.5 page B 


$$
\text { Stare ents: }
$$

Renteded

\section{Appendix A 17: Longhouse 1.5 page $C$}




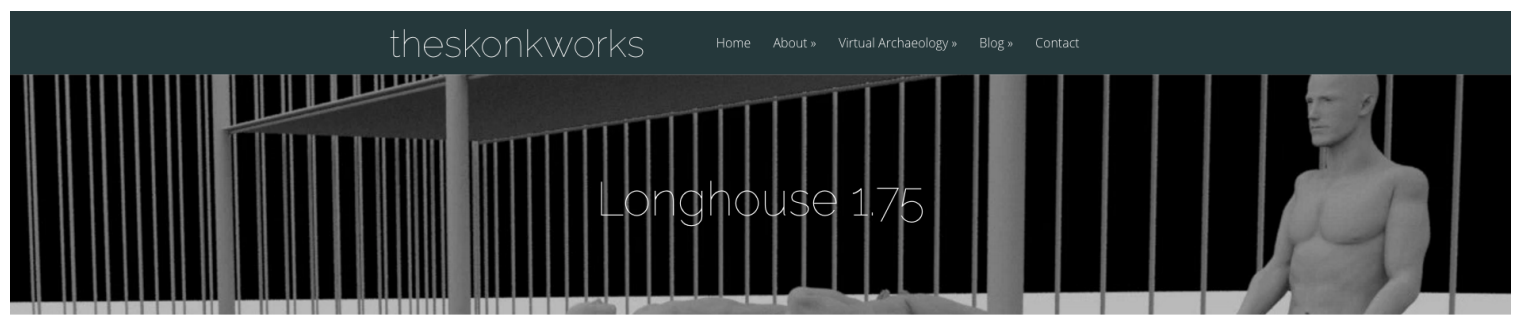

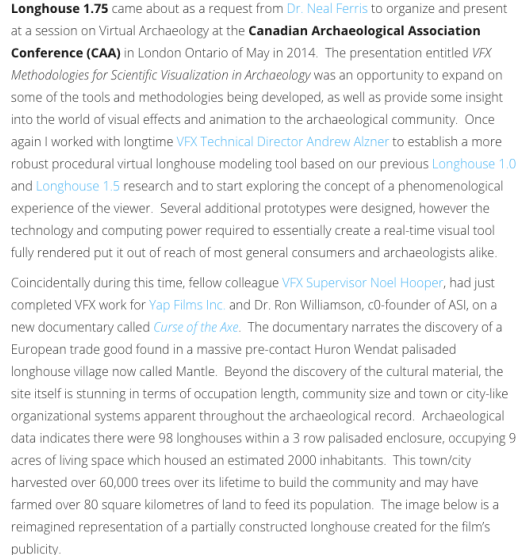

publici

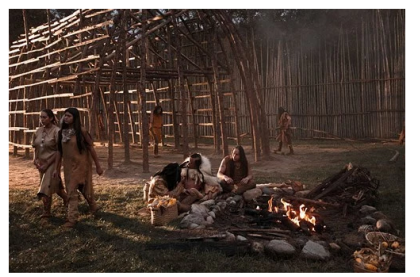

Lost in the rush to embrace so visual effects in representing material culture, I falled at the time of the presentationto mention one of the first representations of Iroquoian longhouses in vsual media: Bruce Berestora's 1991 movie adaptation of Brian Moores novel, Black Robe. The phenomenological experience of the practical set gave the audience a sense of what it was like to live within a communal longhouse. Although practical effects heavy and some scholars would say, highly European centric in vision, eludes to how longhouse life might have been; densely populated, laden with everyd goods and heavily saturated with atmospherits such as smoke, fire light, dust an

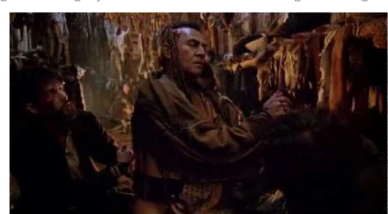

Additionally, in 2012 Ubisoft Games released Assassin's Creed III (AC3) which would take place during the Revolutionary War, presented a new direction in experiential narr ratives. ACS included a main character of Haudenosaunee decent in which part of the game play would include Haudenosaunee inspired longhouse reconstructions. Below are scree shots of the game play associated with some of the longhouse sequences

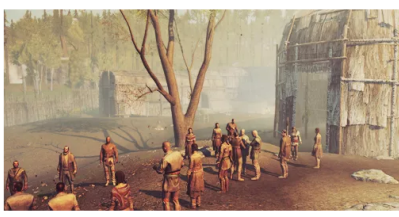

developing AC3, Ubisoft brought on Thomas Deer and Dr. Kevin White, both Mohaw descendents to consult throughou the project. Obviously artistic license pass liberally throughout $A C$, however there are some areas of longhouse design and construction which seem to correspond to the archaeological record In the image above, the shingles are roughly $1 \times 2$ metres in dimension, which corresponds to the historical and oral histories of longhouse building. The entrance and the height ate obviously designed for game play yet the outer support lattice work is suggestive of

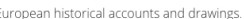

Subscribe

selow

Join 18 other subscribers

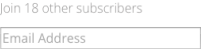

Subscribe

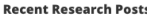

Longhouse 3.5.

- Longhouse 35

- My third draft PhD Proposa

Longhouse 3.57

- Ingeld \& Wayfaring from a Digita

Appendix A 18: Longhouse 1.75 page A 


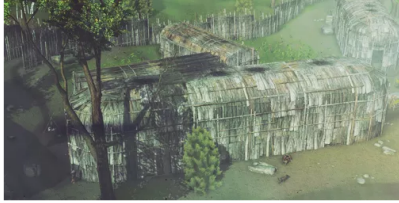

Although lost in the middle back portion of the image above, we see a partially constructed longhouse missing the rounded vestibule of the finished versions in frort and to the right side of the image, again acknowledging the archaeological record. Although Dean Snow has indicated that Haudenosaunee longhouses were thinner and subsequently lower in height compared to Northern Iroquoian examples, these examples are virtually gigantic in size. However, it did allow users to interact with the 3D environment and in doing so, opened up the possibilities of further expanding how the public could interact more effectively with the archaeological record

The VFX for Curse of the Axe, the game design for Assassin's Creed ill and the set design for hed perspective, the procedural longhouse model build ing methodology was mare closely aligned to Paul Riley's concept of Virtual Archaeology, the combination of actual archaeological data in the creation of $3 \mathrm{D}$ visualizations. Our attempt to concentrate exclusively on the mechanics of the actual longhouse build lost sight of the personal

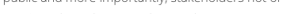
descreme

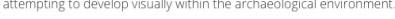

In tandem with the traditional virtual archaeology approach to our longhouse research two additional projects were started. Longhouse 2.1 explored more of the interactivity of the user within 3 D gaming space and longhouse 75 delved into the practical apo lication of longhouse construction through the eyes of modern architects and architectura

visualization

Share this:

- 9 ำ

Relate

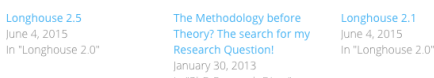

Trackbacks/Pingbacks

Langhouse 15 I I theskonkworks - I I This exercse provide a unique opportunity to
create new tools that could be deployed to the general public as

Leave a Reply

Enter your comment here

Appendix A 19: Longhouse 1.75 page B 

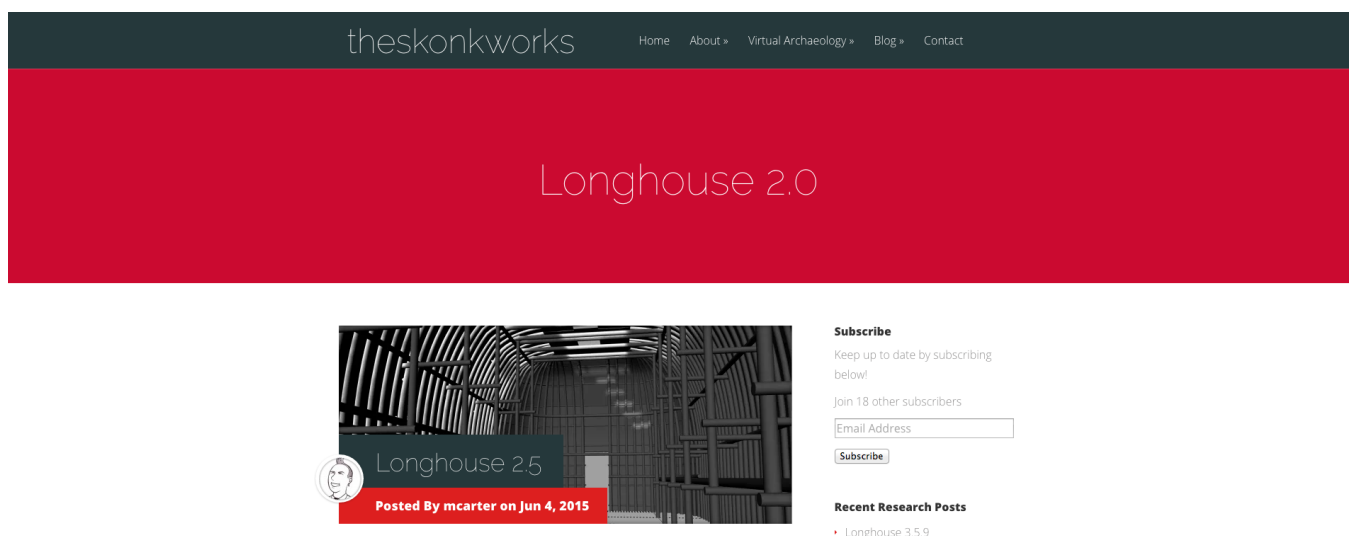

Longhouse 2.5 came about during a long conversation with Ron William son from ASL.

Ron had been very generous with his time to discuss some of the issues of longhouse archaeology, het heories and methodologies for data accuisition as well as some of the Ron provide

Read More

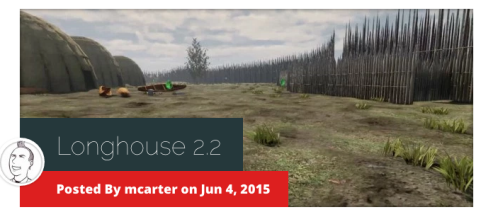

Donghouse 22 became a watershed moment during our research primarly due to two

seenly incon sequental decisions; ; port of the $3 \mathrm{D}$ assets to the Unreal game engine and a chance tour of local High School students. The purpose of the Loyalist College

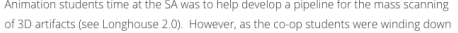
on their 2

Read More

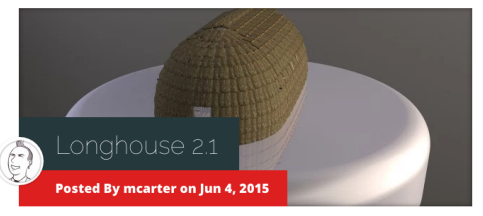

Longhouse 2.1 was originally intended as a preliminary increoduction to our 10 Loyalist College Animation interns to basic archaealogical research and vsualization of Museum of Ontario Archaealogy, the students had direct expossure to the partiatly reconstructed Lawson Neutral Iroquoian Longhouse Village. Additionally they were within driving distance.

Read More

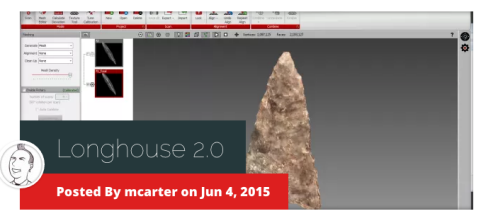

Longhouse 2.0 started as a joint project between Dr. Neal Ferris at Sustainable Archaeology (5A) and theskonkworks (5KW) to explore the possibilities of developing a Ahmed, a Master's student in Archaeology at UWO and someone with previous animath and archaeolo

Recent Research Posts
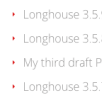


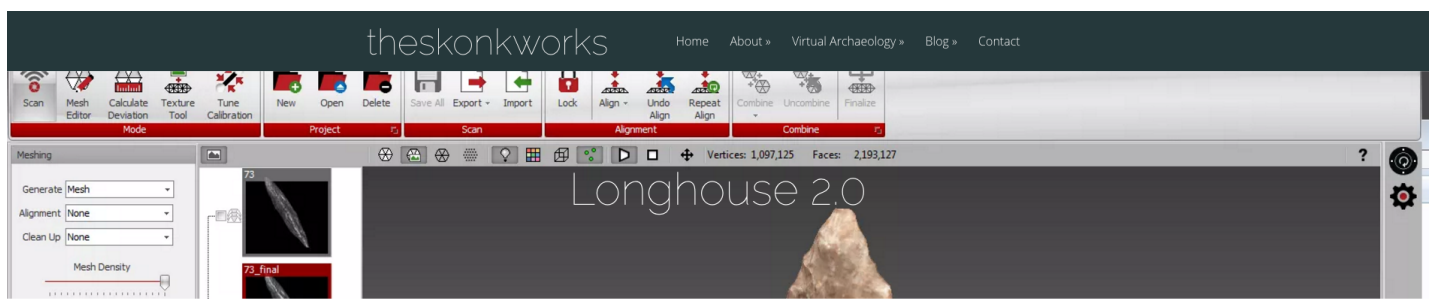

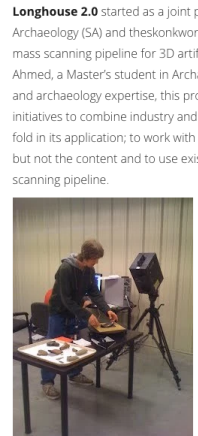

tt between Dr. Neal Ferris at Sustainable (5konkworks (SKW) to explore the possibilities of developing W artifacts in the summer of 2012 . Working with Namir use existing Film \& Television techniques to develop a mas

Te project recruted 10 Loyalist College Animatith

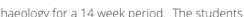
were all in their last year of studies and as such had a tools and basic pipelines. $5 \mathrm{~A}$ provided the equipment which consisted of several variants of sional 30 scanners and SKW provide animation equipment and sipeline

The research team proved to be highly sucessfut only being able to demonstrate th Archaeologists and Animators could effectively and quickly work together on very complex cystems and data but that the SAf fosity when propery provsioned, easily scan over 100 artifacts per week The pipeline itsolf consisted of developing or tools specific to the artifacts sizes, complexity and surface quality as we the practical application of data acquistion, Iighting, mesh integration and texture mapping. 3D3 solutions, a technology supplier, pr

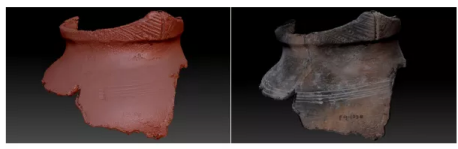

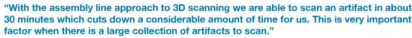

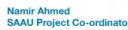

This stucy proved to ve cute valuable in understanding the scanning needs of artiacts and how to both manage the cota and the expectations and limitations of the technology. Our research also spawned a paper for World Archaeolog

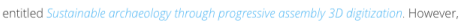

prior to starting our $3 D$ scanning pipetine research, the students started warming up with an ancillary project in which they would apply standard Film \& TV development

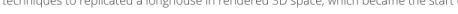
the phenomenologla gaming research intousen gogementwin hextan archaeologkal landscopes. Thus Longhouse 2.1 began as an exertise to engage the

Share this

$\therefore 0$ 잉

Related

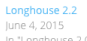

Trackbacks/Pingbacks
Subscribe

celowe

loin 18 other subscribers

Subscribe

Recent Research Posts

\section{Longhouse 3.59}

Langhouse 358

Wy third draft phi D Pronos

- Ingold E Wayfaring from a Digit 


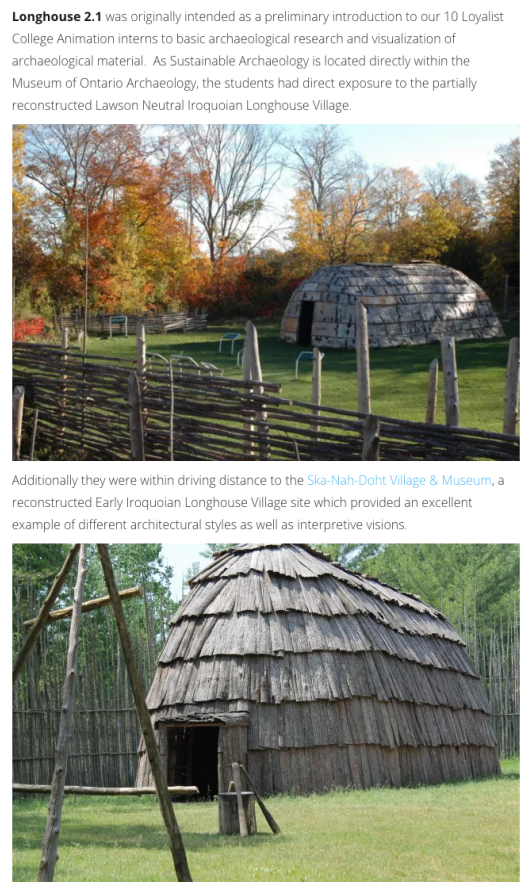

Subscribe

below

oin 18 other subscribers

Subscribe

Recent Research Posts

Longhouse 3.5.

Langhouse 3.5

My third dratt PhD Proposa

Ingold \& Wayfaring from a Digita

derstand the mater als used in the reconssruction and get a sense of the sound, ilgh

and atmosshericis produced in such a buldinins

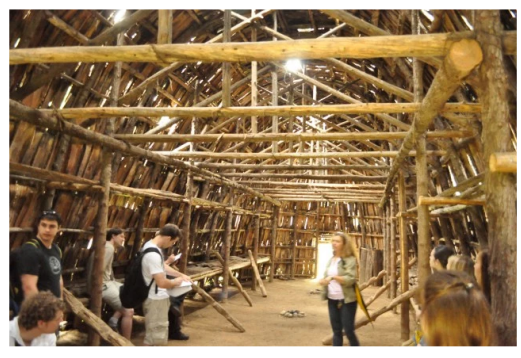

Following traditional Film \& TV methodology, the students used these phycical references

and the archaeological data from the Lawson site to start envisioning what a 3D

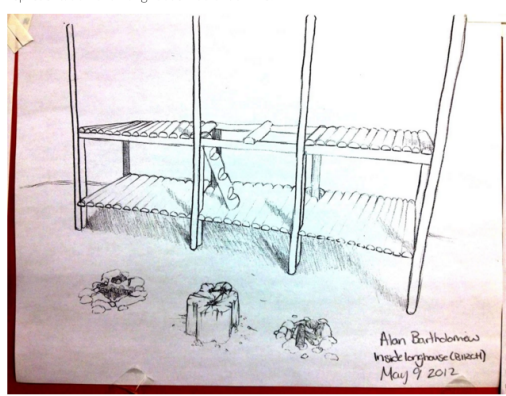

Appendix A 22: Longhouse 2.1 page A 


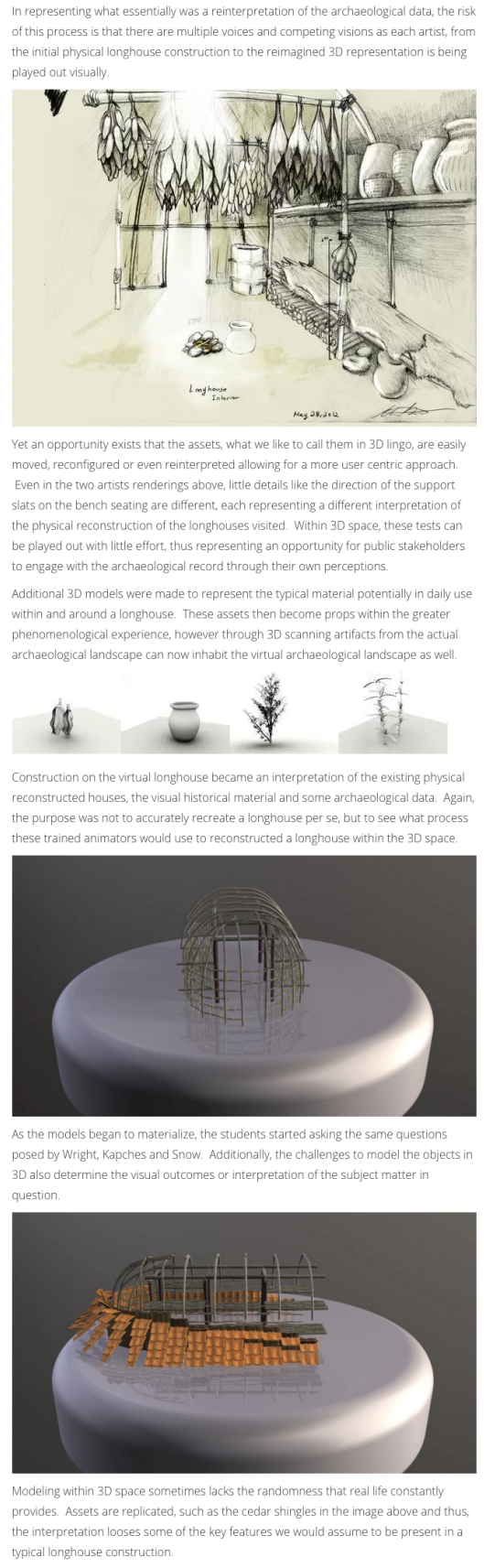

Appendix A 23: Longhouse 2.1 page B 


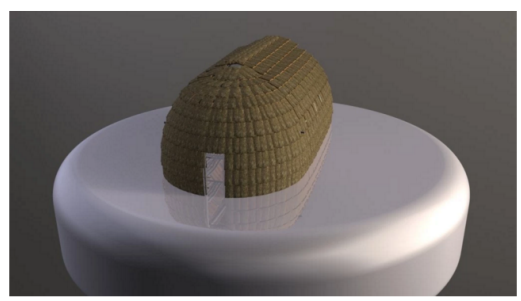

The final product, althougn representative of the subject matter, is in essence a copy of

This was a wonderful initial first run for the students and the archaeologists alike. It

provide a unique opportunity for the 5 A to see the production process from a traditional

3D animation methodology and it inititated the very same questions archaeolog ists would

ask themselves when visualizing the archaeological record. It also provided a jumping of

spot to explore the necessity of having real time, user defined and engaged content
delivery systems.

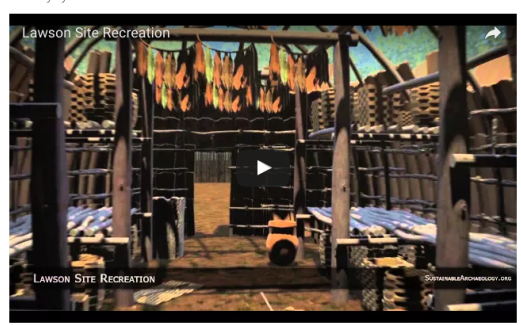

The exercise provide the assets needed to continue the development process. In

conghouse 22, we move into the real-time, user discovery environment It also

represents a major pivot towards a sust:
visualization of archaeological material.

Share this.

- 1 (1)

Related

Longhouse 22.2
|une 4,2015

Longhouse 3.3
September 14,2015
In 'Longhouse $3 x^{\prime \prime}$

Trackbacks/Pingbacks

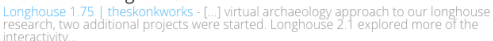

Leave a Reply

Appendix A 24: Longhouse 2.1 page C 

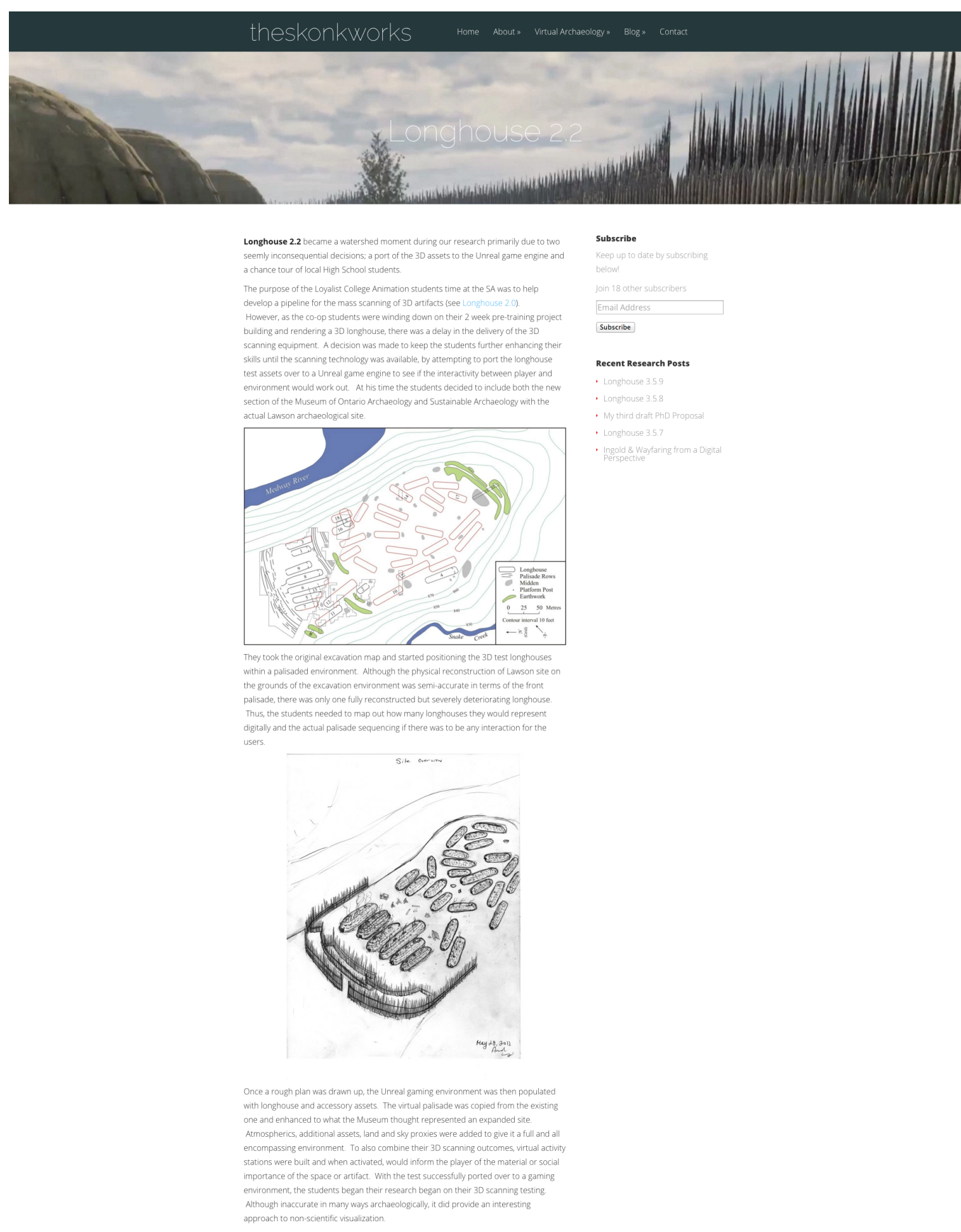

Appendix A 25: Longhouse 2.2 page A 


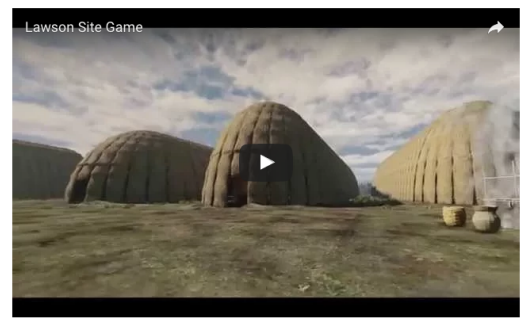

The real "magic" happened after the game was completed. During a random local High School class visit to the Museum of Ontario Archaeology and Sustainable Archaeology, course the dhss warefect lead was exp are around the interactivity within an environment in which all of the High 5 chool studen were not only accustomed to, but was also the first generation to have been bon completely exposed to digtal technology. The "a-ha" moment came when the stuctents after playing the video game attemnted to celve the same virtala experience outside in

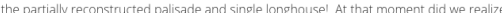
that the reserch was not about aceurtely recol stakeholders to the archaeological landscape through real-time, virtual phenomenological experience.

Share this

$-\infty$ Related

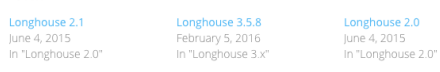

Appendix A 26: Longhouse 2.2 page B 

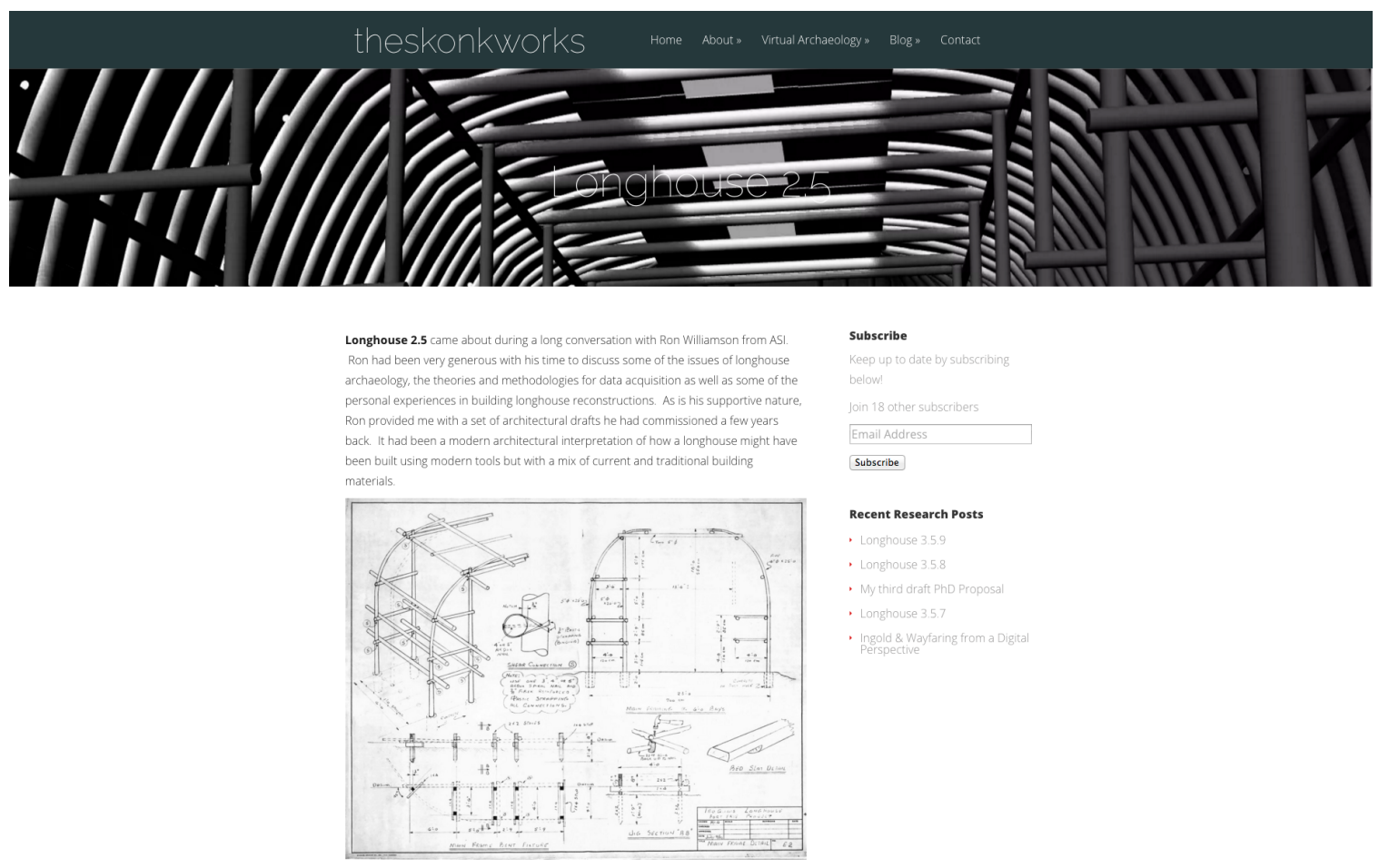

Subscribe

The drawing represented an excellent inter reretation of the archaeological data from a structural perspective. It also blended at that time, more simplistic building code

reconstruction projects (see Crawford Lake Longhouse vil lage - personal communication with Conservacion Hatton Staff)

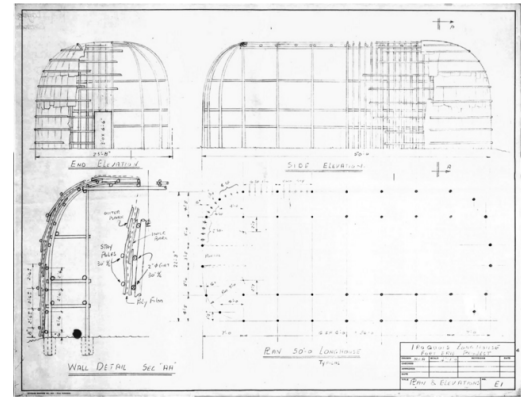

setp to to the

ton 180 the substons

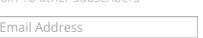

Subscribe

Longhouse 3.5 .5

My third dratt PhiD Propos

Ingold \& Wayfaring from a Digital

wanted to gat an understanding of $3 \mathrm{D}$ building techniques from an architedturally

trained specialist lamie Kwar, a recent Architecture graduate from Ryerson University

and a current Master in Digital Mecia student agreed to take on the challenge. Using the

plans provided. Jamie reinterpreted the material within Rhino30, a robust but very simnle

to use modeling package.

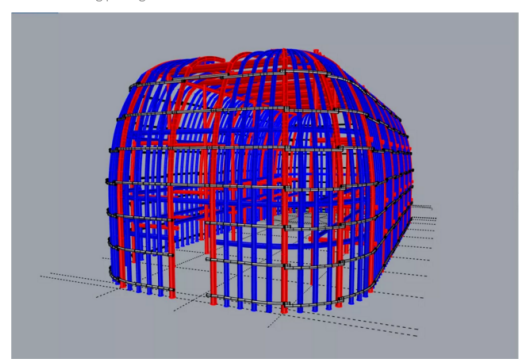

As in real-life construction, the 30 material also has a nature of its own. Jamie encountered some of the same questions we had been chewing over since starting with attachments and smoke hole pocitioning to name a fen

Appendix A 27: Longhouse 2.5 page A 


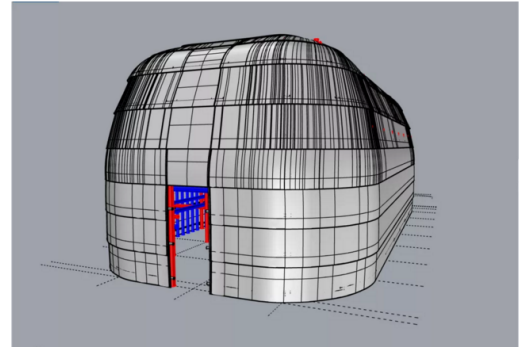

The difficulty in modeling the curvature in the roof has also been discussed in length by Wright, Kapches and $5 n$ now, which is also apparent in how we interpret in $3 \mathrm{D}$ virtual space
as well Immediately when the $2 \mathrm{D}$ plans were visualized in 30 , questions began popping up with regards to how our final longhouse project would be interpreted.

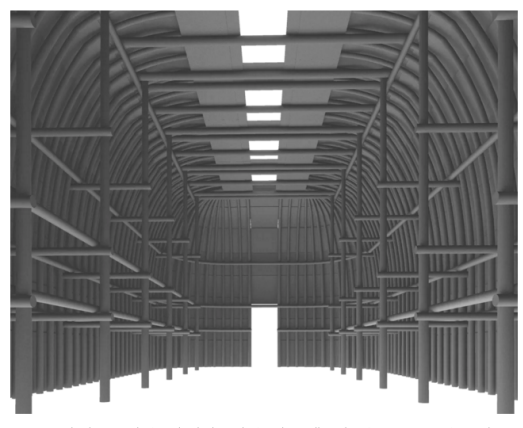

However, the low resolution shaded rendering does allow the viewer to experience the can also start to envision nopulating the space with potential cultural material, textures surfaces, atmospherics and ligh.

The interpretation of an " $\mathrm{h}$ " framing methodology also has given rise to look for support posts in the archaeological record, inmediately along the outer walls when excavating longhouses and/or reviewing existing data sets. Overall, Jamie and Ron's original plans from an modern architectural design perspective.

000 $\overline{\text { Related }}$

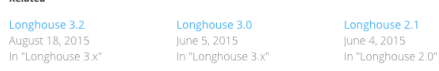

Trackbacks/Pingbacks

Longhouse 1 ?

Appendix A 28: Longhouse 2.5 page B 

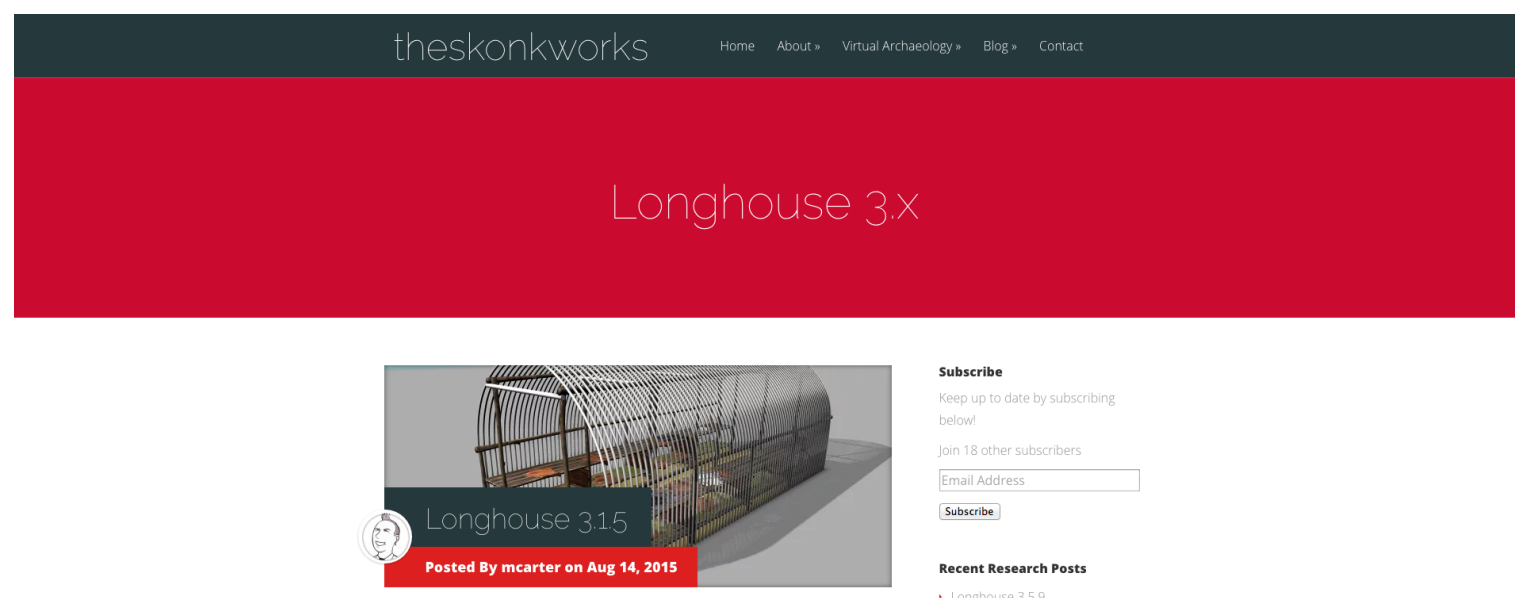

Subscribe

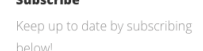

Jain 18 other subserbers

Subscribe

Posted By mcarter on Aug 14, 201

Recent Research Posts

It's been a busy couple of days for the project and Craig, who is still down at

hecent neseact

Siggraph2015 demonstrating at the Unity booth As you can see our project is getting a

- Longhouse 3.5

workout in the Unity 5 gaming enginel Craig's ported the Aurodesk Maya 20 models

their current stage of develooment into Unity 5 . Even with the models in basic fo

Read More

- My third diaft PhD Proposal

- Longhouse 3.57

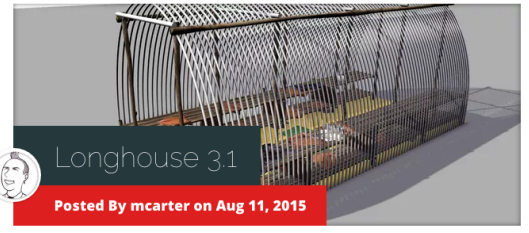

It's been a bit since our last post. My partner in this project, Craig Barr, was off in LA

doing a training shoot for Lyndacom and while he was away, Itook some time for a shor

vacation and a chance to catch up on more readings. During that time something odd

happened which statted me thinking aoout environmental ifiecycle of a longhouse. My

wife and II ve in the country in a wood fremed and sided Britsh Loyalist style.

Read More

Appendix A 29: Longhouse 3.x Index page A http://theskonkworks.com/category/featured/longhouse-3/ 


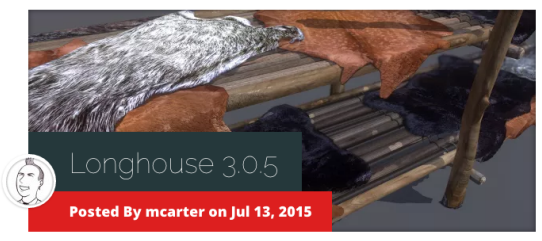

Based on all of the great feechback and some excellent research leads, in Stage 3.0 .5 of

our virtual Irogunian longhouse project, we look at fur, bark and pole positioning ib

envision sleeping platform construction within a 3 D environment. There isn't

considerable amount of reference material available to help guide our visual zat
process and we will go into further detail later on the visual staging of the inter

Read More

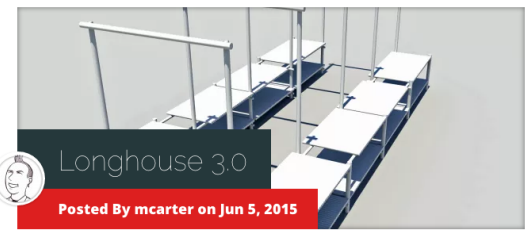

In stating ourvirtual archaeoulogy project to visually reproouce a 15 th century Virtua Iroquolan Longhouse from the archaeological record, our assumption right from the beginning was that we would fallow the process that J.V. Wright had initiated so many years ago when reconstructing a longhouse from the archaeological record. Through excavated...

Read More

Appendix A 30: Longhouse 3.x Index page B 

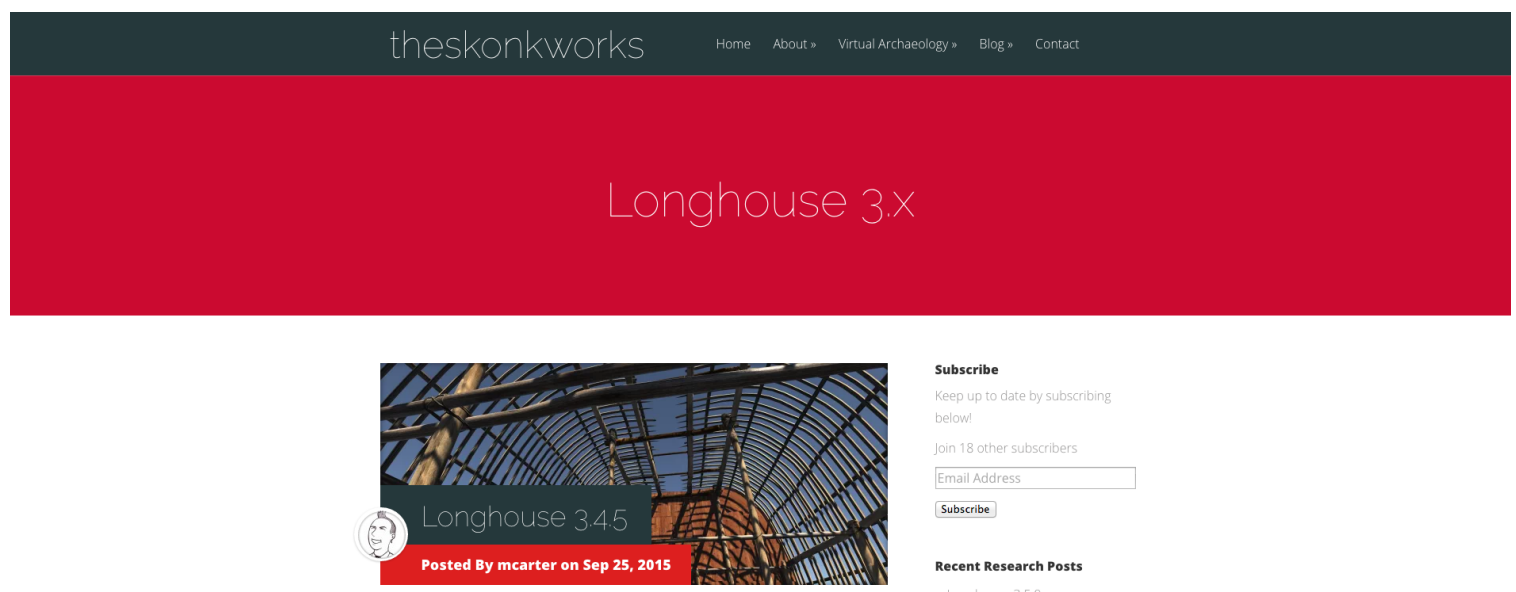

Subscribe

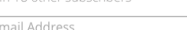

Recent Research Posts

This has been an extemely busy meet Groig and 1 re

- Longhouse 3.5 .9

Design Conference he

5tontelling will include gaming and ?D animation industry guru Athomas Golloberg an

Read More

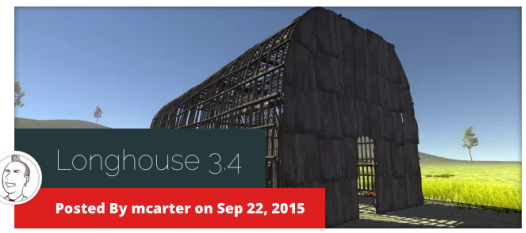
additional assets that will be added in order to populate the longhouses. In Film \& Television production we call these assets "props", which act as tools to enhance the emations or pnenomenologica exh multiple areas...

Read More

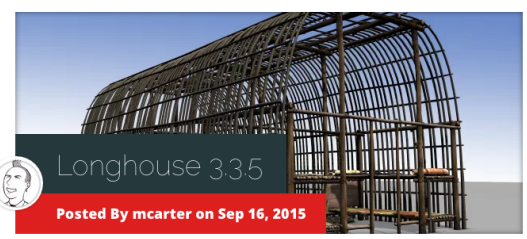

wanted to relay some great news tor the project Craig ano have been asked to unvel the final versicn of the virtual Longhouse on octover 13 th during the reception for the Heritage Toronto Gala. This is an exciting opportunity for us to test in public with methodology However, out the viewers will get some pre-event exposure was we star

Read More

Appendix A 31: Longhouse 3.x Index page C 


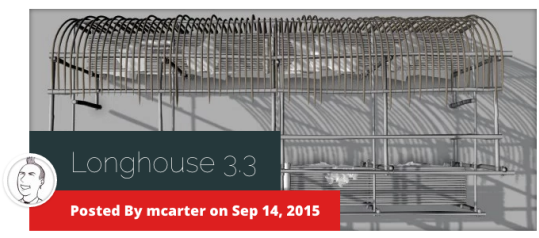

Craig and I had hoped to give you a fully framed longhouse last week, but late into last Thursday night we had a massive panic attack. We had been spending the good part of two weeks debating, researching, consulting and re-researching possible roofing methodolog es that would have been used when Iroquolan builders were constructing their houses. Yes, this seems to be also the main divergent of opinions as well between Read More

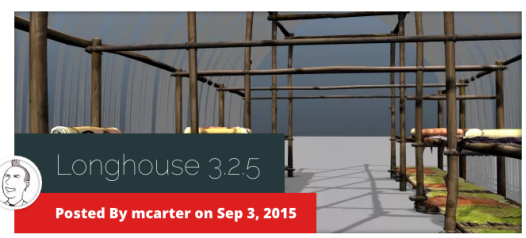

A b big shout out to @EAAGlasgow (EAA Glasgow 2015). Would have loved to participated in this year's timely sessions, but the Ryerson MDM grad students are starting early this weekyeart! a liso want to congratulate my research patne Craig Eart Who ustrecen

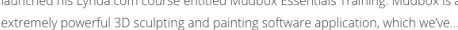

Read More

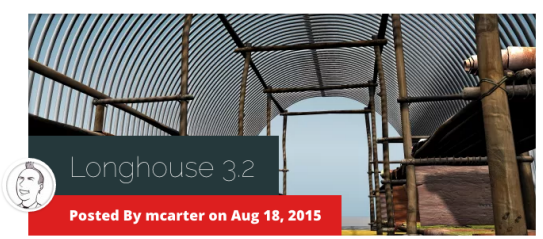

It's been another busy week as we start to refine the longhouse superstructure The iconic "half-cigar" shape is starting to take form, but keep in mind that this visualization is just one of many interprerations that have been brought forward over the years and only upon our rethoc of visual research whtructions to be atte

Appendix A 32: Longhouse 3.x Index page D 

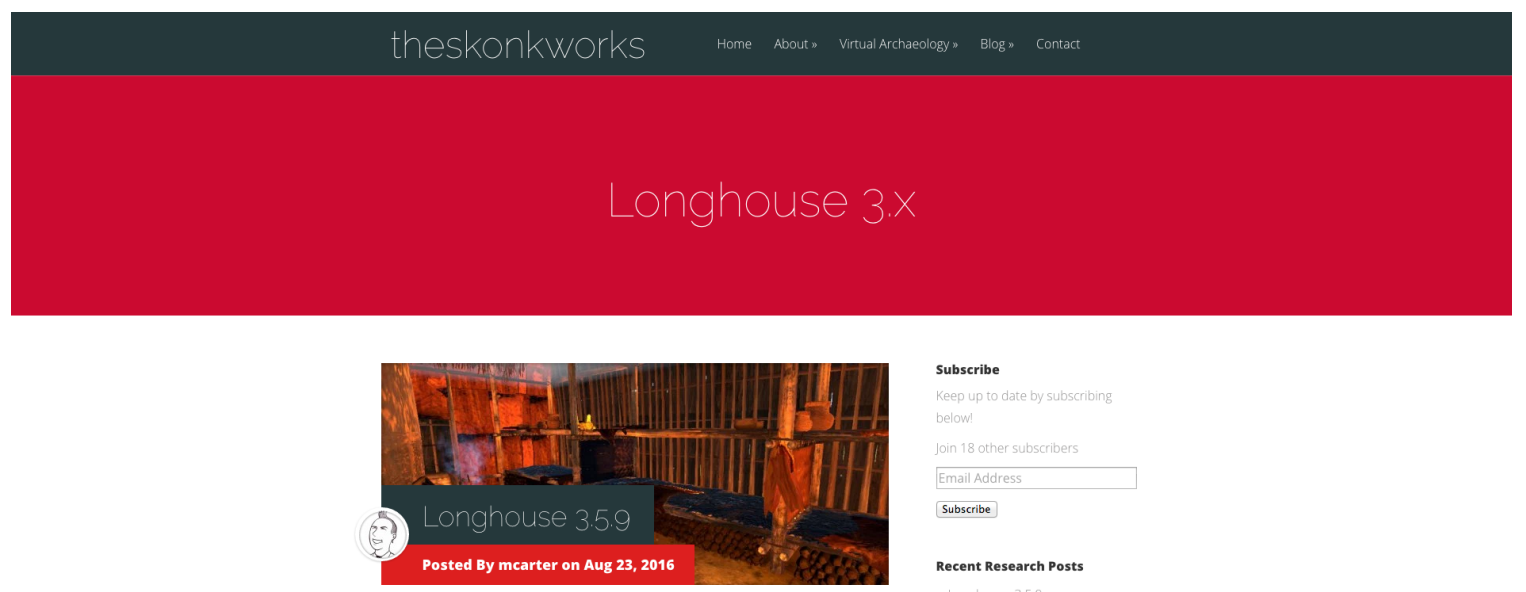

Subscribe

Email Add

Subscribe

Recent Research Posts

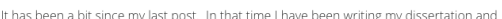

conducting interviews on how warchaeologists react to immersive and non-immersive

representations of virtual archaeological data. It's been a year since we started Lh3.x and

- Longhouse 3.5.

作

- My third draft PhD Proposit

Tait wing a

Read More

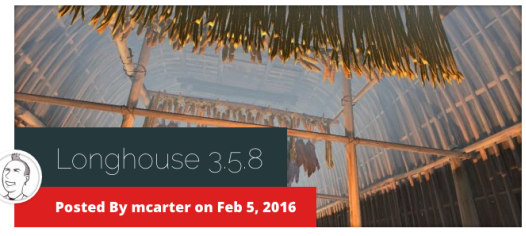

Power, Authority and the Virtual I Imagel This eight-month journey has been an

exploration of nitual archaeology through research, production and knowledge

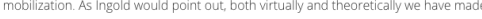

course corrections or waytaring points (201) throughout the process that have been

participant..

Read More

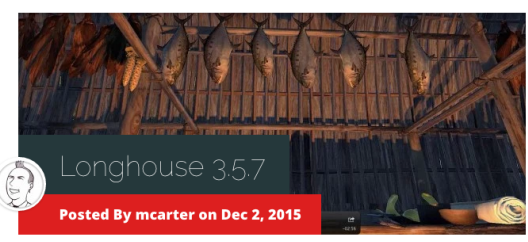

Today's post is really a brain dump of the last four weeks of virtual archaeology

theoretical reading I've been doing and the practical application of the L $\mathrm{L} 3 \mathrm{x}$ project. The

project itself is going along swimmingly but into the tough phase of honing down the

speeds. Atthough "polygon count" is always an issue with.

Read More

Appendix A 33: Longhouse 3.x Index page $E$ 


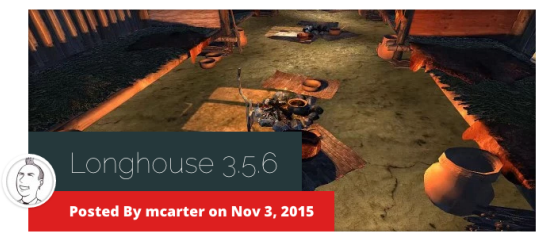

Sorry for the delay over the last couple of weeks. Craig and I were busy with the wonderful 1.0 version of Ryerson Universitys B3D Design Conference two Friday's ago and weve both been catching up since the Heritage Toronto event. B3D proved to be an enlightening set of broad based discussions ranging from Virtual Reality to 3D Printing, however I was really impressed with both the awareness and promotion of

Read More

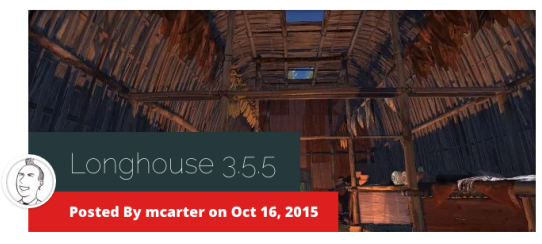

It's been a whirlwind week here Craig, Jamie Kwan and I attended the Heritage Toronto. Gala Tuesday night to roll out the first public viewing of Longhouse3.x. Jamie was my graduate research assistant this year in the Master in Digital Media program here a interpreation of a $3 D$ longhouse in Longhouse $2.5 \mathrm{It}$ proved to be a stellar night and Read More

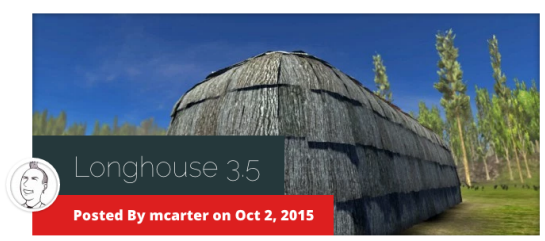

This has been an extremelty busy week Graig and have been working hard on finalizing the vestibule entrances to the longhouse and how the Elm bark shingles would be positioned Because of the Toronto Heritage event on Ortaher 13 th we've also sped in the development process a little so that hopefully Mayor John Tory and the other Toronte Heritage guests will be able to experience something unique during the event. The...

Read More

Appendix A 34: Longhouse 3.x Index page F 


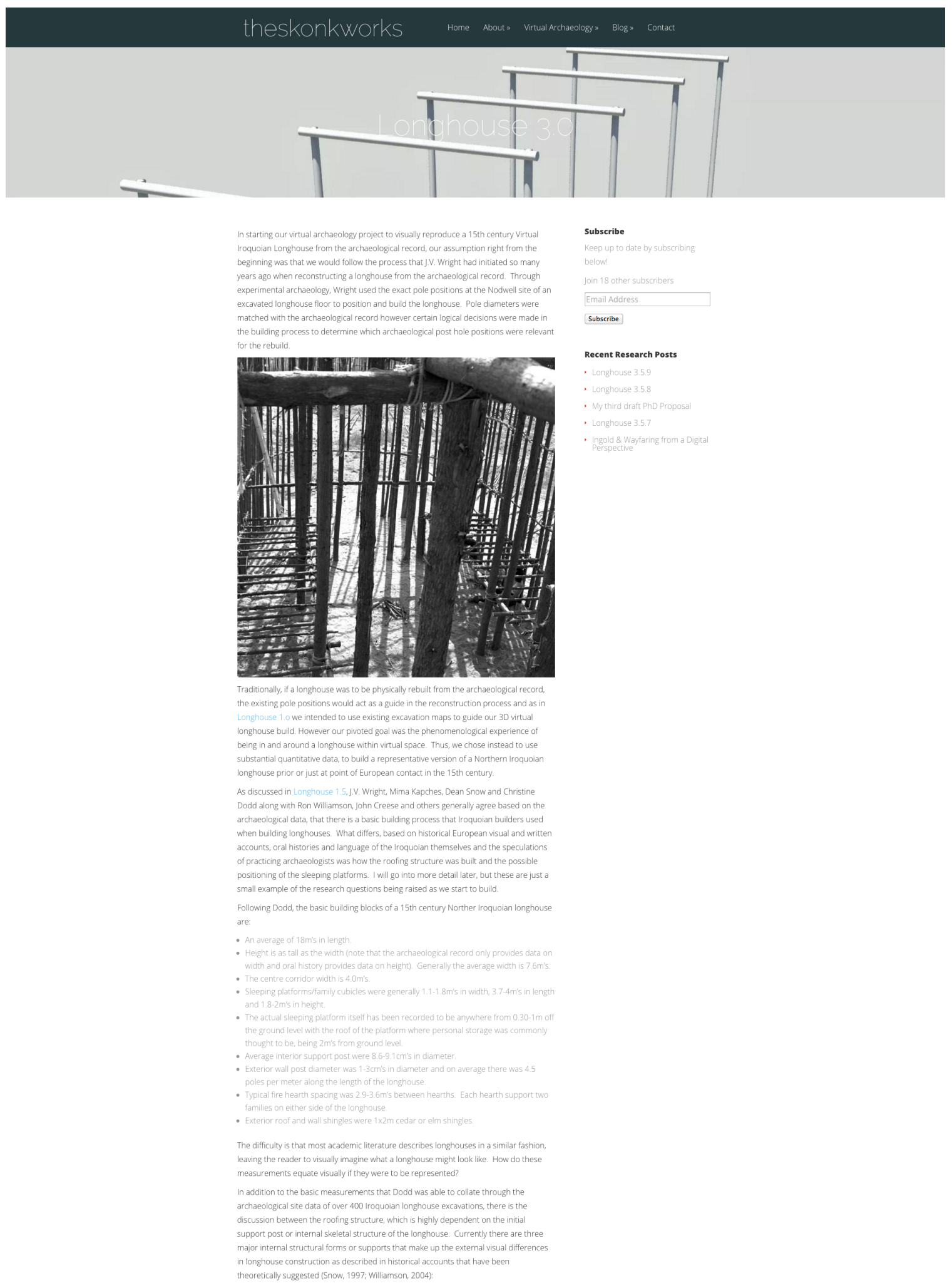

Appendix A 35: Longhouse 3.0 page A 


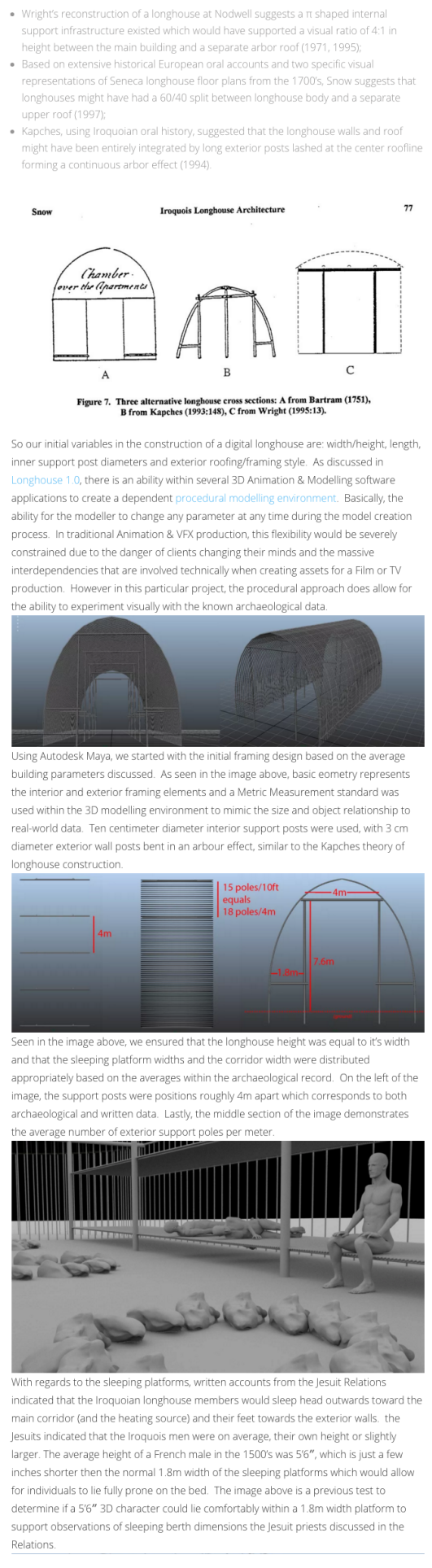

Appendix A 36: Longhouse 3.0 page B 


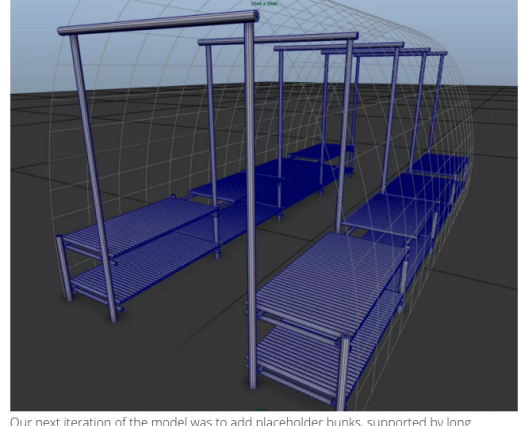

Our next iteration of the model was to add placeholder bunks, supported by long horizontal posts running the length of the longhouse and short plafform and i interpretations of how families might have accessed goods typically stored above and/or the "loft" for additional sleeping. Currently the diameters of all the wooden elements are unifornly $10 \mathrm{crn}$ '. Also, we have to rely on "common sense" to dethe describe this buldding process.

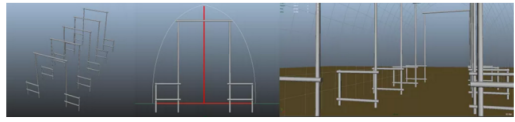

night have been constructed, we borrowed the same technique of makng an " $n$ " support system on etrner side of the complete sense as it would almost be impossible for the outer $3 \mathrm{~cm}$ diameter exterior wal posses supporthe gut bat of not only the bunks, but the numerous people and goods they would hold

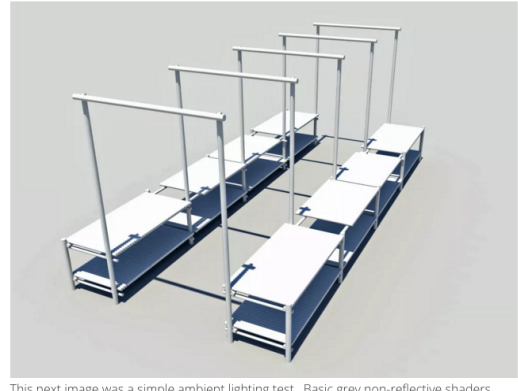

This next image was a simple ambient lighting test. Basic grey non-reflective shaders

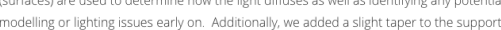
posts from $10 \mathrm{~cm}$ 's at ground level to roughly $9.5 \mathrm{~cm}$ 's at the top to mimic the natural tree

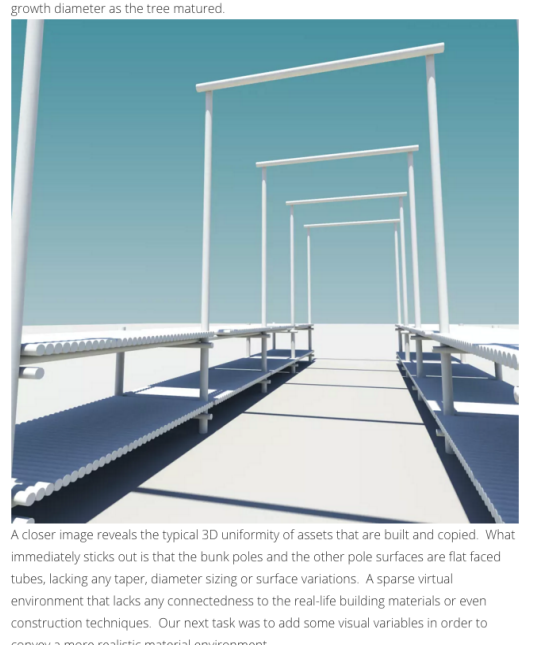

Appendix A 37: Longhouse 3.0 page $C$ 


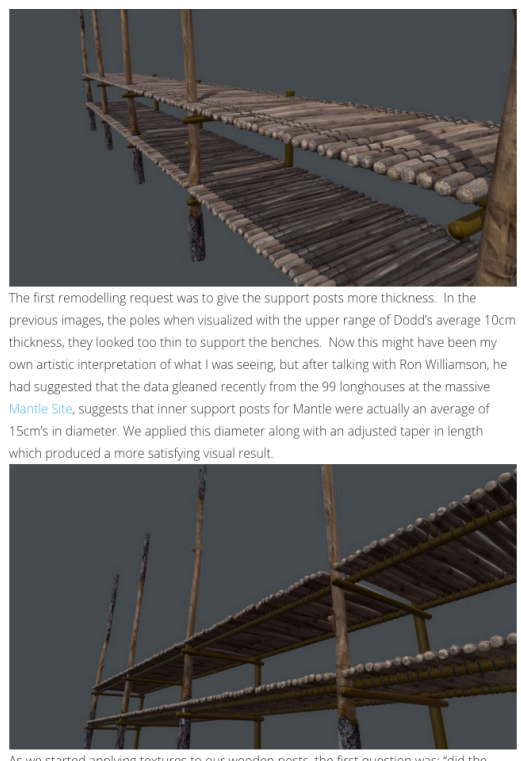

As we started applying textures to our wooden posts, the first question was; "did the Iroquols strip bark from the posts betore they were erected and would that act as a tife hearths'? After discussions with Dean Snow, Neal Ferris and Ron along with an exhaustive searching of the historical writings, the answer was non-conclusive. A chance discussion with Namir Ahmed about the problem led to the suggestion that bark mig have stayed on the support post as it was erected in place, but during time, out of boredom or necessity, the bark would have been stripped away. Thus we mimicked bark where it would airectly adjacen

An additional layer of texture mapping will be applied later to visually suggest a build of creosote which would have mogt definitely been present within the ratters longhouses as numerous fires would have been contributing to the smoke layer withn

Addtionally, no tree grows straight. Thus the 3D posts were gNen a slight randomness and cunvature to represent what would he typical tree growth patterns Tree nots ans protrusions on the support posts were also added in an attempt to better visualize the

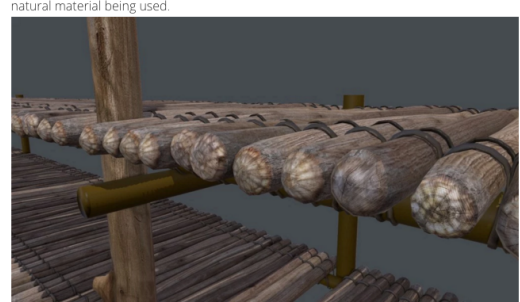

Finally end suffaces of poles were rounded off in an attempt to visualize a rough cut made by stone tools. Texture maps with lateral cracking was added to the ends to also mimic the drying of the wood as it aged. Test 3D cordage was added to determine how the poles would have been secured to the main supports.

Hivisualzing the int al raming process, we were able to not only asse more questions as

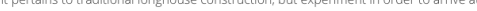
varians from he dish

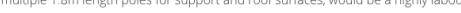
Intensive endeavour. It was more ikey that longer and less quantity or poles would be used along the length of the longhouse instead of the wioth. Asso, our textures and modelling of the end caps of all poles and posts had to be rougher in order to mimictne use of stone tools. Lastly, Issues like the cordage type and even the knotting of the ropes, would have to be researched further

Share this

Resated
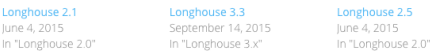

Appendix A 38: Longhouse 3.0 page D 
6 Comments

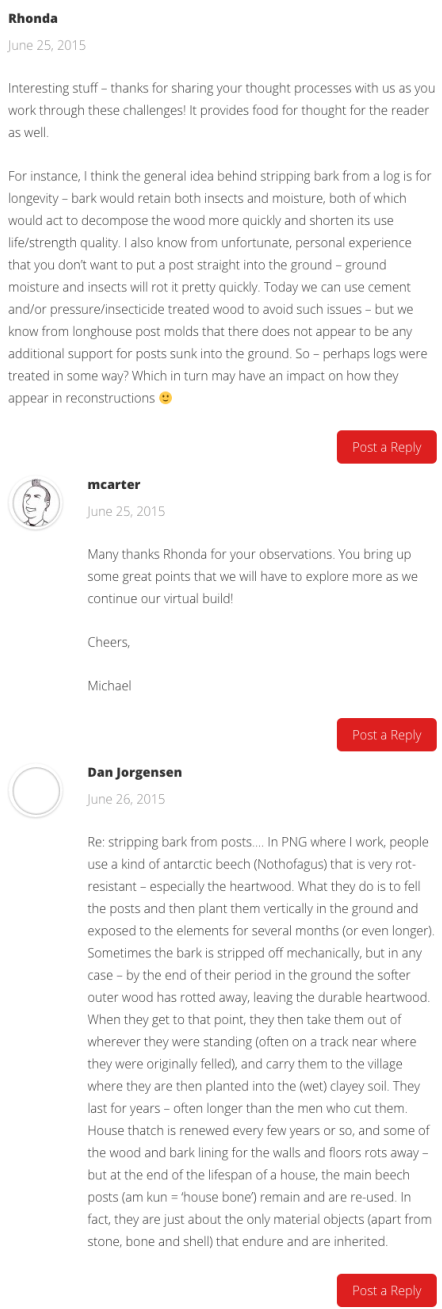

Appendix A 39: Longhouse 3.0 page E 


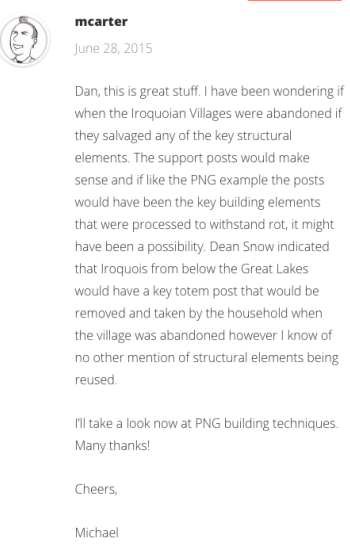

Appendix A 40: Longhouse 3.0 page $F$ 


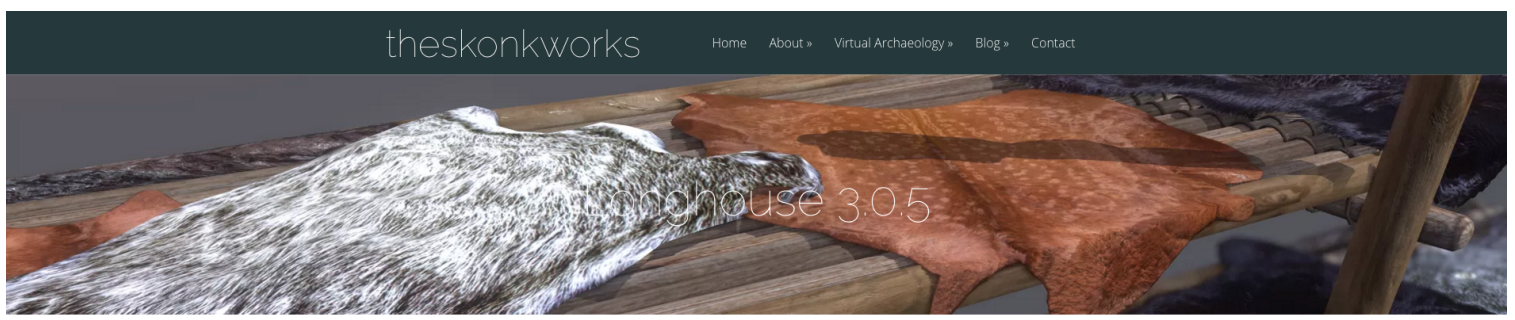

Based on all of the great feedhack and some excellent research leads, in Stage 3.0 .5 of our virtual roquoian longhouse project, we look at fur, bark and pole positioning to envision sleeping platform construction within a 3D environment. There isn't a considerable amount of reference material avaliable to help guide our nsual zation process and we will go into further detail later on the visual staging of the interior environment, but we have relied heavily on Dean Snow's 1997 research entilled the wquois Longhouses to determine how our interior bunks will be

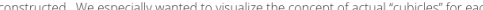
sleeping compartment.

Based on European historical accounts, the sleeping plattorms that occupied either side of the fire hearths along the interior length of the longhouse were raised 4-5t from sound lerd (5 eropeana

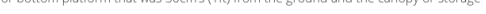

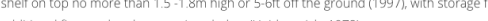

Clearly, if we follow previous histonical accounts of the sleeping platforms being 4.5ft from ground level the young and old as well as most ad the would not only have has great difficulty un

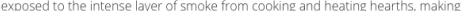

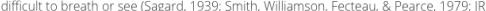
91-421 These contested ethnohistorical obsenvations fail to account for seasonal sleeping preferences or even actual longiouse height, which if architecturally higher as Wright suggests, would have greatly reduced the smoke layer well above standing height (1995)

Further, using references from oral history, the common Iroquoian building measurement Was ten (Allen \& Williams-Shuker, 1998; Kapches, 1993). It was believed to

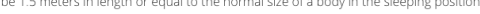
(Allen \& Williams-Shuker, 1998: Kapches, 1993). Dodd discovered based on the

archaeorogical record that he standard lange of the sleeping compartments woulch have been 1.5-2m in depth based on the bunk line pole postions (1984). This assumption would have been supported by -rench Missionary descriptions of the time and their own general he ght in the 16 and 17 centuries of $1.6 \mathrm{~m}$ in size or roughly the same as the Iroquolan hosts (Komlos, 2003). Other's have suggested, primarily in fictional narratives, that family also slept on the top bunk as we.

Therefore, based on support post positioning within the archaeological record, it is generally acceopted that sleeping platforms/family cubicles were generally 1 1-1. $18 \mathrm{~m}$ 's in

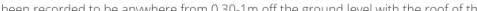
platform where personal storage was commonly thought to be, being $2 \mathrm{~m}$ 's from ground

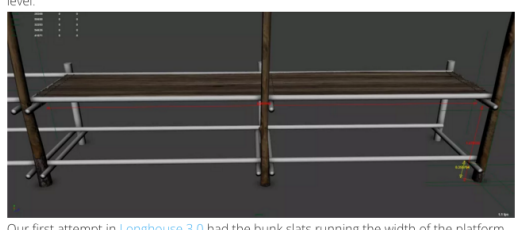

Our tirst attempt in Longhouse $3: 0$ had the bunk slats running the width of the plattio In short 18-2. poles. Keeping in mind that pre-contact Iroquoian longhouse builders Only had the use of stone axes and fire for initial havesting of the trees, the notion th they would be chopping multiple platform poles into even length slats seemed ike d Food Preparation, he states:

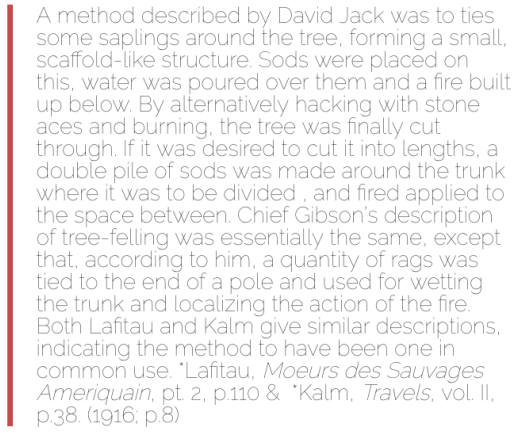

Appendix A 41: Longhouse 3.0.5 page A
Subscribe

below!

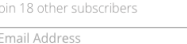

Subscribe

Recent Research Posts

Longhouse 3.5 .

My third draft PhD Proposal

- Ingeld \& Wayfring from a Digita
Perspective 


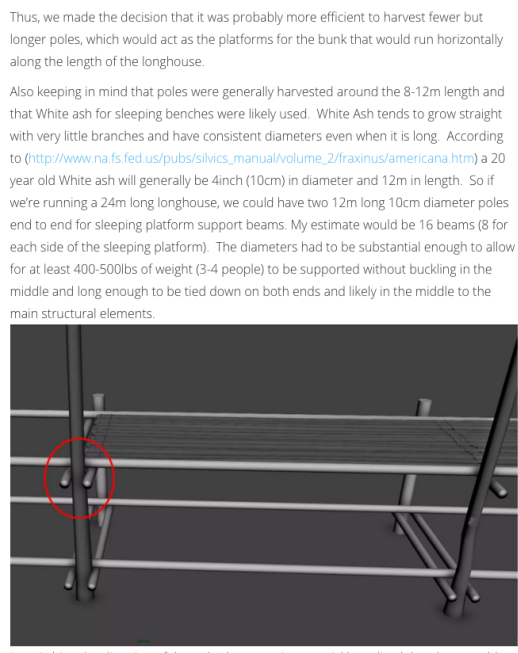

switching the direction of the poles however, it was quickly realized that there could have been a couple of additional enhancements to the bunking system to reinforce the poles and to deal with the weight of family members and their daily activities on the and Craig sugested support poles were added at the major support posts s see abo

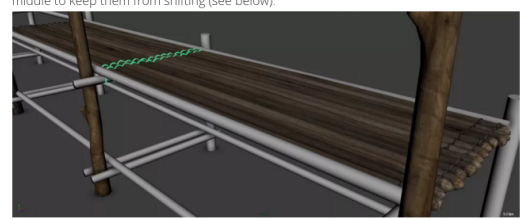

Posts (anything in the ground was Cedar) and beams (White ash) were tied togethe although we dont have much visual or ora history to baskit un. Hitches or knots are explained at all in the historical accounts, but this 1500 's image show a cross hitchikno where the posts were lashed togethe

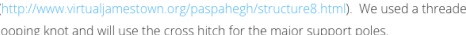

Ang

Another issue on our first try was the rounded look of the ends of the poles. Obviously they wouldnt have been uniformly rounded so we attempted to roughen up the ends of the poles a little more, but recognizing that over time and use, the ends themselves.

would he come rounded and dull. There isnt' a lot of visual references avai able for wood cut by stone tools but Sensible Survival had a blog post on how to make a stone axe Below is an imase from that blog posting which dearly derronstrates tow

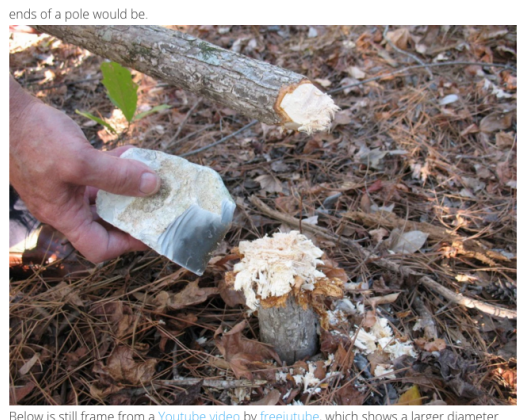
texture and foe

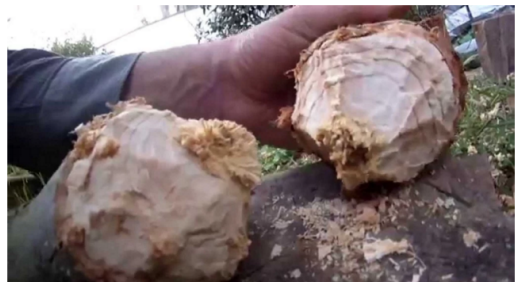

Appendix A 42: Longhouse 3.0.5 page B 
The image below has two end caps that haven't been treated and the middle end caps have been modelled more to $m$ mici

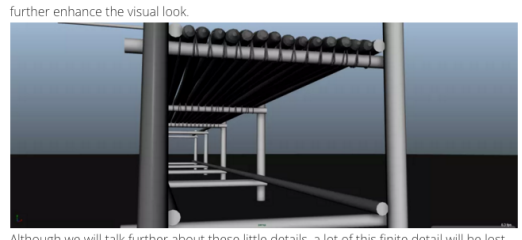

in the final gaming environment mindy because of lighting efe tis and he neetho reduce the model complexiy so the game rins in real time Howover seen or no are trying to logically address all of the visual elements that may be representative in this virtual reimagination of the archaeological record.

Another part of the last blog's discussion was the notion of whether bark was removed from the support posts and bunking poles or whether it was left on This is obviously pure speculation because the oral, historical and archaeological records have no Information on this or not. General consensus from the commentators was that removad of bark would have been preferred. Completely by accident Dr. Jennifer Birch had suggested a great quasi-ethnographical account by F.W. Waugh entitled iroquois Foods about storage of food stuffs within longhouses In it. FW whagh speke extensinely an the use of hark for a multitude of household and work rel teded tocks 50 much so tha

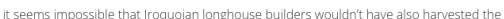
作 testing possit

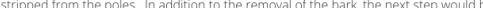
to add dint creoste land pints and other stains to the exposed wood to give the be

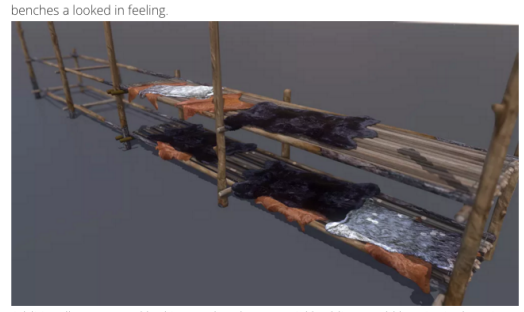

Add tionally, we started looking at what the potential bedding would be. Again there isnt much written on the subject, but everything from cedar boughs, woven mats to various furs were suggested Orignaly we thougnt Black Bear or Grey Wolf current specties that the form of bedding. However, the faunal (animal) remains within most archaeologic Whe area have limited or no Black Bear or Grey Wolf skeleta remains. Deer, along with medium sized fur bearing animals such as Racoon, Rabbit and

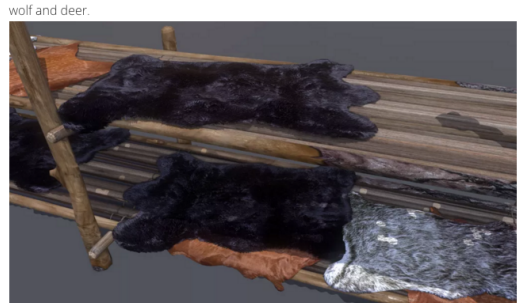

Upon further discussion, we decided the nextifer ation tu the a mixture of cedar bougrs terial. As discussed above, the top level of the bunk may or may not have been used as a sleeping vilatiorm. The histoncal references

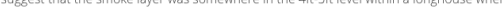
all of the tires were gong. Ron Willarnson reponts from an experiment done at . Ska-NahDot in the middle of the winter during the 1970 s', that when a few warming and cooking fires were at ful-capacity within the reconstructed i onghouses, the smoke level was dense, leading to difficulty in breathing and to see I would specuate oased on the primarily for storage and thus for our next round of renderings, weill start placing

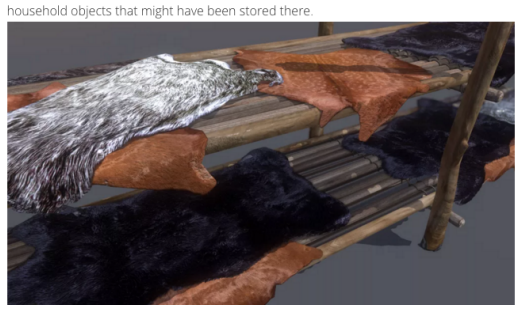

Appendix A 43: Longhouse 3.0.5 page C 


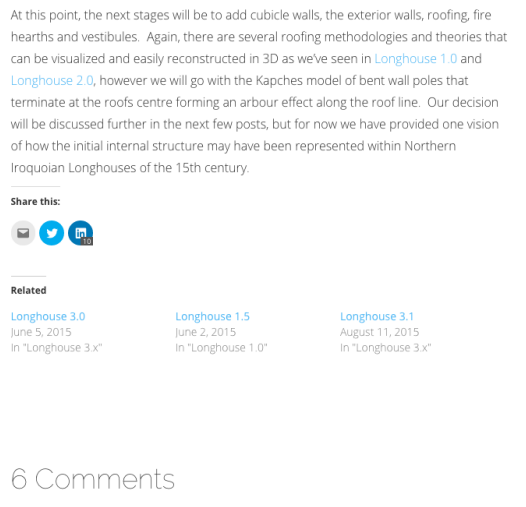

Martin Lominy

In a 3D model I made the choice to position the bottom bench poles in perpendicular fachion as onposed to parallel with the length of the hench My idea was that shorter poles can support an equal amount of wejght while being thinner which would allow to make use of the straightest $1 \mathrm{mb}$ trimmed off the trees Imagine the amount of branches piling up when building a longhouse, that would be a readily avail able material for that purpose. I a lso thought that thinner poles might be more comfortahle than

About barking the poles, they would probably have done so to make use of he bark for cord age and containers and also because removing the bark allows the wood to dry faster and prevents bug infestation.

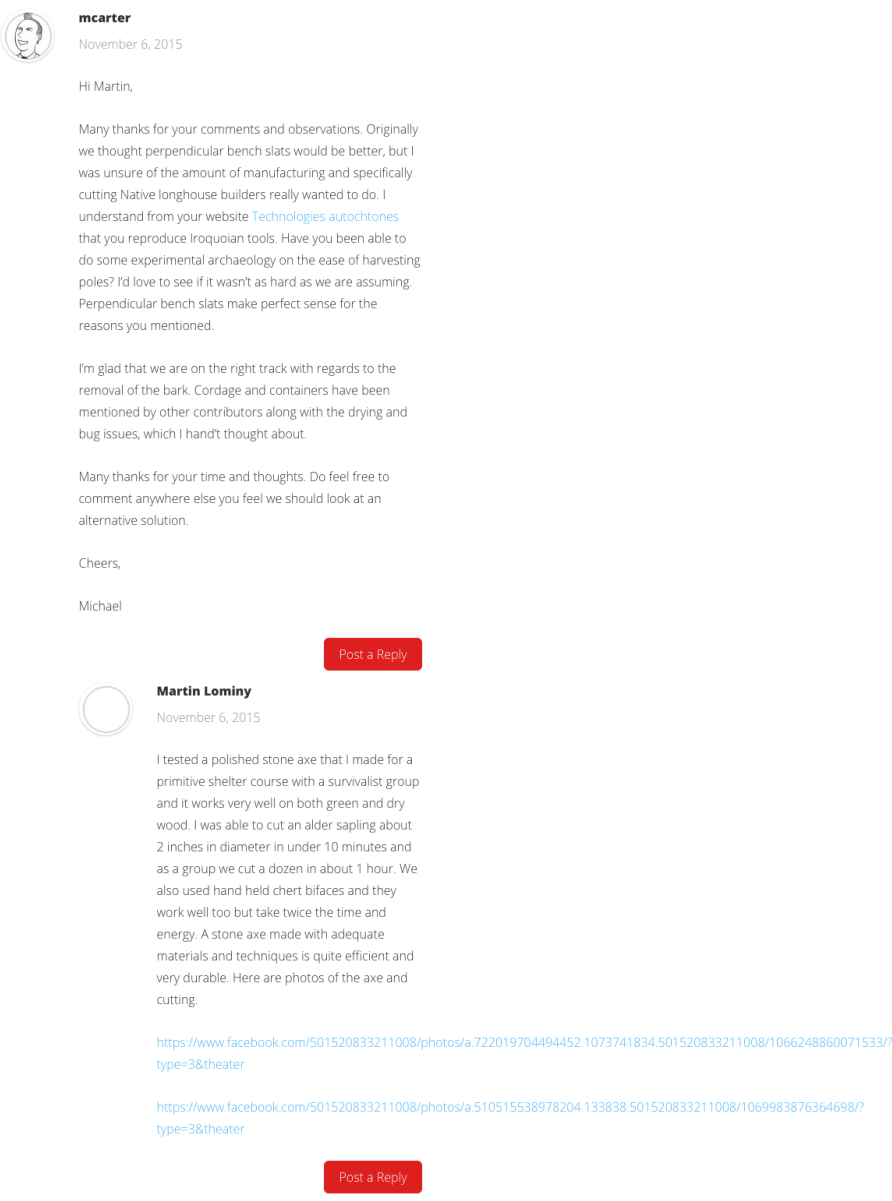

\section{Appendix A 44: Longhouse 3.0.5 page D}




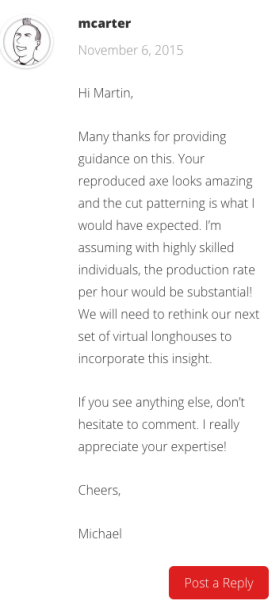

Trackbacks/Pingbacks

Post a Reply

Appendix A 45: Longhouse 3.0.5 page E 

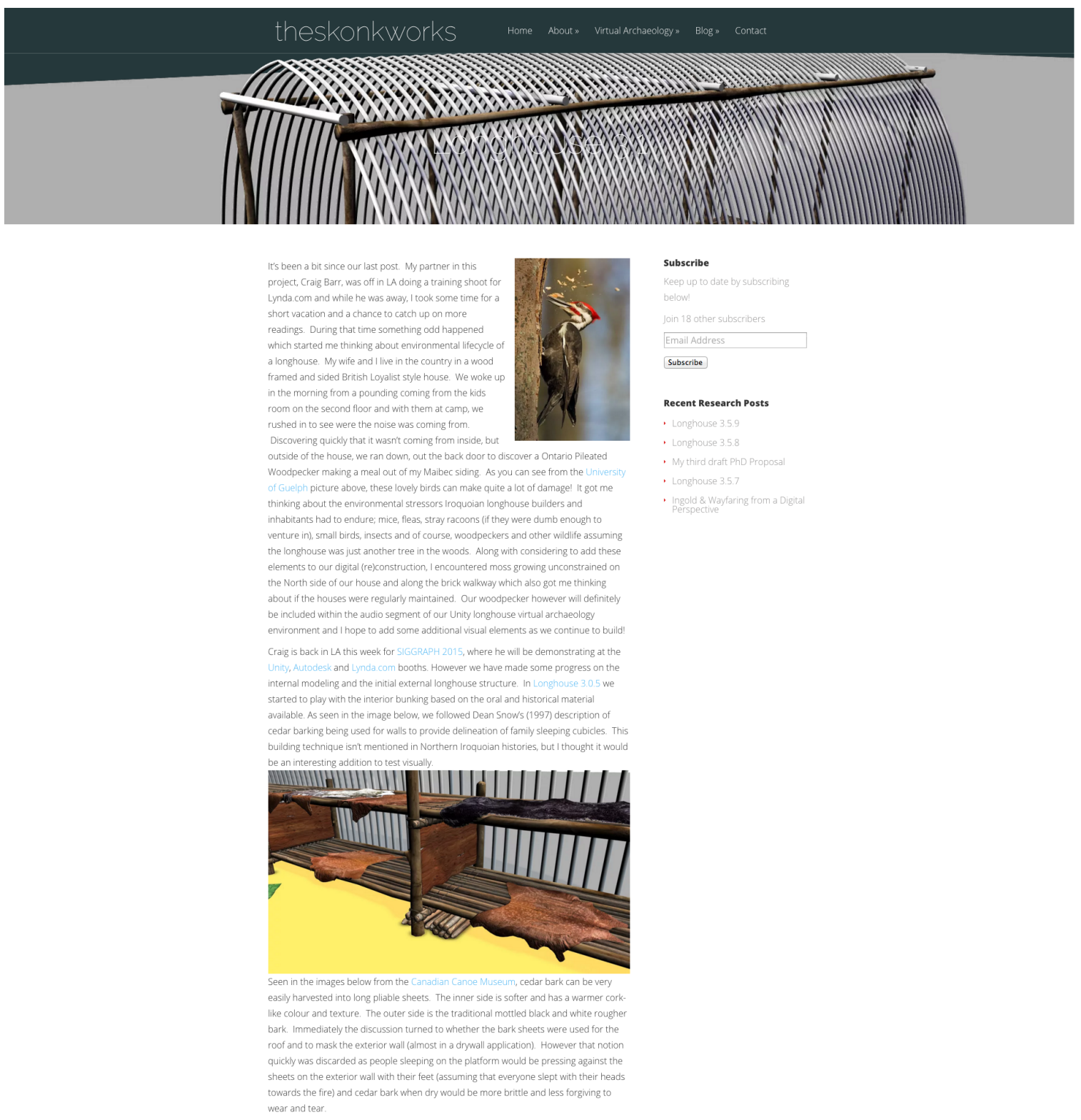

Subscribe

elows

bin 18 other subscribers

Emall Adid

Recent Research Posts

- Lonshouse 358

- My third diraft PhD Proposa

.

- Ingoid \& Waytating 


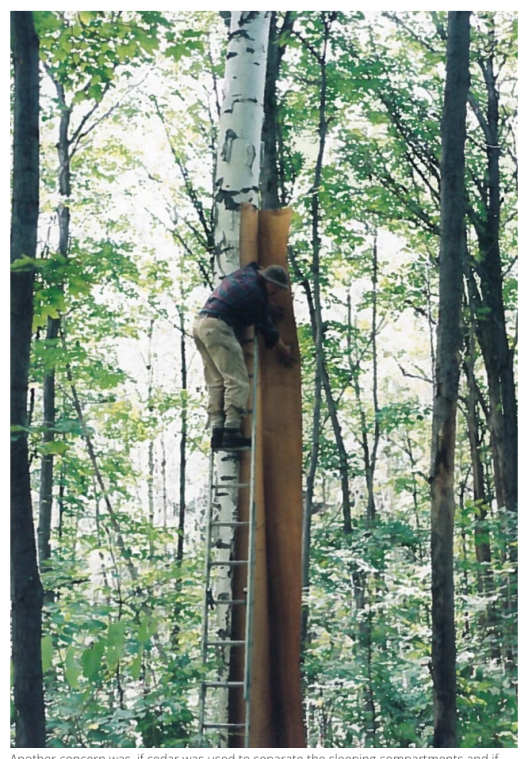
would get the seemingly nicer side? This then led to a discussion on combining wi

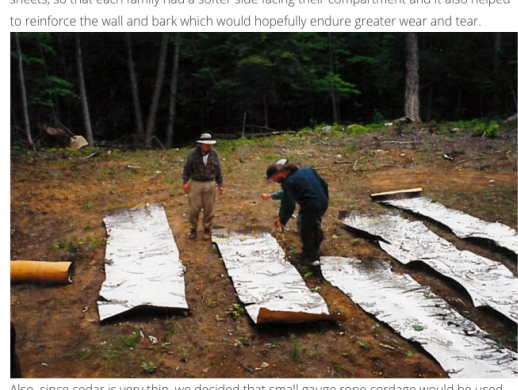

Also, since cedar is very thin, we decided that small gauge rope cordage would be usect to secure of tie down the wall sheets. We have no record whatsoever of this practice or

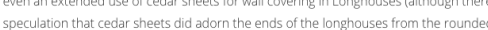
entry areas), however, the beauty of using 30 modelling is the ability to test these assumptions

As seen below final strappins to secure the steeping platom was also used la difficult: feat in $3 \mathrm{D}$ modelling) and we knew that white ash (which might have been used if aval able) for sleeping platforms would generally be about o meters in eng th abmaximum or two sieeping plattorms long Hence we needed to figure out what to do כaded a adseda second suppon and assurntad hat he terminus or he poles would be roughy

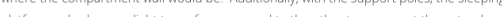

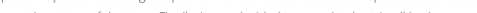
gromentera Craig put dirt smudges into the textures and even finger prints to simulate continued

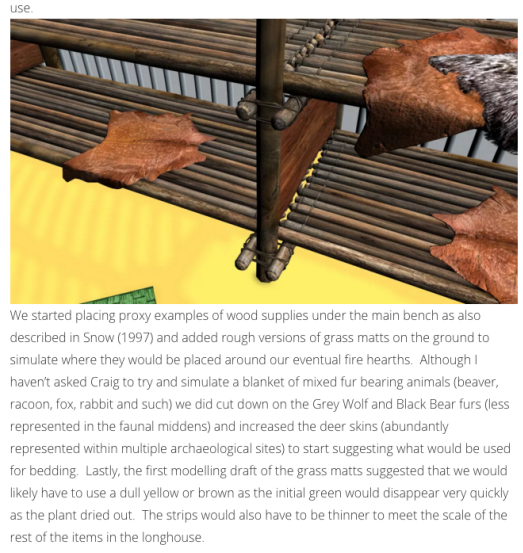

Appendix A 47: Longhouse 3.1 page B 


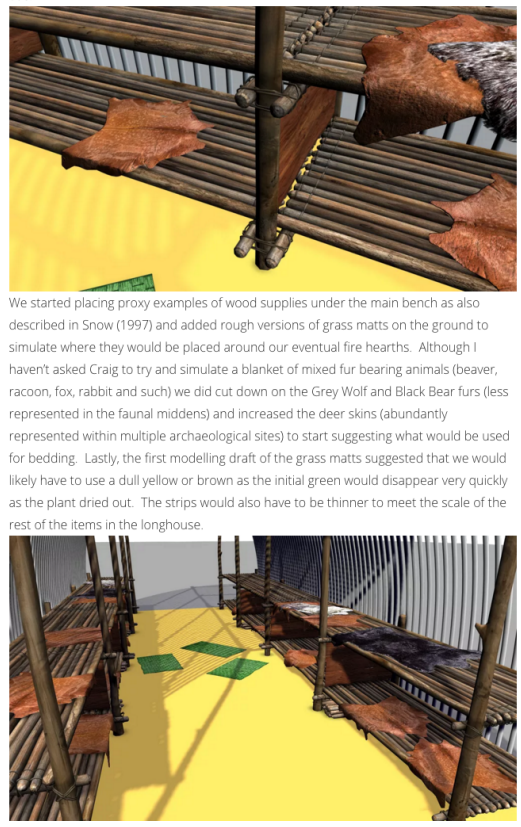

Our next effort started with the exterior poles of the house. As discussed previously, the research group chose to go with a Kapche's longhouse framing methodology as opposed to Wright er Snow's interpretation This was primarily done due to the long history of longhouse construction at the Museum of Ontario Archaeology in which this model has become a key style choice. However as noted, we really have no clue what style any of building refinements. This does not prectude that other styles might have been in used bulding refinements. This does not prectude that other styles might have been in Durposes we hose to go with the traditional framing methodology used wher representing and vsual izing the Lawson Village site

Bel ow is our first attempt at understanding how the support structure would work with the arching wall posts. Based on Dodd's research, exterior wall posts were 1-3cms diameter and on average there was 45 poles per meter along the length of the height of secured dom to some son of rooing sstem As with the support posts a sight taper was introduced from the thick end to the th of the ronf end

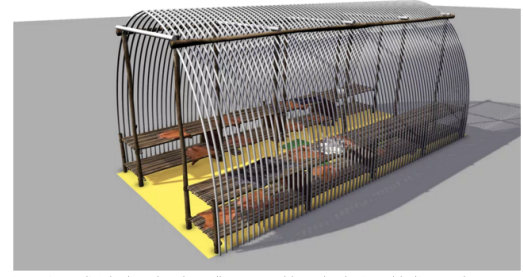

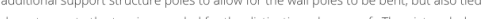
dy

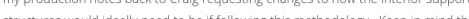

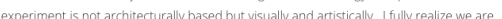
making broad assumotions at every level

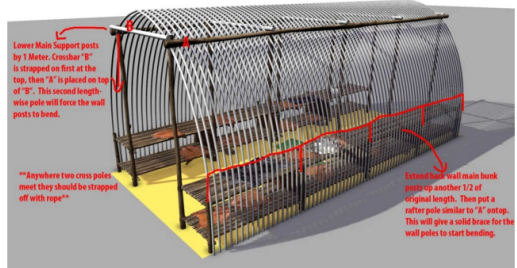

Appendix A 48: Longhouse 3.1 page C 
The assumption is that the exterior poles would be placed into the ground and then ben over the support infrastructure. There is an 11 minute video on Youtube describing how two families built an Iroquois (South of the Great Lakes) Ionghouse more in the tradition of Dean Snow's theories. In it, they describe using rope to pull on the end of the wall pole to bend it in shape as another person tied down the pole to the interior framing creating the arbour style of roof. I can imagine this type of construction methodologit being deployed easly with a two or three person crew

In the next post we will explore the exterior framing further and the refinement of the

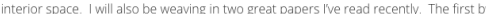

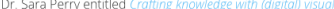

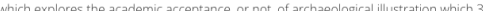

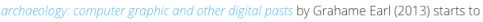

physical arch

visualizing heritage as archaeological research and not just illustrations for public

consumption

-...

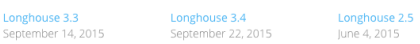

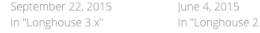

Trackbacks/Pingbacks

record in wrual space Both 5 ara Perny and

Leave a Reply

Enter your comment here...

Appendix A 49: Longhouse 3.1 page D 


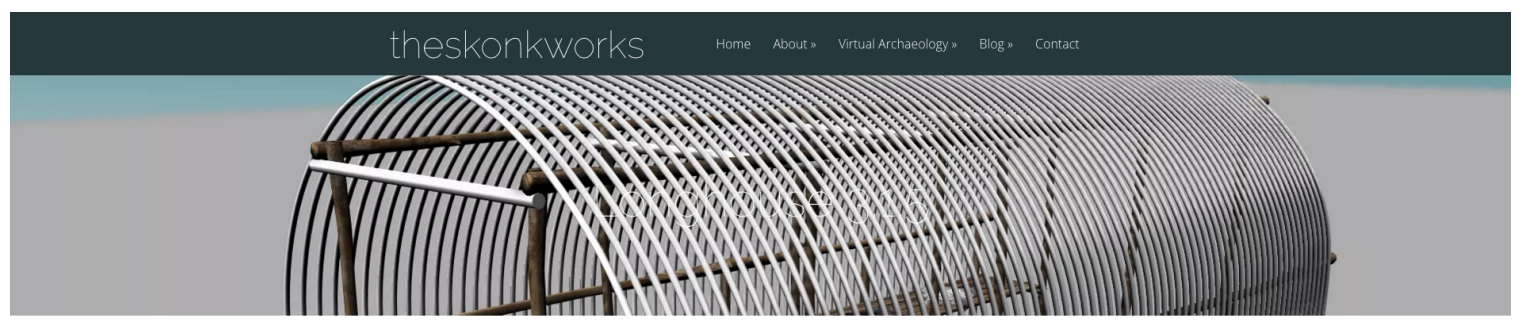

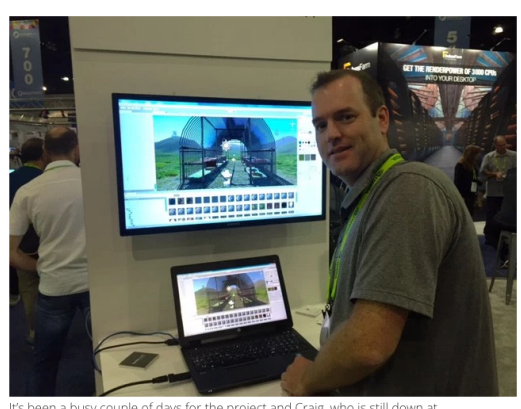

It's been a busy couple of days for the project and Cralig, who Is still down at
5iggraph2015 demonstratng to the 5iggraph2015 demonstrating at the Unity booth. As you can see our project is getting
workout in the Unity 5 gaming enginel Craig's ported the Autodesk Maya 3D models at workout in the Unity 5 gaming engnel Lrag's ported the Autodesk Maya $3 D$ models

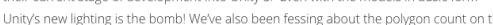

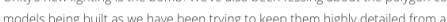
archaeological research perspective, but it looks Iike Unity can handle it so far I asked Craig to also film a quick video of the Longhouse in Unity

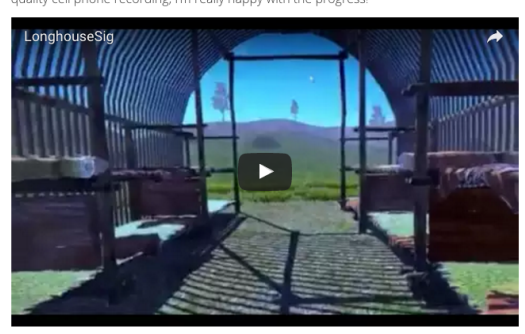

From a research perspective, it's been a good study on the influences the process. technology and artistic craft has on the researcher when interpreting the archaeological
record in virtual space Both Sara Perry and Grahame Earl, who I spoke about briefiy in record in virual space Both Sara Perry and Grathame Ear, who I spoke about briefy being transformative and going beyond just illustrating or visualizing archaeology. The ever expanding methods and growing theocries of Virtual Archaeology are helping to shape how we see archaeological material and in doing so is spawning questions

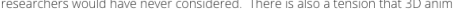

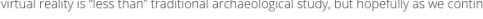
theory

As such, this project has been following the guidelines out tined in the The London

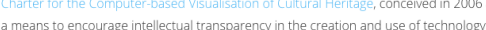
within oultural heritage studios, Ecsentially the Charter lays out the methods researchers should take to encure that the digital material they create has followed academic rigour and if assumntions are made during the process /as we have clearly stated in earlier posts) that they are recorded and ystffed to ensure a thentcity of the research itsef

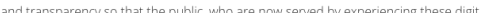
environments, undersands that Lastly, even in the process of blogging you the audience is experiencing the pains decisions, talures and successes of the process to (re),imagine extant archaeological

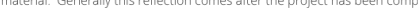
Charter has indicared that it is a worthwhile effort to engage the digtal process as th

happens

Carrying on from Longhiouse 3.1, we were exploring the relationship of the interi supporting struture and how the exterior wall posts would be bent and attached. Craigs quick revisions helped to hetter underctand howltoquoian builders might have forced the wall posts to bend at certain points to creare a continuous arbour roof and wall system. It seems plausible that poles that would run lengthwise and supported by the

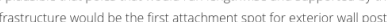

Appendix A 50: Longhouse 3.1.5 page A
Subscribe

jelow

gin 18 other cubserribers

mall Address

Subscribe

Recent Research Posts

Longhouse 3.5 .

My third dratt PhD Proposi:

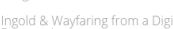




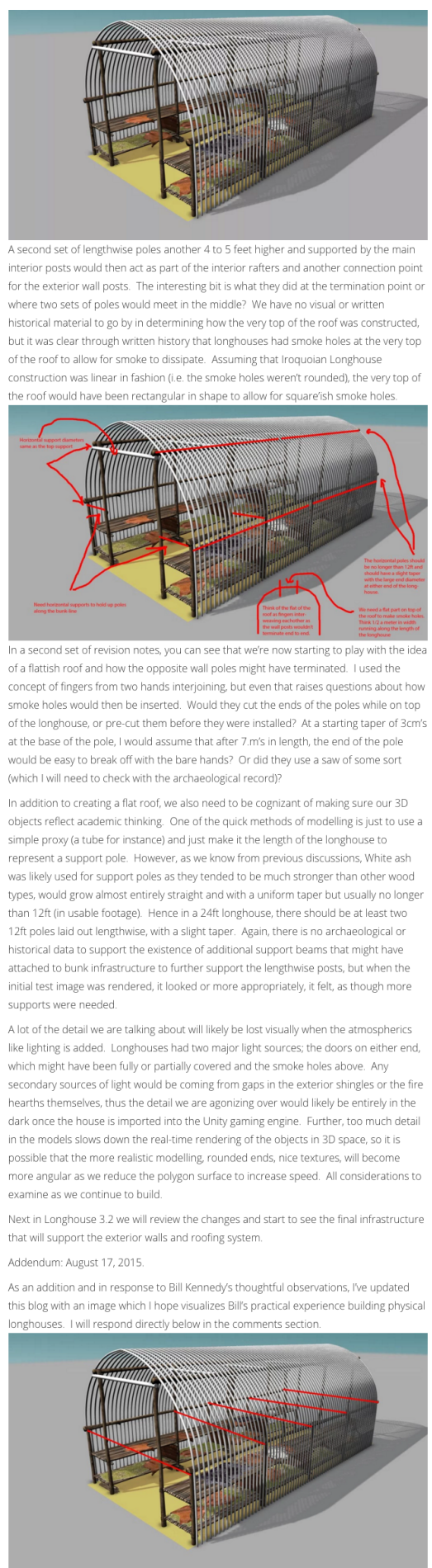

stare tiik

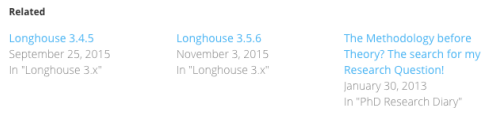

Appendix A 51: Longhouse 3.1.5 page B 
2 Comments

marter

I mistakenly deleted Bill Kennedys original comment on 08/17/15. Here it is in it's entirety:

This looks good; clearly thought out with close attention to detall. I woil make one suggestion. Add ties across the short axis to connect the opposing sides to each other. You have some ties shown (icolored white) to connect your arcade purlins together. You have them shown on every arcade post, which is good. I would add the same thing at the lower level to conneat the opposing wats to keep tne posts stable and plumb. This s an horizontal supports to hold up poles along the bunk line": instead of making these separate, IJst make themn be one continuous tie all the wal across the short axls, In a rigio itramed structure, this woulo be absolutely

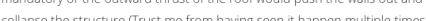
no

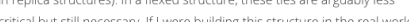

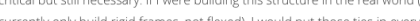

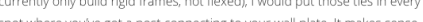

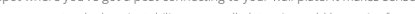

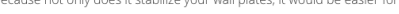
erats good. When I buila benches, have my tench slats turned perpendicular to he way you have thenri gong but can see arguments both ways and? hinkyour way might work about as weil If I were buliding in the real world your way seems like a long span and may sag but it depends as much on he thickness of the tench slats as anyining else tif you have information ar actounts that they would have gone paralle to the long axis, then I say stickwith what youve got. I can tell you trom experience that installing perfectly straight and does not like to cooperate Nice work

Post a Reply

Appendix A 52: Longhouse 3.1.5 page C 

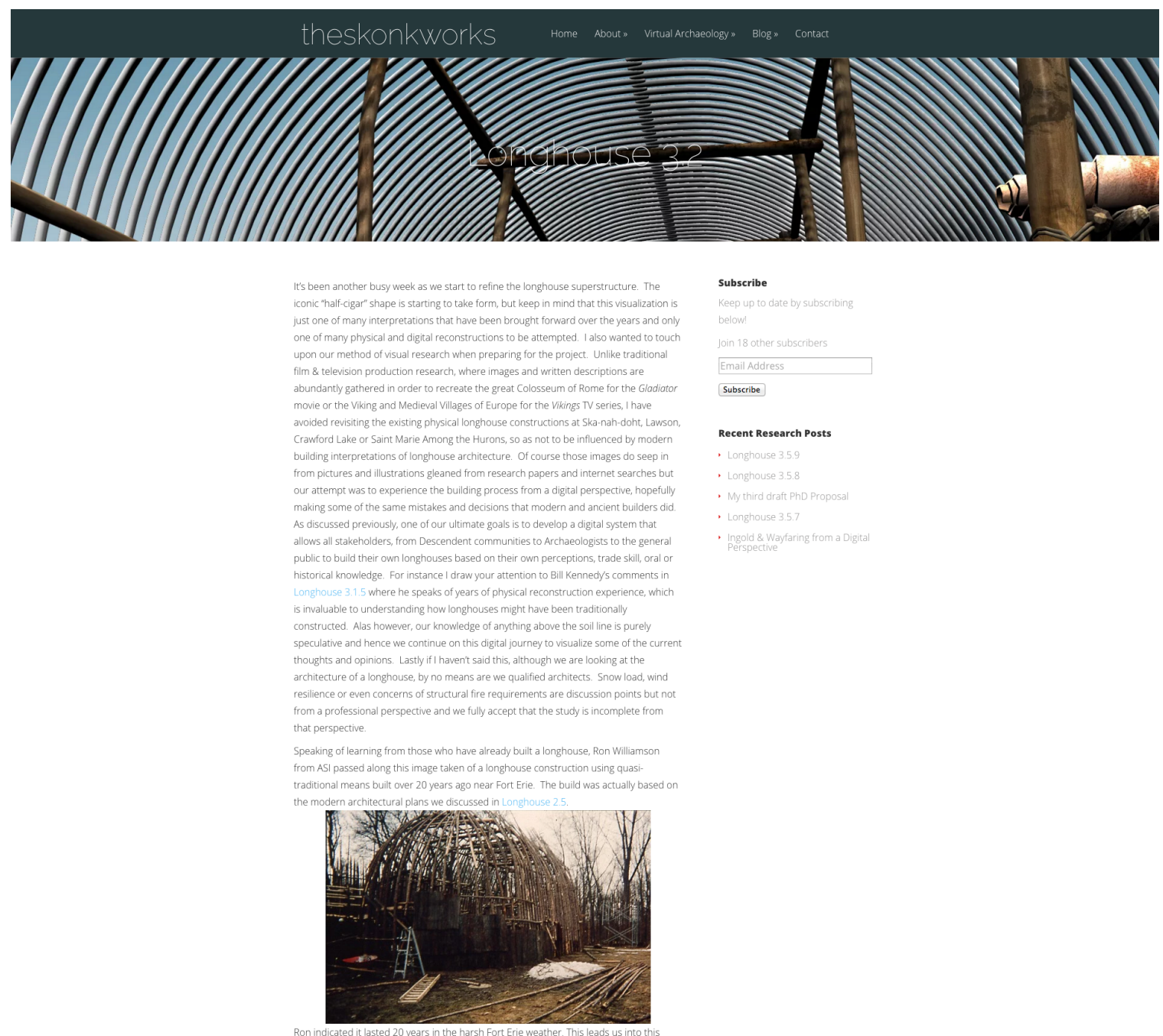

Subscribe
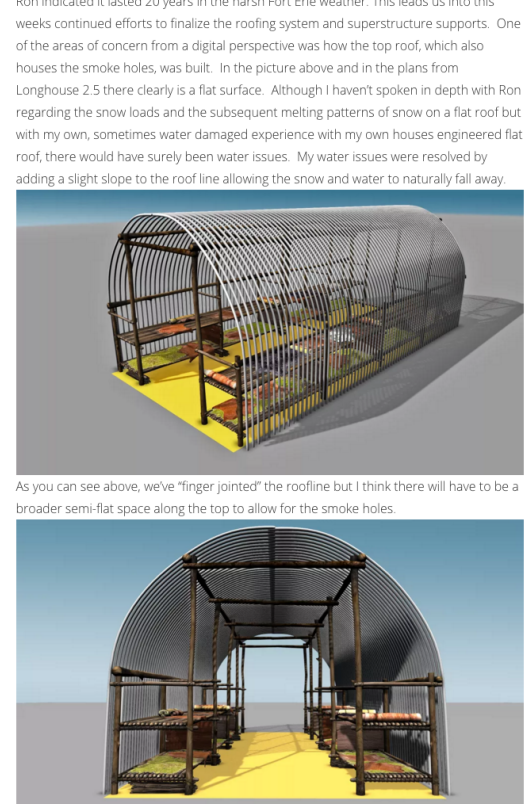

Appendix A 53: Longhouse 3.2 page A 


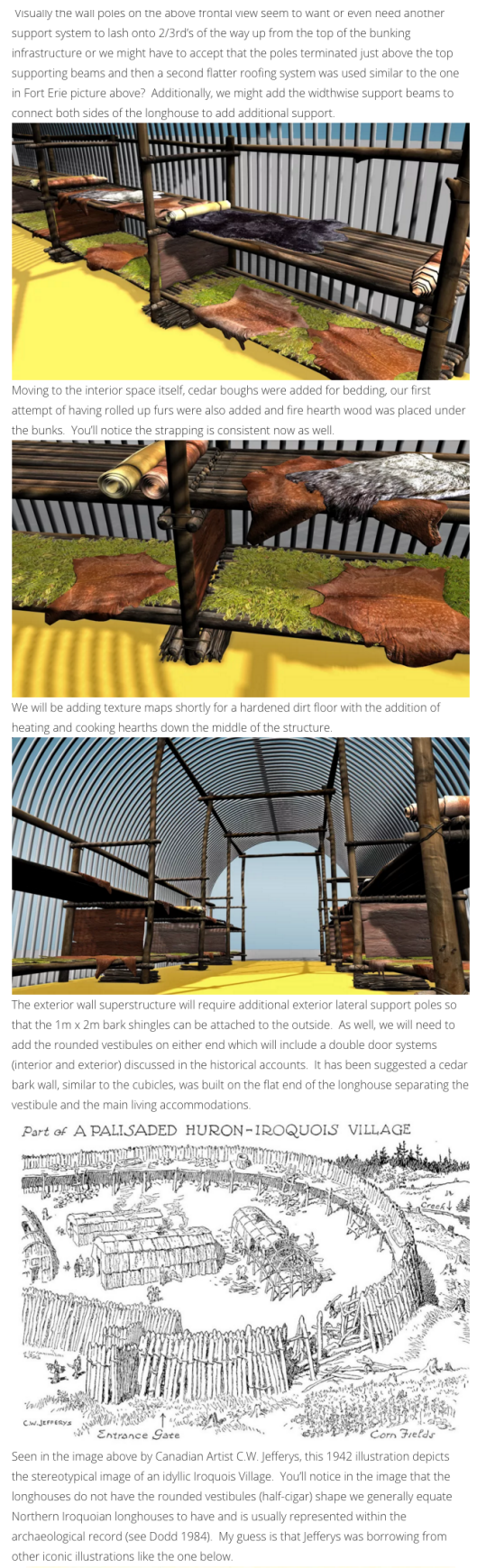

Appendix A 54: Longhouse 3.2 page B 


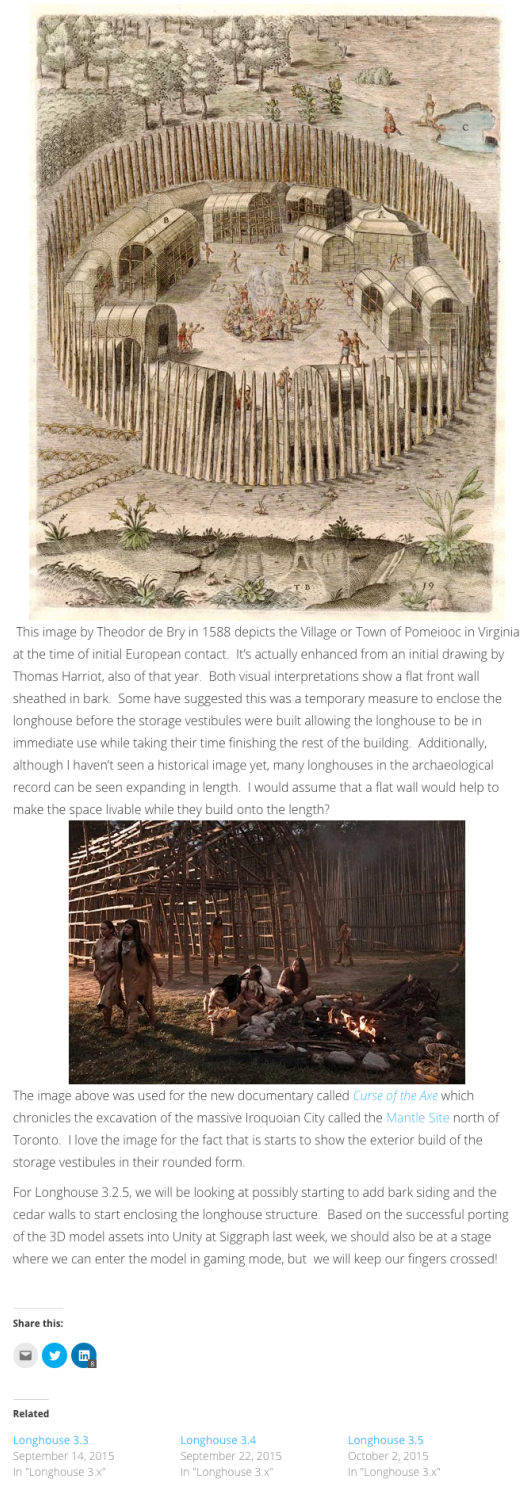

Appendix A 55: Longhouse 3.2 page $C$ 
1 comment

(5) mcarter

(a) August 25,20

Many thanks Bill! Interesting to see another use of Virtual Archaeology in

action. It's clear that our Iroquoian architects had a good sense of

Cheers

Michae

Post a Reply

Trackbacks/Pingbacks

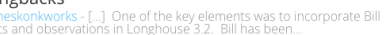

Leave a Reply

Appendix A 56: Longhouse 3.2 page D 


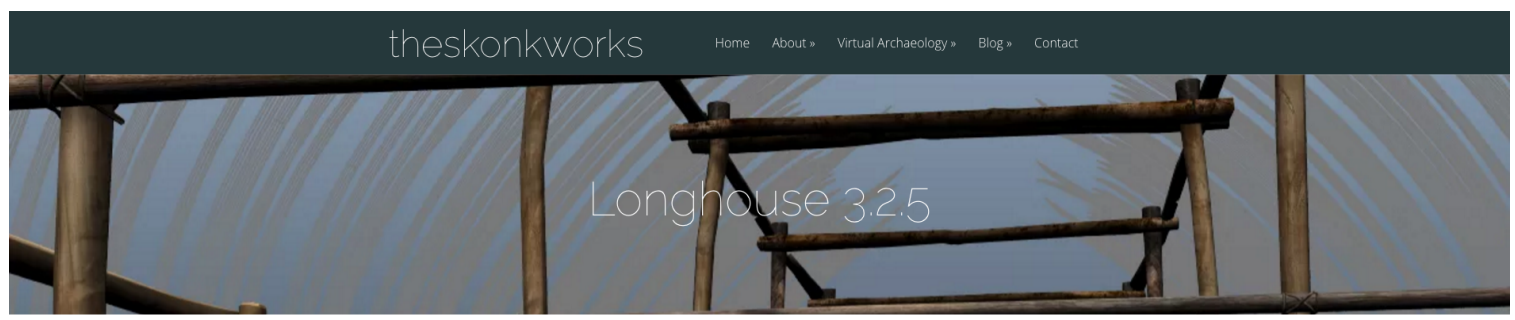

A big shout out to @EAAGlasgow (EAA Glasgow 2075) Would have loved to participated An this years timey secsions but the Ryerson MDM grad students are ctarting earlyths

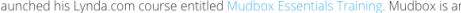
extremely powerful 3D sculpting and painting software application, which wéve also used in this project as we

It has been a veek of minor refiements and some time to review renting structures for Dirlonghouse One of the key elemens was to incorporate Bill Kannedys comments and observations in Longhouse 3.2 . Bill has been building physical heritage reconstructions for years and had indicated that to keep the internal structure from

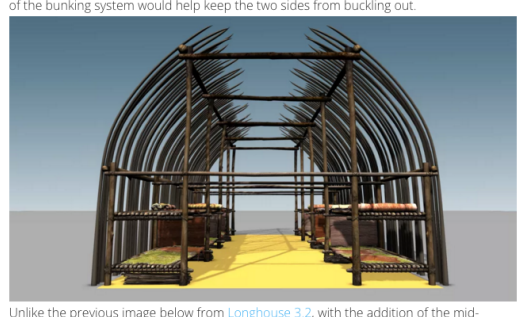
Unlke the previous image below from Longhouse 3.2 , with the addition of the miasecturn tiunzon ai cross-brace, the i image of the Longhouse looked like it became very squat. Lrag and actually went through the settings in Maya to make sure the ren from the camera wasn't being pinched in any way. Artistically it cle

This "paradata" process of writing about the decisions made while producing a heritage J and her a correct which should promnt an invectiogtion on whather there is archanological or

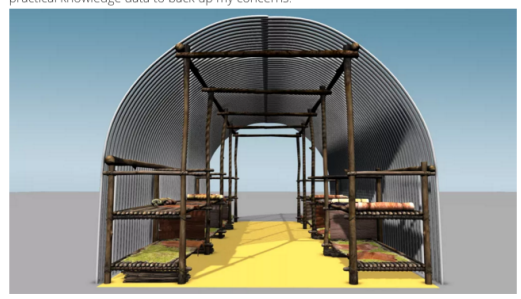
We concluded however that it was an optical illusion due to the change in wall post styles expect. For the next ite roughly $60 \%$ of the total height of the langhouse. As discussed previously, we have been mixing builan gmethudologles from Wright, Kapches and Snow along with nisights from ourconmenters. The bow heght was suggested by Snow (see Lon ghrouse 1.5) originally

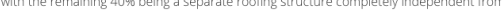
the wall posts. Wright suggested a similar approach but mith a much taller wal system o The assumption being that native builders would have continuously tied down the the exterior wall poles to be bent more naturally and ono wo heght, would also allaw more stable and secure?

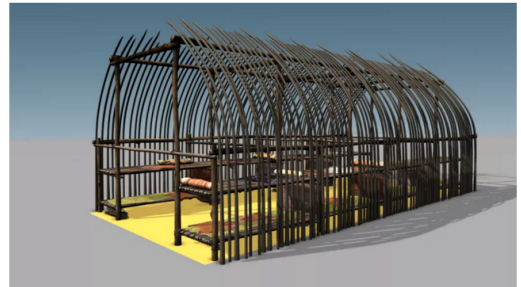

Appendix A 57: Longhouse 3.2.5 page A
Subscribe

belon

oin 18 other subserrbers

Email Addres:

Subscribe

Recent Research Posts

Longhouse 3.5

L.onghouse 35.

- My third draft PhD Proposal

Inoold \& Wayfaring from a Digital 


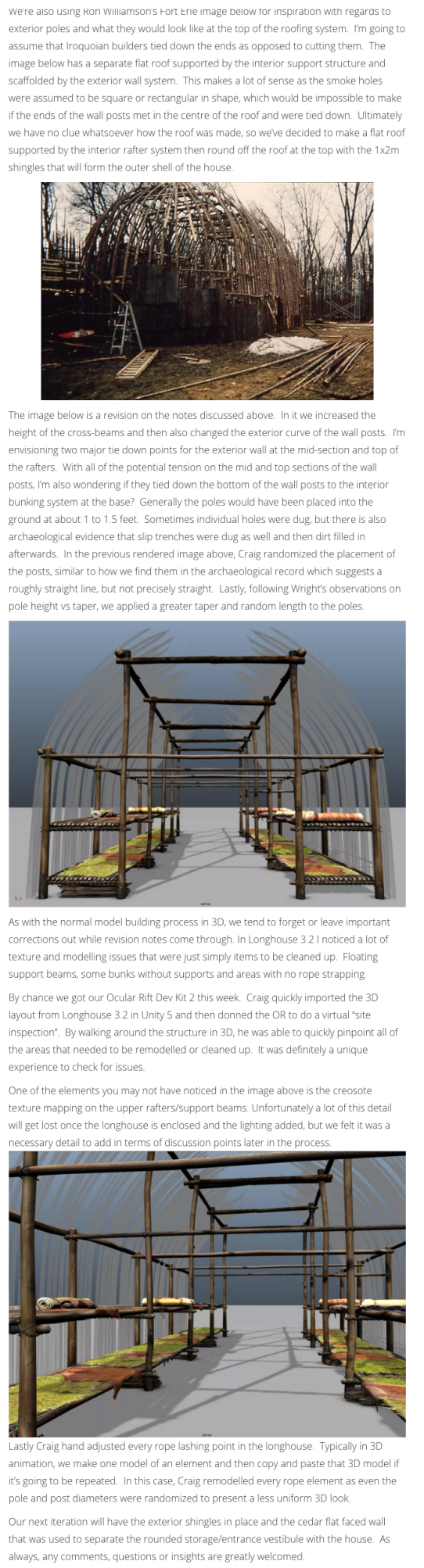

Appendix A 58: Longhouse 3.2.5 page B 
Share this

- 0 요

Reated

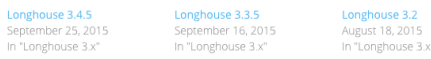

Leave a Reply

Appendix A 59: Longhouse 3.2.5 page C 

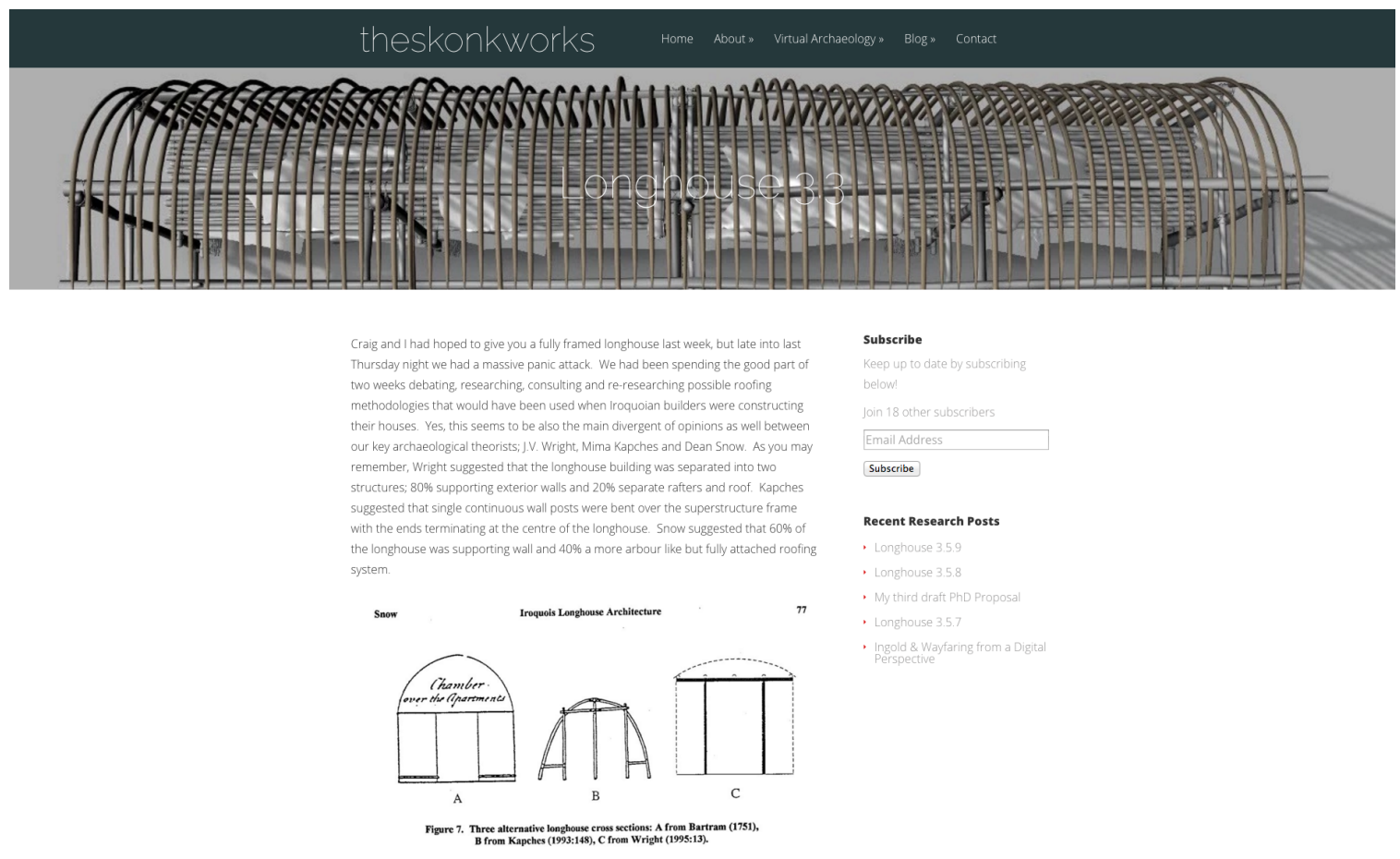

Subscribe

below:

Len 18 other subserchers

Jin 18 other subser bers

Subscribe

Recent Research Posts

Longhouse 3.5

- My third draft PhD Proposal

- ingold \& Wayfaring from a Digital

wersion roof (5now) and a sontingus wall post that begins bending at about $60 \%$ of the height What nobody has really not talked about is how the smoke holes where constructed or even if they were above the fire hearths inside! Thus our ability to understand how

smoke holes were constructed or even if they were purposefully bult into the roof during the construction process has been hindered by a lack of oral, historical or archaeological evidence

One of the first problems is that the archaedogical record tlearlyindicates that fire or cooking hearths can be found throughout the inside floorplan of a longhouse. Generally as Dodd indicated in her 1984 research, they tend to be grouped along the

centre/middle of the longhouse isee imase belour)

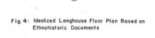

$\theta$

$\theta \cdot \theta=$

$$
\theta
$$

tinos titus in.

.

hearths did move and there could have been both a cooking hearth and a heating hearth in close proximity to each other. Further, there is no indication that the number of hearth's actually represented the number of family units within the longhouse (normal convention is that it is one hearth shared between two family units on either side of the longhouse bunking system). The excavation map below of the Lawson Site, which is Informing our research, shows two fire hearths in House \#5 somewhat inline along the centre of the house. However House \#6 has one larger fire hearth one one end of the becauss they didnt' find ones group on another. Twant to any (they could have been scrapped away during the excavation or they could have been

Appendix A 60: Longhouse 3.3 page A 


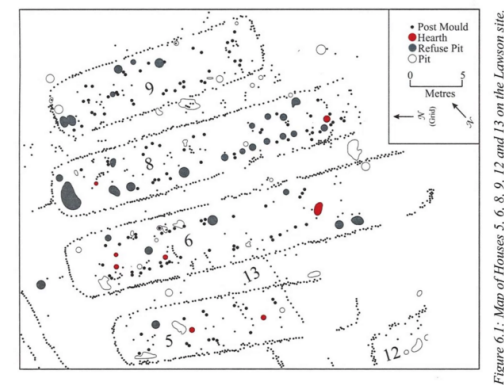

In Ron Williamson, David Smith, Rodolphe Fecteau and Robert Pearce's 1979 Ontario

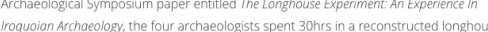

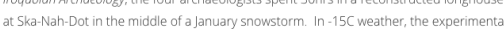
archaeologists stayed in a $213 \mathrm{mln}$. 6 m wide and $45 \mathrm{~m} \mathrm{high}$ wood framed and bark shingled longhoure the houre had four smoke vents along the centre of the roofine that were $4 \mathrm{~m}$ 's in diameter. The smoke holes had hinged covers that could be opened with a pos wets

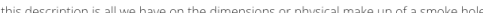
would be.

Further, in discussions with Neal Ferris, there is the question of weather the smoke hole that the smoke hole in the roof would be directly above, however Ferris has raised the paint of rain or meting snow froviding a constant unpping on the tire hearth oetiow this was to happen, the fires would go out. but not betore substantial smoke could accurnulate. A cover, as briefly described above, would not be totally effective in keeping dripping water out, so my assumption would be that the smoke holes would be offset from the fire heaths below.

Lastly, Williamson et al's description indicates a "diameter" of 4m's Longhouse construction is clearly linear and with limited fine cutting tools, I cant see Iroquoian. builders up on the top of a $7 \mathrm{~m}$ high structure tyying to cut a circular hole in the roof. IIm. going to take an educated guess that the "smoke holes" were rectangular or souarish and that the builders would use a similar shaped piece of bark shingling to act as a cover Hence, Cralg and started reconstructing the roof line to be much flatter, allowing for square or rectangular smoke holes to be built into the the roof and rafter system. We

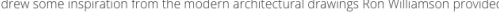

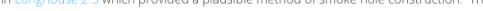
Image below includes a second horizontal set of beams down the middle of the roof

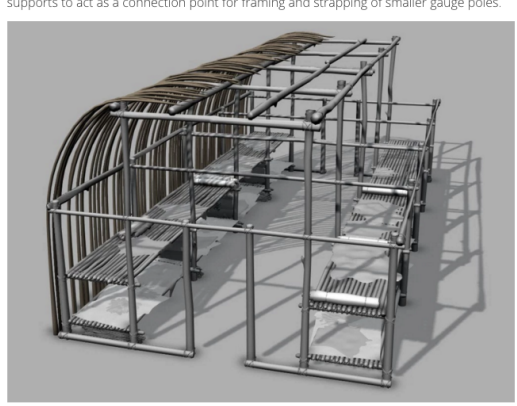

Yoül notice we have also included the interior door frame construction. Again, from historical accounts there are indications that the flat inner doorway was constructed $y$ the same lightweight cedar shingling that was mentioned in Snow's account of bunk compartment walls. After some discussion with Craig on how they would hang the cedar strips, we roncluded that a door frame had to he constructed to act as a brace. In the shot about Craig extended a horizontal pole at the bottom, but the door posts are assumed to have been dug similar to the other posts in the house. The archaeo logica record shows no trenching or vertical lines as soil stains on either end of most Ionghouses sol told Craig to remove the poles touching the ground and just extend the support poles on the first set of benches

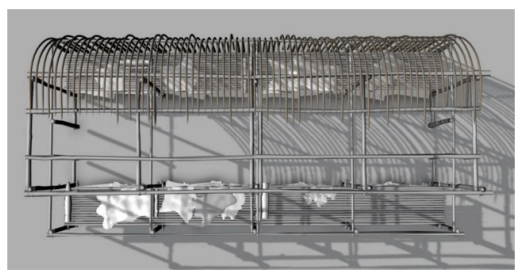

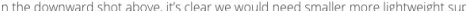
to frame the smoke holes. We decided to use the same diameter poles that are being used for the exterior wall strapping (around $3 \mathrm{~cm}$ 's) to help frame up the roof supports

Appendix A 61: Longhouse 3.3 page B 


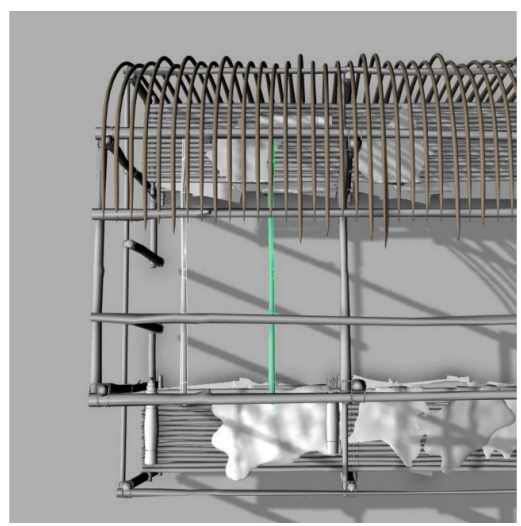
supports for the top roof shingles when we start adding them to the structure

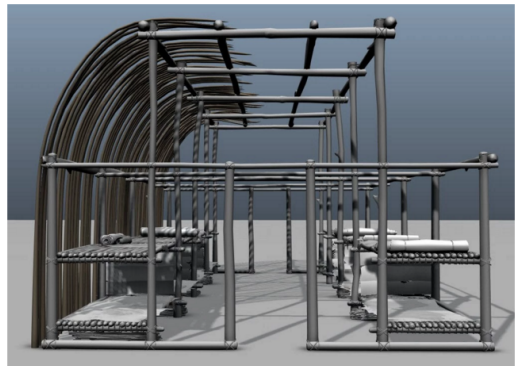

Itts at this point when panic sets in we did a frontal render of the longhouse and it seems somehowit has grown squatter and wider in particularl was having issues with the exterior wall posts and the fact they just looked too elongated. Going back to previous renderings reveal that yes, the longhouse has been getting wider in width and

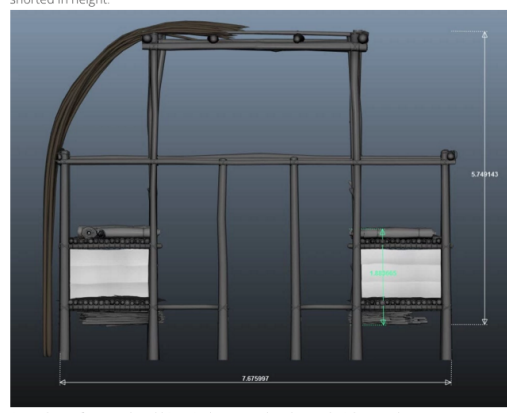

.

suggests the average width for a Northern Iroouoian longhouse was $7 m$ 'm, thus the

height would be $7 \mathrm{~m}$ 's. Craig clid a simple measurement rendering and clearly our

the dimensions without knowing

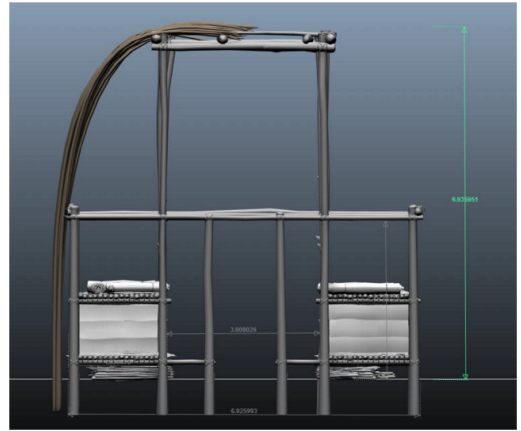

Appendix A 62: Longhouse 3.3 page $C$ 


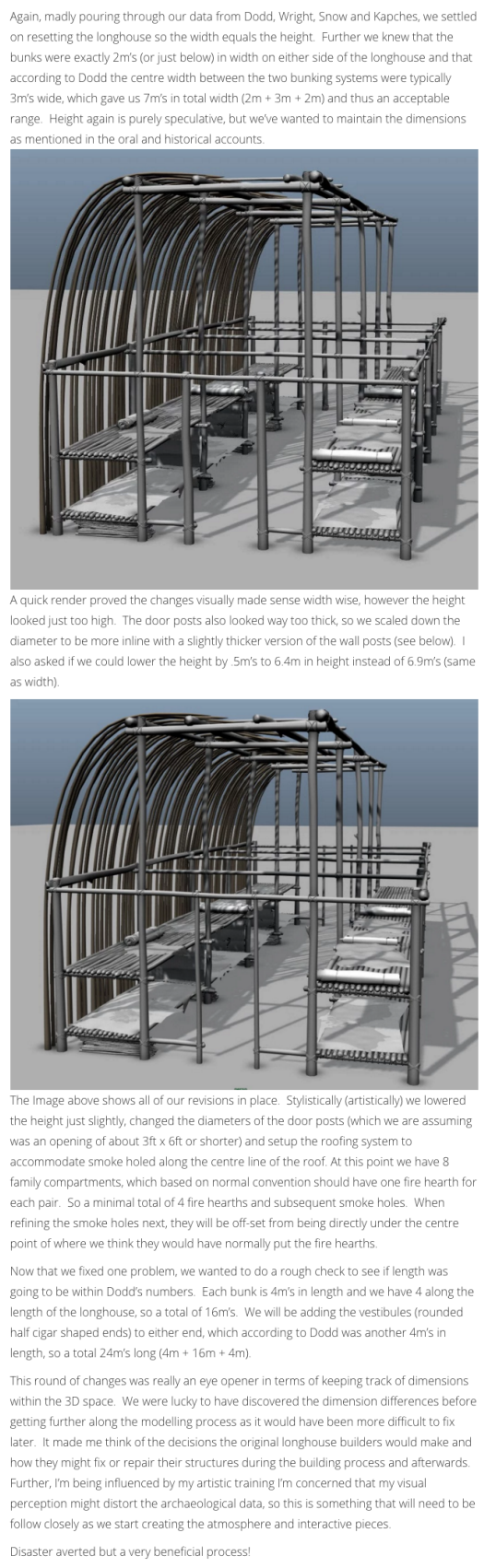

Appendix A 63: Longhouse 3.3 page D 
Share this:

-

Restated

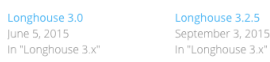

Trackbacks/Pingbacks

Appendix A 64: Longhouse 3.3 page E 

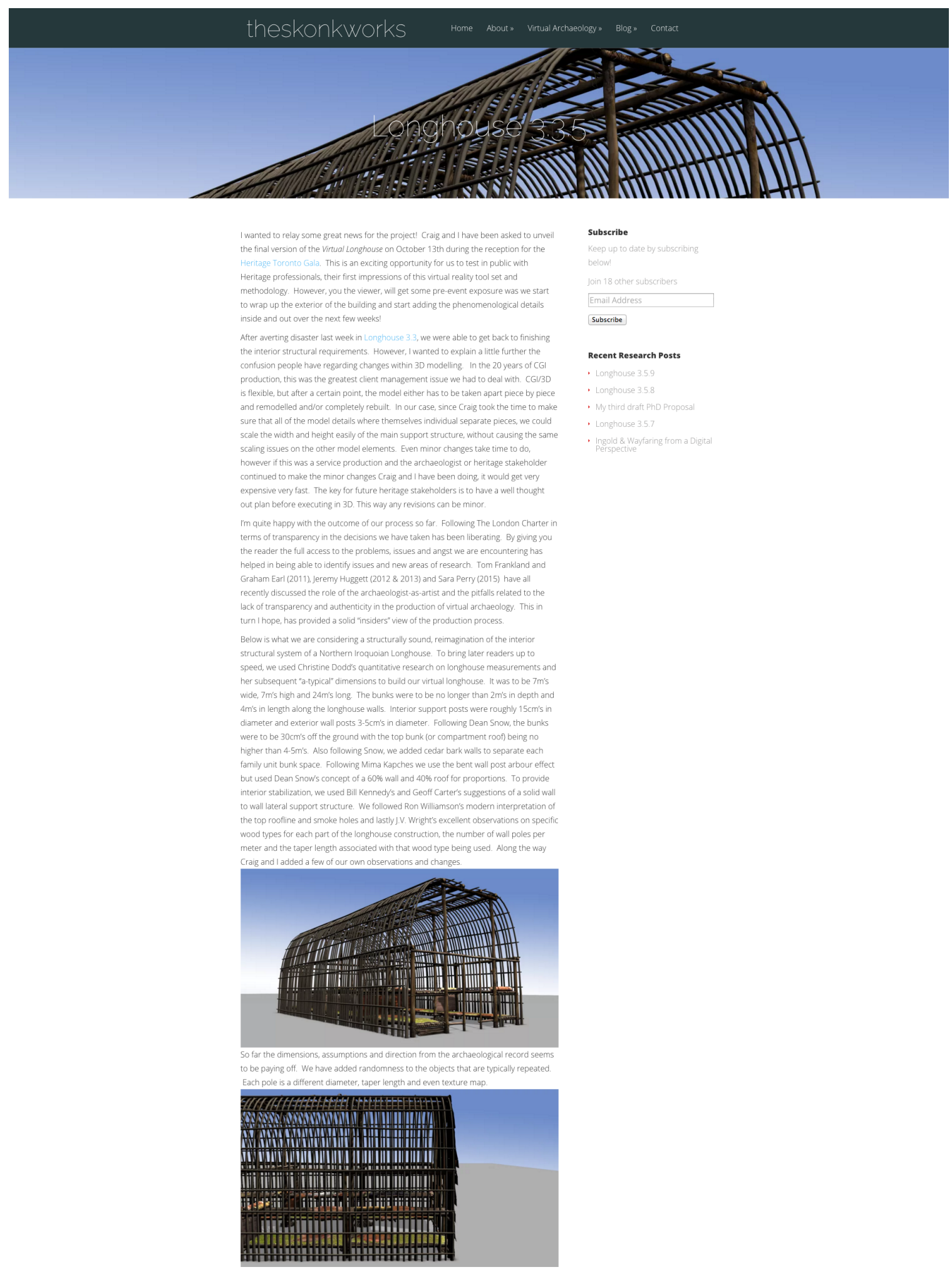

Appendix A 65: Longhouse 3.3.5 page A 

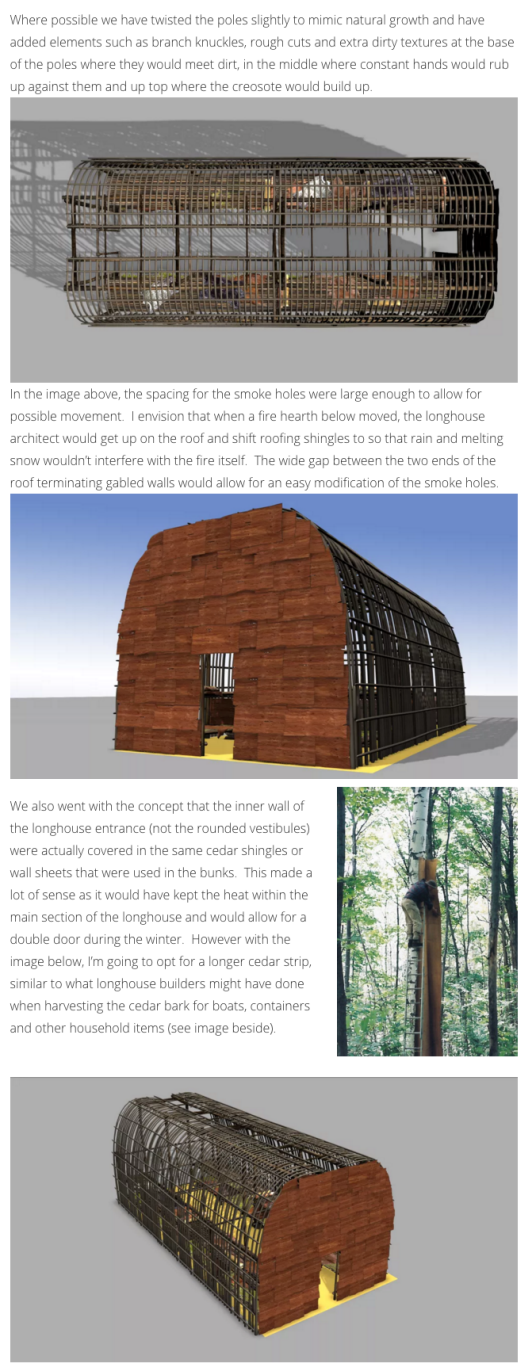

So we are now ready to mount the shingles and add the rounded vestibules. Next week we will have the first real rendered sequences and III go more into depth on the

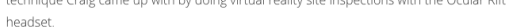

Lastly I wanted to touch upon something Jennifer Birch and Ron Williamson suggested recently in their book, The Montle Site: An Archacological History of an Ancestrat Wendat Community. The Mantle Site was a massive 99+ longhouse city ringed by an

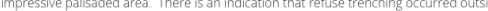
the palisaded walls which would indicate that some basic form of community organization occurred. Obviously my thoughts were whether this particular community had a permanent group of indivduals who were responsible for longhouse design and solely responsibe for their every community of members witnin a longhouse were

Appendix A 66: Longhouse 3.3.5 page B 
share this

- -0

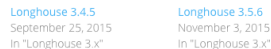

Leave a Reply

Enter your commerent here.

Appendix A 67: Longhouse 3.3.5 page $C$ 

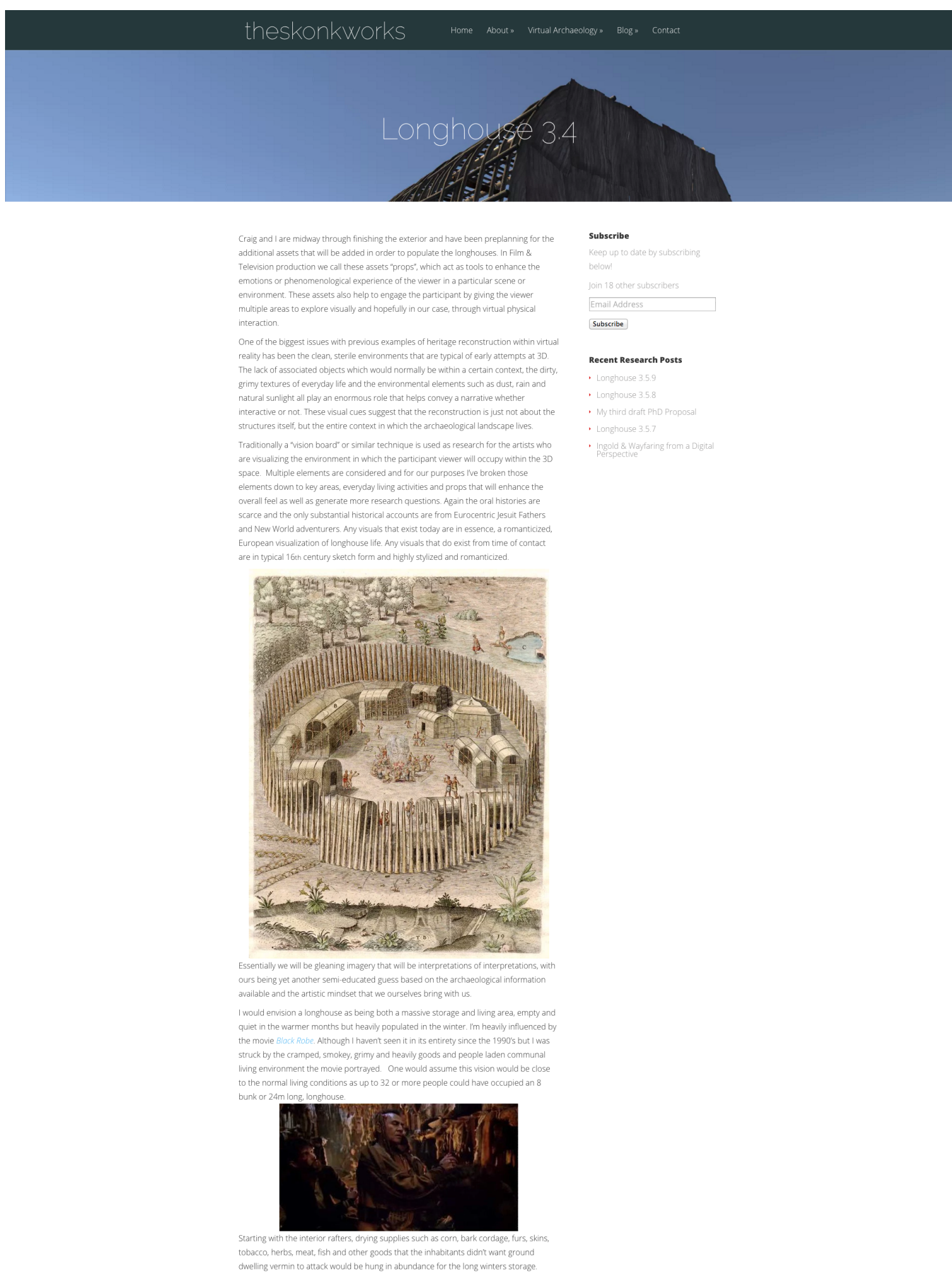

Appendix A 68: Longhouse 3.4 page A 

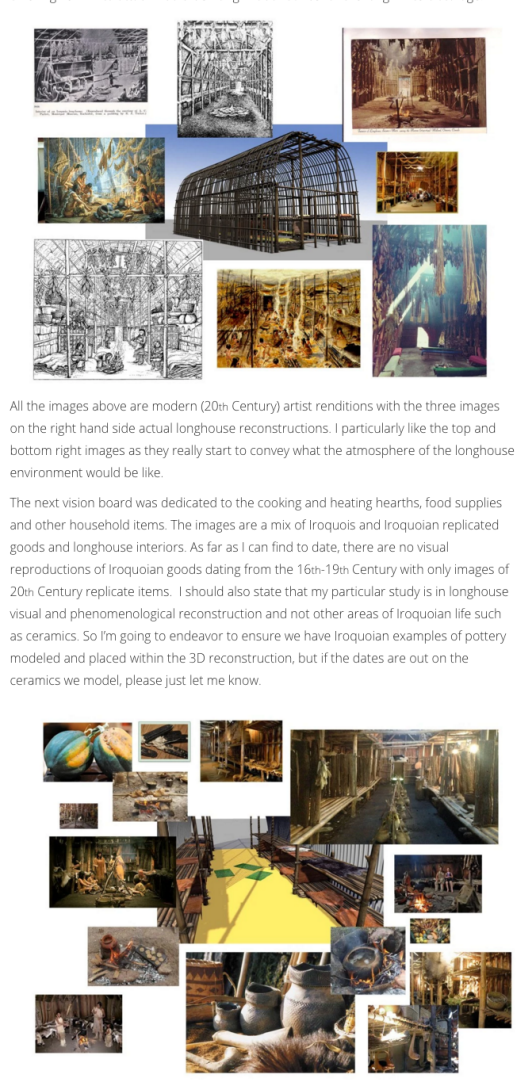

Corn, squash, nuts, berries a wer plants and tubers were part of the Iroquoian diet ad different times of the year, with a mixture of fish and game meat making up the dally intake Cooking those tems ranged from a large pot of boiling water or broth to using flat rocks to bake or fry. Roasting spits are usually depicted, but again the histor
on whit the cooking areas atcual ly lokked like We wssume based on some

on what the cooking areas actualy looked like. We assume based on some

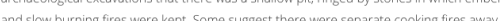

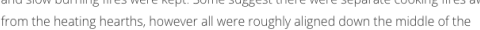
longhouse floor

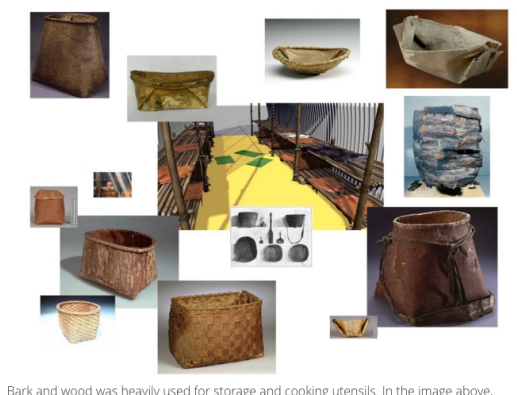
these are examples of early 18 th Century containers. Most are made out of pliable birch bark while there are some modern version of what a bark or reed weaved basked might look like. Bowls and spoons were made out of wood. In the rounded vestubles at the entrance of the longhouses there would have been larger bark caskets to hold grains, corn and other items such as apples or squash

Under the bunks would be the supplies of smaller firewood, with the larger pieces stored in the vestibules Visually we have to remember that the firewood itself wouldn't have been cleanly cut as the tools would have still been stone at this point, so l'm envisioning considerable amount of broken branches, twigs and rotting trunks that would make up

the dally supp lies of wood fuel.

Appendix A 69: Longhouse 3.4 page B 


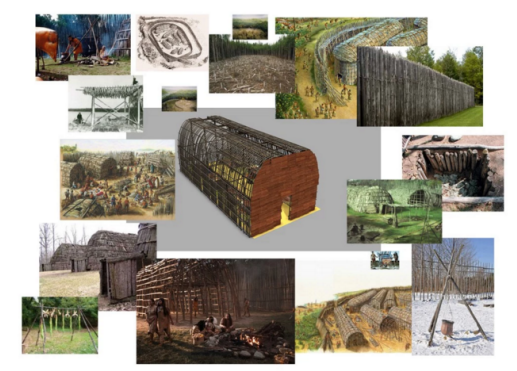

For our virtual experience we have chosen to represent one single longhouse and it's interior. However the exterior longhouse and vilage environment has to be represented Iroquoian villages and environment Perfect palisades, organized longhouses and clean and green ground throughout the village I suspect like any well-used environment grass or organic growth was worn down or non existent. Plant growth would hawe occured in spots where there was less humana traffic such as long the edges of longhouses or out the direct path from one destination to another Rach for dning fish and game, shes

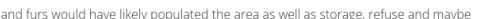

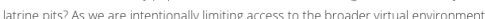
bevend our sine lon

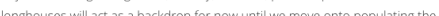
environment with various types of virtual longhouses.

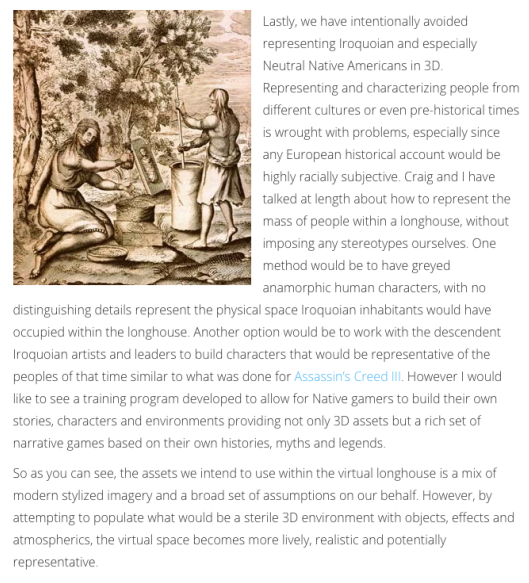

Appendix A 70: Longhouse 3.4 page $C$ 


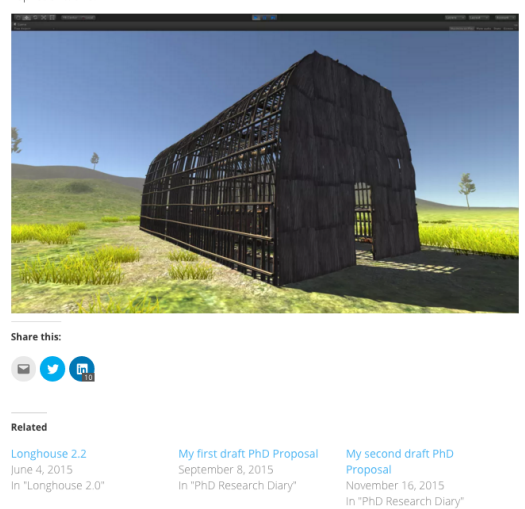

Trackbacks/Pingbacks

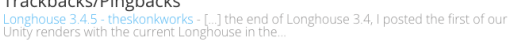

Leave a Reply

Appendix A 71: Longhouse 3.4 page D 

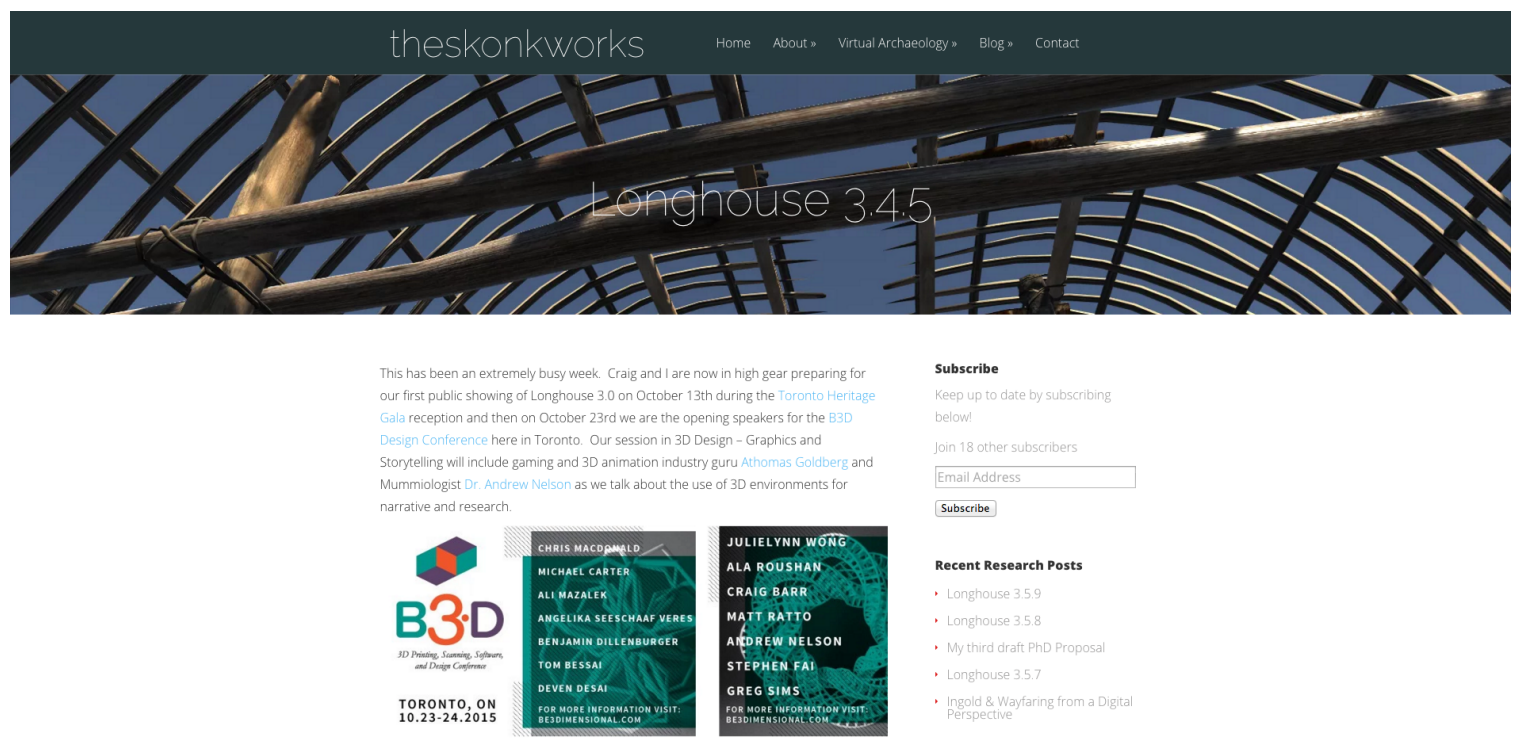

Subscribe

Keep up to date by substribits
below!

Join 18 other subscribers

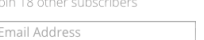

Subscribe

Recent Research Posts

Longhouse 3.5

use 3.5

Longhouse 3.5

Ingold \& Wayfaring from a Digital
Perspective

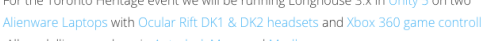

All modelling was done in Autodesk Mayz and Mudbo.

At the end of Longhouse 3.4, l posted the first of our Unity renders with the curre

Longhouse in the gaming givitual reality environment. This was our first real test of

porting the assets over from Maya and configuring the exterior lighting. Adummy

horizon was added

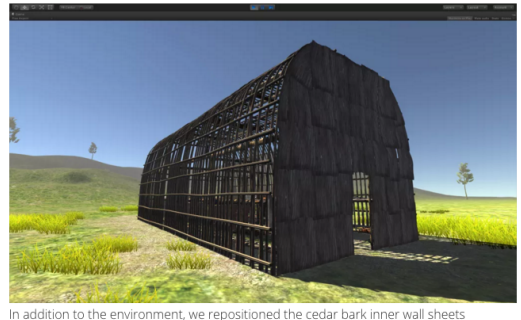

$n$ addition to the environment, we repositioned the cedar bark inner wall sheets

horizontally instead of vertically and made sure that each of the $3 \mathrm{D}$ bark sheets had th

own unique compusition. As you can see in the image above, you can make out the

to the interp in the bark sheets. Again, we have no tlae how the sheets were altactied

to te off the sheets to each other and the superstructure. As cedar bark was used,

which
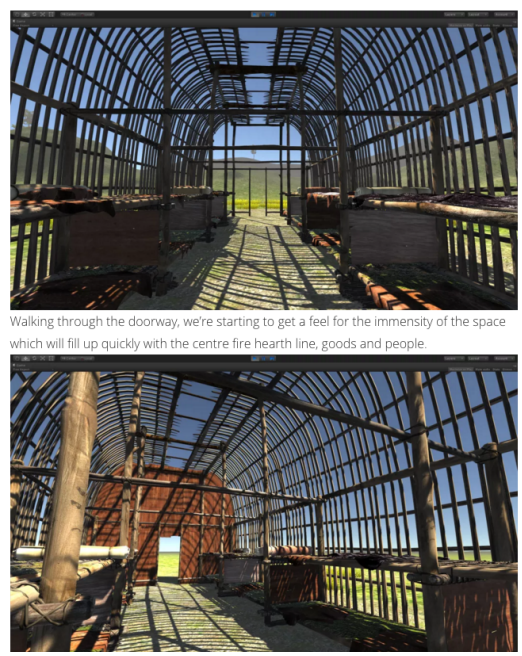

Appendix A 72: Longhouse 3.4.5 page A 
We have been using Unity and the Ucular Ritt glasses to do "ste inspections" to check how the model is holding up in virtual space and to understand if we have missed any of the constant stylistic and research determined micro-changes we are making to thi detail on the rope cordage holding the bunking system togethef

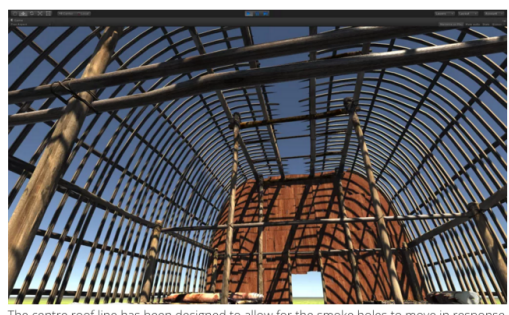

10Varley and Cannon's 1994 research on changing fire hearth/pit postions with excavated longhouses. We are thinking that when the fire hearth below moved, the

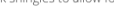

Below is our first real Unity 5 environment test. The test is directly out of Unity in prevew mode, meaning that th hasn't been fully buit, rendered anc baked into the Unity space

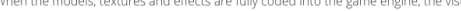
quality and feedback will be substantialy better. Obyiously we have more models on assets to add and build, so the environment when fnished will have a completet/

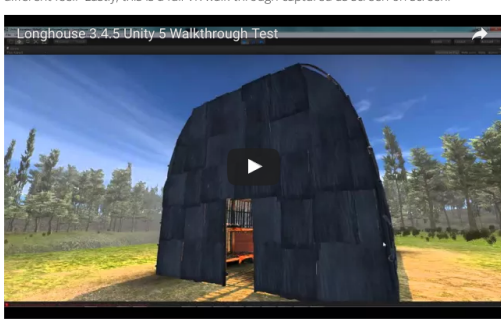

Even in low resolution the first walkthrough raised more questions and observations. The an Ocular Rift DK2 hoadsct and wining a Xbox 360 hand controller to move around, Jump and do directional head movements

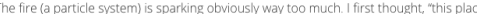
The

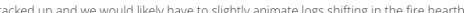

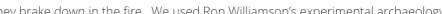
adventure in a real longhouse (mentioned in Longhouse 33 ) as a basis to determine the fire hearth circumference of .6-8m's in diameter. However, the distance between the sleep births or even the sleeping space on the ground around the fire hearth looks dangerously minimal. At about 1.31 in the video, we "hop" over the fire in traditiona tamer mode, but I noticed that even when foll owing the archaeological data, the fire hearth seemed too close to the inner doonvay surroundung the longhiouse woul inkery have teen wel worn or even mudy at certain

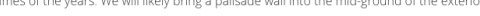
shotjust to enclosectenstran the longhouse vista a the more. Basc bird, wind and other effects sounds have been added and will need to be refinet However it has been an excellent first test an

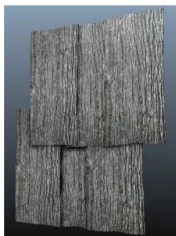

Thesty we are now starting to add the longhouse

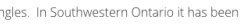
aggestec by Neal Ferris that White Elm would probab/ the ainging the exterior of the tonghouses. The grain. Wer running down the longhouse and they would hely be overlapping from the ground upwards. The taditional "turtle shell" look of over apping layers seems he most logical approach and has been readily used the 1970 : (a)

Once the shinges are on the house, the only light that mil penetrate the structure will be emanatios
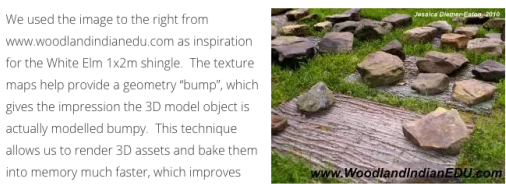
Into memory much faster,

It has been an exciting week to finally see the longhouse within VR space and to be able direction

Appendix A 73: Longhouse 3.4.5 page B 


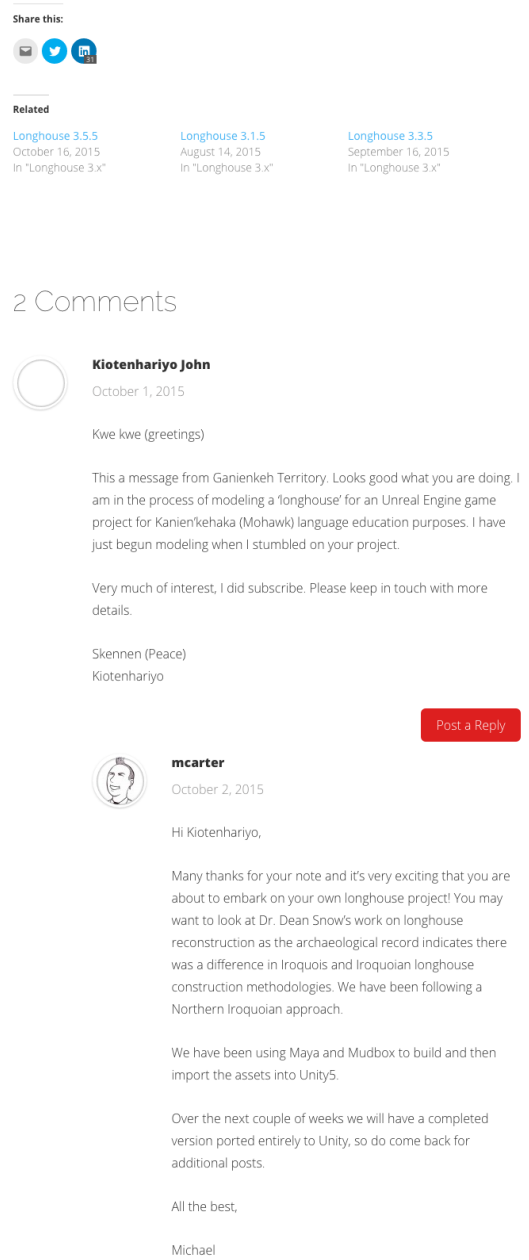

Appendix A 74: Longhouse 3.4.5 page C 

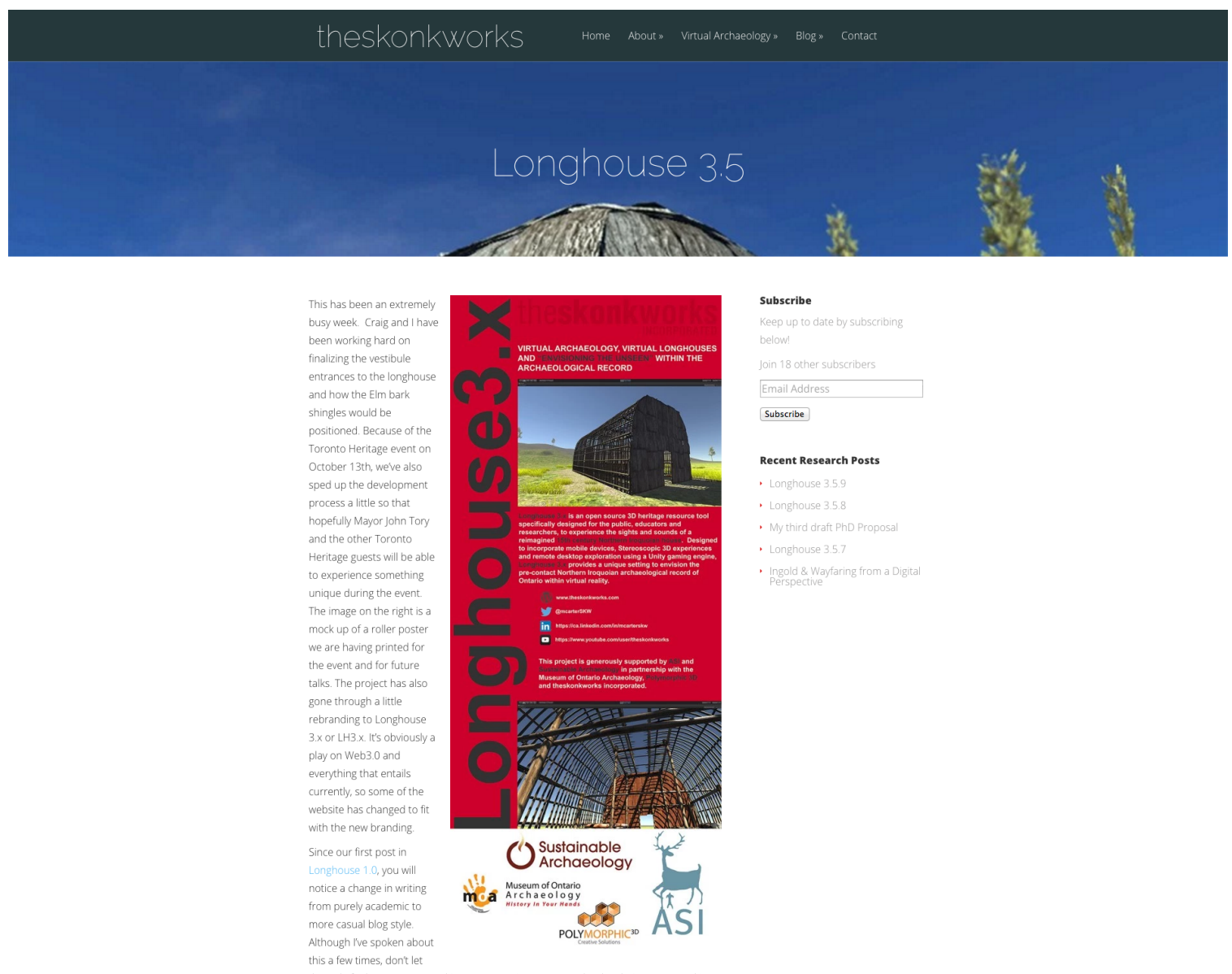

Subscribe

gin 18 other subscribers

Email Addres

Subscribe

Recent Research Posts

Longhouse 3.5

Longhouse 3.58

Whe third draft PhD Proposal

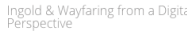

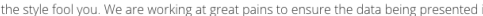

represented within the archaoological historical or oral records and when they are nou.

we are dlearlyidentifying the assumptions being made. This is a conscious effort io

ensure we are conducting this research with transparency and following The London

Charter on witual archaeology research and dissemination The project itselfi is by no

means meant to be a final interpretation but a gareway to further research and

invest gation which segues nicely into todays post.

Weve also been getting a little bit of biug notice as well. It all started at the beginning of

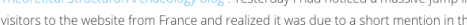

French website 3DVF com mentioning the zrof

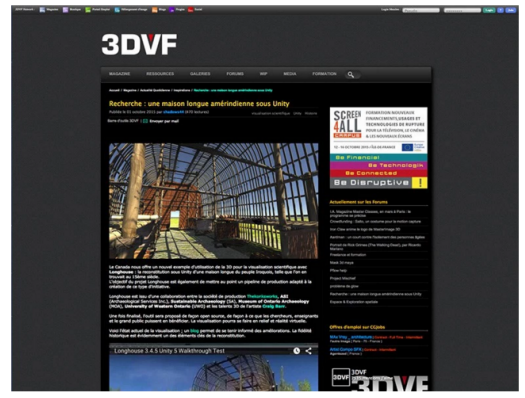

As of this post, there has been over 700 views on the blog above, 50 many thanks to

3DVF for highlighting our proiect

Getting into the project now, we have been working specifically on the vestibule and Elm

bark wood shingles. According to Christine Dodd's 1984 research, the vestibules on

either end of the longhouse had the same width and height dimensions of the ma

longhouse and was generally $42-4.7 \mathrm{~m}$ 's deep. There was also an indication that the

wide on the front entrance

Appendix A 75: Longhouse 3.5 page A 
The image below is from the 2008 Alexandra excavation in Ontario by ASI. It clearly

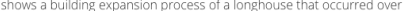
phases. However it does demonstrate the vest thule taper mentioned bove quite nivet. It is also a nice visua to demonstrate the reconstruction process that occured when a longhouse community needed to expand Youl"l notice that the end fof the vess bute continue to he rour

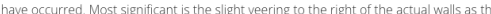

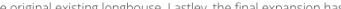
(n) mine

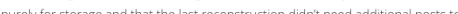
support any roofing or structural issues that may have occurred after the remodeling.

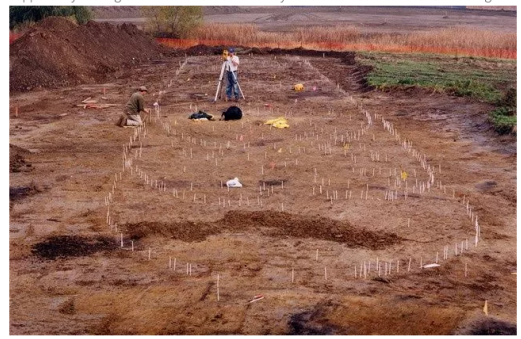

Seen in the image below, we have adopted Dodd's dimensions for the vestibule. Also, our flat roof approach tor the smoke holes and the bark shing ies that surround it worked out well. We will add laps later to allow tor the holes to be tlosed and to long poles
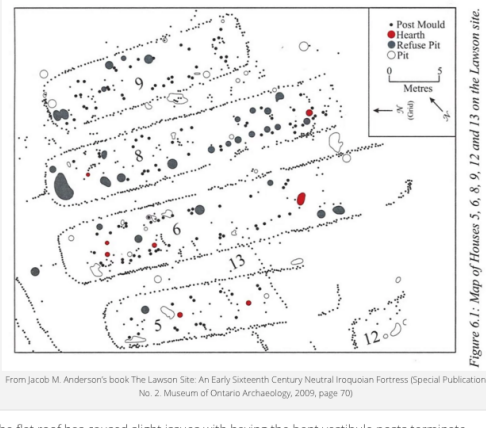

The flat roof has caused slight issues with having the bent vestibule posts terminate properly at the rooffine. We will also need to revisit how the poles would have been main part of the longinouse been more challenging mainly because the framing wouldr't be as stable as the rest of

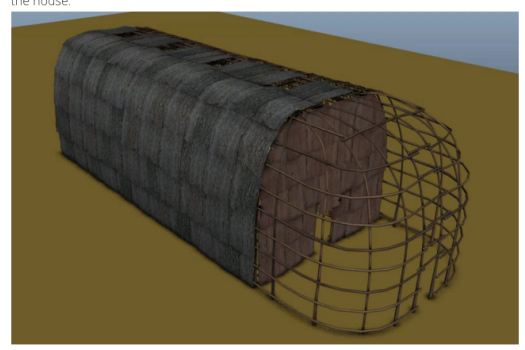
been termir the poles on the sides which Craig and I will have to address later in the revisions. Currently there isnt enough wall posts As you can see in the excavaturn plan from the Lawson stre below, the rounded ends have a substantially larger volume of post holes grouped tighter together. The pronte image below gives us a nice representation of what

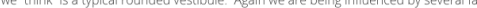
namely previous physical reconstructions, limited historical drawings and to be honest, our grade 4 classes in Native history which always seem to emphasize a "half cigar shaned" shane

Appendix A 76: Longhouse 3.5 page B 


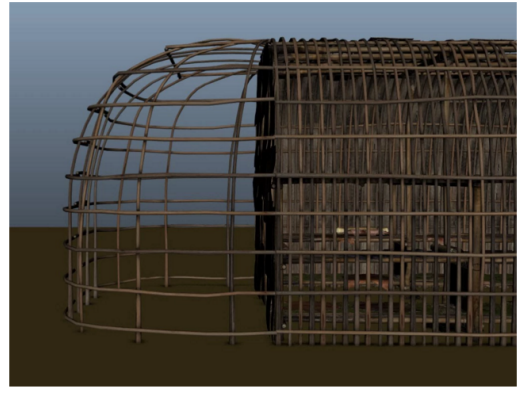

Lastly, to frame the door bel ow and to terminate that framing so it matches the rooffir we've added short bracers above the doorway in order to have a continuous rounded connection between the two halves of the vestibule walls. Again these wall posts/poles also kept the door at $3 \mathrm{ft} \times$ 6ft which will later be covered with a skin curtain

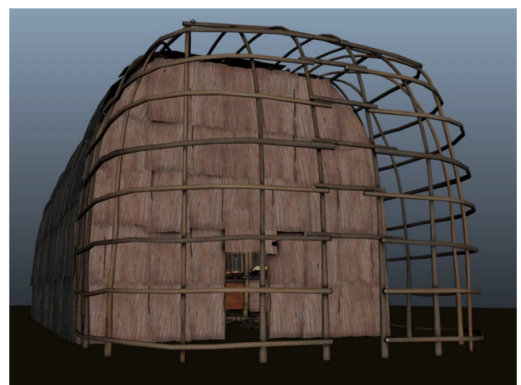

The next set of images are revisions on the structural elements of the vestibules. We added more suppor posts but wo ld likely have to add subtantially more poles to meet archaeological records in terms of post density. I'm still not fully convinced of the curren additional to add to our list for future research

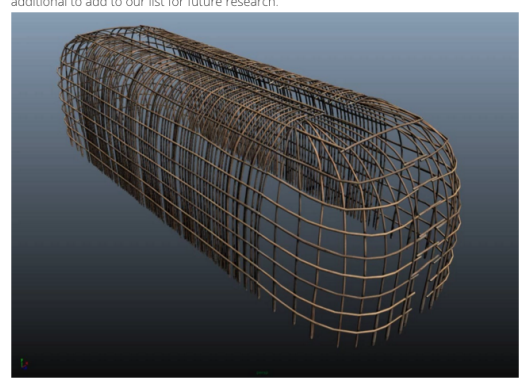
reveals that the doorways were not always centered (either by construction mistakes or by design) and that some longhouses had the doors on the side, along the length of the bullding

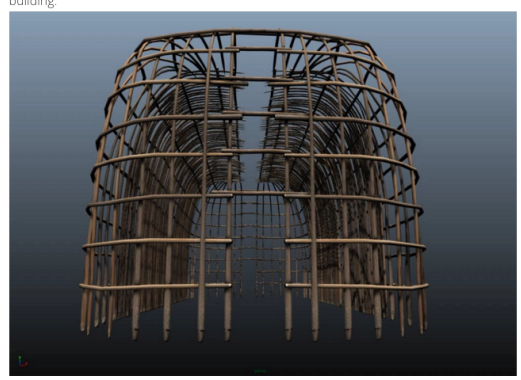

A side profile view of the entire interior and exterior framing to date. It's clear now that we have to increase the amount of poles used in order to replicate the archaeological record, however one of the issues we are now facing is the amount of $3 \mathrm{D}$ data within the attual model. The more modeled surfaces, the slower the interaction when in the game environment, so even at this point l'm starting to weigh the need to maintain

Appendix A 77: Longhouse 3.5 page $C$ 


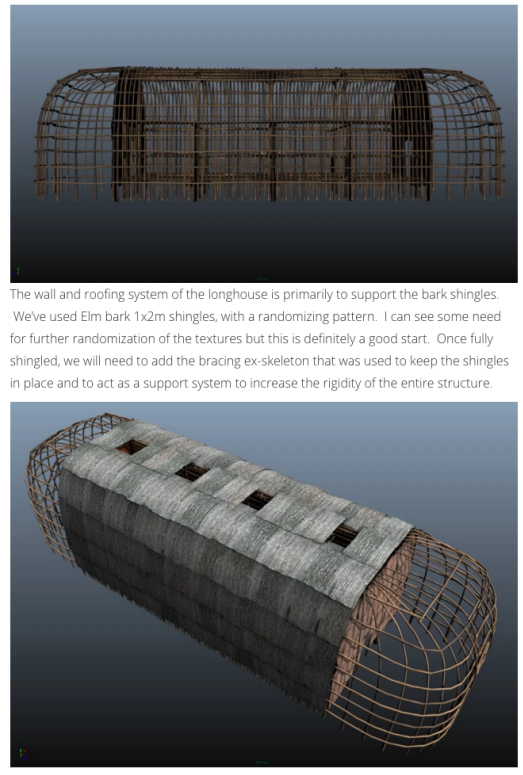

Up until this point, all of our image renders have been in Maya. When I ghting is added within Maya and if the model is created to be hyperreal, then the final mages ther elements like atmospherics and possible real life images, these models above can and will look lifelik

By comparison below, we give you our first rendering in Uniry 5 of the longhouse fully

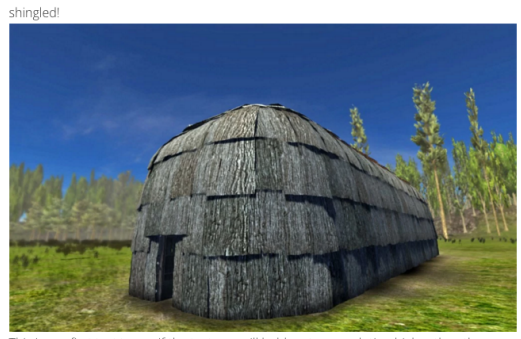

This is ou first test to see f he texuresmil hold up to a resolution higher than the standard 72 dp of digital screens. Below/s the igntung rendering test for the interior of

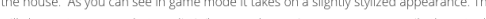

ame in 64 bit and make our lighting and environmental tweaks

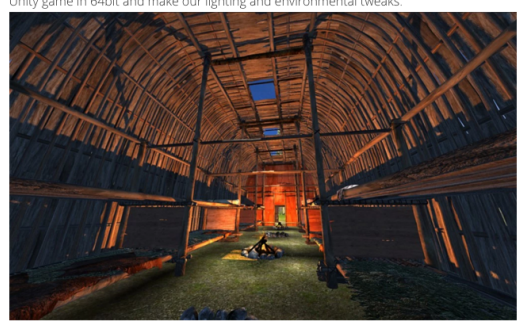

It's heen a very exciting time to finally enclose our structure Ar lot of effort to date has been to provide a transparent model of project development in virtual archaeology ar some insight into the micro decisions that are made throughout the process. Further, it's been a teame effort with Craig who has been an invaluable source providing a wealth of artistic and technical knowledge

We have compiled a simple walkthrough to start testing the experience on various plafforms and wil be spending the next week making all of the model and lightins adjustments needed for our first public reveall:

Again, if you have any comments, please don't hesitate to contact is

**Addendum**

Fn Friday Otober 2nd treceived agreat emal and question from Bill Engel hreche

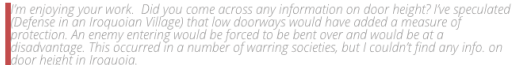

Appendix A 78: Longhouse 3.5 page D 

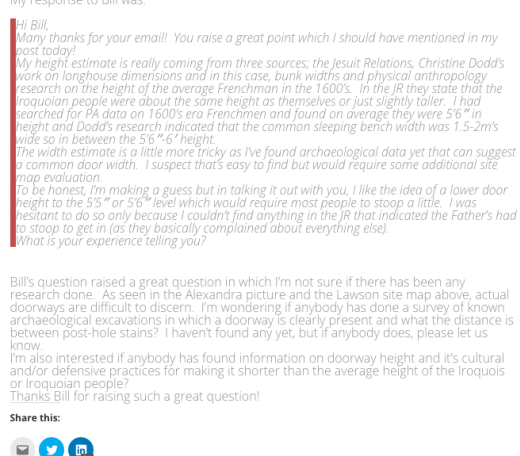

- 0 요

$\overline{\text { Related }}$

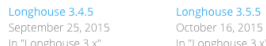

Appendix A 79: Longhouse 3.5 page $E$ 

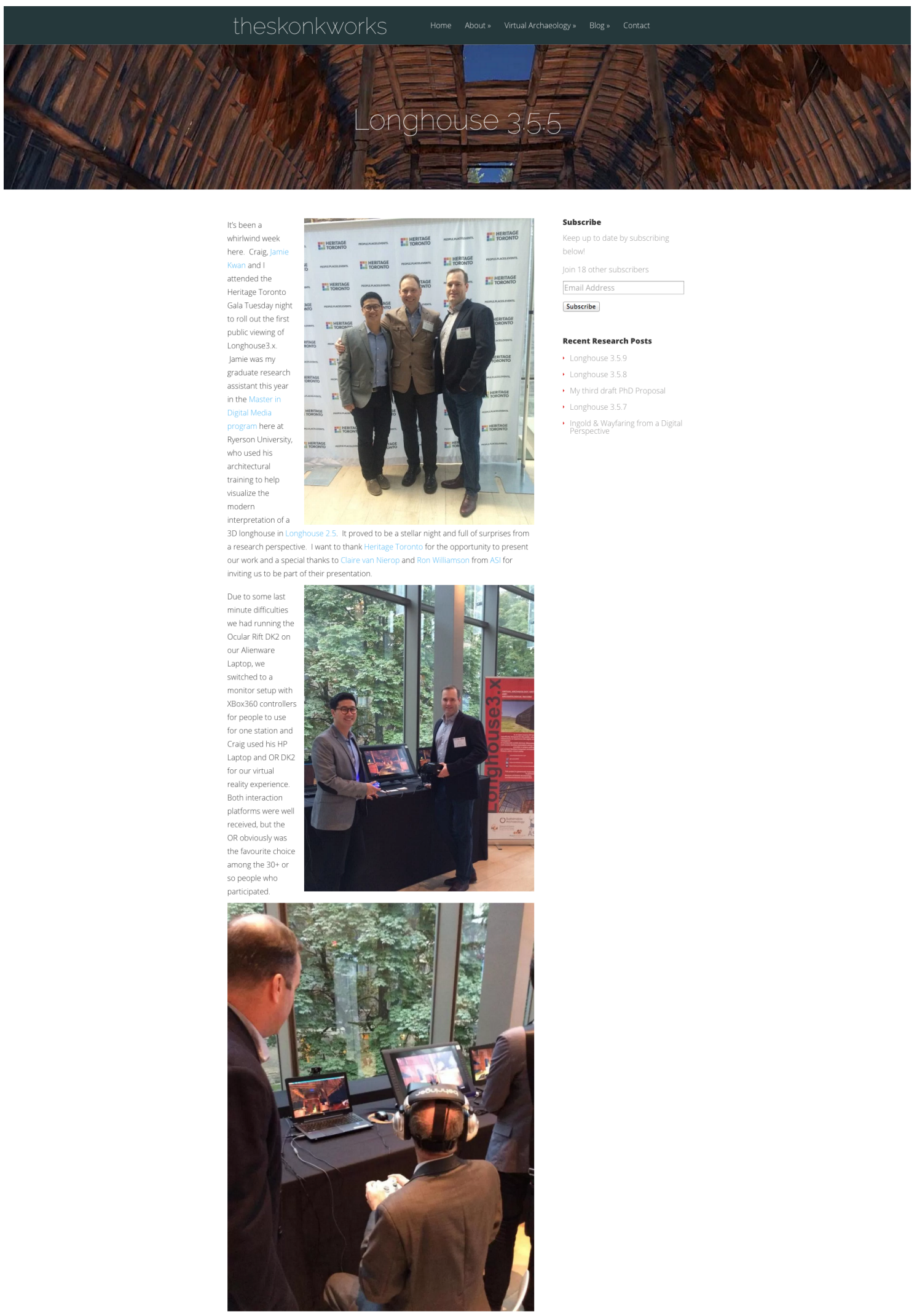

Subscribe

below

Join 18 other subscrite

Email Add

Subscioe

Recent Research Posts

- Longhouse 3.5

- Longhause 3.5

- My third diaft PhD Proposa

- Longhouse 3.5

- Ingold \& Waylaring from a Dirgtat 


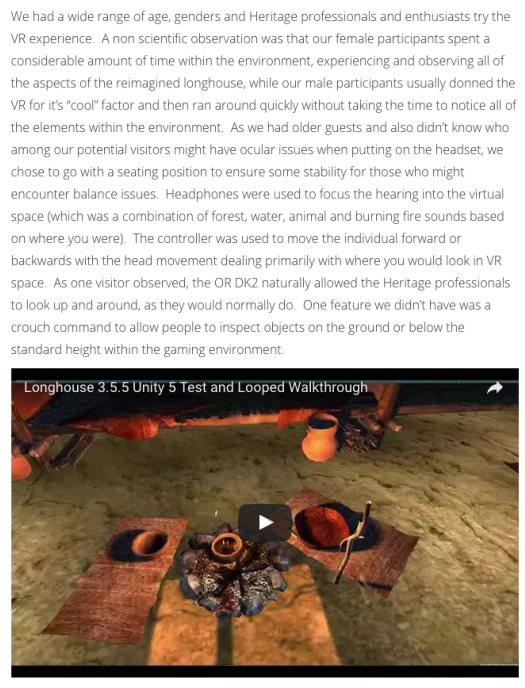

The videol loop above is our latest test of the Ionghouse within Unity5. By staging the visualization of items in the longhouse wth everyday domestic items such as food and cooking utensis, it started further discussions on potenta placement and use or those

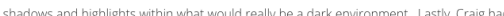

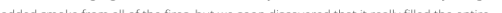
spre eq

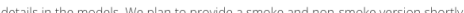
The during the long winter months.

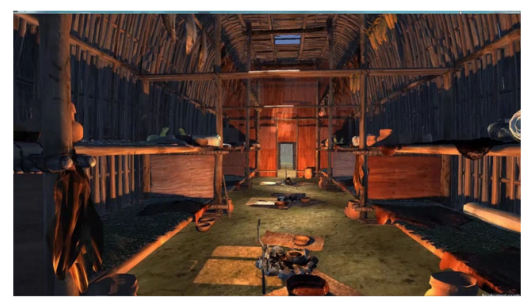

We added items such as cooking tools, pots and bowls (even with liquid in some. boiling to come later) but the placement is completely assumed and somewhat random. We car

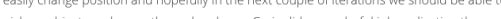
bowls and spons and we used prevously model led trocunian ceramics from the

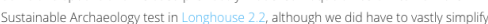
the students models for the gaming environment

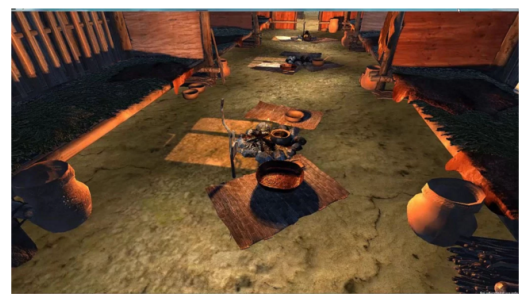

One of the major issues we encountered was the complexity and detal we had been adding into the environment. There has been a lot of thought and detail put into every play would not be compromised, but it was clear with the test we did at Heritage Toronte that some creative "faking" will need to happen so as to speed things up virtually. This fakkng method would be to use texture maps instead of modes for hhings such as bark cordagertope, using more prefendered complex mages and greatly reducing the

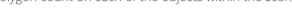

Appendix A 81: Longhouse 3.5.5 page B 


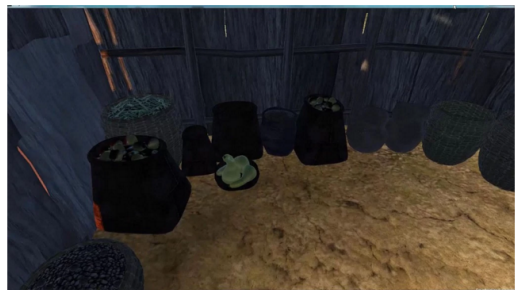

Another observation was with the outside bark shingles. They look bright and new and it's likely that vast amounts of moss and other errant plant material would be growing on the sides, edges and tops of the longhouse. Rotting of some sort would have taken ro
as well with the shingles itself and I suspect there would he discolouration due to

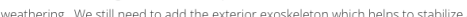
support the shingles

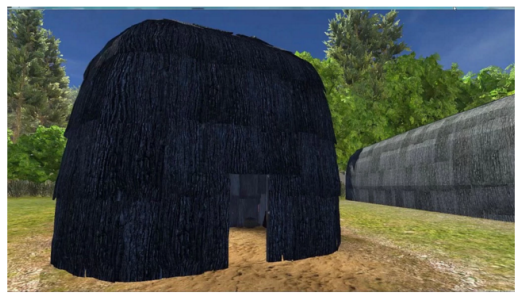

This test marks a major stage in the research. We are fairly close to the final product an will likely be spending the nexc month or so cleaning up the assets, increasing the speed of the virtual interaction and hopefully providing some user abilities at least in this substantally, As an artist, crave the hypercal fully rendered images and sequences bu parch needed and thus that hyperreal look becomes more stylized.

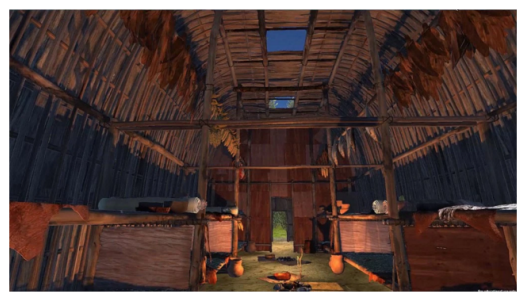

I would encourage our weekly readers to post comments or send questions through email. This is how we are learning about new theories, methods and perspectives which and

If you are in Miricand Ontari this weekend, don't forget to attend the Ontario Archaeology Societies Symposium - Lircles of Interaction! The Wendat and ther

(herest

Michael

Appendix A 82: Longhouse 3.5.5 page $C$ 
Share this:

- 0 용

Redatas

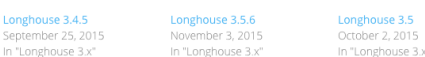

Trackbacks/Pingbacks

nated visual walkthrough of the longho se a

12. onghouse 35.8 - theskonlworks - [] to "kick off" the project and only really connected

Leave a Reply

Designed by Elegant Themes | Powered by WordPress

Appendix A 83: Longhouse 3.5.5 page D 


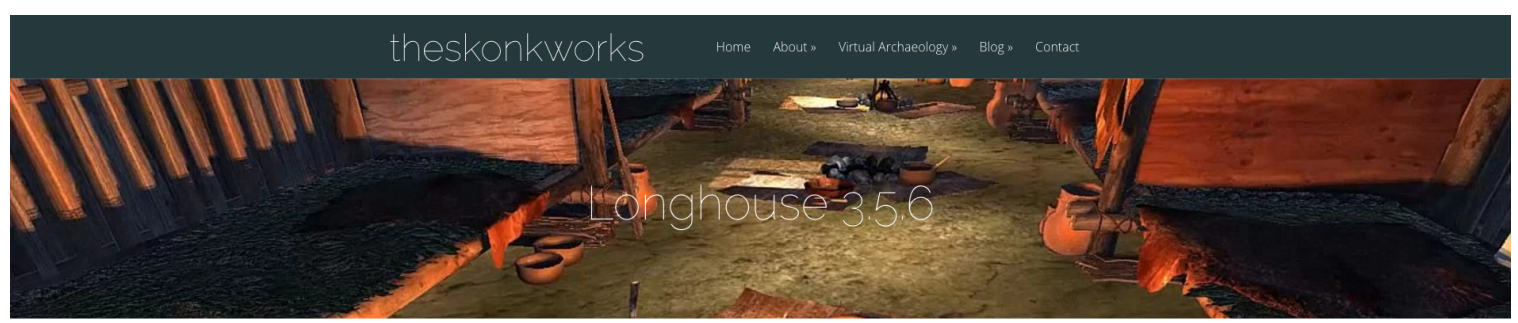

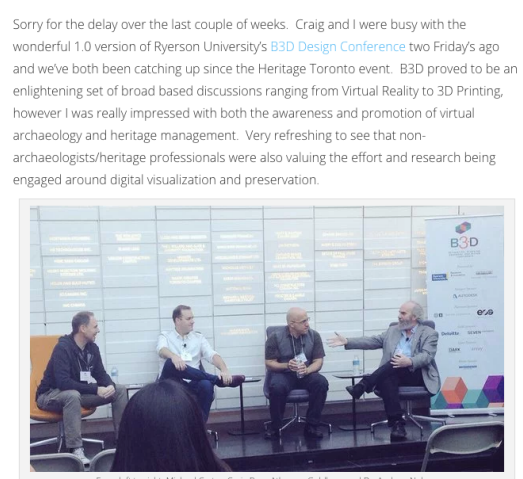

Our session with Athomas Goldterg, Dr. Andrew Nelson and Craig Barr opened up the conference. Craig and 1 were lucky to be able to present one after the other, so that gave me time to talk about the main theoretical themes of the London Charter; Agen Authority, Authentutity and Transparency as it applied to our project and the large considerations tor visualization of heritage objects. This helped to frame further discussions during the day when we got into 3D printing and visual representation Athomas, who has been very active on the gaming engine scene for over 18 years presented some of the real-time interactive work he did for the"s'

Adan"'Lombardo's "Adam"exhibition at the MET, Andrew takked about his extensine research into the use of 3D scanning of Mummonys and other recent fine detalled objects The notion of "agency" loomed big over our discussion with the audience and the "authenticity" of the 3D scans. Overall, the session proved as a great starting point for as of late.

During the conferencel had been thinking of Paul Reilly, the "father of virtual archaeology", and his latest work enttled Additive Archaeology. An Alternative Framemork for

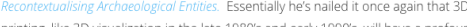
effect on how heritage is not only researched but presened. That our ability to understand the archaeological record through the use of additive manufacturing woul extend not only research, but public engagement.

Ive railed against our misguided notion that digital media will solve everything for years My students seemer bemused that lve spent so much of my career dealing with digts media, that I'm still harking back to the necessity to have some sort of physical materia record for future generations, to discover and research. The digital world disintegrates so there also needs to be a material copy in order to ensure a record of some sort Getting back to Pau's paper, I realized while sitting through the 330 conference that our Longhouse 3.x would also need more than a digtal representation. Conference papers and book chapters, if deemed worthy research, is one way to enable some preservation However, should we also 3D print Longhouse $3 . x$ so that a physical model of the research exists? If we print the model, is it an artefact? If so, should it be housed within Sustanable Archaeology along with the other Southwestern Ontario archaeological material? Is there a London Charter 3.0 in which we need to include 3D printing as a means to make physical, our virtual archaeology'

In an effort toremant ransparent during all stages ar me project, have provided below my B3D presentation enutued Virtual Arch dealogy, Virtual Longhouses and "ENvisioning the Unseen" within the Arthueolughtar Record. The audente at he conterence was abroadmx of specialists and knowledge experts, so the presentation reflects this. As discussed, ralg and broke our presentation out into theory and methodology.

Appendix A 84: Longhouse 3.5.6 page A
Subscribe

keep up to date by subscribing

Join 18 other subscribers

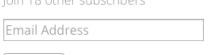

Subscribe

\section{Recent Research Posts}

Longhouse 3.5 .5

My third draft PhD Propos:

onghouse 35 

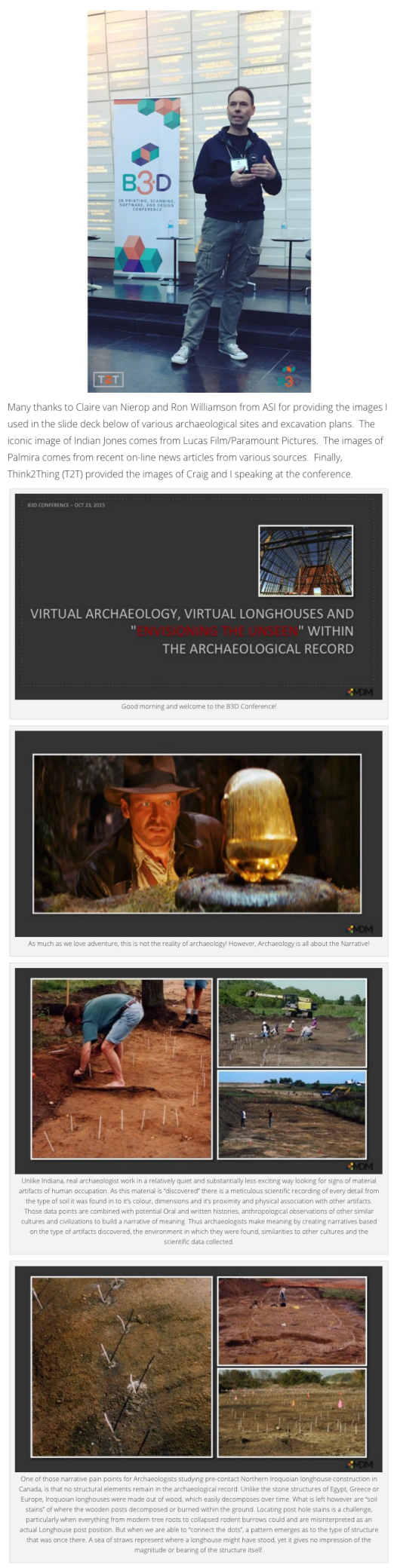

Appendix A 85: Longhouse 3.5.6 page B 

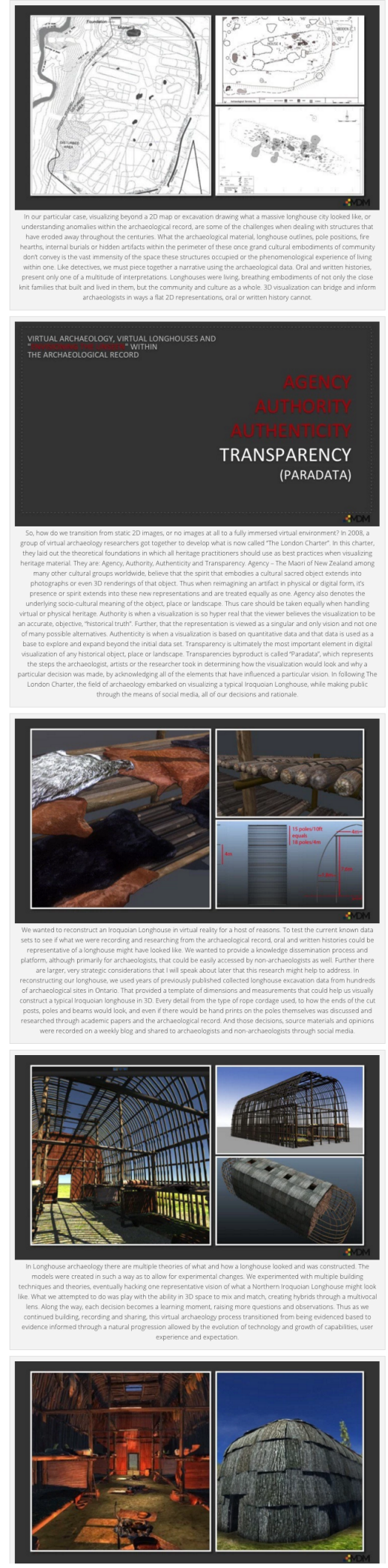

Appendix A 86: Longhouse 3.5.6 page C 

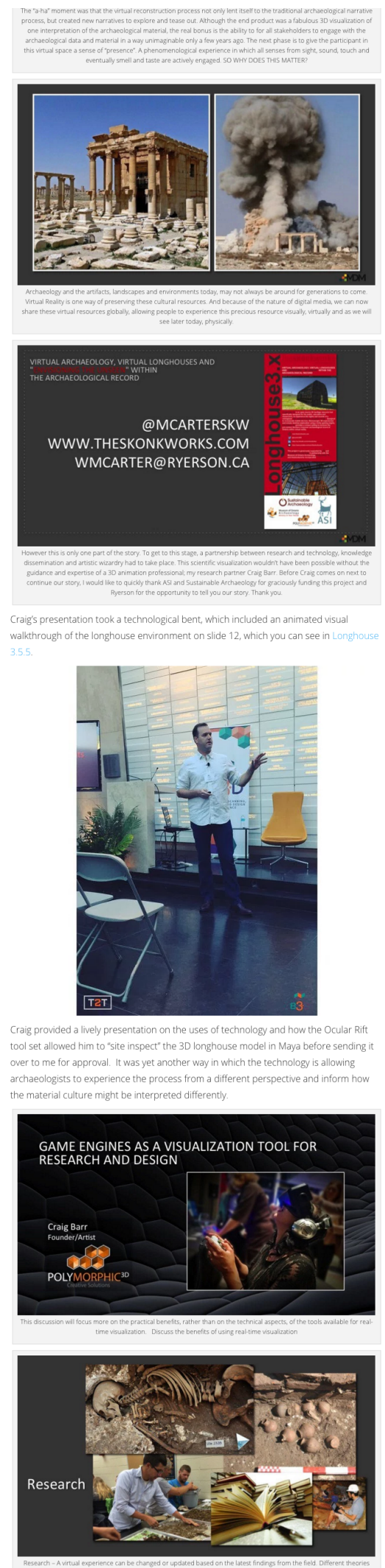

Appendix A 87: Longhouse 3.5.6 page D 

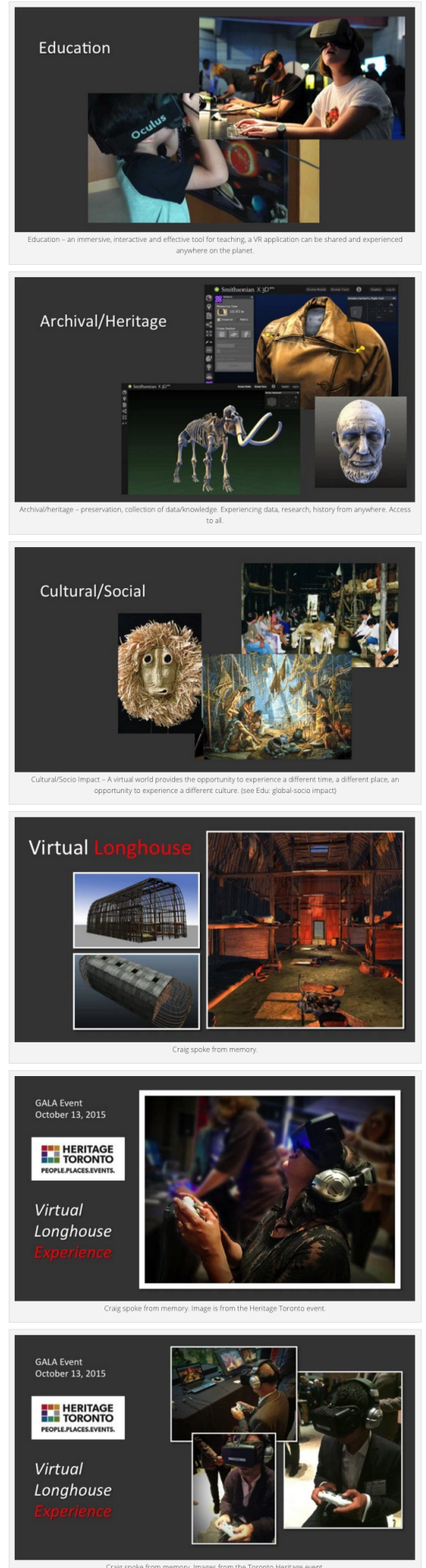

Appendix A 88: Longhouse 3.5.6 page $E$ 

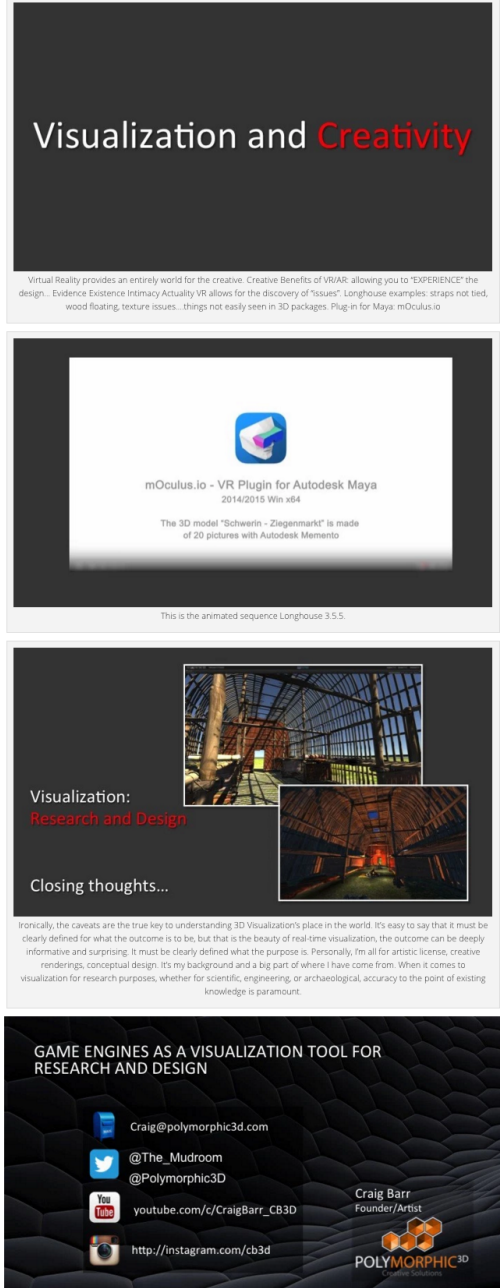

Thope by providing the silde decks of our presentation that we can transparentily demonstrate how the research is being discussed. By now means is this work finished, but it provides a unique opportunity to see the progression in not only our own thinking. but how the material is also leading into new areas of thought. As always, comments are weterned and encourgat

Cheers,

Michael

Share tisis

$\overline{\text { Related }}$ 


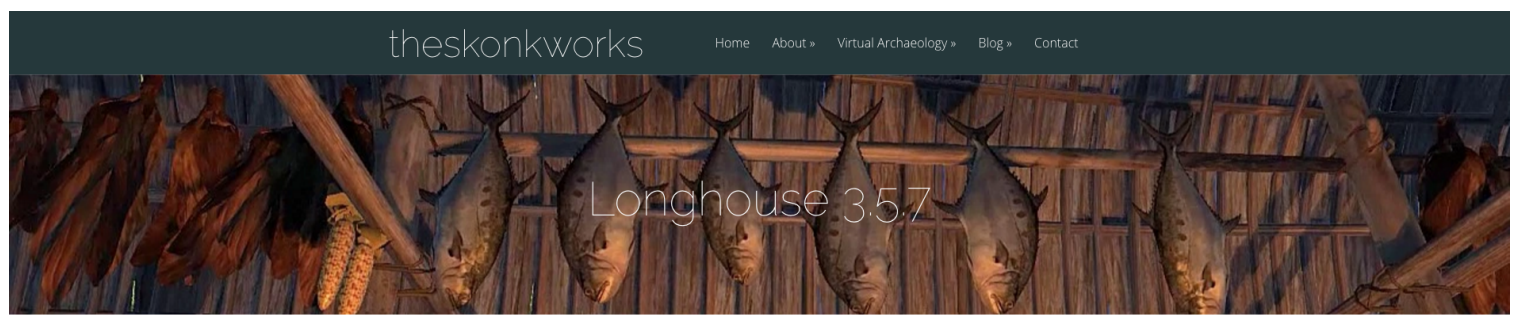

Today's post is really a brain dump of the last four weeks of virtual archaeology theoretical reading Ive been doing and the practical application of the Lin 3 x project. The project itself is going along swimmingly but into the tough phase of honing down the assets so users can run through the experience in real time and with a variety of machine speeds. Athough "polygon count" is always an issue with producing 3D assets for gaming the focus has bee on proving a higherleve of athenticity to the overall virtual experience in retrospect we probably added too much cultural historical detail which has slowed real time play dowa considerably. Toxture maps also pose a problet as the mare comolex and higher resolution they are the more memory fike the 3 D. models) that has to be cached Thus, there has been the painful decision to reduce the visual quality or to take certain asset farteres out norder to retain $\mathrm{z}$ high hevel of interactive play in doing 50 we are altering one set of experiences in order for annthe to take greater presence within the virtual environment

However, this wasn't the negotiated process I had hoped for when we started out. Ideally I wanted to challenge the notion that virtual archaedogy was justa a smokescreen for nor archaeologists to make "pretty pictures". That the project would be evidence based and reflective of a strong scientific methodology. Working with the material however, whether virtual or not, atters your perception of what the term accurate or evidence based really means. Tim Ingold's book Being Alive, which I've just recently reread (and i f you are interested, here is reprint of a theory poper i wrote on Woyjaring in virtual spoce), stresses the material over the materiality of things (2011). The material shapes our way of knowing and in the process of working the material we gain ins ght into all of the artistic, technical and cultural factors involved in the cultural object being created. However, the materials properties, may it be wood, clay or $3 \mathrm{D}$ polyg gons, still trumps all cultural intentions that have gene into the creation of it. Eventually the material will pnce again deminate the materiality of the object in question and as in Iroquoian longhouses. will return it from the envronment in which it came.

Ive been mincful not to use the words accurate or authentic as the project has progressed. Archaeologists make meaning from the artificts, landscapes an environments they study. In doing so they are creating their own interpretations of what the cultural material means, drawing upon personal knowledge creation, other stakeholder knowledge and opinions trom experts such as Historlans, Anthropologiss

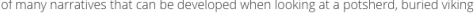
hoards on onghouse pustmold stain'. Readily ladmit that havent reached out io Decedent stakeholders, experimental arch aeologists or other non-Iroquoian built hentage specialists to garner opinion or guidance. I wanted this process to be my interpretation of the archaeological record, oral and written histories. But as you work with the material more, coming across technica, creative or research mater ial limitations there is a negotiated process that kicks in, forcing you to make tough decisions that takes you furth

Ingold considers these "course corrections" as part of the symbiotic relationship between the prantitioner tool and material (2011) Each movement whether deliherate or not is part of the larger holistic process of creating and is thus valid from a theoretical. perspective. In essence my struggies as both an artist and a researcher is part and parcel of larger narrative that Ingold speaks of and that our virtual longhouse embodies. Lately I have been having difficulty as an artist choosing between the two types of visu experiences that this project has created. On the one hand, the virtual real time experience of a gaming environment allows for those phenomenological experiences to play out more readily. On the other, the still or sequenced, highly manicured rendered

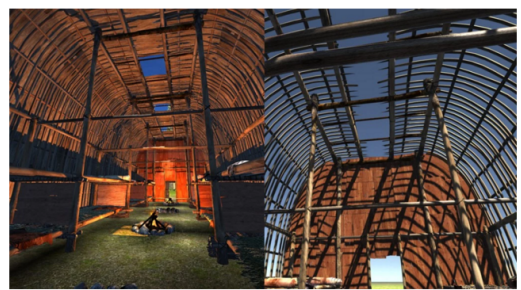

Ont the tert in the mage above is a streen On the right is a high resolution and rendered version of the $3 \mathrm{D}$ assets. The rendering on the right has ighting that is obviously more effective and the textures are more vibrant. You can almost imagine being nght in a real-nife environment. Whereas the game quality version, clearly sets up our expectation that this expenience will be representative but not quite realistic
Subscribe

Kubscribe
kelow!

Jetion: 18 other subserchers

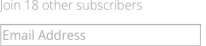

Subscribe

Recent Research Posts

Longhouse 3.5.

My third draft PhiD Proposa

Longhouse 3.57

Ingold \& Wayfaring from a Digita
Perspective

Appendix A 90: Longhouse 3.5.7 page A 


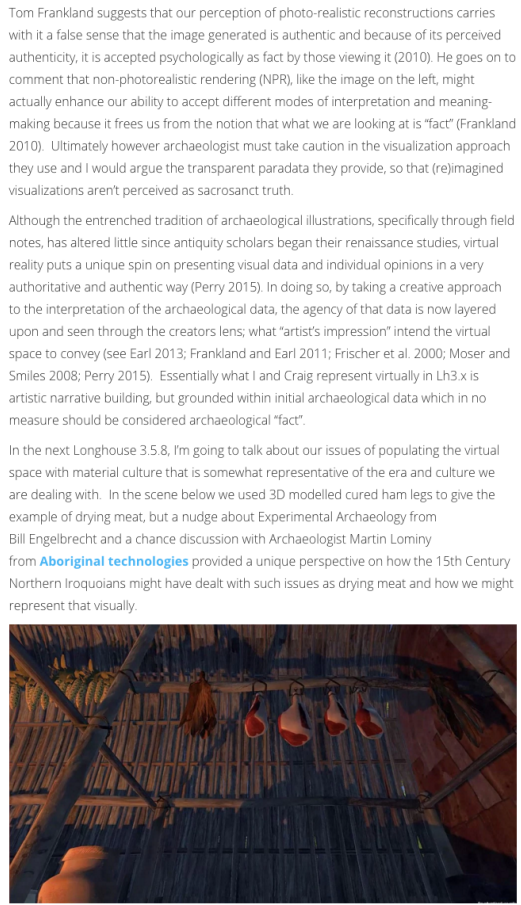

Works Cited:

Frankland, T.

2010 A $C G$ artist's impression. denicting virtual reconstructions using non-photoreal stit rendering techniques In Thinking Beyond the Tool: Archaeological Computing and the Interpretative Process, edited by Angeliki Chyssanthi. Partricia Murrieta.Flores, and Constantinos Papadopoulos. Archaeopress, Oxford, UK. November 11

Frankland, Tom, and Graeme Eart

2011 Authonty and authenticity in future archaeological visualisation. Original Citation:

Frischer, Bernard Franco Niccolucci Nick Ryan, and Juan Barcelo

2000 From CVR to CVRO- The Past, Present, and Future of Cultural Virtual Reality VAST

Conference on Virtual reality, Archeology, and Cultural Heritage, Arezzo, Italy:(November)

$1-12$

Appendix A 91: Longhouse 3.5.7 page B 
Huggett,

2012 What lies beneath lifting the lid on archaeological computing In Thinking Beyond

the Tool: Archaeological Computing and the Interpretative Process, edited by A.

Chrysanthi, P. Murrietta, Fores, and C. Papadopoulos, pp. 204-214. Archeopress.

Ingold, Tim

2011 Being Alve: Essays on Movement, Knowledge and Description. Taylor \& Francis

Moser, Stephanie, and Sam Smiles

2008 Introduction: The Image in Question. In Envisioning the Past: Archaeology and the

Image, pp. 1-12. Blackwell Publishing Ltd, Oxford, UK.

Perry, Sara

2015 Crafting knowledge with (digtal) visual media in archaeology In Material Evidence

Learning from archaeol ogical practice, edited by R Chapman and A wyle, pp 189-270

utledge, New York and London.

$-00$

Related

Langhouse 2.2
june 4, 2015

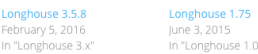

Leave a Reply

Appendix A 92: Longhouse 3.5.7 page C 

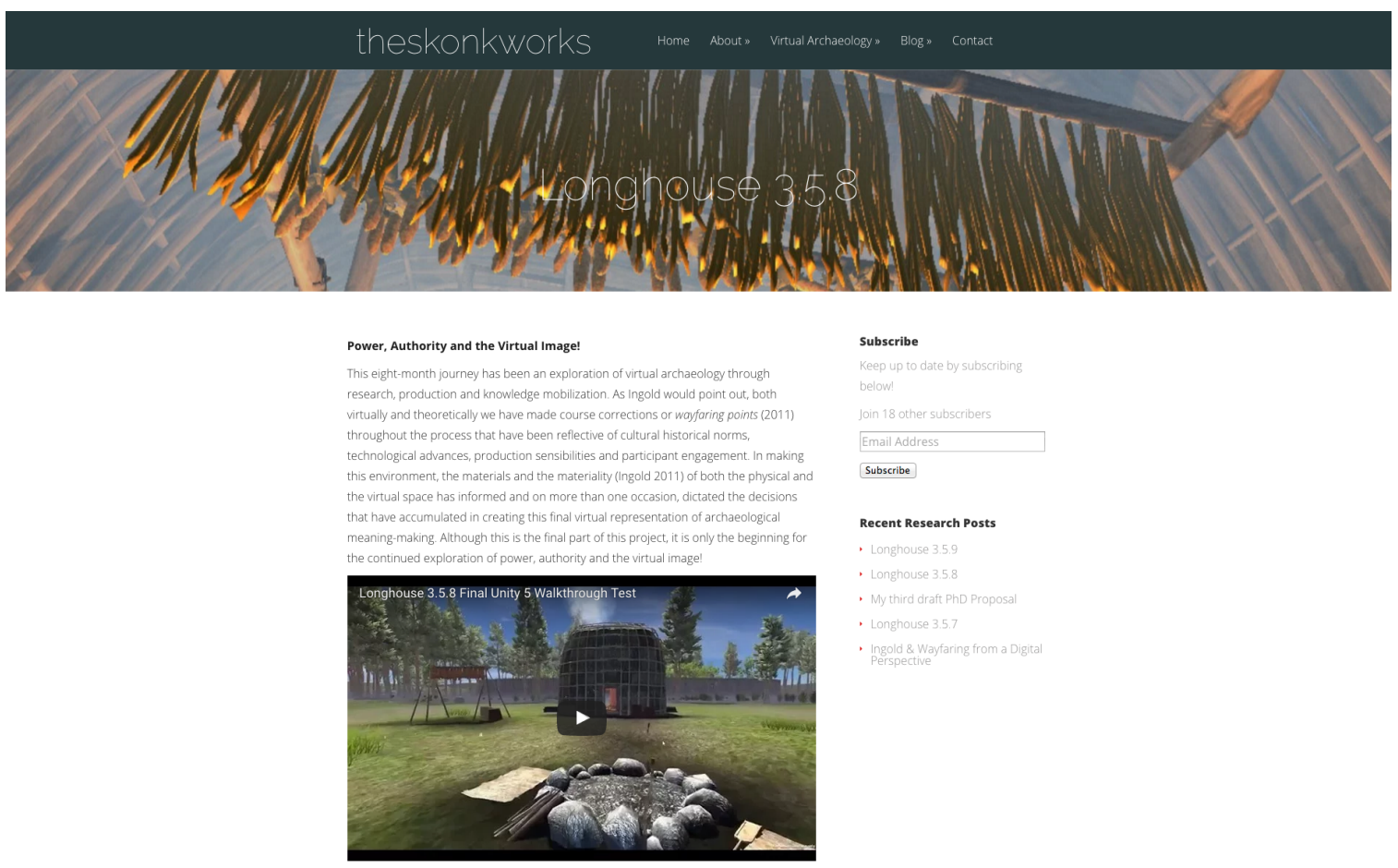

Subscribe

hin 18 nther subserribers

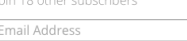

Subscribe

Recent Research Posts

Longhouse 3.5.

Langhouse 3.5

My third draft PhD Proposal

ngeld \& Wayfaring from a Digitc

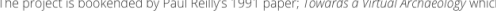
$\mid$ read in 1992 and which inspired me to attend computer animation school and Dawson.

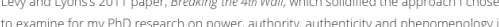
virtual reality

In 2011 virtual reality was still grounded with the notion that large, physical, very expensive immersive clomes, as the only viable ont ion for an authentic experiential virtual experience My own predilection based on years of beng in the animation business was a more cinematographic film-like anornach However in the summer of 2012 a chance cpportunity to port our initial 30 longhouse assets into an Unreal game engine and another change opportunity to have a group of High School students plaj with the test game envirente deploying our longhouse research within a gaming envronment was the ided

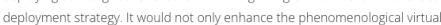
experience but would be on a plat archaed goists would be comfortable in using with litte or no traing it also provided an aponity to democratize the researchin an easy deployable manner.

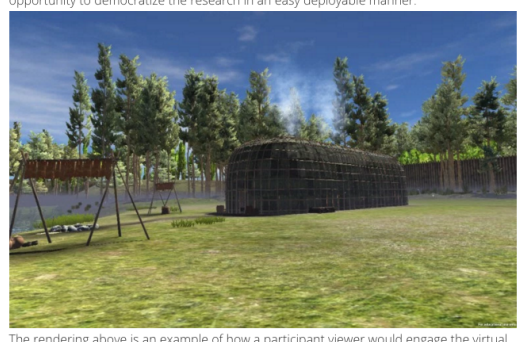

The rendering a hove is an example of how a participant viewer would engage the virtual experience in Oculus Riff or through normal projection within the virtual environment The assets were first built in Autodesk Maya along with any additional objects or environment texture mass. These assets were then ported into Unity5 and assembled into a 30 representative environment where basic interaction controls such as walkin head movement, jump, crouch, and direction were added in add tion, Unity 5 provided the ability to add additional enurrenmetrics such as smoke, dust, water, fire, localized sound and most importanty, interactive lighting

Informed by pubic proiect blog participants some inmediate modeling and texture mag changes where made to better represent their perceived vision of longhouse architecture use and asset placement Adilustments were made within Unity5 on some elements with the reduction of texurue maps and modelled objects for lower resolution to increase user interaction. Some animated visual effects such as smoke, were reduced to their simplest forms to give the impression of the effect without loosing screen refres provide the best visual possible with the less impact on interactivity

Appendix A 93: Longhouse 3.5.8 page A 

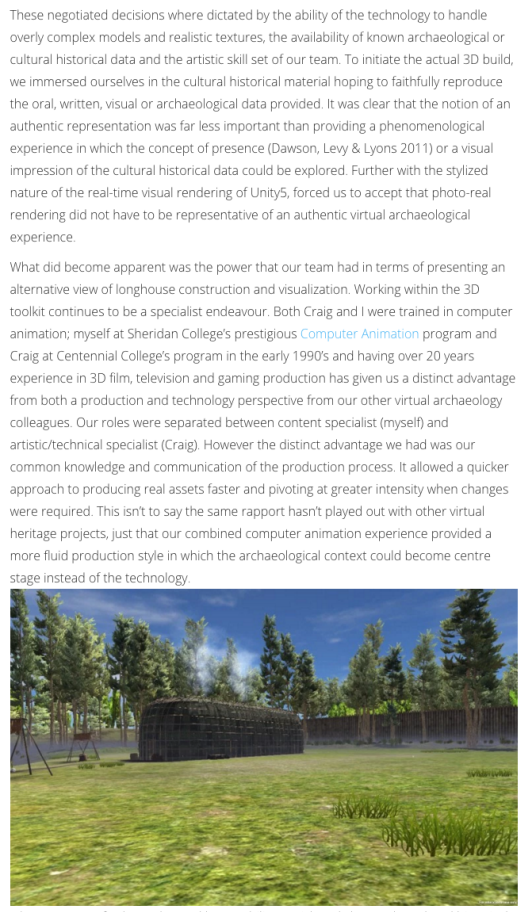

The power was further enhanced by my ability to pick and choose the cultural historical data I wanted to mpesent an potential lower bunk height within Iroquois longhouses (1997) I chose to take his interpretation and that of the potentia use of bark shingles tor the delineation of interio

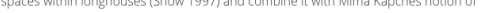
bent arbour construction methodology (1994) (see Longhouse 1.5). I then used JV Wright's notion of wood types and material use to develop our (re)limagination of an Iroquoian longhouse What has resulted is a "mashup" of cultural historical opinions that hope in the future to provide researchers with the abulity to pick and choose in 3D and

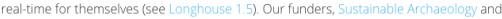
A5. were consulted when data was unavailable and both Neal Ferris and Ron William son's years of practical knowledge helped to inform how certain elements should or could be represented visually,

As Craig and I worked remotely, all of our communication was through email, SKYPE or when necessary, by telephone. We met for lunch at the beginning to "kick off" the project and only really connected in person when we tested the prototype Longhouse 3.5 .5 at the Heritage Toronto event almost 5 months later Production was really dictated by Craig's avalalability which in hindsight proved to he beneficial in allowing longer reflective time soans between revisions Participant viewers were given the chance to reffect and respond to the direction and decisions I was making through the blog or personal communication, which then gave me the opportunity to better inform the revision process with Craig. Craig a lso plaved an important role throughout the project in raising concerns, observations and making alternative suggestions to the data and the direction

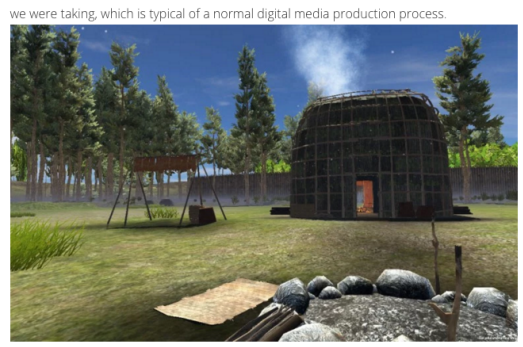

We chose to establish to frame the initial visul experience when the garme begins as a traditional mid-ground establishing perspective shot. I wanted users to take in the discuscions with Neal Ferris on the archoelogicel data regarding positioning of individ

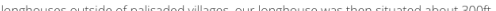

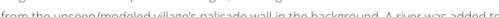
simulate a typical reliance on readily available water for daily use and strategic ra

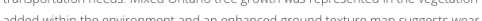
ardech

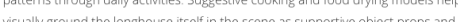

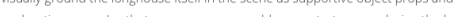
exploraton areas. Lasty, to ensure uses would concentrate on exploring the longno

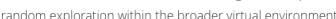

Appendix A 94: Longhouse 3.5.8 page B 


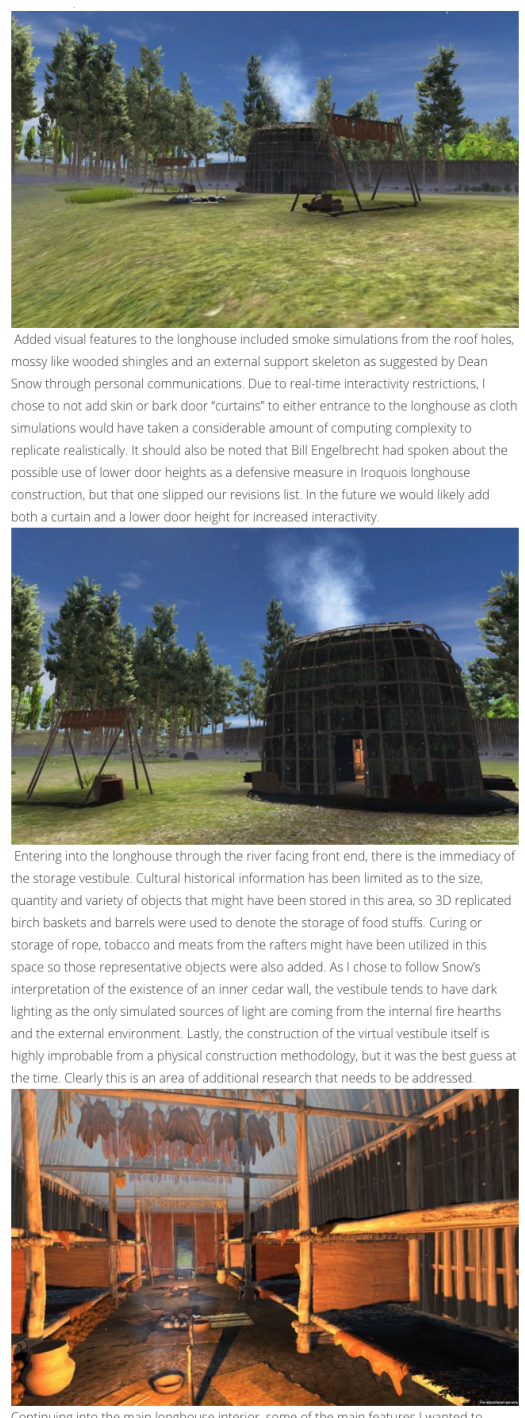

emphasize was the potential individual bunking system, hearth placements and the lay emphasize was the potential individual bunking system, hearth placements and the layer

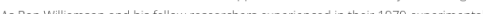
archaeology longhouse stay, constant internal hearth fires and external weather conditions would have kept a substantal amount of smoke within the upper rafters.

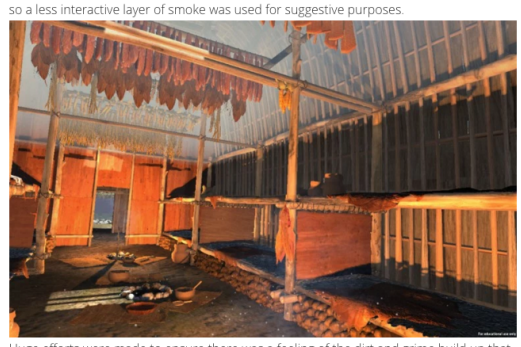

Huge efforts were made to ensure there was a feeling of the dirt and grime build up that normal communal livng would have produced. Athough not readily seen in the rendered version above, finger prints were added to the surfaces of the poles and posts te cent surface to suggest that the bark which was a maipr construction and utility resource. would have beenimmediately havested during construction Addition l dit splater was

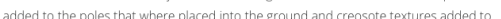

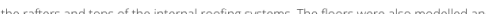
textured to represent a dirt surface along with wear parterns in the normal traffic spots

\section{Appendix A 95: Longhouse 3.5.8 page $C$}




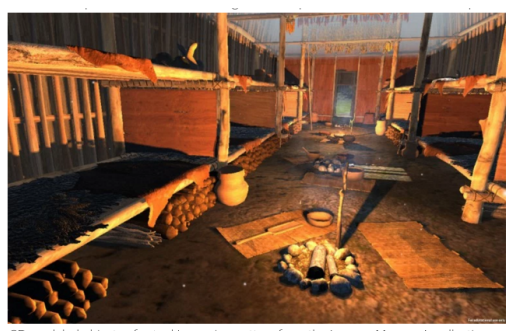

were added throughout the space These objects were lower resolution versions of

actual 30 scans conducted at Sustainable Archaeology and are representative of the

utensils were modelled from suggestive modern reproductions of rroquioian goods. Reed

mats, furs and cedar bough bedding and stor age of wood and other items under the

bunks are suggestive and as with all of the material inhabiting the virtual space, meant to

be points for discussion rather than de facto representations of authenticity

The fire hearths were very important to represent effectively as they would have played a

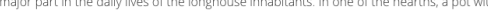
boviling liquid is active and everyything from the burning wood texture maps, to the representation of ash was considered. The addition of the sound of burning wood ws

added along with the occasional flying ember and smoke streams to create a

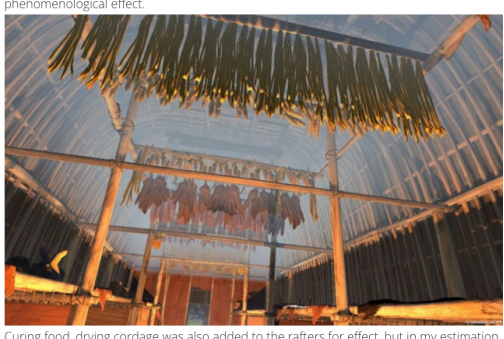

uring food, drying cordage was also added to the rafteris or effect, but in my estimatio ajan this was primaly de to the conputationat issues of representing a substartiat amount of detail within a real-time game engine.

A substantial amount of time was spent trning to be informed by whatever cultural

iistorical data we could find. At times a negotiated process occurred where we wanted to visually suggest a detail or feature but really had no description to go mith. This mirrored the internal issues of the reality of rougurian longhouse ar chaeology, nobody really stains that sunwive in the archasological record

he use of a gamining medium has greatly improved our research capability. It democratizes the research material, provides a unique opportunily to interact with a virtual environment and provides a real-time engine that can be retuned for a variety of hardware applications. Although in our study the use of the game engine has been

strictly for the ability to freely explore the archaeological environment, it doesnt have an, real interattve game play. The next phase would be to determine what if any interactivity should be implemented. Further discussion between stylistic and photorealistic rendering needs to be fully researched especially in terms of perceived authenticity, but
feel this initial visualization provides a perfect launching pad for further investigation.

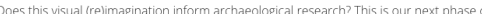
the reserd To der The archaeological material. Can virtual reaility allow for the exchange of ideas, the remodelling of perceived meaning-making or even just to inform the possibility of new

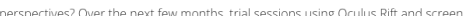
hased play will occur with archaeologists and heritage professionals. The actual Longhouse 3.x Unity 5 game module will be made public but through the auspices of Sustainable Archaeology as our commitment to open source research, immediately. following our inteniem

want to thank Cralg Barr or his dedication, artistic and tectricical skill in delvering my funders, Sustanable Archaeology, ASl and the Museum of Ontano Archaedogy for their

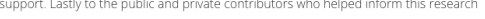
and provided encouragement and support

Continue to monitor this production website for updates as we move into the next phas If research As aways fea tree to a awe comments to this blog or contact me arrectyon anything you feel we could have done differenty

Cheers

Michae

References

Dawson, P., R. Lewy, and N. Lyons

knowledge Repatriation in

Archaeology. Journal of Social Archaeology 11(3): 387-402

Ingold Tin

2011 Being Alive: Essays on Movement. Knowledge and Description. Taylor \& Francis

Kapches. N

Agrthe roquian longhouse architectural and cultural identity Meaningfil

Archetcresocal interpretations of Buld dings, 9, 25

Appendix A 96: Longhouse 3.5.8 page D 


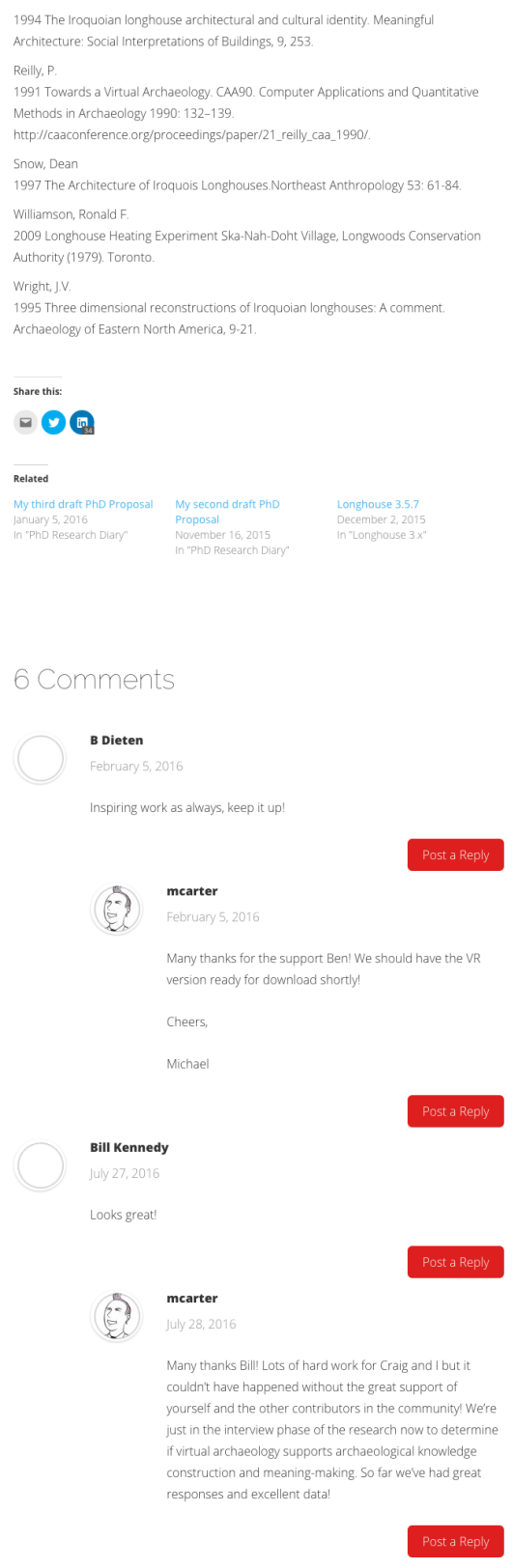

Appendix A 97: Longhouse 3.5.8 page E 
Dean Snow

We live in an era in which the younger you are the higher your expectations

are in VR. I am old enough to appreciate how much work was involved in

the produ

(6) mcarter

Post a Reply

I want to thank you Dean for your kind words and sunport A huge part of this project was the visualization of your extensive research into longhouse construction and use. Ou cheors

Michael

Post a Reply

Appendix A 98: Longhouse 3.5.8 page $F$ 


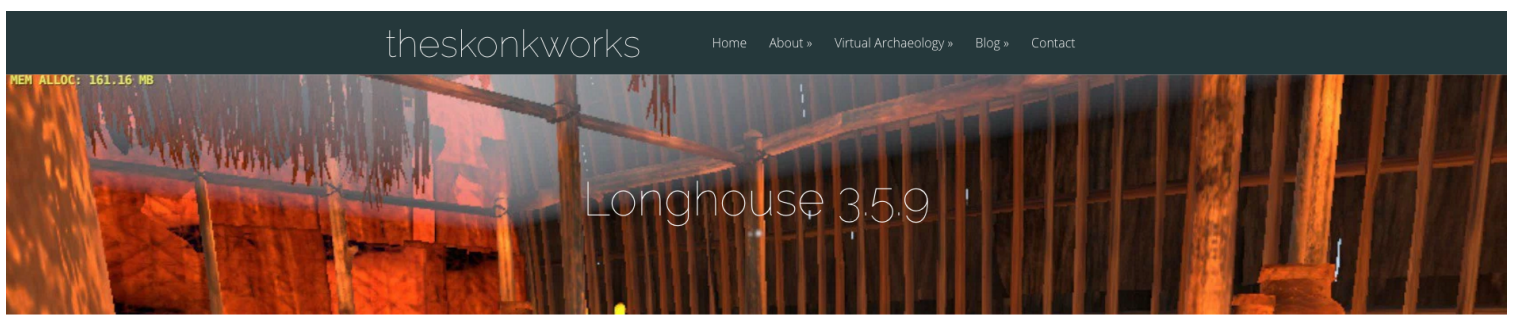

It has been a bit since my last post In that time I have been writing my dissertation and conducting interviews on how archaeolopists react to immersive and non-immersive representations of virtual archaeological data. It's been a year since we started Lh3.x and in that time technology as always has edipsed the originally intended platform. Lh3 $\mathrm{x}$ was built using Autodesk Maya built assets imported into Unity 4.5-5 and then with some additional modelling and texture mapping changes within Unity. Ayear ago the only immersive virtual plattorm we felt could hand

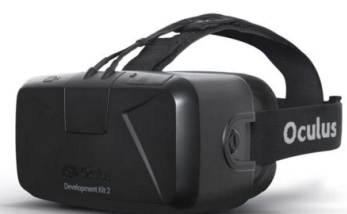

However as the assets came together in Unity towards February, I noticed that there wa considerable issues with frame rate latency within the DK2. A substantial portion of people are unable to use VR headgear due to the frame rate issues, including myself in spent more than 2 min's with the DK2 on, I felt immediately sick So I was stuck with

developing an environnent in which I was unable to participate and quite possibly could cause others issues as well. At the time however, Google Cardboard would have beer uncuitale for the level of detail we were attempting and the HTCVive still hadn't acrived 50 it was decided to continue along a DK2 path. We did try to accuire the commercial

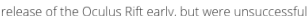

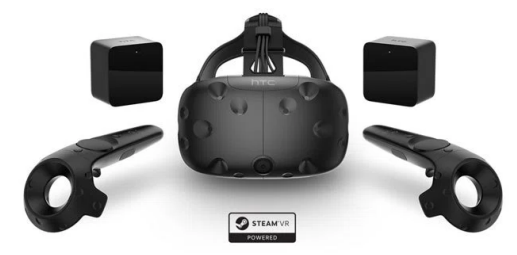

Sustainable Archaeology (5A) had early access to the new HTCVive and atthough the hacking an HTCVve version of Lh $3 x$. Even with the hack, it was clear that the new technology was far superior to what the DK2 was providing. Having a discussion with Craig Barr, who was the key technical partner on this project, it was decided that we would attempt to convert the OR Unity version of Lh3.x into an HTCVive version. Craig had his own HTCUve system so he was able to rapidly test what worked and what diant the OR Unity version over to the HTCVive envirnoto port a large portion of What we had in two hand controllers and two motion sensors. The DK2 requires a single motion sensor Ito detect head mor
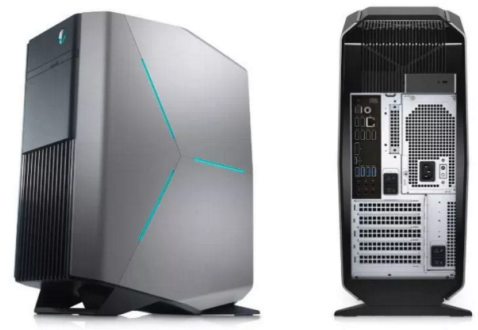
Interviews, we have been using a Alenware Auroras whth an Nudia 970 graphics

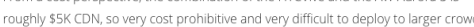
Unike the AW Laptop and DK2 setup we used previously, the HTCVive also required more time and equipment to setup.
Subscribe

e by subscribin

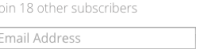

sibcriber

Recent Research Posts

Longhouse 3.5 .

My third draft PhD Propos t

Longhouse 3.5 


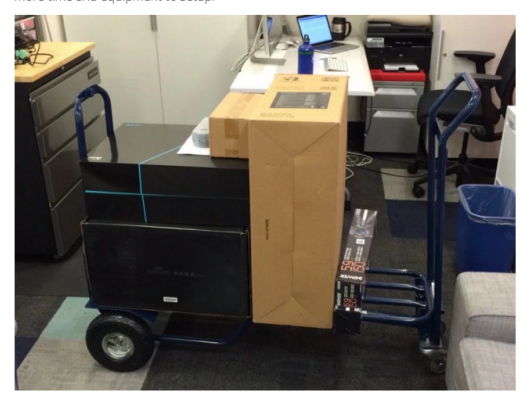

As you can see, just to setup the environment, I needed to bring along the AW Aurora, the trunk' shot of archaeological equi menent going out on a digg, the image belowis

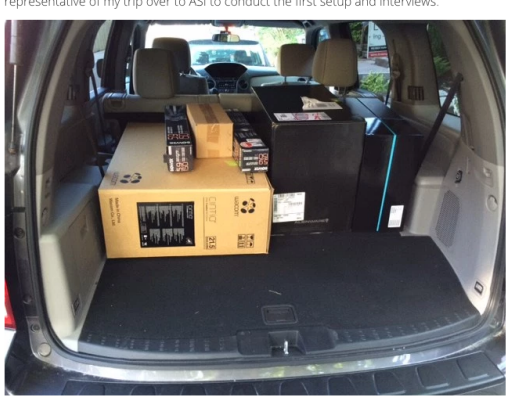

ust getting the equipment into the demonstration space, whether across town or in the ab, was still time consuming Ideally, one should have at least two people to moye

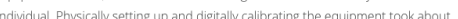
$45 \mathrm{~min}$ 's The HTCVive requires to two sensors elevated above head herent unithe the OR

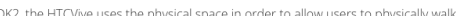

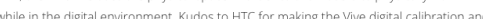

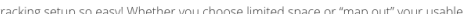

space, both setup procedures are easy and quick

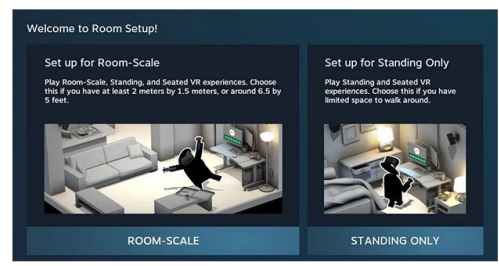

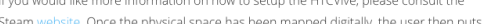
steam webste. Once the physical space has been mapped digitally, the user then puts space and then if controls are pronded within an application, be able to affect objects or allow users to move from section of the digtal environment to another when then physical space ran out. By" teeleporting" this then aliows users to explore throughout the environment and not just the space determined by the room-scale setup

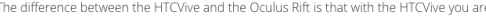
actually engaged The $\mathrm{OR}$ is similar but you are ether stationary standing or sitting and using a game controller to walk within digital space and/or pick up items, which functionality also needs to be programmed. I'm hesitant to use the term "Irmmersive" however, between the two flatforms the HTCVive is a highly physically interactive toolset which can conve,

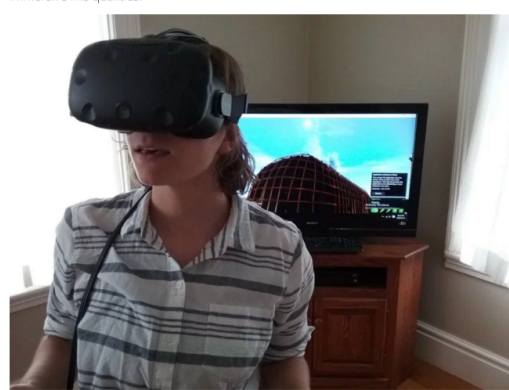

Appendix A 100: Longhouse 3.5.9 page B 
Once the head mounted display is on and the virtual enviranment is activated, users can interact with the environment in the same manner as they would within the physic; environment. Again however, to pickitems up or to affect change within the digtal

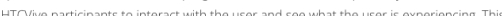
inerention proter virtual space with the user and myset

In Longhouse 4.0, I will be going into depth on the interviews conducted with

archaeologists and heritage professionals as they use the immersive and non-immersive

longhouse experiences. some of the key take-aways trom the internew process have

been; a) users want to interact with the enuronment and are somewhat constrained to

being a passive participant (the Ocul us Story Studio has called this the Swayze Effect,

where you can be within the environment but cannon effect change) b) that us

interactions c) that there is a technological fetish for innovative tools and users have to

go through this stage first before gaining insight into knowledge construction within

virtual space

Stay tuned for the next blog but if you have any questions or comments, please do not

hesitate to post them here!

Cheers,

Michael

Share this:

- 9 요

Related

Longhouse 3.4.5

2 Comments

Ben Van Dieten

Kungust 26, 2016 Keep up the good work Michae! A Aways enjoy reading these updates and
glad to hear the transition to HTC Vive was successful. Fortunately, it seems glad to hear the transition to HTC Vive was successtul. Fortuna
VR capable rigs are becoming less and less cost-prohibitive $\odot$

(3) mcarter

Manythanks Ben!

just tried the new consumer version of Oculus Rift and it is still making me sick. It hink that there must be an issue with the frame rate and peripheral vision that must be causing this. At this point the Vive is definitely the right choice.

With ess expensive head mounted sets, you have to relay on smartphones to drive the experience, which in the end cuts down on the quality of photorealistic or eyen sem. photorealistic images

cheers,

Michael

Appendix A 101: Longhouse 3.5.9 page C 


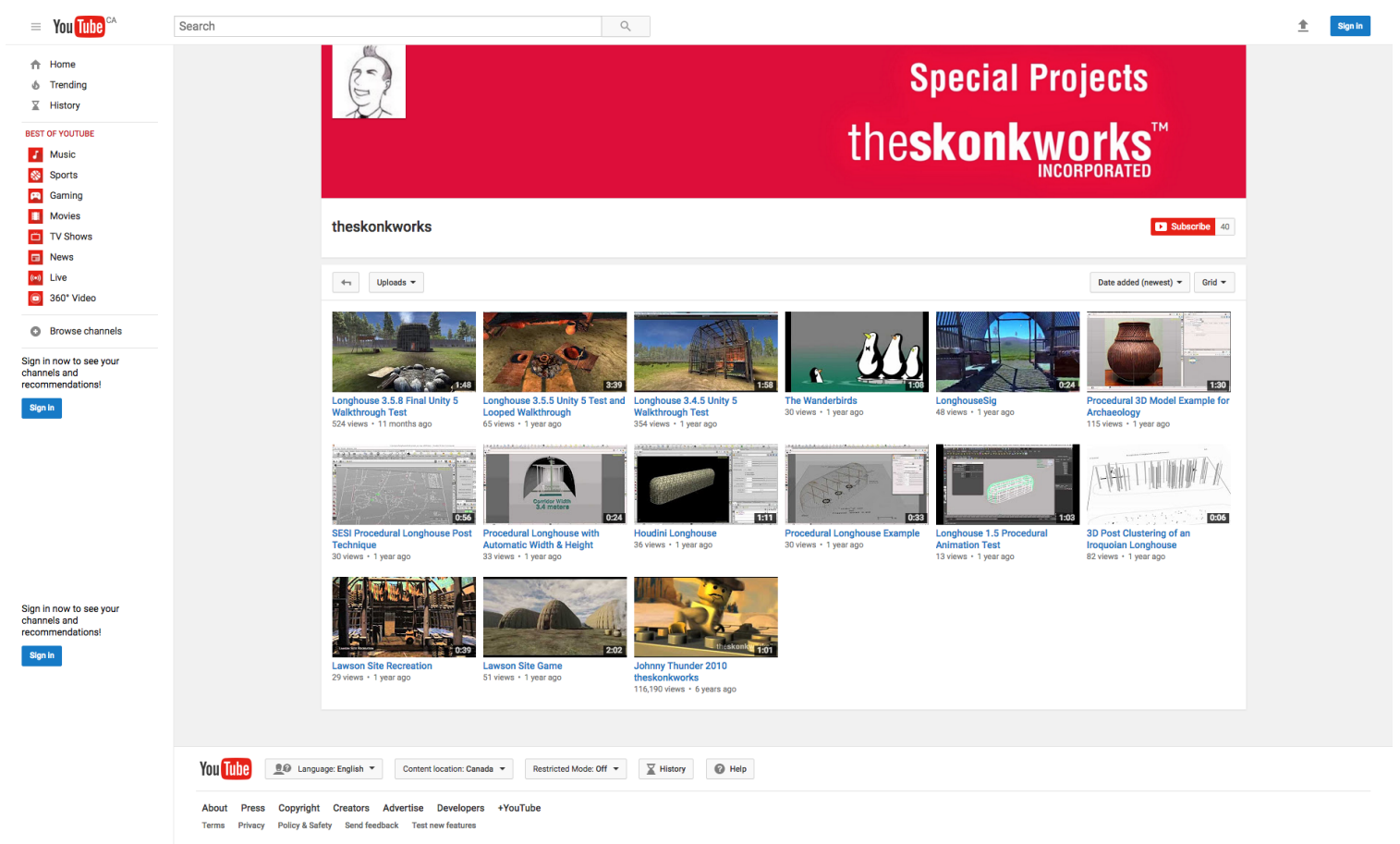

Appendix B 1: YouTube Longhouse Special Projects Index page https://www.youtube.com/user/theskonkworks
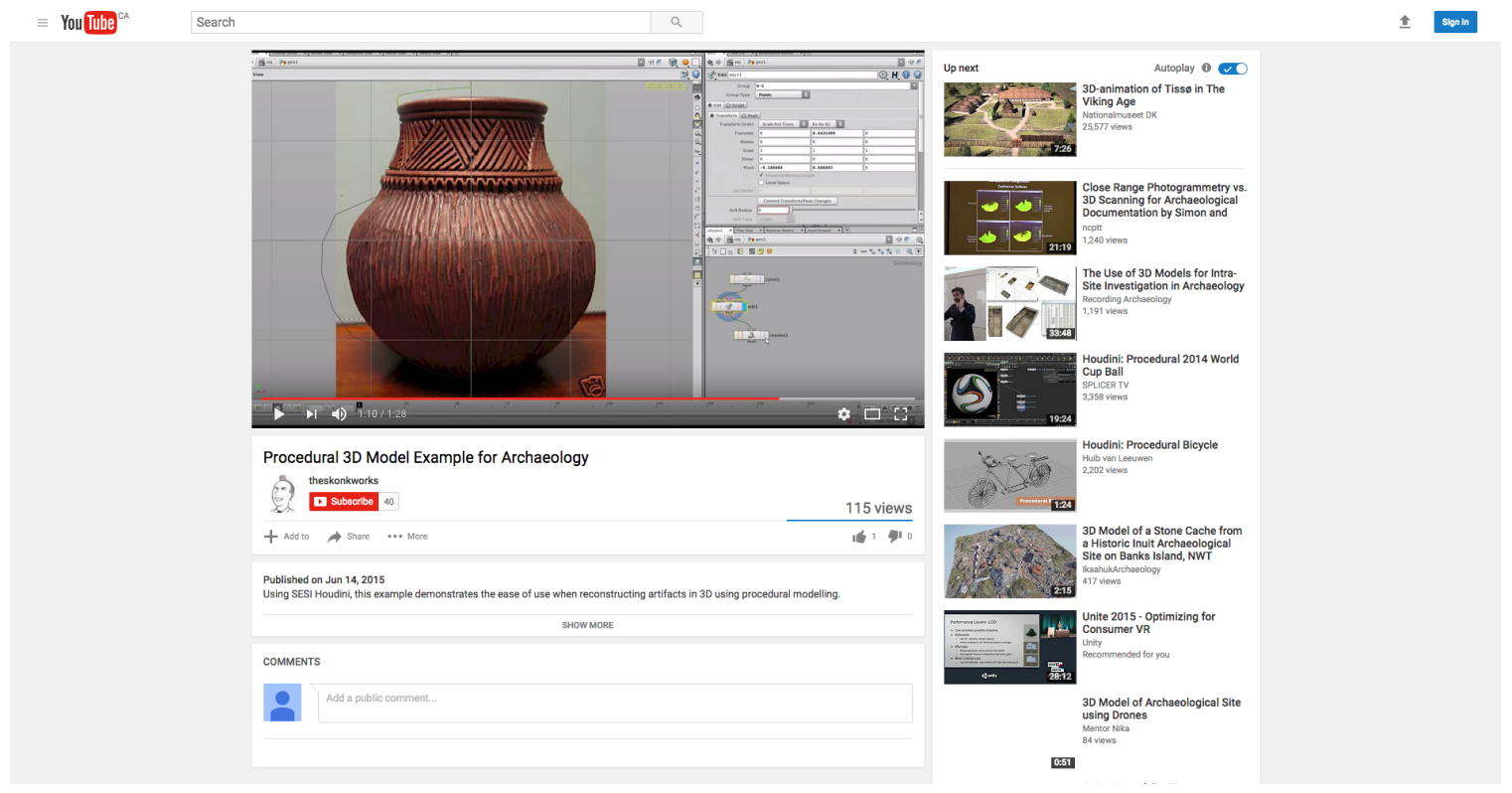

Appendix B 2: Procedural Animation Example - https://youtu.be/C-uZsG-NH4U 

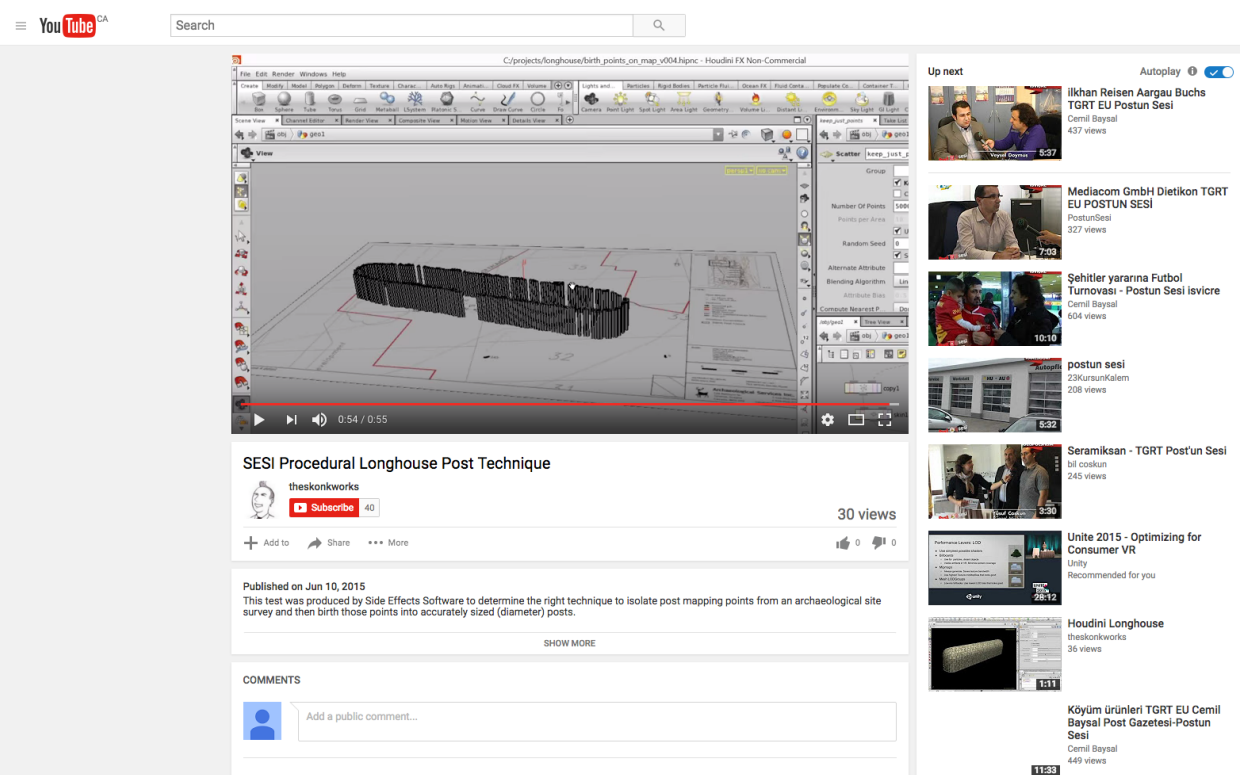

Appendix B 3: Procedural Pole Birthing Test - https://youtu.be/VfBRBLb15wM
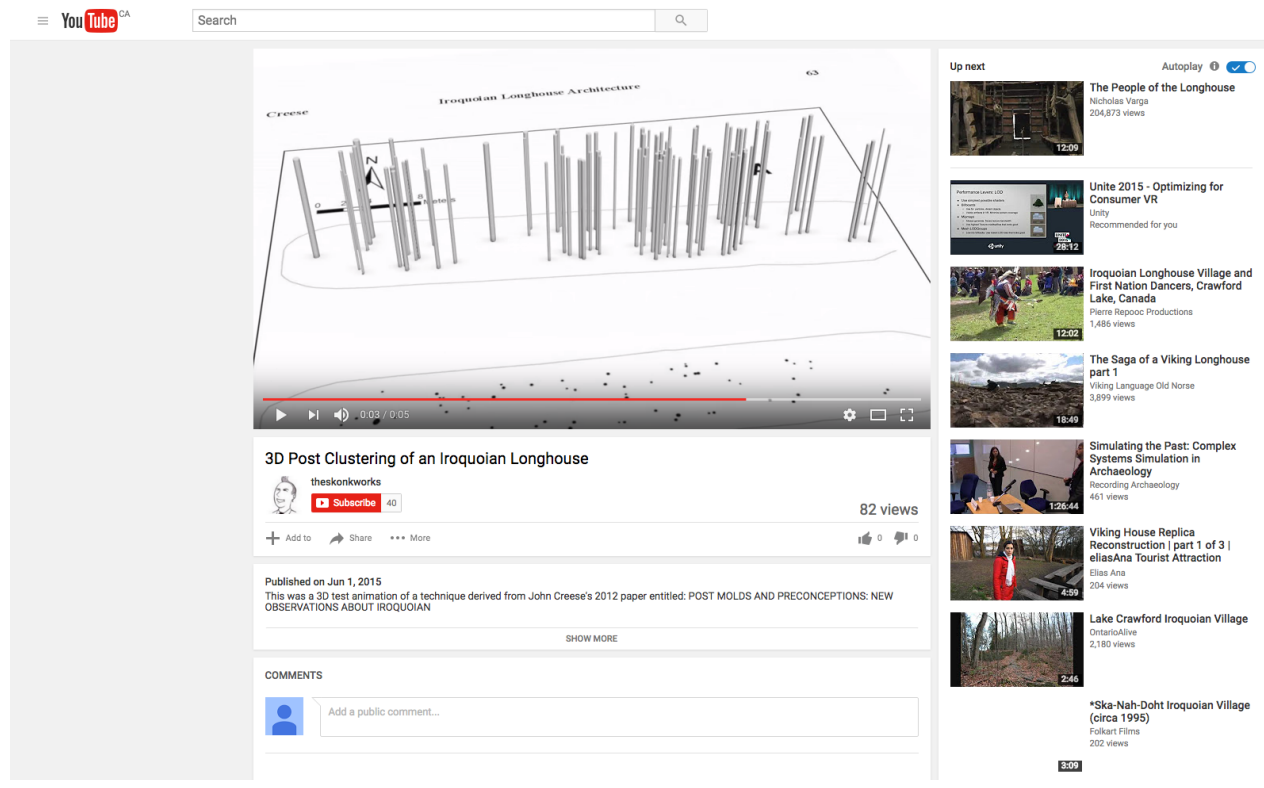

Appendix B 4: Post Clustering Test - https://youtu.be/uRJdWoXVKMY 

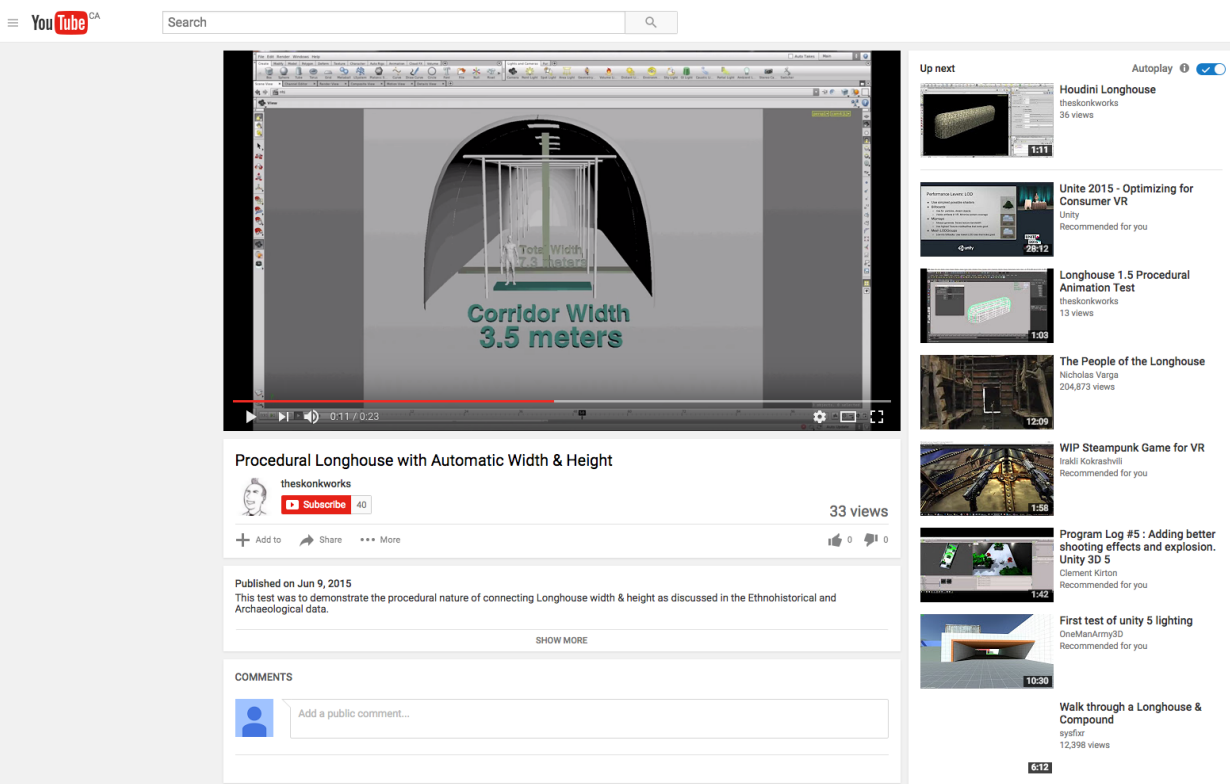

Appendix B 5: Procedural Longhouse Framing Test (Houdini) https://youtu.be/LBCa4xELkuE
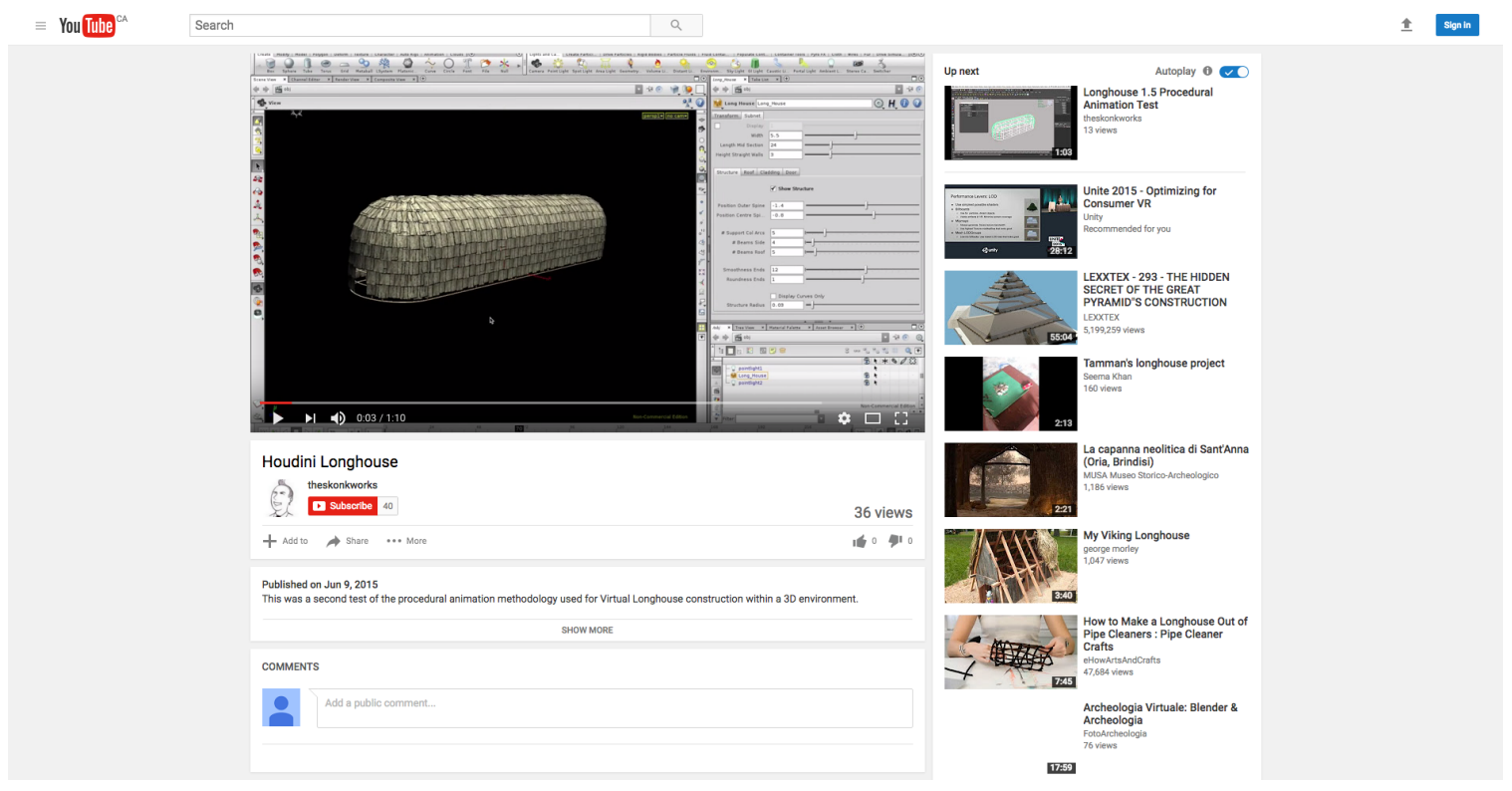

Appendix B 6: Procedural Longhouse Framing Test2 (Houdini) https://youtu.be/5KdJF6boYYo 

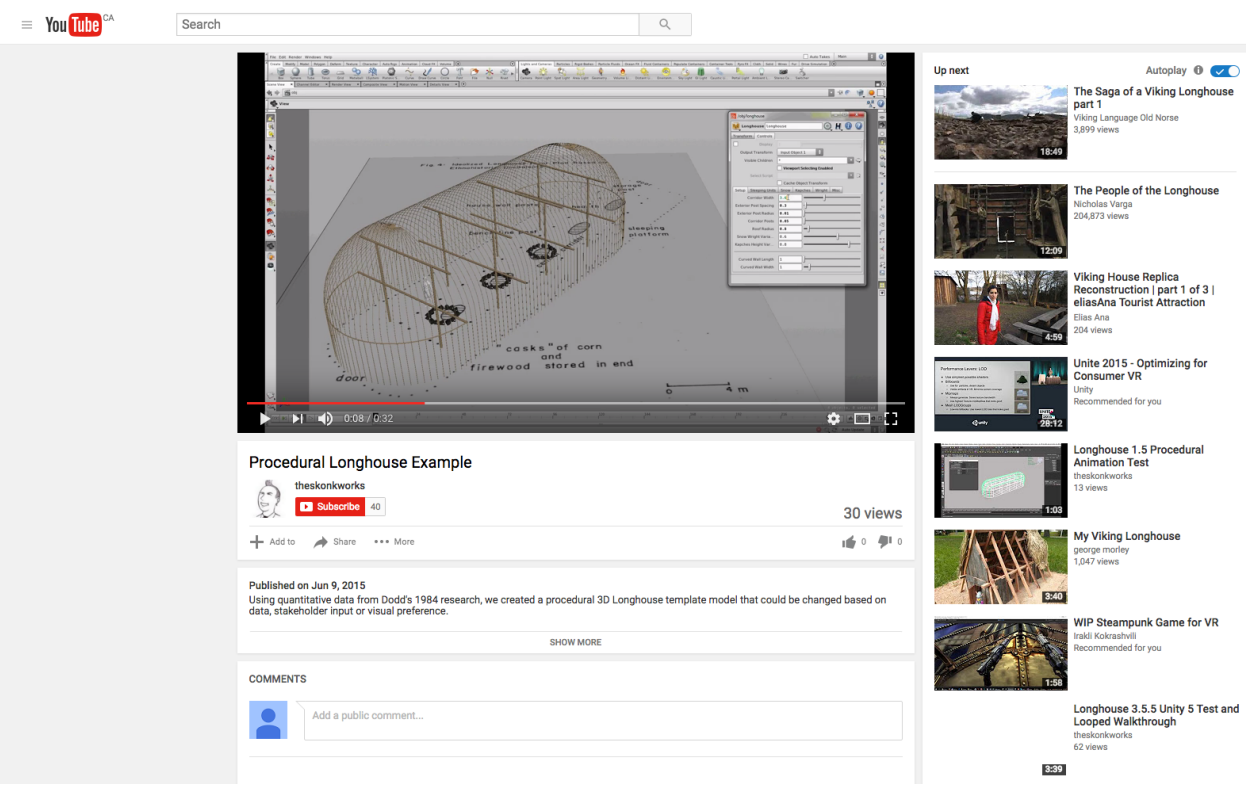

Appendix B 7: Procedural Longhouse, Interior Support and Exterior Walls from Dodd (1984) - https://youtu.be/eX7Upvo1oak

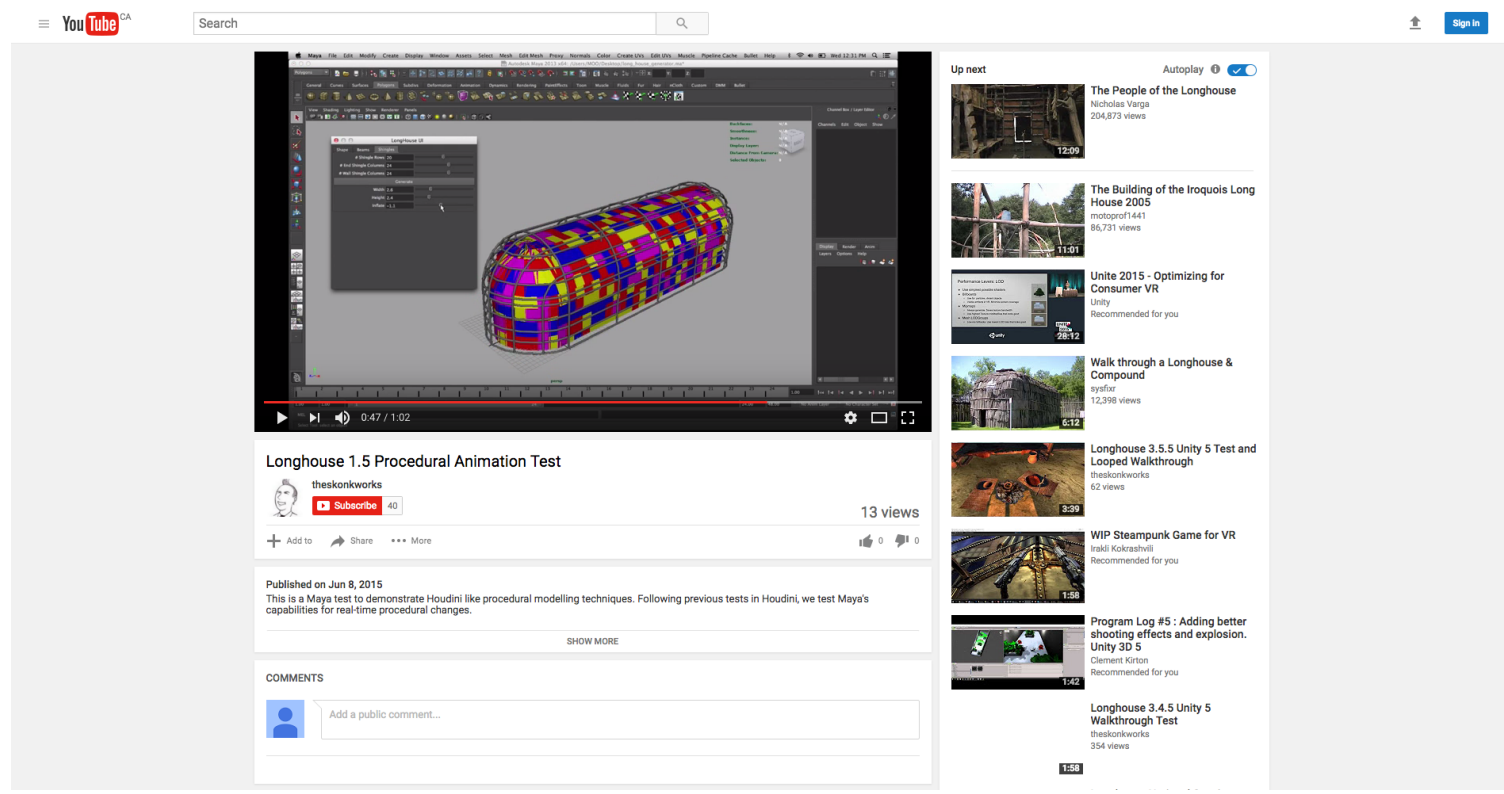

Appendix B 8: Procedural Longhouse Test (Maya) - https://youtu.be/29KJZo7NKrk 


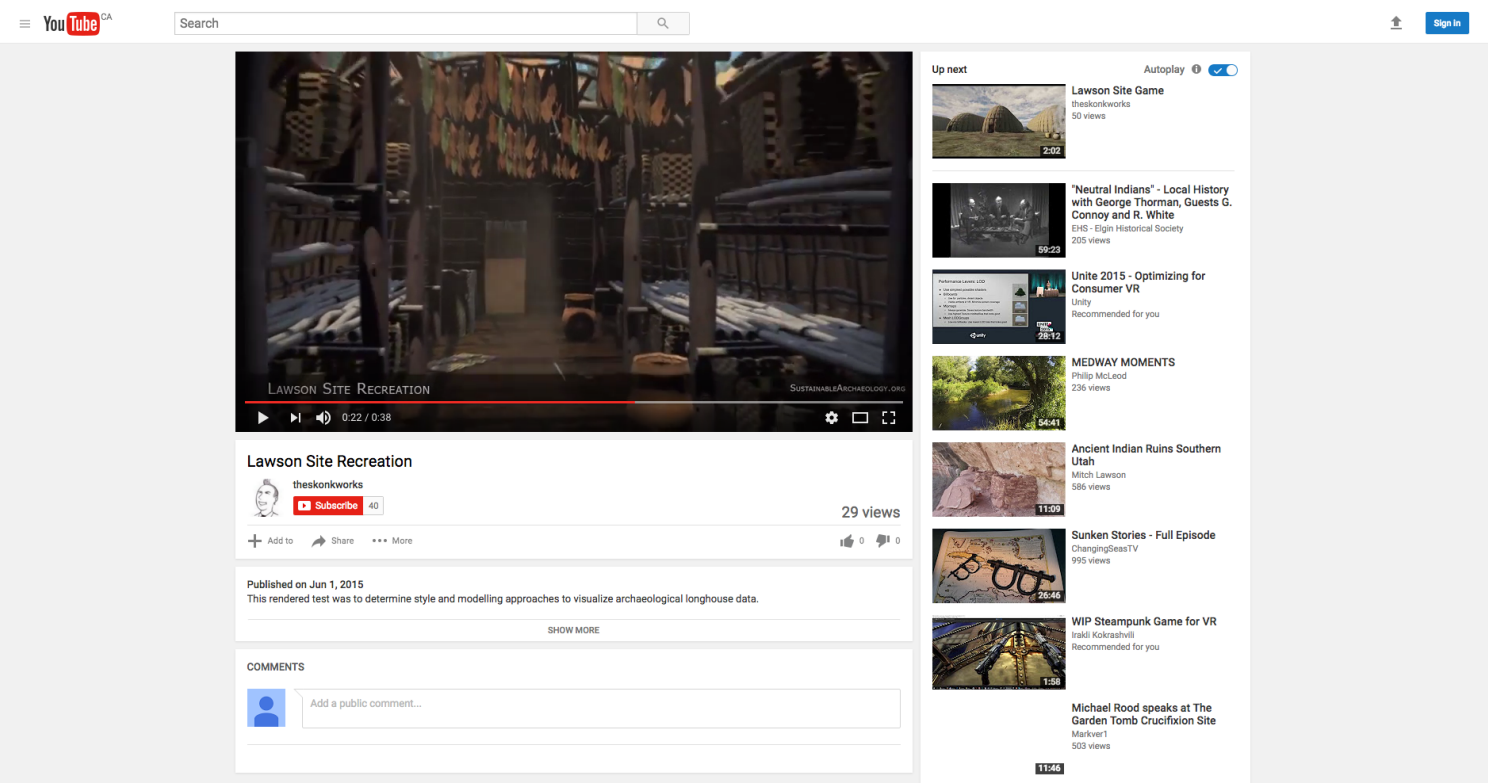

Appendix B 9: Lawson Site Rendered Sequence - https://youtu.be/qg7u5iL4pRg

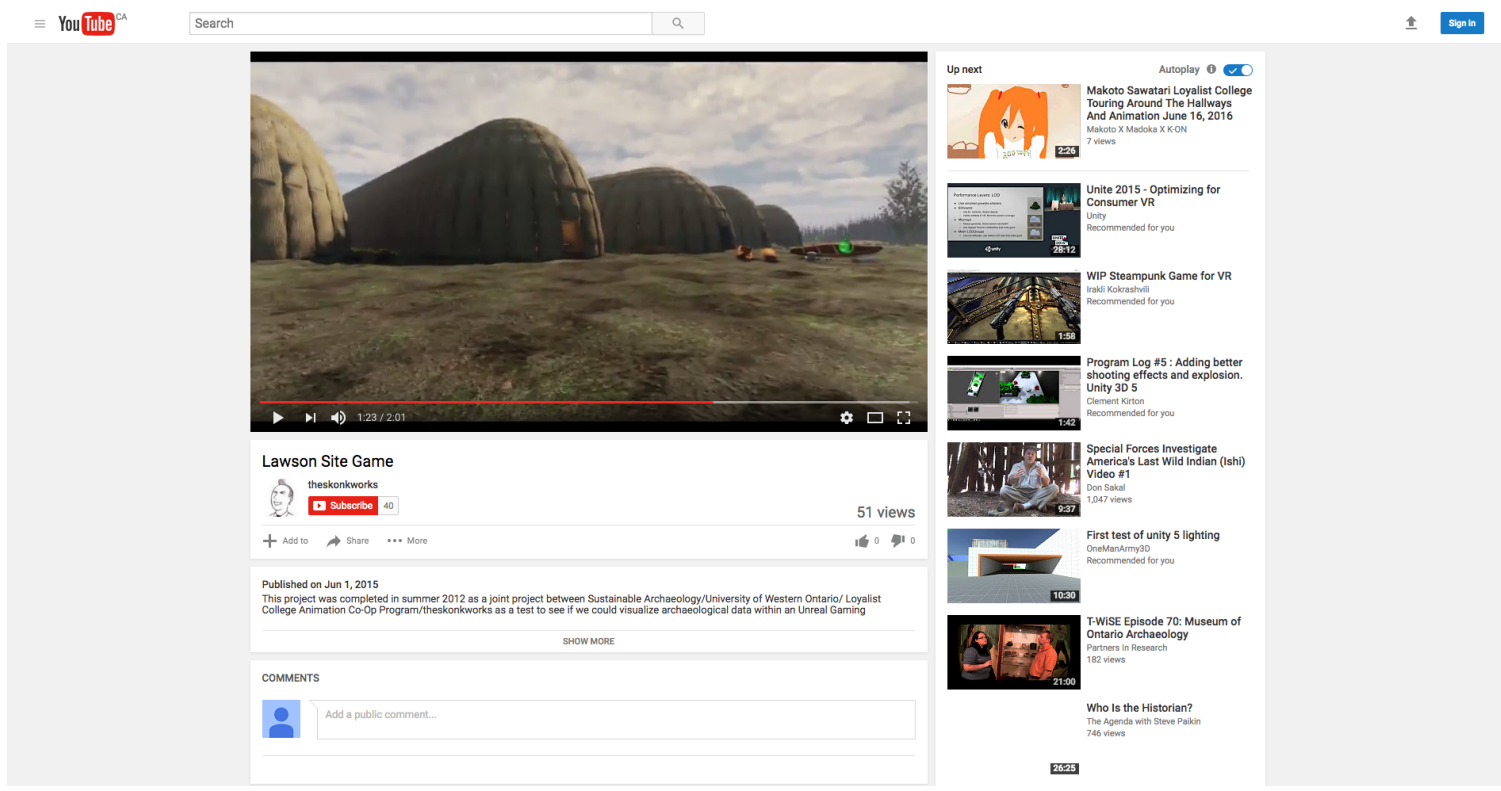

Appendix B 10: Lawson Site Unreal Game Sequence https://youtu.be/0O8sMVRJD3Q 

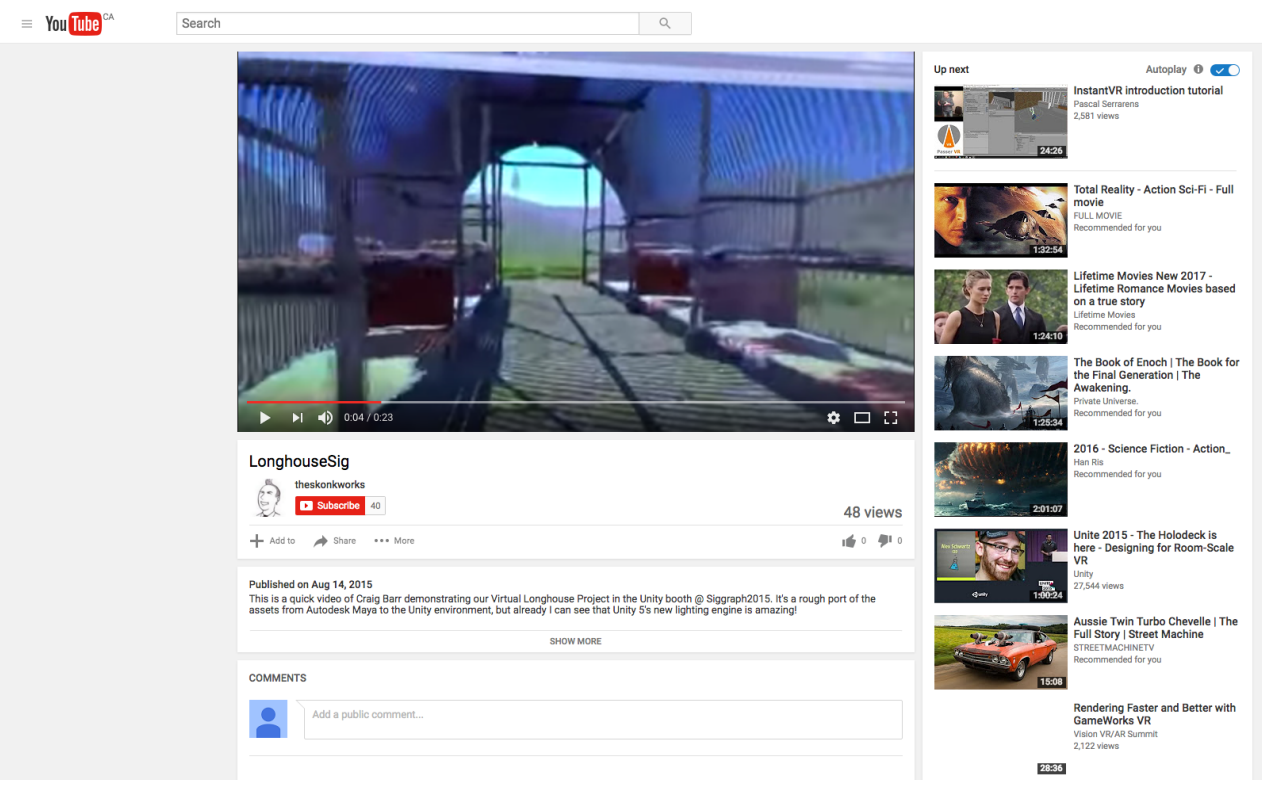

Appendix B 11: Longhouse Example at Siggraph 2016 https://youtu.be/ULIMey10HkY
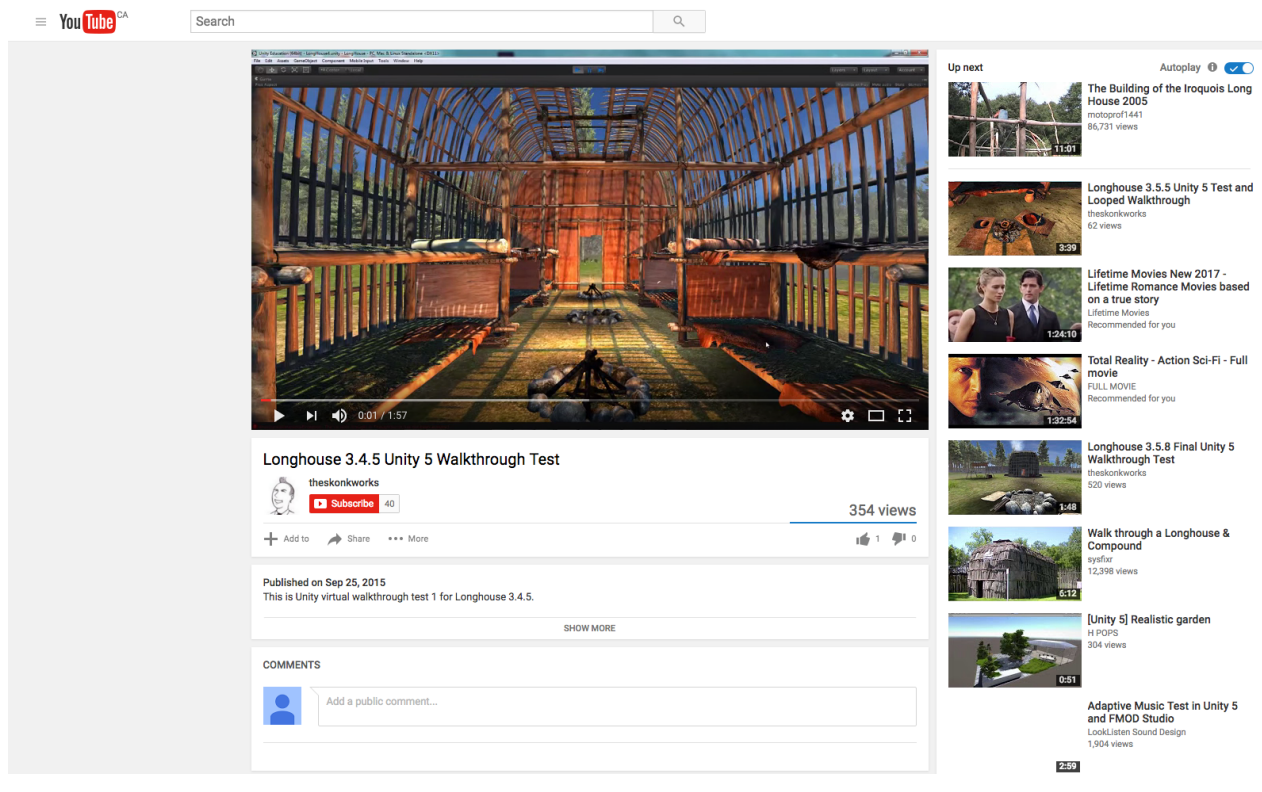

Appendix B 12: Longhouse Unity Walkthrough Test https://youtu.be/eTMxKZSifi4 


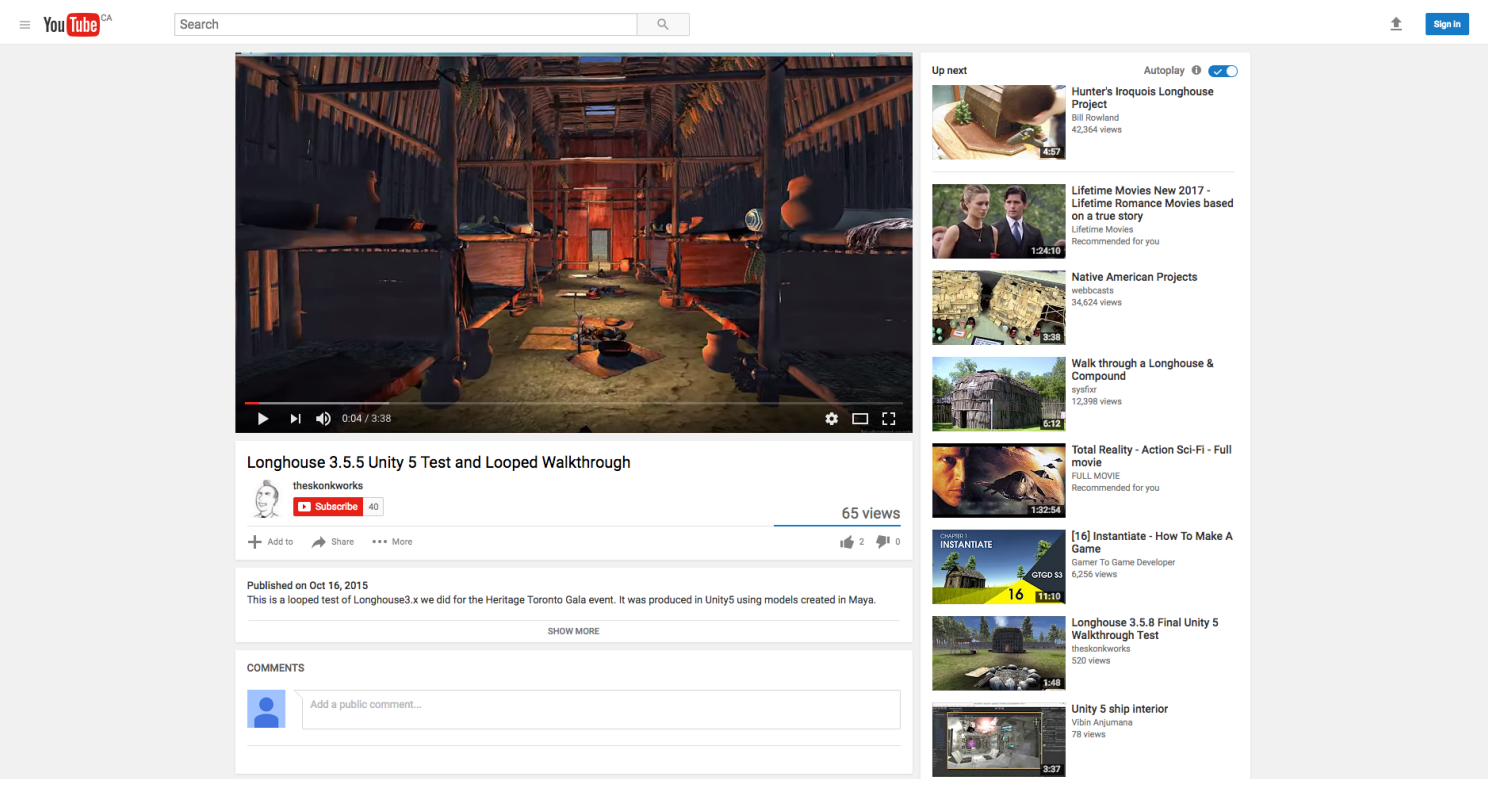

Appendix B 13: Full Longhouse Unity Test - https://youtu.be/1IKYFuAuOKo

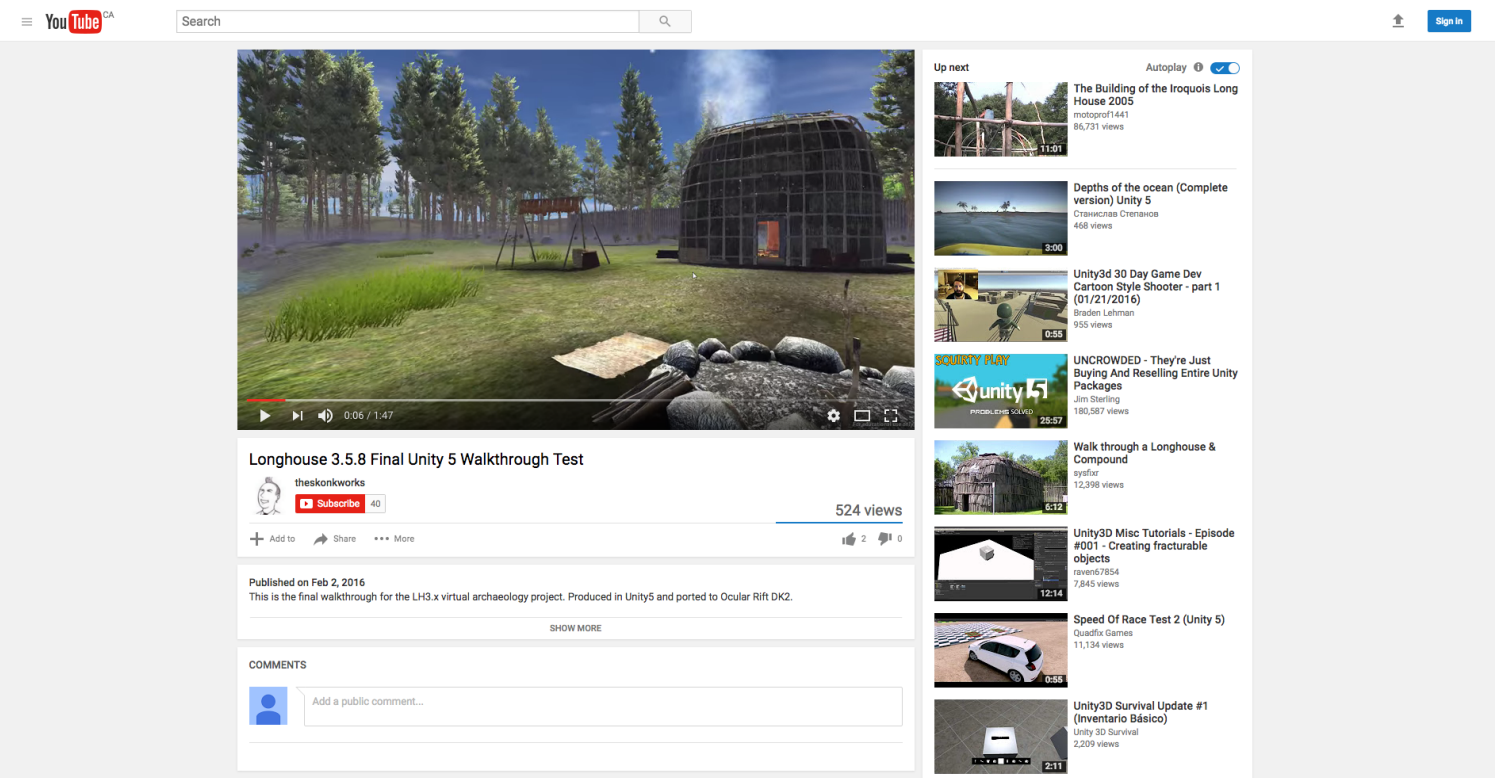

Appendix B 14: Final Unity Longhouse Walkthrough https://youtu.be/9YUrFOWvN_s 


\section{Curriculum Vitae}

Name:

Post-secondary

Degrees:

Honours and

Awards:

Related Work

Experience:
William Michael Carter

University of Western Ontario

Education and London, Ontario, Canada

1987-1993 Hon. B.A. Anthropology \& Visual Arts

Sheridan College

Oakville, Ontario, Canada

1995-1995 Post-Graduate Diploma Computer

Graphics

Sheridan College

Oakville, Ontario, Canada

1995-1995 Post-Graduate Diploma Computer

Animation

The University of Toronto

London, Ontario, Canada

1999-2005 M.Ed. Curriculum, Teaching \& Learning

The University of Western Ontario

London, Ontario, Canada

2011-2017 Ph.D. Archaeology

2015 Team Award Receipient, President's Blue and

Gold Award of Excellence - Ryerson University. For the design, development and implementation of the Master of Digital Media program. Shared along with Dr. Matthew Kyan and Ms. Sonya Taccone.

Assistant Professor, Creative Industries, Ryerson University Current

Publications:

Carter, M., (2017) Getting to the point: Making, Wayfaring, Loss and Memory as Meaning-Making in Virtual Archaeology. Virtual Archaeology Review. Vol. 8, Iss. 16.

Ahmed, N., Carter, M., Ferris, N., (2014) Sustainable archaeology through progressive assembly 3D digitization. World Archaeology. Vol. 46, Iss. 1. 
Barr, David, Carter W.M. (1994/1995) Mapping Biodiversity. Rotunda. Winter: 34-39.

Carter, William Michael. (1992) Digging without a Degree: Understanding the Nature of the Silent Mexican Archaeologist: Zygogemys trichopus. Arch Notes. July/August, 92-4: 25-32.

Research Projects:

Co-Collaborator E-Campus Ontario Grant with Prof Shawn Graham (Carlton University), Dr. Neha Gupta (Memorial University) and Beth Compton (UWO): Digital Archaeology Method and Practice: An Integrated Open Source Textbook and Digital Laboratory.

Dr. Neal Ferris, Principle Investigator, Namir Ahmed, Graduate Student Project Lead, Michael Carter/theskonkworks incorporated, Corporate Partner. MITACS FUNDED Research Project (Summer 2012). Establishment of the Sustainable Archaeology Animation Unit - Museum of Ontario Archaeology/Western University.

Conferences:

Computer Applications \& Quantitative Methods in Archaeology (CAA2017), Conference, March 2017. Visualization as Analysis in Archaeology Session: Making and Meaning-Making in Virtual Archaeology. Paper presentation and Session Organizer.

Computer Applications \& Quantitative Methods in Archaeology (CAA2017), Conference, March 2017. Advanced Challenges in Theory and Practice Session: The Life of Attributes: Meta and Paradata as 3D Point and Object DNA for Heritage Providence. Paper presentation.

Society for American Archaeology (SAA2017), Conference, Vancouver, March 2017. Methods and Models for Teaching Digital Archaeology and Heritage Session: Looting, Robotics and Experiential Archaeology for non-Archaeologists. Co-authored paper presentation.

Virtual Heritage Networks Ireland (VHN2016), Conference, Cork, December 2016. Pride, Prejudice and Zombies: Theoretical Chaos in Virtual Archaeology. Invited paper presentation. - Accepted but declined due to lack of funding.

Ontario Archaeological Society (OAS), Symposium, Waterloo, November 2016, Session: The Digital and the Physical: Knowledge Construction of Iroquoian Longhouse Construction and Use within Virtual Reality.

ARIADNE Summer School, Digital Curation Unit-IMIS, Athena Research Centre, June 2016. Expert forum: The future of archaeological knowledge curation 2021-2026. Invited Panelist. 
Society for American Archaeology, Conference, Orlando, April 2016. Technological Advances in Archaeology Session: Virtual Archaeology, Virtual Longhouses and "Envisioning the Unseen" within the Archaeological Record. Paper presentation.

B3Dimentional Design Conference, Ryerson University, Toronto ON, October 2015. Virtual Archaeology, Virtual Longhouses and "Envisioning the Unseen" within the Archaeological Record. Michael Carter. Paper presentation and Session Organizer.

CAGS-SSHRC: Imagining Canada's Future, Joint University of Western Ontario and University of Windsor Conference, University of Western Ontario, London ON, March 2015. Keynote Speaker.

Brazil-Canada Collaboration Forum, Sao Paulo, Brazil, September 2014. The Role of Government and Academia in the Innovation Economy. Panelist.

Canadian Archaeological Association Conference (CAA), London ON, May 2014. Virtual Archaeology Session: VFX Methodologies for Scientific Visualization in Archaeology. Michael Carter. Paper presentation and Session Organizer.

Animation Today II, Ontario Animation Colleges' perspective \& views on the Industry \& talent as it stands today, CASO Visionary Lunch, April 2014. Michael Carter, Noel Hooper, Mark Jones, Philip Krueger, Jakub Pazera. Panelist.

University of Western Ontario, Big Data, Entrepreneurship and Industry, March 2014. Panelist.

University of Western Ontario, Big Data in the SSHRC Disciplines Data from the Past, Present and Future, March 2014. Conference co-Organizer and Panelist.

Digital Engagement in Archaeology Conference, University College London, UK, November 2012. Digital Artifact Ecosystems: The "Internet of Things" in Archaeology. Namir Ahmed, Michael Carter, Neal Ferris. Co-presenter.

Peer Review:

Peer reviewed 11 papers for Special Issue \#43 of Internet Archaeology (2016) entitled After Virtual Archaeology: Research Stories from Digital Creativity, Image Making and Archaeological Practice, edited by Beale, G \& Reilly, P. 